\title{
Processing, Stability and High-Temperature Properties of Transition Metal Silicide-Refractory Oxide Composites for Electrical Applications
}

Gunes Alp Yakaboylu

Follow this and additional works at: https://researchrepository.wvu.edu/etd

\footnotetext{
Recommended Citation

Yakaboylu, Gunes Alp, "Processing, Stability and High-Temperature Properties of Transition Metal SilicideRefractory Oxide Composites for Electrical Applications" (2018). Graduate Theses, Dissertations, and Problem Reports. 6993.

https://researchrepository.wvu.edu/etd/6993

This Dissertation is protected by copyright and/or related rights. It has been brought to you by the The Research Repository @ WVU with permission from the rights-holder(s). You are free to use this Dissertation in any way that is permitted by the copyright and related rights legislation that applies to your use. For other uses you must obtain permission from the rights-holder(s) directly, unless additional rights are indicated by a Creative Commons license in the record and/ or on the work itself. This Dissertation has been accepted for inclusion in WVU Graduate Theses, Dissertations, and Problem Reports collection by an authorized administrator of The Research Repository @ WVU. For more information, please contact researchrepository@mail.wvu.edu.
} 


\title{
PROCESSING, STABILITY AND HIGH-TEMPERATURE PROPERTIES OF TRANSITION METAL SILICIDE- REFRACTORY OXIDE COMPOSITES FOR ELECTRICAL APPLICATIONS
}

\author{
Gunes Alp Yakaboylu
}

\author{
Dissertation submitted \\ to the Benjamin M. Statler College of Engineering and Mineral Resources \\ at West Virginia University \\ in partial fulfillment of the requirements for the degree of \\ Doctor of Philosophy \\ in \\ Material Science and Engineering
}

\author{
Edward M. Sabolsky, Ph.D., Chair \\ Konstantinos A. Sierros, Ph.D. \\ Xingbo Liu, Ph.D. \\ Nianqiang Wu, Ph.D. \\ Charter D. Stinespring, Ph.D. \\ Department of Mechanical and Aerospace Engineering \\ Morgantown, West Virginia \\ 2018
}

Keywords: electroconductive composites, electroceramics, transition metal silicides, phase stability, microstructure, grain growth, oxidation, pest behavior, electrical conductivity, percolation, high-temperature preoxidation

Copyright 2018 Gunes Alp Yakaboylu 


\title{
Abstract \\ PROCESSING, STABILITY AND HIGH- TEMPERATURE PROPERTIES OF TRANSITION METAL SILICIDE- REFRACTORY OXIDE COMPOSITES FOR ELECTRICAL APPLICATIONS
}

\author{
Gunes Alp Yakaboylu
}

Many common electrical materials used in the current sensing applications suffer from structural and functional issues related to high operating temperatures $\left(750^{\circ}-1600^{\circ} \mathrm{C}\right)$, alternating reducing/oxidizing atmospheres, high pressures and corrosive environments. Therefore, there is a need for development of new materials, which are capable to operate under high-temperature and harsh-environments to provide real-time, accurate sensing during industrial processes such as coal gasification and power generation. In this study, electroconductive ceramic composites were fabricated by incorporating the $20-90 \mathrm{vol} \%$ of transition metal silicides $\left(\mathrm{MoSi}_{2}, \mathrm{WSi}_{2}, \mathrm{NbSi}_{2}, \mathrm{TaSi}_{2}, \mathrm{CrSi}_{2}\right)$ within refractory oxides $\left(\mathrm{Al}_{2} \mathrm{O}_{3}, \mathrm{ZrO}_{2}, \mathrm{Cr}_{2} \mathrm{O}_{3}\right)$, followed by sintering at $1370^{\circ}-1600^{\circ} \mathrm{C}$ in argon. The densification, microstructural evolution, phase development and thermal stability of the composites were studied after sintering and further annealing by Archimedes, Scanning electron microscopy (SEM) and X-ray diffraction/Rietveld (XRD) techniques. Their non-isothermal and isothermal oxidation behavior was studied under ambient air using a thermogravimetric analyzer (TGA) at $50^{\circ}-870^{\circ} \mathrm{C}$ to understand the key parameters influencing their hightemperature oxidation. The selected composites were also preoxidized at $1000^{\circ}-1200^{\circ} \mathrm{C}$ for 10-120 minutes to better understand their high-temperature oxidation kinetics and surface layer formation, and hence, to enhance their oxidation resistance by forming a protective surface layer. XRD, Raman spectroscopy and X-ray photoelectron spectroscopy (XPS) were used for structural and surface characterization. In addition, their 4-point DC electrical conductivities were measured up to $800^{\circ}-1000^{\circ} \mathrm{C}$ to study their electrical performance as a function of the composition and processing. A microstructural image analysis method was also developed for quantitatively characterizing the degree of distribution (homogeneity) within the composites. Lastly, thick-film embedded thermocouples (e.g. $\mathrm{MoSi}_{2}-\mathrm{Al}_{2} \mathrm{O}_{3} / / \mathrm{WSi}_{2}-\mathrm{Al}_{2} \mathrm{O}_{3}$ ) were fabricated using selected composites by a screen printing technique. Their thermoelectric properties were measured in argon by a typical hot-cold junction temperature measurements, while their structural and microstructural analyses were performed by XPS, XRD and SEM. 
DEDICATION

To my wife... 


\section{ACKNOWLEDGEMENTS}

My first thankfulness is surely for my advisor Dr. Edward M. Sabolsky, who provided me the opportunity to work on this research, and thus, allowed me to take this long (believe me, it is very long!) and challenging journey. Thank you for your support and enthusiasm during all our work, which was an enormous motivation for me. Without your scientific guidance and motivation, and freedom that you gave me, the outcome of my doctoral studies would not be at this level. I really learned a lot from all our scientific discussions, even though some of them were slightly tense, particularly when the deliverables were due. I also enjoyed all our non-scientific discussions, especially on our traditional gatherings (e.g. after grading parties, Christmas) and road trips to the meetings. It was a great experience to work with you, thank you for all.

I would also like to thank Kathy Sabolsky for her great support, guidance and friendship throughout this research, which motivated and helped me to think outside of the box and to further improve this work. I am so thankful to Dr. Rajalekshmi C. Pillai, Brian Armour and James Meyer for their team work, it was a great pleasure to work with you in the same research project. In addition, I would like to thank all the committee members Dr. Konstantinos Sierros, Dr. Nianqiang Wu, Dr. Xingbo Liu and Dr. Charter Stinespring, for reviewing my work and their valuable suggestions. I would also like to express my sincere gratitude to Dr. Marcela Redigolo and Dr. Wei Ding (WVU Shared Research Facilities) for their support and assistance on material characterization. I am also deeply thankful to my friend and a great scientist Dr. Tugrul Yumak (Sinop University) for his priceless support on surface characterization studies, which helped me to complete my final chapter in the best possible way. I would also like to thank Dr. Sreekumar Chockalingam for his support and guidance for my future career.

I would like to express my gratitude to my dearest friends Dr. Tony Thomas (muscle man) and Ioannis Kortidis (my hot-blooded Greek brother). I will always miss our alcohol-driven gatherings and open-ended discussions, which made my $\mathrm{PhD}$ years way more beautiful and 
fun in Morgantown. Our trip to Niagara Falls was also unforgettable, and I really hope to see you in near future somewhere in the world, maybe in South Africa or Miami. I would also like to state my thanks to my other fellow labmates Jonathan Yancey (and Mona), Allison Arnold, Kavin Sivaneri, Dr. Engin Ciftyurek and Aneeruddha Bulbule for being good friends.

I guess (and hope) that this is the end of my 23 years in education. As a said in the beginning, it was a very long (5442 miles trip + almost 4 years) and challenging journey. Not only for me, but also for my wife. To be honest, before coming here, we never thought that it would be this much difficult for us. Words are not enough to describe what we have been through during the past four years. More importantly, all I wanted to say is that we succeeded this together with my wife. I am so grateful for your endless support and love all the time, and I would not be here without you. 


\section{Table of Contents}

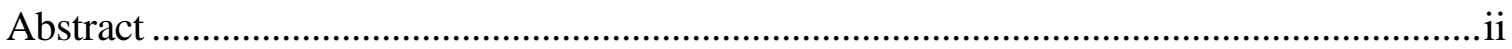

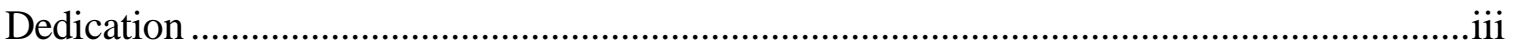

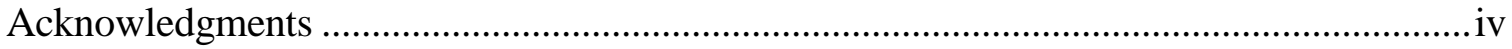

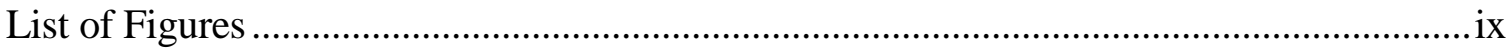

List of Tables .........................................................................................................

List of Symbols and Abbreviations ....................................................................................

INTRODUCTION .............................................................................................................1

Statement of Problem …………………………………………………………... 1

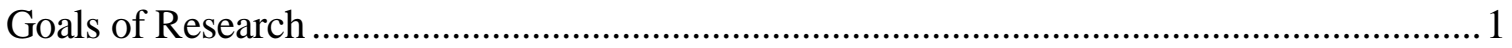

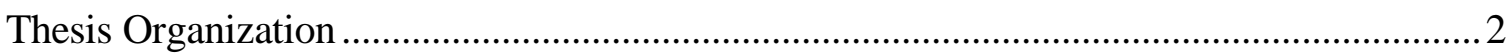

CHAPTER 1: BACKGROUND ......................................................................................4

1.1 Transition Metal Silicides......................................................................................

1.1.1 Structure of the refractory transition metal silicides ......................................................

1.1.2 Mechanical properties of the refractory transition metal silicides ............................ 13

1.1.2.1 Fracture toughness ........................................................................................ 14

1.1.2.2 Modulus of elasticity, yield strength and flexural strength ………………….. 18

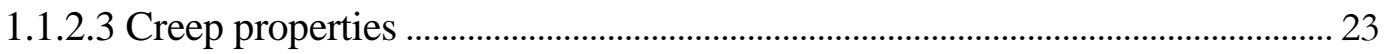

1.1.3 Electrical properties of the refractory transition metal silicides ................................ 25

1.1.4 Oxidation behavior of the refractory transition metal silicides.................................. 30

1.2 Refractory Transition Metal Silicide Composites .............................................................. 34

1.2.1 Mechanical properties of the refractory transition metal silicide composites ........ 35

1.2.1.1 Fracture toughness ......................................................................................... 35

1.2.1.2 Creep properties ……………………………………………………………. 41

1.2.2 Electrical and thermal properties of the refractory transition metal silicide

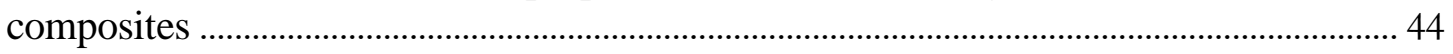

1.2.3 Oxidation behavior of the refractory transition metal silicide composites ............. 47

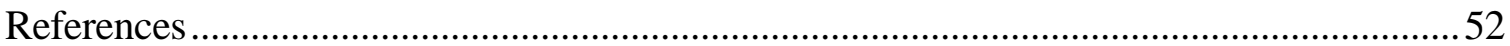

CHAPTER 2: PROCESSING AND PROPERTIES OF MoSi2- AND WSi2-OXIDE

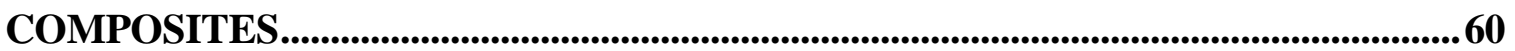

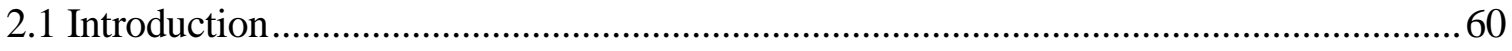

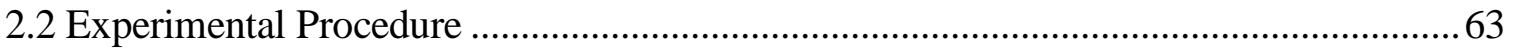

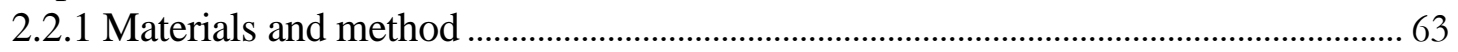

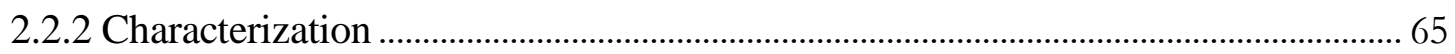

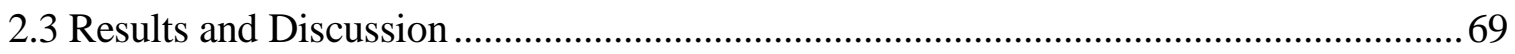

2.3.1 Densification, chemical stability and microstructures after sintering ...................... 69

2.3.2 Thermal stability and grain growth kinetics at high-temperatures............................. 82

2.3.3 Electrical properties at high-temperatures................................................................... 100

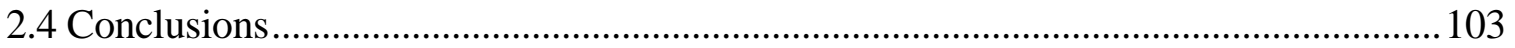

CHAPTER 3: PROCESSING AND PROPERTIES OF NbSi2- AND TaSi2-OXIDE COMPOSITES........................................................................................................110

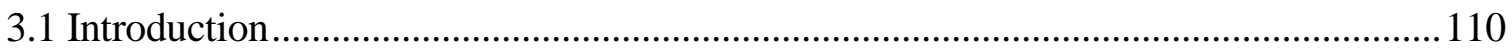

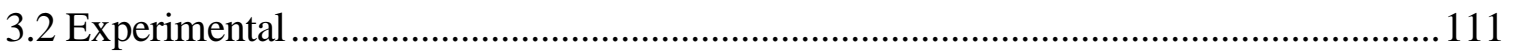




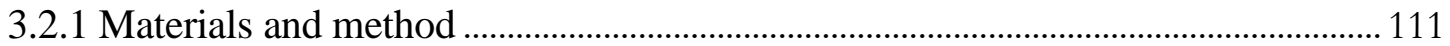

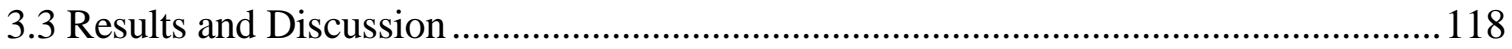

3.3.1 Densification as a function of composition and temperature ..................................... 118

3.3.2 Phase development and stability at high-temperatures ................................................ 121

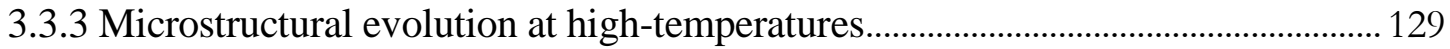

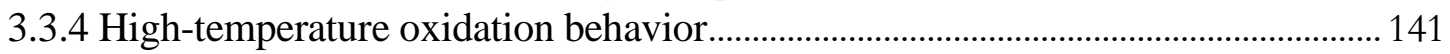

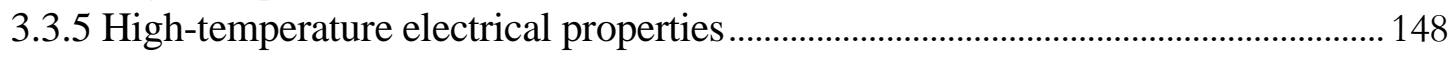

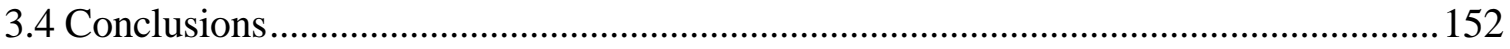

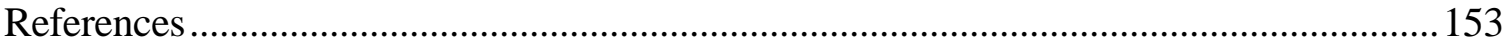

CHAPTER 4: PROCESSING AND PROPERTIES OF CHROMIUM SILICIDE-

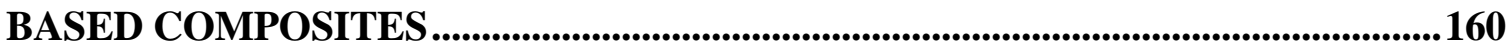

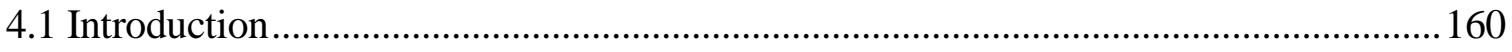

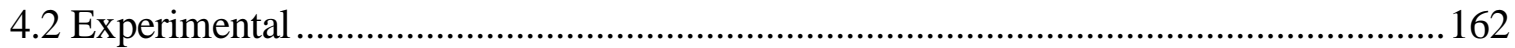

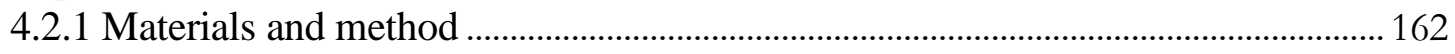

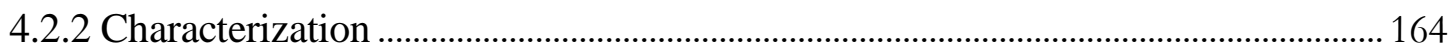

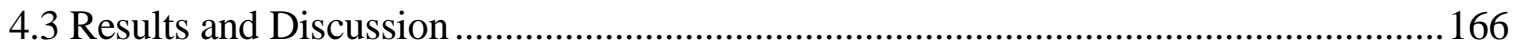

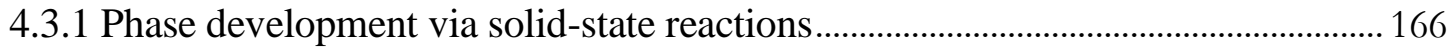

4.3.2 Composite microstructures after solid-state reactions .................................................. 169

4.3.3 High-temperature non-isothermal oxidation of the composites................................. 178

4.3.4 High-temperature electrical properties of the composites...................................... 183

4.3.5 High-temperature stability of the selected $\mathrm{Cr}_{3} \mathrm{Si}$ - and $\mathrm{Cr}_{5} \mathrm{Si}_{3}$-based composites. 188

4.3.5.1 Thermal stability and microstructural evolution .............................................. 189

4.3.5.2 High-temperature oxidation and electrical properties after annealing......... 197

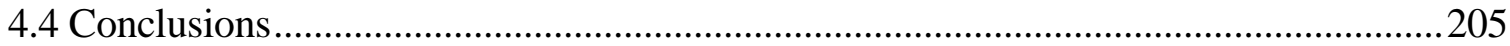

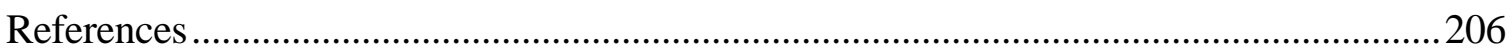

CHAPTER 5: DETERMINATION OF A HOMOGENEITY FACTOR FOR

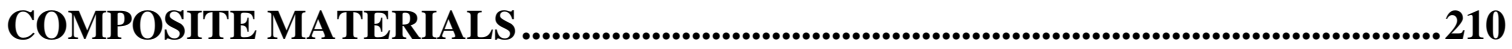

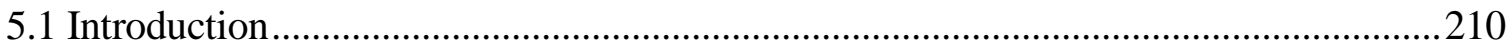

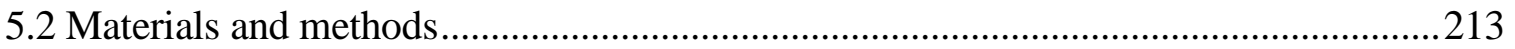

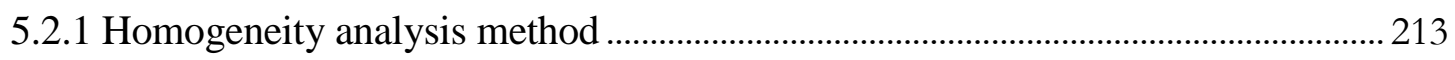

5.2.2 Description of the data and experimental method ....................................................216

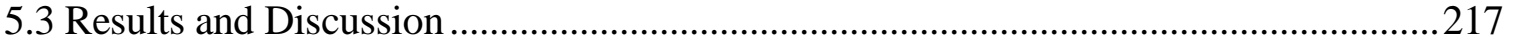

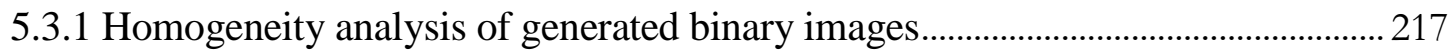

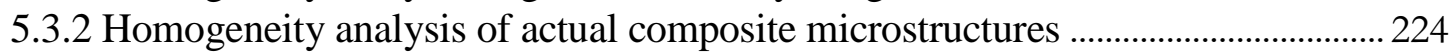

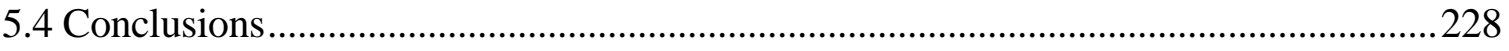

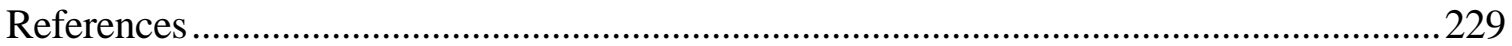

CHAPTER 6: FABRICATION AND THERMOELECTRIC PROPERTIES OF EMBEDDED CERAMIC COMPOSITE THERMOCOUPLES...............................232

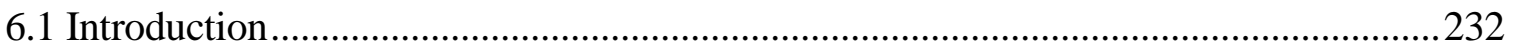

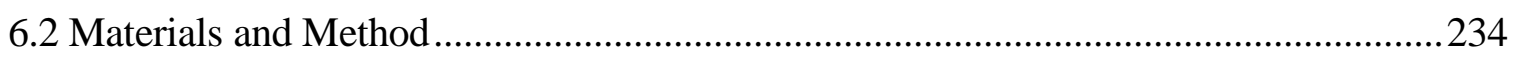

6.2.1 Formulation of ink and screen printing on alumina substrates ............................... 234

6.2.2 Structural and thermoelectric characterization of thermocouples .......................... 236

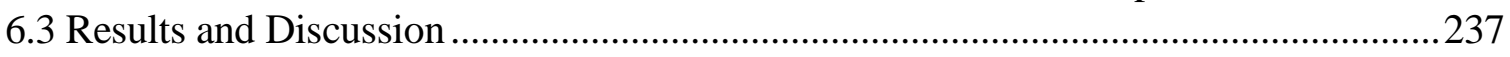




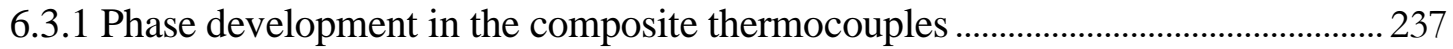

6.3.2 Microstructures of the composite thermocouples.................................................... 244

6.3.3 Thermoelectric characterization of the composite thermocouples............................ 247

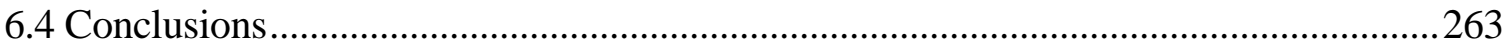

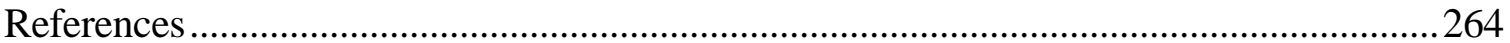

CHAPTER 7: EFFECT OF ALUMINA PHASE AND HIGH-TEMPERATURE

PREOXIDATION TREATMENT ON OXIDATION BEHAVIOR OF

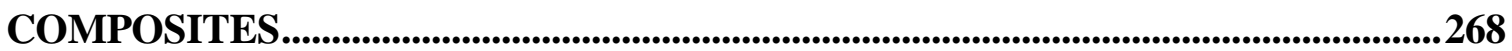

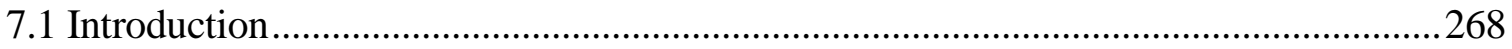

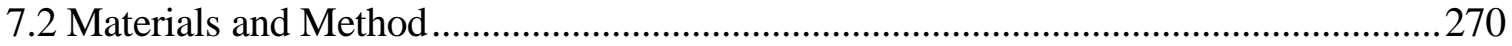

7.2.1 Processing of the $\mathrm{MoSi}_{2}$ and $\mathrm{WSi}_{2}-\mathrm{Al}_{2} \mathrm{O}_{3}$ composites ........................................... 270

7.2.2 High-temperature preoxidation treatment ................................................................... 271

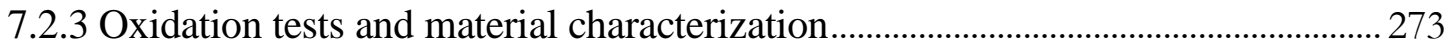

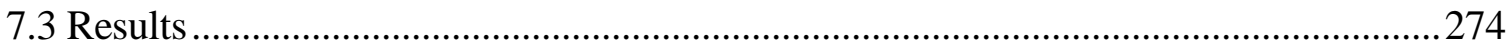

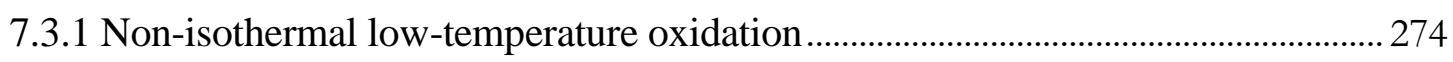

7.3.2 Optical micrographs and SEM microstructures of surface layer morphologies .. 282

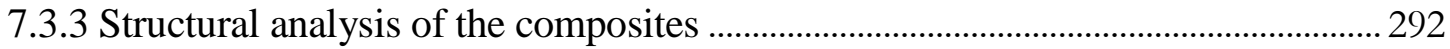

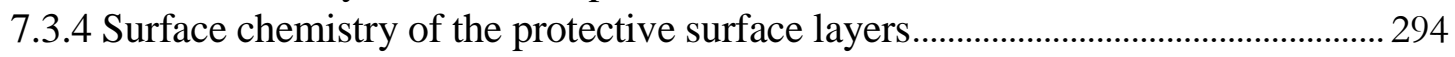

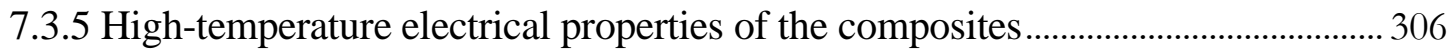

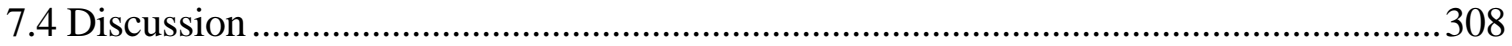

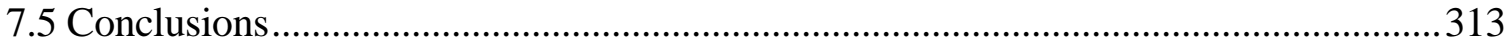

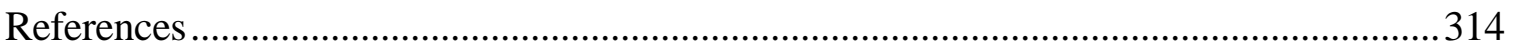

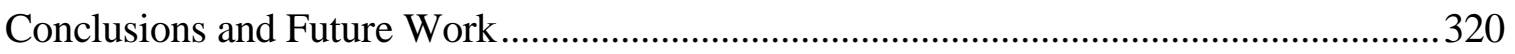

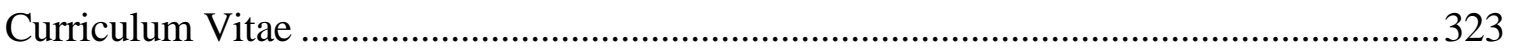




\section{LIST OF FIGURES}

Figure 1. Molybdenum-silicon (Mo-Si) binary phase diagram [7]..................................... 10

Figure 2. Projection of a pseudo-quaternary phase diagram summarizing the formation of mostly studied/used refractory metal disilicides [7]................................................. 11

Figure 3. Crystal structure and stacking sequences of refractory transition metal disilicides:

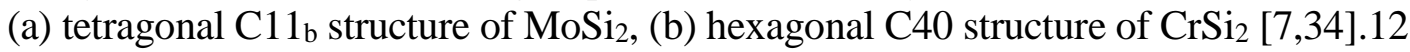

Figure 4. Comparison of the room temperature fracture toughness values $\left(\mathrm{K}_{\mathrm{Q}}\right)$ of the monolithic $\mathrm{MoSi}_{2}$ with the particulate (Mo, W, and $\mathrm{Nb}$ ) reinforced $\mathrm{MoSi}_{2}$ [41] ... 15

Figure 5. Effect of aluminum addition on the room temperature fracture toughness and other mechanical properties of the $\mathrm{MoSi}_{2}$ [13] ......................................................16

Figure 6. High temperature fracture toughness of monolithic $\mathrm{MoSi}_{2}$ and $\mathrm{MoSi}_{2}$ alloyed with $1-4$ wt.\% of carbon as a function of temperature [49].

Figure 7. Average elastic modulus (modulus of elasticity or Young's modulus) of several refractory metal silicides as a function of temperature [44].

Figure 8. (a) Yield stress of a polycrystalline $\mathrm{MoSi}_{2}$ [38], and (b) R characteristic of $\mathrm{MoSi}_{2}$ (change in yield strength) [23] as a function of temperature.

Figure 9. Yield strength of the pure $\mathrm{MoSi}_{2}$ and $\mathrm{MoSi}_{2}$ alloyed/doped with 1 at $\% \mathrm{Nb}$ as a function of temperature (above $1500^{\circ} \mathrm{C}$ ) [52] ...................................................... 21

Figure 10. Flexural strength of (a) $\mathrm{MoSi}_{2}$ [22], and (b) $\mathrm{Mo}_{5} \mathrm{Si}_{3}$ [54] as a function of temperature ....................................................................................................2 22

Figure 11. Creep rate of the polycrystalline $\mathrm{MoSi}_{2}$ at $1200^{\circ} \mathrm{C}$ as a function of the grain size [38]. .23

Figure 12. Minimum creep rates in compression vs. stress for several refractory metal

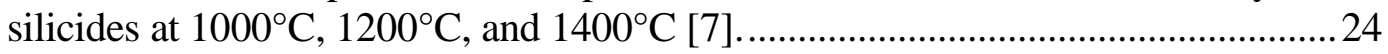

Figure 13. (a) Electrical resistivities, $\rho$, and (b) Seebeck coefficients, $\mathrm{S}$ of the

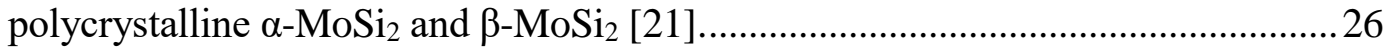

Figure 14. Temperature dependence of the electrical resistivity of $\mathrm{MoSi}_{2}, \mathrm{WSi}_{2}, \mathrm{TaSi}_{2}$, and $\mathrm{TiSi}_{2}$ refractory metal silicide thin films [56]......................................................2

Figure 15. The electronic density of states of $\mathrm{Ta}_{5} \mathrm{Si}_{3}$ and $\mathrm{W}_{5} \mathrm{Si}_{3}$ close to the Fermi level [17]

Figure 16. Temperature dependence of the electrical resistivity of the (a) $\mathrm{Cr}_{3} \mathrm{Si}$, and (b) $\mathrm{Cr}_{5} \mathrm{Si}_{3}$ refractory metal silicide thin films [55]....................................................29

Figure 17. (a) Oxidation behavior of fully dense and porous $\mathrm{MoSi}_{2}$ at $500^{\circ} \mathrm{C}$ in air, and (b) SEM micrograph of the surface of porous $\mathrm{MoSi}_{2}$ oxidized at $500^{\circ} \mathrm{C}$ for $360 \mathrm{ks}(100$ hours) [63]. 31

Figure 18. Comparison of the isothermal oxidation behavior of $\mathrm{MoSi}_{2}$ with several intermetallic compounds and nickel superalloy (PWA 1484) [1] ..............................32

Figure 19. The specific weight gain at high temperatures $\left(1400^{\circ}-1700^{\circ} \mathrm{C}\right)$ during isothermal

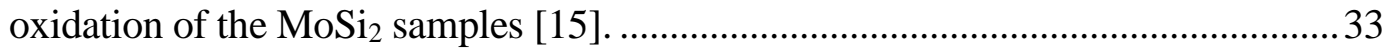

Figure 20 . The room temperature fracture toughness $\left(\mathrm{K}_{\mathrm{IC}}\right)$ and flexural strength $\left(\sigma_{\mathrm{FS}}\right)$ of the

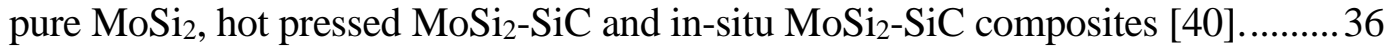


Figure 21. Effect of the TiC particle content on the fracture toughness $\left(\mathrm{K}_{\mathrm{IC}}\right)$ and flexural strength $\left(\sigma_{f}\right)$ of the $\mathrm{MoSi}_{2}$-TiC composites [68]..................................................... 37

Figure 22. Changes in room temperature fracture toughness of the $\mathrm{MoSi}_{2}-\mathrm{Si}_{3} \mathrm{~N}_{4}$ composites as a function of the volume fraction and particle size of the $\mathrm{MoSi}_{2}$ phase $(\mathrm{MgO}$ was used as a densification aid for $\mathrm{Si}_{3} \mathrm{~N}_{4}$ ) [10].

Figure 23. Effect of the $\mathrm{MoSi}_{2}$ weight percentage on the room temperature mechanical properties of the $\mathrm{MoSi}_{2}-\mathrm{Al}_{2} \mathrm{O}_{3}$ composites [62]. 40

Figure 24. Room temperature fracture toughness of the monolithic $\mathrm{MoSi}_{2}$ and different $\mathrm{MoSi}_{2}$-matrix composites reinforced with unstabilized $\mathrm{ZrO}_{2}$ (0YPSZ), yttria partially stabilized $\mathrm{ZrO}_{2}$ (2.5YPSZ), and $\mathrm{SiC}$ (reinforcement content was $20 \mathrm{vol} \%$ for all) [74]. 41

Figure 25. (a) Creep rate of the $\mathrm{MoSi}_{2}-\mathrm{SiC}_{\mathrm{w}}$ composites at $1200^{\circ} \mathrm{C}$ with different volume fractions of SiC phase [38], and (b) comparison of the creep deformation of the monolithic $\mathrm{MoSi}_{2}$ and $\mathrm{MoSi}_{2}-20 \mathrm{vol} \% \mathrm{SiC}_{\mathrm{w}}$ at $1200^{\circ} \mathrm{C}$ and $78 \mathrm{MPa}$ stress level [1].42

Figure 26. (a) Effect of the $\mathrm{Si}_{3} \mathrm{~N}_{4}$ volume fraction and stress on creep rate of the $\mathrm{MoSi}_{2}-$ $\mathrm{Si}_{3} \mathrm{~N}_{4}$ composites [78], and (b) improvements in the high temperature creep resistance of $\mathrm{MoSi}_{2}$-non-oxide composites over the years [3]. .43

Figure 27. Creep rate of the $\mathrm{C} 1\left(\mathrm{MoSi}_{2}-20 \mathrm{vol} \% \mathrm{Al}_{2} \mathrm{O}_{3}\right), \mathrm{C} 2\left(\mathrm{MoSi}_{2}-56.1\right.$ vol\% $\left.\mathrm{Al}_{2} \mathrm{O}_{3}\right)$, and $\mathrm{C} 3\left(\mathrm{MoSi}_{2}-68.1 \mathrm{vol} \% \mathrm{Al}_{2} \mathrm{O}_{3}\right)$ at $1200^{\circ} \mathrm{C}$ as a function of different stress levels, and their comparison with the pure $\mathrm{MoSi}_{2}$ and $\mathrm{Al}_{2} \mathrm{O}_{3}$ [79]. 44

Figure 28. (a) Electrical conductivity of pure $\mathrm{MoSi}_{2}$ and $\mathrm{MoSi}_{2}-\mathrm{Al}_{2} \mathrm{O}_{3}$ composites as a function of temperature, and (b) Coefficient of thermal expansion (CTE) for pure $\mathrm{MoSi}_{2}$, pure $\mathrm{Al}_{2} \mathrm{O}_{3}$, and $\mathrm{MoSi}_{2}-\mathrm{Al}_{2} \mathrm{O}_{3}$ composite [61]. . .45

Figure 29. Coefficients of thermal expansion (CTE) for high temperature materials [1] ...46

Figure 30. Electrical conductivity of the $\mathrm{Si}_{3} \mathrm{~N}_{4}-\mathrm{MoSi}_{2}$ composites with 32 vol\% (SML-32), $40 \mathrm{vol} \%$ (SML-40), and $60 \mathrm{vol} \%$ (SML-60) $\mathrm{MoSi}_{2}$ as a function of temperature [9].47

Figure 31. Oxidation behavior of the (a) $\mathrm{Si}_{3} \mathrm{~N}_{4}-35$ vol\% $\mathrm{MoSi}_{2}$ composite after 100 hours as a function of temperature [81], and (b) $\mathrm{Si}_{3} \mathrm{~N}_{4}$ and $\mathrm{Si}_{3} \mathrm{~N}_{4}-6$ vol\% $\mathrm{MoSi}_{2}$ composite at $1500^{\circ} \mathrm{C}$ as a function of time [82]. 48

Figure 32. (a) Cyclic oxidation behavior of the pure $\mathrm{MoSi}_{2}, \mathrm{MoSi}_{2}$-based composites, and superalloys at $1200^{\circ} \mathrm{C}$ (24 hours) [1], and (b) Oxidation behavior of the pure $\mathrm{MoSi}_{2}$ and $\mathrm{MoSi}_{2}$-based composites as a function of temperature up to $1500^{\circ} \mathrm{C}$ ( 24 hours) [84].

Figure 33. Mass changes of the pure $\mathrm{MoSi}_{2}$ (MA0), $\mathrm{MoSi}_{2}-10$ vol.\% $\mathrm{Al}_{2} \mathrm{O}_{3}$ (MA1), and $\mathrm{MoSi}_{2}-30$ vol. $\% \mathrm{Al}_{2} \mathrm{O}_{3}$ composite coatings at $1500^{\circ} \mathrm{C}$ as a function of time [85] ..50

Figure 34. XRD patterns of the commercial (a) molybdenum disilicide $\left(\mathrm{MoSi}_{2}\right)$, and (b) tungsten disilicide $\left(\mathrm{WSi}_{2}\right)$ starting powders.

Figure 35. SEM microstructures of the commercial (a) $\mathrm{MoSi}_{2}$, (b) $\mathrm{WSi}_{2}$, (c) $\mathrm{f} . \mathrm{Al}_{2} \mathrm{O}_{3}$ (fine$\mathrm{Al}_{2} \mathrm{O}_{3}$ ) (d) c. $\mathrm{Al}_{2} \mathrm{O}_{3}$ (coarse- $\mathrm{Al}_{2} \mathrm{O}_{3}$ ), and (e) $\mathrm{ZrO}_{2}$ starting powders. 66

Figure 36. XRD patterns of the (a) 60-40 $\mathrm{MoSi}_{2}$-based composites, and (b) 60-40 $\mathrm{WSi}_{2}-$ based composites reinforced by $\mathrm{f}_{\mathrm{Al}} \mathrm{Al}_{3}, \mathrm{c} . \mathrm{Al}_{2} \mathrm{O}_{3}$ and $\mathrm{ZrO}_{2}$ particles after sintering at $1600^{\circ} \mathrm{C}$ for $2 \mathrm{~h}$ 
Figure 37. SEM microstructures of the (a) $\mathrm{MoSi}_{2}-\mathrm{f}_{\mathrm{Al}} \mathrm{O}_{3}$, (b) $\mathrm{MoSi}_{2}-\mathrm{c} \cdot \mathrm{Al}_{2} \mathrm{O}_{3}$, (c) $\mathrm{MoSi}_{2}-$ $\mathrm{ZrO}_{2}$, (d) $\mathrm{WSi}_{2}-\mathrm{f} . \mathrm{Al}_{2} \mathrm{O}_{3}$, (e) $\mathrm{WSi}_{2}-\mathrm{c} . \mathrm{Al}_{2} \mathrm{O}_{3}$, and (f) $\mathrm{WSi}_{2}-\mathrm{ZrO}_{2}$ composites all having 60-40 metal silicide-refractory oxide fractions after sintering at $1600^{\circ} \mathrm{C}$ for $2 \mathrm{~h}$... 76

Figure 38. SEM microstructures of the (a) 60-40 $\mathrm{MoSi}_{2}-\mathrm{c} . \mathrm{Al}_{2} \mathrm{O}_{3}$, and (b) 60-40 $\mathrm{WSi}_{2}-$ f. $\mathrm{Al}_{2} \mathrm{O}_{3}$ composites after sintering (chemically etched), and (c) EDS analysis results of the grey (R-grey) and bright (R-bright) regions specified on the 60-40 $\mathrm{WSi}_{2}$ f. $\mathrm{Al}_{2} \mathrm{O}_{3}$ composite microstructure.

Figure 39. XRD patterns of the (a) $\mathrm{MoSi}_{2}-\mathrm{f}_{2} \mathrm{Al}_{2} \mathrm{O}_{3}$, (b) $\mathrm{MoSi}_{2}-\mathrm{c} . \mathrm{Al}_{2} \mathrm{O}_{3}$, (c) $\mathrm{MoSi}_{2}-\mathrm{ZrO}_{2}$, (d) $\mathrm{WSi}_{2}-\mathrm{f} . \mathrm{Al}_{2} \mathrm{O}_{3}$, (e) $\mathrm{WSi}_{2}-\mathrm{c} . \mathrm{Al}_{2} \mathrm{O}_{3}$, and (f) $\mathrm{WSi}_{2}-\mathrm{ZrO}_{2}$ composites all having 60-40 metal silicide-refractory oxide fractions after sintering at $1600^{\circ} \mathrm{C}$, and then annealing at $1400^{\circ} \mathrm{C}$ for $24-48 \mathrm{~h}$ (sintered sample was defined as " $0 \mathrm{~h}$ " indicating zero annealing time as a starting point). 83

Figure 40. Changes in the amount (vol\%) of (a) $\mathrm{Mo}_{5} \mathrm{Si}_{3}$, and (b) $\mathrm{W}_{5} \mathrm{Si}_{3}$ secondary phases as a function of annealing time.

Figure 41. SEM microstructures of the (a-b-c) $\mathrm{MoSi}_{2}$, and (d-e-f) 60-40 $\mathrm{MoSi}_{2}-\mathrm{f}_{\mathrm{Al}} \mathrm{Al}_{2} \mathrm{O}_{3}$ composite after sintering at $1600^{\circ} \mathrm{C}$, and then annealing at $1400^{\circ} \mathrm{C}$ for $24-48 \mathrm{~h} . . . .90$

Figure 42. SEM microstructures of the (a-b) 60-40 $\mathrm{MoSi}_{2}-\mathrm{c} . \mathrm{Al}_{2} \mathrm{O}_{3}$, (c-d) 60-40 $\mathrm{MoSi}_{2}-$ $\mathrm{ZrO}_{2}$, (e-f) 60-40 WSi2-f. $\mathrm{Al}_{2} \mathrm{O}_{3}$, (g-h) 60-40 WSi $2-\mathrm{c} . \mathrm{Al}_{2} \mathrm{O}_{3}$, and (i-j) 60-40 $\mathrm{WSi}_{2-}$ $\mathrm{ZrO}_{2}$ composites after annealing at $1400^{\circ} \mathrm{C}$ for $24-48 \mathrm{~h}$.

Figure 43. Changes in the average size of the (a) $\mathrm{MoSi}_{2}$ and (b) $\mathrm{WSi}_{2}$ grains (grain growth rates) as a function of annealing time.

Figure 44. The electrical conductivity of the (a) $\mathrm{MoSi}_{2}$-based and (b) $\mathrm{WSi}_{2}$-based composites and pure metal disilicides $\left(\mathrm{MoSi}_{2}, \mathrm{WSi}_{2}\right)$ as a function of temperature (Electrical conductivity data is presented on the logarithmic scale). 101

Figure 45. XRD patterns of the commercial (a) niobium disilicide ( $\left.\mathrm{NbSi}_{2}\right)$, and (b) tantalum disilicide $\left(\mathrm{TaSi}_{2}\right)$ starting powders.

Figure 46. SEM microstructures of the commercial (a) $\mathrm{NbSi}_{2}$, (b) $\mathrm{TaSi}_{2}$, (c) $\mathrm{Al}_{2} \mathrm{O}_{3}$, and (d) $\mathrm{ZrO}_{2}$ starting powders.

Figure 47. Apparent porosity levels (\%) of the (a) $\mathrm{NbSi}_{2}$-based, and (b) $\mathrm{TaSi}_{2}$-based composites with the addition of the $\mathrm{Al}_{2} \mathrm{O}_{3}$ and $\mathrm{ZrO}_{2}$ particles, as a function of sintering temperature.

Figure 48. XRD patterns of the (a) 60-40 $\mathrm{NbSi}_{2}$-based, and (b) 60-40 $\mathrm{TaSi}_{2}$-based composites, with the addition of 40 vol\% $\mathrm{Al}_{2} \mathrm{O}_{3}$ and $\mathrm{ZrO}_{2}$ particles, sintered at $1600^{\circ} \mathrm{C}$ for $2 \mathrm{~h}$ in argon.

Figure 49. XRD patterns of the (a) $\mathrm{NbSi}_{2}-\mathrm{Al}_{2} \mathrm{O}_{3}$, (b) $\mathrm{NbSi}_{2}-\mathrm{ZrO}_{2}$, (c) $\mathrm{TaSi}_{2}-\mathrm{Al}_{2} \mathrm{O}_{3}$, and (d) $\mathrm{TaSi}_{2}-\mathrm{ZrO}_{2}$ composites with the addition of $40 \mathrm{vol} \%$ alumina and zirconia particles, all further annealed at $1400^{\circ} \mathrm{C}$ for 24,48 and $96 \mathrm{~h}$ in argon. 125

Figure 50. Changes in the volume percentage of the $\mathrm{Nb}_{5} \mathrm{Si}_{3}$ secondary phase within the 60$40 \mathrm{NbSi}_{2}-\mathrm{Al}_{2} \mathrm{O}_{3}$ and $\mathrm{NbSi}_{2}-\mathrm{ZrO}_{2}$ composites as a function of annealing time. ..... 128

Figure 51. Low magnification backscattered SEM microstructures of the (a) $\mathrm{NbSi}_{2}-\mathrm{Al}_{2} \mathrm{O}_{3}$, (b) $\mathrm{NbSi}_{2}-\mathrm{ZrO}_{2}$, (c) $\mathrm{TaSi}_{2}-\mathrm{Al}_{2} \mathrm{O}_{3}$, and (d) $\mathrm{TaSi}_{2}-\mathrm{ZrO}_{2}$ composites with the addition of $40 \mathrm{vol} \% \mathrm{Al}_{2} \mathrm{O}_{3}$ and $\mathrm{ZrO}_{2}$ particles after sintering at $1600^{\circ} \mathrm{C}$ for $2 \mathrm{~h}$ in argon... 130 
Figure 52. High magnification backscattered SEM microstructures of the (a) $\mathrm{NbSi}_{2}-\mathrm{Al}_{2} \mathrm{O}_{3}$, (b) $\mathrm{NbSi}_{2}-\mathrm{ZrO}_{2}$, (c) $\mathrm{TaSi}_{2}-\mathrm{Al}_{2} \mathrm{O}_{3}$, and (d) $\mathrm{TaSi}_{2}-\mathrm{ZrO}_{2}$ composites with the addition of $40 \mathrm{vol} \% \mathrm{Al}_{2} \mathrm{O}_{3}$ and $\mathrm{ZrO}_{2}$ particles after sintering at $1600^{\circ} \mathrm{C}$ for $2 \mathrm{~h}$ in argon...133

Figure 53. SEM microstructures of the (a1-a2) $\mathrm{NbSi}_{2}-\mathrm{Al}_{2} \mathrm{O}_{3}$, (b1-b2) $\mathrm{NbSi}_{2}-\mathrm{ZrO}_{2}$, (c1-c2) $\mathrm{TaSi}_{2}-\mathrm{Al}_{2} \mathrm{O}_{3}$, and (d1-d2) $\mathrm{TaSi}_{2}-\mathrm{ZrO}_{2}$ composites with addition of $40 \mathrm{vol} \% \mathrm{Al}_{2} \mathrm{O}_{3}$ and $\mathrm{ZrO}_{2}$ particles after annealing at $1400^{\circ} \mathrm{C}$ for 48 and $96 \mathrm{~h}$ in argon, respectively. (a1-b1-c1-d1: after annealing for $48 \mathrm{~h}$; a2-b2-c2-d2: after annealing for $96 \mathrm{~h}$ ).....136

Figure 54. Oxidation-induced mass change per unit surface area $\left(\mathrm{mg} / \mathrm{cm}^{2}\right)$ of the various $\mathrm{NbSi}_{2}$ - and $\mathrm{TaSi}_{2}$-based composites in air as a function of oxidation temperature, sintering temperature (denoted in parenthesis) and silicide-oxide volume ratio.... 142

Figure 55. Comparison of the oxidation-induced mass changes $\left(\mathrm{mg} / \mathrm{cm}^{2}\right)$ of the (a) $\mathrm{NbSi}_{2}-$ based composites with $\mathrm{NbSi}_{2}$ and $\mathrm{Nb}_{5} \mathrm{Si}_{3}$, and (b) $\mathrm{TaSi}_{2}$-based composites with $\mathrm{TaSi}_{2}$, all sintered at $1600^{\circ} \mathrm{C}$ in argon, as a function of the oxidation temperature. 146

Figure 56. Electrical conductivity of the dense monolithic $\mathrm{NbSi}_{2}, \mathrm{Nb}_{5} \mathrm{Si}_{3}$ and $\mathrm{TaSi}_{2}$ as a reference data, all sintered at $1600^{\circ} \mathrm{C}$ in argon, as a function of the temperature (Electrical conductivity data is shown on the logarithmic scale). .......................149

Figure 57. Electrical conductivity of the $\mathrm{NbSi}_{2}$ - and $\mathrm{TaSi}_{2}$-based composites having (a) 60 40 and (b) 30-70 metal silicide-refractory oxide volume percentages, all sintered at $1600^{\circ} \mathrm{C}$ in argon, as a function of the temperature (Electrical conductivity data is

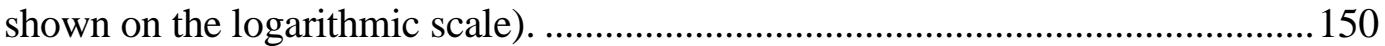

Figure 58. XRD pattern of the commercial chromium silicide starting powder. ............... 163

Figure 59. XRD patterns of the (a) CC-4060, CC-5050, CC-5545 and CC-6040, and (b) CC-6535, CC-7030, CC-8020 and CC-9010 chromium silicides-based composites, which were all sintered at $1370^{\circ} \mathrm{C}$ for $2 \mathrm{~h}$ in argon............................................. 167

Figure 60. SEM microstructures of the (a1-a2) CC-4060, (b1) CC-5050, (c1-c2) CC-5545 and (d1-d2) CC-6040 chromium silicides-based composites after sintering at $1370^{\circ} \mathrm{C}$ for $2 \mathrm{~h}$ in argon 170

Figure 61. SEM microstructures of the (a1-a2) CC-6535, (b1) CC-7030, (c1) CC-8020 and (d1-d2) CC-9010 chromium silicides-based composites after sintering at $1370^{\circ} \mathrm{C}$ for $2 \mathrm{~h}$ in argon. 175

Figure 62. Mass change per unit surface area as a function of oxidation temperature for the (a) CC-4060, CC-5050, CC-5545, (b) CC-6040, CC-6535, CC-7030, and (c) CC8020, CC-9010, reference $\mathrm{CrSi}_{2}+\mathrm{CrSi}$ sample during non-isothermal oxidation from $50^{\circ} \mathrm{C}$ to $870^{\circ} \mathrm{C}$ in air. 180

Figure 63. Electrical conductivity as a function of the temperature for the (a) CC-4060, CC5050, CC-5545 and CC-6040, and (b) CC-6535, CC-7030, CC-8020 and CC-9010 chromium silicide-based composites, which were all sintered at $1370^{\circ} \mathrm{C}$ in argon (Electrical conductivity data is shown on the logarithmic scale).

Figure 64. Schematic review (spline diagram) of changes in the electrical conductivities of the chromium silicide-based composites at $1000^{\circ} \mathrm{C}$ as a function of the initial chromium silicide/oxide ratios. 187

Figure 65. XRD patterns of the (a) CC-5050, (b) CC-5545, and (c) CC-6040 composites after sintering (denoted as " $0 \mathrm{~h}$ " annealing), and after further annealing at $1350^{\circ} \mathrm{C}$ for 24,48 and $96 \mathrm{~h}$ in argon. 190 
Figure 66. SEM microstructures of the (a1-a2-a3) CC-5050, (b1-b2-b3) CC-5545, and (c1c2-c3) CC-6040 composites after further annealing at $1350^{\circ} \mathrm{C}$ for 24,48 and $96 \mathrm{~h}$ in argon (a1-b1-c1: after annealing for 24 h; a2-b2-c2: after annealing for 48 h; a3-b3c3: after annealing for $96 \mathrm{~h}$ ).

Figure 67. SEM microstructure of the highly dense silica surface layer formed within the CC-5545 composite after annealing at $1350^{\circ} \mathrm{C}$ for $48 \mathrm{~h}$ in argon 198

Figure 68. Isothermal oxidation of the CC-5050, CC-5545 and CC-6040 composites in air at $850^{\circ} \mathrm{C}$ for $12 \mathrm{~h}$. 199

Figure 69. Mass change per unit surface area as a function of oxidation temperature for the as-sintered and as-annealed (a) CC-5050, (b) CC-5545, and (c) CC-6040 composites during non-isothermal oxidation from $50^{\circ} \mathrm{C}$ to $870^{\circ} \mathrm{C}$ in air..............200

Figure 70. Electrical conductivity as a function of temperature for the as-sintered and asannealed (a) CC-5050, (b) CC-5545, and (c) CC-6040 composites (Electrical conductivity data is shown on the logarithmic scale). 203

Figure 71. Schematic illustration of the proposed image analysis method for quantifying the degree of distribution (homogeneity) in composite materials on a representative microstructure. (Black circles represent the particles on the image). .214

Figure 72. Images of six 19x19 reference patterns (P1-P6) which act as representative composite microstructures with different degrees of distribution of identical reinforcement particles. (Black squares represent the particles on the binary images). 218

Figure 73. D index values calculated for six reference patterns (microstructures) from P1 to P6 as a function of total number of lines analyzed $(2 \mathrm{~N})$ by using the proposed method. (Blue triangles of the P1 are under the orange triangles of the P6)..........219

Figure 74. Classification of the homogeneity (degree of distribution) levels for composites based on $\mathrm{D}$ index ranges in the proposed method. 221

Figure 75. Original cross-sectional SEM images of the metal silicide-refractory oxide composites and their converted binary images showing individual metal silicide grains as black regions: a) (60-40) vol\% $\mathrm{WSi}_{2}-\mathrm{ZrO}_{2}$, b) (60-40) vol\% $\mathrm{WSi}_{2}-\mathrm{Y}_{2} \mathrm{O}_{3}$,

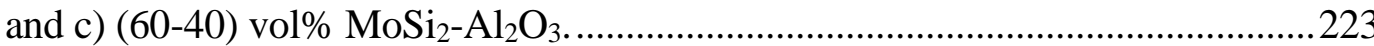

Figure 76. The D index values calculated for three different metal silicide-refractory oxide composite SEM microstructures as a function of total number of lines analyzed $(2 \mathrm{~N})$ by using the proposed method.... 225

Figure 77. Optical photograph and SEM micrographs of the [75-25] $\mathrm{MoSi}_{2}-\mathrm{Al}_{2} \mathrm{O}_{3} / / \mathrm{WSi}_{2}-$ $\mathrm{Al}_{2} \mathrm{O}_{3}$ composite thermocouple screen printed on an alumina substrate and then sintered at $1500^{\circ} \mathrm{C}$ for $2 \mathrm{~h}$.

Figure 78. (a) XPS wide range survey spectra and (b) high-resolution XPS spectra (Mo3d, $\mathrm{Si} 2 \mathrm{p}, \mathrm{Al} 2 \mathrm{p}, \mathrm{O} 1 \mathrm{~s}$ ) of the various $\mathrm{MoSi}_{2}-\mathrm{Al}_{2} \mathrm{O}_{3}$ composites after sintering at $1500^{\circ} \mathrm{C}$ for $2 \mathrm{~h}$. 238

Figure 79. (a) XPS wide range survey spectra and (b) high-resolution XPS spectra (W4f, $\mathrm{Si} 2 \mathrm{p}, \mathrm{Al} 2 \mathrm{p}, \mathrm{O} 1 \mathrm{~s}$ ) of the various $\mathrm{WSi}_{2}-\mathrm{Al}_{2} \mathrm{O}_{3}$ composites after sintering at $1500^{\circ} \mathrm{C}$ for $2 \mathrm{~h}$

Figure 80. (a) XRD patterns of the [50-50] and [90-10] $\mathrm{MoSi}_{2}-\mathrm{Al}_{2} \mathrm{O}_{3}$ composites after sintering at $1500^{\circ} \mathrm{C}$ for $2 \mathrm{~h}$; (b-c) Rietveld refinement results of the [50-50] and [90- 
10] $\mathrm{MoSi}_{2}-\mathrm{Al}_{2} \mathrm{O}_{3}$ composites, respectively [solid red lines = fitting curves; black dots $=$ experimental XRD data] .................................................................242

Figure 81. SEM micrographs of the (a) [50-50], (b) [60-40], (c) [75-25] and (d) [90-10] $\mathrm{MoSi}_{2}-\mathrm{Al}_{2} \mathrm{O}_{3}$ composites after sintering at $1500^{\circ} \mathrm{C}$ for $2 \mathrm{~h}$..................................24

Figure 82. SEM micrographs of the (a) [50-50], (b) [60-40], (c) [75-25] and (d) [90-10] $\mathrm{WSi}_{2}-\mathrm{Al}_{2} \mathrm{O}_{3}$ composites after sintering at $1500^{\circ} \mathrm{C}$ for $2 \mathrm{~h}$.....................................245

Figure 83. Optical photograph and SEM micrographs (alumina substrate, left leg, right leg, junction) of the [75-25] $\mathrm{MoSi}_{2}-\mathrm{Al}_{2} \mathrm{O}_{3} / / \mathrm{Pt}$ thermocouple screen printed on an alumina substrate and then sintered at $1500^{\circ} \mathrm{C}$ for $2 \mathrm{~h}$.

Figure 84. (a-c) Thermoelectric voltages (E) and (b-d) effective Seebeck coefficients (S) measured for the various $\mathrm{MoSi}_{2}-\mathrm{Al}_{2} \mathrm{O}_{3} / / \mathrm{Pt}$ and $\mathrm{WSi}_{2}-\mathrm{Al}_{2} \mathrm{O}_{3} / / \mathrm{Pt}$ thermocouples as a function of temperature difference. 250

Figure 85. Estimated Seebeck coefficients $(\mathrm{S})$ of the various $\mathrm{MoSi}_{2}-\mathrm{Al}_{2} \mathrm{O}_{3}$ and $\mathrm{WSi}_{2}-\mathrm{Al}_{2} \mathrm{O}_{3}$ composites as a function of temperature difference ( $\mathrm{S}_{\mathrm{Pt}}$ is also presented)............255

Figure 86. (a) Thermoelectric voltage (E) and (b) effective Seebeck coefficients (S) measured for the $\mathrm{MoSi}_{2} / / \mathrm{WSi}_{2}$ and various $\mathrm{MoSi}_{2}-\mathrm{Al}_{2} \mathrm{O}_{3} / / \mathrm{WSi}_{2}-\mathrm{Al}_{2} \mathrm{O}_{3}$ thermocouples as a function of temperature difference. .......................................257

Figure 87. Comparison of the estimated (dashed lines) and measured effective (solid lines) Seebeck coefficients of the various $\mathrm{MoSi}_{2}-\mathrm{Al}_{2} \mathrm{O}_{3} / / \mathrm{WSi}_{2}-\mathrm{Al}_{2} \mathrm{O}_{3}$ (abbreviated as $\mathrm{MA} / \mathrm{WA}$ ) composite thermocouples as a function of temperature difference. .....260

Figure 88. Thermoelectric performance of the [90-10] $\mathrm{MoSi}_{2}-\mathrm{Al}_{2} \mathrm{O}_{3} / /[90-10] \mathrm{WSi}_{2}-\mathrm{Al}_{2} \mathrm{O}_{3}$ long composite thermocouple $\left(22.9 \mathrm{~cm}\right.$ length, $0.6 \mathrm{~cm}$ width) up to $1350^{\circ} \mathrm{C}$, as a function of cold- and hot-junction temperature, and time.

Figure 89. Mass change per unit surface area of the as-sintered (non-preoxidized) (a) $\mathrm{MoSi}_{2}$ and 30-70 vol\% $\mathrm{MoSi}_{2}-\mathrm{Al}_{2} \mathrm{O}_{3}$, and (b) $\mathrm{WSi}_{2}$ and $30-70$ vol\% $\mathrm{WSi}_{2}-\mathrm{Al}_{2} \mathrm{O}_{3}$ samples as a function of oxidation temperature in air ("w/o" term refers to non-preoxidized samples).

Figure 90. Mass change per unit surface area of the non-preoxidized (w/o) and preoxidized (w/) (a-b-c) 30-70 vol\% $\mathrm{MoSi}_{2}-\mathrm{Al}_{2} \mathrm{O}_{3}$, and (d-e-f) $30-70$ vol\% $\mathrm{WSi}_{2}-\mathrm{Al}_{2} \mathrm{O}_{3}$ composites as a function of oxidation temperature in air (a-d, b-e, c-f presents the samples preoxidized at $1000^{\circ} \mathrm{C}, 1100^{\circ} \mathrm{C}$ and $1200^{\circ} \mathrm{C}$, respectively). 277

Figure 91. Effect of preoxidation time and temperature on the overall mass gain at $870^{\circ} \mathrm{C}$ for the (a) 30-70 vol\% $\mathrm{MoSi}_{2}-\mathrm{Al}_{2} \mathrm{O}_{3}$, (b) 30-70 vol\% $\mathrm{WSi}_{2}-\mathrm{Al}_{2} \mathrm{O}_{3}$ composites, and (c) mass change per unit surface area in the pest oxidation temperature regime for the composites preoxidized at $1000^{\circ}-1200^{\circ} \mathrm{C}$ for $120 \mathrm{~min}$....................................2.28

Figure 92. Optical micrographs of the surface of the non-preoxidized (w/o PO) and preoxidized (w/ PO) (a-b-c-d) 30-70 $\mathrm{MoSi}_{2}-\mathrm{Al}_{2} \mathrm{O}_{3}$ and (e-f-g-h) 30-70 $\mathrm{WSi}_{2}-\mathrm{Al}_{2} \mathrm{O}_{3}$ composites (non-preoxidized sample surfaces are presented as baseline).............283

Figure 93. Cross-sectional SEM microstructures of the (a-b-c-d-e) 30-70 $\mathrm{MoSi}_{2}-\mathrm{Al}_{2} \mathrm{O}_{3}$ and (f-g-h-i) 30-70 $\mathrm{WSi}_{2}-\mathrm{Al}_{2} \mathrm{O}_{3}$ composites after preoxidation at $1000^{\circ}-1200^{\circ} \mathrm{C}$ for 120 $\min$. 288

Figure 94. XRD patterns of the 30-70 vol\% (a) $\mathrm{MoSi}_{2}-\mathrm{Al}_{2} \mathrm{O}_{3}$ and (b) $\mathrm{WSi}_{2}-\mathrm{Al}_{2} \mathrm{O}_{3}$ composites after preoxidation at $1000^{\circ}-1200^{\circ} \mathrm{C}$ for $120 \mathrm{~min}$ (XRD results of the non-preoxidized samples are used as baseline). 293 
Figure 95. Raman spectra taken from the surfaces of the 30-70 vol\% (a) $\mathrm{MoSi}_{2}-\mathrm{Al}_{2} \mathrm{O}_{3}$ and (b) $\mathrm{WSi}_{2}-\mathrm{Al}_{2} \mathrm{O}_{3}$ composites after preoxidation at $1000^{\circ}-1200^{\circ} \mathrm{C}$ for $120 \mathrm{~min}$ (Raman spectra of the non-preoxidized samples are presented as baseline).........295

Figure 96. XPS survey spectra taken from the surfaces of the $30-70 \mathrm{vol} \%$ (a) $\mathrm{MoSi}_{2}-\mathrm{Al}_{2} \mathrm{O}_{3}$ and (b) $\mathrm{WSi}_{2}-\mathrm{Al}_{2} \mathrm{O}_{3}$ composites after preoxidation at $1000^{\circ}-1200^{\circ} \mathrm{C}$ for $120 \mathrm{~min}$ (XPS spectra of the non-preoxidized samples are used as baseline).

Figure 97. Deconvoluted high-resolution XPS peaks of the Si $2 p$ for the non-preoxidized and preoxidized (a-b-c-d) 30-70 vol\% $\mathrm{MoSi}_{2}-\mathrm{Al}_{2} \mathrm{O}_{3}$ and (e-f-g) 30-70 vol\% $\mathrm{WSi}_{2}-$ $\mathrm{Al}_{2} \mathrm{O}_{3}$ composites.

Figure 98. Deconvoluted high-resolution XPS peaks of the Al $2 p$ for the non-preoxidized and preoxidized (a-b-c) 30-70 vol\% $\mathrm{MoSi}_{2}-\mathrm{Al}_{2} \mathrm{O}_{3}$ and (d-e-f) $30-70$ vol\% $\mathrm{WSi}_{2}-$ $\mathrm{Al}_{2} \mathrm{O}_{3}$ composites. 303

Figure 99. Electrical conductivity of the 30-70 vol\% (a) $\mathrm{MoSi}_{2}-\mathrm{Al}_{2} \mathrm{O}_{3}$ and (b) $\mathrm{WSi}_{2}-\mathrm{Al}_{2} \mathrm{O}_{3}$ composites after preoxidation at $1000^{\circ}-1200^{\circ} \mathrm{C}$ for $120 \mathrm{~min}$ (Electrical data of the non-preoxidized samples are also presented as baseline). 307

Figure 100. Optical micrographs of the edges of the composite samples (top surfaces): (a) $\mathrm{MoSi}_{2}-\mathrm{Al}_{2} \mathrm{O}_{3}$ preoxidized at $1200^{\circ} \mathrm{C}$ for $120 \mathrm{~min}$, and (b) $\mathrm{WSi}_{2}-\mathrm{Al}_{2} \mathrm{O}_{3}$ preoxidized at $1100^{\circ} \mathrm{C}$ for $120 \mathrm{~min}$. 310 


\section{LIST OF TABLES}

Table 1. All transition metal silicide phases represented in the periodic table $[24,26]$......... 8

Table 2. Crystal system, space group and lattice parameters of the binary refractory metal disilicides as a primary group for the high temperature structural and electrical applications $[21,26]$.

Table 3. High temperature oxidation resistance of the several refractory transition metal silicides with high melting points based on the oxidation-induced mass changes [1].34

Table 4. Weight changes for the pure $\mathrm{MoSi}_{2}$ and several $\mathrm{MoSi}_{2}$-based composites after 100 $\mathrm{h}$ of exposure to air at $1600^{\circ} \mathrm{C}$ [83].

Table 5. Relative densities of the $\mathrm{MoSi}_{2}$-based and $\mathrm{WSi}_{2}$-based composites reinforced by f. $\mathrm{Al}_{2} \mathrm{O}_{3}, c . \mathrm{Al}_{2} \mathrm{O}_{3}$ and $\mathrm{ZrO}_{2}$ particles as function of sintering temperature.

Table 6. Apparent density and apparent porosity of the $\mathrm{MoSi}_{2}$-based and $\mathrm{WSi}_{2}$-based composites reinforced by $\mathrm{f}_{\mathrm{Al}} \mathrm{Al}_{2} \mathrm{O}_{3}, \mathrm{c} . \mathrm{Al}_{2} \mathrm{O}_{3}$ and $\mathrm{ZrO}_{2}$ particles as function of sintering temperature. 71

Table 7. The rates of the formation of secondary 5-3 metal silicide phases ( $\left.\mathrm{Mo}_{5} \mathrm{Si}_{3}, \mathrm{~W}_{5} \mathrm{Si}_{3}\right)$ in the 60-40 composites over two annealing periods.

Table 8. Apparent density of the $\mathrm{NbSi}_{2}$ - and $\mathrm{TaSi}_{2}$-based composites with the addition of $\mathrm{Al}_{2} \mathrm{O}_{3}$ and $\mathrm{ZrO}_{2}$ particles, as function of the sintering temperature.

Table 9. Compositions and denotations of the chromium silicide-based composites........ 164

Table 10. Summary of the composite compositions, and high-temperature oxidation and electrical properties of the chromium silicide-based composites. 188

Table 11. Review of the results obtained for three different metal silicide-refractory oxide composites after 40 lines analyzed by using the proposed method........................226

Table 12. Review of the Skewness index $(\beta)$ values as a function of the number of quadrats, and their comparison with the $\mathrm{D}$ index values for the metal silicide-refractory oxide composites.

Table 13. Configurations and compositions of the various metal silicide-oxide//Pt, metal silicide//metal silicide and metal silicide-oxide//metal silicide-oxide thermocouples studied (volume percentages are represented by [ ]).

Table 14. Summary of the fitting parameters (A, B and D) and $\mathrm{R}^{2}$ values calculated, and then, used in thermoelectric calculations.

Table 15. Summary of the measured thermoelectric voltage $\left(\mathrm{E}_{1000}\right)$ and effective Seebeck coefficients $\left(\mathrm{S}_{500}, \mathrm{~S}_{1000}\right)$ of all thermocouples at $500^{\circ} \mathrm{C}$ and $1000^{\circ} \mathrm{C}$.....................254

Table 16. High-temperature preoxidation (PO) treatment conditions and sample denotations 


\section{LIST OF SYMBOLS AND ABBREVIATIONS}

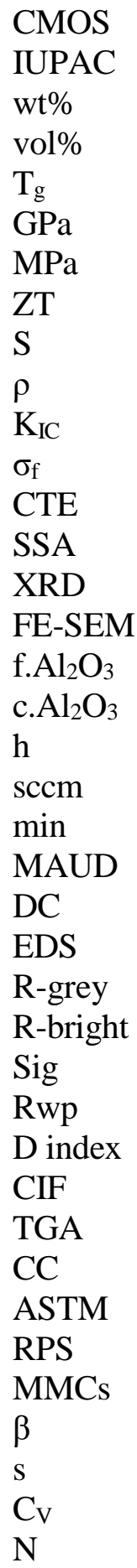

Complementary metal-oxide semiconductor International Union of Pure and Applied Chemistry

Weight percentage Volume percentage Glass transition temperature Gigapascal Megapascal Figure-of-merit Seebeck coefficient Electrical resistivity Fracture toughness Flexural strength Coefficient of thermal expansion Specific surface area $\mathrm{X}$-ray diffraction Field emission scanning electron microcopy Fine-alumina Coarse-alumina Hour Standard cubic centimeter per minute Minute Material Analysis Using Diffraction Direct current Energy dispersive spectroscopy Grey region Bright region goodness of fit Weighted profile R-factor Degree (level) of distribution Crystallographic information file Thermogravimetric analyzer Chromium silicide-Chromium oxide (composite) American Standards for Testing of Materials Relative particle size Metal matrix composites Skewness index Standard deviation Coefficient of variation Number of lines analyzed 
$\mathrm{pO}_{2}$

HDPE

//

XPS

$\mathrm{E}$

$\Delta \mathrm{T}$

$\mathrm{S}_{\mathrm{A}}$

$\mathrm{S}_{\mathrm{B}}$

$\mathrm{S}_{\mathrm{AB}}$

$\Delta \mathrm{V}_{\mathrm{AB}}$

$\mathrm{S}_{\mathrm{MA}}$

$\mathrm{S}_{\mathrm{WA}}$

SMAPt

SWAPt

SMAWA

NIST

DAQ

A,B,C,D

$\mathrm{MA} / \mathrm{WA}$

$\mathrm{PO}$

w/o PO

w/ PO
Partial pressure of oxygen

High-density polyethylene

A thermocouple being formed X-ray photoelectron spectroscopy

Thermoelectric voltage

Temperature difference (gradient)

Seebeck coefficient of a material-A

Seebeck coefficient of a material-B

Difference in Seebeck coefficients of A-B materials

Electric potential across the interface of $\mathrm{A}-\mathrm{B}$ materials Intrinsic Seebeck coefficient of a $\mathrm{MoSi}_{2}-\mathrm{Al}_{2} \mathrm{O}_{3}$ composite Intrinsic Seebeck coefficient of a $\mathrm{WSi}_{2}-\mathrm{Al}_{2} \mathrm{O}_{3}$ composite Effective Seebeck coefficient of a $\mathrm{MoSi}_{2}-\mathrm{Al}_{2} \mathrm{O}_{3} / / \mathrm{Pt}$ thermocouple Effective Seebeck coefficient of a WSi $2-\mathrm{Al}_{2} \mathrm{O}_{3} / / \mathrm{Pt}$ thermocouple Effective Seebeck coefficient of a $\mathrm{MoSi}_{2}-\mathrm{Al}_{2} \mathrm{O}_{3} / / \mathrm{WSi}_{2}-\mathrm{Al}_{2} \mathrm{O}_{3}$ thermocouple National Institute of Standards and Technology Data acquisition Fitting coefficients $\mathrm{MoSi}_{2}-\mathrm{Al}_{2} \mathrm{O}_{3} / / \mathrm{WSi}_{2}-\mathrm{Al}_{2} \mathrm{O}_{3}$ composite thermocouple Preoxidation treatment Non-preoxidized samples (without PO) Preoxidized samples (with PO) 


\section{IN T R O D U C T I O N}

\section{Statement of Problem}

High temperatures and extreme harsh environments are commonly described as one of the major challenges in a broad range of industries such as power generation, coal gasification, and steel and glass manufacturing. The main sources of these harsh conditions are known as very high operating temperatures, high pressures, and oxidative and corrosive atmospheres. To achieve better process control, high efficiency, less environmental impact and increased lifetime of the process units, it is required to closely monitor the process conditions such as temperature and pressure, as well as, the structural health and degradation (e.g. spallation) of the ceramic refractories widely used in the high-temperature reactors. However, commonly used materials ( $\mathrm{Pt}, \mathrm{Rh}$ as noble metals) and their alloys undergo structural and functional challenges, such as selective oxidation, compositional and mechanical degradation, microstructural changes, leading to their increased failure rate and highly reduced lifetime. Therefore, it is apparent that there is a great demand for the development of high-temperature electrical and sensing materials, which are capable to operate reliably and accurately for extended operation hours without any degradation.

\section{Goals of Research}

Due to the extensive material requirements of the high-temperature electrical applications, transition metal silicides (e.g. $\mathrm{MoSi}_{2}, \mathrm{WSi}_{2}$ ) offer promising advantages due to their high melting points, excellent high-temperature oxidation resistance, low corrosion rates, thermal stability, sufficient mechanical properties, thermodynamic compatibility with potential ceramic reinforcements, and electrical conductivities at elevated temperatures. Therefore, the main focus of this research is to develop high-temperature electroconductive composites composed of transition metal silicides and refractory oxides for a broad range of electrical applications. In order to accomplish this, the following objectives were determined and completed: 
- Preparation of highly stable and electrically conductive transition metal siliciderefractory oxide composites that are able to operate at high temperatures

- Study their densification as a function of composition and temperature

- Investigate their phase (thermal) stability and secondary phase formation at high temperatures

- Understand their microstructural evolution and effect of the oxide phase on grain growth mechanism

- Study their oxidation behavior in a wide temperature range in air atmosphere

- Improve their oxidation resistance via oxide phase addition and high-temperature preoxidation treatment

- Perform electrical measurements at high temperatures to study their electrical performance as a function of composition, processing and temperature

- Fabricate thick-film embedded thermocouples from the selected composites, and study their thermoelectric performance along with structural and microstructural analyses

\section{Thesis Organization}

This dissertation is composed of seven chapters. The first chapter provides a comprehensive literature review (background) reporting the needs for high temperature applications, importance of transition metal silicides, and earlier studies on intermetallics, transition metal silicides and their composites. Chapter 2 presents the densification, phase stability, secondary phase formation, microstructural evolution, grain growth and hightemperature electrical properties for the molybdenum silicide- and tungsten silicide-based composites with the addition of alumina and zirconia phases. Chapter 3 explores the processing of the niobium silicide- and tantalum silicide-based electroconductive composites, and their detailed characterization for phase (thermal) stability, microstructures, oxidation behavior, and electrical properties at elevated temperatures. Chapter 4 discusses the fabrication of the chromium silicide-based composites via solidstate reactions, formation of various composites with different type of metal silicides, and their detailed characterization for phase stability, microstructures, oxidation behavior and 
high-temperature electrical properties. Chapter 5 presents the microstructural image analysis technique developed to quantitively measure the mixedness (homogeneity) of the composite materials to help better understanding of the microstructure-property relations (e.g. homogeneity - percolation/electrical conductivity). Chapter 6 provides the fabrication of the molybdenum silicide- and tungsten silicide-based thick-film ceramic composite thermocouples as deposited on alumina substrates via a screen printing technique, and their structural and thermoelectric characterization. Chapter 7 explores the influence of the alumina phase addition and high-temperature preoxidation treatment on the oxidation behavior of the molybdenum silicide- and tungsten silicide-based composites for further improvement of their oxidation resistance. 


\section{CHA P T E R 1: B A C K G R O U N D}

There has been a growing interest in the development of high temperature structural materials for a wide range of industrial and military applications such as gas turbine engines, combustion chambers, missile nozzles, diesel engine glow plugs, gas burners, lances for molten metal and glasses, and high temperature load bearing [1-3]. In such applications, different parts and components are all exposed to extreme physical conditions in various mechanical, corrosive, and oxidizing environments. For example, high operating temperatures, high thermal conductivities, high stiffness, high strength to weight ratio, and good resistance to oxidation and corrosion are required for the aerospace gas turbine engines [2-5]. In addition, structural materials used in industrial gas burners, and steel and glass manufacturing as lances need to have excellent oxidation and corrosion resistance at high temperatures due to their interaction with oxygen gas combustion environment, and their physical contact with molten metals and glasses $[2,6]$. Similar materials also require improved mechanical properties such as high yield strength, high fracture toughness, low creep rate, and high wear resistance at high temperatures $[1,3,7]$.

In order to achieve those advanced properties that can withstand highly oxidizing and corrosive environments at elevated temperatures, many high temperature structural materials have been developed over the years. These structural materials, which consist of (1) nickel-base superalloys, (2) structural ceramics, and (3) intermetallics, are mainly classified and discussed based on operating temperatures at their applications $[1,4,8]$. For temperatures below $1200^{\circ} \mathrm{C}$, nickel-base superalloys have been mostly used as gas turbine elements in aerospace applications due to their excellent oxidation and mechanical properties. However, these superalloys show some disadvantages such as requirement of cooling during the operation of the gas turbine engines, low operating temperature, high density, and low strength to weight ratio $[1,8]$. As alternatives of nickel-base superalloys, several nickel and titanium aluminides such as $\mathrm{Ni}_{3} \mathrm{Al}, \mathrm{TiAl}$, and $\mathrm{Ti}_{3} \mathrm{Al}$ in the class of intermetallics have been also utilized for similar applications in the range of $800^{\circ} \mathrm{C}$ and 
$1200^{\circ} \mathrm{C}$ due to their mechanical properties and lower densities $[1,6,8]$. But their poor oxidation resistance above $650^{\circ} \mathrm{C}$ and low melting temperature limits their use in structural applications. At higher temperatures above $1200^{\circ} \mathrm{C}$, structural ceramics and intermetallics are known as primary candidates that can fulfill most of the required combination of properties for high temperature structural applications [4,6,8]. Structural ceramics, which are mostly silicon-based ceramic materials, such as $\mathrm{SiC}$ and $\mathrm{Si}_{3} \mathrm{~N}_{4}$ are important high temperature structural materials since they present excellent resistance to oxidation and high strength at elevated temperatures with high melting points. Apart from their advantages, low ductility at high temperatures, difficulty of alloying and machining, cost of manufacture due to cost of starting materials/fabrication, and relatively lower fracture toughness are main limitations of these silicon-based structural ceramics $[1,9,10]$. Therefore, alternative materials called as intermetallics have been studied and developed for high temperature structural applications as alternatives to the other materials. In this field, high temperature intermetallics are generally divided into two groups which are (1) aluminides, and (2) silicides. Nickel-, niobium-, iron-, and titanium-aluminides such as $\mathrm{NiAl}, \mathrm{NbAl}_{3}, \mathrm{Fe}_{3} \mathrm{Al}$ and $\mathrm{Ti}_{3} \mathrm{Al}$ are mostly used intermetallics as high temperature structural materials in the group of aluminides [1-3]. Although these aluminide intermetallics have lower density and high operating temperature than nickel-base superalloys, they do not have significant advantages in comparison to the high temperature silicon-based structural ceramics. In addition, their use at high temperature structural applications are quite limited due to their low strength and creep resistance at the temperatures above $1000^{\circ} \mathrm{C}$, as well as their low resistance to oxidation above $1200^{\circ} \mathrm{C}[1,8]$. Another problem related to the use of aluminide intermetallics is their incompatibility with many reinforcing materials such as $\mathrm{Nb}, \mathrm{SiC}$, and $\mathrm{Y}_{2} \mathrm{O}_{3}$ resulting in unstable chemical reactions and thus formation of undesired phases, since their reinforcement is essential in this field for obtaining improved mechanical properties, creep and oxidation resistance.

As a second group of advanced intermetallics, transition metal silicides such as $\mathrm{MoSi}_{2}, \mathrm{WSi}_{2}, \mathrm{Mo}_{5} \mathrm{Si}_{3}$, and $\mathrm{TiSi}_{2}$, that are silicides of refractory metals, have been 
extensively studied as high temperature structural materials for applications in highly oxidizing and corrosive environments [1,3,4,11-15]. Transition metal silicides generally provide higher melting temperatures, similar densities, higher oxidation resistance (higher oxidation temperature), high thermal stability, and better mechanical properties than aluminide intermetallics [1,7]. In comparison to the silicon-based structural ceramics like $\mathrm{SiC}$, metal silicides take advantages of ease of alloying with other structural silicides and thermodynamic compatibility with potential ceramic reinforcements $\left(\mathrm{Al}_{2} \mathrm{O}_{3}, \mathrm{SiC}, \mathrm{Si}_{3} \mathrm{~N}_{4}\right.$, etc.), while they all have high melting temperatures, excellent oxidation resistance, high thermal conductivity, and good creep resistance. Another advantage of these high temperature structural metal silicides is the formation of a thin protective silica $\left(\mathrm{SiO}_{2}\right)$ layer on the surface up to $1700^{\circ} \mathrm{C}$ in highly oxidizing environments, which also acts as a great barrier against chemical attacks $[4,11,13]$. Their only weaknesses as high temperature structural materials are all stated as insufficient mechanical properties which are low toughness and reduced strength at elevated temperatures $[1,11-13,16]$. In addition to their use in high temperature structural applications, there has been a remarkable interest to transition metal silicides ( $\mathrm{MoSi}_{2}, \mathrm{WSi}_{2}, \mathrm{Ta}_{5} \mathrm{Si}_{3}, \mathrm{CrSi}_{2}$ etc.) in high temperature electrical applications due to their high electrical conductivity, high chemical and thermal stability, excellent diffusion-barrier characteristics, low toxicity, and cost efficiency [2,17-19]. These electrical applications include interconnects and barrier layers in micro-electronic devices, and particularly high temperature thermoelectrics for generating electricity. Therefore, transition metal silicides also exhibit a great potential for high temperature electrical applications, and particularly thermoelectrics in comparison to the widely used, highly toxic, and expensive materials such as thallium-, germanium, and tellurium-based alloys $[17,20]$. In summary, it is required for advanced high-temperature materials to provide adequate combination of properties such as oxidation resistance, thermal stability, creep resistance, fracture toughness, strength, thermal conductivity and electrical conductivity at high temperatures, which make them capable to operate in highly oxidizing and corrosive environments for long terms. Among all potential high temperature structural materials, transition metal silicides as intermetallics are described as most promising candidates 
$[1,4,7,12,16,21,22]$ for high-temperature structural and also electrical applications due to their excellent high-temperature oxidation resistance, high melting point and operating temperature, high-temperature thermal/chemical stability and strength, relatively low density, good creep resistance, high thermal conductivity, high-temperature electrical conductivity, and also thermodynamic compatibility with potential ceramic reinforcements.

\subsection{Transition Metal Silicides}

Transition metal silicides have been implemented into a wide range of engineering and technological applications including heating elements, thin film coatings, molten metal lances, interconnects, gas burners, photovoltaics, CMOS devices, and thermoelectrics $[2,23,24]$. Transition metal silicides are generally described as intermetallic compounds of transition metals and silicon, which have diverse physical properties and crystal structures [24,25]. As a general review, all transition metal silicides that can be practically formed as compounds of transition metals, which are groups from IB to VIIIB of the periodic table (groups 3-11 based on IUPAC), and silicon are listed in Table 1 [24,26]. A broad set of transition metal silicides (binary metal silicides) such as monosilicides (TiSi, MnSi, and CoSi etc.) and disilicides ( $\mathrm{MoSi}_{2}, \mathrm{WSi}_{2}$, and $\mathrm{ZrSi}_{2}$ etc.) can be clearly seen. Therefore, they present a range of mechanical, chemical, thermal, and electrical properties depending on their constituent metals, stoichiometries, and crystal structures. Based on the literature, it can be generally seen that the main focus has been on disilicides of refractory metals in group IV, V, and VI (mostly $\mathrm{MoSi}_{2}, \mathrm{WSi}_{2}, \mathrm{TiSi}_{2}, \mathrm{TaSi}_{2}, \mathrm{NbSi}_{2}$, and $\mathrm{CrSi}_{2}$ as highlighted with bold letters in Table 1) because of their relatively higher melting temperature, good thermal and chemical stability at high temperatures, excellent oxidation resistance, good mechanical properties, relatively low density, and electrical conductivity at high temperatures, which make them best candidates for high temperature structural and also electrical applications in harsh (oxidizing and corrosive) environments [27-31]. Therefore, structure and properties of the refractory transition metal silicides, which have been mostly studied in the literature, are extensively reviewed in the following section. 
Table 1. All transition metal silicide phases represented in the periodic table $[24,26]$.

\begin{tabular}{|c|c|c|c|c|c|c|c|}
\hline \multirow{2}{*}{$\begin{array}{c}\text { IVB } \\
(4)\end{array}$} & \multirow{2}{*}{$\begin{array}{l}\text { VB } \\
\text { (5) }\end{array}$} & \multirow{2}{*}{$\begin{array}{c}\text { VIB } \\
(6)\end{array}$} & \multirow{2}{*}{$\begin{array}{c}\text { VIIB } \\
(7)\end{array}$} & \multicolumn{3}{|c|}{ VIIIB } & \multirow{2}{*}{$\begin{array}{c}\text { IB } \\
(11)\end{array}$} \\
\hline & & & & (8) & (9) & (10) & \\
\hline (Ti-Si) & $(\mathbf{V}-\mathbf{S i})$ & $(\mathrm{Cr}-\mathrm{Si})$ & $\begin{array}{c}(\mathbf{M n}-\mathrm{Si}) \\
\mathrm{Mn}_{4} \mathrm{Si}\end{array}$ & $(\mathrm{Fe}-\mathrm{Si})$ & (Co-Si) & (Ni-Si) & $(\mathbf{C u}-\mathrm{Si})$ \\
\hline $\mathrm{Ti}_{5} \mathrm{Si}_{3}$ & $\mathrm{~V}_{3} \mathrm{Si}$ & $\mathrm{Cr}_{3} \mathrm{Si}$ & $\mathrm{Mn}_{3} \mathrm{Si}$ & $\mathrm{Fe}_{3} \mathrm{Si}$ & $\mathrm{Co}_{3} \mathrm{Si}$ & $\mathrm{Ni}_{3} \mathrm{Si}$ & $\mathrm{Cu}_{3} \mathrm{Si}$ \\
\hline $\mathrm{Ti}_{5} \mathrm{Si}_{4}$ & $\mathrm{~V}_{5} \mathrm{Si}_{3}$ & $\mathrm{Cr}_{5} \mathrm{Si}_{3}$ & $\mathrm{Mn}_{5} \mathrm{Si}_{2}$ & $\mathrm{Fe}_{2} \mathrm{Si}$ & $\mathrm{Co}_{2} \mathrm{Si}$ & $\mathrm{Ni}_{2} \mathrm{Si}$ & $\mathrm{Cu}_{15} \mathrm{Si}_{4}$ \\
\hline TiSi & $\mathrm{V}_{6} \mathrm{Si}_{5}$ & $\mathrm{CrSi}$ & $\mathrm{Mn}_{5} \mathrm{Si}_{3}$ & $\mathrm{Fe}_{5} \mathrm{Si}_{3}$ & $\mathrm{CoSi}$ & $\mathrm{Ni}_{3} \mathrm{Si}_{2}$ & $\mathrm{Cu}_{5} \mathrm{Si}$ \\
\hline $\mathbf{T i S i}_{2}$ & $\mathrm{VSi}_{2}$ & $\mathrm{CrSi}_{2}$ & $\mathrm{MnSi}$ & $\mathrm{FeSi}$ & $\mathrm{Co}_{2} \mathrm{Si}_{3}$ & $\mathrm{Ni}_{31} \mathrm{Si}_{12}$ & $\mathrm{Cu}_{7} \mathrm{Si}$ \\
\hline $\mathrm{Ti}_{3} \mathrm{Si}$ & $\mathrm{V}_{2} \mathrm{Si}$ & & $\begin{array}{c}\mathrm{MnSi}_{2-x} \\
\mathrm{Mn}_{6} \mathrm{Si}\end{array}$ & $\mathrm{FeSi}_{2}$ & $\mathrm{CoSi}_{2}$ & $\begin{array}{l}\mathrm{NiSi} \\
\mathrm{NiSi}_{2}\end{array}$ & \\
\hline$(\mathbf{Z r}-\mathbf{S i})$ & $(\mathbf{N b}-\mathbf{S i})$ & (Mo-Si) & (Tc-Si) & (Ru-Si) & (Rh-Si) & (Pd-Si) & \\
\hline $\mathrm{Zr}_{3} \mathrm{Si}$ & & & & & $\mathrm{Rh}_{2} \mathrm{Si}$ & $\mathrm{Pd}_{5} \mathrm{Si}$ & \\
\hline $\mathrm{Zr}_{2} \mathrm{Si}$ & $\mathrm{Nb}_{4} \mathrm{Si}$ & $\mathrm{Mo}_{3} \mathrm{Si}$ & $\mathrm{Tc}_{4} \mathrm{Si}$ & $\mathrm{Ru}_{2} \mathrm{Si}$ & $\mathrm{Rh}_{5} \mathrm{Si}_{3}$ & $\mathrm{Pd}_{4} \mathrm{Si}$ & \\
\hline $\mathrm{Zr}_{5} \mathrm{Si}_{3}$ & $\mathrm{Nb}_{3} \mathrm{Si}$ & $\mathrm{Mo}_{5} \mathrm{Si}_{3}$ & $\mathrm{Tc}_{3} \mathrm{Si}$ & $\mathrm{Ru}_{5} \mathrm{Si}_{3}$ & $\mathrm{Rh}_{3} \mathrm{Si}_{2}$ & $\mathrm{Pd}_{3} \mathrm{Si}$ & -- \\
\hline $\mathrm{Zr}_{3} \mathrm{Si}_{2}$ & $\mathrm{Nb}_{5} \mathrm{Si}$ & $\mathrm{Mo}_{3} \mathrm{Si}_{2}$ & $\mathrm{Tc}_{5} \mathrm{Si}_{3}$ & $\mathrm{Ru}_{4} \mathrm{Si}_{3}$ & $\mathrm{RhSi}$ & $\mathrm{Pd}_{2} \mathrm{Si}$ & \\
\hline $\mathrm{Zr}_{6} \mathrm{Si}_{3}$ & $\mathrm{NbSi}_{2}$ & $\mathbf{M o S i}_{2}$ & $\mathrm{TcSi}$ & RuSi & $\mathrm{Rh}_{4} \mathrm{Si}_{5}$ & $\mathrm{PdSi}$ & \\
\hline $\begin{array}{l}\mathrm{ZrSi} \\
\mathrm{ZrSi}_{2}\end{array}$ & $\mathrm{Nb}_{5} \mathrm{Si}_{3}$ & & $\mathrm{Tc}_{4} \mathrm{Si}_{7}$ & $\mathrm{Ru}_{2} \mathrm{Si}_{3}$ & $\begin{array}{c}\mathrm{Rh}_{3} \mathrm{Si}_{4} \\
\mathrm{Rh}_{20} \mathrm{Si}_{13}\end{array}$ & $\begin{array}{l}\mathrm{Pd}_{9} \mathrm{Si}_{2} \\
\mathrm{Pd}_{4} \mathrm{Si}_{20}\end{array}$ & \\
\hline (Hf-Si) & (Ta-Si) & $(\mathbf{W}-\mathbf{S i})$ & $(\mathbf{R e}-\mathrm{Si})$ & (Os-Si) & $\begin{array}{c}(\mathbf{I r}-\mathrm{Si}) \\
\mathrm{Ir}_{3} \mathrm{Si}\end{array}$ & (Pt-Si) & \\
\hline $\mathrm{Hf}_{2} \mathrm{Si}$ & $\mathrm{Ta}_{3} \mathrm{Si}$ & $\mathrm{W}_{3} \mathrm{Si}$ & $\mathrm{Re}_{3} \mathrm{Si}$ & OsSi & $\mathrm{Ir}_{2} \mathrm{Si}$ & $\mathrm{Pt}_{3} \mathrm{Si}$ & \\
\hline $\mathrm{Hf}_{5} \mathrm{Si}_{3}$ & $\mathrm{Ta}_{2} \mathrm{Si}$ & $\mathrm{W}_{5} \mathrm{Si}_{3}$ & $\mathrm{Re}_{5} \mathrm{Si}_{3}$ & $\mathrm{OsSi}_{2}$ & $\mathrm{Ir}_{3} \mathrm{Si}_{2}$ & $\mathrm{Pt}_{12} \mathrm{Si}_{5}$ & -- \\
\hline $\mathrm{Hf}_{3} \mathrm{Si}_{2}$ & $\mathrm{Ta}_{5} \mathrm{Si}_{3}$ & $\mathrm{WSi}_{2}$ & ReSi & $\mathrm{Os}_{2} \mathrm{Si}_{3}$ & IrSi & $\mathrm{Pt}_{2} \mathrm{Si}$ & \\
\hline $\mathrm{Hf}_{5} \mathrm{Si}_{4}$ & $\mathbf{T a S i}_{2}$ & & $\mathrm{ReSi}_{2}$ & $\mathrm{OsSi}_{3}$ & $\mathrm{IrSi}_{3}$ & $\mathrm{Pt}_{6} \mathrm{Si}_{5}$ & \\
\hline $\begin{array}{l}\mathrm{HfSi} \\
\mathrm{HfSi}_{2}\end{array}$ & & & $\operatorname{ReSi}_{1.75}$ & $\mathrm{OsSi}_{1.8}$ & $\begin{array}{l}\mathrm{Ir}_{4} \mathrm{Si}_{5} \\
\mathrm{Ir}_{3} \mathrm{Si}_{4}\end{array}$ & $\mathrm{PtSi}$ & \\
\hline
\end{tabular}




\subsubsection{Structure of the refractory transition metal silicides}

The refractory metal silicides are known as intermetallics compounds of transition metals in group IV, V, and VI (Ti, V, Cr, Zr, Nb, Mo, Hf, Ta, W) and silicon ( $\mathrm{Si}$ ). Therefore, they combine both metallic and covalent bonding in their structure. Although bonding between transition metals and silicon atoms are metallic in nature, covalent $\mathrm{Si}-\mathrm{Si}$ bonds between silicon atoms also exist in these metal silicide structures [14,32]. The occupation of $\mathrm{d}$ - and f-electron shells of transition metals and fraction of transition metal and silicon atoms in the structure affects the contribution of these bonds determining the exact structure of the transition metal silicides and properties. For example; weak metallic bonds may form with increasing silicon content within a silicide structure. But formation of these metal silicides are different than some carbide and boride structures, which are called as interstitial compounds that can be obtained by dissolving the non-metals with small atomic radius into existing interstitial sites of the metal lattice. In the case of transition metal silicides, silicon atoms can only substitute (not interstitial) with transition metal atoms in the lattice positions since the ratios of silicon atom radius to the transition metal atom radius are all greater than 0.59 (for example; $r_{S i} / r_{M o}=0.84$ and $r_{S i} / r_{T a}=0.80$ ) as contrary to the Hagg's condition [32,33]. This can be also described as the origin of the complex structures of various refractory transition metal silicides.

To understand the formation of mostly studied and used refractory transition metal silicides, molybdenum-silicon (Mo-Si) binary phase diagram is presented in Figure 1 [7]. As seen in the Mo-Si binary phase diagram, there are three principal groups of refractory silicide compounds, which are (1) silicon rich, metal disilicides as $\mathrm{MoSi}_{2}$, (2) complex, 5-3 silicides as $\mathrm{Mo}_{5} \mathrm{Si}_{3}$, and (3) metal rich, metal monosilicides as $\mathrm{Mo}_{3} \mathrm{Si}$, respectively. The crystal structure of $\mathrm{Mo}_{3} \mathrm{Si}$, which decomposes with a peritectic reaction at $2025^{\circ} \mathrm{C}$, is $\mathrm{A} 15$ type cubic; while $\mathrm{Mo}_{5} \mathrm{Si}_{3}$ compound as 5-3 silicide exhibits a $\mathrm{D} 8_{\mathrm{m}}$ type tetragonal lattice structure [2,23]. In addition, it can be seen on the Mo-Si binary phase diagram that there are two polymorphs of molybdenum disilicide, which are stable $\alpha-\mathrm{MoSi}_{2}$ with $\mathrm{C} 11_{\mathrm{b}}$ type tetragonal body-centered structure (space group $\mathrm{I} / \mathrm{mmm}$ ), and metastable $\beta-\mathrm{MoSi}_{2}$ with a 


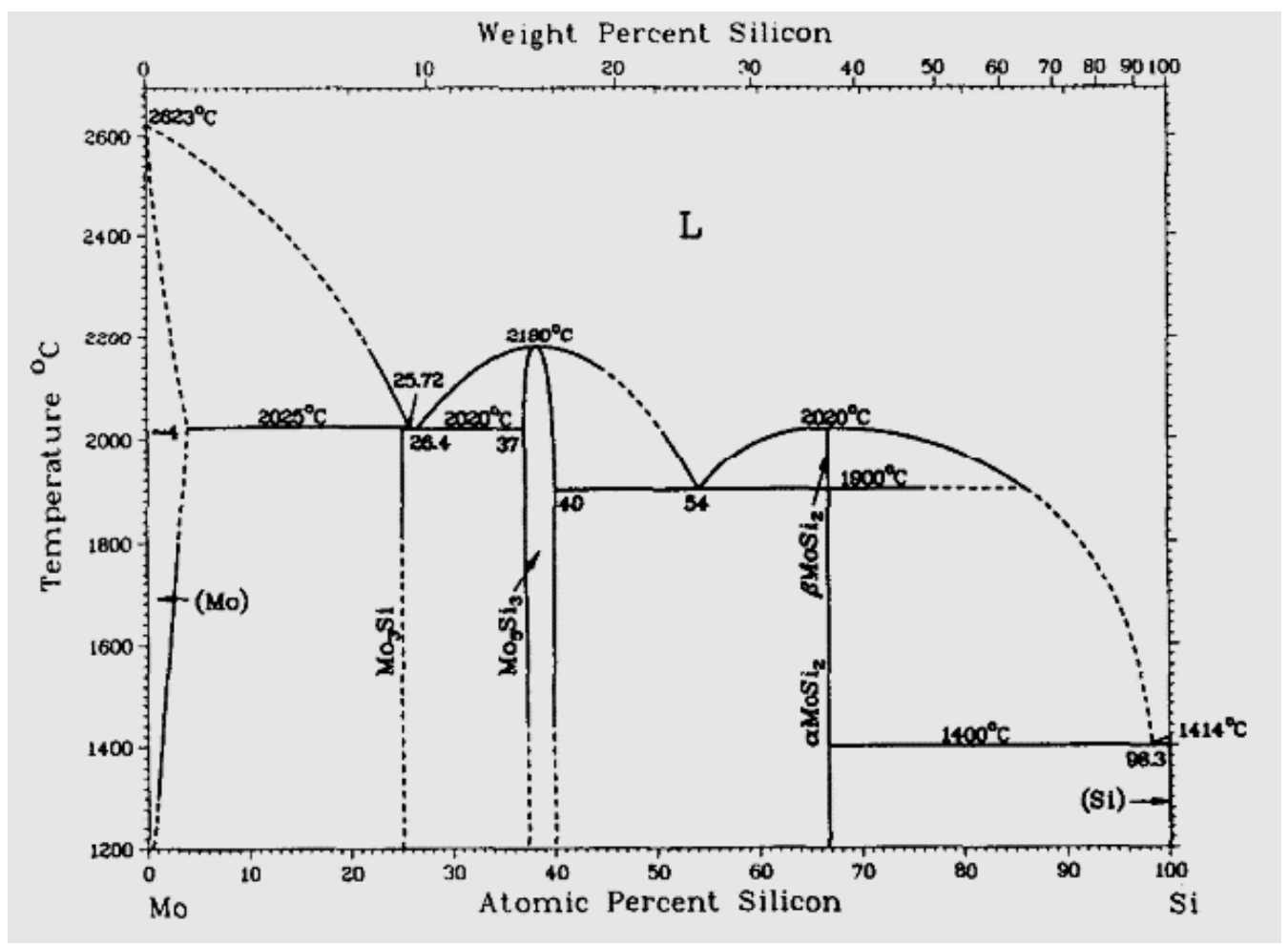

Figure 1. Molybdenum-silicon (Mo-Si) binary phase diagram [7].

C40 type hexagonal close-packed structure (space group P6222) [21,23]. The tetragonal $\alpha$ $\mathrm{MoSi}_{2}$ phase is only stable up to $1900^{\circ} \mathrm{C}$, while it transforms to the $\beta$-phase above this temperature. Although the crystal structures of both $\alpha$ - and $\beta-\mathrm{MoSi}_{2}$ contain $\mathrm{Mo}_{-} \mathrm{Si}_{2}$ layers, where six Si atoms exist around each Mo atom, their stacking sequences are different like $\mathrm{AB}$ and $\mathrm{ABC}$ for $\alpha-$ and $\beta-\mathrm{MoSi}_{2}$, respectively. In order to fully understand their structure, crystal structures of various refractory metal disilicides are discussed since they have been mostly studied and used in many applications. As shown in the projection of a pseudoquaternary phase diagram with $\mathrm{Si}$ at the apex and base ternary of three groups of transition elements (Figure 2), refractory metal disilicides have different type of crystal structures such as $\mathrm{C} 11_{b}, \mathrm{C} 40, \mathrm{C} 54$, and $\mathrm{C} 49$ [7,27,34]. While $\mathrm{WSi}_{2}$ exhibits the same tetragonal $\mathrm{C} 11_{\mathrm{b}}$ structure with $\mathrm{MoSi}_{2} ; \mathrm{CrSi}_{2}, \mathrm{VSi}_{2}, \mathrm{NbSi}_{2}$, and $\mathrm{TaSi}_{2}$ present hexagonal $\mathrm{C} 40$ structure having same $\mathrm{ABC}$ stacking sequence with $\beta-\mathrm{MoSi}_{2}$. It is also shown that $\mathrm{TiSi}_{2}$ and $\mathrm{ZrSi}_{2}$ have orthorhombic C54 and C49 structures, respectively. These orthorhombic structures of 


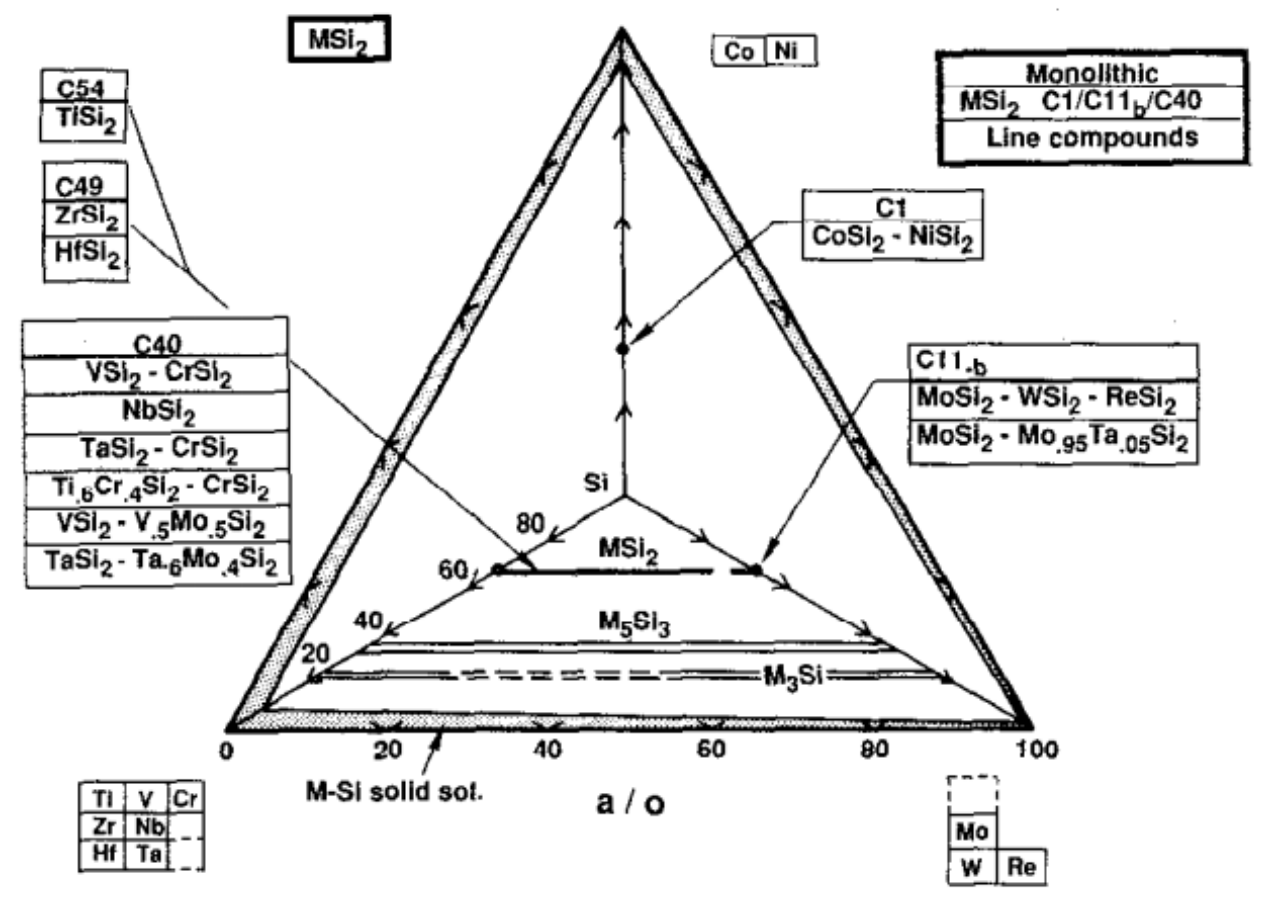

Figure 2. Projection of a pseudo-quaternary phase diagram summarizing the formation of mostly studied/used refractory metal disilicides [7].

disilicides differently contain four-layer of ABCD or two-layer of AB' stacking sequences depending on their types [27]. As a general review, the refractory metal disilicides can be classified based on their crystal structures as three main groups, which are (1) Mo and W disilicides with tetragonal $\mathrm{C} 11_{\mathrm{b}}$ structure, (2) $\mathrm{Cr}, \mathrm{V}, \mathrm{Nb}$, and Ta with hexagonal (C40 type), and (3) $\mathrm{Ti}, \mathrm{Zr}$, and Hf with orthorhombic (C49 or C54 types) structure. The tetragonal and hexagonal crystal structures of refractory metal disilicides in terms of different stacking sequences of $\mathrm{C} 11_{\mathrm{b}}$ and $\mathrm{C} 40$ types can be seen in Figure 3 for better understanding of their structures [7,34]. Figure $3 \mathrm{a}$ presents the tetragonal $\mathrm{C} 11_{\mathrm{b}}$ crystal structure of $\alpha-\mathrm{MoSi}_{2}$ having $\mathrm{I} / \mathrm{mmm}$ space group and lattice parameters of $\mathrm{a}=3.2 \AA$ and $\mathrm{c}=7.85 \AA(\mathrm{c} / \mathrm{a}=\sqrt{6})$. In this structure, molybdenum atoms are positioned at $(0,0,0)$ and $(1 / 2,1 / 2,1 / 2)$ positions, while silicon atom positions are $(0,0,1 / 3),(0,0,2 / 3),(1 / 2,1 / 2,1 / 6)$, and $(1 / 2,1 / 2,5 / 6)[2,26,35,36]$. In addition, hexagonal $\mathrm{C} 40$ crystal structure of $\mathrm{CrSi}_{2}$ has a $\mathrm{P}_{2} 22$ space group and lattice 


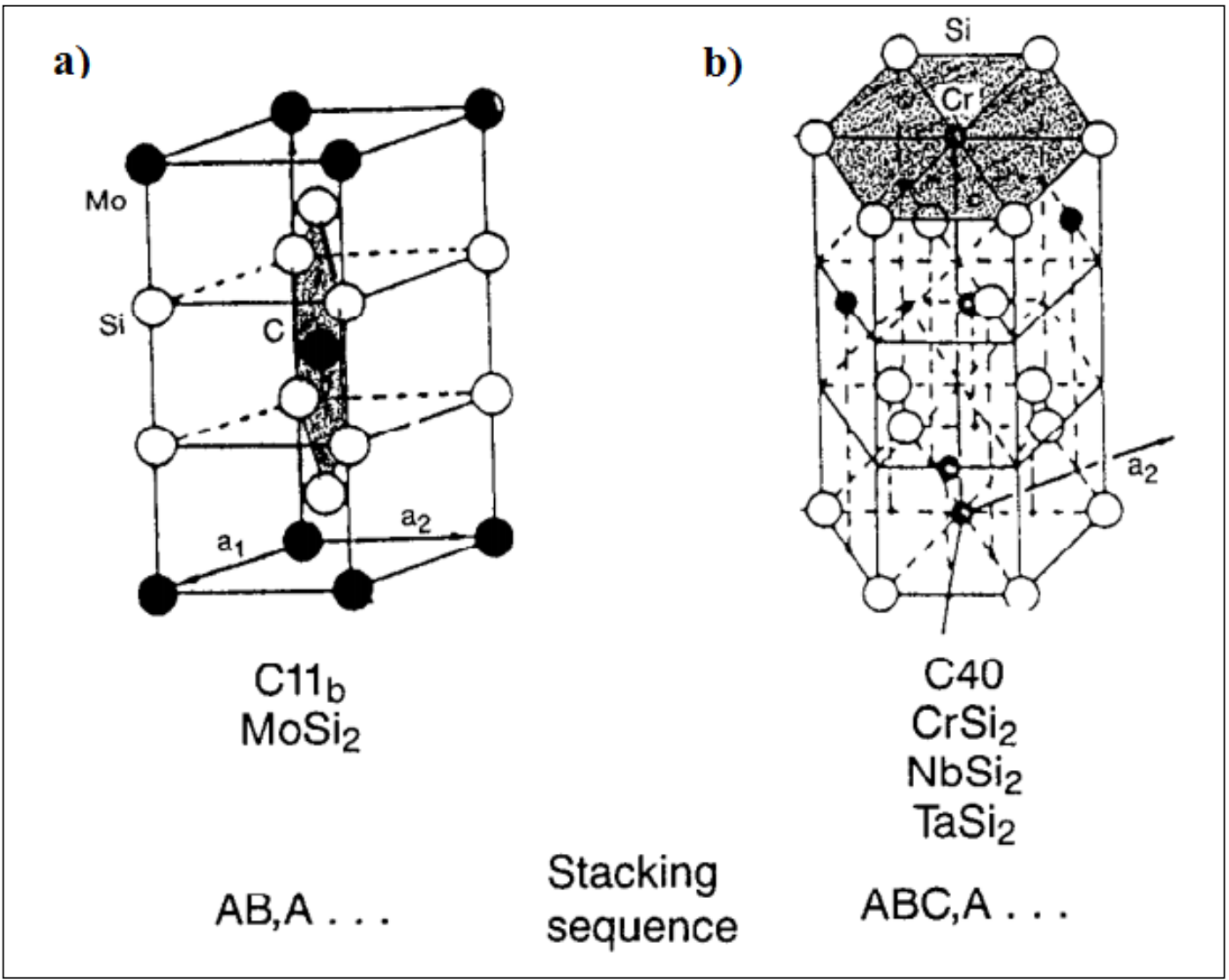

Figure 3. Crystal structure and stacking sequences of refractory transition metal disilicides: (a) tetragonal $\mathrm{C}_{1} 1_{\mathrm{b}}$ structure of $\mathrm{MoSi}_{2}$, (b) hexagonal $\mathrm{C} 40$ structure of $\mathrm{CrSi}_{2}$ [7,34].

parameters of $\mathrm{a}=4.43 \AA$ and $\mathrm{c}=6.37 \AA$ with a different stacking sequence $(\mathrm{ABCABC})$ than tetragonal structure of $\mathrm{MoSi}_{2}(\mathrm{ABAB})$ as shown in Figure 3b. As a review, it is essential to summarize different crystal structure parameters of the refractory metal disilicides, which are mostly studied as high temperature structural and electrical materials due to their excellent property combination and refractoriness. Therefore, their crystal systems, space groups, and lattice parameters are summarized in Table 2 [26]. It can be stated that $\alpha-\mathrm{MoSi}_{2}$ and $\mathrm{WSi}_{2}$ exhibit quite similar tetragonal crystal structures, while $\mathrm{CrSi}_{2}, \mathrm{VSi}_{2}, \mathrm{NbSi}_{2}, \beta-$ $\mathrm{MoSi}_{2}$, and $\mathrm{TaSi}_{2}$ also have similar hexagonal crystal structures. 
Table 2. Crystal system, space group and lattice parameters of the binary refractory metal disilicides as a primary group for the high temperature structural and electrical applications $[21,26]$.

\begin{tabular}{|c|c|c|c|c|c|}
\hline \multirow{2}{*}{$\begin{array}{c}\text { Metal } \\
\text { Disilicides }\end{array}$} & \multirow{2}{*}{$\begin{array}{c}\text { Crystal } \\
\text { Structure }\end{array}$} & \multirow{2}{*}{$\begin{array}{l}\text { Space } \\
\text { Group }\end{array}$} & \multicolumn{3}{|c|}{ Lattice parameters $(\AA)$} \\
\hline & & & $\mathbf{a}$ & b & c \\
\hline $\mathbf{T i S i}_{2}$ & Orthorhombic & Fddd & 8.2687 & 8.5534 & 4.7983 \\
\hline $\mathbf{V S i}_{2}$ & Hexagonal & $\mathrm{P}_{2} 22$ & 4.5723 & --- & 6.3730 \\
\hline $\mathrm{CrSi}_{2}$ & Hexagonal & $\mathrm{P}_{2} 22$ & 4.4281 & --- & 6.3691 \\
\hline $\mathbf{Z r S i}_{2}$ & Orthorhombic & $\mathrm{Cmcm}$ & 3.6958 & 14.7510 & 3.6654 \\
\hline $\mathbf{N b S i}_{2}$ & Hexagonal & $\mathrm{P}_{4} 22$ & 4.7970 & --- & 6.5920 \\
\hline$\alpha-\mathrm{MoSi}_{2}$ & Tetragonal & $\mathrm{I} 4 / \mathrm{mmm}$ & 3.2000 & --- & 7.8500 \\
\hline$\beta-\mathrm{MoSi}_{2}$ & Hexagonal & $\mathrm{P}_{2} 22$ & 4.5960 & --- & 6.5500 \\
\hline $\mathbf{H f S i}_{2}$ & Orthorhombic & $\mathrm{Cmcm}$ & 3.6798 & 14.5562 & 3.6491 \\
\hline $\mathrm{TaSi}_{2}$ & Hexagonal & $\mathrm{P}_{2} 22$ & 4.7835 & --- & 6.5698 \\
\hline $\mathbf{W S i}_{2}$ & Tetragonal & $\mathrm{I} 4 / \mathrm{mmm}$ & 3.2110 & --- & 7.8290 \\
\hline
\end{tabular}

\subsubsection{Mechanical properties of the refractory transition metal silicides}

The mechanical behavior and properties of the refractory transition metal silicides have been extensively investigated in the literature due to their high potential for high temperature structural applications. Their fracture toughness, hardness, elastic modulus, yield strength, flexural strength and creep rate (resistance) have been mostly studied [37]. 


\subsubsection{Fracture toughness}

The main focus was on the molybdenum silicide structures and particularly the molybdenum disilicide $\left(\mathrm{MoSi}_{2}\right)$ in the literature [1-4,7,11-15,21-23]. For its use in high temperature structural applications, mechanical properties of $\mathrm{MoSi}_{2}$ have been examined over the years to present their mechanical capability for such applications. It is known that polycrystalline $\mathrm{MoSi}_{2}$ shows a brittle behavior at low temperatures like ceramic materials [16,38]. For their fracture behavior, Wade and Petrovic (1992) presented that transgranular fracture is dominant in the fracture mode of $\mathrm{MoSi}_{2}$ at room temperature [39]. They also measured the fracture toughness of $\mathrm{MoSi}_{2}$ at room temperature as $3.0 \mathrm{MPa} \cdot \mathrm{m}^{1 / 2}$. Zhang et al. (1999) reported a very low fracture toughness value for the $\mathrm{MoSi}_{2}$, since hot pressed $\mathrm{MoSi}_{2}$ exhibited 2.0 MPa.m ${ }^{1 / 2}$ fracture toughness at room temperature without any reinforcements [13]. In the study of Pan et al. (1998), the fracture toughness of monolithic $\mathrm{MoSi}_{2}$ prepared by hot press sintering was measured at room temperature [40]. They reported the fracture toughness of the monolithic $\mathrm{MoSi}_{2}$ at that temperature approximately as 4.3 MPa.m ${ }^{1 / 2}$, which is relatively higher than the value provided by Wade and Petrovic. As reviewed by Mitra (2006), fracture toughness values measured at room temperature for polycrystalline $\mathrm{MoSi}_{2}$ were all between 3.0 and 5.0 MPa.m ${ }^{1 / 2}$ based on the published studies [37]. The low fracture toughness of $\mathrm{MoSi}_{2}$ was explained by its brittle nature interrelated with the covalent character of Mo-Si bonds and existence of high number of cleavage planes in its structure. To overcome its brittleness and low fracture toughness, some elements such as niobium and aluminum have been used for alloying and reinforcing in low fractions [2,16,22], since it is known that the fracture toughness can be improved by incorporation of a ductile secondary phase to the matrix phase. Soboyejo et al. (1996) reported that fracture toughness of the $\mathrm{MoSi}_{2}$ could be increased from 3.6 to $5.7 \mathrm{MPa} . \mathrm{m}^{1 / 2}$ by addition of Mo, W, and $\mathrm{Nb}$ particles to the system [41]. As presented in the Figure 4, highest fracture toughness value for the $\mathrm{MoSi}_{2}\left(5.7 \mathrm{MPa} \cdot \mathrm{m}^{1 / 2}\right)$ was achieved by using $\mathrm{Nb}$ particles as a secondary phase, which also resulted in the formation of $\mathrm{Mo}_{5} \mathrm{Si}_{3}, \mathrm{SiO}_{2}$, and $(\mathrm{Mo}, \mathrm{Nb})_{5} \mathrm{Si}_{3}$ phases in the system. However, in another study, no significant improvement has been achieved by addition of the Nb particles [42]. In the study of Zhang et al. (1999), 


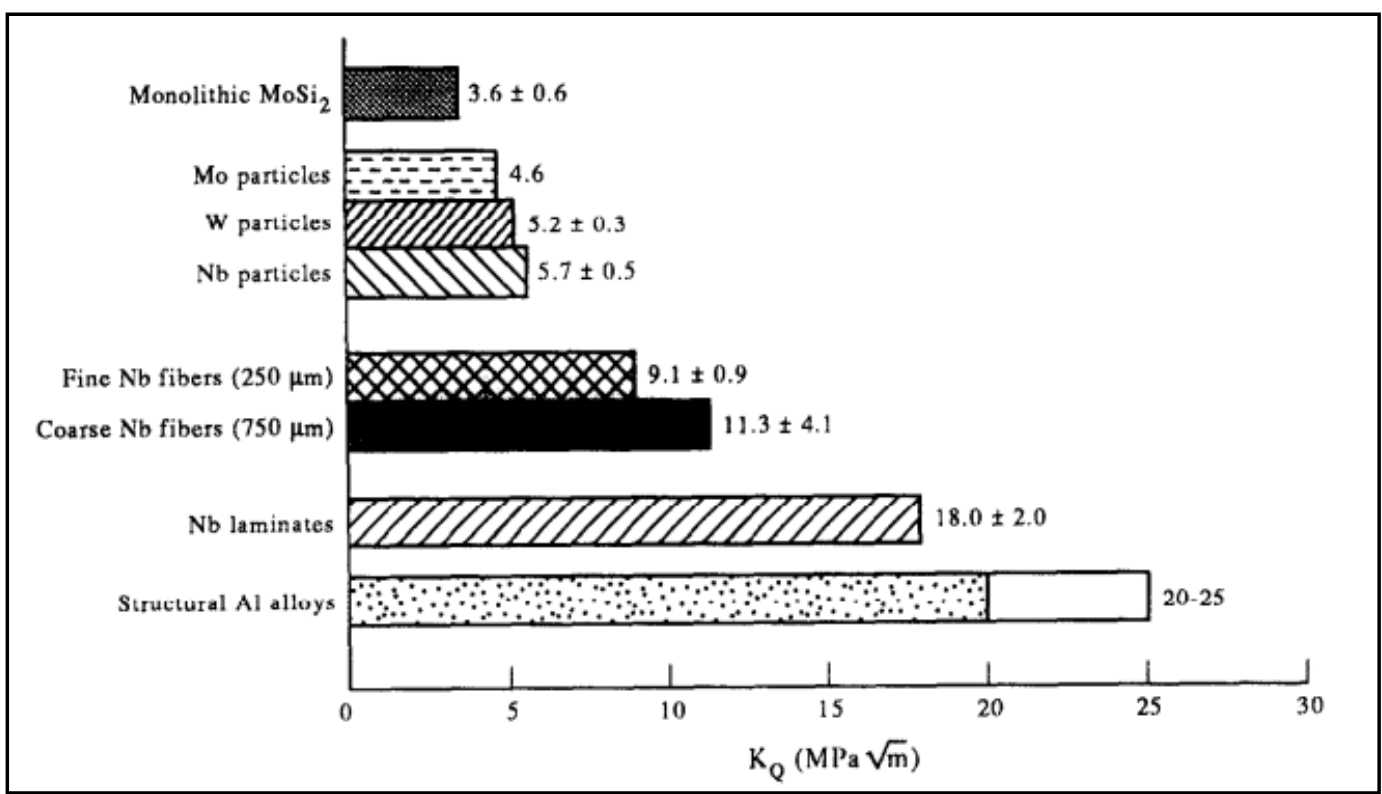

Figure 4. Comparison of the room temperature fracture toughness values $\left(\mathrm{K}_{\mathrm{Q}}\right)$ of the monolithic $\mathrm{MoSi}_{2}$ with the particulate $\left(\mathrm{Mo}, \mathrm{W}\right.$, and $\mathrm{Nb}$ ) reinforced $\mathrm{MoSi}_{2}$ [41].

influence of the aluminum addition on the mechanical properties of $\mathrm{MoSi}_{2}$ has been studied [13]. The room temperature fracture toughness of $\mathrm{MoSi}_{2}$ increased from 2.0 to 2.8 MPa.m ${ }^{1 / 2}$ with the addition of 5 wt.\% Al into the system, then slightly decreased approximately to $2.3 \mathrm{MPa} . \mathrm{m}^{1 / 2}$ with increasing $\mathrm{Al}$ content as shown in the Figure 5. In another study, molybdenum aluminosilicide, $\mathrm{Mo}\left(\mathrm{Si}_{0.8} \mathrm{Al}_{0.2}\right)_{2}$ as a ternary intermetallic compound was synthesized by alloying $\mathrm{MoSi}_{2}$ with aluminum [16]. The indentation fracture toughness of alloyed $\mathrm{MoSi}_{2}$ was calculated as $3.68 \mathrm{MPa}^{1 / 2}$, which is relatively higher than the data reported (2.0-3.0 MPa.m ${ }^{1 / 2}$ ) for the $\mathrm{MoSi}_{2}$ by Wade and Petrovic (1992), and Zhang et al. (1999). In such alloying studies with aluminum, they all proposed to improve the mechanical properties due to enhanced metallic character of $\mathrm{MoSi}_{2}$ and presence of a C40-type $\mathrm{Mo}\left(\mathrm{Si}_{1-\mathrm{x}} \mathrm{Al}_{\mathrm{x}}\right)_{2}$ phase $[16,43,44]$.

On the other hand, there are only a several studies in the literature focusing on the mechanical properties and particularly the room temperature fracture toughness of the other refractory transition metal silicides such as $\mathrm{WSi}_{2}, \mathrm{NbSi}_{2}$, and $\mathrm{TaSi}_{2}[30,45-48]$. Ko et al. 


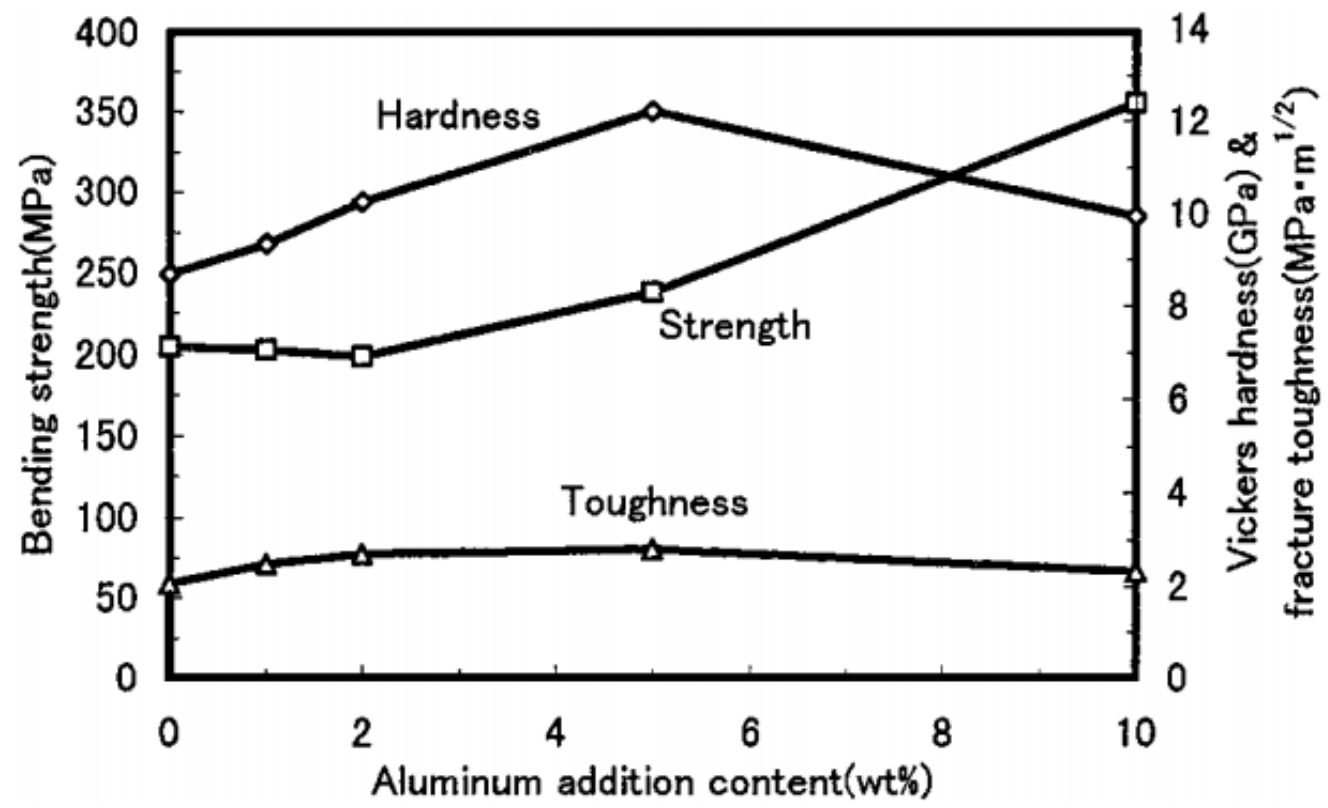

Figure 5. Effect of aluminum addition on the room temperature fracture toughness and other mechanical properties of the $\mathrm{MoSi}_{2}$ [13].

(2009) reported that average fracture toughness of the $\mathrm{NbSi}_{2}$, that was calculated from the indentation data, was approximately $2.5 \mathrm{MPa}^{1 / 2}$ at room temperature [45], which is relatively lower than the fracture toughness of $\mathrm{MoSi}_{2}$. In another study, relatively higher fracture toughness value for the $\mathrm{NbSi}_{2}$ was obtained as $3.0 \mathrm{MPa} \cdot \mathrm{m}^{1 / 2}$ similarly from the indentation results [48]. The fracture toughness of the $\mathrm{WSi}_{2}$ without and with $20 \mathrm{wt} . \% \mathrm{Nb}$ reinforcements has been studied by Shon et al. (2000) [47]. At room temperature, pure $\mathrm{WSi}_{2}$ and $\mathrm{Nb}$-reinforced $\mathrm{WSi}_{2}$ exhibited the fracture toughness values of 3.2 and 9.1 MPa.m ${ }^{1 / 2}$, respectively, based on the indentation crack measurements. This result clearly indicates that $\mathrm{WSi}_{2}$ has relatively higher fracture toughness than $\mathrm{NbSi}_{2}$, and its fracture toughness can be substantially enhanced by addition of a ductile $\mathrm{Nb}$ particles. Furthermore, in the study of Ko et al. (2010), the fracture toughness of $\mathrm{TaSi}_{2}$ was measured as 3.7 MPa.m ${ }^{1 / 2}$ [30], which is relatively higher than the average fracture toughness values of $\mathrm{NbSi}_{2}$ and $\mathrm{WSi}_{2}$, but similar to that of $\mathrm{MoSi}_{2}$. 
The fracture toughness of $\mathrm{MoSi}_{2}$ has been also investigated at elevated temperatures as a function of temperature with/without existence of alloying and/or reinforcing elements. In the study of Maloy et al. (1992), mechanical properties of the $\mathrm{MoSi}_{2}$ and alloyed $\mathrm{MoSi}_{2}$ were studied up to $1400^{\circ} \mathrm{C}$ in order to determine the effect of carbon additions [49]. Therefore, $\mathrm{MoSi}_{2}$ was alloyed with carbon (C) element up to $4 \mathrm{wt} . \%$, and then their high temperature fracture toughness values were measured. As presented in the Figure 6, fracture toughness of the monolithic $\mathrm{MoSi}_{2}$ (without addition of carbon) decreased approximately from 3.9 to $1.0 \mathrm{MPa} \cdot \mathrm{m}^{1 / 2}$ with increasing temperature from $800^{\circ}$ to $1400^{\circ} \mathrm{C}$. This reduction in fracture toughness of $\mathrm{MoSi}_{2}$ was found to be directly interrelated with the viscosity of silica grain boundary phase, which decreased with increasing temperature resulting in more grain boundary sliding with cavitation and low energy intergranular fracture via preferential path formed at high temperatures (above $\mathrm{T}_{\mathrm{g}}$ of silica, $1200^{\circ} \mathrm{C}$ ) $[49,1,38]$. This result revealed that high temperature fracture toughness of $\mathrm{MoSi}_{2}$ is highly

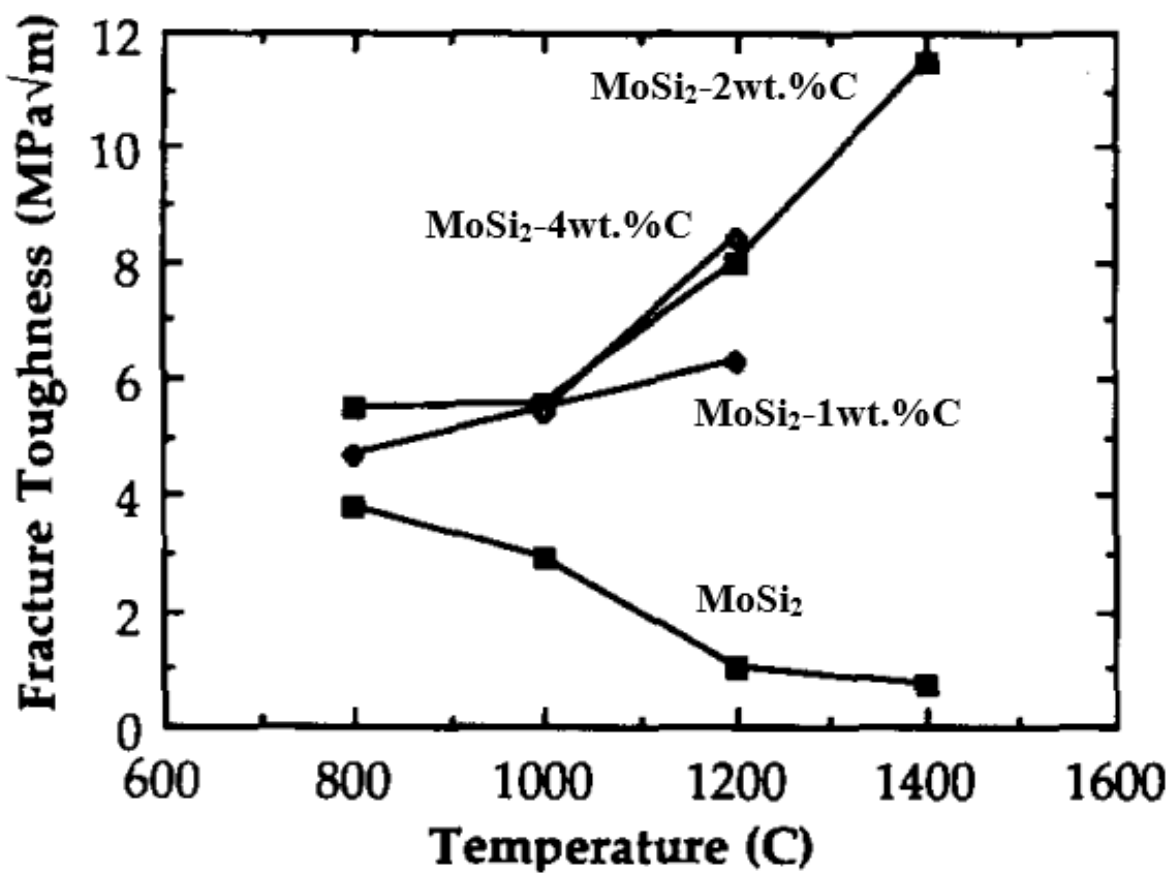

Figure 6. High temperature fracture toughness of monolithic $\mathrm{MoSi}_{2}$ and $\mathrm{MoSi}_{2}$ alloyed with 1-4 wt.\% of carbon as a function of temperature [49]. 
affected by base purity of $\mathrm{MoSi}_{2}$ and existence of grain boundary phases. In addition, significant increases in the fracture toughness were observed for all carbon-alloyed $\mathrm{MoSi}_{2}$ samples with increasing temperature up to $1200^{\circ}$ and $1400^{\circ} \mathrm{C}$ due to removal of the grain boundary silica phase resulting in the change of fracture mode from intergranular to transgranular at high temperatures (Figure 6). The fracture toughness of the alloyed $\mathrm{MoSi}_{2}$ with 2 wt.\% carbon was increased approximately from 5.6 to $11.5 \mathrm{MPa} \cdot \mathrm{m}^{1 / 2}$ with increasing temperature from $800^{\circ}$ to $1400^{\circ} \mathrm{C}$, which clearly presented the positive influence of alloying on the fracture toughness of $\mathrm{MoSi}_{2}$.

\subsubsection{Modulus of elasticity, yield strength and flexural strength}

Modulus of elasticity or Young's modulus (E) is mainly described as a measure of a material's resistance to elastic deformation, and it is one of the mechanical properties studied for the refractory transition metal silicides [50]. In the study of Pan et al. (1998), room temperature mechanical properties of $\mathrm{MoSi}_{2}$ were examined [40]. The modulus of elasticity of $\mathrm{MoSi}_{2}$ was measured between 378 and $517 \mathrm{GPa}$, since different phases existing in the structure such as $\mathrm{MoSi}_{2}, \mathrm{Mo}_{5} \mathrm{Si}_{3}$, and $\mathrm{SiO}_{2}$ all affected its modulus of elasticity. However, they reported that the $\mathrm{MoSi}_{2}$ matrix phase displayed approximately $440 \mathrm{GPa}$ for its modulus of elasticity. Similar to this study, modulus of elasticity of the $\mathrm{MoSi}_{2}$ was also reported as $430 \mathrm{GPa}$ at room temperature [50]. The elastic properties of hexagonal C40 refractory metal disilicides such as polycrystalline $\mathrm{NbSi}_{2}$ and $\mathrm{TaSi}_{2}$ were studied by Chu et al. (1996) [51]. The average modulus of elasticity values of $\mathrm{NbSi}_{2}$ and $\mathrm{TaSi}_{2}$ at room temperature were determined as 362.8 and $359.0 \mathrm{GPa}$, respectively. Furthermore, relatively lower modulus of elasticity was reported for $\mathrm{NbSi}_{2}$ as $255.1 \mathrm{GPa}$ [50]. These results clearly demonstrated that the $\mathrm{MoSi}_{2}$ has higher modulus of elasticity than $\mathrm{NbSi}_{2}$ and $\mathrm{TaSi}_{2}$ at room temperature. On the other hand, there is only a few studies in the literature reported the elastic modulus of the refractory metal silicides at high temperatures [7,44]. The average elastic modulus of several refractory metal silicides $\left(\mathrm{MoSi}_{2}, \mathrm{WSi}_{2}, \mathrm{CrSi}_{2}, \mathrm{VSi}_{2}, \mathrm{TiSi}_{2}\right.$, $\mathrm{Ti}_{5} \mathrm{Si}_{3}, \mathrm{Cr}_{3} \mathrm{Si}, \mathrm{V}_{3} \mathrm{Si}$, and $\mathrm{Mo}_{5} \mathrm{Si}_{3}$ ) as a function of temperature can be seen in the Figure 7 [44]. The elastic modulus of the $\mathrm{MoSi}_{2}$ decreased approximately from 430 to $350 \mathrm{GPa}$ with 


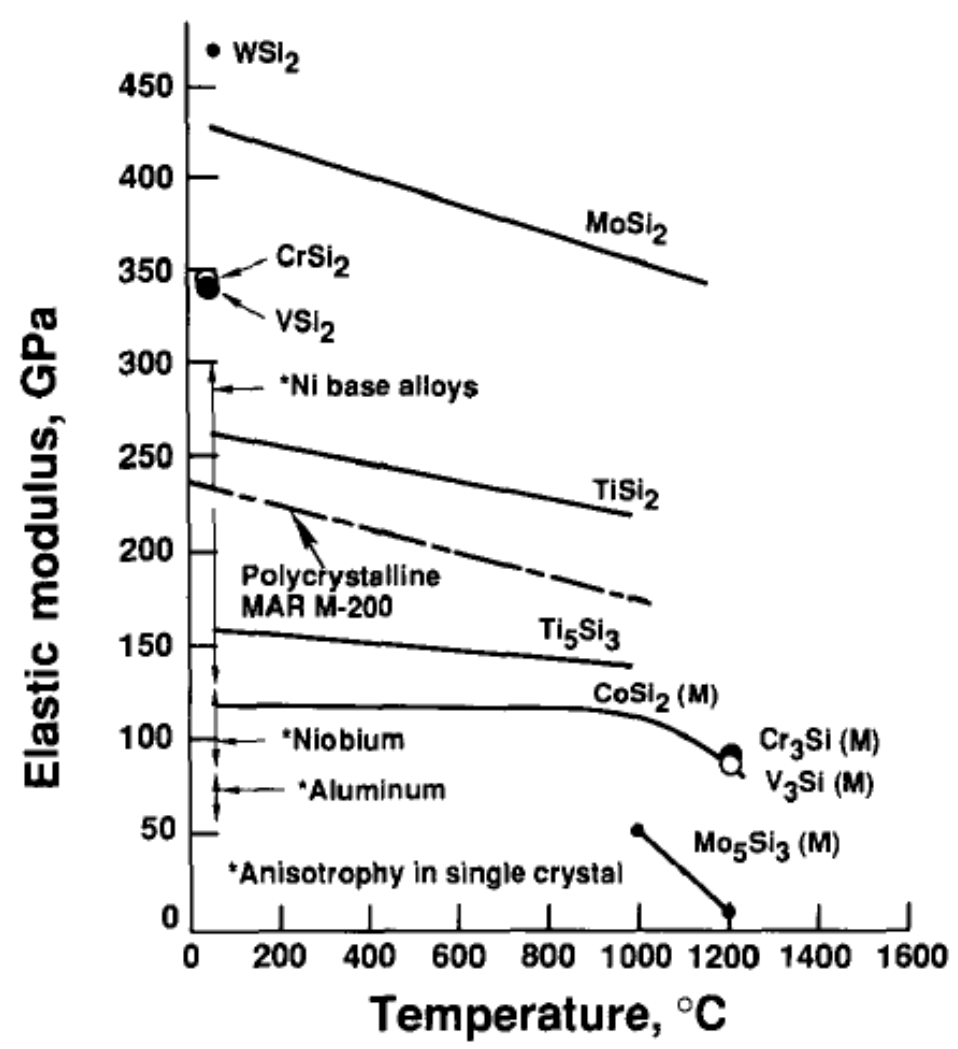

Figure 7. Average elastic modulus (modulus of elasticity or Young's modulus) of several refractory metal silicides as a function of temperature [44].

increasing temperature up to $1100^{\circ} \mathrm{C}$. Similar trends were observed for $\mathrm{TiSi}_{2}, \mathrm{Ti}_{5} \mathrm{Si}_{3}$, $\mathrm{Mo}_{5} \mathrm{Si}_{3}$, and $\mathrm{Cr}_{3} \mathrm{Si}$. It was also determined that $\mathrm{WSi}_{2}, \mathrm{MoSi}_{2}, \mathrm{CrSi}_{2}$, and $\mathrm{VSi}_{2}$ have higher elastic modulus than other refractory metal silicides, but quite comparable to the nickelbase superalloys. It can be pointed out that the refractory metal disilicides such as $\mathrm{MoSi}_{2}$, $\mathrm{VSi}_{2}$, and $\mathrm{CrSi}_{2}$ have relatively higher modulus of elasticity than that of their forms in monosilicides $\left(\mathrm{Cr}_{3} \mathrm{Si}, \mathrm{V}_{3} \mathrm{Si}\right)$ and 5-3 silicides $\left(\mathrm{Mo}_{5} \mathrm{Si}_{3}\right)$.

The yield strength, which is generally described as the stress value (yield stress or point) at which a material starts to deform plastically, of the refractory metal silicides has been also studied at both room temperature and high temperatures [1,7,23,38,40,44,52,53]. It is known that strength of a polycrystalline $\mathrm{MoSi}_{2}$ is highly affected by silica content and grain size. Thus, grain boundary sliding, which can operate at lower stress levels than 
dislocation plasticity, becomes more dominant in $\mathrm{MoSi}_{2}$ as a deformation mechanism with increasing silica content and decreasing grain size [38]. The yield stress behavior of a largegrained, polycrystalline $\mathrm{MoSi}_{2}$ was reported in that study as a function of temperature between $800^{\circ}$ and $1400^{\circ} \mathrm{C}$ (Figure 8a). Under compressive deformation, it was found that the yield stress of $\mathrm{MoSi}_{2}$ drastically decreased approximately from 730 to $180 \mathrm{MPa}$ with increasing temperature. Besides, $\mathrm{MoSi}_{2}$ exhibited a brittle-to-ductile transition temperature between $1300^{\circ}$ and $1400^{\circ} \mathrm{C}$ in bending (flexural) deformation, since approximately 200 $\mathrm{MPa}$ yield stress was achieved at $1400^{\circ} \mathrm{C}$ for both compression and bending modes [38]. But, in another study, quite different yield stress data for the $\mathrm{MoSi}_{2}$ was reported as a function of temperature [23]. In many intermetallic compounds, the yield strength increases with increasing temperature, and then starts to decrease drastically after a certain peak temperature, which is called as $\mathrm{R}$ feature. As shown in the Figure 8b, the yield strength of the $\mathrm{MoSi}_{2}$ slightly increased up to around $1400^{\circ} \mathrm{C}$, and then it drastically decreased to a very low level of yield strength $(\sim 100 \mathrm{MPa})$, which is not sufficient for high-temperature structural applications, and therefore, needs to be improved. It is also important to note that
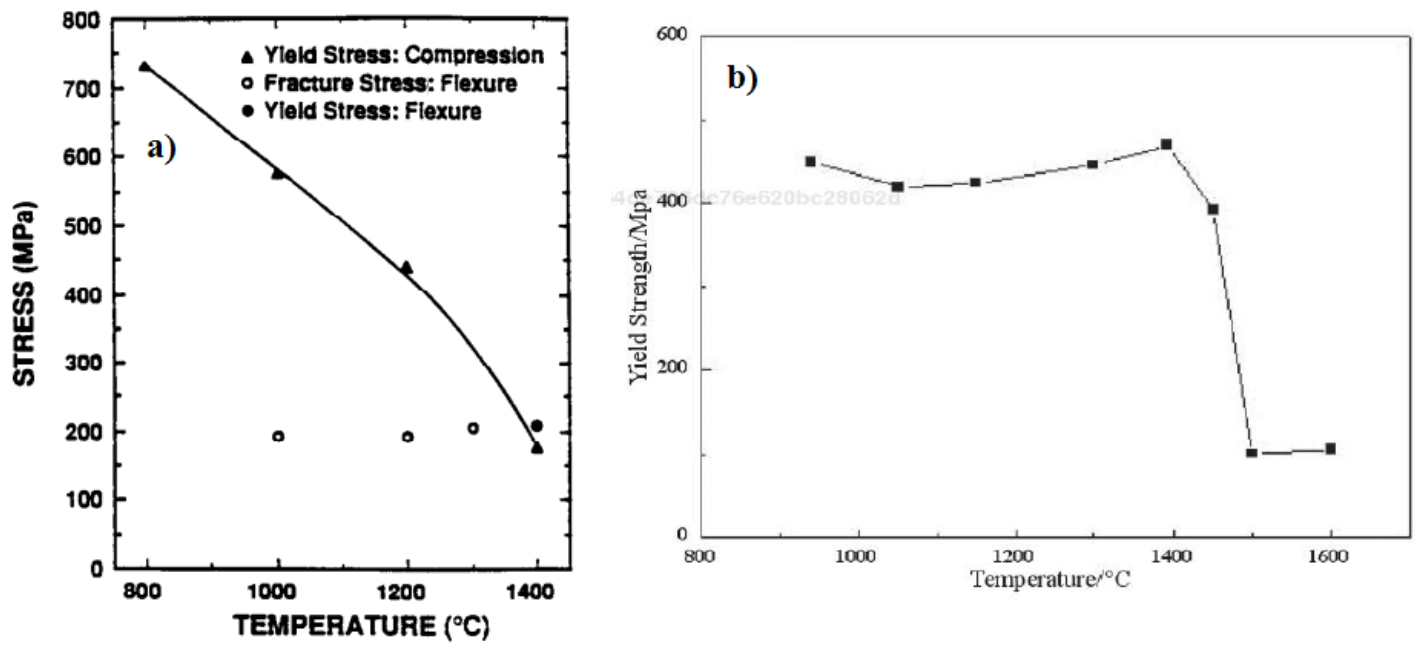

Figure 8. (a) Yield stress of a polycrystalline $\mathrm{MoSi}_{2}$ [38], and (b) R characteristic of $\mathrm{MoSi}_{2}$ (change in yield strength) [23] as a function of temperature. 


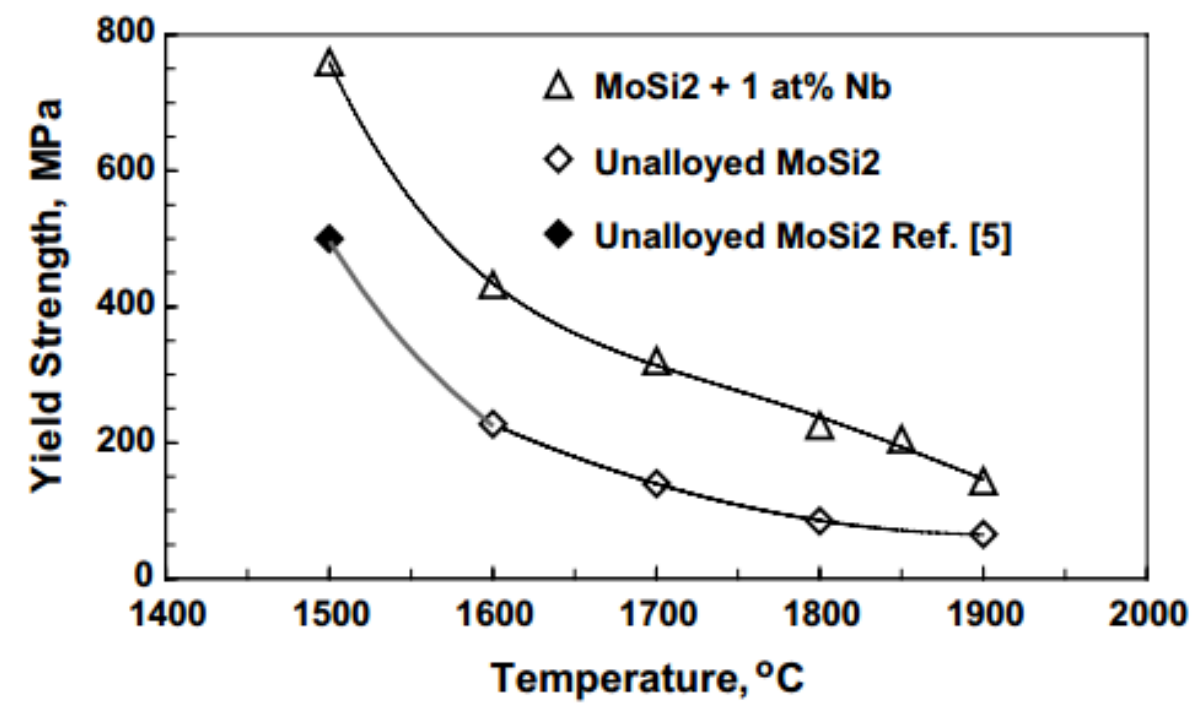

Figure 9. Yield strength of the pure $\mathrm{MoSi}_{2}$ and $\mathrm{MoSi}_{2}$ alloyed/doped with $1 \mathrm{at} \% \mathrm{Nb}$ as a function of temperature (above $1500^{\circ} \mathrm{C}$ ) [52].

there is a conflict between the high temperature yield strength values and trends obtained in these studies as compared in Figure 8. In the study of Pan et al. (1998), the compressive yield strength of monolithic $\mathrm{MoSi}_{2}$ at $1200^{\circ}$ and $1400^{\circ} \mathrm{C}$ were measured approximately as 370 and $80 \mathrm{MPa}$, respectively [40]. Therefore, there was a drastic decrease (76-78\%) in yield strength of $\mathrm{MoSi}_{2}$ at $1400^{\circ} \mathrm{C}$, which is similar to the $\mathrm{R}$ characteristic of the $\mathrm{MoSi}_{2}$. The yield strength of pure $\mathrm{MoSi}_{2}$ and $\mathrm{MoSi}_{2}$ alloyed with 1 at $\% \mathrm{Nb}$ at high temperatures were studied by Sharif et al. (2005) [52]. It was determined that yield strength of pure $\mathrm{MoSi}_{2}$ decreased approximately from 240 to $70 \mathrm{MPa}$ with increasing temperature from $1600^{\circ}$ to $1900^{\circ} \mathrm{C}$. However, it is clear that yield strength of the $\mathrm{MoSi}_{2}$ was substantially enhanced at elevated temperatures by alloying/doping with $\mathrm{Nb}$ as presented in Figure 9.

Another mechanical property studied for the refractory metal silicides (particularly $\mathrm{MoSi}_{2}$ ) is flexural strength or bending strength, which can be described as material's ability to resist failure or deformation under bending [13,22,40,54]. Lee et al. (2005) reported that the flexural strength of the $\mathrm{MoSi}_{2}$ was $324 \mathrm{MPa}$ at room temperature [22]. It was also found 

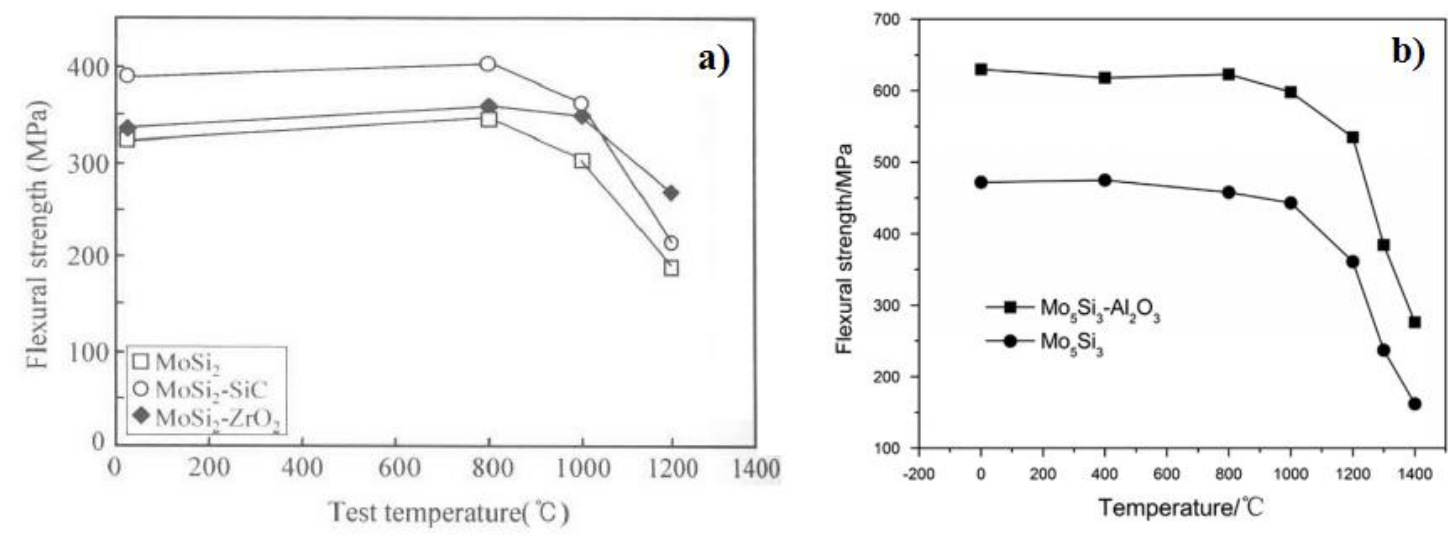

Figure 10. Flexural strength of (a) $\mathrm{MoSi}_{2}$ [22], and (b) $\mathrm{Mo}_{5} \mathrm{Si}_{3}$ [54] as a function of temperature.

that the flexural strength of the $\mathrm{MoSi}_{2}$ relatively increased up to around $800^{\circ} \mathrm{C}$, and then significantly decreased approximately to $190 \mathrm{MPa}$ with increasing temperature from $800^{\circ} \mathrm{C}$ to $1200^{\circ} \mathrm{C}$ (Figure 10a). This decrease in the high temperature flexural strength was attributed to the existence of a brittle-to-ductile transition temperature, since its brittle behavior at room temperature changed into ductile behavior without drastic fracture due to its softening above $1000^{\circ} \mathrm{C}$ [2,22]. In the study of Pan et al. (1998) [40], flexural strength of the $\mathrm{MoSi}_{2}$ at room temperature was reported as $420 \mathrm{MPa}$, which is relatively higher than that the data presented by Lee et al. (2005). Also, as shown in the Figure 5, bending strength of the $\mathrm{MoSi}_{2}$ was improved by the addition of aluminum into the matrix [13]. Although its bending strength did not change in the presence of up to $2 \mathrm{wt} \% \mathrm{Al}$ content, addition of more $\mathrm{Al}\left(2-10\right.$ wt.\%) increased the bending strength of $\mathrm{MoSi}_{2}$ at room temperature approximately from 200 to $350 \mathrm{MPa}$. In addition, mechanical properties and particularly flexural strength of $\mathrm{Mo}_{5} \mathrm{Si}_{3}$ as a 5-3 silicide phase have been investigated by Chen et al. (2014) [54]. The flexural strength of the $\mathrm{Mo}_{5} \mathrm{Si}_{3}$ was found to be quite stable up to $1000^{\circ} \mathrm{C}$ (around $470 \mathrm{MPa}$ ), but then it significantly decreased at higher temperatures (Figure 10b). Therefore, the flexural strength values of the $\mathrm{Mo}_{5} \mathrm{Si}_{3}$ at $1200^{\circ}$ and $1400^{\circ} \mathrm{C}$ were obtained as 320 and $162 \mathrm{MPa}$. In comparison of the $\mathrm{MoSi}_{2}$ with the $\mathrm{Mo}_{5} \mathrm{Si}_{3}$ phase in terms of their flexural strength values, it can be noted that $\mathrm{Mo}_{5} \mathrm{Si}_{3}$ exhibited higher flexural strength than the $\mathrm{MoSi}_{2}$ at both room and elevated temperatures. 


\subsubsection{Creep properties}

The time dependent strain that occurs under load at elevated temperatures is called as creep, and hereby creep resistance can be described as a material's ability to resist deformation over an extended time. Therefore, high temperature creep resistance and low creep rates are crucial for refractory metal silicides as high temperature structural materials $[2,7,23]$. In the study of Petrovic (1995), high temperature creep behavior of polycrystalline $\mathrm{MoSi}_{2}$ at $1200^{\circ} \mathrm{C}$ has been studied as a function of stress and grain size values [38]. As presented in Figure 11, creep rate of the $\mathrm{MoSi}_{2}$ increased with increasing applied stress, but decreased with increasing $\mathrm{MoSi}_{2}$ grain size at high temperatures, which is not well understood. It is known that the temperature and stress values affect creep properties of the $\mathrm{MoSi}_{2}$. While combination of grain boundary sliding and dislocation glide is dominant as a creep mechanism at high temperatures, grain boundary sliding becomes more dominant at low temperatures for $\mathrm{MoSi}_{2}$ [23]. The creep behavior is also related with the applied stress,

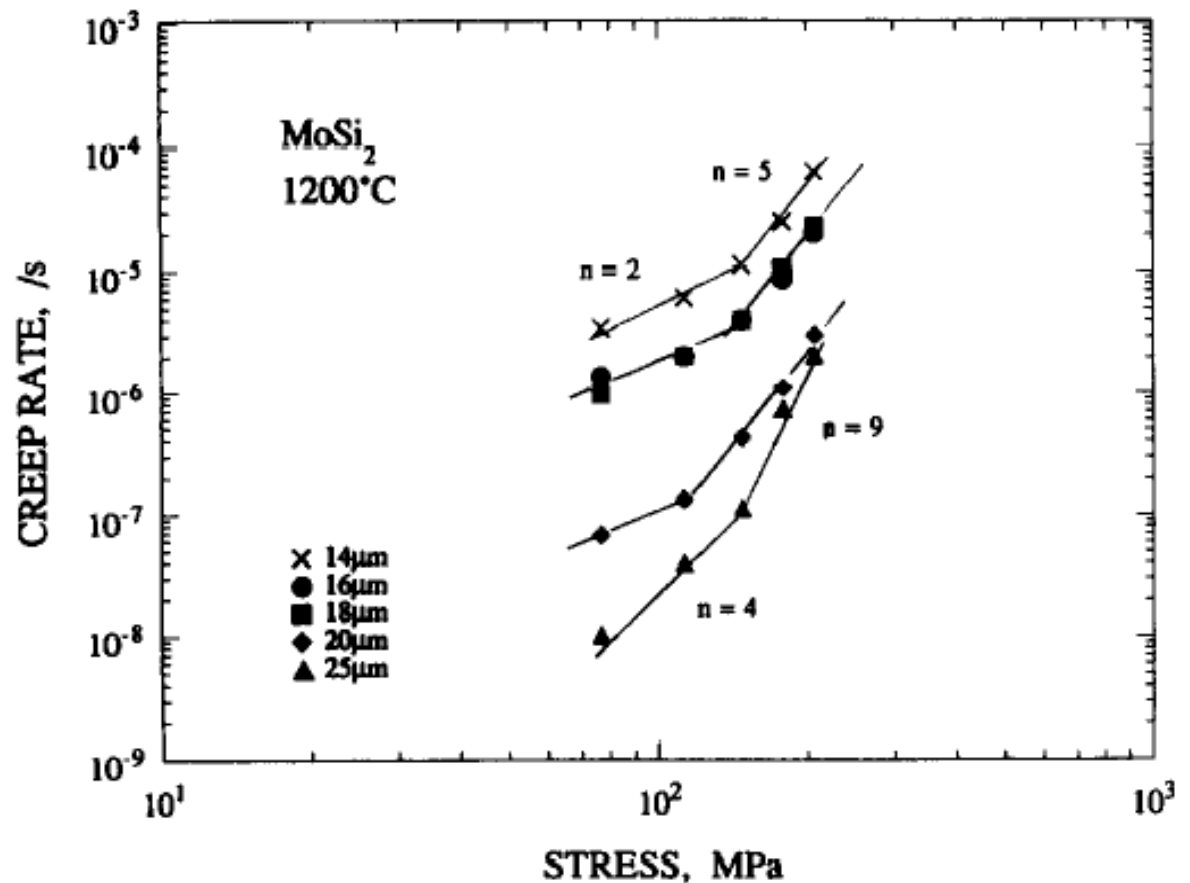

Figure 11. Creep rate of the polycrystalline $\mathrm{MoSi}_{2}$ at $1200^{\circ} \mathrm{C}$ as a function of the grain size [38]. 


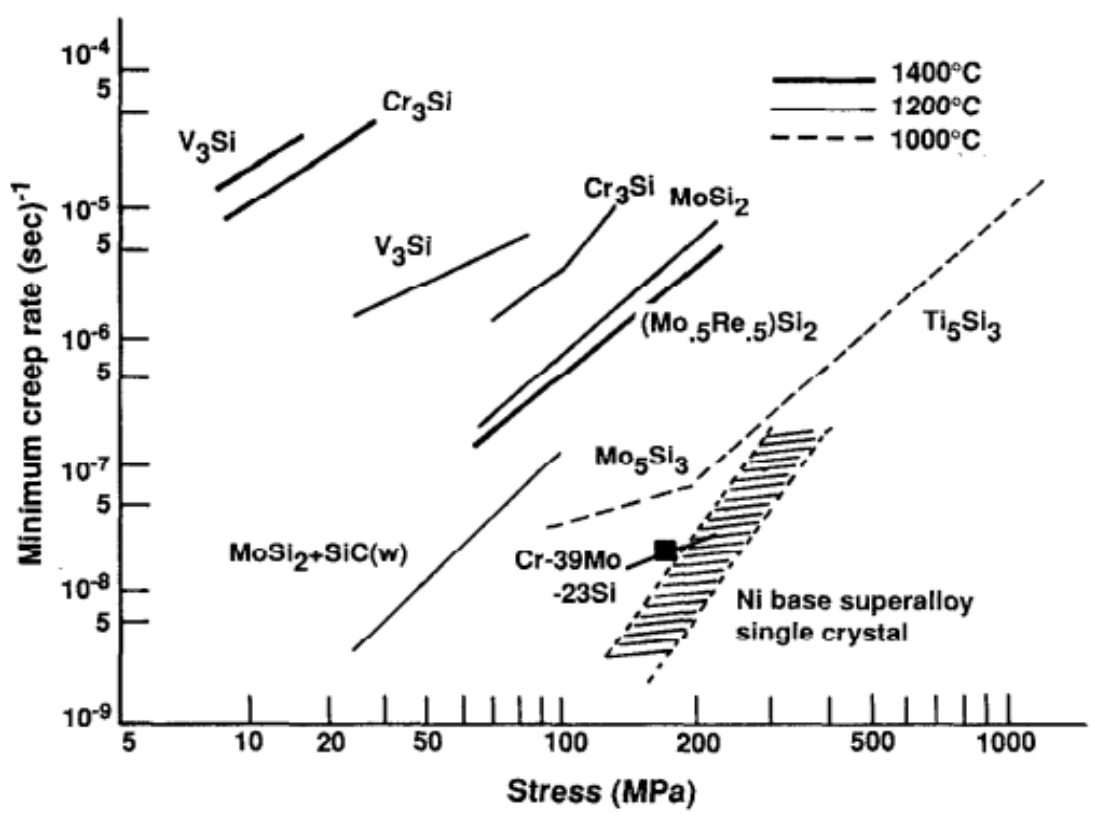

Figure 12. Minimum creep rates in compression vs. stress for several refractory metal silicides at $1000^{\circ} \mathrm{C}, 1200^{\circ} \mathrm{C}$, and $1400^{\circ} \mathrm{C}$ [7].

since dislocation slipping and grain boundary sliding mostly occur under high and low stress conditions, respectively. Furthermore, weak silica phase remaining in the grain boundaries can increase the degree of grain boundary sliding at high temperatures as well, which results in reduced creep resistance. Since the amount of the $\mathrm{SiO}_{2}$ phase and grain size of the $\mathrm{MoSi}_{2}$ matrix directly affect the degree of grain boundary sliding, the grain size effect on creep rate of the $\mathrm{MoSi}_{2}$ observed in the study of Petrovic (1995) can be explained by this way $[23,38]$. On the other hand, minimum creep rate values of several refractory metal silicides $\left(\mathrm{Cr}_{3} \mathrm{Si}, \mathrm{V}_{3} \mathrm{Si}, \mathrm{MoSi}_{2}, \mathrm{Mo}_{5} \mathrm{Si}_{3}, \mathrm{Ti}_{5} \mathrm{Si}_{3}\right)$ in compression versus stress at $1000^{\circ} \mathrm{C}$, $1200^{\circ} \mathrm{C}$ and $1400^{\circ} \mathrm{C}$ were reported [7,44]. Based on the given data (Figure 12), creep rate of the $\mathrm{MoSi}_{2}$ is relatively lower than that of the $\mathrm{Cr}_{3} \mathrm{Si}$ and $\mathrm{V}_{3} \mathrm{Si}$ at $1200^{\circ} \mathrm{C}$, which indicates that the $\mathrm{MoSi}_{2}$ has better creep resistance than other intermetallics. At $1000^{\circ} \mathrm{C}$, it is evident that the creep resistance of the $\mathrm{Ti}_{5} \mathrm{Si}_{3}$ and $\mathrm{Mo}_{5} \mathrm{Si}_{3}$ is similar to that of the superalloys [44]. Therefore, it can be concluded that $\mathrm{Cr}_{3} \mathrm{Si}, \mathrm{MoSi}_{2}$, and $\mathrm{Mo}_{5} \mathrm{Si}_{3}$ have very promising creep resistance values for high temperature structural applications. 


\subsubsection{Electrical properties of the refractory transition metal silicides}

The electrical properties of the refractory transition metal silicides vary from metallic to semiconducting, and therefore, it is important to classify these silicides into two primary groups as metallic and semiconducting metal silicides [55,56]. Most of the refractory metal silicides, which are $\mathrm{TiSi}_{2}, \mathrm{VSi}_{2}, \mathrm{~V}_{5} \mathrm{Si}_{3}, \mathrm{Cr}_{3} \mathrm{Si}, \mathrm{Cr}_{5} \mathrm{Si}_{3}, \mathrm{NbSi}_{2}, \mathrm{Nb}_{3} \mathrm{Si}_{1} \mathrm{MoSi}_{2}$, $\mathrm{Mo}_{3} \mathrm{Si}, \mathrm{TaSi}_{2}, \mathrm{HfSi}_{2}$, and $\mathrm{WSi}_{2}$, are known as metallic silicides. In addition, $\mathrm{CrSi}_{2}$ exhibits a degenerate semiconducting behavior, while some of the refractory metal silicides such as $\mathrm{V}_{3} \mathrm{Si}, \mathrm{NbSi}_{2}, \mathrm{Mo}_{3} \mathrm{Si}$, and $\mathrm{TaSi}_{2}$ also have superconducting characteristics. Due to their various electrical properties and characteristics, refractory transition metal silicides have attracted a great attention for electrical applications, in addition to their high temperature structural applications. Thermoelectrics and gate electrodes, interconnects and barrier layers in micro-electronic devices are known as their major electrical applications of refractory transition metal silicides [2,17-20,57].

The refractory transition metal silicides have a great potential for high temperature thermoelectrics due to their high working temperature, low electrical resistance, high Seebeck coefficient, high thermal and chemical stability [18,20,21]. Other advantages of the transition metal silicides are their low toxicity and low cost compared to the mostly used thermoelectric materials, such as thallium-, chalcogen-, and germanium-based alloys. Due to their potential, the electrical properties of the $\mathrm{CrSi}_{2}, \mathrm{MoSi}_{2}, \mathrm{WSi}_{2}, \mathrm{Ta}_{5} \mathrm{Si}_{3}$, and $\mathrm{W}_{5} \mathrm{Si}_{3}$ phases have been mostly investigated in the literature [17-21,58]. Since thermoelectric effect provides the direct conversion of heat into electrical energy (Seebeck effect), the figure-of-merit (ZT) is a function of electrical conductivity, Seebeck coefficient, and thermal conductivity. Therefore, high electrical conductivity, high charge carrier concentration, high density of state, metallic behavior, and poor thermal conductivity are required for achieving high thermoelectric performance with high ZT [18]. In the study of Yamada and Yamane (2011), thermoelectric properties of both $\alpha-\mathrm{MoSi}_{2}$ and $\beta-\mathrm{MoSi}_{2}$ such as electrical resistivity $(\rho)$, Seebeck coefficient $(S)$, and thermoelectric power factor $\left(\alpha^{2} \sigma\right)$ have been studied in detail [21]. Figure 13 displays the positive temperature 


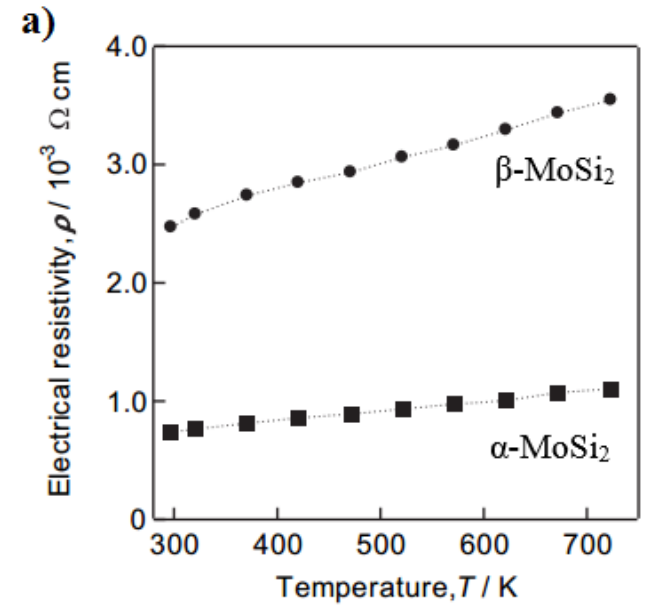

Figure 13. (a) Electrical resistivities, $\rho$, an polycrystalline $\alpha-\mathrm{MoSi}_{2}$ and $\beta-\mathrm{MoSi}_{2}$ [21].

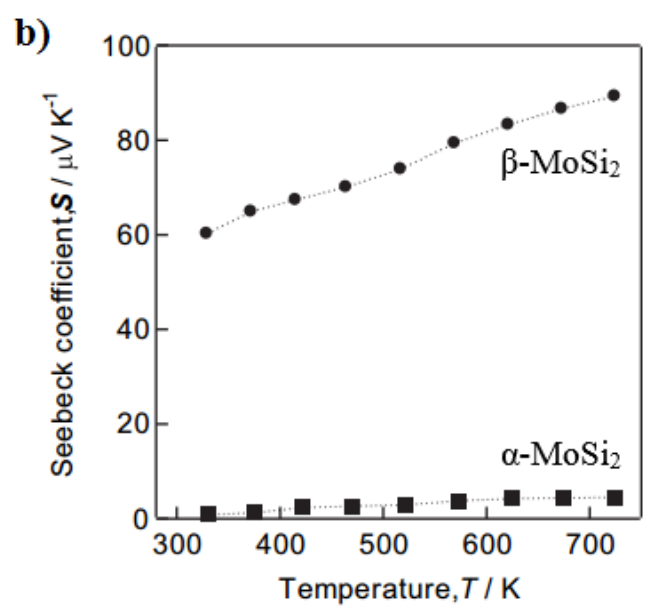

(b) Seebeck coefficients, $\mathrm{S}$ of the dependence of electrical resistivities and Seebeck coefficients for the samples, respectively. It was observed that the electrical resistivity of $\alpha-\mathrm{MoSi}_{2}$ increased from 0.74 to $1.1 \mathrm{~m} \Omega \cdot \mathrm{cm}$ with increasing temperature from $300 \mathrm{~K}$ to $725 \mathrm{~K}$, while $\beta-\mathrm{MoSi}_{2}$ exhibited electrical resistivity of 2.5-3.4 $\mathrm{m} \Omega \cdot \mathrm{cm}$, which is almost three times higher compared to the $\alpha-\mathrm{MoSi}_{2}$. These resistivities are relatively higher than the resistivities $(0.06-0.43 \mathrm{~m} \Omega \cdot \mathrm{cm})$, which were presented for the $\alpha-\mathrm{MoSi}_{2}$ and $\beta-\mathrm{MoSi}_{2}$ thin films at room temperature by Krontiras et al. (1987) [59]. As seen in Figure 13b, the Seebeck coefficients of the $\alpha-\mathrm{MoSi}_{2}$ were very low and in the range of 0.8 to $4.5 \mu \mathrm{V} / \mathrm{K}$ at $330-725 \mathrm{~K}$ compared to the $\beta-\mathrm{MoSi}_{2}$, which exhibited $60 \mu \mathrm{V} / \mathrm{K}$ at $330 \mathrm{~K}$, and $89 \mu \mathrm{V} / \mathrm{K}$ at $725 \mathrm{~K}$. These results imply that the $\alpha-\mathrm{MoSi}_{2}$ reveals higher electrical conductivity, but lower Seebeck coefficient. Furthermore, the temperature dependence of the electrical resistivity of the widely studied metallic silicides $\left(\mathrm{MoSi}_{2}, \mathrm{TaSi}_{2}, \mathrm{TiSi}_{2}, \mathrm{WSi}_{2}\right)$ have been reviewed using their thin films [56]. As presented in Figure 14, electrical resistivity of the $\mathrm{TiSi}_{2}$ linearly increased up to $0.088 \mathrm{~m} \Omega \cdot \mathrm{cm}$ with increasing temperature $(1100 \mathrm{~K})$ like a typical metallic-type of behavior. In addition, $\mathrm{MoSi}_{2}, \mathrm{WSi}_{2}$, and $\mathrm{TaSi}_{2}$ thin films exhibited the electrical resistivities of $0.134,0.093$ and $0.119 \mathrm{~m} \Omega \cdot \mathrm{cm}$ at around $1100 \mathrm{~K}$. Based on these results, it should be noted that $\mathrm{WSi}_{2}$ and $\mathrm{TiSi}_{2}$ thin films have higher electrical conductivity than the $\mathrm{MoSi}_{2}$ and $\mathrm{TaSi}_{2}$ thin films at 


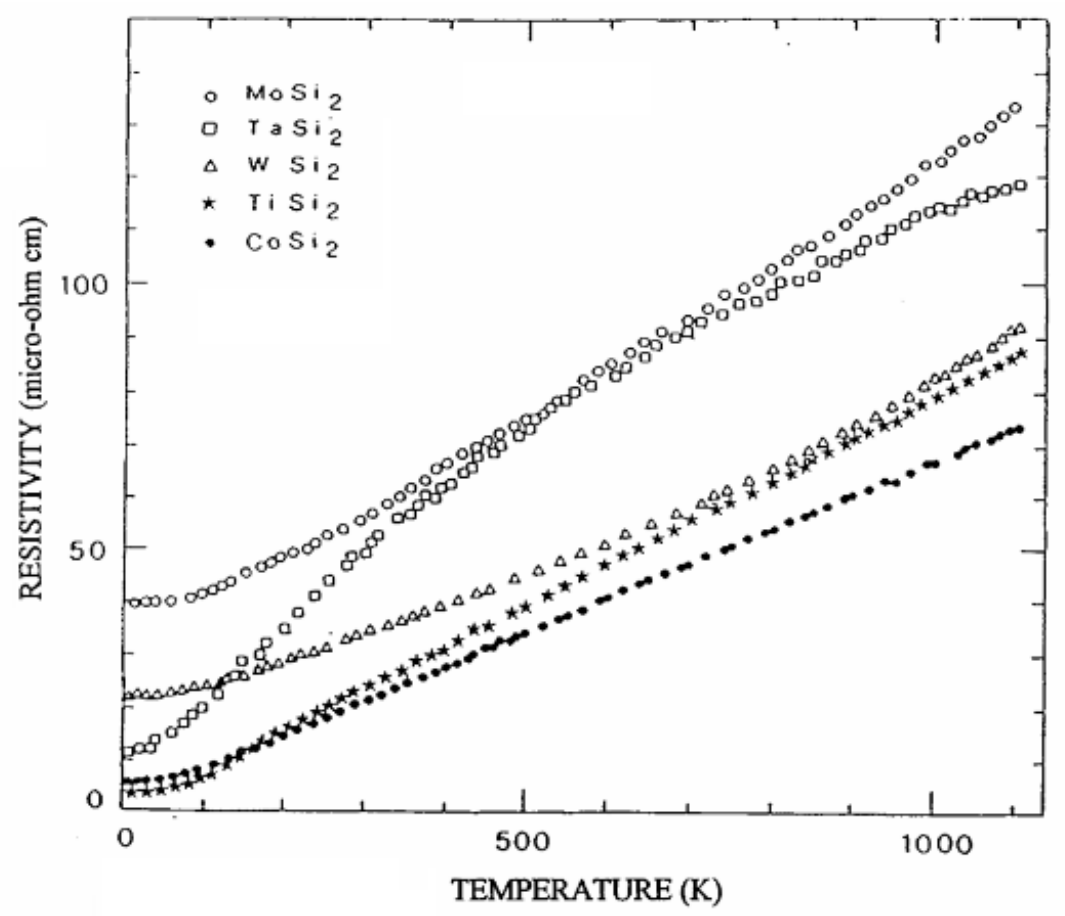

Figure 14. Temperature dependence of the electrical resistivity of $\mathrm{MoSi}_{2}, \mathrm{WSi}_{2}, \mathrm{TaSi}_{2}$, and $\mathrm{TiSi}_{2}$ refractory metal silicide thin films [56].

high temperatures, which provides a great advantage for their use in high temperature electrical applications. Furthermore, Viennois et al. (2011) reported a study with a focus on the high temperature thermoelectric properties of the $\mathrm{Ta}_{5} \mathrm{Si}_{3}$ and $\mathrm{W}_{5} \mathrm{Si}_{3}$, since they are known to be stable up to around $2000^{\circ} \mathrm{C}$ [17]. Figure 15 displays the electronic density of states for the $\mathrm{Ta}_{5} \mathrm{Si}_{3}$ and $\mathrm{W}_{5} \mathrm{Si}_{3}$ close to the Fermi energy level. More abrupt changes were observed in density of states of the $\mathrm{W}_{5} \mathrm{Si}_{3}$. In addition to that, they calculated the Seebeck coefficients (thermoelectric output) of the $\mathrm{Ta}_{5} \mathrm{Si}_{3}$ and $\mathrm{W}_{5} \mathrm{Si}_{3}$ from the Mott's relationship as -1.8 and $-17 \mu \mathrm{V} / \mathrm{K}$ at room temperature. These results all present that the $\mathrm{W}_{5} \mathrm{Si}_{3}$ is more promising candidate than $\mathrm{Ta}_{5} \mathrm{Si}_{3}$ for thermoelectric applications, although its thermoelectric power is relatively low. In addition to these refractory metal silicides, electrical properties of the $\mathrm{Cr}_{3} \mathrm{Si}$ and $\mathrm{Cr}_{5} \mathrm{Si}_{3}$ have been also investigated by Mazzega et al. (1987) [55]. The electrical resistivities of these chromium silicides in their thin film forms as a function of temperature can be seen in Figure 16. Based on the data presented, the $\mathrm{Cr}_{3} \mathrm{Si}$ provided a 


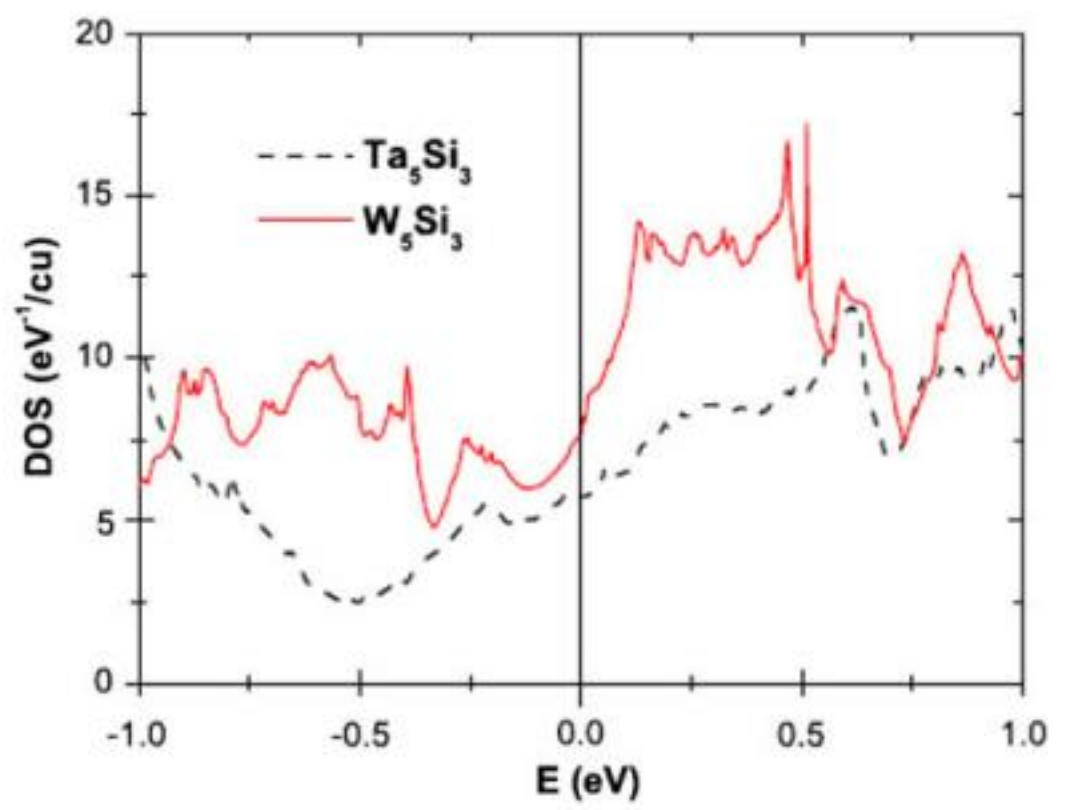

Figure 15. The electronic density of states of $\mathrm{Ta}_{5} \mathrm{Si}_{3}$ and $\mathrm{W}_{5} \mathrm{Si}_{3}$ close to the Fermi level [17].

linear curve of electrical resistivity with increasing temperature up to $1100 \mathrm{~K}$ since its electrical resistance was measured as $\sim 0.1 \mathrm{~m} \Omega \cdot \mathrm{cm}$ at the maximum temperature. It was also determined that the $\mathrm{Cr}_{5} \mathrm{Si}_{3}$ has higher electrical resistivity $(\sim 0.16 \mathrm{~m} \Omega \cdot \mathrm{cm})$ than the $\mathrm{Cr}_{3} \mathrm{Si}$ at this temperature, which clearly indicated that the $\mathrm{Cr}_{3} \mathrm{Si}$ has higher electrical conductivity at high temperatures. As a review of these results, it is important to state that $\mathrm{TiSi}_{2}, \mathrm{WSi}_{2}$, and $\mathrm{Cr}_{3} \mathrm{Si}$ have higher electrical conductivity than $\mathrm{MoSi}_{2}, \mathrm{TaSi}_{2}$, and $\mathrm{Cr}_{5} \mathrm{Si}_{3}$ at high temperatures $(\sim 1100 \mathrm{~K})$.

The electrical properties of the semiconducting refractory transition metal silicides and particularly $\mathrm{CrSi}_{2}$ phase have been also studied in the literature. It is known that the transition metal silicides are promising candidates in the field of thermoelectrics, and particularly for use in the microelectronic devices due to their wide range of energy gaps ( 0.1-1.1 eV), ability to grow silicon dioxide as a native oxide, high thermal stability, and excellent diffusion-barrier characteristics $[2,20,56]$. In the study of Fedorov and Zaitsev [20], thermoelectric properties of the single crystal $\mathrm{CrSi}_{2}$ have been investigated. The 


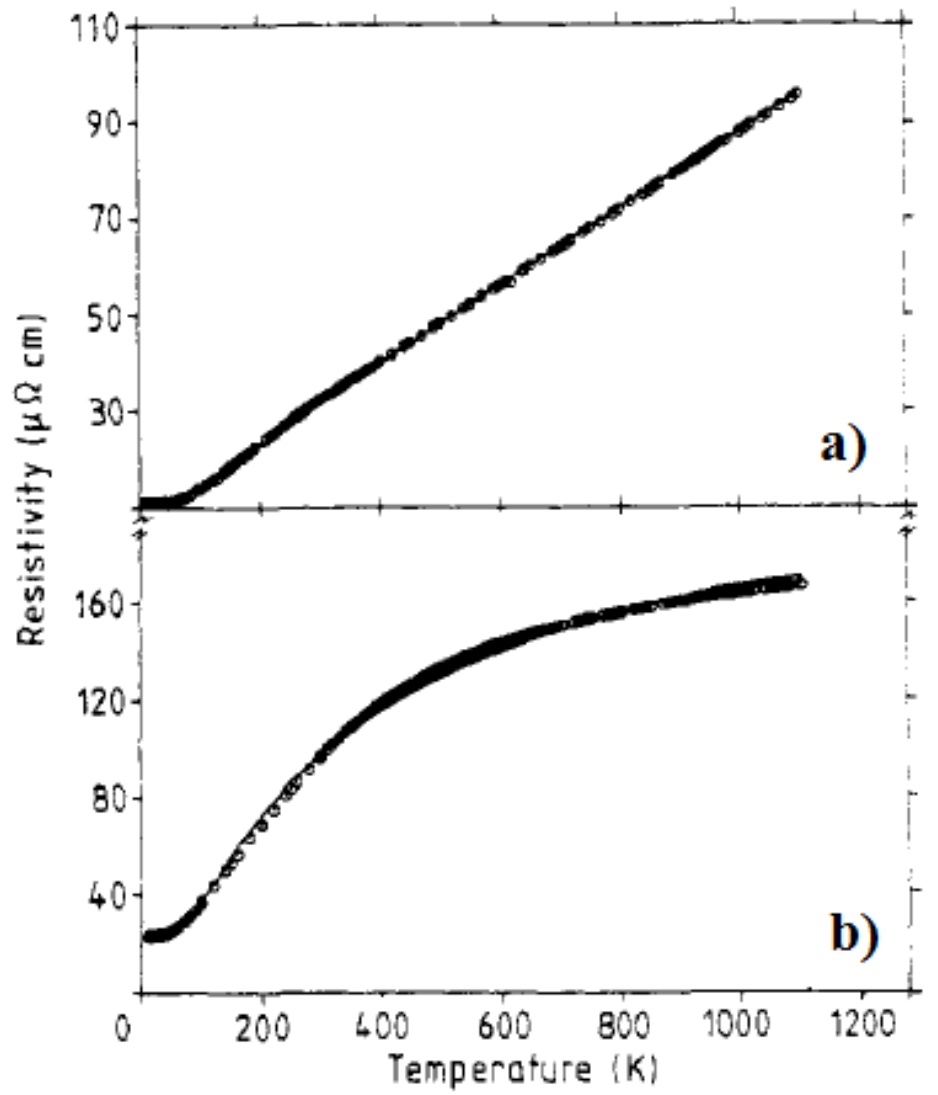

Figure 16. Temperature dependence of the electrical resistivity of the (a) $\mathrm{Cr}_{3} \mathrm{Si}$, and (b) $\mathrm{Cr}_{5} \mathrm{Si}_{3}$ refractory metal silicide thin films [55].

Seebeck coefficient of the $\mathrm{CrSi}_{2}$ single crystal along c-axis was determined approximately as in the range of $100-200 \mu \mathrm{V} / \mathrm{K}(300-900 \mathrm{~K})$. This provides a significant advantage for the use of the $\mathrm{CrSi}_{2}$ in thermoelectric applications. In addition, its maximum thermoelectric figure-of-merit (ZT) was found to be 0.25 , which was relatively low. A similar trend in the Seebeck coefficient of the $\mathrm{CrSi}_{2}$ single crystals was also reported by Nishida (1972) [60]. On the other hand, Kobel et al. (2004) reported in their study for the development of $\mathrm{MoSi}_{2}-\mathrm{Al}_{2} \mathrm{O}_{3}$ electroconductive ceramic composites that $\mathrm{MoSi}_{2}$ exhibited a very high electrical conductivity $(\sim 6000 \mathrm{~S} / \mathrm{cm})$ at around $750^{\circ} \mathrm{C}$ [61]. However, it is important to point out that surprisingly studies are highly limited focusing on the electrical properties of the refractory transition metal silicides and their development for use in advanced hightemperature electrical applications (e.g. sensing, interconnects) $[61,62]$. 


\subsubsection{Oxidation behavior of the refractory transition metal silicides}

The oxidation resistance is one of the most important properties that need to be fulfilled by the refractory transition metal silicides for their particular use at high temperatures for extended operation hours. The oxidation resistance of the refractory metal silicides are mainly related with the formation of silica $\left(\mathrm{SiO}_{2}\right)$ layer on the surface, which is known to be highly protective due to its high thermodynamic stability and low diffusivity for molecular oxygen indicating low parabolic rate constants for its growth [37]. In order to understand the oxidation resistance mechanism of such metal silicides, $\mathrm{MoSi}_{2}$ can be discussed in detail, since its low- and high-temperature oxidation behavior have been extensively studied $[1,2,7,11,14,15,23,44,37]$. Its oxidation behavior is generally studied in three temperature regimes as low temperature $\left(400^{\circ}-600^{\circ} \mathrm{C}\right)$, medium temperature $\left(600^{\circ}\right.$ $1000^{\circ} \mathrm{C}$ ), and high temperature (above $1000^{\circ} \mathrm{C}$ ) regions. At low temperature region $\left(400^{\circ}-\right.$ $600^{\circ} \mathrm{C}$ ), an accelerated simultaneous oxidation occurs in $\mathrm{MoSi}_{2}$ structure by the following reaction (1), which results in a dramatic structural disintegration into a powdery product $[2,11,37]$. This oxidation phenomenon is referred as pest effect or pest oxidation, which is directly related with the formation of crystalline $\mathrm{MoO}_{3}$ and amorphous $\mathrm{SiO}_{2}$ clusters inhibiting formation of a dense protective $\mathrm{SiO}_{2}$ layer and also substantial volume expansion

$$
2 \mathrm{MoSi}_{2}(\mathrm{~s})+7 \mathrm{O}_{2}(\mathrm{~g}) \rightarrow 2 \mathrm{MoO}_{3}(\mathrm{~s})+4 \mathrm{SiO}_{2}(\mathrm{~s})
$$

(molar volume increased by $250 \%$ ). The disintegration of the $\mathrm{MoSi}_{2}$ is also affected by the growth of the $\mathrm{MoO}_{3}$ crystals from the grain boundary resulting in high stress, and thus, crack propagation [2]. Due to high volatility of the $\mathrm{MoO}_{3}$ phase, loose $\mathrm{SiO}_{2}$ layer remains on the surface, while oxygen continues to diffuse through these weak grain boundaries and finally causes the complete structural disintegration [23]. The oxidation behavior of porous and fully dense $\mathrm{MoSi}_{2}$ at $500^{\circ} \mathrm{C}$ in air atmosphere has been studied by Kurokawa et al. (1999) [63]. The mass gain as a main indication of the oxidation was found to be highly low for the fully dense $\mathrm{MoSi}_{2}$, while the porous one showed a high mass gain and accelerated oxidation behavior, which was caused by high oxidation rates after initial oxidation stage (called as an induction time), as shown in Figure 17a. Due to this rapid oxidation, a substantial increase in the mass gain, cracking and structural disintegration of 

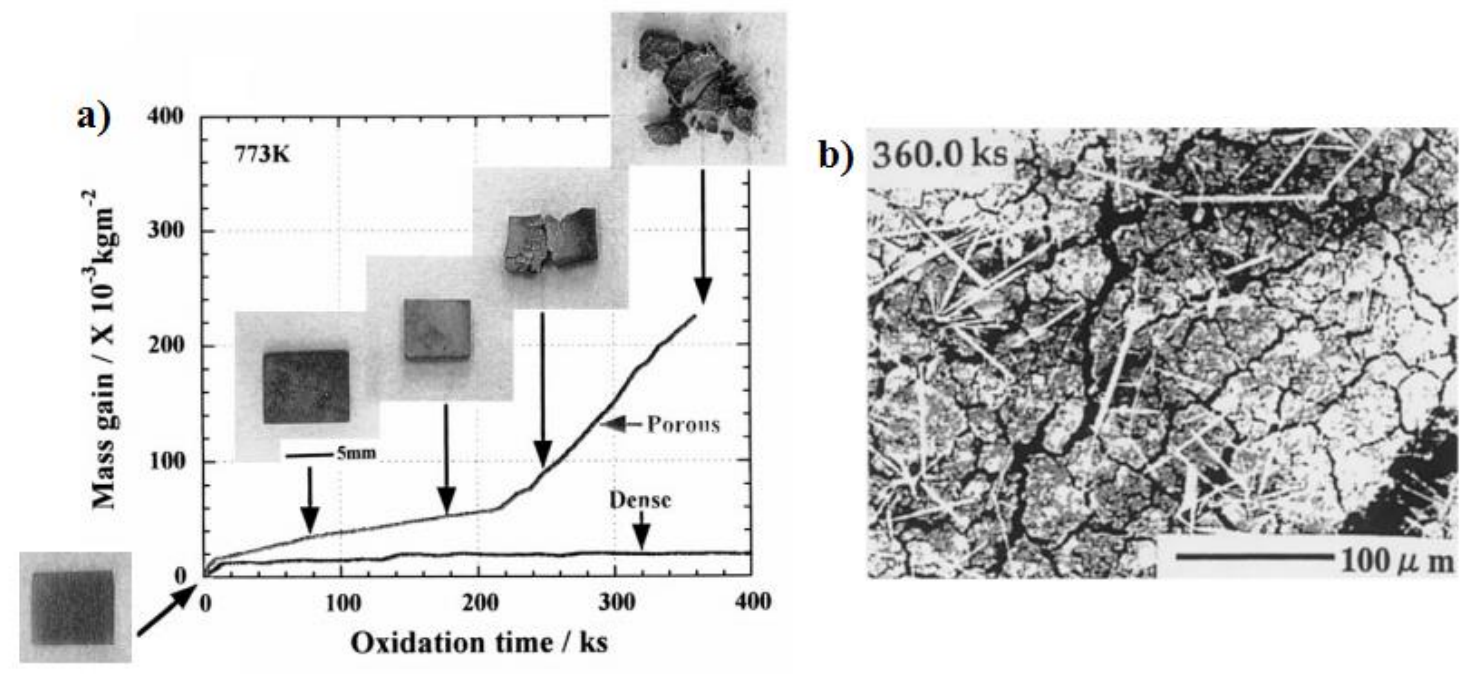

Figure 17. (a) Oxidation behavior of fully dense and porous $\mathrm{MoSi}_{2}$ at $500^{\circ} \mathrm{C}$ in air, and (b) SEM micrograph of the surface of porous $\mathrm{MoSi}_{2}$ oxidized at $500^{\circ} \mathrm{C}$ for $360 \mathrm{ks}(100$ hours) [63].

the $\mathrm{MoSi}_{2}$ (pest effect) were observed. In addition, mostly needle-like $\mathrm{MoO}_{3}$ particles were formed on the surface, which then resulted in cracking and pesting at $500^{\circ} \mathrm{C}$ after $360 \mathrm{ks}$ (100 hours) as seen in Figure $17 \mathrm{~b}$ [63]. At the medium temperature $\left(600^{\circ}-1000^{\circ} \mathrm{C}\right)$ region, vapor pressure of the $\mathrm{MoO}_{3}$ phase initially increased with increasing temperature, and then it started to evaporate at $500^{\circ}-600^{\circ} \mathrm{C}$ [11]. Afterwards, formation and evaporation of the $\mathrm{MoO}_{3}$ were balanced at around $770^{\circ} \mathrm{C}$, which decelerated the volumetric expansion and internal stress level. Therefore, no disintegration and pest oxidation were observed for the $\mathrm{MoSi}_{2}$ at this temperature region.

At higher temperatures above $1000^{\circ} \mathrm{C}, \mathrm{MoSi}_{2}$ has excellent oxidation resistance (up to $1600^{\circ} \mathrm{C}$ ) due to the formation of a highly dense and protective $\mathrm{SiO}_{2}$ layer on the surface $[11,37]$. Since the $\mathrm{MoO}_{3}$ volatilizes rapidly with increasing temperature, a continuous $\mathrm{SiO}_{2}$ layer could be formed as a protective barrier on the surface of the $\mathrm{MoSi}_{2}$. In addition, further formation of the volatile $\mathrm{MoO}_{3}$ phase could be prevented by low oxygen partial pressure at the interface between $\mathrm{SiO}_{2}$ layer and $\mathrm{MoSi}_{2}$, which improves the oxidation 
resistance at high temperatures. Therefore, at this temperature region, there is only a formation of the $\mathrm{Mo}_{5} \mathrm{Si}_{3}$ and $\mathrm{SiO}_{2}$ on the surface as presented in the reaction (2) [2,11]. The

$$
5 \mathrm{MoSi}_{2}(\mathrm{~s})+7 \mathrm{O}_{2(\mathrm{~g})} \rightarrow \mathrm{Mo}_{5} \mathrm{Si}_{3}(\mathrm{~s})+7 \mathrm{SiO}_{2}(\mathrm{~s})
$$

oxidation resistance of the $\mathrm{MoSi}_{2}$ was compared with several high temperature materials such as Nb-, Ti, and Ta-based intermetallic compounds and single crystal nickel superalloy (PWA1484) [1]. Based on the data presented in Figure 18, lowest weight gain and highest oxidation resistance was achieved by the $\mathrm{MoSi}_{2}$, particularly at the temperatures above $1100^{\circ} \mathrm{C}$ after 24 hours of exposure to air. Also, at the temperatures above $1700^{\circ} \mathrm{C}$, it was presented that the oxidation resistance of the $\mathrm{MoSi}_{2}$ decreased owing to the drastic decrease in viscosity of the $\mathrm{SiO}_{2}$ phase and increase in the defect concentration [37]. Sharif (2010) studied the high temperature oxidation behavior of the $\mathrm{MoSi}_{2}$ to determine the changes in the oxidation mechanism of the $\mathrm{MoSi}_{2}$ above $1400^{\circ} \mathrm{C}$ [15]. As shown in Figure 19, the weight gain highly increased with increasing temperature from $1400^{\circ} \mathrm{C}$ to $1700^{\circ} \mathrm{C}$ after exposed to air up to $100 \mathrm{~h}$. This result hereby implied that there is a change in the oxidation rate of $\mathrm{MoSi}_{2}$ with increasing temperature and time. Although formation of the $\mathrm{Mo}_{5} \mathrm{Si}_{3}$ was

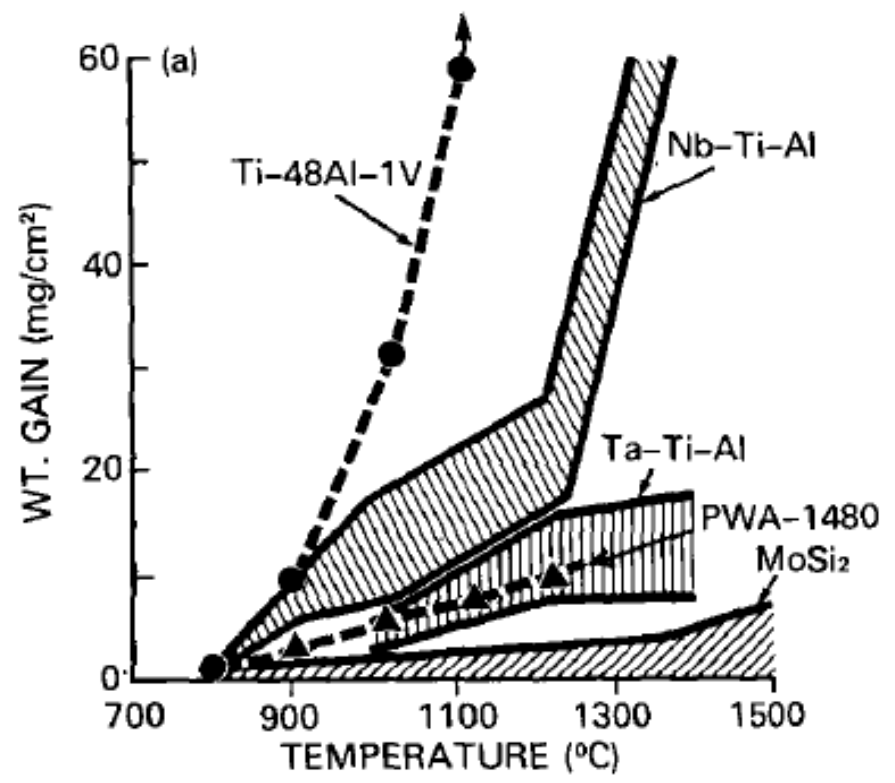

Figure 18. Comparison of the isothermal oxidation behavior of $\mathrm{MoSi}_{2}$ with several intermetallic compounds and nickel superalloy (PWA 1484) [1]. 


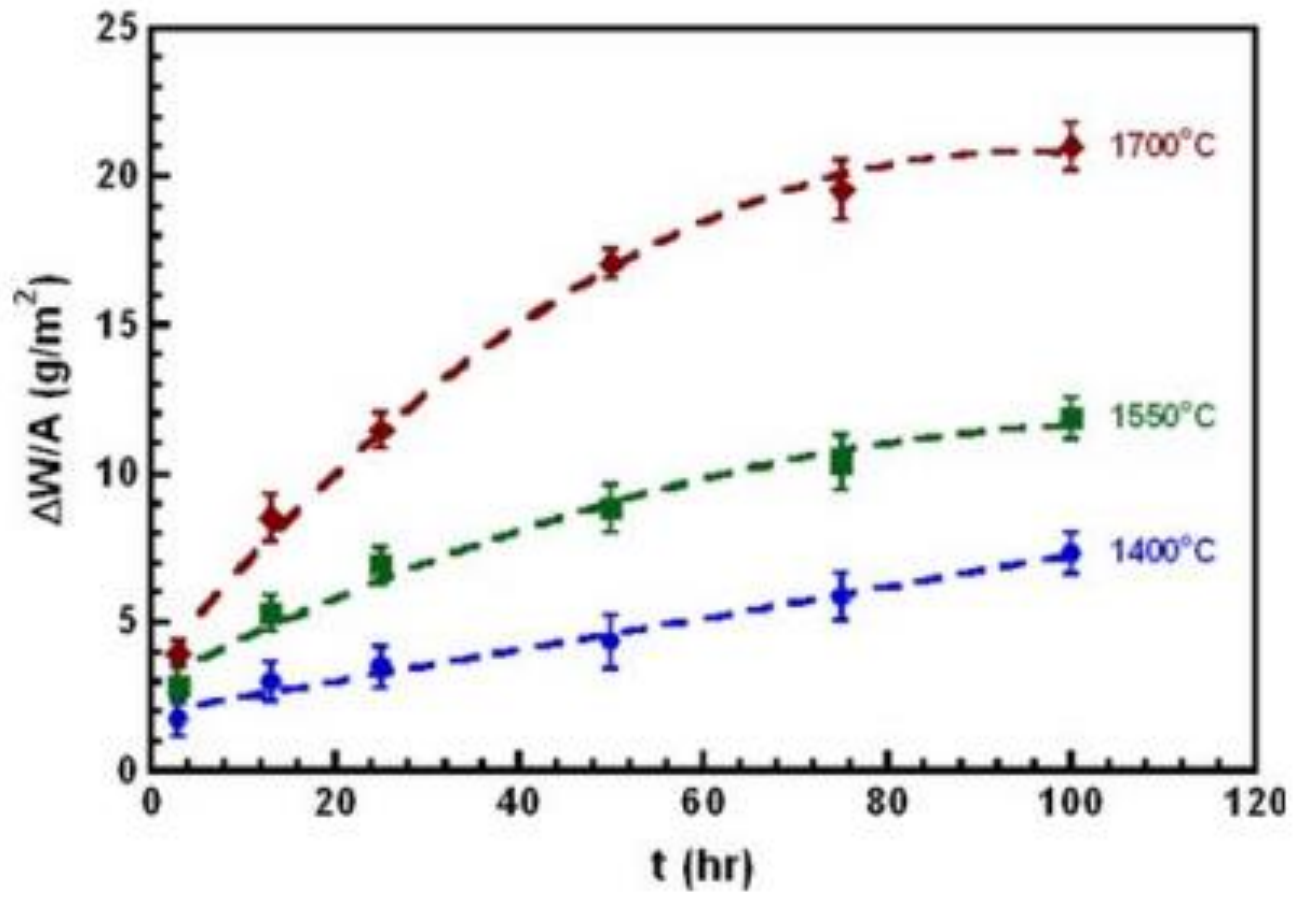

Figure 19. The specific weight gain at high temperatures $\left(1400^{\circ}-1700^{\circ} \mathrm{C}\right)$ during isothermal oxidation of the $\mathrm{MoSi}_{2}$ samples [15].

not observed at $1400^{\circ} \mathrm{C}$ and $1550^{\circ} \mathrm{C}$, silica layer crystallized into $\beta$-cristobalite form at $1700^{\circ} \mathrm{C}$, which caused a substantially high oxygen diffusion through the layer, and hereby reduced oxidation resistance at the temperatures approaching the melting point of the silica phase [15]. As a review of the high temperature oxidation resistance of the refractory transition metal silicides, it should be noted that the $\mathrm{MoSi}_{2}$ and $\mathrm{WSi}_{2}$ have significantly higher oxidation resistance than the other refractory metal silicides $\left(\mathrm{TaSi}_{2}, \mathrm{TiSi}_{2}, \mathrm{Mo}_{5} \mathrm{Si}_{3}\right.$, $\mathrm{W}_{5} \mathrm{Si}_{3}$ etc.) as listed in the Table 3 [1]. It is known that volatility of the $\mathrm{MoO}_{3}$ phase has an important role in the oxidation behavior of the $\mathrm{MoSi}_{2}$, and $\mathrm{WSi}_{2}$ exhibits a quite similar oxidation behavior to the $\mathrm{MoSi}_{2}$ [7,37]. In addition, $\mathrm{Ti}_{5} \mathrm{Si}_{3}$ is known to have a reasonable oxidation resistance at high temperatures, compared to the other Mo-, Nb-, W-, Ta-based 53 metal silicides, since disintegration occurs within $\mathrm{Mo}_{5} \mathrm{Si}_{3}$ and $\mathrm{Nb}_{5} \mathrm{Si}_{3}$ at high temperatures [7,44]. Also, the $\mathrm{Cr}_{3} \mathrm{Si}$ exhibits a good high temperature oxidation resistance, compared to the other monosilicides, while the least oxidation resistant silicides are $\mathrm{W}_{5} \mathrm{Si}_{3}$ and $\mathrm{Ta}_{5} \mathrm{Si}_{3}$. 
Table 3. High temperature oxidation resistance of the several refractory transition metal silicides with high melting points based on the oxidation-induced mass changes [1].

\begin{tabular}{|c|c|c|c|}
\hline Metal Silicide & $\begin{array}{c}\text { Oxidation temperature } \\
\left({ }^{\circ} \mathbf{C}\right)\end{array}$ & $\begin{array}{l}\text { Oxidation time } \\
\text { (h) }\end{array}$ & $\begin{array}{c}\text { Mass change } \\
\left(\mathrm{mg} / \mathrm{cm}^{2}\right)\end{array}$ \\
\hline $\mathrm{MoSi}_{2}$ & $\begin{array}{l}1200 \\
1500\end{array}$ & $\begin{array}{l}4 \\
4\end{array}$ & $\begin{array}{l}+0.3 \\
+1.3\end{array}$ \\
\hline $\mathrm{WSi}_{2}$ & $\begin{array}{l}1200 \\
1500 \\
\end{array}$ & $\begin{array}{l}4 \\
4 \\
\end{array}$ & $\begin{array}{l}-17.0 \\
-23.0 \\
\end{array}$ \\
\hline $\mathrm{NbSi}_{2}$ & 1200 & 6 & +40.0 \\
\hline $\mathrm{TaSi}_{2}$ & 1200 & 4 & +60.0 \\
\hline $\mathrm{TiSi}_{2}$ & 1200 & 4 & +22.0 \\
\hline $\mathrm{Mo}_{5} \mathrm{Si}_{3}$ & 1500 & 4 & -67.0 \\
\hline $\mathrm{W}_{5} \mathrm{Si}_{3}$ & 1500 & 4 & -205.0 \\
\hline $\mathrm{Ta}_{5} \mathrm{Si}_{3}$ & 1500 & 1 & +125.0 \\
\hline $\mathrm{Ti}_{5} \mathrm{Si}_{3}$ & 1500 & 2 & +32.0 \\
\hline
\end{tabular}

\subsection{Refractory Transition Metal Silicide Composites}

Although the refractory transition metal silicides have a great potential for high temperature structural and electrical applications, they have some major disadvantages that restrict their use in some applications. These disadvantages could be summarized as (1) low fracture toughness below the ductile-brittle transition temperature $\left(\sim 1000^{\circ} \mathrm{C}\right)$, (2) low strength above the ductile-brittle transition temperature, (3) low creep resistance at high temperatures (above $1200^{\circ} \mathrm{C}$ ), and (4) pest oxidation behavior (poor oxidation resistance) at around $600^{\circ} \mathrm{C}[1-4,12,54,64-66]$. Therefore, composite approach has been extensively utilized to overcome such disadvantages of the refractory transition metal silicides, and hence, to make them capable to operate as high temperature structural materials more reliably and precisely. Based on the studies performed on the literature (mostly on the 
$\mathrm{MoSi}_{2}$-based composites), oxide and non-oxide ceramic materials, such as $\mathrm{SiC}, \mathrm{Si}_{3} \mathrm{~N}_{4}$, $\mathrm{ZrO}_{2}, \mathrm{Al}_{2} \mathrm{O}_{3}, \mathrm{AlN}, \mathrm{TiC}$, and $\mathrm{TiB}_{2}$, are mostly used as reinforcement materials to develop refractory transition metal silicide-based composites due to their high melting point, thermodynamic compatibility with refractory metal silicides, high thermal stability, good mechanical properties, and high oxidation and creep properties.

\subsubsection{Mechanical properties of the refractory transition metal silicide composites}

The mechanical behavior and properties of the refractory transition metal silicide composites have been examined in the literature due to their high potential for use in high temperature applications. The room temperature fracture toughness and creep properties of different composite compositions have been extensively reported over the years.

\subsubsection{Fracture toughness}

The fracture toughness of the $\mathrm{MoSi}_{2}$-based composites has been studied in detail, since it is essential to improve the fracture toughness of the $\mathrm{MoSi}_{2}$. Therefore, $\mathrm{SiC}_{2} \mathrm{Si}_{3} \mathrm{~N}_{4}$, and TiC are mostly used as non-oxide ceramic reinforcements. Newman et al. (1999) performed a study with a focus on the development of mechanical properties of the $\mathrm{MoSi}_{2}$ by the addition of the $\mathrm{SiC}$ and $\mathrm{Al}_{2} \mathrm{O}_{3}$ phases [4]. The room temperature fracture toughness of the $\mathrm{MoSi}_{2}-\mathrm{Al}_{2} \mathrm{O}_{3}$ composites $\left(\sim 3.1-3.2 \mathrm{MPa} \cdot \mathrm{m}^{1 / 2}\right)$ almost did not change compared to the pure $\mathrm{MoSi}_{2}$, whereas $\mathrm{MoSi}_{2}-\mathrm{SiC}$ composites exhibited relatively high fracture toughness depending on the volume fraction of the $\mathrm{SiC}$. The fracture toughness of the $\mathrm{MoSi}_{2}$ was increased from 3.2 to $5.8 \mathrm{MPa} \cdot \mathrm{m}^{1 / 2}$ by utilizing the $\mathrm{MoSi}_{2}-\mathrm{SiC}$ composite with $16 \mathrm{vol} \%$ $\mathrm{SiC}$ content, since it provided a crack deflection toughening. In addition, it is important to point out that less grain growth was observed in the $\mathrm{MoSi}_{2}-\mathrm{Al}_{2} \mathrm{O}_{3}$ composites owing to the positive effect of the $\mathrm{Al}_{2} \mathrm{O}_{3}$ addition on the grain growth kinetics, which could be an additional advantage for long operation hours at high temperatures [4]. In the study of Pan et al. (1998), the mechanical properties of the MoSi2-SiC composites prepared by hot press sintering (20 vol\% $\alpha$-SiC) and in-situ reaction sintering $(24.5$ vol\% $\beta$-SiC) have been examined in detail [40]. As presented in Figure 20, room temperature fracture toughness 


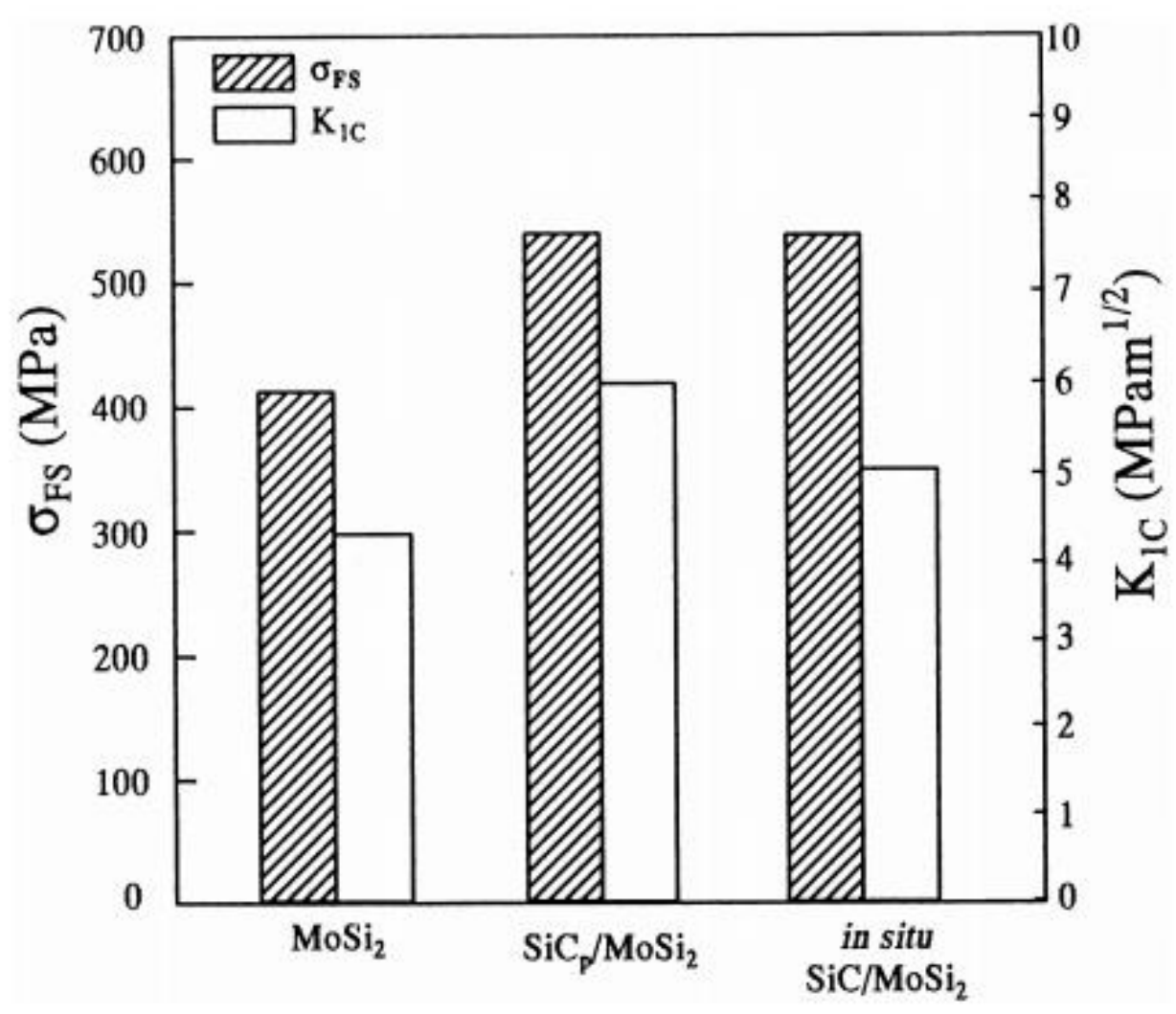

Figure 20. The room temperature fracture toughness $\left(\mathrm{K}_{\mathrm{IC}}\right)$ and flexural strength $\left(\sigma_{\mathrm{FS}}\right)$ of the pure $\mathrm{MoSi}_{2}$, hot pressed $\mathrm{MoSi}_{2}-\mathrm{SiC}$ and in-situ $\mathrm{MoSi}_{2}-\mathrm{SiC}$ composites [40].

values of the hot pressed $\mathrm{MoSi}_{2}-\mathrm{SiC}$ and in-situ $\mathrm{MoSi}_{2}-\mathrm{SiC}$ composites were measured as 5.95 and $4.94 \mathrm{MPa} \cdot \mathrm{m}^{1 / 2}$, respectively. These values are relatively higher than the fracture toughness of the pure $\mathrm{MoSi}_{2}\left(\sim 4.3 \mathrm{MPa} \cdot \mathrm{m}^{1 / 2}\right)$, and thus, it could be clearly stated that the SiC-reinforced $\mathrm{MoSi}_{2}$ composite has enhanced fracture toughness at room temperature. The result obtained for the hot pressed $\mathrm{MoSi}_{2}-\mathrm{SiC}$ composite were found to be very similar to the data presented by Newman et al. (1999) [4,40].

Sun and Pan (2002) also presented that the room temperature fracture toughness values of the $\mathrm{MoSi}_{2}$ composites reinforced with 20 vol\% $\mathrm{TiC}$ - and SiC-whiskers were 5.2 and 5.5 $\mathrm{MPa} \cdot \mathrm{m}^{1 / 2}$, respectively [67]. Therefore, these results demonstrated that fracture toughness of the $\mathrm{MoSi}_{2}\left(3.2 \mathrm{MPa} \cdot \mathrm{m}^{1 / 2}\right)$ was highly increased by reinforcing with $\mathrm{SiC}$ and TiC particles due to reduced crack propagation within the $\mathrm{MoSi}_{2}$ structure with whiskers. 


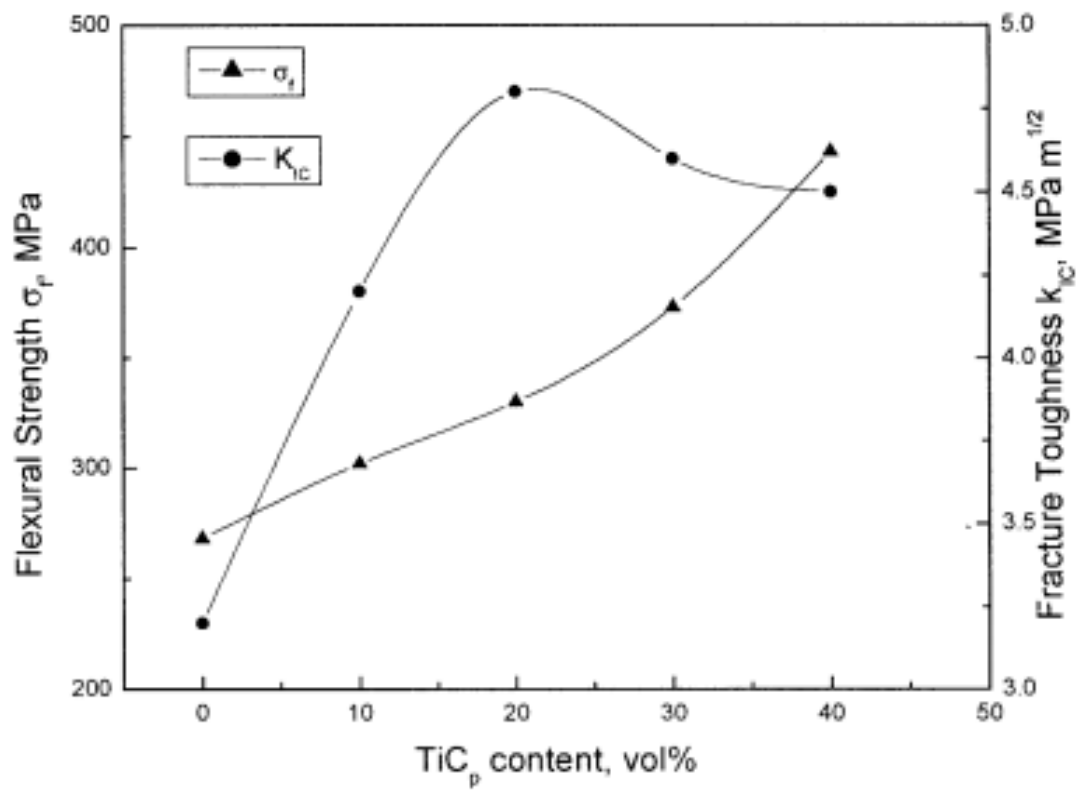

Figure 21. Effect of the TiC particle content on the fracture toughness $\left(\mathrm{K}_{\mathrm{IC}}\right)$ and flexural strength $\left(\sigma_{\mathrm{f}}\right)$ of the $\mathrm{MoSi}_{2}$-TiC composites [68].

These values are quite comparable to the data obtained for the $\mathrm{MoSi}_{2}-\mathrm{SiC}$ composites in other studies $[4,40]$. In contrast, relatively lower room temperature fracture toughness values (4.0-4.4 $\mathrm{MPa} \cdot \mathrm{m}^{1 / 2}$ ) were also presented for the $\mathrm{MoSi}_{2}$ composites reinforced by 20 vol\% SiC particles (e.g. whiskers) [38]. In the study of Sun and Pan (2002), effect of the $\mathrm{TiC}$ particle reinforcement on the room temperature fracture toughness of the $\mathrm{MoSi}_{2}-\mathrm{TiC}$ composites has been investigated [68]. Figure 21 shows the change in fracture toughness as a function of the $\mathrm{TiC}$ volume fraction. The fracture toughness of the $\mathrm{MoSi}_{2}-\mathrm{TiC}$ composites increased up to $4.9 \mathrm{MPa} \cdot \mathrm{m}^{1 / 2}$ with the addition of $20 \mathrm{vol} \% \mathrm{TiC}$, which is much higher than the fracture toughness of the monolithic $\mathrm{MoSi}_{2}\left(3.2 \mathrm{MPa} \cdot \mathrm{m}^{1 / 2}\right)$. It was also identified that the fracture toughness slightly decreased when the TiC content was above 20 vol\%, due to brittle fracture. In another study, room temperature fracture toughness of the $\mathrm{MoSi}_{2}$ was increased from 3.2 to $5.2 \mathrm{MPa} \cdot \mathrm{m}^{1 / 2}$ by reinforcing with 20 vol\% TiC-whiskers [69]. Apart from the $\mathrm{SiC}$ and $\mathrm{TiC}$, the $\mathrm{Si}_{3} \mathrm{~N}_{4}$ was also used as a ceramic reinforcement. Wang et al. (2004) studied the mechanical properties of the $\mathrm{MoSi}_{2}-\mathrm{Si}_{3} \mathrm{~N}_{4}$ composites by using $20 \mathrm{vol} \%$ of $\mathrm{Si}_{3} \mathrm{~N}_{4}$ rod-like crystals [70]. The room temperature fracture toughness of the $\mathrm{MoSi}_{2}$ - 
$\mathrm{Si}_{3} \mathrm{~N}_{4}$ composite was measured as $5.1 \mathrm{MPa} \cdot \mathrm{m}^{1 / 2}$, which is relatively higher than that of the monolithic $\mathrm{MoSi}_{2}$ (3.6 MPa $\mathrm{m}^{1 / 2}$ ). In the study of Petrovic et al. (1997), room temperature indentation fracture toughness of the $\mathrm{MoSi}_{2}-\mathrm{Si}_{3} \mathrm{~N}_{4}$ composites was reported [10]. Figure 22 presents the changes in the fracture toughness as a function of the $\mathrm{MoSi}_{2}$ volume percentage and particle size of the $\mathrm{MoSi}_{2}$. The $\mathrm{MoSi}_{2}$ particle size was found to have a significant effect on fracture toughness, since improvements were achieved using $\mathrm{MoSi}_{2}$ particles with $10 \mu \mathrm{m}$ size. The maximum room temperature fracture toughness value was obtained as $8.3 \mathrm{MPa} \cdot \mathrm{m}^{1 / 2}$ at the composition of (40-60) vol\% $\mathrm{MoSi}_{2}-\mathrm{Si}_{3} \mathrm{~N}_{4}$ having $10 \mu \mathrm{m}$ sized $\mathrm{MoSi}_{2}$ particles, which was higher than the $\mathrm{MoSi}_{2}-\mathrm{Si}_{3} \mathrm{~N}_{4}$ composite with $3 \mu \mathrm{m}$ sized $\mathrm{MoSi}_{2}$ particles $\left(5.7 \mathrm{MPa} \cdot \mathrm{m}^{1 / 2}\right.$ ) and monolithic $\mathrm{MoSi}_{2}\left(3.0 \mathrm{MPa} \cdot \mathrm{m}^{1 / 2}\right.$ ). The improved fracture toughness was explained by the effect of thermal expansion coefficient mismatch between $\mathrm{MoSi}_{2}$ and $\mathrm{Si}_{3} \mathrm{~N}_{4}$ phases, providing internal stress-toughening mechanism [10,71].

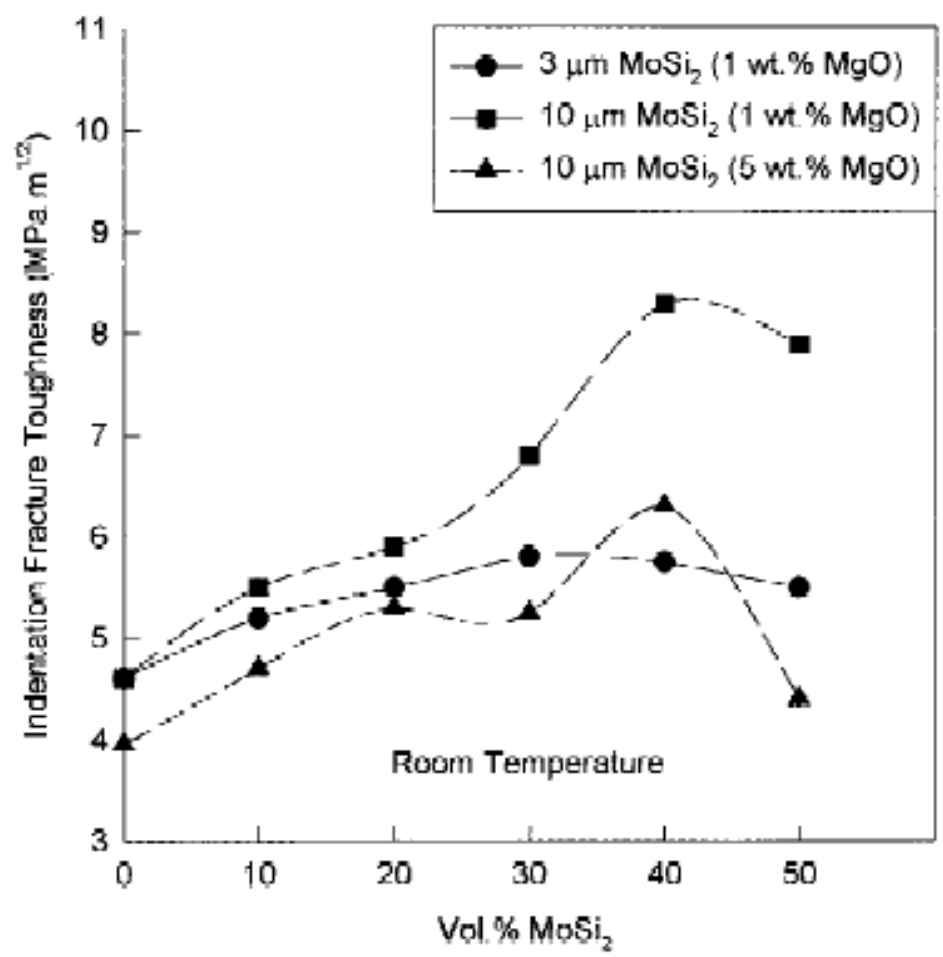

Figure 22. Changes in room temperature fracture toughness of the $\mathrm{MoSi}_{2}-\mathrm{Si}_{3} \mathrm{~N}_{4}$ composites as a function of the volume fraction and particle size of the $\mathrm{MoSi}_{2}$ phase ( $\mathrm{MgO}$ was used as a densification aid for $\mathrm{Si}_{3} \mathrm{~N}_{4}$ ) [10]. 
As alternatives of the non-oxide ceramic reinforcements, $\mathrm{Al}_{2} \mathrm{O}_{3}$ and $\mathrm{ZrO}_{2}$ oxide ceramics have been also used for the development of refractory transition metal silicideoxide composites. Wang et al. (2014) studied the mechanical properties of the $\mathrm{MoSi}_{2}-5$ vol\% $\mathrm{Al}_{2} \mathrm{O}_{3}$ composites at room temperature as a function of the sintering temperature [72]. The room temperature fracture toughness of the $\mathrm{MoSi}_{2}-\mathrm{Al}_{2} \mathrm{O}_{3}$ composites increased from 3.69 to $4.53 \mathrm{MPa} \cdot \mathrm{m}^{1 / 2}$ with increasing sintering temperature from $1300^{\circ} \mathrm{C}$ to $1400^{\circ} \mathrm{C}$, but then, decreased to $3.63 \mathrm{MPa} \cdot \mathrm{m}^{1 / 2}$ at $1600^{\circ} \mathrm{C}$. This result could be directly interrelated with a drastic increase in the $\mathrm{MoSi}_{2}$ grain size approximately from 5 to $15 \mu \mathrm{m}$ with increasing sintering temperature from $1400^{\circ} \mathrm{C}$ to $1600^{\circ} \mathrm{C}$, which resulted in a decreased toughness. Therefore, volume percentage of the $\mathrm{Al}_{2} \mathrm{O}_{3}$ phase should be relatively higher for retarding the grain growth, and hence, enhancing the fracture toughness at the same time. In addition, room temperature fracture toughness of the $\mathrm{MoSi}_{2}-\mathrm{Al}_{2} \mathrm{O}_{3}$ composites has been studied [62]. The maximum fracture toughness was measured at around $4.8 \mathrm{MPa} \cdot \mathrm{m}^{1 / 2}$ for $(35-65) \mathrm{wt} \%$ $\mathrm{MoSi}_{2}-\mathrm{Al}_{2} \mathrm{O}_{3}$, as presented in Figure 23. The room temperature fracture toughness of the $\mathrm{Mo}_{5} \mathrm{Si}_{3}-20$ wt.\% $\mathrm{Al}_{2} \mathrm{O}_{3}$ composite was reported as $6.53 \mathrm{MPa} \cdot \mathrm{m}^{1 / 2}$ by Chen et al. (2014) [54], which is relatively higher than that of the $\mathrm{MoSi}_{2}-\mathrm{Al}_{2} \mathrm{O}_{3}$ composites. In addition, $\mathrm{ZrO}_{2}$ has been also utilized as an oxide reinforcement. In the study of Yi and Li (1999), the mechanical properties of the $\mathrm{MoSi}_{2}-\mathrm{ZrO}_{2}$ composites were reported by using both unstabilized (monoclinic) and yttria partially stabilized- $\mathrm{ZrO}_{2}$ (tetragonal) particles [64]. Also, both commercial and mechanically alloyed $\mathrm{MoSi}_{2}$ powders were used in this study. The maximum room temperature fracture toughness values were obtained as 6.66 and 6.75 $\mathrm{MPa} \cdot \mathrm{m}^{1 / 2}$ for the commercial $\mathrm{MoSi}_{2}-20 \mathrm{vol} \%$ unstabilized $-\mathrm{ZrO}_{2}$ and mechanically alloyed $\mathrm{MoSi}_{2}-20$ vol\% unstabilized- $\mathrm{ZrO}_{2}$ composites, respectively. The $\mathrm{MoSi}_{2}$-yttria partially stabilized- $\mathrm{ZrO}_{2}$ composites all exhibited lower fracture toughness values (2.73-3.44 $\mathrm{MPa} \cdot \mathrm{m}^{1 / 2}$ ). These results clearly indicated that the unstabilized $\mathrm{ZrO}_{2}$ is more effective as a reinforcement material owing to the existence of large number of microcracks initiating the microcracking as a dominant toughening mechanism [64]. Furthermore, Dogan and Hawk (1997) studied the mechanical properties of the $\mathrm{MoSi}_{2}-\mathrm{ZrO}_{2}$ composites all having $20 \mathrm{vol} \%$ $\mathrm{ZrO}_{2}$ content [73]. They also conducted their study by using the unstabilized, partially 


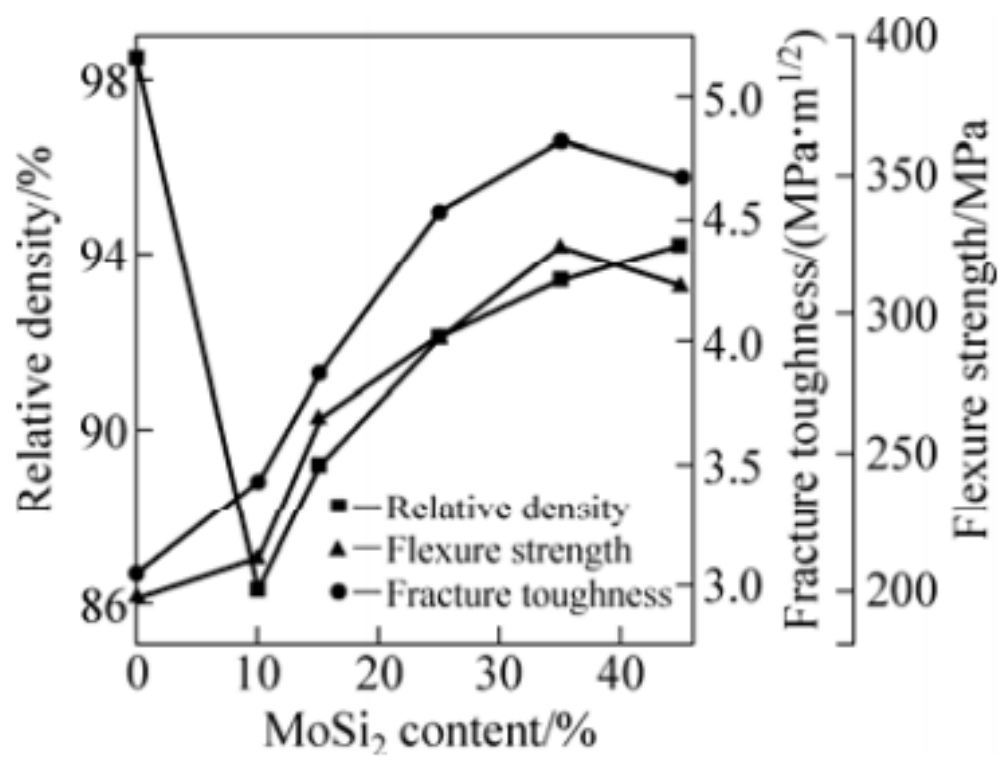

Figure 23. Effect of the $\mathrm{MoSi}_{2}$ weight percentage on the room temperature mechanical properties of the $\mathrm{MoSi}_{2}-\mathrm{Al}_{2} \mathrm{O}_{3}$ composites [62].

stabilized, and fully stabilized $\mathrm{ZrO}_{2}$ particles. Based on the data presented, the $\mathrm{MoSi}_{2}-20$ vol\% unstabilized $\mathrm{ZrO}_{2}$ composite revealed higher room temperature fracture toughness with 6.7 $\mathrm{MPa} \cdot \mathrm{m}^{1 / 2}$ compared to the other composites $\left(4.0-4.1 \mathrm{MPa} \cdot \mathrm{m}^{1 / 2}\right)$. This result was found to be related to the large number of microcracks existing in the composite structure, which predominated the microcracking toughening mechanism. In another study, the fracture toughness of the $\mathrm{MoSi}_{2}-20 \mathrm{vol} \% \mathrm{ZrO}_{2}$ composite was measured as $7.8 \mathrm{MPa} \cdot \mathrm{m}^{1 / 2}$ [38]. Ma et al. (2001) also reported a study with a focus on the effect of unstabilized $\mathrm{ZrO}_{2}$, yttria partially stabilized $\mathrm{ZrO}_{2}$, and $\mathrm{SiC}$ reinforcements on the mechanical properties of the $\mathrm{MoSi}_{2}$-based composites [74]. Figure 24 shows the room temperature fracture toughness of the monolithic $\mathrm{MoSi}_{2}$ and different $\mathrm{MoSi}_{2}$-matrix composites. The highest fracture toughness values were found as 6.1 and $7.6 \mathrm{MPa} \cdot \mathrm{m}^{1 / 2}$ for the $\mathrm{MoSi}_{2}-20$ vol\% unstabilized$\mathrm{ZrO}_{2}$ and $\mathrm{MoSi}_{2}-10$ vol\% SiC-10 vol\% unstabilized- $\mathrm{ZrO}_{2}$ composites, respectively. These results also demonstrated that the unstabilized $-\mathrm{ZrO}_{2}$ and $\mathrm{SiC}$ are highly effective ceramic reinforcements, particularly compared to the yttria partially stabilized $\mathrm{ZrO}_{2}$. It was additionally determined that the $\mathrm{MoSi}_{2}-\left(\mathrm{SiC}+\mathrm{ZrO}_{2}\right)$ composite is another highly promising candidate for enhancing the mechanical properties. 


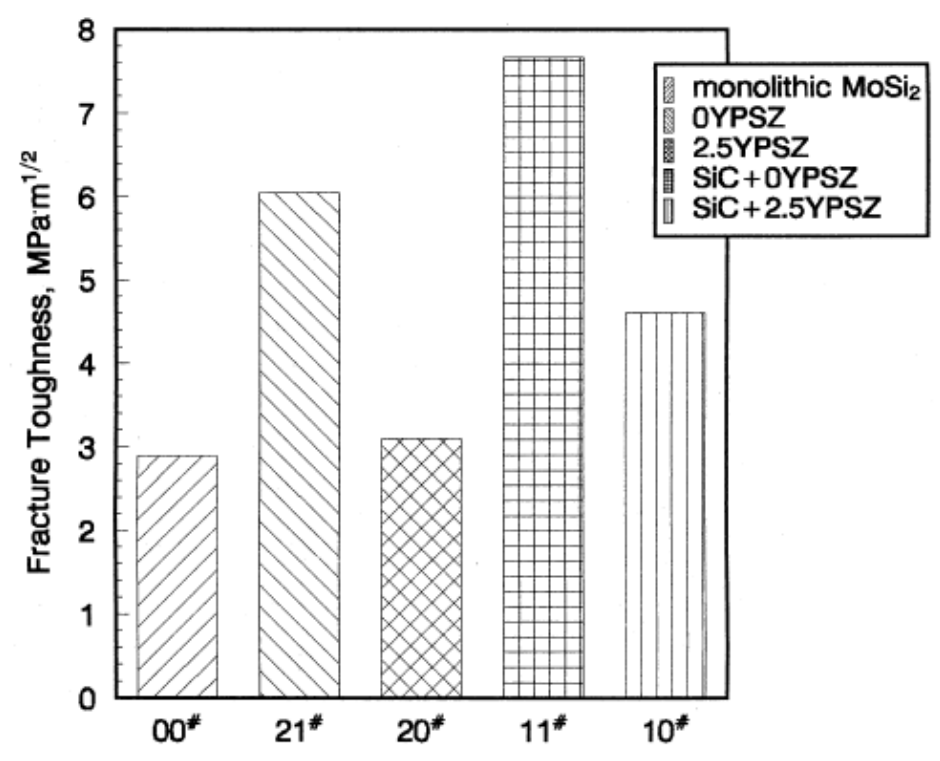

Figure 24. Room temperature fracture toughness of the monolithic $\mathrm{MoSi}_{2}$ and different $\mathrm{MoSi}_{2}$-matrix composites reinforced with unstabilized $\mathrm{ZrO}_{2}$ (0YPSZ), yttria partially stabilized $\mathrm{ZrO}_{2}$ (2.5YPSZ), and $\mathrm{SiC}$ (reinforcement content was $20 \mathrm{vol} \%$ for all) [74].

Apart from the $\mathrm{MoSi}_{2}$-based composites, there are very limited number of studies, which conducted on the $\mathrm{WSi}_{2}$ - and $\mathrm{NbSi}_{2}$-based composites in the literature. Muraoka et al. (1996) reported that room temperature fracture toughness values of the (40-60) mol\% and (20-80) mol\% WSi2-yttria partially stabilized $\mathrm{ZrO}_{2}$ composites were 7.7 and 12.4 $\mathrm{MPa} \cdot \mathrm{m}^{1 / 2}$, respectively [75]. These values were found to be relatively higher than that of the $\mathrm{MoSi}_{2}$-based composites. In the study of Ko et al. (2010), room temperature fracture toughness of the $\mathrm{NbSi}_{2}-\mathrm{Si}_{3} \mathrm{~N}_{4}$ composite was reported as $3.5 \mathrm{MPa} \cdot \mathrm{m}^{1 / 2}$ [76]. Furthermore, fracture toughness of the $\mathrm{NbSi}_{2}-\mathrm{SiC}$ composite was measured at room temperature as $\sim 5.3$ $\mathrm{MPa} \cdot \mathrm{m}^{1 / 2}[77]$.

\subsubsection{Creep properties}

The high temperature creep resistance of the refractory transition metal silicide composites has been investigated in the literature to determine the influence of different oxide $\left(\mathrm{Al}_{2} \mathrm{O}_{3}, \mathrm{ZrO}_{2}\right.$ etc. $)$ and non-oxide $\left(\mathrm{SiC}, \mathrm{Si}_{3} \mathrm{~N}_{4}\right.$ etc. $)$ ceramic reinforcements, since it is known that the creep resistance of the refractory metal silicides need to be improved for 
their reliable use in high temperature applications. Petrovic (1995) reviewed the high temperature creep behavior of the $\mathrm{MoSi}_{2}-\mathrm{SiC}$ composites [38]. As presented in the Figure $25 \mathrm{a}$, the high temperature $\left(1200^{\circ} \mathrm{C}\right)$ creep resistance at different stress levels was significantly improved by addition of $40 \mathrm{vol} \%$ of the $\mathrm{SiC}$ particles into the $\mathrm{MoSi}_{2}$ structure. On the other hand, the creep rates relatively increased, when volume percentages of the $\mathrm{SiC}$ were between 5 and $20 \mathrm{vol} \%$. This was directly related to the reduced matrix grain size promoting the operation grain boundary sliding as a creep mechanism. In the study of Vasudevan and Petrovic (1992), the creep rates of the monolithic $\mathrm{MoSi}_{2}$ and the $\mathrm{MoSi}_{2}-20$ $\mathrm{vol} \% \mathrm{SiC}_{\mathrm{w}}$ were compared as shown in Figure 25b [1]. It is apparent that the creep rates were highly decreased (creep strain increased) at $1200^{\circ} \mathrm{C}$ and $78 \mathrm{MPa}$ stress level by using $\mathrm{SiC}$ whiskers as a reinforcement, while a rapid deformation was observed for the monolithic $\mathrm{MoSi}_{2}$. The creep resistance of the $\mathrm{MoSi}_{2}-\mathrm{SiC}_{1}$ composite was also found quite comparable to that of the $\mathrm{Si}_{3} \mathrm{~N}_{4}-\mathrm{SiC}$ composite, which implied that the creep resistance of the $\mathrm{MoSi}_{2}$ can be substantially improved by developing $\mathrm{MoSi}_{2}-\mathrm{SiC}_{\mathrm{C}}$ composites. In addition, $\mathrm{Si}_{3} \mathrm{~N}_{4}$ has been also used as a particulate reinforcement for improving the high temperature creep resistance, since it is known that the pest problems existing at around $600^{\circ} \mathrm{C}$ could be relatively lowered by the $\mathrm{Si}_{3} \mathrm{~N}_{4}$ reinforcement. Sadananda et al. (1999) reported a research
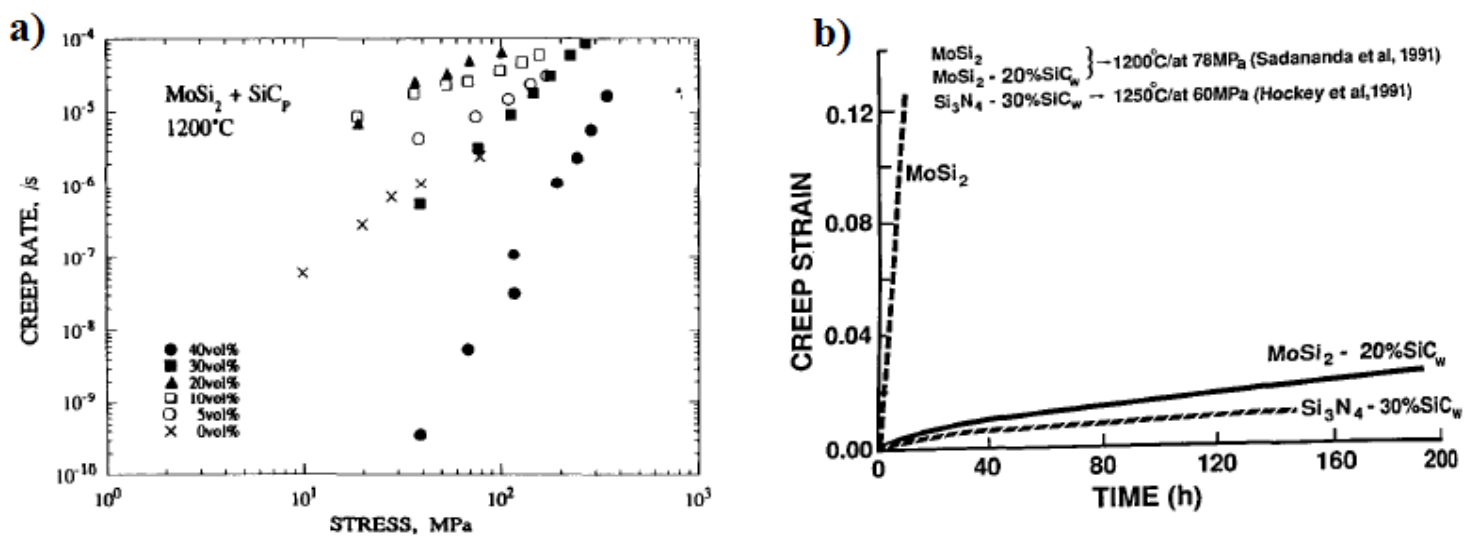

Figure 25. (a) Creep rate of the $\mathrm{MoSi}_{2}-\mathrm{SiC}_{\mathrm{w}}$ composites at $1200^{\circ} \mathrm{C}$ with different volume fractions of $\mathrm{SiC}$ phase [38], and (b) comparison of the creep deformation of the monolithic $\mathrm{MoSi}_{2}$ and $\mathrm{MoSi}_{2}-20 \mathrm{vol} \% \mathrm{SiC}_{\mathrm{w}}$ at $1200^{\circ} \mathrm{C}$ and $78 \mathrm{MPa}$ stress level [1]. 

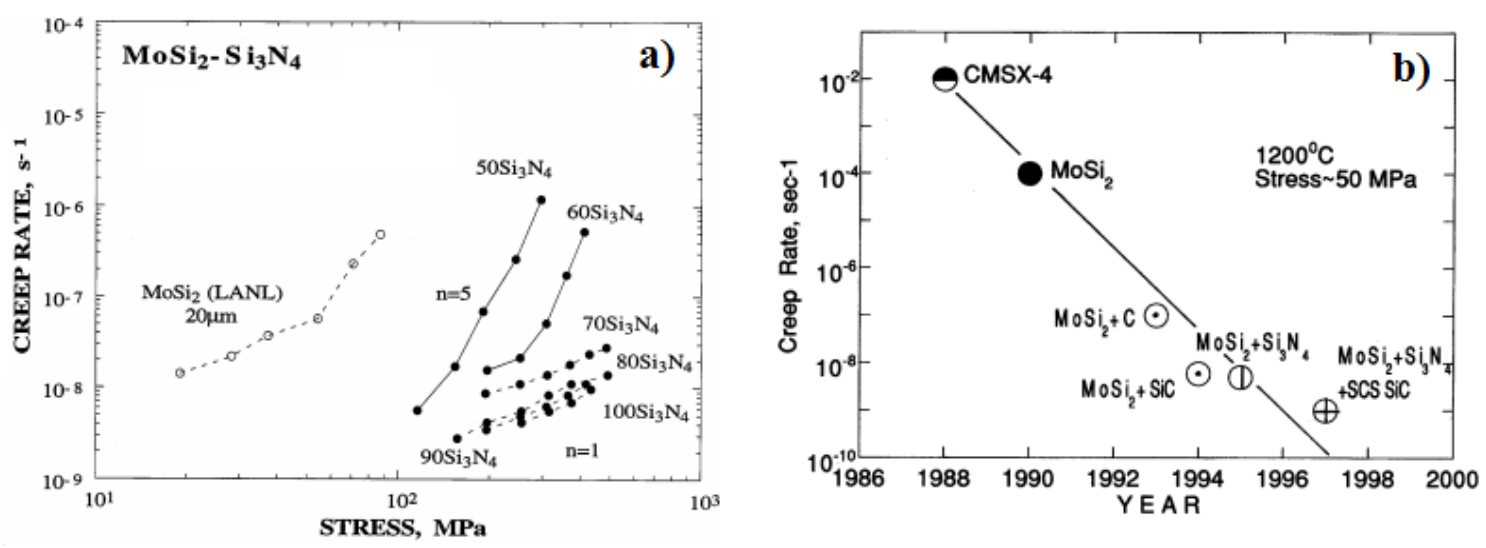

Figure 26. (a) Effect of the $\mathrm{Si}_{3} \mathrm{~N}_{4}$ volume fraction and stress on creep rate of the $\mathrm{MoSi}_{2}$ $\mathrm{Si}_{3} \mathrm{~N}_{4}$ composites [78], and (b) improvements in the high temperature creep resistance of $\mathrm{MoSi}_{2}$-non-oxide composites over the years [3].

study with a focus on creep properties of the high temperature refractory metal silicides and their composites [78]. Figure 26a presents the effect of the $\mathrm{Si}_{3} \mathrm{~N}_{4}$ volume fraction on the creep rate of the $\mathrm{MoSi}_{2}$. The creep rates for the $\mathrm{MoSi}_{2}-50$ vol\% $\mathrm{Si}_{3} \mathrm{~N}_{4}$ composites at $1200^{\circ} \mathrm{C}$ were very low compared to the $\mathrm{MoSi}_{2}$. The changes in the creep rate of the $\mathrm{MoSi}_{2}$ and $\mathrm{MoSi}_{2}$-non-oxide composites $\left(\mathrm{MoSi}_{2}-\mathrm{SiC}_{\mathrm{C}}\right.$ and $\left.\mathrm{MoSi}_{2}-\mathrm{Si}_{3} \mathrm{~N}_{4}\right)$ as a function of years were presented as a review, which clearly displayed improvements in the high temperature creep resistance [3]. Based on the plot presented in the Figure 26b, it can be noted that the creep rates of the $\mathrm{MoSi}_{2}$ significantly decreased over years with the development of the refractory transition metal silicide-non-oxide composites, mostly with the addition of the $\mathrm{SiC}$ and $\mathrm{Si}_{3} \mathrm{~N}_{4}$ particles. On the other hand, it is surprising that very limited studies were found, which investigated the high temperature creep resistance of the refractory metal silicide-oxide ceramic composites $\left(\mathrm{MoSi}_{2}-\mathrm{Al}_{2} \mathrm{O}_{3}, \mathrm{MoSi}_{2}-\mathrm{ZrO}_{2}\right.$ etc.) in the literature. In the study of Dumont et al. (1999), high temperature creep behavior of the $\mathrm{MoSi}_{2}-\mathrm{Al}_{2} \mathrm{O}_{3}$ composites were reported [79]. Three $\mathrm{MoSi}_{2}$-based composites were prepared with 21.0, 56.1, and $68.1 \mathrm{vol} \%$ of the $\mathrm{Al}_{2} \mathrm{O}_{3}$ content. As presented in the Figure 27, creep rates at $1200^{\circ} \mathrm{C}$ decreased compared to the $\mathrm{MoSi}_{2}$ by increasing the volume percentage of the $\mathrm{Al}_{2} \mathrm{O}_{3}$. This result demonstrated that the $\mathrm{Al}_{2} \mathrm{O}_{3}$ can be efficiently used as an oxide ceramic reinforcement to improve the high temperature creep resistance of the $\mathrm{MoSi}_{2}$. 


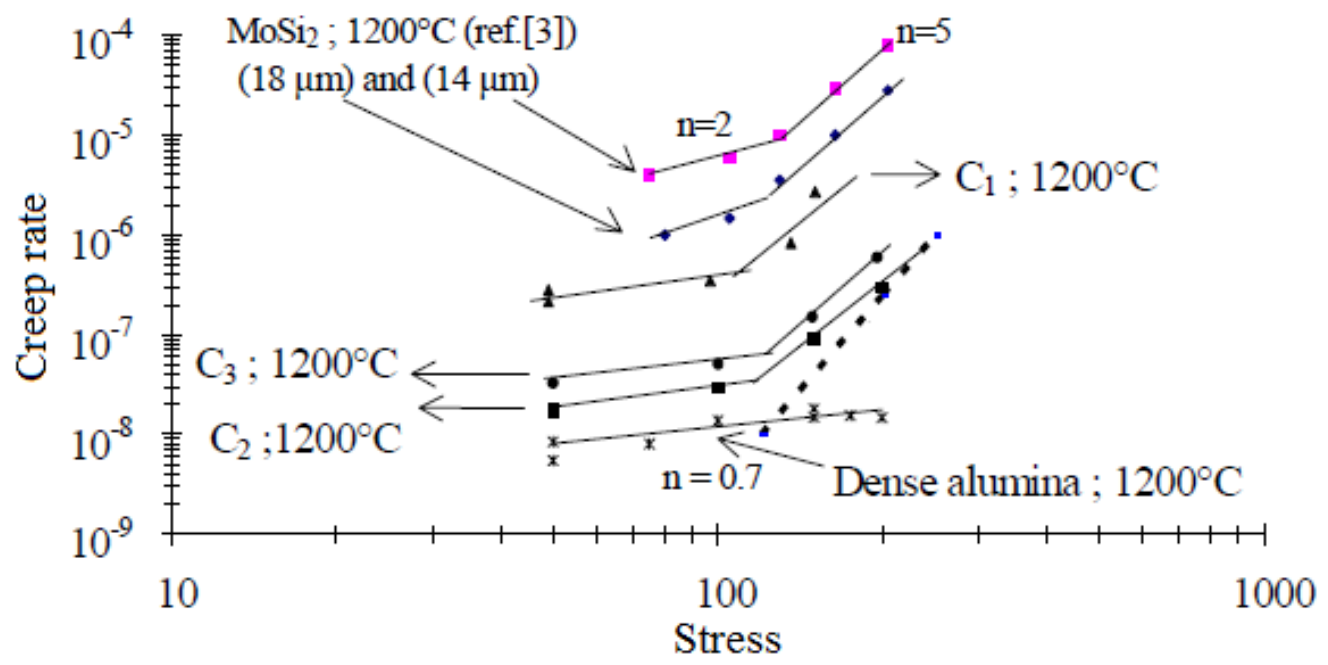

Figure 27. Creep rate of the $\mathrm{C} 1\left(\mathrm{MoSi}_{2}-20 \mathrm{vol} \% \mathrm{Al}_{2} \mathrm{O}_{3}\right), \mathrm{C} 2\left(\mathrm{MoSi}_{2}-56.1 \mathrm{vol} \% \mathrm{Al}_{2} \mathrm{O}_{3}\right)$, and $\mathrm{C} 3\left(\mathrm{MoSi}_{2}-68.1 \mathrm{vol} \% \mathrm{Al}_{2} \mathrm{O}_{3}\right)$ at $1200^{\circ} \mathrm{C}$ as a function of different stress levels, and their comparison with the pure $\mathrm{MoSi}_{2}$ and $\mathrm{Al}_{2} \mathrm{O}_{3}$ [79].

\subsubsection{Electrical and thermal properties of the refractory transition metal silicide composites}

For high-temperature electrical applications, it is known that high operating temperature, electrical conductivity at high temperatures, high oxidation/corrosion resistance, close thermal expansion coefficients of different components (matrix and reinforcement), and good mechanical properties are essential for the composite systems $[9,61,80]$. Therefore, it is known that there is a high potential for the refractory transition metal silicide composites in such applications subjected to high temperatures due to their capability of fulfilling all the required properties and the compatibility of refractory metal silicides with many ceramic reinforcements. But, surprisingly, there are very limited studies conducted on the investigation of the electrical properties of the refractory transition metal silicides and the development of electroconductive ceramic composites in the literature.

Kobel et al. (2004) reported a study with a focus on development of the $\mathrm{MoSi}_{2}$ $\mathrm{Al}_{2} \mathrm{O}_{3}$ electroconductive ceramic composites for high temperature applications [61]. They fabricated various $\mathrm{MoSi}_{2}-\mathrm{Al}_{2} \mathrm{O}_{3}$ composites with $16-40 \mathrm{vol} \% \mathrm{MoSi}_{2}$ content, and measured 
their high temperature electrical conductivity and coefficient of thermal expansion in their study. Figure 28a presents the electrical conductivities of the pure $\mathrm{MoSi}_{2}$, (40-60) vol\% $\mathrm{MoSi}_{2}-\mathrm{Al}_{2} \mathrm{O}_{3}$, and (25-75) vol\% $\mathrm{MoSi}_{2}-\mathrm{Al}_{2} \mathrm{O}_{3}$ composites as a function of temperature $\left(50^{\circ} \mathrm{C}\right.$ to $\left.750^{\circ} \mathrm{C}\right)$. It was found that electrical conductivity of the $\mathrm{MoSi}_{2}-\mathrm{Al}_{2} \mathrm{O}_{3}$ composites increased with increasing $\mathrm{MoSi}_{2}$ volume percentage; while decreased with increasing temperature. It is important to point out that they have a high potential for high temperature electrical applications due to their high electrical conductivity values even at elevated temperatures. Another important criterion is the close thermal expansion coefficients of the different phases in the composite systems both for their processing and properties of the composite materials. As shown in Figure 28b, the thermal expansion coefficient (CTE) of the $\mathrm{MoSi}_{2}$ is very close to that of the $\mathrm{Al}_{2} \mathrm{O}_{3}$, which is essential to minimize thermal stresses, effect of interfacial cracks on mechanical properties, and also to improve the thermal shock resistance [61,1]. This is one of the major advantages (high temperature electrical conductivity, high operating temperature, chemical and thermal stability) of the $\mathrm{MoSi}_{2}$ $\mathrm{Al}_{2} \mathrm{O}_{3}$ composites for high temperature electrical applications. In another study, thermal expansion coefficients (CTE) of several high temperature materials were summarized (Figure 29) [1]. Based on the data presented, it is apparent that CTE of the $\mathrm{MoSi}_{2}(\sim$ $\left.8.2 \times 10^{-6} \mathrm{~K}^{-1}\right)$ has a close match with that of the $\mathrm{Al}_{2} \mathrm{O}_{3}\left(\sim 8.0 \times 10^{-6} \mathrm{~K}^{-1}\right)$, particularly compared
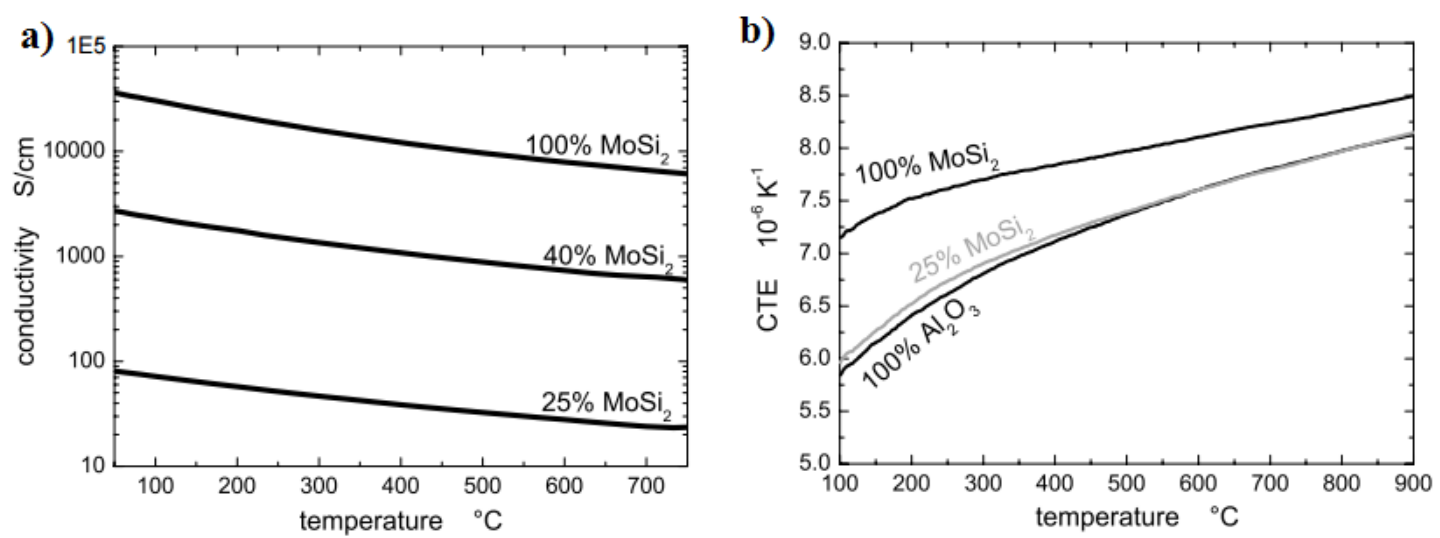

Figure 28. (a) Electrical conductivity of pure $\mathrm{MoSi}_{2}$ and $\mathrm{MoSi}_{2}-\mathrm{Al}_{2} \mathrm{O}_{3}$ composites as a function of temperature, and (b) Coefficient of thermal expansion (CTE) for pure $\mathrm{MoSi}_{2}$, pure $\mathrm{Al}_{2} \mathrm{O}_{3}$, and $\mathrm{MoSi}_{2}-\mathrm{Al}_{2} \mathrm{O}_{3}$ composite [61]. 


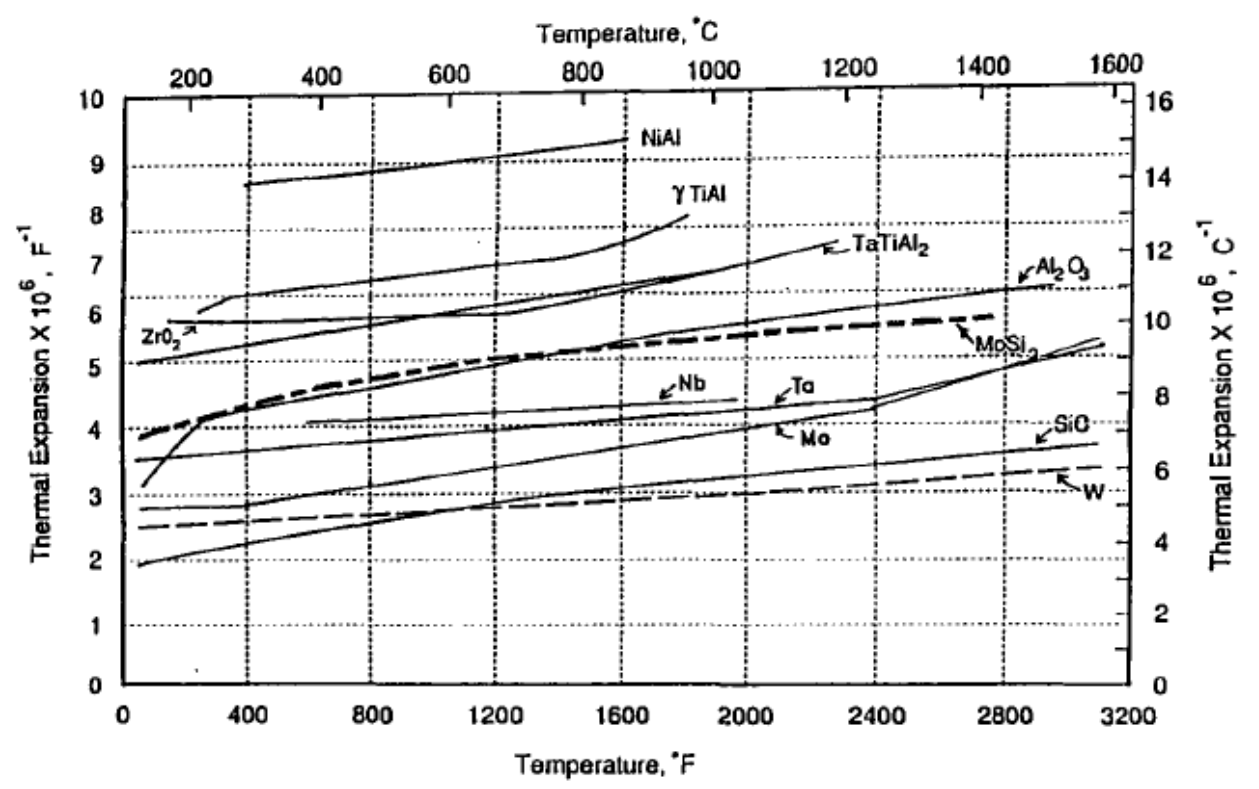

Figure 29. Coefficients of thermal expansion (CTE) for high temperature materials [1].

to the other reinforcement materials such as $\mathrm{SiC}\left(\sim 5.0 \times 10^{-6} \mathrm{~K}^{-1}\right)$. Therefore, the MoSi $2^{-}$ $\mathrm{Al}_{2} \mathrm{O}_{3}$ composite system has a higher potential compared to the other composite systems such as $\mathrm{MoSi}_{2}-\mathrm{SiC}$ and $\mathrm{MoSi}_{2}-\mathrm{Si}_{3} \mathrm{~N}_{4}$ for high temperature electrical applications. In addition to the $\mathrm{MoSi}_{2}-\mathrm{Al}_{2} \mathrm{O}_{3}$ composite system, there are also very limited studies on the electrical properties of the $\mathrm{MoSi}_{2}-\mathrm{SiC}$ and $\mathrm{MoSi}_{2}-\mathrm{Si}_{3} \mathrm{~N}_{4}$, because the main focus in these studies was high temperature structural applications. In the study of Guo et al. (2007), high temperature electrical conductivity of the $\mathrm{Si}_{3} \mathrm{~N}_{4}-\mathrm{MoSi}_{2}$ composites $\left(5 \mathrm{vol} \% \mathrm{Lu}_{2} \mathrm{O}_{3}\right.$ as a sintering additive) was reported with a focus on their use in high temperature electrical applications such as heating elements of ceramic glow plugs for diesel engines [9]. As shown in Figure 30, the $\mathrm{MoSi}_{2}-\mathrm{Si}_{3} \mathrm{~N}_{4}$ composites with 32, 40, and $60 \mathrm{vol} \% \mathrm{MoSi} 2$ content all exhibited high electrical conductivity at high temperatures up to $1250^{\circ} \mathrm{C}$. But it is important to point out that their high temperature electrical conductivities are relatively lower than that of the $\mathrm{MoSi}_{2}-\mathrm{Al}_{2} \mathrm{O}_{3}$ composites. As a review of the electrical and thermal properties of the refractory transition metal silicide composites, it can be concluded that the refractory metal silicide-oxide ceramic composites are very promising candidates for high temperature applications. 


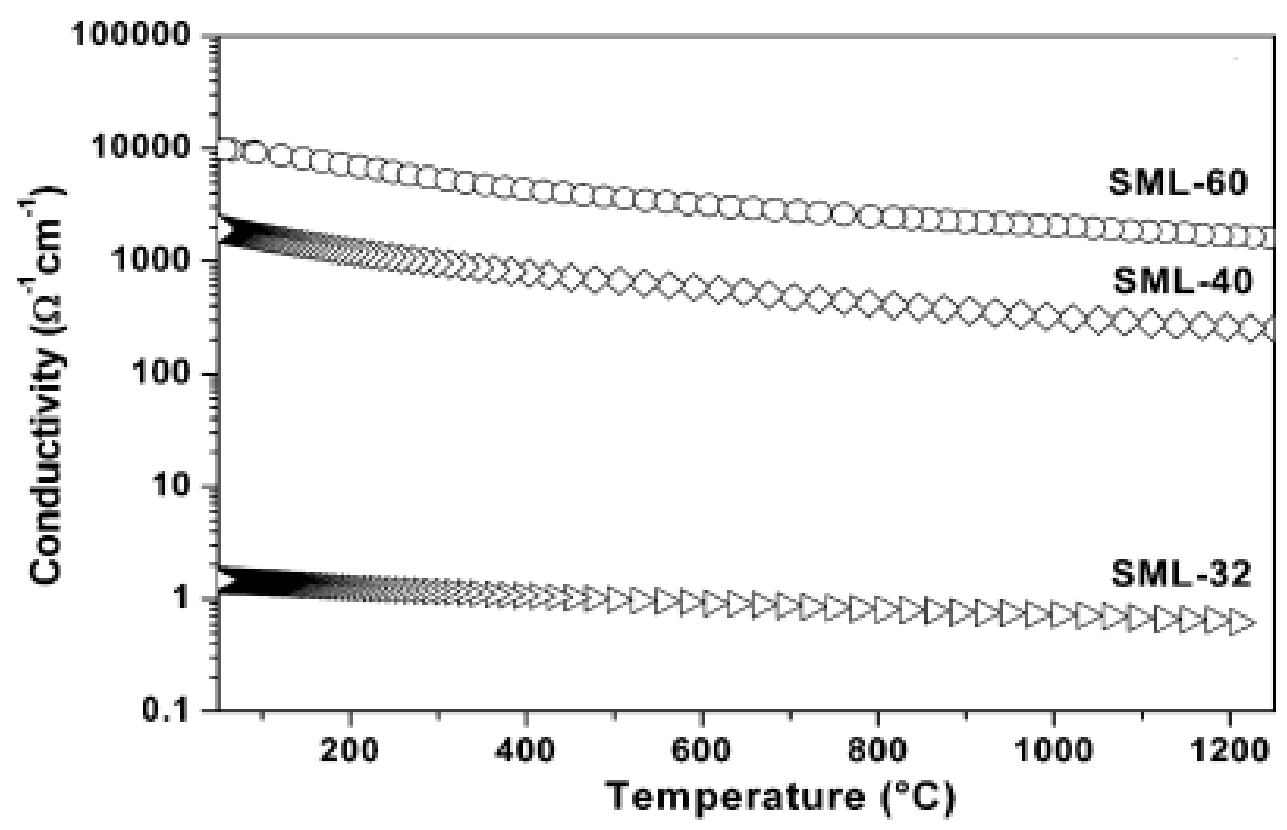

Figure 30. Electrical conductivity of the $\mathrm{Si}_{3} \mathrm{~N}_{4}-\mathrm{MoSi}_{2}$ composites with 32 vol\% (SML32), $40 \mathrm{vol} \%$ (SML-40), and $60 \mathrm{vol} \%$ (SML-60) $\mathrm{MoSi}_{2}$ as a function of temperature [9].

\subsubsection{Oxidation behavior of the refractory transition metal silicide composites}

The improved oxidation resistance at elevated temperatures is very important for refractory transition metal silicide composites to be capable of functioning at high temperatures in highly oxidizing and corrosive environments for extended operation hours as structural and electrical materials. It is known that most of the refractory transition metal silicides exhibit high oxidation resistance, and particle reinforcement is the most commonly applied route to alter their mechanical and thermal properties. However, after particle reinforcement, oxidation resistance of these transition metal silicides must not be degraded [11]. Therefore, the oxidation behavior of the refractory metal silicide composites has been also investigated in the literature.

Medri and Bellosi (2004) conducted a study on degradation of the $\mathrm{Si}_{3} \mathrm{~N}_{4}-35$ vol\% $\mathrm{MoSi}_{2}$ composite after long-term $(100 \mathrm{~h})$ oxidation in air atmosphere up to $1500^{\circ} \mathrm{C}$ [81]. It was determined that the oxidation-induced weight gain was less than $1.0 \mathrm{mg} / \mathrm{cm}^{2}$ at the 
temperatures up to $1300^{\circ} \mathrm{C}$. Afterwards, there was a drastic increase from $\sim 1.0$ to $\sim 5.2$ $\mathrm{mg} / \mathrm{cm}^{2}$ with increasing temperature from $1300^{\circ} \mathrm{C}$ to $1500^{\circ} \mathrm{C}$ (Figure 31a). This result indicated that the oxidation rate for the $\mathrm{Si}_{3} \mathrm{~N}_{4}-\mathrm{MoSi}_{2}$ composites increased at temperatures above $1400^{\circ} \mathrm{C}$, whereas they were highly resistant to oxidation up to $1400^{\circ} \mathrm{C}$. In another study, oxidation behavior of the $\mathrm{Si}_{3} \mathrm{~N}_{4}$ and $\mathrm{Si}_{3} \mathrm{~N}_{4}-6$ vol\% $\mathrm{MoSi}_{2}$ at $1500^{\circ} \mathrm{C}$ was examined for a very long period of time $(10000 \mathrm{~h})$ [82]. Although they displayed a same oxidation behavior up to $1600 \mathrm{~h}$, a slight difference between their oxidation rates was observed after that time period (Figure 31b). Therefore, it should be pointed out that the $\mathrm{Si}_{3} \mathrm{~N}_{4}-\mathrm{MoSi}_{2}$ composites may have relatively higher oxidation resistance than the $\mathrm{Si}_{3} \mathrm{~N}_{4}$ for longer operation hours at $1500^{\circ} \mathrm{C}$. In addition to that, $\mathrm{SiC}, \mathrm{TiB}_{2}, \mathrm{ZrB}_{2}$, and $\mathrm{HfB}_{2}$ have been used as reinforcement materials in the literature for the $\mathrm{MoSi}_{2}$ structure. Vasudevan and Petrovic (1992) reported a review study on the cyclic oxidation behavior of several intermetallic compounds, superalloys, and refractory transition metal silicide composites [1]. It is evident that oxidation resistance of the $\mathrm{MoSi}_{2}-\mathrm{SiC}$ composite is relatively higher than that of the pure $\mathrm{MoSi}_{2}$ at $1200^{\circ} \mathrm{C}$ up to $144 \mathrm{~h}$ (Figure 32a). Additionally, oxidation resistance of the $\mathrm{MoSi}_{2}$ significantly reduced after utilizing the $\mathrm{TiB}_{2}$ as a reinforcement. The weight gain level for the $\mathrm{MoSi}_{2}-\mathrm{SiC}$ composite at $1200^{\circ} \mathrm{C}$ after $100 \mathrm{~h}$ exposure to air was reported as less than $0.1 \mathrm{mg} / \mathrm{cm}^{2}$. The weight gain for the $\mathrm{MoSi}_{2}-15 \mathrm{vol} \% \mathrm{SiC}$ composite at $1600^{\circ} \mathrm{C}$
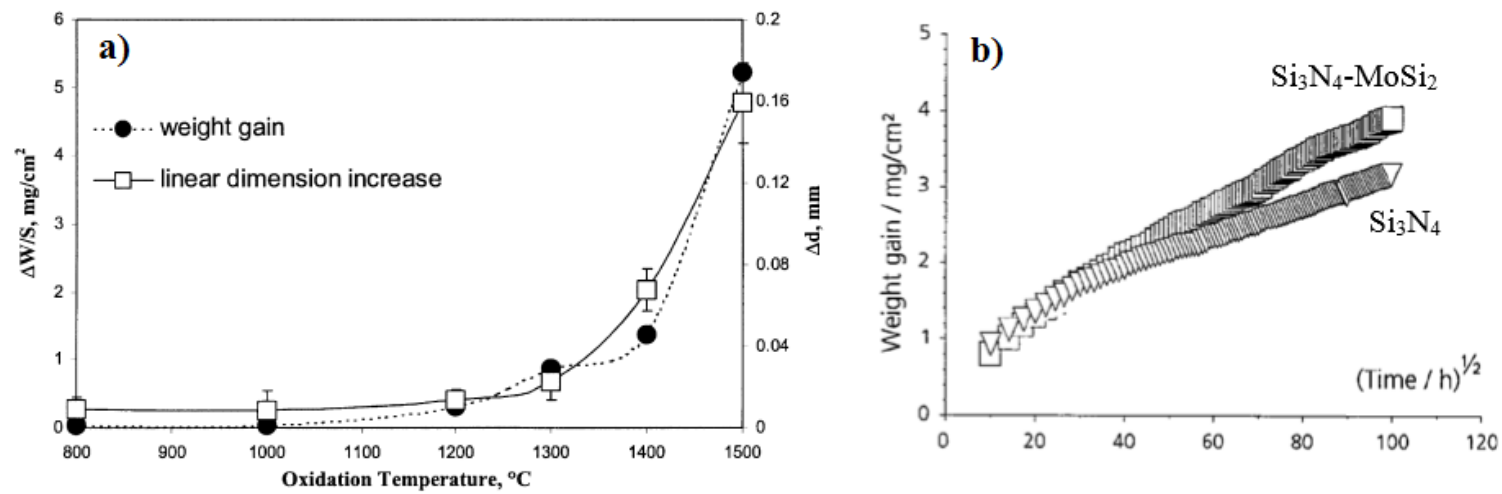

Figure 31. Oxidation behavior of the (a) $\mathrm{Si}_{3} \mathrm{~N}_{4}-35$ vol\% $\mathrm{MoSi}_{2}$ composite after 100 hours as a function of temperature [81], and (b) $\mathrm{Si}_{3} \mathrm{~N}_{4}$ and $\mathrm{Si}_{3} \mathrm{~N}_{4}-6$ vol\% $\mathrm{MoSi}_{2}$ composite at $1500^{\circ} \mathrm{C}$ as a function of time [82]. 

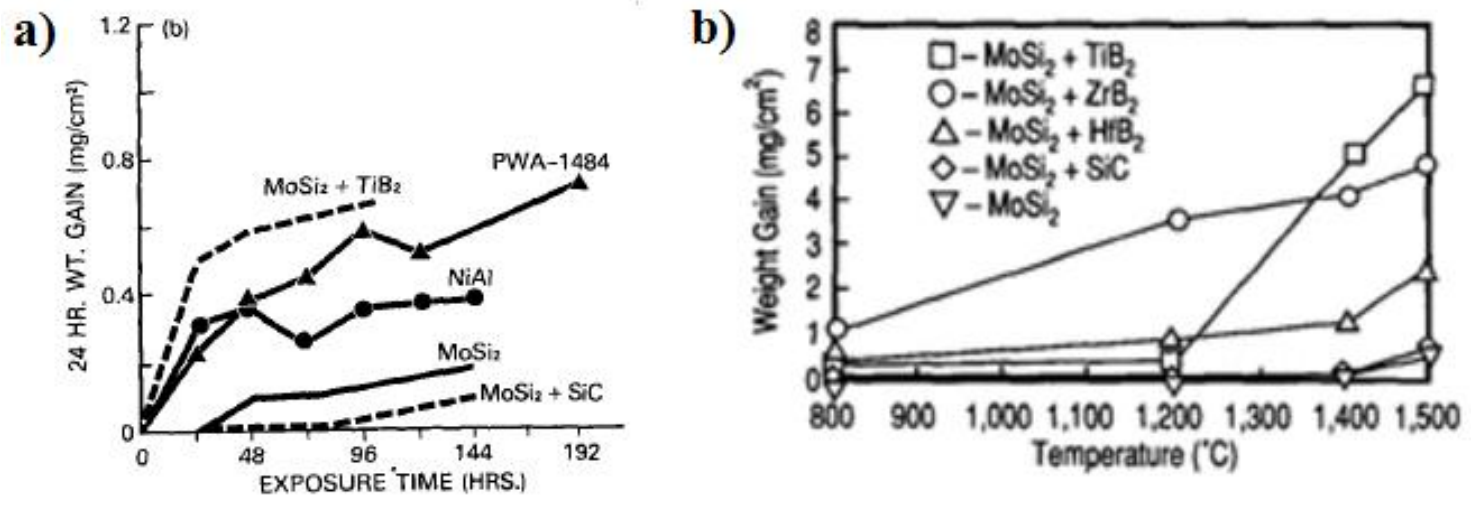

Figure 32. (a) Cyclic oxidation behavior of the pure $\mathrm{MoSi}_{2}, \mathrm{MoSi}_{2}$-based composites, and superalloys at $1200^{\circ} \mathrm{C}$ (24 hours) [1], and (b) Oxidation behavior of the pure $\mathrm{MoSi}_{2}$ and $\mathrm{MoSi}_{2}$-based composites as a function of temperature up to $1500^{\circ} \mathrm{C}$ (24 hours) [84].

after $100 \mathrm{~h}$ was also reported as $0.44 \mathrm{mg} / \mathrm{cm}^{2}$ in another study [83]. Furthermore, Lee et al. (1991) studied the high temperature oxidation behavior of the pure $\mathrm{MoSi}_{2}$ and $\mathrm{MoSi}_{2}$-based composites reinforced with $\mathrm{TiB}_{2}, \mathrm{ZrB}_{2}, \mathrm{HfB}_{2}$, and $\mathrm{SiC}$ up to $1500^{\circ} \mathrm{C}$ for $24 \mathrm{~h}$ [84]. The lowest weight gains were achieved by pure $\mathrm{MoSi}_{2}$ and $\mathrm{MoSi}_{2}-\mathrm{SiC}$ composite as presented in Figure 32b. $\mathrm{MoSi}_{2}-\mathrm{HfB}_{2}$ composite also exhibited comparable oxidation resistance up to $1400^{\circ} \mathrm{C}$, but the oxidation rates were found to be very high for the $\mathrm{MoSi}_{2}-\mathrm{TiB}_{2}$ and $\mathrm{MoSi}_{2}-$ $\mathrm{ZrB}_{2}$ composites above $1200^{\circ} \mathrm{C}$ and $800^{\circ} \mathrm{C}$, respectively. These results clearly implied that the $\mathrm{MoSi}_{2}-\mathrm{SiC}$ and $\mathrm{MoSi}_{2}-\mathrm{Si}_{3} \mathrm{~N}_{4}$ composites have higher oxidation resistance than the other $\mathrm{MoSi}_{2}$-non-oxide composites at elevated temperatures.

The oxidation behavior of the refractory metal silicide-oxide ceramic composites has been also studied, but there are very limited studies in the literature $[54,83,85]$. Fei et al. (2010) reported a study on the oxidation behavior of the pure $\mathrm{MoSi}_{2}$ and $\mathrm{MoSi}_{2}-\mathrm{Al}_{2} \mathrm{O}_{3}$

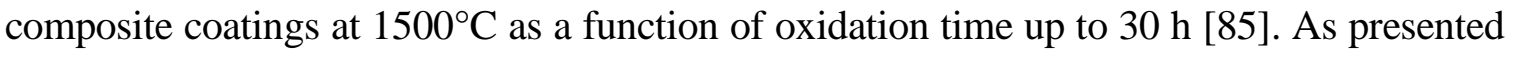
in Figure 33, oxidation behavior of the pure $\mathrm{MoSi}_{2}$ and $\mathrm{MoSi}_{2}-10$ vol\% $\mathrm{Al}_{2} \mathrm{O}_{3}$ composite coatings was quite similar. However, the $\mathrm{MoSi}_{2}-30$ vol\% $\mathrm{Al}_{2} \mathrm{O}_{3}$ composite revealed relatively low oxidation resistance at $1500^{\circ} \mathrm{C}$. The most detailed study on high temperature oxidation behavior of the particle-reinforced $\mathrm{MoSi}_{2}$ composites was reported by Lohfeld et 


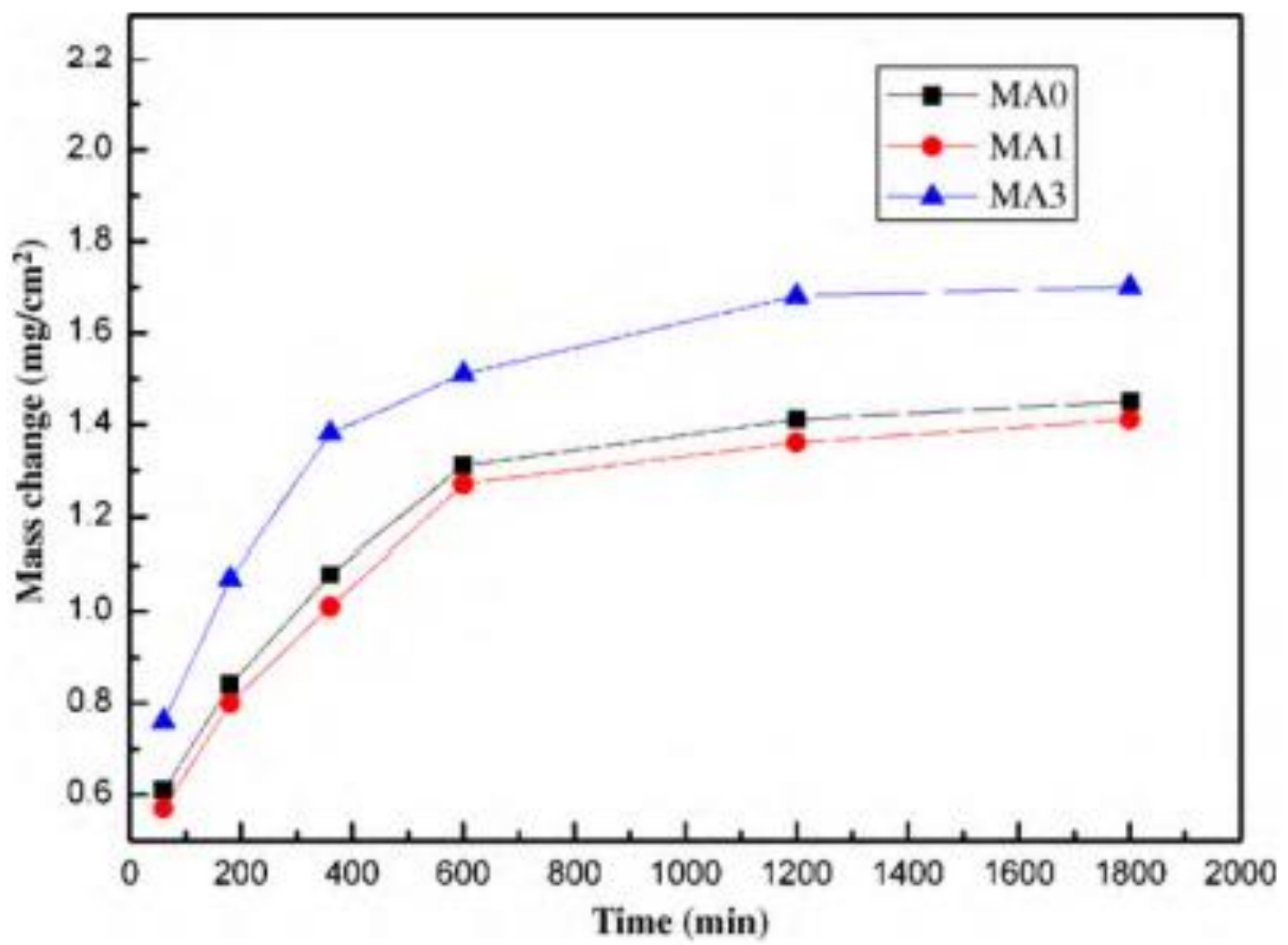

Figure 33. Mass changes of the pure $\mathrm{MoSi}_{2}$ (MA0), $\mathrm{MoSi}_{2}-10$ vol.\% $\mathrm{Al}_{2} \mathrm{O}_{3}$ (MA1), and $\mathrm{MoSi}_{2}-30$ vol. $\% \mathrm{Al}_{2} \mathrm{O}_{3}$ composite coatings at $1500^{\circ} \mathrm{C}$ as a function of time [85].

al. (2005) [83]. In this study, the $\mathrm{Al}_{2} \mathrm{O}_{3}, \mathrm{Y}_{2} \mathrm{O}_{3}, \mathrm{ZrO}_{2}$, and $\mathrm{HfO}_{2}$ were used as oxide ceramic reinforcements, while the $\mathrm{TiB}_{2}, \mathrm{ZrB}_{2}$, and $\mathrm{HfB}_{2}$ were selected as non-oxide ceramic reinforcements with a fixed amount of $15 \mathrm{vol} \%$. Table 4 presents the weight changes of the different $\mathrm{MoSi}_{2}$-based composites after $100 \mathrm{~h}$ of exposure to air at $1600^{\circ} \mathrm{C}$. Based on these results, the $\mathrm{MoSi}_{2}-\mathrm{SiC}$ is the most oxidation resistant composite material in comparison to others. The $\mathrm{MoSi}_{2}-\mathrm{HfO}_{2}, \mathrm{MoSi}_{2}-\mathrm{Y}_{2} \mathrm{O}_{3}$, and $\mathrm{MoSi}_{2}-\mathrm{TiB}_{2}$ also presented relatively good oxidation behavior at $1600^{\circ} \mathrm{C}$. Although the $\mathrm{MoSi}_{2}-\mathrm{Al}_{2} \mathrm{O}_{3}$ composite displayed poor oxidation resistance at this temperature, there are only a few studies in the literature for comparison. Therefore, further studies are essential for the determination of high temperature oxidation behavior of different refractory transition metal silicide-oxide composites. As a review of these research studies on the refractory transition metal silicide 
Table 4. Weight changes for the pure $\mathrm{MoSi}_{2}$ and several $\mathrm{MoSi}_{2}$-based composites after $100 \mathrm{~h}$ of exposure to air at $1600^{\circ} \mathrm{C}$ [83].

\begin{tabular}{|c|c|}
\hline Composite System & Weight Change $\left(\mathbf{m g} / \mathbf{c m}^{2}\right)$ \\
\hline $\mathrm{MoSi}_{2} / \mathrm{Al}_{2} \mathrm{O}_{3}$ & +5.97 \\
\hline $\mathrm{MoSi}_{2} / \mathrm{ZrO}_{2}$ & +1.80 \\
\hline $\mathrm{MoSi}_{2} / \mathrm{HfO}_{2}$ & +1.00 \\
\hline $\mathrm{MoSi}_{2} / \mathrm{Y}_{2} \mathrm{O}_{3}$ & +0.44 \\
\hline $\mathrm{MoSi}_{2} / \mathrm{SiC}$ & +1.33 \\
\hline $\mathrm{MoSi}_{2} / \mathrm{TiB}_{2}$ & +3.98 \\
\hline $\mathrm{MoSi}_{2} / \mathrm{ZrB}_{2}$ & +2.62 \\
\hline $\mathrm{MoSi}_{2} / \mathrm{HfB}_{2}$ & +0.11 \\
\hline${\mathrm{pure} \mathrm{MoSi}_{2}}$ \\
\hline
\end{tabular}

composites, significant improvements have been achieved in both mechanical and electrical properties, particularly by developing the refractory transition metal silicide-oxide composites such as the $\mathrm{MoSi}_{2}-\mathrm{Al}_{2} \mathrm{O}_{3}$ and $\mathrm{MoSi}_{2}-\mathrm{ZrO}_{2}$. The refractory metal silicide-oxide composites provided high operating temperature, high electrical conductivity at elevated temperatures, high oxidation/corrosion resistance, good mechanical properties, and high thermal stability. Furthermore, close match between the coefficients of thermal expansion of the refractory metal silicides and oxide ceramic reinforcements displayed an important advantage for minimizing thermal stresses and effect of interfacial cracks on mechanical properties, as well as, for improving the thermal shock resistance. The thermodynamic compatibility of the refractory transition metal silicides with many of the oxide ceramic reinforcements was also determined to be very beneficial for achieving high chemical stability. Additionally, the grain growth can be potentially minimized by use of the oxide ceramic reinforcements as grain growth inhibitors, which may improve the lifetime of 
materials and performance under real operation for longer service hours. The electrical conductivity can be also tuned by adjusting the metal silicide/oxide content. Therefore, the refractory transition metal silicide-oxide electroconductive ceramic composites are very promising candidates for high-temperature electrical applications, such as interconnects, and high temperature and harsh environment sensors (e.g. thermocouple, thermistor). However, it should be pointed out that there are very limited studies conducted on their high-temperature electrical properties, related sensing applications and oxidation behavior/kinetics, and there are no studies on their thermal (phase) stability, sintering/phase transformations and grain growth kinetics.

\section{References}

[1] A.K. Vasudevan, J.J. Petrovic, A comparative overview of molybdenum disilicides composites, Materials Science and Engineering A155, 1 (1992).

[2] Z. Yao, J. Stiglich, T.S. Sudarshan, Molybdenum silicide based materials and their properties, Journal of Materials Engineering and Performance 8, 291 (1999).

[3] J.J. Petrovic, A.K. Vasudevan, Key developments in high temperature structural silicides, Materials Science and Engineering A 261, 1 (1999).

[4] A. Newman, S. Sampath, H. Herman, Processing and properties of MoSi2-SiC and $\mathrm{MoSi}_{2}-\mathrm{Al}_{2} \mathrm{O}_{3}$, Materials Science and Engineering A 261, 252 (1999).

[5] A. Chakraborty, S.V. Kamat, R. Mitra, K.K. Ray, Effect of $\mathrm{MoSi}_{2}$ and $\mathrm{Nb}$ reinforcements on mechanical properties of $\mathrm{Al}_{2} \mathrm{O}_{3}$ matrix composites, Journal of Materials Science 35, 3827 (2000).

[6] J.J. Petrovic, High temperature structural silicides, in Ceramic Engineering and Science Proceedings, edited by J.P. Singh, Proceedings of the $21^{\text {st }}$ Annual Conference on Composites, Advanced Ceramics, Materials and Structures: A18, Cocoa Beach FL, (1997). [7] D.M. Shah, $\mathrm{MoSi}_{2}$ and other silicides as high temperature structural materials, in Superalloys, edited by S.D. Antolovich, R.W. Stusrud, R.A. MacKay, D.L. Anton, T. Khan, R.D. Kissinger, and D.L. Klarstrom, The Seventh International Symposium on Superalloys 92, Champion PA, p. 409 (1992). 
[8] M.C. Kushan, Y. Uzunonat, S.C. Uzgur, F. Diltemiz, Potential of $\mathrm{MoSi}_{2}$ and $\mathrm{MoSi}_{2-}$ $\mathrm{Si}_{3} \mathrm{~N}_{4}$ composites for aircraft gas turbine engines, in Recent Advances in Aircraft Technology, edited by R. Agarwal, Intech Open Access Publisher, Rijeka, Croatia, pp. 97, $116(2012)$.

[9] Z. Guo, G. Blugan, T. Graule, M. Reece, J. Kuebler, The effect of different sintering additives on the electrical and oxidation properties of $\mathrm{Si}_{3} \mathrm{~N}_{4}-\mathrm{MoSi}_{2}$ composites, Journal of the European Ceramic Society 27, 2153 (2007).

[10] J.J. Petrovic, M.I. Pena, I.E. Reimanis, M.S. Sandlin, S.D. Conzone, H.H. Kung, D.P. Butt, Mechanical behavior $\mathrm{MoSi}_{2}$ reinforced-Si $\mathrm{N}_{4}$ matrix composites, J. Am. Ceram. Soc. 80, 3070 (1997).

[11] S. Lohfeld, M. Schutze, Oxidation behavior of particle reinforced $\mathrm{MoSi}_{2}$ composites at temperatures up to $1700^{\circ} \mathrm{C}$ Part 1: Literature review, Materials and Corrosion 56, 93 (2005).

[12] P.V. Krakhmalev, E. Strom, M. Sunberg, C. Li, Processing, microstructure and properties of $\mathrm{C} 40 \mathrm{Mo}(\mathrm{Si}, \mathrm{Al})_{2} / \mathrm{Al}_{2} \mathrm{O}_{3}$ composites, Mater. Sci. Eng. A 360, 207 (2003).

[13] G-J. Zhang, X-M. Yue, T. Watanabe, Addition effects of aluminum and in situ formation of alumina in $\mathrm{MoSi}_{2}$, Journal of Materials Science 34, 997 (1999).

[14] A.D. Chirkin, V.O. Lavrenko, V.M. Talash, High-temperature and electrochemical oxidation of transition metal silicides, Powder Metallurgy and Metal Ceramics 48, 330 (2009).

[15] A.A. Sharif, High-temperature oxidation of MoSi2, J. Mater. Sci. 45, 865 (2010).

[16] M. Fu, J.A. Sekhar, Processing, microstructure, and properties of molybdenum aluminosilicide, J. Am. Ceram. Soc. 81, 3205 (1998).

[17] R. Viennois, X. Tao, P. Jund, J-C. Tedenac, Stability and thermoelectric properties of transition-metal silicides, Journal of Electronic Materials 40, 597 (2011).

[18] A.P. Goncalves, C. Godart, New promising bulk thermoelectrics: intermetallics, pnictides and chalcogenides, Eur. Phys. J. B 87, 1 (2014). 
[19] T. Nonomura, C. Wen, A. Kato, K. Isobe, Y. Kubota, T. Nakamura, M. Yamashita, Y. Hayakawa, H. Tatsuoka, Thermoelectric properties of group VI metal silicide semiconductors, Physics Procedia 11, 110 (2011).

[20] M.I. Fedorov, V.K. Zaitsev, The features of silicide thermoelectrics development, 6th European Conference on Thermoelectrics Proceedings I-11, Paris, France (2008).

[21] T. Yamada, H. Yamane, Crystal structure and thermoelectric properties of $\beta-\mathrm{MoSi}_{2}$, Intermetallics 19, 908 (2011).

[22] S-P. Lee, J-K. Lee, B-H. Min, Y-S. Shin, D-S. Bae, J-Y. Park, G. Sasaki, Microstructure and mechanical property of $\mathrm{MoSi}_{2}$ based composites, Materials Science Forum 475-479, 707 (2005).

[23] P. Feng, X. Wang, Molybdenum disilicides: Production, properties and applications, in Molybdenum: Characteristics, Production and Applications, edited by M. Ortiz and T. Herrera, Nova Science Publishers Inc., New York, United States, pp. 41, 75 (2012).

[24] A.L. Schmitt, J.M. Higgins, J.R. Szczech, S. Jin, Synthesis and applications of metal silicide nanowires, J. Mater. Chem. 20, 223 (2010).

[25] J.M. McEnaney, R.E. Schaak, Solution synthesis of metal silicide nanoparticles, Inorg. Chem. 54, 707 (2015).

[26] K. Maex, M. Van Rossum, A. Reader, Crystal structure of TM silicides, in Properties of Metal Silicides, edited by K. Maex and M. Van Rossum, Inspec/Iee, London, United Kingdom, pp. 3, 14 (1995).

[27] L.F. Mattheiss, Calculated structural properties of $\mathrm{CrSi}_{2}, \mathrm{MoSi}_{2}$, and $\mathrm{WSi}_{2}$, Physical Review B 45, 3252 (1992).

[28] W. Henrion, H. Lange, Optical properties of high-refractory disilicides thin films, Phys. Stat. Sol. 151, 375 (1989).

[29] K. Yuge, Y. Koizumi, K. Hagihara, T. Nakano, K. Kishida, H. Inui, First-principles study on phase stability of $\mathrm{MoSi}_{2}-\mathrm{NbSi}_{2}$ pseudobinary alloys, Physical Review B 85, 134106 (2012). 
[30] I-Y. Ko, J-H. Park, K-S. Nam, I-J. Shon, Pulsed current activated combustion synthesis and consolidation of nanostructured $\mathrm{TaSi}_{2}$, Journal of Ceramic Processing Research 11, 69 (2010).

[31] K. Tanaka, K. Nawata, H. Inui, M. Yamaguchi, M. Koiwa, Refinement of crystallographic parameters in refractory metal disilicides, Materials Research Society Symposia Proceedings 646, Boston MA, (2001).

[32] L.J. Schwartz, Interactions of refractory metal silicide coatings with substrates, $\mathrm{PhD}$ Dissertation in Engineering, The City University of New York, New York NY (1970).

[33] A.L. Bowman, N.H. Krikorian, Interstitial phases, in Treatise on Solid State Chemistry: Volume 3 Crystalline and Noncrystalline Solids, edited by N. Hannay, Springer, New York NY, pp. 253, 255 (2012).

[34] M.J. Maloney, D. Shah, Silicides, in Physical Metallurgy and Processing of Intermetallic Compounds, edited by N.S. Stoloff and V.K. Sikka, Chapman \& Hall, New York NY, pp. 441, 475 (1996).

[35] Y. Harada, M. Morinaga, D. Saso, M. Takata, M. Sakata, Refinement in crystal structure of $\mathrm{MoSi}_{2}$, Intermetallics 6, 523 (1998).

[36] O. Thomas, J.P. Senateur, R. Madar, O. Laborde, E. Rosencher, Molybdenum disilicide: Crystal growth, thermal expansion and resistivity, Solid State Communications 55, 629 (1985).

[37] R. Mitra, Mechanical behavior and oxidation resistance of structural silicides, International Materials Reviews 51, 13 (2006).

[38] J.J. Petrovic, Mechanical behavior of $\mathrm{MoSi}_{2}$ and $\mathrm{MoSi}_{2}$ composites, Materials Science and Engineering A 192/193, 31 (1995).

[39] R.K. Wade, J.J. Petrovic, Fracture modes in $\mathrm{MoSi}_{2}$, J. Am. Ceram. Soc. 75, 1682 (1992).

[40] J. Pan, M.K. Surappa, R.A. Saravanan, B.W. Liu, D.M. Yang, Fabrication and characterization of $\mathrm{SiC} / \mathrm{MoSi}_{2}$ composites, Mater. Sci. Eng. A 244, 191 (1998). 
[41] W.O. Soboyejo, F. Ye, L-C. Chen, N. Bahtishi, D.S. Schwartz, R.J. Lederich, Effects of reinforcement morphology on the fatigue and fracture behavior of $\mathrm{MoSi}_{2} / \mathrm{Nb}$ composites, Acta Mater. 44, 2027 (1996).

[42] K.T.V. Rao, W.O. Soboyejo, R.O. Ritchie, Ductile-phase toughening and fatiguecrack growth in Nb-reinforced molybdenum disilicide intermetallic composites, Metallurgical Transactions A 23A, 2249 (1992).

[43] A.C. Silva, M.J. Kaufman, Microstructural modification of $\mathrm{MoSi}_{2}$ through aluminum additions, Scr. Metall. Mater. 29, 1141 (1993).

[44] D.M. Shah, D. Berczik, D.L. Anton, R. Hecht, Appraisal of other silicides as structural materials, Materials Science and Engineering A 155, 45 (1992).

[45] I-Y. Ko, B-R. Kim, K-S. Nam, B-M. Moon, B-S. Lee, I-J. Shon, Pulsed current activated combustion synthesis and consolidation of ultrafine $\mathrm{NbSi}_{2}$ from mechanically activated powders, Met. Mater. Int. 15, 399 (2009).

[46] T. Nakano, M. Azuma, Y. Umakoshi, Tensile deformation and fracture behavior in $\mathrm{NbSi}_{2}$ and $\mathrm{MoSi}_{2}$ single crystals, Acta Materialia 50, 3731 (2002).

[47] I.J. Shon, D.H. Rho, H.C. Kim, Simultaneous synthesis and densification of $\mathrm{WSi}_{2}$ and $\mathrm{WSi}_{2}-20$ vol. $\% \mathrm{Nb}$ composite by field-activated and pressure-assisted combustion, Metals and Materials 6, 533 (2000).

[48] B-R. Kim, J-K. Yoon, K-S. Nam, I-J. Shon, High-frequency induction-heated combustion synthesis and consolidation of nanostructured $\mathrm{NbSi}_{2}$ from mechanically activated powders, Journal of Korean Powder Metallurgy Institute 15, 279 (2008).

[49] S.A. Maloy, J.J. Lewandowski, A.H. Heuer, J.J. Petrovic, Effect of carbon additions on the high temperature mechanical properties of molybdenum disilicide, Materials Science and Engineering A 155, 159 (1992).

[50] M. Ostling, C. Zaring, Mechanical properties of TM silicides, in Properties of Metal Silicides, edited by K. Maex and M. Van Rossum, Inspec/Iee, London, United Kingdom, pp. 15, 30 (1995).

[51] F. Chu, M. Lei, S.A. Maloy, J.J. Petrovic, T.E. Mitchell, Elastic properties of C40 transition metal disilicides, Acta Mater. 44, 3035 (1996). 
[52] A.A. Sharif, A. Misra, T.E. Mitchell, Strength of $\mathrm{MoSi}_{2}$-based crystals at ultra-high temperature, Scripta Materialia 52, 399 (2005).

[53] A.A. Sharif, A. Misra, J.J. Petrovic, T.E. Mitchell, Alloying of $\mathrm{MoSi}_{2}$ for improved mechanical properties, Intermetallics 9, 869 (2001).

[54] H. Chen, Q. Ma, X. Shao, J. Ma, C. Wang, B. Huang, Microstructure, mechanical properties and oxidation resistance of $\mathrm{Mo}_{5} \mathrm{Si}_{3}-\mathrm{Al}_{2} \mathrm{O}_{3}$ composite, Materials Science and Engineering A 592, 12 (2014).

[55] E. Mazzega, M. Michelini, F. Nava, Electrical properties of chromium silicide films: $\mathrm{Cr}_{3} \mathrm{Si}$ and $\mathrm{Cr}_{5} \mathrm{Si}_{3}$, J. Phys. F: Met. Phys. 17, 1135 (1987).

[56] U. Gottlieb, F. Nava, M. Affronte, O. Laborde, R. Madar, Electrical transport in metallic TM silicides and Electrical transport in semiconducting TM silicides, in Properties of Metal Silicides, edited by K. Maex and M. Van Rossum, Inspec/Iee, London, United Kingdom, pp. 189, 216 (1995).

[57] A.K. Sinha, Refractory metal silicides for VLSI applications, J. Vac. Sci. Technol. 19, 778 (1981).

[58] T. Kajikawa, K. Shiraishi, T. Sugiyama, M. Omori, T. Hirai, Thermoelectric properties of high temperature transition metal silicides prepared by spark plasma sintering method, 18th International Conference on Thermoelectrics, Baltimore, MD (1999).

[59] C. Krontiras, I. Suni, F.M. d'Heurle, F.K. LeGoues, R. Joshi, Electronic transport properties of thin films of $\mathrm{WSi}_{2}$ and $\mathrm{MoSi}_{2}$, J. Phys. F: Met. Phys. 17, 1953 (1987).

[60] I. Nishida, The crystal growth and thermoelectric properties of chromium disilicide, Journal of Materials Science 7, 1119 (1972).

[61] S. Kobel, J. Pluschke, U. Vogt, T.J. Graule, $\mathrm{MoSi}_{2}-\mathrm{Al}_{2} \mathrm{O}_{3}$ electroconductive ceramic composites, Ceramics International 30, 2105 (2004).

[62] Z-H. Wu, W-C. Zhou, F. Luo, D-M. Zhu, Effect of $\mathrm{MoSi}_{2}$ content on dielectric and mechanical properties of $\mathrm{MoSi}_{2} / \mathrm{Al}_{2} \mathrm{O}_{3}$ composite coatings, Trans. Nonferrous Met. Soc. China 22, 111 (2012).

[63] K. Kurokawa, H. Houzumi, I. Saeki, H. Takahashi, Low temperature oxidation of fully dense and porous $\mathrm{MoSi}_{2}$, Materials Science and Engineering A 261, 292 (1999). 
[64] D. $\mathrm{Yi}, \mathrm{C}$. $\mathrm{Li}, \mathrm{MoSi}_{2}-\mathrm{ZrO}_{2}$ composites - fabrication, microstructures and properties, Materials Science and Engineering A 261, 89 (1999).

[65] R.V. Krishnarao, J. Subrahmanyam, Formation of $\mathrm{MoSi}_{2}-\mathrm{Si}_{3} \mathrm{~N}_{4} / \mathrm{SiC}$ by reacting molybdenum with silicon nitride, Materials and Manufacturing Processes 18, 609 (2003).

[66] D. Sciti, S. Guicciardi, C. Melandri, A. Bellosi, High-temperature resistant composites in the AlN-SiC-MoSi 2 system, J. Am. Ceram. Soc. 86, 1720 (2003).

[67] L. Sun, J. Pan, Fabrication and characterization of $\mathrm{TiC}_{\mathrm{w}} / \mathrm{MoSi}_{2}$ and $\mathrm{SiC}_{\mathrm{w}} / \mathrm{MoSi}_{2}$ composites, Materials Letters 53, 63 (2002).

[68] L. Sun, J. Pan, Fabrication and characterization of TiC-particle-reinforced $\mathrm{MoSi}_{2}$ composites, Journal of the European Ceramic Society 22, 791 (2002).

[69] L. Sun, J. Pan, TiC whisker-reinforced $\mathrm{MoSi}_{2}$ matrix composites, Materials Letters 51, 270 (2001).

[70] G. Wang, W. Jiang, G. Bai, D. Chen, $\mathrm{Si}_{3} \mathrm{~N}_{4}$ rodlike crystal-reinforced $\mathrm{MoSi}_{2}$ matrix composites, Materials Letters 58, 308 (2004).

[71] J.A. Hawk, D.E. Alman, J.J. Petrovic, Abrasive wear of $\mathrm{Si}_{3} \mathrm{~N}_{4}-\mathrm{MoSi}_{2}$ composites, Wear 203-204, 247 (1997).

[72] J. Wang, P. Feng, J. Niu, R. Guo, Z. Liu, F. Akhtar, Synthesis, microstructure and properties of $\mathrm{MoSi}_{2}-5 \mathrm{vol} \% \mathrm{Al}_{2} \mathrm{O}_{3}$ composites, Ceramics International 40, 16381 (2014).

[73] C.P. Dogan, J.A. Hawk, Role of zirconia toughening in the abrasive wear of intermetallic and ceramic composites, Wear 212, 110 (1997).

[74] Q. Ma, Y. Yang, M. Kang, Q. Xue, Microstructures and mechanical properties of hotpressed $\mathrm{MoSi}_{2}$-matrix composites reinforced with $\mathrm{SiC}$ and $\mathrm{ZrO}_{2}$ particles, Composites Science and Technology 61, 963 (2001).

[75] Y. Muraoka, S. Kawahara, K. Hirota, O. Yamaguchi, Electrical and mechanical properties of $\mathrm{ZrO}_{2}\left(2 \mathrm{~mol} \% \mathrm{Y}_{2} \mathrm{O}_{3}\right) / \mathrm{WSi}_{2}$ composites and their laminated materials, Materials Research Bulletin 31, 397 (1996).

[76] I-Y. Ko, J-H. Park, K-S. Nam, I-J. Shon, Rapid consolidation of nanocrystalline $\mathrm{NbSi}_{2}-\mathrm{Si}_{3} \mathrm{~N}_{4}$ composites by pulsed current activated combustion synthesis, Met. Mater. Int. $16,393(2010)$. 
[77] I-J. Shon, H-K. Park, H-C. Kim, J-K. Yoon, I-Y. Ko, Simultaneous pulsed current activated combustion synthesis and densification of $\mathrm{NbSi}_{2}-\mathrm{SiC}$ composite, Ceramics International 34, 615 (2008).

[78] K. Sadananda, C.R. Feng, R. Mitra, S.C. Deevi, Creep and fatigue properties of high temperature silicides and their composites, Mater. Sci. Eng. A 261, 223 (1999).

[79] A.L. Dumont, J.P. Bonnet, C. Gault, Mechanical properties of $\mathrm{MoSi}_{2}-\mathrm{Al}_{2} \mathrm{O}_{3}$ composites processed by SHS, ICCM12 Conference Proceedings, Paris, France (1999).

[80] S. Hussain, I. Barbariol, S. Roitti, O. Sbaizero, Electrical conductivity of an insulator matrix (alumina) and conductor particle (molybdenum) composites, Journal of the European Ceramic Society 23, 315 (2003).

[81] V. Medri, A. Bellosi, Factors inducing degradation of properties after long-term oxidation of $\mathrm{Si}_{3} \mathrm{~N}_{4}-\mathrm{MoSi}_{2}$ electroconductive composites, J. Mater. Res. 19, 1567 (2004).

[82] H. Klemm, C. Schubert, Silicon nitride/molybdenum disilicide composite with superior long-term oxidation resistance at $1500^{\circ} \mathrm{C}$, J. Am. Ceram. Soc. 84, 2430 (2001).

[83] S. Lohfeld, M. Schutze, A. Bohm, V. Guther, R. Rix, R. Scholl, Oxidation behavior of particle reinforced $\mathrm{MoSi}_{2}$ composites at high temperatures up to $1700^{\circ} \mathrm{C}$ Part II: initial screening of the oxidation behavior of $\mathrm{MoSi}_{2}$ composites, Materials and Corrosion 56, 149 (2005).

[84] E.W. Lee, J. Cook, A. Khan, R. Mahapatra, J. Waldman, The oxidation resistance of MoSi $i_{2}$ composites, High Temperature Material Research Summary JOM 43, 54 (1991).

[85] X. Fei, Y. Niu, H. Ji, L. Huang, X. Zheng, Oxidation behavior of $\mathrm{Al}_{2} \mathrm{O}_{3}$ reinforced $\mathrm{MoSi}_{2}$ composite coatings fabricated by vacuum plasma spraying, Ceramics International 36,2235 (2010). 


\section{CHA P T R 2: PROCESSING AND PROPERTIES OF}

$\underline{\mathrm{MOSI}_{2}}-\mathrm{AND}_{\mathrm{W} \mathrm{S} \mathrm{I}}-{ }_{2}-\mathrm{OXIDE}$ C OM P O S T E S

\subsection{Introduction}

Extreme harsh-environments are emphasized as one of the major challenges in many industries such as coal gasification, power generation, oil refineries and steel/glass manufacturing. These harsh conditions are due to the very high operating temperatures $\left(1200^{\circ}-1650^{\circ} \mathrm{C}\right)$, oxidizing/corrosive environments and high pressures [1,2]. Technologies are sought to monitor the process conditions such as temperature and pressure for these processes, and also the structural health and degradation of the ceramic refractories used in the high-temperature reactors. This is crucial for achieving better process control, improved efficiency, reduced environmental impact and increased lifetime of the process units. However, materials commonly used for real-time sensing in harsh-environments, like noble metals (Pt, Rh, Ir etc.) and their alloys, suffer from serious structural and functional issues such as selective oxidation via formation of volatile oxides, detrimental microstructural/compositional changes and mechanical degradation [1-4]. Therefore, there is a great demand for advanced sensing materials capable of operating under such extreme conditions reliably and precisely for long-term without high-temperature degradations $[2,4,5]$.

Sensing applications in high-temperature and harsh-environments require advanced materials that can fulfill the required combination of physical, thermal, electrical and mechanical properties, such as a high melting point, good oxidation and corrosion resistance, high-temperature thermal/chemical stability and electrical conductivity at elevated temperatures $[4,6,7]$. Therefore, refractory transition metal silicides $\left(\mathrm{MoSi}_{2}, \mathrm{WSi}_{2}\right.$, $\mathrm{TaSi}_{2}$ etc.), which have been mostly studied for high-temperature structural applications

along with silicon-based ceramics $\left(\mathrm{SiC}_{2} \mathrm{Si}_{3} \mathrm{~N}_{4}\right)$, offer great advantages for such sensing applications due to their high melting temperatures $\left(>1900^{\circ} \mathrm{C}\right)$, very low oxidation and corrosion rates at high temperatures, high-temperature stability, good mechanical properties 
and high-temperature electrical conductivity [8-10]. They are intermetallic compounds of transition metals in group IV, V, VI and silicon, so the bonding in these metal silicides is more metallic in nature [11,12]. Among all refractory transition metal silicides, molybdenum disilicide $\left(\mathrm{MoSi}_{2}\right)$ and tungsten disilicide $\left(\mathrm{WSi}_{2}\right)$ are the most promising candidate materials for advanced sensing applications, since they are more thermally/chemically stable and oxidation resistant at the temperatures between $1000^{\circ} \mathrm{C}$ and $1600^{\circ} \mathrm{C}$ under harsh environments. The weight gain level for the $\mathrm{MoSi}_{2}$ and $\mathrm{WSi}_{2}$ at around $1600^{\circ} \mathrm{C}$ in air was approximately measured as 0.007 and $0.2 \mathrm{mg} / \mathrm{cm}^{2}$ per hour, respectively [4]. These low oxidation rates are directly attributed to the formation of highly stable, dense silicon oxide $\left(\mathrm{SiO}_{2}\right)$ layer on the surface that protects from further oxidation in highly oxidizing atmospheres at high temperatures $[4,8,13]$. It was also demonstrated that they are good metallic conductors even at high temperatures, which is necessary for high-temperature sensing applications. The electrical resistivity of the $\mathrm{MoSi}_{2}$ and $\mathrm{WSi}_{2}$ thin films were found as 134 and $93 \mu \Omega \cdot \mathrm{cm}$ at around $830^{\circ} \mathrm{C}$ [14]. Kobel et al. (2004) also reported that the $\mathrm{MoSi}_{2}$ exhibited very high electrical conductivity $(\sim 6000 \mathrm{~S} / \mathrm{cm})$ at around $750^{\circ} \mathrm{C}$ [15]. However, the poor low temperature toughness, pest effect (or accelerated oxidation at $400^{\circ}-600^{\circ} \mathrm{C}$ ), low mechanical strength and poor creep resistance at high temperatures $\left(\geq 1200^{\circ} \mathrm{C}\right)$ were identified as their major limitations that need to be addressed $[8,15,16]$.

Therefore, a composite approach has been applied by some researchers to overcome such disadvantages and to enhance their performance/reliability at high temperatures, since $\mathrm{MoSi}_{2}$ and $\mathrm{WSi}_{2}$ are chemically compatible with many ceramic reinforcements including $\mathrm{SiC}, \mathrm{Al}_{2} \mathrm{O}_{3}, \mathrm{ZrO}_{2}, \mathrm{TiC}, \mathrm{Si}_{3} \mathrm{~N}_{4}$ and $\mathrm{TiB}_{2}$ [16-18]. It was reported in studies that their mechanical strength, fracture toughness and high-temperature creep resistance could be substantially increased by reinforcing with $\mathrm{Al}_{2} \mathrm{O}_{3}, \mathrm{ZrO}_{2}, \mathrm{SiC}$ and $\mathrm{TiC}$ [8,19-23]. The refractory oxide addition of choice is typically $\mathrm{Al}_{2} \mathrm{O}_{3}$ and $\mathrm{ZrO}_{2}$ in these composite systems (mostly $\mathrm{MoSi}_{2}-\mathrm{Al}_{2} \mathrm{O}_{3}$ and $\mathrm{MoSi}_{2}-\mathrm{ZrO}_{2}$ ), since these materials have a close match of their thermal expansion coefficients $\left(\sim 8.0 \times 10^{-6} \mathrm{~K}^{-1}\right.$ for $\mathrm{Al}_{2} \mathrm{O}_{3} ; 9.6 \times 10^{-6} \mathrm{~K}^{-1}$ for $\left.\mathrm{ZrO}_{2}\right)$ with $\mathrm{MoSi}_{2}$ 
$\left(8.2 \times 10^{-6} \mathrm{~K}^{-1}\right)$ and $\mathrm{WSi}_{2}\left(7.9 \times 10^{-6} \mathrm{~K}^{-1}\right)$ in a wide temperature range from $20^{\circ} \mathrm{C}$ to $1400^{\circ} \mathrm{C}$ $[12,24,25]$. This is very beneficial in composite systems for minimizing thermal stresses and interfacial cracks, and thus, for improving their thermal shock resistance and stability at high temperatures $[8,26]$. In addition, it is anticipated that oxygen diffusion pathways may be blocked by reinforcing with these oxidation-resistant refractory oxides, and therefore, the high temperature oxidation resistance could be enhanced, while eliminating the problematic pest oxide formation [13,25]. Zmii et al. (2008) showed that the $\mathrm{MoSi}_{2}$ $\mathrm{Al}_{2} \mathrm{O}_{3}$ and $\mathrm{WSi}_{2}-\mathrm{Al}_{2} \mathrm{O}_{3}$ coatings with 5-30 wt $\%$ of alumina reinforcement have significantly higher oxidation resistance at $1800^{\circ} \mathrm{C}$ than monolithic disilicide coatings [27]. However, it was reported on the $\mathrm{MoSi}_{2}-\mathrm{Al}_{2} \mathrm{O}_{3}$ composite coatings that the oxidation rate at $1500^{\circ} \mathrm{C}$ slightly increased with $30 \mathrm{vol} \%$ of $\mathrm{Al}_{2} \mathrm{O}_{3}$ addition, which was explained by formation of mullite resulted in less protective, porous oxide layer on the surface [13]. But the effect of the $\mathrm{Al}_{2} \mathrm{O}_{3}$ and $\mathrm{ZrO}_{2}$ reinforcements on the oxidation resistance of the $\mathrm{MoSi}_{2}-$ and $\mathrm{WSi}_{2}$-based composites has not been well understood yet. Furthermore, it is well known from ceramic composite systems that grain growth can be efficiently retarded at elevated temperatures by grain boundary pinning of reinforcement (second-phase) particles such as alumina and zirconia [28-30]. This is also advantageous for achieving more stable microstructures that may improve the long-term stability and performance of the metal silicide/refractory oxide composites at high temperatures. It is important to note that grain growth kinetics and long-term stability of these composites have not been studied.

Metal silicide/refractory oxide ceramic composites (particularly $\mathrm{MoSi}_{2}-\mathrm{Al}_{2} \mathrm{O}_{3}$, $\mathrm{MoSi}_{2}-\mathrm{ZrO}_{2}, \mathrm{WSi}_{2}-\mathrm{Al}_{2} \mathrm{O}_{3}$ and $\mathrm{WSi}_{2}-\mathrm{ZrO}_{2}$ ) are very promising high-temperature electroconductive materials for advanced sensing applications under harsh-environments, based upon their current and potential advantages discussed. Regarding to their electroconductive behavior and metallic nature, Yamamoto and Sendai developed a method for producing $\mathrm{MoSi}_{2}$-based composite heating elements and high-temperature thermistors with granular $\mathrm{Al}_{2} \mathrm{O}_{3}$ reinforcement [31,32]. The $\mathrm{MoSi}_{2}-\mathrm{Al}_{2} \mathrm{O}_{3}$ composites exhibited an adequate low-temperature electrical conductivity even at alumina fractions above $80 \mathrm{wt} \%$, 
as well as, improved mechanical strength and high-temperature oxidation/erosion resistance. In the study performed by Kobel et al. (2004), electrical properties of the MoSiz$\mathrm{Al}_{2} \mathrm{O}_{3}$ composites with 16-40 vol\% silicide contents were investigated as a function of temperature [15]. The electrical conductivity of the 25-75 and 40-60 vol\% $\mathrm{MoSi}_{2}-\mathrm{Al}_{2} \mathrm{O}_{3}$ composites at $750^{\circ} \mathrm{C}$ was approximately measured as 24 and $600 \mathrm{~S} / \mathrm{cm}$, respectively. However, there are very limited studies conducted on their high-temperature electrical properties and potential advanced sensing applications; there are no studies on their short/long-term thermal stability and grain growth kinetics. Therefore, the main objectives of this research were to fabricate the $\mathrm{MoSi}_{2}$ - and $\mathrm{WSi}_{2}$-based ceramic composites reinforced by $\mathrm{Al}_{2} \mathrm{O}_{3}$ and $\mathrm{ZrO}_{2}$ particles, and to investigate their chemical/thermal stability, microstructural evolution, grain growth kinetics and electrical properties at high temperatures.

\subsection{Experimental Procedure}

\subsubsection{Materials and method}

Commercial $\mathrm{MoSi}_{2}$ (99.5\% metals basis), WSi 2 (99.5\% metals basis) and $\mathrm{ZrO}_{2}$ $(99+\%)$ powders, all purchased from Alfa Aesar (Tewksbury, MA, USA), were used as starting powders. In addition, fine- $\mathrm{Al}_{2} \mathrm{O}_{3}\left(99.8 \%, 8.6 \mathrm{~m}^{2} / \mathrm{g} \mathrm{SSA}\right)$ and coarse- $\mathrm{Al}_{2} \mathrm{O}_{3}(99.6 \%$, $1.2 \mathrm{~m}^{2} / \mathrm{g} \mathrm{SSA}$ ) powders used were purchased from Almatis (Leetsdale, PA, USA); and they are abbreviated as $\mathrm{f}_{\mathrm{Al}} \mathrm{Al}_{2} \mathrm{O}_{3}$ and c. $\mathrm{Al}_{2} \mathrm{O}_{3}$, respectively, for simplicity. Prior to the processing of the composites, phase and microstructure analysis of the starting powders were completed by X-ray diffraction (XRD, Panalytical X'Pert Pro, Westborough, MA, USA) and field emission scanning electron microscopy (FE-SEM, Hitachi S-4700F, Tokyo, Japan), respectively. Figure 34 presents the XRD patterns of the starting $\mathrm{MoSi}_{2}$ and $\mathrm{WSi}_{2}$ powders. It was found that 5-3 metal silicides $\left(\mathrm{Mo}_{5} \mathrm{Si}_{3}, \mathrm{~W}_{5} \mathrm{Si}_{3}\right)$ and metals (Mo, W) exist along with the major $\mathrm{MoSi}_{2}$ (tetragonal, I4/mmm, \#01-080-0544) and $\mathrm{WSi}_{2}$ (tetragonal, I4/mmm, \#00-011-0195) phases. In addition, the XRD results of the refractory oxide powders (not shown) demonstrated that both $\mathrm{Al}_{2} \mathrm{O}_{3}$ powders have the corundum structure with rhombohedral symmetry ( $\mathrm{R} 3 \mathrm{c}$, \#01-078-2427), while the $\mathrm{ZrO}_{2}$ displayed a monoclinic 

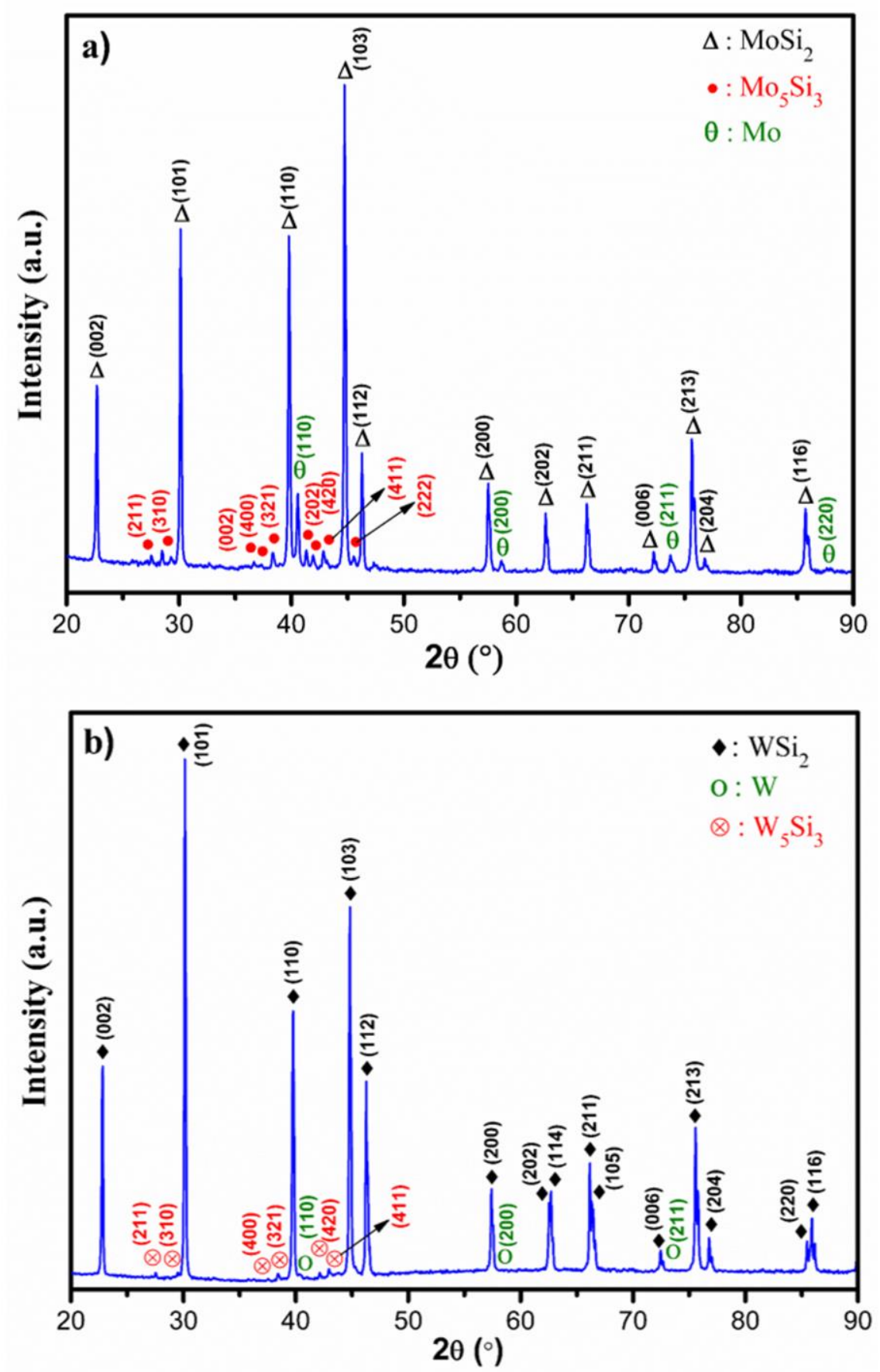

Figure 34. XRD patterns of the commercial (a) molybdenum disilicide $\left(\mathrm{MoSi}_{2}\right)$, and (b) tungsten disilicide $\left(\mathrm{WSi}_{2}\right)$ starting powders. 
structure (P21/c, \#00-024-1165). Also, SEM microstructures of the starting powders are presented in the Figure 35. The results showed that the $\mathrm{MoSi}_{2}$ and $\mathrm{WSi}_{2}$ particles have random-shaped morphology with average sizes of 4.2 and $5.3 \mu \mathrm{m}$, respectively. The average sizes of equiaxed-shaped f. $\mathrm{Al}_{2} \mathrm{O}_{3}$ and random-shaped c. $\mathrm{Al}_{2} \mathrm{O}_{3}$ particles were measured by using the ImageJ software [33] as 0.4 and $2.5 \mu \mathrm{m}$, respectively. It was also found that the $\mathrm{ZrO}_{2}$ had both equiaxed and elongated particles with $12.1 \mu \mathrm{m}$ average size.

The fractions of the metal silicide powders in the composite compositions were all determined based on the volume, thus only the volume percentages (vol\%) were used to describe the composites as $20-80$ and $60-40$ for simplicity. The $20-80$ and $60-40$ volume fractions were selected in this study to work in the regions (1) near percolation and (2) above percolation, respectively. $\mathrm{MoSi}_{2}$ - and $\mathrm{WSi}_{2}$-based ceramic composite powders reinforced by $\mathrm{Al}_{2} \mathrm{O}_{3}, c . \mathrm{Al}_{2} \mathrm{O}_{3}$ and $\mathrm{ZrO}_{2}$ were prepared by ball-milling in ethanol for $24 \mathrm{~h}$ followed by drying at room temperature in a fume hood. The as-prepared composite powders were uniaxially pressed into small (13 $\mathrm{mm}$ diameter) and large (26 $\mathrm{mm}$ diameter) cylindrical pellets having 2-4 mm thickness by using a stainless steel die under the pressure of $13.8 \mathrm{MPa}$. These pellets were then sintered at $1400^{\circ}-1600^{\circ} \mathrm{C}$ in a tube furnace in flowing argon gas $(50 \mathrm{sccm})$. The rate of heating was set as $3^{\circ} \mathrm{C} / \mathrm{min}$. The samples were held for $2 \mathrm{~h}$ at that temperature and subsequently cooled to room temperature at a rate of $3^{\circ} \mathrm{C} / \mathrm{min}$. After sintering of the composites was completed, three small pellets of each composition were further annealed at $1400^{\circ} \mathrm{C}$ for 24 and $48 \mathrm{~h}$, respectively, in order to investigate their thermal stability, microstructural evolution and grain growth kinetics at high temperatures.

\subsubsection{Characterization}

Characterization studies were performed regarding their density, phase development, microstructure/grain growth and electrical properties. Densities of the sintered composite samples were measured by employing the Archimedes principle using ethanol $\left(0.789 \mathrm{~g} / \mathrm{cm}^{3}\right)$ as the immersion liquid. The volume fractions of the secondary phases formed after sintering were not included in the theoretical density calculations. 

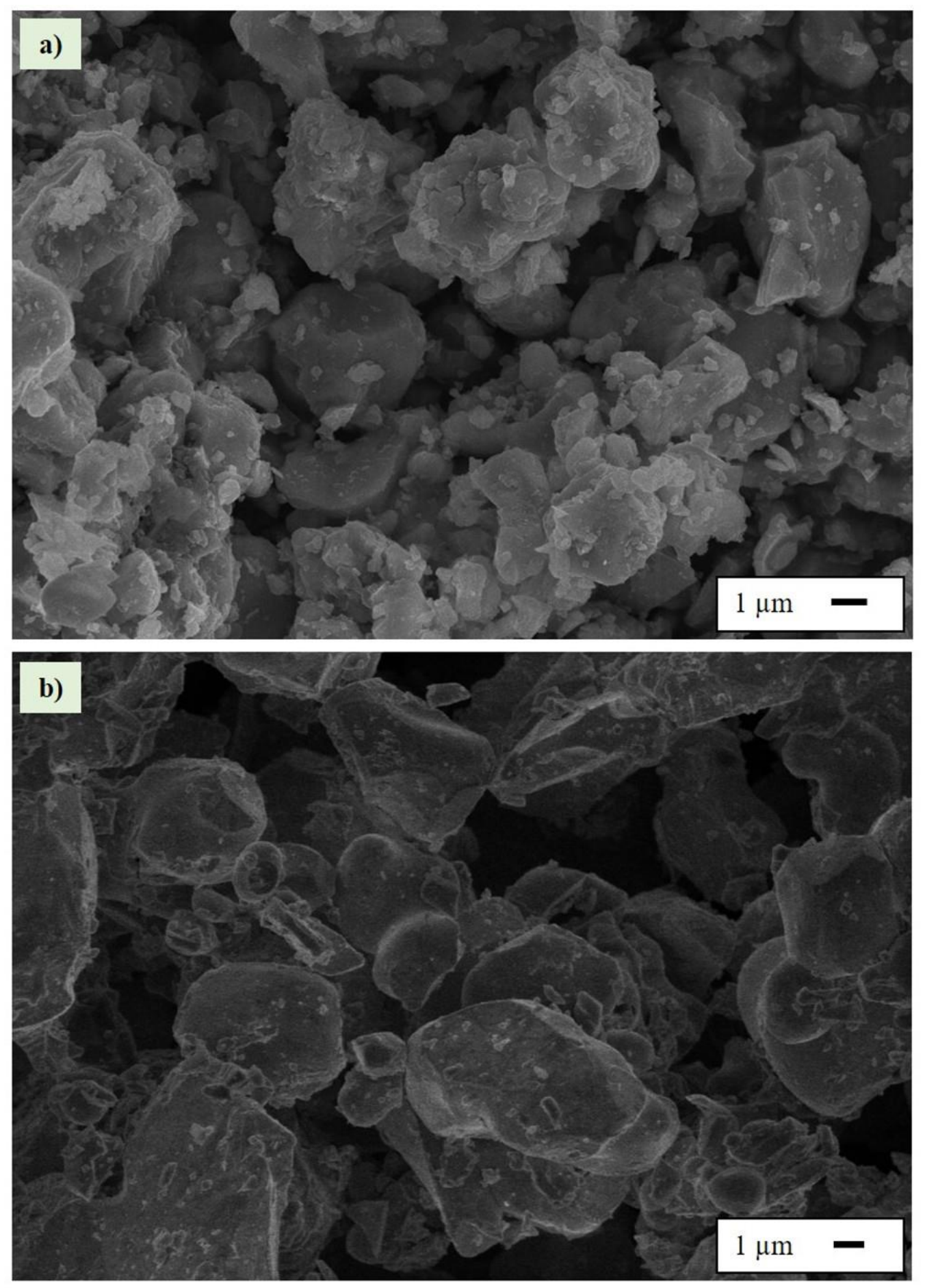

Figure 35. SEM microstructures of the commercial (a) $\mathrm{MoSi}_{2}$, (b) $\mathrm{WSi}_{2}$, (c) f. $\mathrm{Al}_{2} \mathrm{O}_{3}$ (fine- $\mathrm{Al}_{2} \mathrm{O}_{3}$ ) (d) c. $\mathrm{Al}_{2} \mathrm{O}_{3}$ (coarse- $\mathrm{Al}_{2} \mathrm{O}_{3}$ ), and (e) $\mathrm{ZrO}_{2}$ starting powders. 

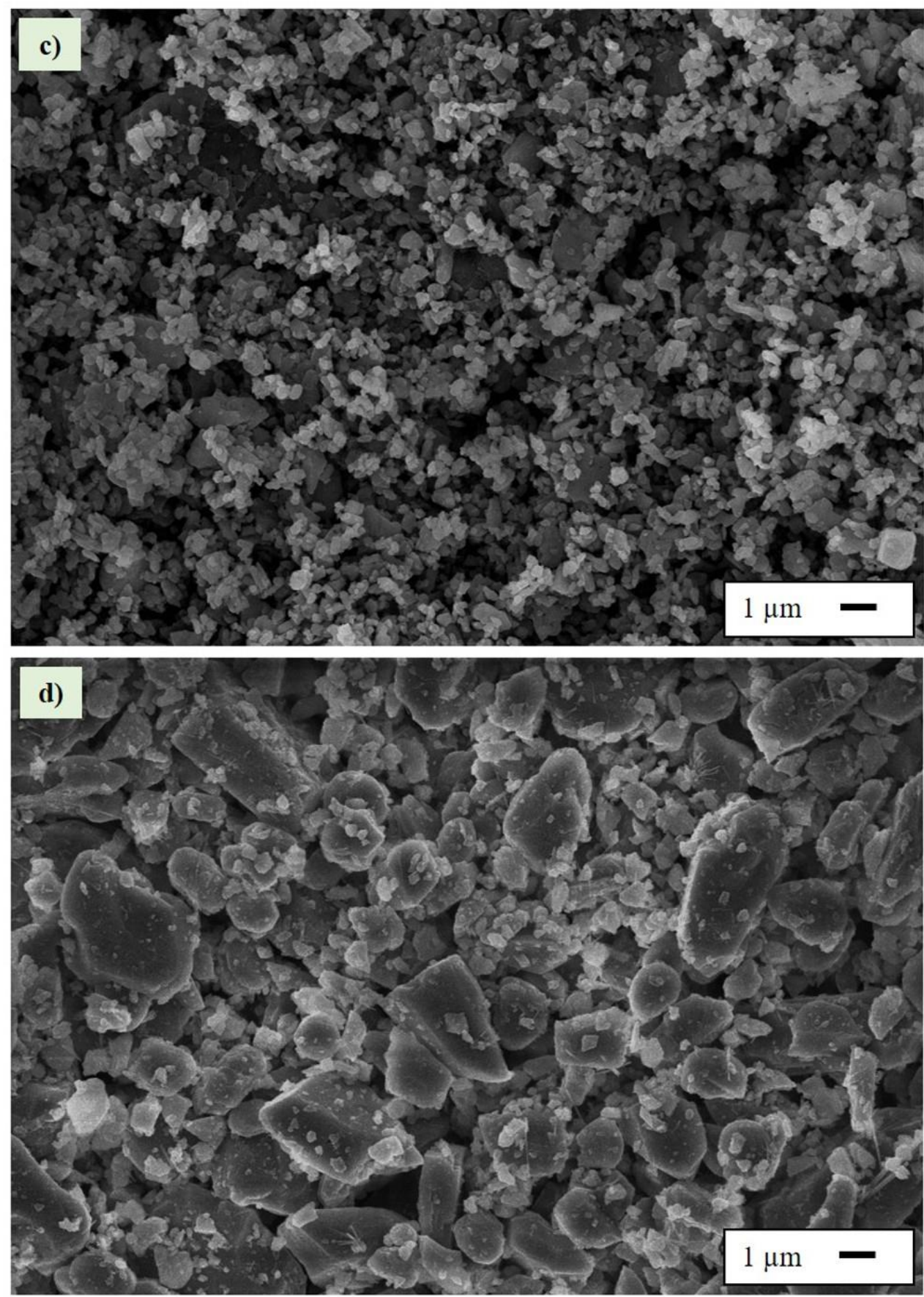

Figure 35. (continued) SEM microstructures of the commercial (a) $\mathrm{MoSi}_{2}$, (b) $\mathrm{WSi}_{2}$, (c) f. $\mathrm{Al}_{2} \mathrm{O}_{3}$ (fine- $\mathrm{Al}_{2} \mathrm{O}_{3}$ ) (d) c. $\mathrm{Al}_{2} \mathrm{O}_{3}$ (coarse- $\mathrm{Al}_{2} \mathrm{O}_{3}$ ), and (e) $\mathrm{ZrO}_{2}$ starting powders. 


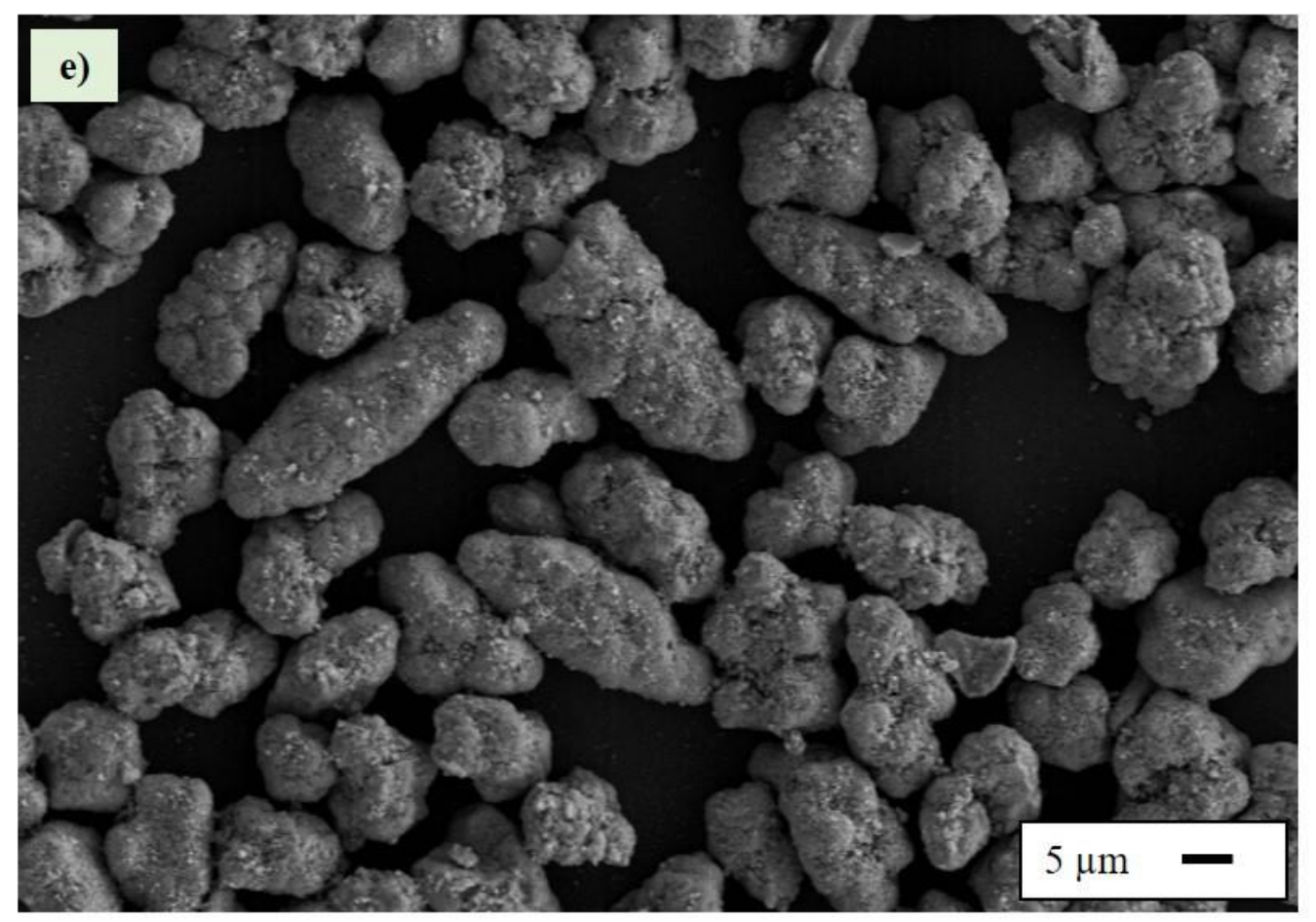

Figure 35. (continued) SEM microstructures of the commercial (a) $\mathrm{MoSi}_{2}$, (b) $\mathrm{WSi}_{2}$, (c) f. $\mathrm{Al}_{2} \mathrm{O}_{3}$ (fine- $\mathrm{Al}_{2} \mathrm{O}_{3}$ ) (d) c. $\mathrm{Al}_{2} \mathrm{O}_{3}$ (coarse- $\mathrm{Al}_{2} \mathrm{O}_{3}$ ), and (e) $\mathrm{ZrO}_{2}$ starting powders.

Phase analyses of the composite samples were performed both after sintering and annealing by XRD with $\mathrm{CuK} \alpha$ radiation source. Additionally, quantitative phase analysis studies via Rietveld method were performed by using the MAUD software [34] to determine the fractions of secondary phases formed after sintering and annealing. Sample preparation for microstructural analyses was carried out by cutting of the samples with a diamond saw, and then fine polishing with SiC sanding papers (600-1200 grits) and diamond paste $(0.5 \mu \mathrm{m})$. Chemical etching was also utilized by soaking the samples in $2 \mathrm{M} \mathrm{HCl}$ or 1:1:1 $\mathrm{HCl}: \mathrm{HNO}_{3}: \mathrm{H}_{2} \mathrm{O}$ acid solutions for $2 \mathrm{~min}$. Afterwards, field emission scanning electron microscopy (FE-SEM, Hitachi S-4700F, Tokyo, Japan) was used to examine the microstructures of composite samples, and also to study the grain growth of the metal silicides. Average grain size of the metal silicides were determined from their SEM micrographs by using the ImageJ. For electrical measurements, a high temperature test rig was made using a high purity 4-bore alumina tube and platinum connection leads. The 
rectangular bar samples, with average dimensions of $20 \times 4 \times 4 \mathrm{~mm}$, were prepared from the large cylindrical pellets for a standard measurement (ASTM B193-16) [35], and then, they connected to the test rig and the entire system was sealed in a tube furnace. Electrical resistance of the sintered composite samples was measured with a digital multimeter (Keithley 2100, Tektronix, Beaverton, OR, USA) by the DC four-probe method. A B-type of thermocouple was also used to monitor the temperature. The electrical measurements were conducted at temperatures up to $900^{\circ}-1000^{\circ} \mathrm{C}$ in argon atmosphere to avoid material degradation. The resistance data was acquired as a function of time and temperature by LabView and Keithley programs, and lastly, the electrical resistivity/conductivity were calculated by using the specific sample dimensions.

\subsection{Results and Discussion}

\subsubsection{Densification, chemical stability and microstructures after sintering}

$\mathrm{MoSi}_{2}$ - and $\mathrm{WSi}_{2}$-based composites were all prepared by reinforcing with different refractory oxides based on the metal silicide-refractory oxide volume fractions of 20-80 and 60-40. Then, these twelve composites were sintered at the temperatures range from $1400^{\circ} \mathrm{C}$ to $1600^{\circ} \mathrm{C}$ in order to determine their densification as a function of composition and temperature, as well as, to define the optimum sintering temperature for further studies. Table 5 and Table 6 presents the relative density, apparent density and apparent porosity of the $\mathrm{MoSi}_{2}$ - and $\mathrm{WSi}_{2}$-based composites as a function of sintering temperature. The results showed that all composites except for $60-40$ WSi $2-\mathrm{f}_{2} \mathrm{Al}_{2} \mathrm{O}_{3}$ have relative densities lower than $74.7 \%$ at $1400^{\circ} \mathrm{C}$. With increasing temperature to $1500^{\circ} \mathrm{C}$, there was a $4.8-6.2 \%$ increase in relative densities of the $\mathrm{MoSi}_{2}-\mathrm{c} \cdot \mathrm{Al}_{2} \mathrm{O}_{3}, \mathrm{MoSi}_{2}-\mathrm{ZrO}_{2}$ and $\mathrm{WSi}_{2}-\mathrm{c} . \mathrm{Al}_{2} \mathrm{O}_{3}$ composites. But it is clear that $\mathrm{MoSi}_{2}$ - and $\mathrm{WSi}_{2}$-based composites reinforced with finealumina particles (f. $\mathrm{Al}_{2} \mathrm{O}_{3}$ ) exhibited higher relative densities ranging from 77.8 to $98.0 \%$ at $1500^{\circ}$ and $1600^{\circ} \mathrm{C}$, particularly at low metal silicide fractions. The relative densities of

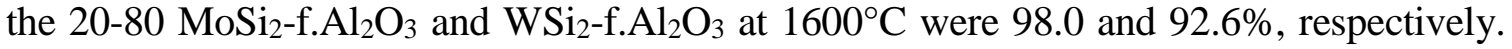
The increase in their relative densities ranged from 17.9 to 26.5 with increasing sintering temperature from $1400^{\circ}$ to $1600^{\circ} \mathrm{C}$. The lowest apparent porosity values (1.2-2.9\%) were 
Table 5. Relative densities of the $\mathrm{MoSi}_{2}$-based and $\mathrm{WSi}_{2}$-based composites reinforced by f. $\mathrm{Al}_{2} \mathrm{O}_{3}, c . \mathrm{Al}_{2} \mathrm{O}_{3}$ and $\mathrm{ZrO}_{2}$ particles as function of sintering temperature.

\begin{tabular}{|c|c|c|c|}
\hline \multirow{2}{*}{ Composite } & \multicolumn{3}{|c|}{ Relative density (\%) } \\
\hline & $1400^{\circ} \mathrm{C}$ & $1500^{\circ} \mathrm{C}$ & $1600^{\circ} \mathrm{C}$ \\
\hline 20-80 $\mathrm{MoSi}_{2}$-f. $\mathrm{Al}_{2} \mathrm{O}_{3}$ & 71.5 & 92.5 & 98.0 \\
\hline 20-80 $\mathrm{MoSi}_{2}$-c. $\mathrm{Al}_{2} \mathrm{O}_{3}$ & 66.8 & 71.5 & 74.1 \\
\hline 20-80 $\mathrm{MoSi}_{2}-\mathrm{ZrO}_{2}$ & 69.6 & 76.3 & 89.7 \\
\hline 60-40 $\mathrm{MoSi}_{2}-\mathrm{f} . \mathrm{Al}_{2} \mathrm{O}_{3}$ & 71.6 & 81.7 & 90.9 \\
\hline 60-40 $\mathrm{MoSi}_{2}-\mathrm{c} . \mathrm{Al}_{2} \mathrm{O}_{3}$ & 63.1 & 68.4 & 77.7 \\
\hline 60-40 $\mathrm{MoSi}_{2}-\mathrm{ZrO}_{2}$ & 68.9 & 74.3 & 87.9 \\
\hline 20-80 WSi 2 -f. $\mathrm{Al}_{2} \mathrm{O}_{3}$ & 74.7 & 92.5 & 92.6 \\
\hline 20-80 WSi $\mathbf{W i}_{2}-\mathrm{c} \cdot \mathrm{Al}_{2} \mathrm{O}_{3}$ & 67.2 & 73.4 & 74.3 \\
\hline $20-80 \mathrm{WSi}_{2}-\mathrm{ZrO}_{2}$ & 72.3 & 73.4 & 72.9 \\
\hline 60-40 WSi ${ }_{2}-\mathrm{f}_{.} \mathrm{Al}_{2} \mathrm{O}_{3}$ & 78.1 & 77.8 & 88.6 \\
\hline 60-40 WSi $\mathrm{Wi}_{2}-\mathrm{c} \cdot \mathrm{Al}_{2} \mathrm{O}_{3}$ & 70.8 & 72.0 & 79.8 \\
\hline $60-40 \mathrm{WSi}_{2}-\mathrm{ZrO}_{2}$ & 74.0 & 72.5 & 85.0 \\
\hline
\end{tabular}

also achieved by these composites sintered above $1500^{\circ} \mathrm{C}$. Similar density results (86.598.2\%) were reported on the $\mathrm{MoSi}_{2}-\mathrm{Al}_{2} \mathrm{O}_{3}$ composites in the literature [26,36]. Besides, a similar effect was also observed by reinforcing the metal silicides with larger zirconia particles $(\sim 12.1 \mu \mathrm{m})$, which improved the densification mostly at $1600^{\circ} \mathrm{C}$. Although the $\mathrm{MoSi}_{2}-\mathrm{ZrO}_{2}$ and $\mathrm{WSi}_{2}-\mathrm{ZrO}_{2}$ composites (except for the 20-80 $\mathrm{WSi}_{2}-\mathrm{ZrO}_{2}$ ) revealed high 
Table 6. Apparent density and apparent porosity of the $\mathrm{MoSi}_{2}$-based and $\mathrm{WSi}_{2}$-based composites reinforced by f. $\mathrm{Al}_{2} \mathrm{O}_{3}, c . \mathrm{Al}_{2} \mathrm{O}_{3}$ and $\mathrm{ZrO}_{2}$ particles as function of sintering temperature.

\begin{tabular}{|c|c|c|c|c|c|c|}
\hline \multirow{2}{*}{ Composite } & \multicolumn{3}{|c|}{ Apparent density $\left(\mathrm{g} / \mathrm{cm}^{3}\right)$} & \multicolumn{3}{|c|}{ Apparent porosity (\%) } \\
\hline & $1400^{\circ} \mathrm{C}$ & $1500^{\circ} \mathrm{C}$ & $1600^{\circ} \mathrm{C}$ & $1400^{\circ} \mathrm{C}$ & $1500^{\circ} \mathrm{C}$ & $1600^{\circ} \mathrm{C}$ \\
\hline 20-80 $\mathrm{MoSi}_{2}$-f. $\mathrm{Al}_{2} \mathrm{O}_{3}$ & 4.52 & 4.17 & 4.37 & 26.7 & 2.4 & 1.2 \\
\hline 20-80 $\mathrm{MoSi}_{2}$-c. $\mathrm{Al}_{2} \mathrm{O}_{3}$ & 4.32 & 4.40 & 4.44 & 31.8 & 28.3 & 26.5 \\
\hline 20-80 $\mathrm{MoSi}_{2}-\mathrm{ZrO}_{2}$ & 5.99 & 5.97 & 5.92 & 32.8 & 26.0 & 12.3 \\
\hline 60-40 $\mathrm{MoSi}_{2}-\mathrm{f}_{0} \mathrm{Al}_{2} \mathrm{O}_{3}$ & 5.14 & 4.90 & 5.33 & 25.8 & 11.2 & 9.2 \\
\hline 60-40 $\mathrm{MoSi}_{2}-\mathrm{c} . \mathrm{Al}_{2} \mathrm{O}_{3}$ & 5.18 & 5.23 & 5.34 & 35.1 & 30.3 & 22.5 \\
\hline $60-40 \mathrm{MoSi}_{2}-\mathrm{ZrO}_{2}$ & 6.03 & 6.28 & 6.18 & 31.2 & 28.9 & 14.5 \\
\hline 20-80 WSi 2 -f. $\mathrm{Al}_{2} \mathrm{O}_{3}$ & 5.09 & 4.78 & 4.79 & 26.3 & 2.8 & 2.9 \\
\hline $20-80 \mathrm{WSi}_{2}$-c. $\mathrm{Al}_{2} \mathrm{O}_{3}$ & 5.06 & 5.11 & 5.05 & 33.4 & 27.9 & 26.2 \\
\hline 20-80 $\mathrm{WSi}_{2}-\mathrm{ZrO}_{2}$ & 6.71 & 6.67 & 6.66 & 31.1 & 29.6 & 29.9 \\
\hline 60-40 WSi 2 -f. $\mathrm{Al}_{2} \mathrm{O}_{3}$ & 6.68 & 5.90 & 7.40 & 15.7 & 5.6 & 14.2 \\
\hline 60-40 WSi $\mathrm{Wi}_{2}-\mathrm{c} . \mathrm{Al}_{2} \mathrm{O}_{3}$ & 7.19 & 7.30 & 7.54 & 29.5 & 29.4 & 24.3 \\
\hline $60-40 \mathrm{WSi}_{2}-\mathrm{ZrO}_{2}$ & 8.27 & 8.30 & 8.10 & 29.7 & 31.5 & 17.6 \\
\hline
\end{tabular}


relative densities above $85.0 \%$ at $1600^{\circ} \mathrm{C}$, their densities were found to be significantly low (68.9-76.3\%) at the lower temperatures. The porosity level was also significantly higher (26.0-32.8\%) for these composites sintered at $1400^{\circ}-1500^{\circ} \mathrm{C}$, but a drastic decrease was observed at $1600^{\circ} \mathrm{C}$. Therefore, their low densities at $1400^{\circ}-1500^{\circ} \mathrm{C}$ could be explained by insufficient thermal energy for sintering and possible formation of microcracks due to the $\mathrm{ZrO}_{2}$ monoclinic-tetragonal phase transition at around $1170^{\circ} \mathrm{C}$, respectively $[37,38]$. Matsuo and Homma (1964) similarly showed that densities of the $\mathrm{MoSi}_{2}-\mathrm{ZrO}_{2}$ composites increased at the sintering temperatures above $1500^{\circ} \mathrm{C}$ [39]. The lowest relative densities (72.9-79.8\%) for the composites sintered at $1600^{\circ} \mathrm{C}$ were measured by the $\mathrm{MoSi}_{2}-\mathrm{C} . \mathrm{Al}_{2} \mathrm{O}_{3}$ and $\mathrm{WSi}_{2}-\mathrm{c} . \mathrm{Al}_{2} \mathrm{O}_{3}$ along with the $20-80 \mathrm{WSi}_{2}-\mathrm{ZrO}_{2}$. They also displayed higher apparent porosities (22.5-29.9\%) among all the composites.

It is known that densification of the composites could be highly influenced by volume fraction, particle size and distribution of the reinforcement particles (second phase) $[40,41]$. It was reported that densification could be improved by increasing the particle size ratio of the reinforcement to the matrix, which could result in more efficient particle packing [42]. The zirconia/metal silicide particle size ratios (2.3-2.9) were significantly higher than coarse-alumina/metal silicide particle size ratios (0.5-0.6), which would lead to more efficient particle packing and higher densification for the zirconia/metal silicide composites. However, it was difficult to calculate the fine-alumina/metal silicide particle size ratios due to the agglomeration of fine-alumina particles after milling. However, if the fine-alumina/metal silicide particle size ratios are assumed relatively higher due to that agglomeration, enhanced densification in the silicide-f. $\mathrm{Al}_{2} \mathrm{O}_{3}$ composites could be explained with the same effect. Additionally, it is known that matrix-matrix (silicidesilicide or oxide-oxide) locations within the composite sinter and grow faster than the matrix-reinforcement (silicide-oxide) locations due to the difference in surface energy between the two grains and due to potentially higher transport along the grain boundaries of the contacts with similar chemistry and structure $[40,42,43]$. The number of matrixmatrix contacts significantly decreases with addition of the reinforcement particles within 
the composite structures. Therefore, homogeneous particle distribution may not be beneficial for improving the densification due to the formation of more dissimilar silicideoxide contacts throughout the microstructure resulting in constrained sintering (i.e. lower densification kinetics). The number of silicide-silicide and oxide-oxide contacts was higher in the silicide-f. $\mathrm{Al}_{2} \mathrm{O}_{3}$ composites due to agglomeration of the fine-alumina particles; thus, large regions of these composites contained a higher concentration of single-phase grain boundaries leading to local densification kinetics controlled by single-phase sintering mechanisms. As a review of the results, it can be concluded that the densification of the composites was highly affected by sintering temperature, reinforcement material, particle size ratio of the reinforcement to the matrix, particle agglomeration and distribution level of particles. The higher relative densities were generally achieved by sintering of the composites at $1600^{\circ} \mathrm{C}$, and therefore, further studies were conducted on the composite samples sintered at that temperature.

The phase analysis studies of the composites were initially performed after sintering in order to determine the chemical stability of the metal silicides within different refractory oxide ceramics. The XRD patterns of the 60-40 MoSi2-based composites sintered at $1600^{\circ} \mathrm{C}$ are presented in the Figure 36a. The phases identified for the $\mathrm{MoSi}_{2}-\mathrm{f} \mathrm{Al}_{2} \mathrm{O}_{3}$ and $\mathrm{MoSi}_{2}$-c. $\mathrm{Al}_{2} \mathrm{O}_{3}$ were $\mathrm{MoSi}_{2}, \mathrm{Al}_{2} \mathrm{O}_{3}$ and $\mathrm{Mos}_{5} \mathrm{Si}_{3}$. Similarly, the $\mathrm{Mo}_{5} \mathrm{Si}_{3}$ phase was also observed for the $\mathrm{MoSi}_{2}-\mathrm{ZrO}_{2}$ composite. In addition, it is clear that $\mathrm{Mo}_{5} \mathrm{Si}_{3}$ peaks are more intense in the $\mathrm{MoSi}_{2}-\mathrm{c} \cdot \mathrm{Al}_{2} \mathrm{O}_{3}$ and $\mathrm{MoSi}_{2}-\mathrm{ZrO}_{2}$. This result demonstrates that the interaction between $\mathrm{MoSi}_{2}$ and coarse-grained $(\geq 2.5 \mu \mathrm{m})$ refractory oxides was relatively higher, which may be related to the high number of silicide-oxide contacts within these composites. However, the agglomeration of the fine-alumina particles may highly lower the number of silicide-oxide contacts, and thus, the related particle interaction. The secondary phase formation was also found to be related to interaction of $\mathrm{MoSi}_{2}$ with residual oxygen that may remain in the starting silicide powder $[44,45]$. It is well known that $\mathrm{MoSi}_{2}$ reacts with oxygen to form $\mathrm{Mo}_{5} \mathrm{Si}_{3}$ and $\mathrm{SiO}_{2}$ at high temperatures (above the boiling point of $\mathrm{MoO}_{3}$ ) based on its thermodynamics and enhanced reaction rate [10,46,47]. Furthermore, 

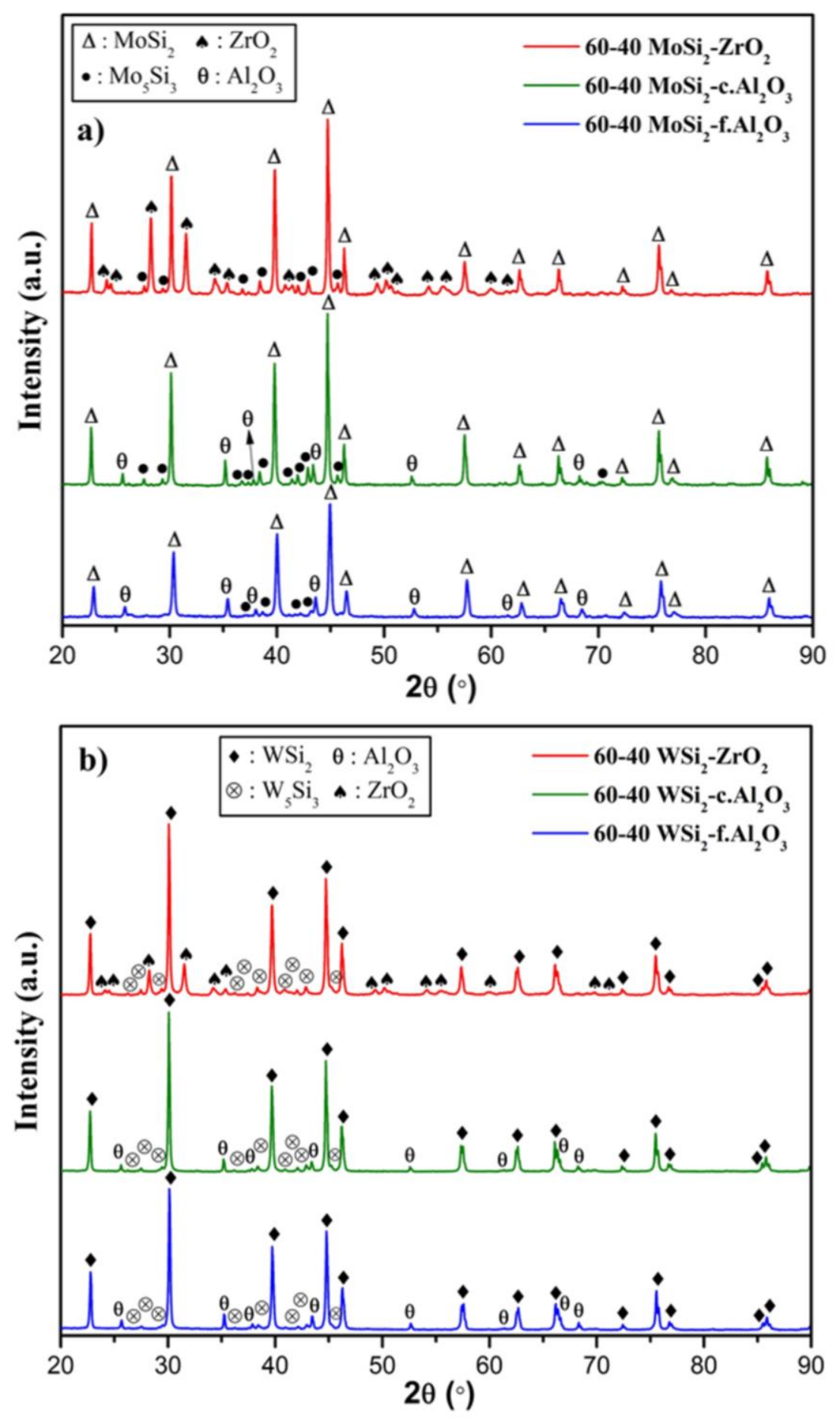

Figure 36. XRD patterns of the (a) 60-40 $\mathrm{MoSi}_{2}$-based composites, and (b) 60-40 $\mathrm{WSi}_{2}$ based composites reinforced by f. $\mathrm{Al}_{2} \mathrm{O}_{3}$, c. $\mathrm{Al}_{2} \mathrm{O}_{3}$ and $\mathrm{ZrO}_{2}$ particles after sintering at $1600^{\circ} \mathrm{C}$ for $2 \mathrm{~h}$. 
existence of the $\mathrm{Mo}_{5} \mathrm{Si}_{3}$ phase in the system may not constitute an issue, since it has a higher melting point $\left(2160^{\circ} \mathrm{C}\right)$, relatively low oxidation resistance and higher creep resistance [8,9]. Figure 36b shows the XRD patterns of the 60-40 $\mathrm{WSi}_{2}-\mathrm{f}_{2} \mathrm{Al}_{2} \mathrm{O}_{3}, \mathrm{WSi}_{2}-$ c. $\mathrm{Al}_{2} \mathrm{O}_{3}$ and $\mathrm{WSi}_{2}-\mathrm{ZrO}_{2}$ composites all sintered at $1600^{\circ} \mathrm{C}$. Similar results can be clearly seen for these composites as well. It is determined that only $\mathrm{W}_{5} \mathrm{Si}_{3}$ secondary phase formed in all three composites after sintering, since $\mathrm{WSi}_{2}$ also has a high-temperature oxidation process similar to $\mathrm{MoSi}_{2}$ [11]. This formation was explained differently by the decomposition of $\mathrm{WSi}_{2}$ into $\mathrm{W}_{5} \mathrm{Si}_{3}$ and $\mathrm{Si}$ during hot isostatic pressing at $1500^{\circ} \mathrm{C}$ and 196 $\mathrm{MPa}[22,48]$. But it is important to note that the oxidation rate of $\mathrm{W}_{5} \mathrm{Si}_{3}$ at high temperature $\left(1500^{\circ} \mathrm{C}\right)$ is high, particularly compared to the $\mathrm{WSi}_{2}$, as well as $\mathrm{MoSi}_{2}$ and $\mathrm{Mo}_{5} \mathrm{Si}_{3}$; therefore, the low fraction of $\mathrm{W}_{5} \mathrm{Si}_{3}$ should be preferred as a secondary phase in these composites [8]. As a review of the XRD results, it can be concluded that both $\mathrm{MoSi}_{2}$ and $\mathrm{WSi}_{2}$ are found to be chemically stable within $\mathrm{Al}_{2} \mathrm{O}_{3}$ and $\mathrm{ZrO}_{2}$ oxide ceramics at $1600^{\circ} \mathrm{C}$, proving the high stability of these composites at high temperatures only with formation of 5-3 silicides.

For mixtures of the conductive and insulating materials like the $\mathrm{MoSi}_{2}-\mathrm{Al}_{2} \mathrm{O}_{3}$ composite system, it is well known that the homogeneous distribution of conductive particles within an insulating material is essential when seeking to achieve consistent electrical properties and an electrical network near the critical percolation threshold $[15,17,49]$. Therefore, SEM microstructural analyses were performed after sintering of the composites at $1600^{\circ} \mathrm{C}$. Figure 37 presents the backscattered SEM microstructures of all 60$40 \mathrm{MoSi}_{2}$ - and $\mathrm{WSi}_{2}$-based composites reinforced by f. $\mathrm{Al}_{2} \mathrm{O}_{3}$, c. $\mathrm{Al}_{2} \mathrm{O}_{3}$ and $\mathrm{ZrO}_{2}$. The bright and dark regions within all microstructures refer to the metal silicide and refractory oxide particles, respectively. It is demonstrated that $\mathrm{MoSi}_{2}$ and $\mathrm{WSi}_{2}$ particles were distributed very homogeneously within the coarse-alumina and zirconia particles; therefore, a better percolating network was obtained particularly in the $\mathrm{MoSi}_{2}-\mathrm{c} . \mathrm{Al}_{2} \mathrm{O}_{3}, \mathrm{WSi}_{2}-\mathrm{c} \cdot \mathrm{Al}_{2} \mathrm{O}_{3}$ and $\mathrm{WSi}_{2}-\mathrm{ZrO}_{2}$ composites (Figure 37b-e-f). However, agglomerated regions of molybdenum disilicide, tungsten disilicide and fine-alumina grains can be clearly seen in Figure 37(a-d), 

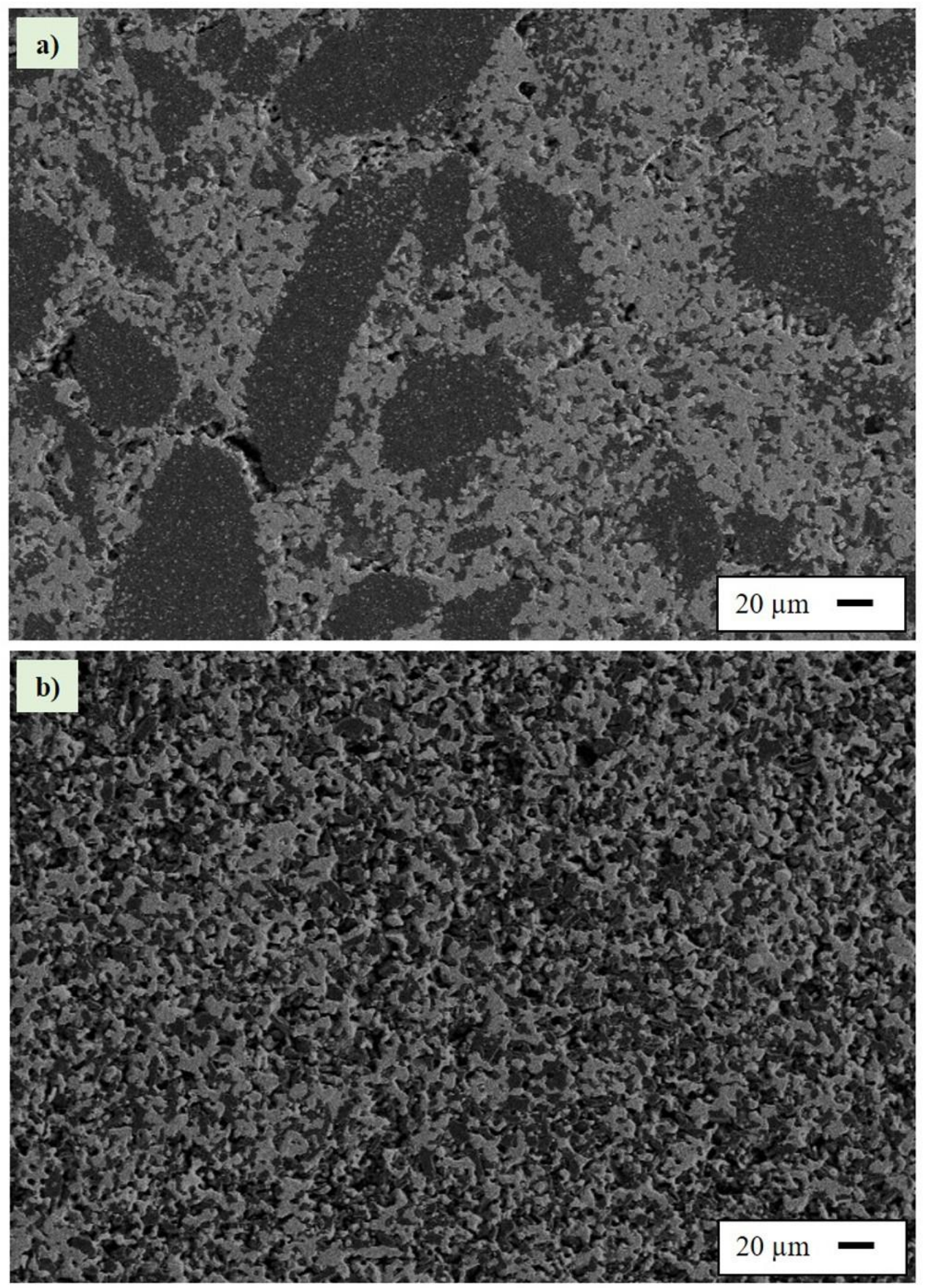

Figure 37. SEM microstructures of the (a) $\mathrm{MoSi}_{2}-\mathrm{f}_{\mathrm{Al}} \mathrm{O}_{3}$, (b) $\mathrm{MoSi}_{2}-\mathrm{c} \cdot \mathrm{Al}_{2} \mathrm{O}_{3}$, (c) $\mathrm{MoSi}_{2}-$ $\mathrm{ZrO}_{2}$, (d) $\mathrm{WSi}_{2}-\mathrm{f} . \mathrm{Al}_{2} \mathrm{O}_{3}$, (e) $\mathrm{WSi}_{2}-\mathrm{c} \cdot \mathrm{Al}_{2} \mathrm{O}_{3}$, and (f) $\mathrm{WSi}_{2}-\mathrm{ZrO}_{2}$ composites all having 6040 metal silicide-refractory oxide fractions after sintering at $1600^{\circ} \mathrm{C}$ for $2 \mathrm{~h}$. 

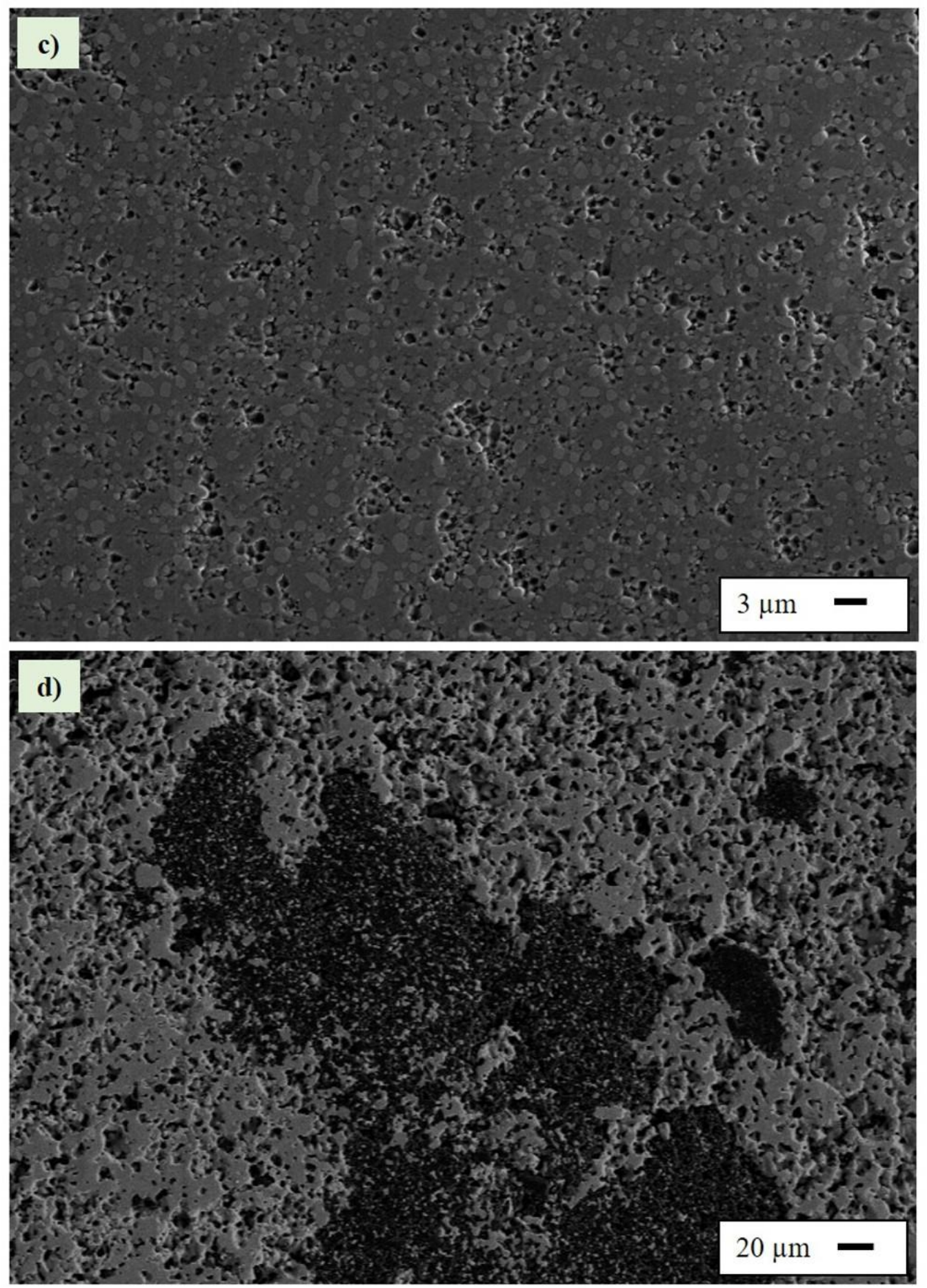

Figure 37. (continued) $\mathrm{SEM}$ microstructures of the (a) $\mathrm{MoSi}_{2}-\mathrm{f} \cdot \mathrm{Al}_{2} \mathrm{O}_{3}$, (b) $\mathrm{MoSi}_{2}-\mathrm{c} \cdot \mathrm{Al}_{2} \mathrm{O}_{3}$, (c) $\mathrm{MoSi}_{2}-\mathrm{ZrO}_{2}$, (d) $\mathrm{WSi}_{2}-\mathrm{f} . \mathrm{Al}_{2} \mathrm{O}_{3}$, (e) $\mathrm{WSi}_{2}-\mathrm{c} . \mathrm{Al}_{2} \mathrm{O}_{3}$, and (f) $\mathrm{WSi}_{2}-\mathrm{ZrO}_{2}$ composites all having 60-40 metal silicide-refractory oxide fractions after sintering at $1600^{\circ} \mathrm{C}$ for $2 \mathrm{~h}$. 

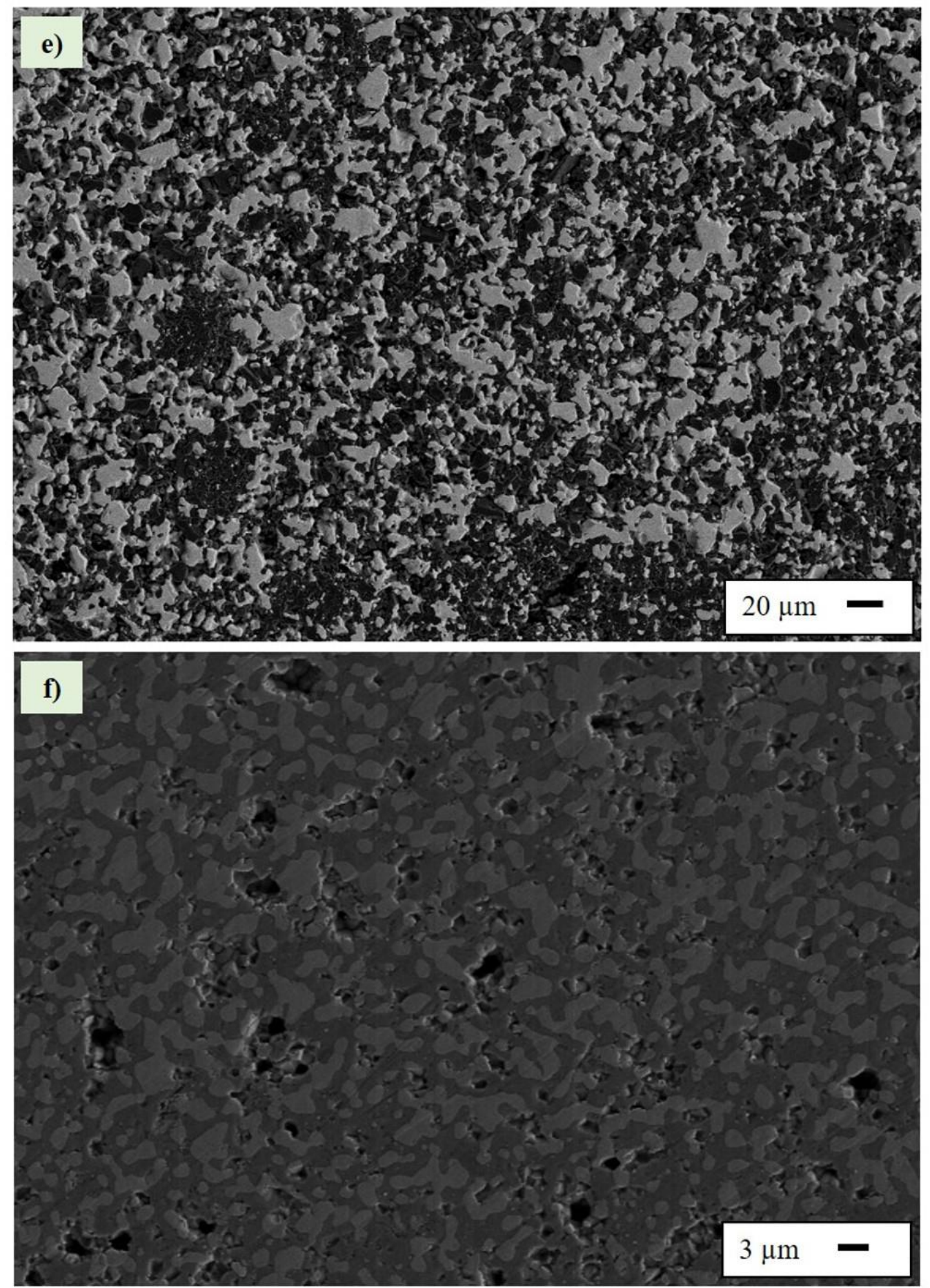

Figure 37. (continued) $\mathrm{SEM}$ microstructures of the (a) $\mathrm{MoSi}_{2}-\mathrm{f} \cdot \mathrm{Al}_{2} \mathrm{O}_{3}$, (b) $\mathrm{MoSi}_{2}-\mathrm{c} \cdot \mathrm{Al}_{2} \mathrm{O}_{3}$, (c) $\mathrm{MoSi}_{2}-\mathrm{ZrO}_{2}$, (d) $\mathrm{WSi}_{2}-\mathrm{f} . \mathrm{Al}_{2} \mathrm{O}_{3}$, (e) $\mathrm{WSi}_{2}-\mathrm{c} . \mathrm{Al}_{2} \mathrm{O}_{3}$, and (f) $\mathrm{WSi}_{2}-\mathrm{ZrO}_{2}$ composites all having 60-40 metal silicide-refractory oxide fractions after sintering at $1600^{\circ} \mathrm{C}$ for $2 \mathrm{~h}$. 
which are highly associated with the initial agglomeration of the fine-alumina particles $(0.4$ $\mu \mathrm{m})$ possessed a higher surface area after ball-milling. In addition, more porous regions were observed in the $\mathrm{MoSi}_{2}$ - and $\mathrm{WSi}_{2}$-based composites reinforced by $\mathrm{c} . \mathrm{Al}_{2} \mathrm{O}_{3}$ and $\mathrm{ZrO}_{2}$ particles (Figure 37b-c-e-f). These results imply that particle distribution in the composite systems is highly influenced by matrix/reinforcement particle size ratio and particle size of reinforcement itself, which could also affect the electrical properties. It is reported that improved distribution, particles with large aspect ratios and also lower size ratio of conductive to insulating particles could provide significant advantage for formation of continuous percolating network and also for lowering the percolation concentration $[15,50,51]$. Therefore, achieving highly homogeneous microstructures is very important to lower the critical percolation concentration and to fabricate metal silicide-refractory oxide composites that are electrically conductive even at low metal silicide contents.

In addition to the SEM studies discussed above, some of the composite samples were chemically etched after sintering in order to increase the contrast between different phases and, by this way, to observe the formation of secondary 5-3 silicide phases on the microstructures. Figure 38(a-b) show the SEM images of the 60-40 $\mathrm{MoSi}_{2}-\mathrm{c}_{2} \mathrm{Al}_{2} \mathrm{O}_{3}$ and $\mathrm{WSi}_{2}-\mathrm{f} . \mathrm{Al}_{2} \mathrm{O}_{3}$ composites that were previously soaked in $\mathrm{HCl}$ and $\mathrm{HCl}: \mathrm{HNO}_{3}: \mathrm{H}_{2} \mathrm{O}$, respectively. The bright, grey and dark regions indicate 5-3 silicides ( $\left.\mathrm{Mo}_{5} \mathrm{Si}_{3}, \mathrm{~W}_{5} \mathrm{Si}_{3}\right)$, metal disilicides $\left(\mathrm{MoSi}_{2}, \mathrm{WSi}_{2}\right)$ and alumina grains, respectively. It was found that secondary 5-3 silicide phases mostly formed around alumina grains. Similar observation was also reported on the $\mathrm{MoSi}_{2}-\mathrm{Al}_{2} \mathrm{O}_{3}$ composite consisting only 5 vol\% alumina by Wang et al. (2014) [12]. Additionally, energy dispersive spectroscopy (EDS) was performed on the SEM microstructure of the 60-40 $\mathrm{WSi}_{2}-\mathrm{f}_{-} \mathrm{Al}_{2} \mathrm{O}_{3}$ composite, which is presented in the Figure 38c. For the grey region (R-grey), only W and Si peaks were obtained except for the gold (Au) peak coming from the sputtered coating made just for SEM analysis. The atomic percentages (at\%) of $\mathrm{W}$ and $\mathrm{Si}$ elements were quantified as 37.3 and 62.7, which implied the $\mathrm{WSi}_{2}$ composition in the grey region. However, 15.4 at\% oxygen $(\mathrm{O})$ was determined in addition to the $\mathrm{W}$ and $\mathrm{Si}$ elements in the bright region (R-bright). The atomic percentage 

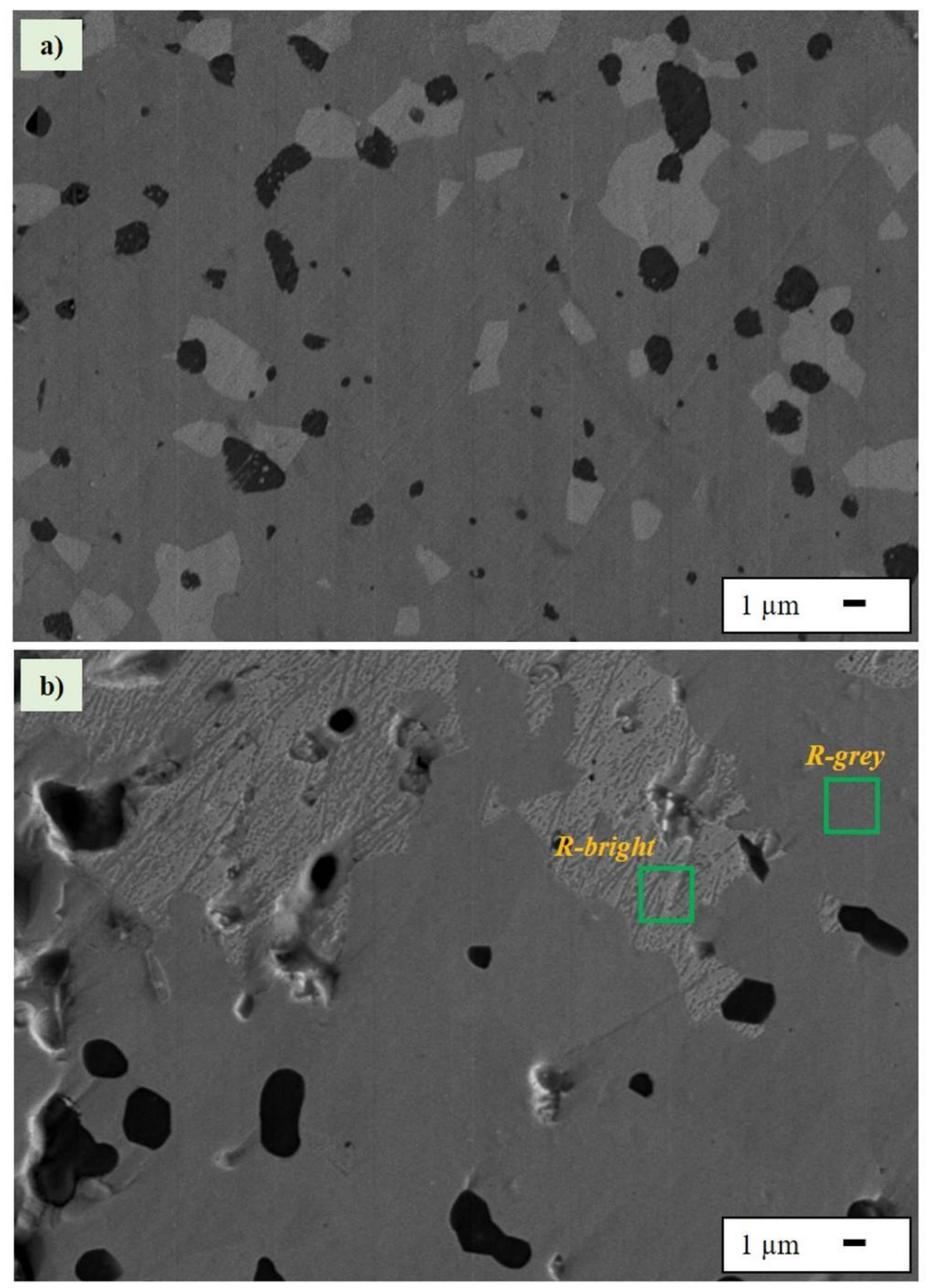

Figure 38. SEM microstructures of the (a) 60-40 $\mathrm{MoSi}_{2}-\mathrm{c} . \mathrm{Al}_{2} \mathrm{O}_{3}$, and (b) 60-40 $\mathrm{WSi}_{2}$ f. $\mathrm{Al}_{2} \mathrm{O}_{3}$ composites after sintering (chemically etched), and (c) EDS analysis results of the grey (R-grey) and bright $\left(R\right.$-bright) regions specified on the 60-40 $\mathrm{WSi}_{2}-\mathrm{f} \mathrm{Al}_{2} \mathrm{O}_{3}$ composite microstructure. 

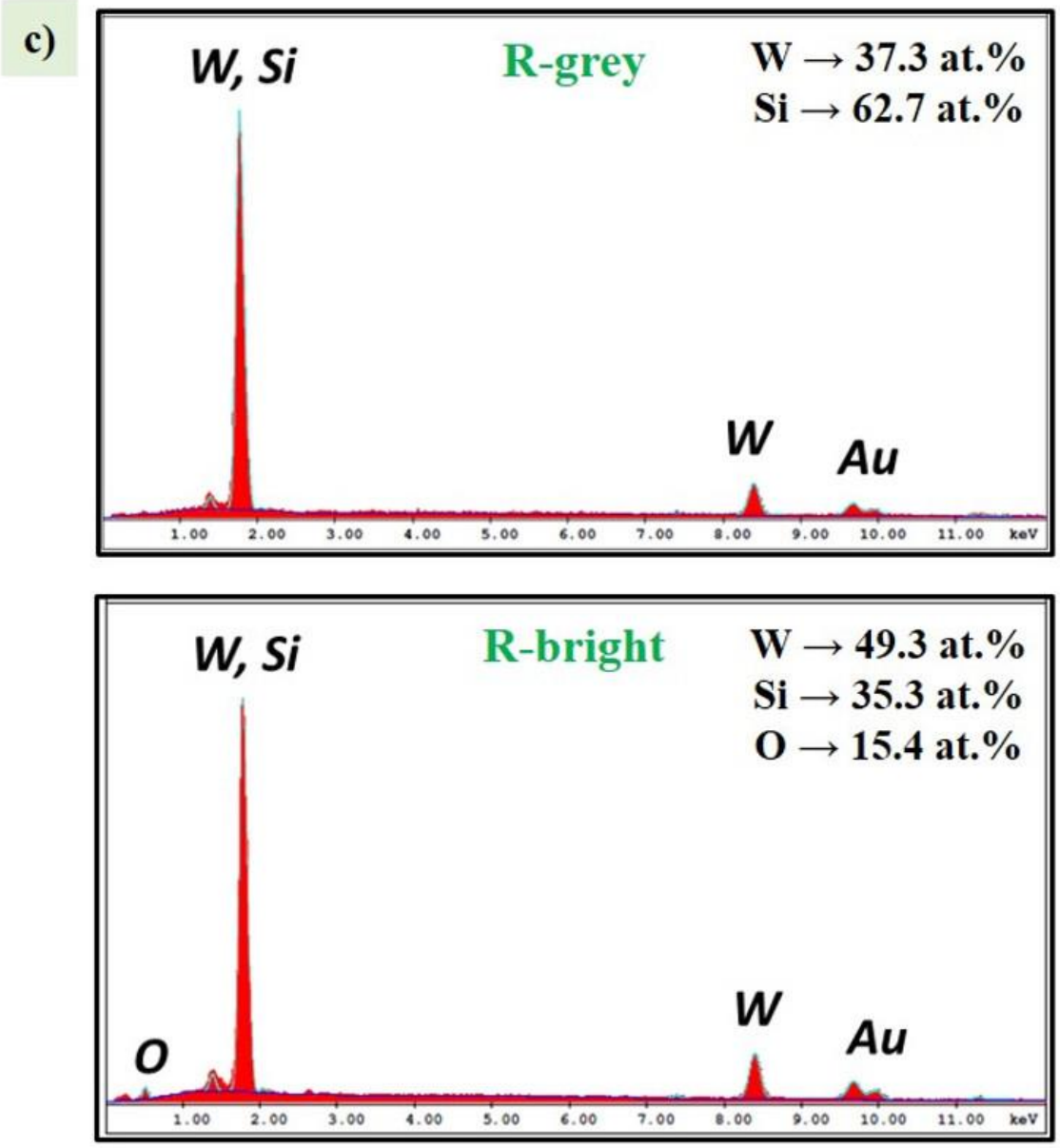

Figure 38. (continued) SEM microstructures of the (a) 60-40 $\mathrm{MoSi}_{2}-\mathrm{c} \cdot \mathrm{Al}_{2} \mathrm{O}_{3}$, and (b) 60$40 \mathrm{WSi}_{2}-\mathrm{f}_{2} \mathrm{Al}_{2} \mathrm{O}_{3}$ composites after sintering (chemically etched), and (c) EDS analysis results of the grey (R-grey) and bright (R-bright) regions specified on the $60-40 \mathrm{WSi}_{2}-$ f. $\mathrm{Al}_{2} \mathrm{O}_{3}$ composite microstructure.

of $\mathrm{W}$ element increased to 49.3 , but $\mathrm{Si}$ decreased to 35.3 at\%, as expected for the secondary 5-3 silicide phase formed. These results clearly established the presence of $\mathrm{W}_{5} \mathrm{Si}_{3}$ with a small amount of glassy $\mathrm{SiO}_{2}$ grain boundary phase in the bright region. But it is important to note that silica phase could not be detected by XRD due to its very low amount on the grain boundaries, since it mostly formed on the surface as a protective layer to further oxidation [8]. Therefore, the formation of the 5-3 secondary phases could also be associated with the reaction of metal disilicides with oxygen that may be residual in the system or may penetrate into the system through silica layer in the existence of 
microcracking, because it is known that $\mathrm{Mo}_{5} \mathrm{Si}_{3}$ and $\mathrm{W}_{5} \mathrm{Si}_{3}$ mostly form in small amounts and beneath the silica layer [46,52,53]. Therefore, such studies reported the difficulty of identifying the presence of these 5-3 metal silicide phases by XRD in most cases.

\subsubsection{Thermal stability and grain growth kinetics at high-temperatures}

Due to the high operating temperatures $\left(1200^{\circ}-1650^{\circ} \mathrm{C}\right)$, harsh environments and long operation hours experienced in many industries, advanced sensing materials like electroconductive ceramic composites need to be thermally stable at high temperatures both for short- and long-term without any compositional decomposition [2,4]. Therefore, the $\mathrm{MoSi}_{2}$ - and $\mathrm{WSi}_{2}$-based composites reinforced by alumina and zirconia particles were further annealed (after sintering) at $1400^{\circ} \mathrm{C}$ for 24 and $48 \mathrm{~h}$ for better understanding their thermal stability at significantly high temperatures. Figure 39 presents the XRD patterns of these six composites (60-40) after sintering at $1600^{\circ} \mathrm{C}$ and annealing at $1400^{\circ} \mathrm{C}$ for $24-48 \mathrm{~h}$. The XRD results of these composites after sintering were used only for a better comparison, and defined with " $0 \mathrm{~h}$ " indicating zero annealing time as a starting point. For all composites, no thermal decomposition was observed after annealing at $1400^{\circ} \mathrm{C}$ up to 48 h. The major phases were metal disilicides $\left.\left(\mathrm{MoSi}_{2}, \mathrm{WSi}\right)_{2}\right)$ and refractory oxides $\left(\mathrm{Al}_{2} \mathrm{O}_{3}\right.$, $\left.\mathrm{ZrO}_{2}\right)$, while the 5-3 silicides $\left(\mathrm{Mo}_{5} \mathrm{Si}_{3}, \mathrm{~W}_{5} \mathrm{Si}_{3}\right)$ still existed in the composite systems as secondary phases. In addition, peak intensities of the $\mathrm{Mo}_{5} \mathrm{Si}_{3}$ and $\mathrm{W}_{5} \mathrm{Si}_{3}$ phases slightly increased in all 60-40 composites as a function of annealing time, but this increase was relatively higher in the $\mathrm{MoSi}_{2}$ - and $\mathrm{WSi}_{2}$-based composites reinforced by coarse-alumina and zirconia, as shown with arrows in the Figure 39(b-c-e-f). This may be related with more interaction between metal disilicide and coarser oxide grains. It is important to point out that no significant changes were observed after $24 \mathrm{~h}$ annealing period. All these results imply that amount of the secondary 5-3 silicide phases may have slightly increased as a function of annealing time, but eventually all these composites exhibited excellent thermal stability at $1400^{\circ} \mathrm{C}$, particularly after $24 \mathrm{~h}$, without undergoing any decomposition. No studies on the high-temperature thermal stability of the metal silicide-refractory oxide bulk composites were found in the literature for a comparison. Only the thermal stability of the 

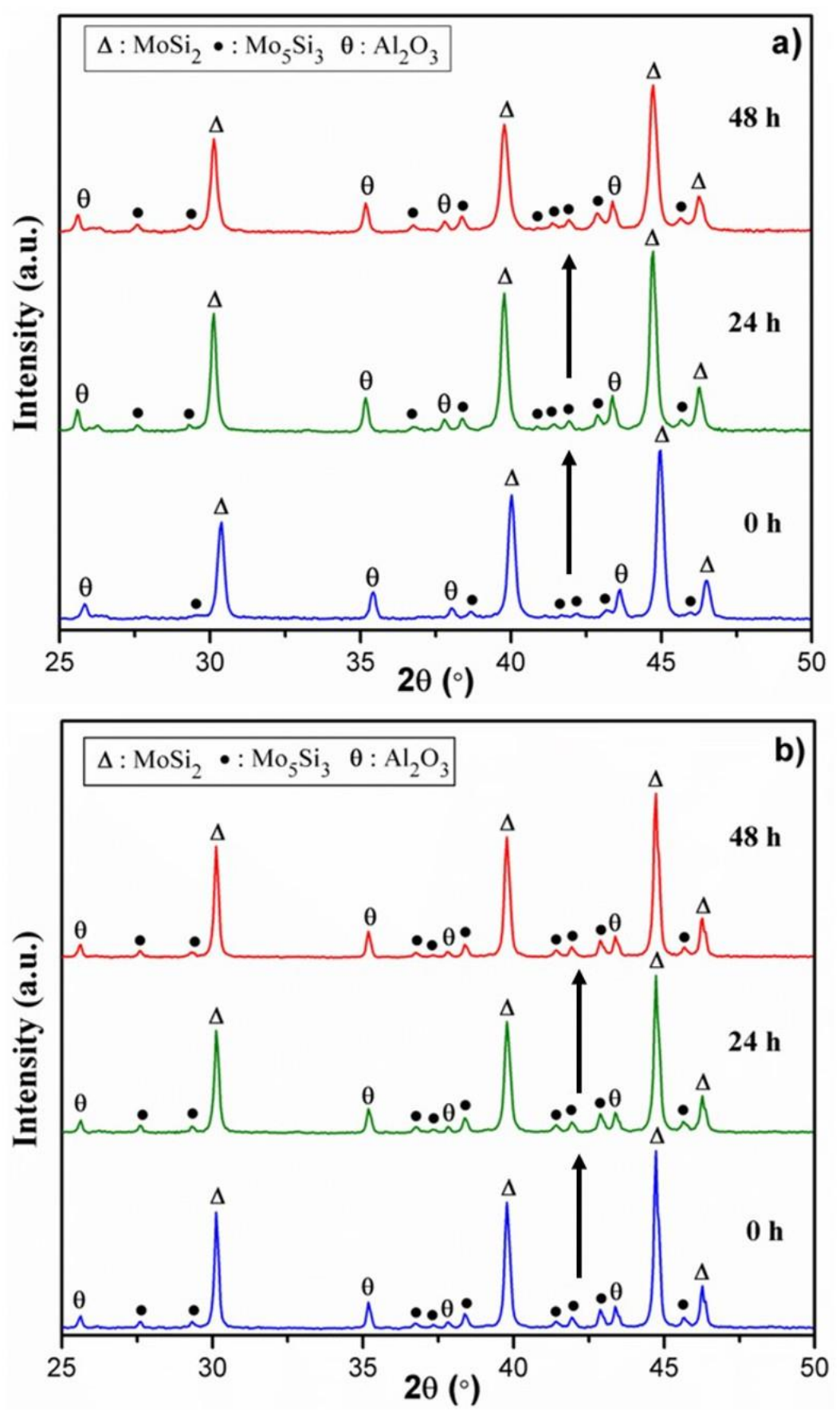

Figure 39. $\mathrm{XRD}$ patterns of the (a) $\mathrm{MoSi}_{2}-\mathrm{f} . \mathrm{Al}_{2} \mathrm{O}_{3}$, (b) $\mathrm{MoSi}_{2}-\mathrm{c} \cdot \mathrm{Al}_{2} \mathrm{O}_{3}$, (c) $\mathrm{MoSi}_{2}-\mathrm{ZrO}_{2}$, (d) $\mathrm{WSi}_{2}-\mathrm{f} . \mathrm{Al}_{2} \mathrm{O}_{3}$, (e) $\mathrm{WSi}_{2}-\mathrm{c} \cdot \mathrm{Al}_{2} \mathrm{O}_{3}$, and (f) $\mathrm{WSi}_{2}-\mathrm{ZrO}_{2}$ composites all having 60-40 metal silicide-refractory oxide fractions after sintering at $1600^{\circ} \mathrm{C}$, and then annealing at $1400^{\circ} \mathrm{C}$ for $24-48 \mathrm{~h}$ (sintered sample was defined as " $0 \mathrm{~h}$ " indicating zero annealing time as a starting point). 

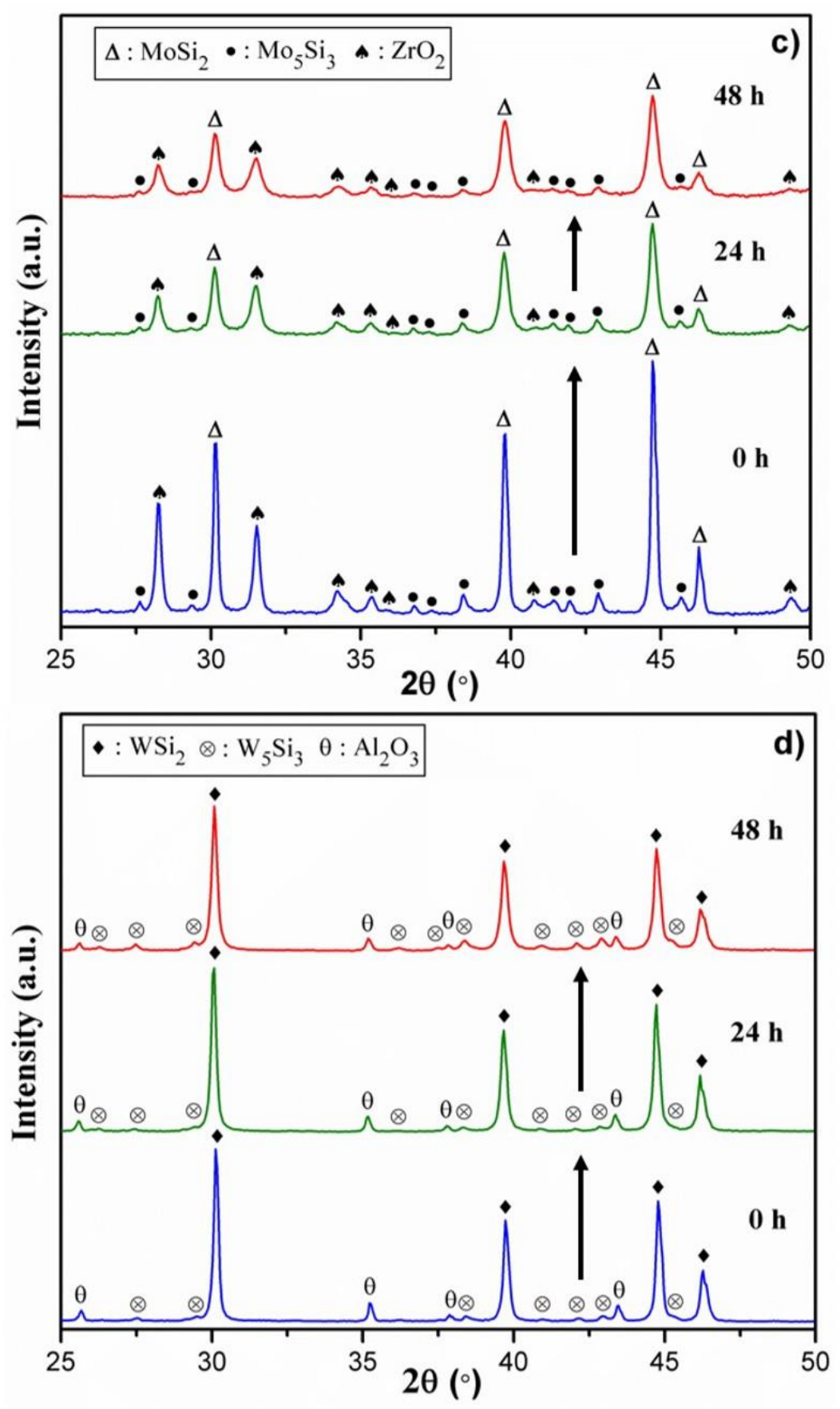

Figure 39. (continued) $\mathrm{XRD}$ patterns of the (a) $\mathrm{MoSi}_{2}-\mathrm{f} . \mathrm{Al}_{2} \mathrm{O}_{3}$, (b) $\mathrm{MoSi}_{2}-\mathrm{c} \cdot \mathrm{Al}_{2} \mathrm{O}_{3}$, (c) $\mathrm{MoSi}_{2}-\mathrm{ZrO}_{2}$, (d) $\mathrm{WSi}_{2}-\mathrm{f} . \mathrm{Al}_{2} \mathrm{O}_{3}$, (e) $\mathrm{WSi}_{2}-\mathrm{c} . \mathrm{Al}_{2} \mathrm{O}_{3}$, and (f) $\mathrm{WSi}_{2}-\mathrm{ZrO}_{2}$ composites all having 60-40 metal silicide-refractory oxide fractions after sintering at $1600^{\circ} \mathrm{C}$, and then annealing at $1400^{\circ} \mathrm{C}$ for $24-48 \mathrm{~h}$ (sintered sample was defined as " $0 \mathrm{~h}$ " indicating zero annealing time as a starting point). 

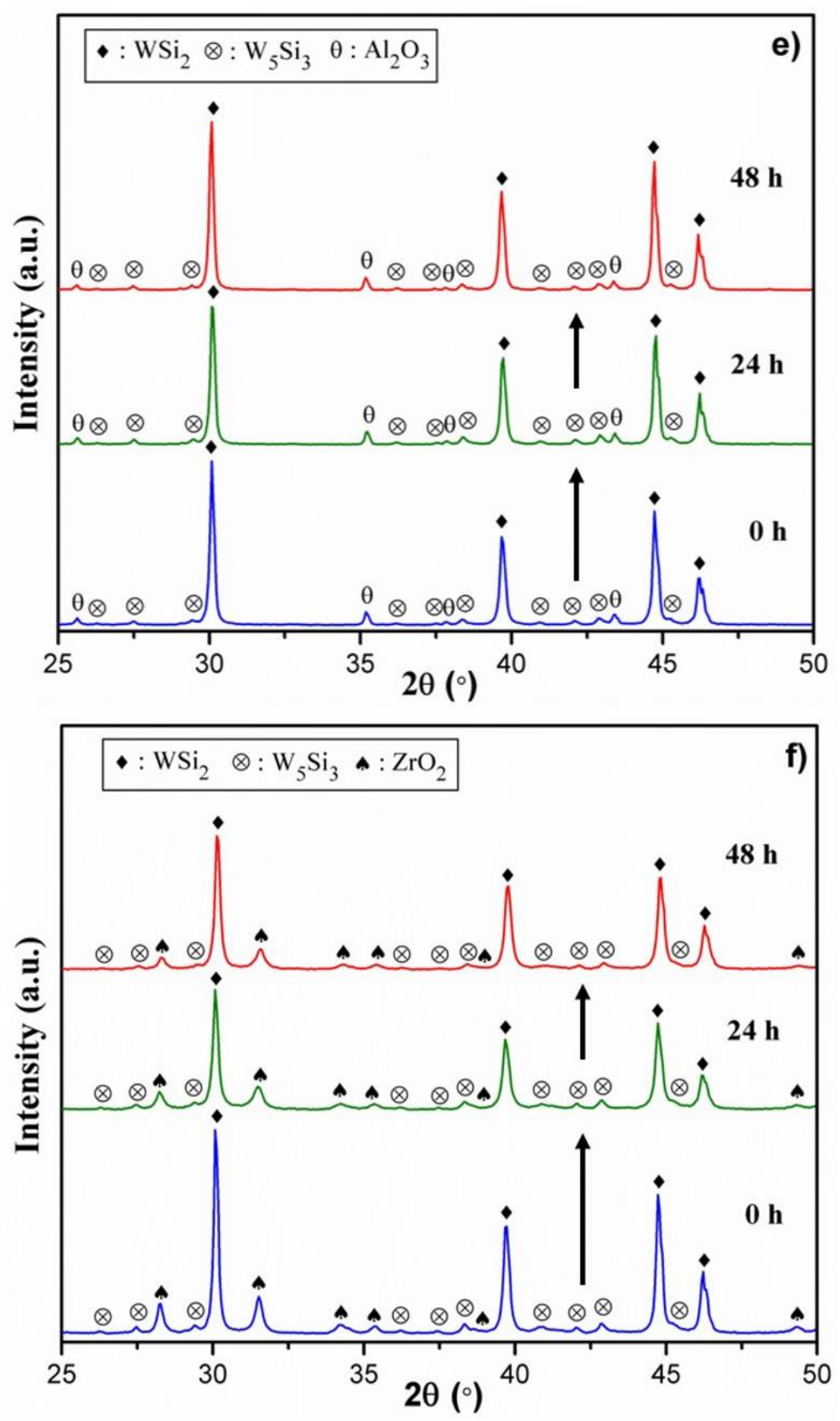

Figure 39. (continued) $\mathrm{XRD}$ patterns of the (a) $\mathrm{MoSi}_{2}-\mathrm{f} \cdot \mathrm{Al}_{2} \mathrm{O}_{3}$, (b) $\mathrm{MoSi}_{2}-\mathrm{c} \cdot \mathrm{Al}_{2} \mathrm{O}_{3}$, (c) $\mathrm{MoSi}_{2}-\mathrm{ZrO}_{2}$, (d) $\mathrm{WSi}_{2}-\mathrm{f} . \mathrm{Al}_{2} \mathrm{O}_{3}$, (e) $\mathrm{WSi}_{2}-\mathrm{c} . \mathrm{Al}_{2} \mathrm{O}_{3}$, and (f) $\mathrm{WSi}_{2}-\mathrm{ZrO}_{2}$ composites all having 60-40 metal silicide-refractory oxide fractions after sintering at $1600^{\circ} \mathrm{C}$, and then annealing at $1400^{\circ} \mathrm{C}$ for $24-48 \mathrm{~h}$ (sintered sample was defined as " $\mathrm{h}$ " indicating zero annealing time as a starting point). 
mechanically alloyed and then milled $\mathrm{MoSi}_{2}-\mathrm{Al}_{2} \mathrm{O}_{3}$ powders was studied by annealing at $1000^{\circ} \mathrm{C}$ for $1 \mathrm{~h}$ under argon atmosphere [45]. They also reported the formation of the $\mathrm{Mo}_{5} \mathrm{Si}_{3}$ phase with annealing caused by residual molybdenum and silicon elements, but it should be noted that this was a very short-term thermal stability study of only powder.

The quantitative phase analysis studies were also performed by utilizing the Rietveld method on the XRD patterns to determine the volume fractions of the secondary phases compared to all other phases in the composite systems. According to the Rietveld analysis, it is known that the goodness of fit (sig) and weighted profile R-factor (Rwp) values representing the quality of refinement should be less than 2.0 and 0.15 , respectively [34]. In all composites except for the $60-40 \mathrm{WSi}_{2}-\mathrm{ZrO}_{2}$, the sig values ranged from 1.3 to 1.9, while the Rwp values ranged from 0.05 to 0.09 . For the $60-40 \mathrm{WSi}_{2}-\mathrm{ZrO}_{2}$, the Rwp values were all less than 0.1 , but the sig values were between 2.2 and 2.5. In addition, these factors could not be lowered to the recommended values only for the $60-40 \mathrm{WSi}_{2}-\mathrm{f}_{2} \mathrm{Al}_{2} \mathrm{O}_{3}$ composite sample annealed for $24 \mathrm{~h}$ due to the noisy background and several peak shifts on its XRD pattern. However, it is important to note that the quality of the Rietveld refinement was highly sufficient in all cases. Figure 40(a-b) show changes in the amount (vol\%) of $\mathrm{Mo}_{5} \mathrm{Si}_{3}$ and $\mathrm{W}_{5} \mathrm{Si}_{3}$ secondary phases as a function of annealing time, respectively. It is clear that the amount of both 5-3 metal silicide phases increased in all composite systems with increasing annealing time up to $48 \mathrm{~h}$, but at different levels. The amount of $\mathrm{Mo}_{5} \mathrm{Si}_{3}$ in the 60-40 $\mathrm{MoSi}_{2}-\mathrm{f} . \mathrm{Al}_{2} \mathrm{O}_{3}$ composite slightly increased from 0.3 to 3.3 vol\% with annealing

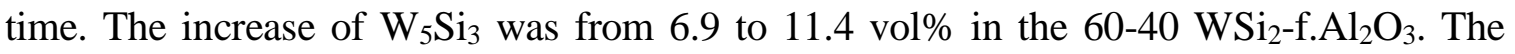
amount of $\mathrm{Mo}_{5} \mathrm{Si}_{3}$ and $\mathrm{W}_{5} \mathrm{Si}_{3}$ increased from 5.3 to 7.2 , and from 21.8 to $38.8 \mathrm{vol} \%$ in the 60-40 $\mathrm{MoSi}_{2}-\mathrm{c} . \mathrm{Al}_{2} \mathrm{O}_{3}$ and $\mathrm{WSi}_{2}-\mathrm{c} . \mathrm{Al}_{2} \mathrm{O}_{3}$ composites, respectively. As a review, it can be concluded that the amount of the secondary $\mathrm{W}_{5} \mathrm{Si}_{3}$ phase (11.4-38.8 vol\%) was significantly higher than that of the $\mathrm{Mo}_{5} \mathrm{Si}_{3}$ (3.3-7.3 vol\%) in the composites after annealing at $1400^{\circ} \mathrm{C}$ for $48 \mathrm{~h}$. The secondary 5-3 metal silicide phase formation was found to be significantly lower in the $\mathrm{MoSi}_{2}-\mathrm{f}_{-} \mathrm{Al}_{2} \mathrm{O}_{3}$ and $\mathrm{WSi}_{2}-\mathrm{f}_{\text {. }} \mathrm{Al}_{2} \mathrm{O}_{3}$ composites compared to the ones reinforced by coarse-alumina and zirconia particles as clearly seen in Figure 40. 

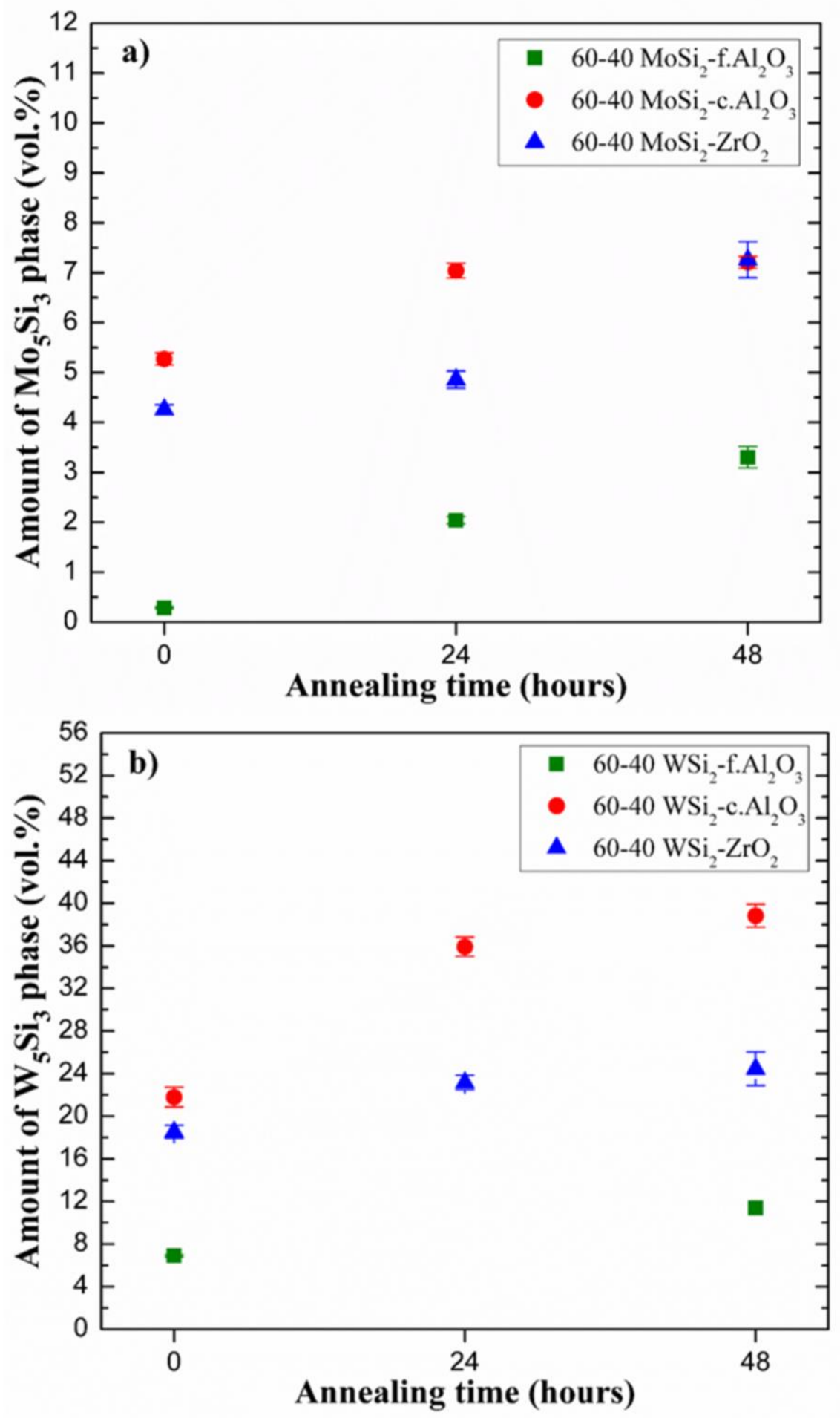

Figure 40. Changes in the amount (vol\%) of (a) $\mathrm{Mo}_{5} \mathrm{Si}_{3}$, and (b) $\mathrm{W}_{5} \mathrm{Si}_{3}$ secondary phases as a function of annealing time. 
Table 7. The rates of the formation of secondary 5-3 metal silicide phases ( $\mathrm{Mo}_{5} \mathrm{Si}_{3}$, $\left.\mathrm{W}_{5} \mathrm{Si}_{3}\right)$ in the 60-40 composites over two annealing periods.

\begin{tabular}{|c|c|c|}
\hline Composite & $\begin{array}{c}\text { From } 0 \text { to } 24 \text { hours } \\
\text { annealing period } \\
(\text { vol\%/h) }\end{array}$ & $\begin{array}{c}\text { From } 24 \text { to } 48 \text { hours } \\
\text { annealing period } \\
(\text { vol } \% / h)\end{array}$ \\
\hline $\mathrm{MoSi}_{2}-\mathbf{f} \cdot \mathrm{Al}_{2} \mathrm{O}_{3}$ & 0.073 & 0.053 (decreased) \\
\hline $\mathrm{MoSi}_{2}-\mathbf{c} \cdot \mathrm{Al}_{2} \mathbf{O}_{3}$ & 0.074 & 0.007 (decreased) \\
\hline $\mathrm{MoSi}_{2}-\mathrm{ZrO}_{2}$ & 0.025 & 0.100 (increased) \\
\hline $\mathrm{WSi}_{2}-\mathbf{c} \cdot \mathrm{Al}_{2} \mathrm{O}_{3}$ & 0.589 & 0.121 (decreased) \\
\hline $\mathrm{WSi}_{2}-\mathrm{ZrO}_{2}$ & 0.193 & 0.054 (decreased) \\
\hline
\end{tabular}

In correlation with the XRD data, these results indicate that the interaction between metal disilicide and coarse-grained particles was higher, and also fine-alumina grains potentially restricted oxygen diffusion into the material from residual environmental sources. Since the relative densities of the 60-40 $\mathrm{MoSi}_{2}-\mathrm{c} . \mathrm{Al}_{2} \mathrm{O}_{3}$ and $\mathrm{WSi}_{2}-\mathrm{c} . \mathrm{Al}_{2} \mathrm{O}_{3}(77.7-79.8 \%)$ were lower than that of the other composites, the related high-temperature oxidation reactions were more favored, resulting in the formation of $\mathrm{Mo}_{5} \mathrm{Si}_{3}$ and $\mathrm{W}_{5} \mathrm{Si}_{3}$ secondary phases with higher levels below the surface oxide layer $[10,46,54]$. This result demonstrates that secondary phase formation was also affected by density of the composites and degree of porosity. Additionally, the phase transformation kinetics were measured by assuming a linear transformation process, since the formation reaction of secondary 5-3 silicide phases is not only limited to the surface interaction (interface-controlled), but also controlled by thermodynamically feasible oxidation reactions of metal disilicides at high temperatures. Therefore, the increase in the volume fraction of the 5-3 silicide phase was divided by the annealing time for these calculations. By this way, it was determined that rates of the formation of secondary phases (vol\% per hour) highly decreased in all composites except for the $\mathrm{MoSi}_{2}-\mathrm{ZrO}_{2}$ after annealing for $24 \mathrm{~h}$, as presented in the Table 7, indicating their improved thermal stability over time. However, it is important to point out that high 
fractions of secondary $\mathrm{W}_{5} \mathrm{Si}_{3}$ phase up to $38.8 \mathrm{vol} \%$ may cause serious issues in real applications under air atmosphere due to its low oxidation resistance [8,11]. Therefore, $\mathrm{MoSi}_{2}$-based composites are found to be more thermally stable with the formation of low fractions of $\mathrm{Mo}_{5} \mathrm{Si}_{3}$ having reasonable high-temperature oxidation resistance, and hence, to be more suitable for advanced sensing applications at high-temperature and harshenvironments.

In addition to the high thermal stability, low grain growth rates are essential for such ceramic composite systems; since mechanical and electrical properties are highly influenced by grain size $[55,56]$. Therefore, it is crucial to keep the growth rates of metal disilicide grains lower for maintaining the stability and performance of the composites at high temperatures for longer terms. In order to understand the effect of refractory oxide reinforcement on growth rates of the metal silicide grains, the $\mathrm{MoSi}_{2}$ and $60-40 \mathrm{MoSi}_{2}-$ f. $\mathrm{Al}_{2} \mathrm{O}_{3}$ samples were initially characterized by SEM. Figure 41 presents the SEM microstructures of the $\mathrm{MoSi}_{2}$ and 60-40 $\mathrm{MoSi}_{2}-\mathrm{f}_{2} \mathrm{Al}_{2} \mathrm{O}_{3}$ samples after sintering and annealing at the same conditions. The grey and bright regions indicate $\mathrm{MoSi}_{2}$ and $\mathrm{Mo}_{5} \mathrm{Si}_{3}$ grains, respectively. For the $\mathrm{MoSi}_{2}$ sample, the average size of the $\mathrm{MoSi}_{2}$ grains was measured after sintering as $8.3 \mu \mathrm{m}$ (Figure 41a), which then increased to 11.8 and $12.7 \mu \mathrm{m}$ with increasing annealing time (Figure 41b-c). Although the individual $\mathrm{MoSi}_{2}$ grains could not be observed for the $60-40 \mathrm{MoSi}_{2}-\mathrm{f} . \mathrm{Al}_{2} \mathrm{O}_{3}$ after sintering (Figure 37a), average sizes of the $\mathrm{MoSi}_{2}$ grains within this composite were measured as 4.6 and $5.2 \mu \mathrm{m}$ after annealing at $1400^{\circ} \mathrm{C}$ for 24 and $48 \mathrm{~h}$, respectively (Figure $41 \mathrm{~d}-\mathrm{e}-\mathrm{f}$ ). Therefore, it is found that growth rate of $\mathrm{MoSi}_{2}$ grains in the $\mathrm{MoSi}_{2}-\mathrm{f} . \mathrm{Al}_{2} \mathrm{O}_{3}$ composite $(\sim 0.021 \mu \mathrm{m} / \mathrm{h})$ was significantly lower than that in the $\mathrm{MoSi}_{2}$ sample $(\sim 0.092 \mu \mathrm{m} / \mathrm{h})$. It is important to note that the grain growth rates were calculated by assuming a linear relation, and thus, by dividing the change in silicide grain size to the total annealing time. The reason of this simplification of the growth process was due to the difficulty of fitting the obtained grain growth data to simple grain growth power laws due to the limited data, and the existence of three grain boundary phases (refractory oxide, 5-3 metal silicide, silica) that potentially have a significant role on 

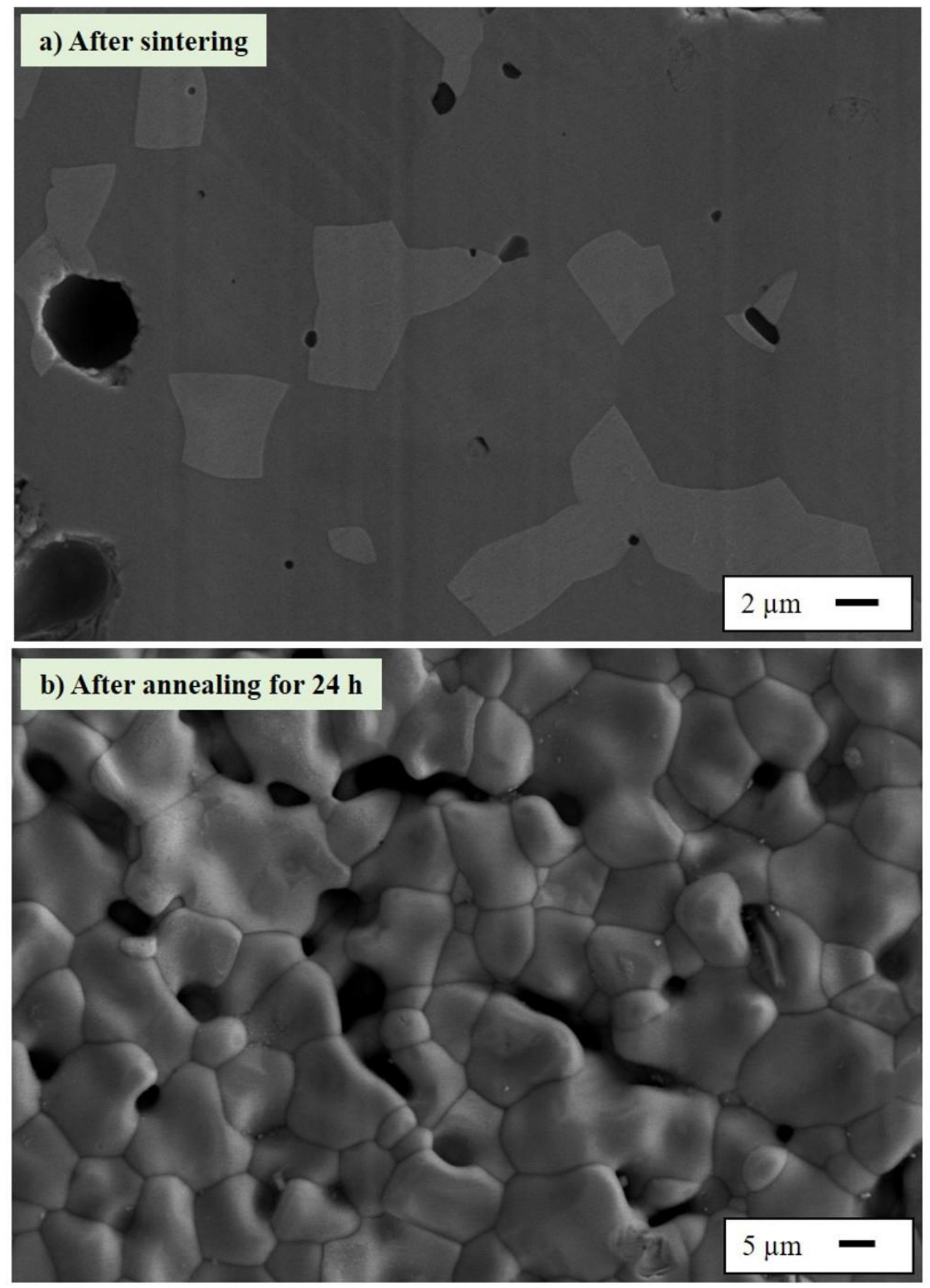

Figure 41. SEM microstructures of the (a-b-c) $\mathrm{MoSi}_{2}$, and (d-e-f) 60-40 $\mathrm{MoSi}_{2}-\mathrm{f} . \mathrm{Al}_{2} \mathrm{O}_{3}$ composite after sintering at $1600^{\circ} \mathrm{C}$, and then annealing at $1400^{\circ} \mathrm{C}$ for $24-48 \mathrm{~h}$. 

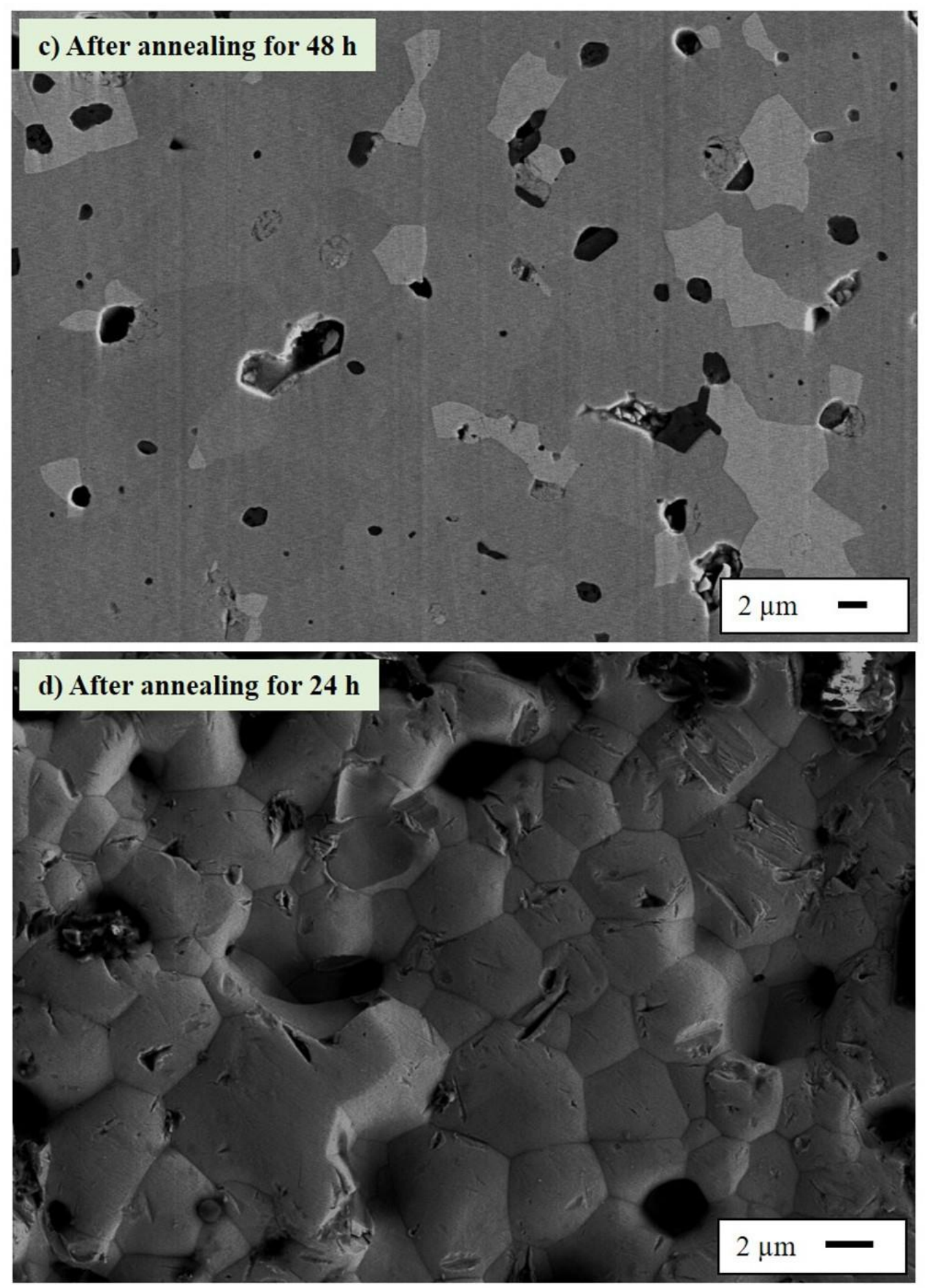

Figure 41. (continued) SEM microstructures of the (a-b-c) $\mathrm{MoSi}_{2}$, and (d-e-f) 60-40 $\mathrm{MoSi}_{2}-\mathrm{f} . \mathrm{Al}_{2} \mathrm{O}_{3}$ composite after sintering at $1600^{\circ} \mathrm{C}$, and then annealing at $1400^{\circ} \mathrm{C}$ for $24-48$ h. 

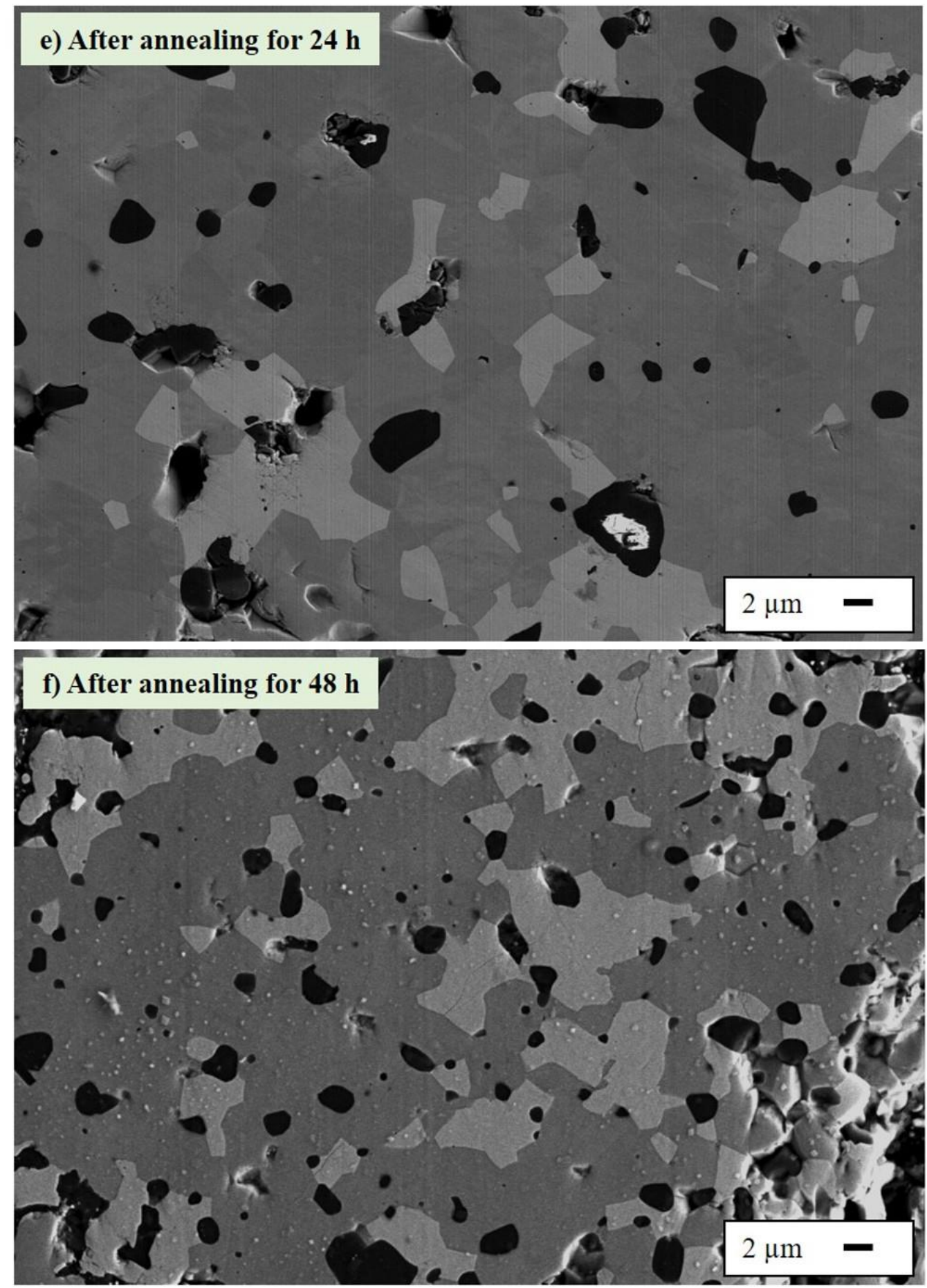

Figure 41. (continued) $\mathrm{SEM}$ microstructures of the (a-b-c) $\mathrm{MoSi}_{2}$, and (d-e-f) 60-40 $\mathrm{MoSi}_{2}-\mathrm{f} . \mathrm{Al}_{2} \mathrm{O}_{3}$ composite after sintering at $1600^{\circ} \mathrm{C}$, and then annealing at $1400^{\circ} \mathrm{C}$ for $24-48$ h. 

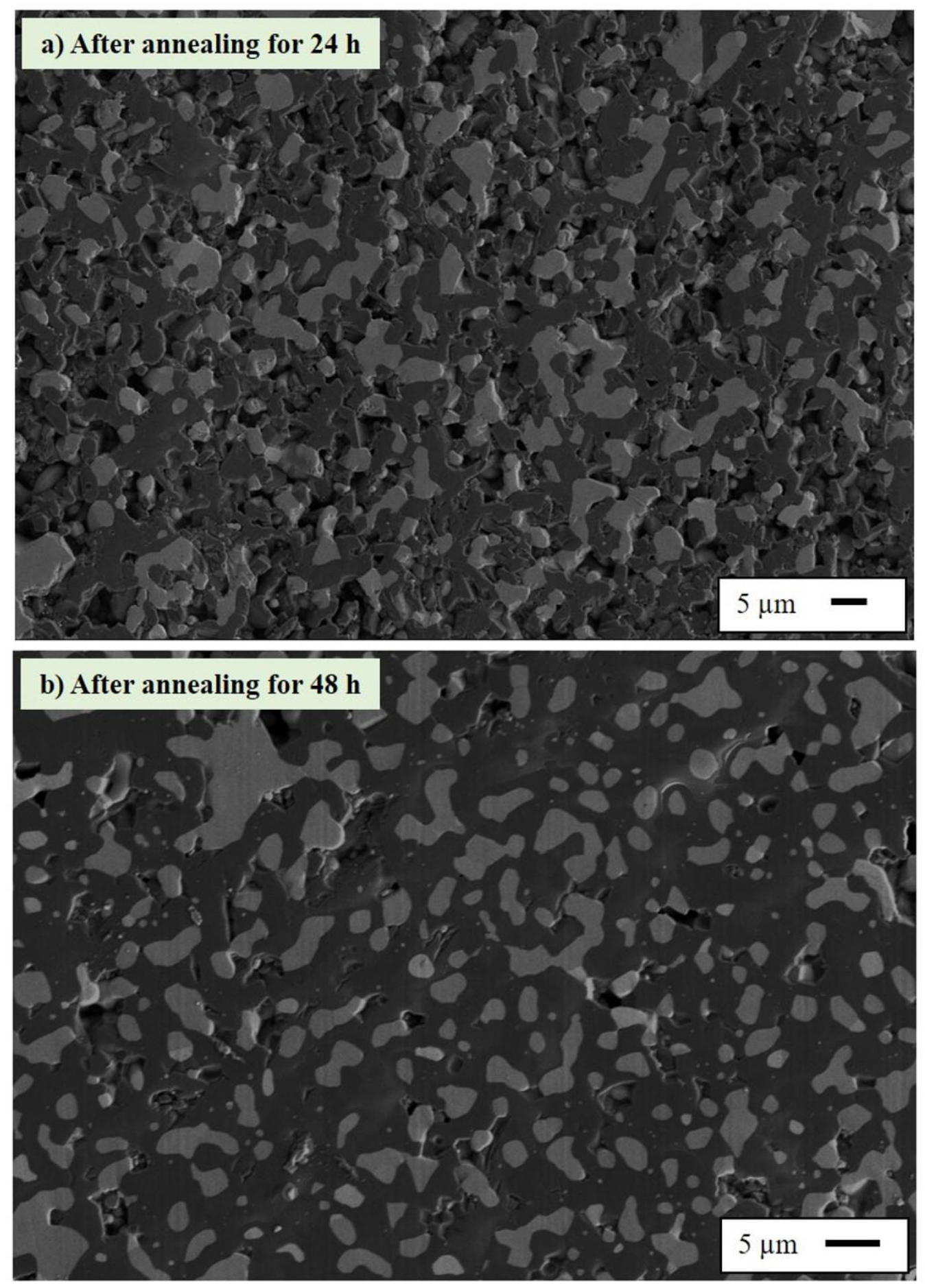

Figure 42. SEM microstructures of the (a-b) 60-40 $\mathrm{MoSi}_{2}-\mathrm{c} \cdot \mathrm{Al}_{2} \mathrm{O}_{3}$, (c-d) 60-40 $\mathrm{MoSi}_{2}$ $\mathrm{ZrO}_{2}$, (e-f) 60-40 WSi 2 -f. $\mathrm{Al}_{2} \mathrm{O}_{3}$, (g-h) 60-40 WSi 2 -c. $\mathrm{Al}_{2} \mathrm{O}_{3}$, and (i-j) 60-40 $\mathrm{WSi}_{2}-\mathrm{ZrO}_{2}$ composites after annealing at $1400^{\circ} \mathrm{C}$ for $24-48 \mathrm{~h}$. 

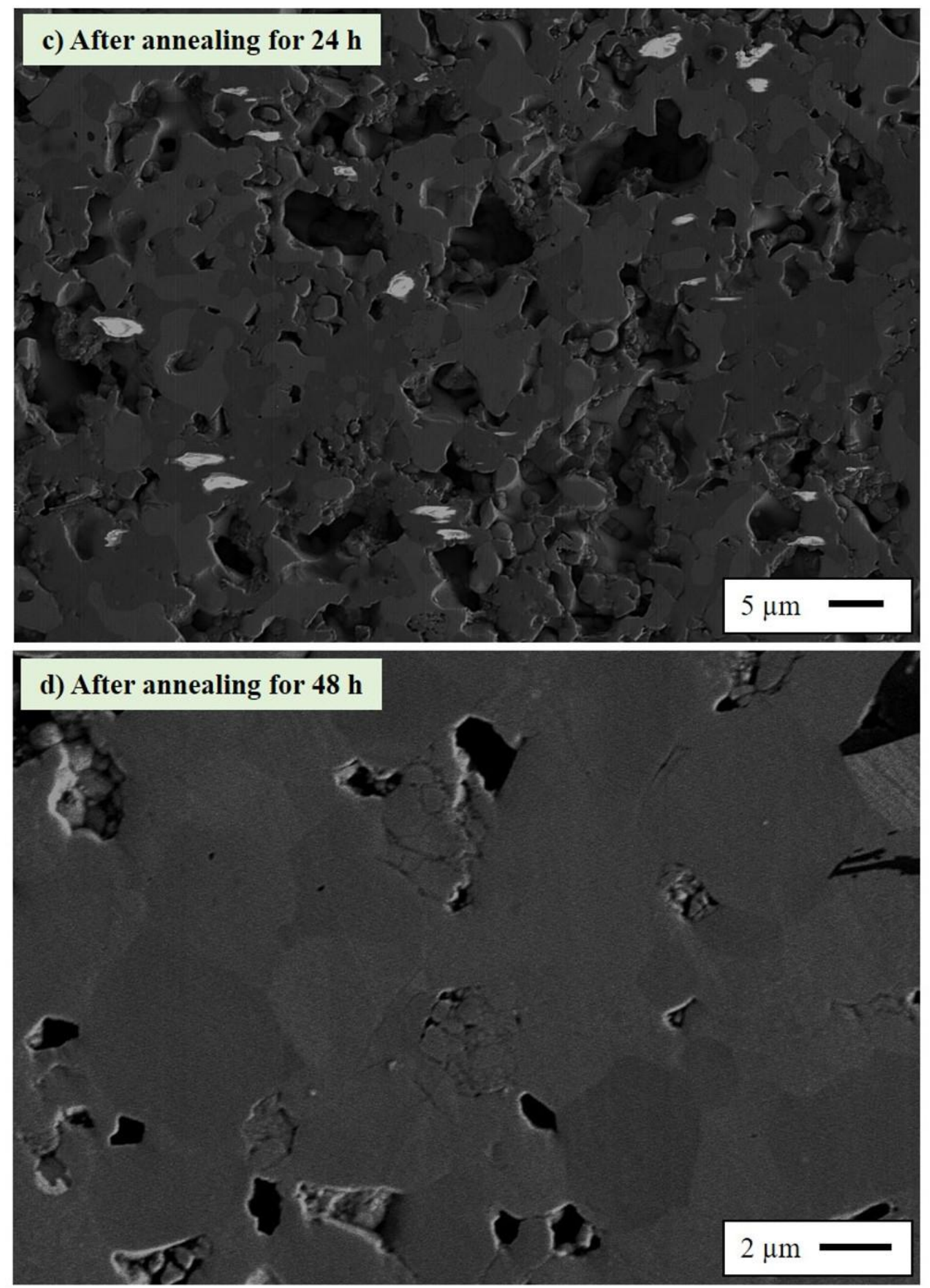

Figure 42. (continued) SEM microstructures of the (a-b) 60-40 $\mathrm{MoSi}_{2}-\mathrm{c} . \mathrm{Al}_{2} \mathrm{O}_{3}$, (c-d) 60$40 \mathrm{MoSi}_{2}-\mathrm{ZrO}_{2}$, (e-f) 60-40 WSi 2 -f. $\mathrm{Al}_{2} \mathrm{O}_{3}$, (g-h) 60-40 WSi 2 -c. $\mathrm{Al}_{2} \mathrm{O}_{3}$, and (i-j) 60-40 $\mathrm{WSi}_{2}-$ $\mathrm{ZrO}_{2}$ composites after annealing at $1400^{\circ} \mathrm{C}$ for $24-48 \mathrm{~h}$. 

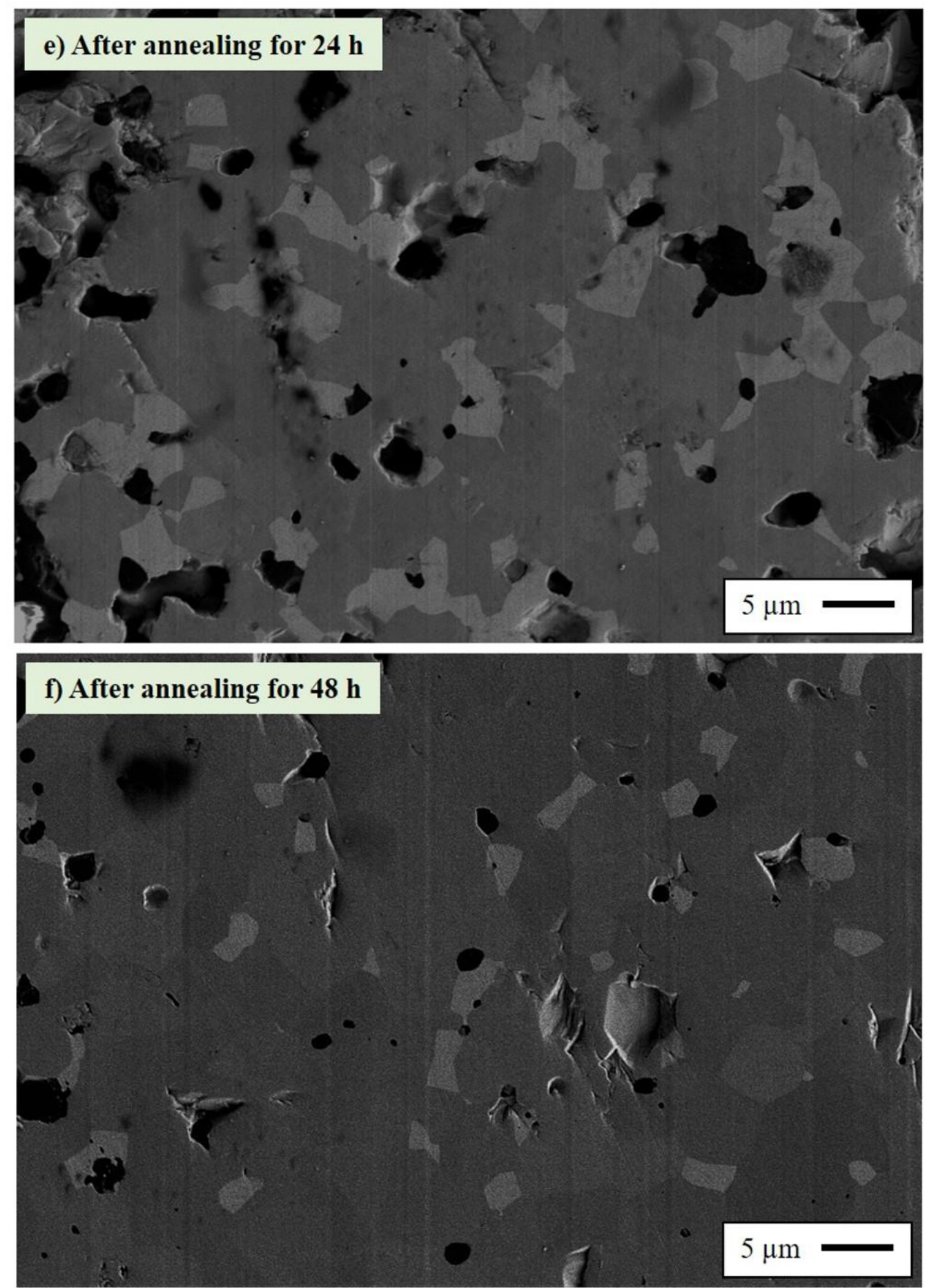

Figure 42. (continued) SEM microstructures of the (a-b) 60-40 $\mathrm{MoSi}_{2}-\mathrm{c} . \mathrm{Al}_{2} \mathrm{O}_{3}$, (c-d) 60$40 \mathrm{MoSi}_{2}-\mathrm{ZrO}_{2}$, (e-f) 60-40 WSi 2 -f. $\mathrm{Al}_{2} \mathrm{O}_{3}$, (g-h) 60-40 WSi 2 -c. $\mathrm{Al}_{2} \mathrm{O}_{3}$, and (i-j) 60-40 $\mathrm{WSi}_{2}-$ $\mathrm{ZrO}_{2}$ composites after annealing at $1400^{\circ} \mathrm{C}$ for $24-48 \mathrm{~h}$. 

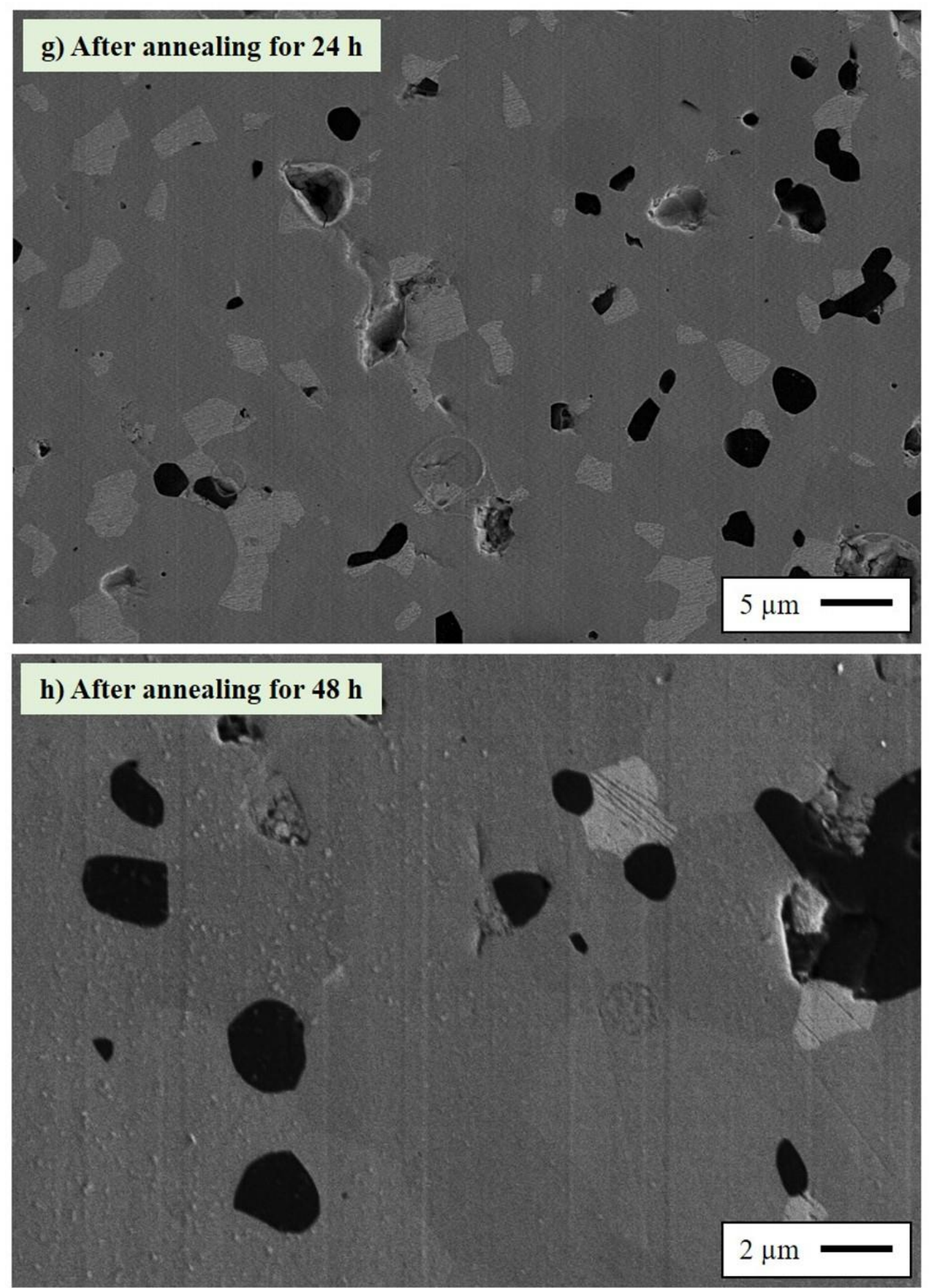

Figure 42. (continued) SEM microstructures of the (a-b) 60-40 $\mathrm{MoSi}_{2}-\mathrm{c} . \mathrm{Al}_{2} \mathrm{O}_{3}$, (c-d) 60$40 \mathrm{MoSi}_{2}-\mathrm{ZrO}_{2}$, (e-f) 60-40 WSi 2 -f. $\mathrm{Al}_{2} \mathrm{O}_{3}$, (g-h) 60-40 WSi 2 -c. $\mathrm{Al}_{2} \mathrm{O}_{3}$, and (i-j) 60-40 WSi ${ }_{2}-$ $\mathrm{ZrO}_{2}$ composites after annealing at $1400^{\circ} \mathrm{C}$ for $24-48 \mathrm{~h}$. 

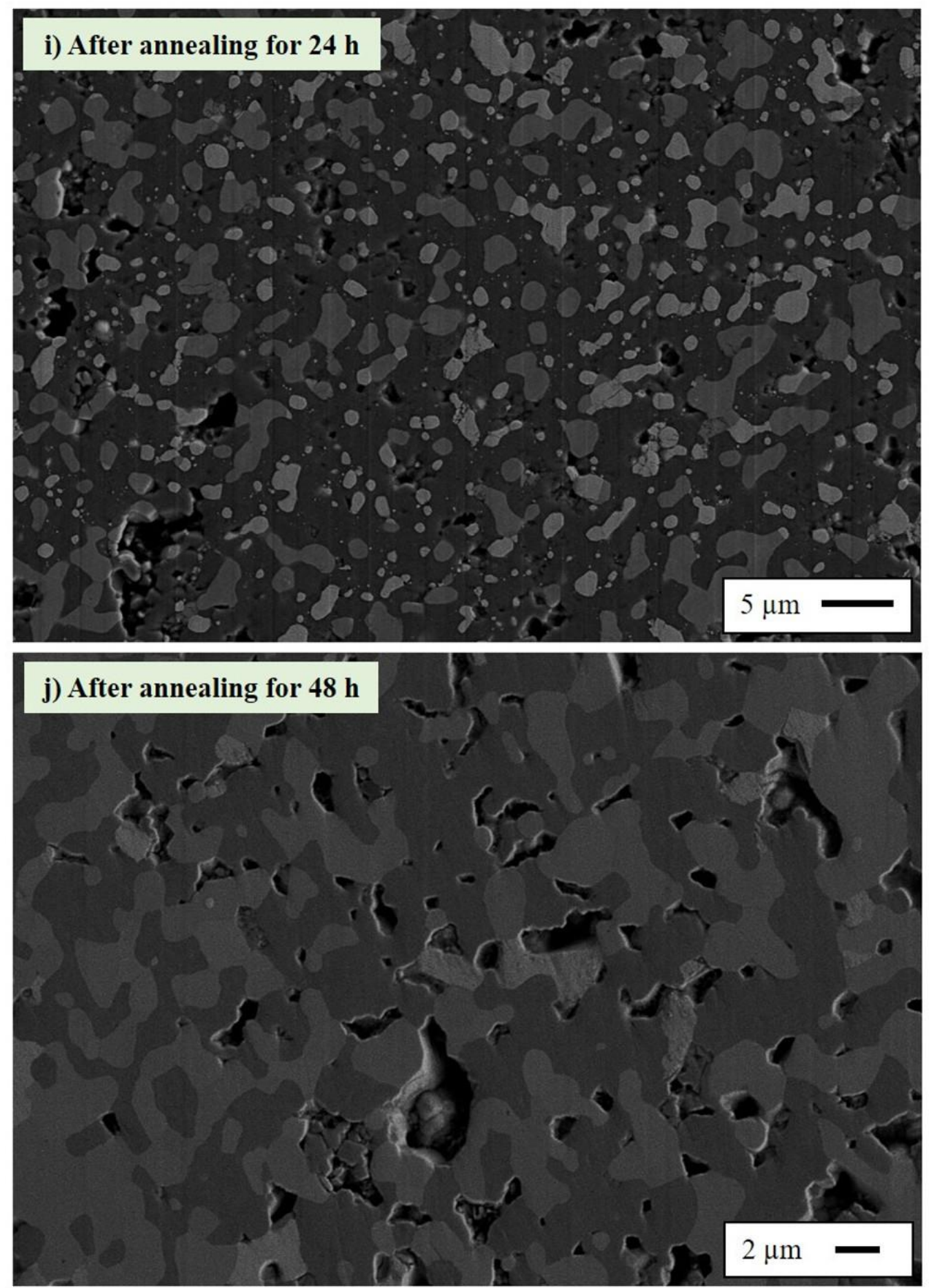

Figure 42. (continued) SEM microstructures of the (a-b) 60-40 $\mathrm{MoSi}_{2}-\mathrm{c} . \mathrm{Al}_{2} \mathrm{O}_{3}$, (c-d) 60$40 \mathrm{MoSi}_{2}-\mathrm{ZrO}_{2}$, (e-f) 60-40 WSi 2 -f. $\mathrm{Al}_{2} \mathrm{O}_{3}$, (g-h) 60-40 WSi 2 -c. $\mathrm{Al}_{2} \mathrm{O}_{3}$, and (i-j) 60-40 $\mathrm{WSi}_{2}-$ $\mathrm{ZrO}_{2}$ composites after annealing at $1400^{\circ} \mathrm{C}$ for $24-48 \mathrm{~h}$. 
the grain growth kinetics, and thus, more complicated microstructure. This aspect will be studied further in the future, which will include the analysis of the grain boundary phases present. But these results clearly demonstrate that the grain growth of $\mathrm{MoSi}_{2}$ was highly inhibited by using the fine-alumina particle reinforcements. This could be explained with the grain boundary pinning effect of second-phase (reinforcement) particles, since it is known that they increase the energy necessary for the migration of a grain boundary (total grain boundary energy) and thus decrease the grain growth rate [28]. Afterwards, the average size of the $\mathrm{MoSi}_{2}$ and $\mathrm{WSi}_{2}$ grains were all measured from the SEM microstructures of the other $60-40 \mathrm{MoSi}_{2}$ - and $\mathrm{WSi}_{2}$-based composites after sintering (Figure 37) and annealing (Figure 42). However, average grain sizes could not be measured only for sintered $\mathrm{MoSi}_{2}-\mathrm{f} . \mathrm{Al}_{2} \mathrm{O}_{3}$, sintered $\mathrm{WSi}_{2}-\mathrm{f}_{-} \mathrm{Al}_{2} \mathrm{O}_{3}$ and also $\mathrm{WSi}_{2}$ samples due to difficulty of fine polishing and/or chemical etching for these samples. The changes in the average size of the $\mathrm{MoSi}_{2}$ and $\mathrm{WSi}_{2}$ grains are shown in the Figure 43 as a function of annealing time. The grain growth rates for all $\mathrm{MoSi}_{2}$-based composites $(0.013-0.021 \mu \mathrm{m} / \mathrm{h})$ were found to be substantially lower than that of $\mathrm{MoSi}_{2}$ sample. The rates of grain growth $(0.015-0.023 \mu \mathrm{m} / \mathrm{h})$ were also quite lower for all $\mathrm{WSi}_{2}$-based composites. However, it is important to point out that $\mathrm{MoSi}_{2}$ - and $\mathrm{WSi}_{2}$-based composites reinforced by coarsegrained reinforcements (c. $\mathrm{Al}_{2} \mathrm{O}_{3}$ and $\mathrm{ZrO}_{2}$ ) revealed relatively lower grain growth rates in comparison to the $\mathrm{MoSi}_{2}-\mathrm{f} . \mathrm{Al}_{2} \mathrm{O}_{3}$ and $\mathrm{WSi}_{2}-\mathrm{f}_{\mathrm{Al}} \mathrm{Al}_{2} \mathrm{O}_{3}$ composites. This result could be associated with more homogeneous distribution of the coarse-grained reinforcement particles on the grain boundaries and also their high aspect ratio (particle morphology) [57,58]. The more homogeneous distribution can be visually seen from the microstructures of these composites (Figure 37b-c-e-f). In addition, the D index values representing the level of distribution (homogeneity) in the binary composites were measured in our previous study as 0.14 and 0.56 for the $60-40 \mathrm{WSi}_{2}-\mathrm{ZrO}_{2}$ and $\mathrm{MoSi}_{2}-\mathrm{f}_{-} \mathrm{Al}_{2} \mathrm{O}_{3}$, respectively [59]. Since a low $\mathrm{D}$ index presents more homogeneous distribution, the $\mathrm{WSi}_{2}-\mathrm{ZrO}_{2}$ exhibited better distribution, and thus, low rate of grain growth $(0.015 \mu \mathrm{m} / \mathrm{h})$ in comparison to the $\mathrm{MoSi}_{2}-\mathrm{f}_{\mathrm{Al}} \mathrm{O}_{2} \mathrm{O}_{3}(\sim 0.021 \mu \mathrm{m} / \mathrm{h})$. These results clearly prove the effect of particle distribution or homogeneity on the grain growth kinetics. Based on these studies, it could be concluded 

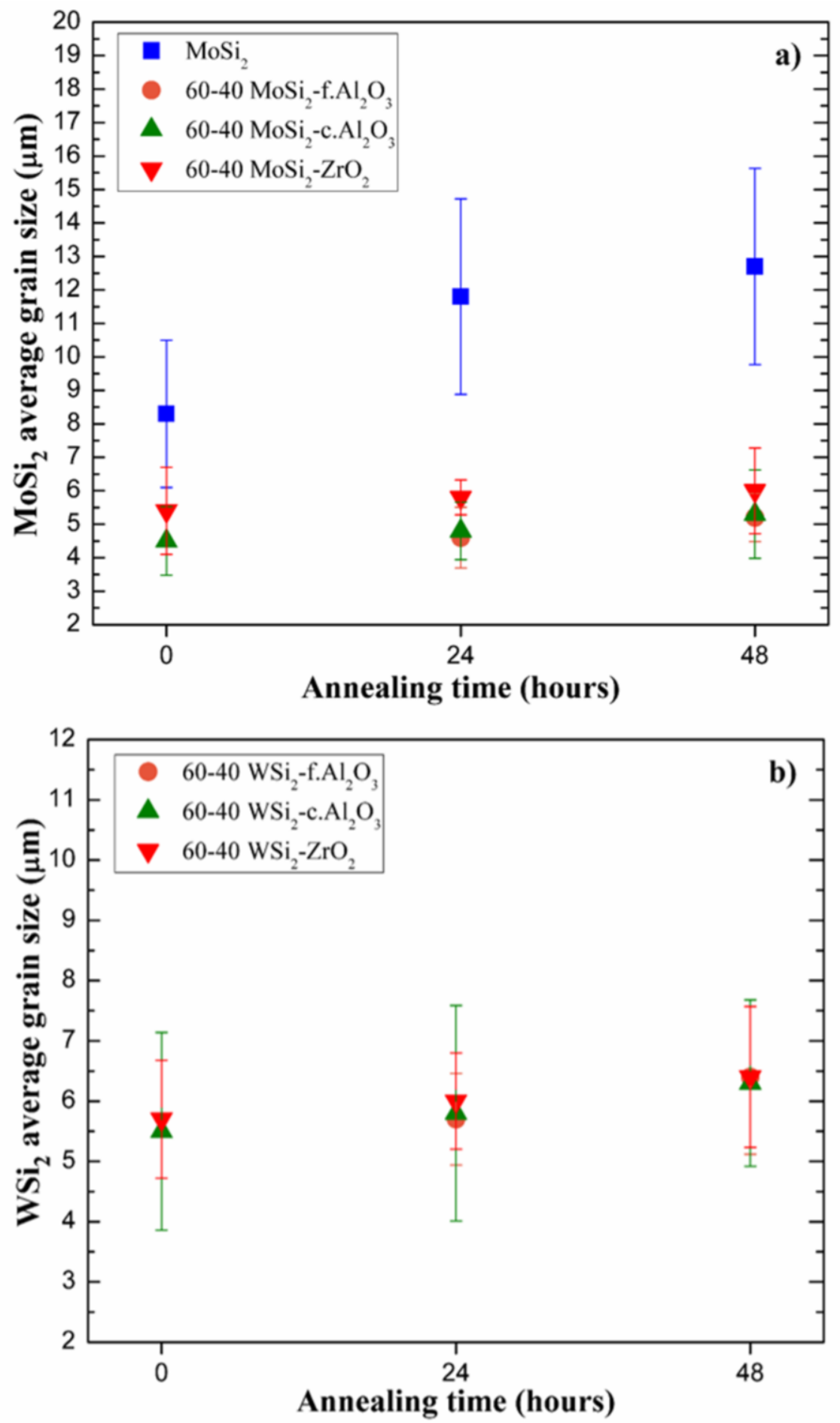

Figure 43. Changes in the average size of the (a) $\mathrm{MoSi}_{2}$ and (b) $\mathrm{WSi}_{2}$ grains (grain growth rates) as a function of annealing time. 
that the metal silicide-refractory oxide composites displayed significant advantages due to low grain growth rates, which may potentially improve their long-term stability at hightemperatures.

\subsubsection{Electrical properties at high-temperatures}

The high-temperature electrical conductivity of the $\mathrm{MoSi}_{2-}$ and $\mathrm{WSi}_{2}$-based composites reinforced by alumina and zirconia particles is shown as a function of temperature in the Figure 44. It is known that these composites are metallic conductors above a critical percolation limit [14], and thus, their electrical conductivity was shown to decrease with increasing temperature as expected. It is also important to note that the electrical conductivity data was achieved only at the temperatures above $400^{\circ} \mathrm{C}$ for all the 60-40 composites (except for 20-80 $\mathrm{MoSi}_{2}-\mathrm{f}_{\mathrm{Al}} \mathrm{Al}_{2} \mathrm{O}_{3}$ ), because of the very low resistance below this temperature which resulted in highly inaccurate measurements using the current digital multimeter. For the given sample dimensions, the upper limit for the electrical conductivity was near $3550 \mathrm{~S} / \mathrm{cm}$. Additionally, four-point electrical connections made by Pt wire and ink were lost at $820^{\circ}-900^{\circ} \mathrm{C}$, which inhibited the electrical conductivity measurements above that temperatures. This may be associated with the local reaction between $\mathrm{Pt}$ and metal disilicides to form platinum silicide (PtSi) phase having low meltingpoint on the sample surface $[60,61]$. Therefore, the exponential fitting was applied to some of the results (60-40 $\left.\mathrm{MoSi}_{2}-\mathrm{c} . \mathrm{Al}_{2} \mathrm{O}_{3}, \mathrm{WSi}_{2}-\mathrm{f} . \mathrm{Al}_{2} \mathrm{O}_{3}, \mathrm{WSi}_{2}-\mathrm{ZrO}_{2}\right)$ in order to extrapolate the electrical conductivity data from $820^{\circ} \mathrm{C}$ to $900^{\circ} \mathrm{C}$ for a better data comparison (adjusted Rsquare values: 0.93-0.97). Furthermore, the electrical conductivity data could not be obtained at $20 \mathrm{vol} \%$ metal silicide content, except for the $20-80 \mathrm{MoSi}_{2}-\mathrm{f}_{2} \mathrm{Al}_{2} \mathrm{O}_{3}$ composite. Since the main conduction mechanism within these composites is the formation of threedimensional continuous percolating network, it is found that the certain percolation threshold could not be exceeded for other 20-80 composites [15,51]. The electrical conductivity of the 20-80 $\mathrm{MoSi}_{2}-\mathrm{f}_{\mathrm{Al}} \mathrm{Al}_{2} \mathrm{O}_{3}$ was measured as 8.8 and $8.1 \mathrm{~S} / \mathrm{cm}$ at the temperatures of $900^{\circ}$ and $1000^{\circ} \mathrm{C}$, respectively (Figure 44a). This level of electrical conductivity, for instance $46.6 \mathrm{~S} / \mathrm{cm}$ at around $110^{\circ} \mathrm{C}$, was significantly higher than that for 

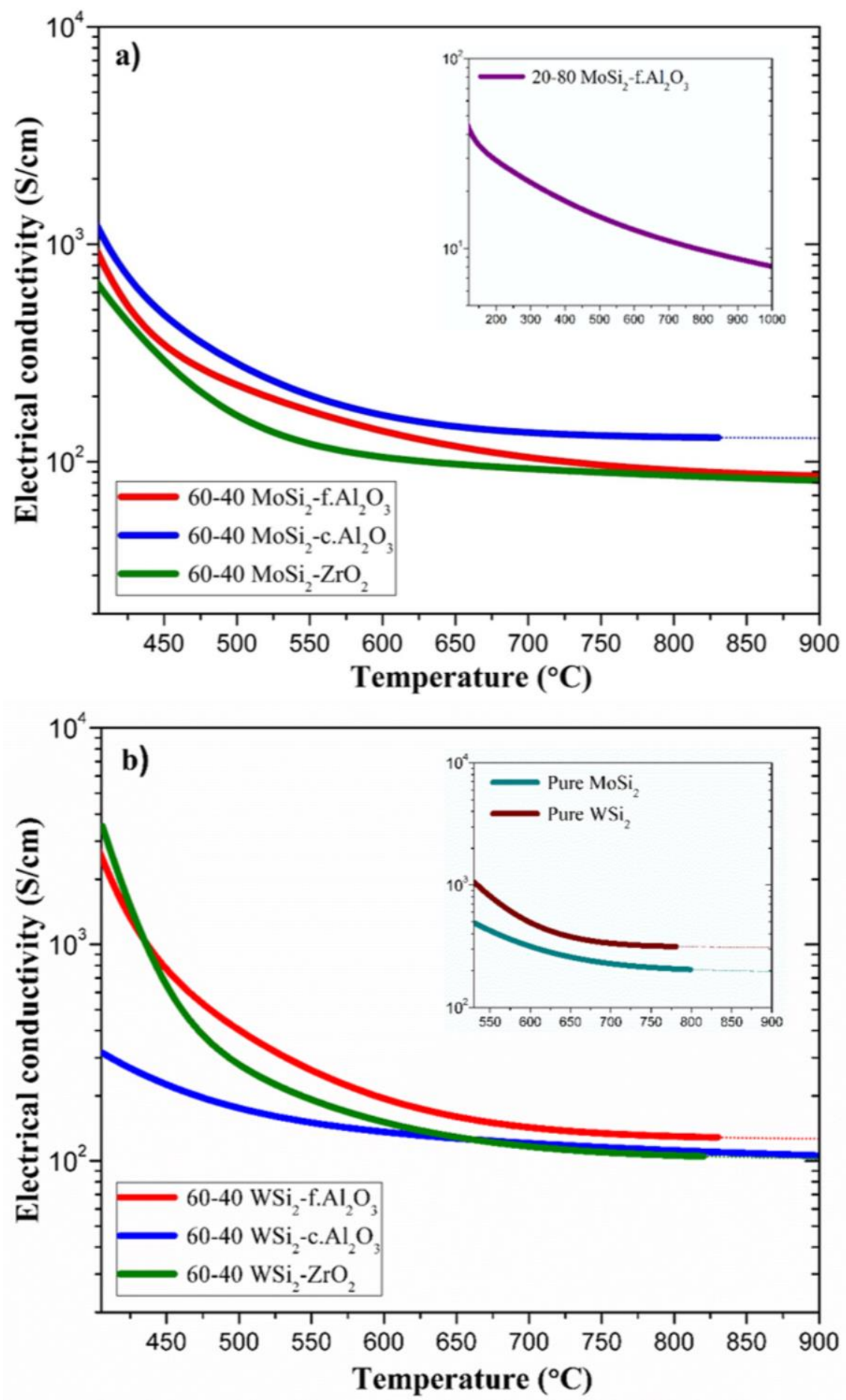

Figure 44. The electrical conductivity of the (a) $\mathrm{MoSi}_{2}$-based and (b) $\mathrm{WSi}_{2}$-based composites and pure metal disilicides $\left(\mathrm{MoSi}_{2}, \mathrm{WSi}_{2}\right)$ as a function of temperature (Electrical conductivity data is presented on the logarithmic scale). 
a similar $20-80 \mathrm{MoSi}_{2}-\mathrm{Al}_{2} \mathrm{O}_{3}$ composite $\left(0.01 \mathrm{~S} / \mathrm{cm}\right.$ at around $\left.50^{\circ} \mathrm{C}\right)$ reported by Kobel et al. [15]. The difference in the percolation concentration of 20-80 composites was found to be highly related to their relative densities and apparent porosities. The relative density of the 20-80 $\mathrm{MoSi}_{2}-\mathrm{f}_{-} \mathrm{Al}_{2} \mathrm{O}_{3}$ composite $(98.0 \%)$ was substantially greater than that of the other composites (72.9-92.6\%). It also displayed a very low apparent porosity (1.2\%) compared to the other composites, proving the effect of the degree of porosity on the critical percolation concentration. Therefore, it is clear that densification of the composites should be highly improved to fabricate electroconductive ceramic composites even at very low fractions of conductive phase by decreasing the critical percolation concentration.

Among the 60-40 MoSi2 -based composites, $\mathrm{MoSi}_{2}-\mathrm{c} . \mathrm{Al}_{2} \mathrm{O}_{3}$ exhibited significantly higher electrical conductivity $(128 \mathrm{~S} / \mathrm{cm})$ than the other compositions $(81.9-86 \mathrm{~S} / \mathrm{cm})$ at $900^{\circ} \mathrm{C}$, as seen in the Figure $44 \mathrm{a}$. The relative density of the $\mathrm{MoSi}_{2}-\mathrm{c} \cdot \mathrm{Al}_{2} \mathrm{O}_{3}(77.7 \%)$ was lower than that of the $\mathrm{MoSi}_{2}-\mathrm{f}_{2} \mathrm{Al}_{2} \mathrm{O}_{3}$ and $\mathrm{MoSi}_{2}-\mathrm{ZrO}_{2}$ (87.9-90.9\%). It still displayed a higher electrical performance that could be correlated with the more homogeneous distribution of conductive silicide particles within insulating oxide phase, since it is well known that the electrical properties are highly influenced by distribution of particles or homogeneity of microstructure as well as particle size/morphology and density $[15,17,49,62]$. On the other hand, the $60-40 \mathrm{WSi}_{2}-\mathrm{f}^{-} \mathrm{Al}_{2} \mathrm{O}_{3}$ showed substantially higher electrical conductivity $(126 \mathrm{~S} / \mathrm{cm})$ than other $\mathrm{WSi}_{2}$-based composites $(102-106 \mathrm{~S} / \mathrm{cm})$ as seen in the Figure $44 \mathrm{~b}$, due to its relatively high relative density $(88.6 \%)$ and low apparent porosity $(14.2 \%)$. No significant effect of conductive to insulating particle size ratio was observed. Therefore, this result may be also related to the amount of secondary $\mathrm{W}_{5} \mathrm{Si}_{3}$ phase within the composite system, since its content in the $\mathrm{WSi}_{2}-\mathrm{f} . \mathrm{Al}_{2} \mathrm{O}_{3}(6.9 \mathrm{vol} \%)$ after sintering was significantly lower than that in the $\mathrm{WSi}_{2}-\mathrm{c} . \mathrm{Al}_{2} \mathrm{O}_{3}$ and $\mathrm{WSi}_{2}-\mathrm{ZrO}_{2}$ composites (18.5-21.8 vol\%) as presented in the Figure 40. However, there is no data reported in the literature regarding to the intrinsic electrical properties of the $\mathrm{W}_{5} \mathrm{Si}_{3}$ phase. Among all the 60-40 composites, it is determined that the $\mathrm{MoSi}_{2}-\mathrm{c} . \mathrm{Al}_{2} \mathrm{O}_{3}$ and $\mathrm{WSi}_{2}-\mathrm{f}_{2} \mathrm{Al}_{2} \mathrm{O}_{3}$ revealed similar, but the highest electrical conductivities at $900^{\circ} \mathrm{C}$. Besides, electrical conductivities 
of the pure $\mathrm{MoSi}_{2}$ and $\mathrm{WSi}_{2}$ samples are presented as a function of temperature in the Figure 44b. It can be clearly seen that $\mathrm{WSi}_{2}$ exhibited higher electrical conductivity (310 $\mathrm{S} / \mathrm{cm})$ than $\mathrm{MoSi}_{2}(198 \mathrm{~S} / \mathrm{cm})$ at $900^{\circ} \mathrm{C}$ based on the extrapolated data (dotted lines above $780^{\circ}-800^{\circ} \mathrm{C}$ ) using exponential fitting (adjusted R-square values: 0.93-0.97). Similarly, the significantly high intrinsic electrical conductivity of $\mathrm{WSi}_{2}$ compared to $\mathrm{MoSi}_{2}$ was reported on thin films by Gottlieb et al. [14]. This also enhanced the electrical conductivity of the $\mathrm{WSi}_{2}$-based composites. As a review of these results, it can be clearly concluded that these composites exhibited promising electrical properties at high-temperatures, which were affected by their relative density and degree of porosity, distribution level of particles (homogeneity), intrinsic conductivity of conductive phase, particle size/morphology and perhaps fraction of secondary 5-3 silicide phase.

\subsection{Conclusions}

The metal silicide-refractory oxide electroconductive ceramic composites were successfully fabricated by including molybdenum disilicide and tungsten disilicide with fine- and coarse-alumina and zirconia particles, and then their chemical/thermal stability, microstructural evolution, grain growth kinetics and electrical properties at high temperatures were investigated. The phase analysis studies demonstrated that all $\mathrm{MoSi}_{2}-$ and $\mathrm{WSi}_{2}$-based composites are chemically stable at $1600^{\circ} \mathrm{C}$, only with formation of secondary 5-3 metal silicide phases. It was found that secondary phase formation is associated with interaction between metal disilicide and refractory oxide particles, as well as, the high-temperature oxidation reactions of metal disilicides with residual oxygen. The increase in the fractions of secondary 5-3 metal silicides was observed for all 60-40 composites with increasing annealing time at $1400^{\circ} \mathrm{C}$. The amount of $\mathrm{W}_{5} \mathrm{Si}_{3}$ phase was significantly higher than that of the $\mathrm{Mo}_{5} \mathrm{Si}_{3}$ in the composites after annealing for $48 \mathrm{~h}$, but the increased rate highly decreased after $24 \mathrm{~h}$. Therefore, all these composites exhibited enhanced thermal stability at that temperature, particularly after $24 \mathrm{~h}$, without undergoing any decomposition. Additionally, more homogeneous particle distribution was achieved for the $\mathrm{MoSi}_{2}$ - and $\mathrm{WSi}_{2}$-based composites reinforced by coarse-alumina and zirconia. The 
SEM and EDS studies demonstrated that the secondary 5-3 metal silicides with a small amount of silica formed mostly around the alumina grains. But the silica phase could not be detected by XRD due to its low amount mostly formed on the surface as a protective layer to further oxidation. Also, it was found that the rate of grain growth could be significantly inhibited by a grain boundary pinning effect. The grain growth rates were lower in the $\mathrm{MoSi}_{2}$ - and $\mathrm{WSi}_{2}$-based composites reinforced by coarse-grained reinforcements, which explained with their more homogeneous distribution on the grain boundaries and also high aspect ratio. Furthermore, their electrical conductivity decreased with increasing temperature as expected from metal disilicide metallic conductors. At high metal disilicide content, $\mathrm{MoSi}_{2}-\mathrm{c} \cdot \mathrm{Al}_{2} \mathrm{O}_{3}$ and $\mathrm{WSi}_{2}-\mathrm{f}_{\mathrm{Al}} \mathrm{Al}_{2} \mathrm{O}_{3}$ showed higher electrical conductivity at $900^{\circ} \mathrm{C}$. Their electrical properties were found to be highly influenced by density, porosity level, distribution level of particles (homogeneity), intrinsic conductivity of conductive phase, particle size/morphology and fraction of secondary 5-3 silicide phase. In brief, these metal silicide-refractory oxide electroconductive ceramic composites displayed high chemical/thermal stability, low rates of grain growth and high electrical conductivity at high-temperatures $\left(900^{\circ}-1600^{\circ} \mathrm{C}\right)$, which make them very promising materials for advanced sensing applications at high-temperatures and harsh-environments. Further studies are needed to investigate their thermal stability and electrical properties at hightemperatures for longer-terms, and to study the physical properties of 5-3 metal silicide phases for better understanding of the properties/performance of the composites.

\section{References}

[1] S.J. Mihailov, Fiber Bragg grating sensors for harsh environments, Sensors 12, 18981918 (2012).

[2] I.M. Tougas, M. Amani, O.J. Gregory, Metallic and ceramic thin film thermocouples for gas turbine engines, Sensors 13, 15324-15347 (2013).

[3] K.G. Kreider, Sputtered high temperature thin film thermocouples, J. Vac. Sci. Technol. 11, 1401-1405 (1993). 
[4] W.H. Bennethum, L.T. Sherwood, Sensors for ceramic components in advanced propulsion systems, NASA Contractor Report, 180900, August (1988).

[5] X. Jiang, K. Kim, S. Zhang, J. Johnson, G. Salazar, High-temperature piezoelectric sensing, Sensors 14, 144-169 (2014).

[6] H.D. Ngo, B. Mukhopadhyay, P. Mackowia, K. Krohnert, O. Ehrmann, K.D. Lang, A WSi-WSiN-Pt metallization scheme for silicon carbide-based high temperature microsystems, Micromachines 7, 193 (2016).

[7] Y. Zhang, Novel optical sensors for high temperature measurement in harsh environments, Ph.D. Dissertation; in Electrical and Computer Engineering, Virginia Polytechnic Institute and State University (2003).

[8] A.K. Vasudevan, J.J. Petrovic, A comparative overview of molybdenum disilicide composites, Mater. Sci. Eng. A 155, 1-17 (1992).

[9] J.J. Petrovic, A.K. Vasudevan, Key developments in high temperature structural silicides, Mater. Sci. Eng. A 261, 1-5 (1999).

[10] Z. Yao, J. Stiglich, T.S. Sudarshan, Molybdenum silicide based materials and their properties, J. Mater. Eng. Perform. 8, 291-304 (1999).

[11] A.D. Chirkin, V.O. Lavrenko, V.M. Talash, High-temperature and electrochemical oxidation of transition metal silicides, Powder Metall. Met. Ceram. 48, 330-345 (2009).

[12] J. Wang, P. Feng, J. Niu, R. Guo, Z. Liu, F. Akhtar, Synthesis, microstructure and properties of $\mathrm{MoSi}_{2}-5 \mathrm{vol} \% \mathrm{Al}_{2} \mathrm{O}_{3}$ composites, Ceram. Int. 40, 16381-16387 (2014).

[13] X. Fei, Y. Niu, H. Ji, L. Huang, X. Zhang, Oxidation behavior of $\mathrm{Al}_{2} \mathrm{O}_{3}$ reinforced $\mathrm{MoSi}_{2}$ composite coatings fabricated by vacuum plasma spraying, Ceram. Int. 36, 22352239 (2010).

[14] U. Gottlieb, F. Nava, M. Affronte, O. Laborde, R. Madar, Electrical transport in metallic TM silicides, In: Maex K, Rossum MV, eds. Properties of Metal Silicides, London UK, Inspec/Iee, 189-204 (1995).

[15] S. Kobel, J. Pluschke, U. Vogt, T.J. Graule, $\mathrm{MoSi}_{2}-\mathrm{Al}_{2} \mathrm{O}_{3}$ electroconductive ceramic composites, Ceram. Int. 30, 2105-2110 (2004). 
[16] P. Safaie, E. Haghshenas-Jazi, G.H. Borhani, S.R. Bakhshi, M. Alizadeh, In situ synthesis of $\mathrm{MoSi}_{2}-\mathrm{Al}_{2} \mathrm{O}_{3}$ composite by mechanical milling and subsequent heat treatment, Synth. React. Inorg. M. 45, 879-883 (2015).

[17] X. Zhang, Z. Lu, Z. Jin, Electrical resistivity and microstructure of pressureless reactive sintered $\mathrm{MoSi}_{2}-\mathrm{SiC}$ composite, Mater. Chem. Phys. 86, 16-20 (2004).

[18] H. Chen, Q. Ma, X. Shao, J. Ma, C. Wang, B. Huang, Microstructure, mechanical properties and oxidation resistance of $\mathrm{Mo}_{5} \mathrm{Si}_{3}-\mathrm{Al}_{2} \mathrm{O}_{3}$ composite, Mater. Sci. Eng. A 592, 12-18 (2014).

[19] A. Kakitsuji, H. Miyamoto, In-situ synthesis of $\mathrm{MoSi}_{2}-\mathrm{Al}_{2} \mathrm{O}_{3}$ composites by selfpropagating high temperature synthesis, J. Jpn. Soc. Powder and Powder Metall. 39, 819822 (1992).

[20] J. Pan, M.K. Surappa, R.A. Saravanan, B.W. Liu, D.M. Yang, Fabrication and characterization of $\mathrm{SiC} / \mathrm{MoSi}_{2}$ composites, Mater. Sci. Eng. A 244, 191-198 (1998).

[21] L. Sun, J. Pan, Fabrication and characterization of TiC-particle-reinforced $\mathrm{MoSi}_{2}$ composites, J. Eur. Ceram. Soc. 22, 791-796 (2002).

[22] Y. Muraoka, M. Yoshinaka, K. Hirota, O. Yamaguchi, Hot isostatic pressing of composite powder in the system $\mathrm{ZrO}_{2}-\mathrm{WSi}_{2}$ Part 1: microstructure and mechanical properties of $\mathrm{ZrO}_{2}\left(2 \mathrm{~mol} \% \mathrm{Y}_{2} \mathrm{O}_{3}\right)$-reinforced $\mathrm{WSi}_{2}$ composites, Journal of the Association of Materials Engineering for Resources 8, 30-35 (1995).

[23] J.J. Petrovic, Mechanical behavior of $\mathrm{MoSi}_{2}$ and $\mathrm{MoSi}_{2}$ composites, Mater. Sci. Eng. A 192/193, 31-37 (1995).

[24] M. Ostling, C. Zaring, Thermal properties of TM silicides, In: Maex K, Rossum MV, eds. Properties of Metal Silicides. London UK, Inspec/Iee, 31-44 (1995).

[25] X. Fei, Y. Niu, H. Ji, L. Huang, X. Zheng, Oxidation behavior of $\mathrm{ZrO}_{2}$ reinforced $\mathrm{MoSi}_{2}$ composite coatings fabricated by vacuum plasma spraying technology, J. Therm. Spray Technol. 19, 1074-1080 (2010).

[26] A. Chakraborty, S.V. Kamat, R. Mitra, K.K. Ray, Effect of $\mathrm{MoSi}_{2}$ and $\mathrm{Nb}$ reinforcements on mechanical properties of $\mathrm{Al}_{2} \mathrm{O}_{3}$ matrix composites, J. Mater. Sci. 35, $3827-3835$ (2000). 
[27] V.I. Zmii, A.P. Patokin, V.L. Khrebtov, B.M. Shirked, Molybdenum-based oxidationresistant $\mathrm{MoSi}_{2}-\mathrm{Al}_{2} \mathrm{O}_{3}$ and $\mathrm{WSi}_{2}-\mathrm{Al}_{2} \mathrm{O}_{3}$ coatings, Powder Metall. Met. Ceram. 47, 693-697 (2008).

[28] L.A. Xue, K. Meyer, I-W. Chen, Control of grain-boundary pinning in $\mathrm{Al}_{2} \mathrm{O}_{3} / \mathrm{ZrO}_{2}$ composites with $\mathrm{Ce}^{3+} / \mathrm{Ce}^{4+}$ doping, J. Am. Ceram. Soc. 75, 822-829 (1992).

[29] J.M. Calderon-Moreno, M. Schehl, M. Popa, Superplastic behavior of zirconiareinforced alumina nanocomposites from powder alcoxide mixtures, Acta Mater. 50, 39733983 (2002).

[30] A. Afshar, A. Simchi, Abnormal grain growth in alumina dispersion-strengthened copper produced by an internal oxidation process, Scr. Mater. 58, 966-969 (2008).

[31] H. Yamamoto, S. Sendai, Sintered composite of $\mathrm{MoSi}_{2}$-granular $\mathrm{Al}_{2} \mathrm{O}_{3}$, J. Ceram. Soc. Jpn. 87, 18-22 (1979).

[32] H. Yamamoto, S. Sendai, Study on high temperature thermistor made of MoSizgranular $\mathrm{Al}_{2} \mathrm{O}_{3}$ composite, J. Ceram. Soc. Jpn. 97, 783-786 (1989).

[33] C.A. Schneider, W.S. Rasband, K.W. Eliceiri, NIH image to ImageJ: 25 years of image analysis, Nature Methods 9, 671-675 (2012).

[34] L. Lutterotti, S. Matthies, H.R. Wenk, MAUD: a friendly Java program for material analysis using diffraction, IUCr Newsletter of the CPD 21, 14-15 (1999).

[35] ASTM B193-16 Standard test method for resistivity of electrical conductor materials. ASTM International, West Conshohocken, PA (2016).

[36] G.Y. Lin, V. Costil, Y. Jorand, G. Fantozzi, Experiments on packing and sintering of composite powder mixtures of $\mathrm{MoSi}_{2}+\mathrm{Al}_{2} \mathrm{O}_{3}$ platelets, Ceram. Int. 25, 367-373 (1999).

[37] F. Namavar, C.L. Cheung, R.F. Sabirianov, W.N. Mei, X.C. Zeng, G. Wang, H. Haider, K.L. Garvin, Lotus effect in engineered zirconia, Nano Lett. 8, 988-996 (2008).

[38] J.T. Bauer, A. Scholz, C. Berger, L. Weiler, M. Achtermann, Influence of metastable tetragonal $\mathrm{ZrO}_{2}$-reinforcements on the properties of $\mathrm{MoSi}_{2}$-composites, Int. J. Mater. Res. 99, 352-358 (2008).

[39] S. Matsuo, K. Homma, Sintering in the binary system $\mathrm{MoSi}_{2}-\mathrm{ZrO}_{2}$, J. Ceram. Soc. Jpn. 72, 63-66 (1964). 
[40] M.N. Rahaman, Ceramic Processing and Sintering, New York, NY, Marcel Dekker (2003).

[41] Y. Nakada, T. Kimura, Effects of shape and size of inclusions on the sintering of $\mathrm{ZnO}$ $\mathrm{ZrO}_{2}$ composites, J. Am. Ceram. Soc. 80, 401-406 (1997).

[42] Z. Yan, C.L. Martin, O. Guillon, D. Bouvard, Effect of size and homogeneity of rigid inclusions on the sintering of composites, Scripta Mater. 69, 327-330 (2013).

[43] R. Epherre, J. Lesseur, M. Albino, P. Veber, A. Weibel, G. Chevallier, M. Maglione, D. Bernard, C. Elissalde, C. Estournes, Adjustable dielectric properties of $\mathrm{BaTiO}_{3}$ containing $\mathrm{MgO}$ inclusions deformable under Spark Plasma Sintering, Scripta Mater. 110, $82-86$ (2016).

[44] G. Jiang, S. Bai, L. Chen, W. Li, H. Zhuang, Fabrication and microstructure of $\mathrm{MoSi}_{2} / \mathrm{Al}_{2} \mathrm{O}_{3}$ functionally graded material, Mater. Sci. Forum 423-425, 195-198 (2003).

[45] M. Zakeri, R. Yazdani-Rad, M.H. Enayati, M.R. Rahimipoor, Synthesis of MoSi $2_{2}$ $\mathrm{Al}_{2} \mathrm{O}_{3}$ nanocomposite by mechanical alloying, Mater. Sci. Eng. A 430, 185-188 (2006).

[46] G.J. Zhang, X.M. Yue, T. Watanabe, Addition effects of aluminum and in situ formation of alumina in $\mathrm{MoSi}_{2}$, J. Mater. Sci. 34:997-1001 (1999).

[47] C.D. Wirkus, D.R. Wilder, High-temperature oxidation of molybdenum disilicide. J. Am. Ceram. Soc. 49, 173-177 (1966).

[48] K. Arata, M. Yoshinaka, K. Hirota, O. Yamaguchi, Fabrication and mechanical properties of continuously graded $\mathrm{WSi}_{2}-\mathrm{ZrO}_{2}(2 \mathrm{Y})$ materials using wet-molding, Mater. Res. Bull. 33, 627-633 (1998).

[49] F. Lux, Models proposed to explain the electrical conductivity of mixtures made of conductive and insulating materials, J. Mater. Sci. 28, 285-301 (1993).

[50] A. Ishida, H. Matsubara, K. Furukawa, M. Miyayama, H. Yanagida, Computer simulation of percolation structure in composites, J. Ceram. Soc. Jpn. 103, 996-999 (1995).

[51] Z. Guo, G. Blugan, T. Graule, M. Reece, J. Kuebler, The effect of different sintering additives on the electrical and oxidation properties of $\mathrm{Si}_{3} \mathrm{~N}_{4}-\mathrm{MoSi}_{2}$ composites, J. Eur. Ceram. Soc. 27, 2153-2161 (2007). 
[52] Y.T. Zhu, M. Stan, S.D. Conzone, D.P. Butt, Thermal oxidation kinetics of $\mathrm{MoSi}_{2}{ }^{-}$ based powders, J. Am. Ceram. Soc. 82, 2785-2790 (1999).

[53] K. Yamaguchi, M. Yoshinaka, K. Hirota, O. Yamaguchi, Microstructure and mechanical properties of hot isostatically pressed zirconia ( $2 \mathrm{~mol} \%$ yttria)-reinforced tungsten disilicide composites, Mater. Res. Bull. 30, 953-958 (1995).

[54] S. Lohfeld, M. Schutze, Oxidation behaviour of particle reinforced $\mathrm{MoSi}_{2}$ composites at temperatures up to $1700^{\circ} \mathrm{C}$ Part I: literature review, Mater. Corros. 56, $93-97$ (2005).

[55] R.W. Rice, Mechanical Properties of Ceramics and Composites: Grain and Particle Effects, New York NY, CRC Press (2000).

[56] Y.W. Kim, T.Y. Cho, K.J. Kim, Effect of grain growth on electrical properties of silicon carbide ceramics sintered with gadolinia and yttria, J. Eur. Ceram. Soc. 35, 41374142 (2015).

[57] S.J.L. Kang, Sintering: Densification, Grain Growth and Microstructure, Burlington, MA, Elsevier Butterworth-Heinemann (2005).

[58] K. Chang, W. Feng, L.Q. Chen, Effect of second-phase particle morphology on grain growth kinetics, Acta Mater. 57, 5229-5236 (2009).

[59] G.A. Yakaboylu, E.M. Sabolsky, Determination of a homogeneity factor for composite materials by a microstructural image analysis method, Journal of Microscopy 266, 263-272 (2017).

[60] S. Madhukar, S. Aggarwal, A.M. Dhote, R. Ramesh, S.B. Samavedam, S. Choopun, R.P. Sharma, Pulsed laser-ablation deposition of thin films of molybdenum silicide and its properties as a conducting barrier for ferroelectric random-access memory technology, J. Mater. Res. 14, 940-947 (1999).

[61] Y. Ito, M. Sato, K. Wakisaka, S. Yoshikado, Improvement of heating characteristics of molybdenum silicide thin film electric heaters, Electr. Eng. Jpn. 168, 11-19 (2009).

[62] W.Z. Cai, S.T. Tu, J.M. Gong, A physically based percolation model of the effective electrical conductivity of particle filled composites, J. Compos. Mater. 40, 2131-2142 (2006). 


\section{CHA P T R 3: PROCESSING AND PROPERTIES OF $\underline{\mathrm{NBSI}_{2}-\mathrm{AND} \text { TAS I }} 2-\mathrm{OXIDE}$ C OMPOSITES}

\subsection{Introduction}

Niobium silicide $\left(\mathrm{NbSi}_{2}\right)$ and tantalum silicide $\left(\mathrm{TaSi}_{2}\right)$ were previously studied for use in various high temperature structural applications (such as reinforcement for advanced gas turbine and other high-temperature materials) and microelectronic application (such as low-resistance gate and interconnect materials) [1-3]. The high-temperature application of these materials is related to their high melting point $\left(>1930^{\circ} \mathrm{C}\right)$, relatively low density, high-temperature oxidation/corrosion resistance and high electrical conductivity [4-6]. Owing to the microelectronics as their major fields of application, electrical transport properties were mostly studied on the thin films of $\mathrm{NbSi}_{2}$ and $\mathrm{TaSi}_{2}$ due to the thermodynamic stability of metal disilicides on silicon [7]. In several studies, their thin films were fabricated by utilizing different deposition techniques such as evaporation, cosputtering and chemical vapor deposition, followed by high-temperature heat treatment at different conditions [7-11]. The room-temperature electrical resistivities of the $\mathrm{NbSi}_{2}$ and $\mathrm{TaSi}_{2}$ thin films were measured at the ranges of $49.9-203.3$ and $35-60 \mu \Omega \cdot \mathrm{cm}$, respectively, which were highly dependent upon the deposition method, film thickness and annealing temperature [8-10]. Several theoretical studies on the structural stability, mechanical and thermodynamic properties, and experimental high-temperature oxidation studies were also reported for the $\mathrm{NbSi}_{2}$ and $\mathrm{TaSi}_{2}$ thin films and monoliths [2,3,5,12,13]. It was demonstrated that the $\mathrm{NbSi}_{2}$ and $\mathrm{TaSi}_{2}$ monoliths display relatively lower oxidation resistant than similar disilicides ( $\mathrm{such}$ as $\mathrm{MoSi}_{2}$ and $\mathrm{WSi}_{2}$ ), since a continuous protective oxide layer like silica $\left(\mathrm{SiO}_{2}\right)$ cannot be formed on their surfaces due to the formation of $\mathrm{Nb}$ and Ta-oxides (e.g. $\mathrm{NbO}_{2}, \mathrm{Nb}_{2} \mathrm{O}_{5}, \mathrm{Ta}_{2} \mathrm{O}_{5}$ ) [14]. Some other studies reported that the oxidation rate of the $\mathrm{TaSi}_{2}$ is comparable to that of the $\mathrm{MoSi}_{2}$, which is known as the most oxidation resistant transition metal silicide at high-temperatures $[15,16]$. 
Most of the studies on the $\mathrm{NbSi}_{2}$ and $\mathrm{TaSi}_{2}$ were conducted on their various composite forms. The main reasons of focusing on the $\mathrm{NbSi}_{2}$ - and $\mathrm{TaSi}_{2}$-based composites instead on their monolithic forms were to improve their ductility, fracture toughness (below the ductile-brittle transition temperature), high-temperature strength, oxidation and creep resistance (at high-temperatures) [17-20]. Niobium ( $\mathrm{Nb}$ ) metal is commonly used for reinforcing the niobium silicides $\left(\mathrm{NbSi}_{2}, \mathrm{Nb}_{5} \mathrm{Si}_{3}\right)$ to improve their mechanical properties via ductile phase toughening [21,22]. Significant improvements particularly on their mechanical properties were also achieved with the addition of $\mathrm{MoSi}_{2}, \mathrm{SiC}, \mathrm{Al}_{2} \mathrm{O}_{3}$ and $\mathrm{WSi}_{2}$ reinforcements $[4,18,20,23]$. However, in the case of $\mathrm{TaSi}_{2}$-composites, $\mathrm{TaSi}_{2}$ was mainly utilized as a reinforcement material for enhancing the densification (sinterability), mechanical properties, oxidation resistance and thermal shock behavior of the carbides and borides such as $\mathrm{ZrB}_{2}, \mathrm{HfB}_{2}, \mathrm{TaC}$ and $\mathrm{HfC}$ [24-27]. Unfortunately, these same compositions were not evaluated for use in high-temperature electronics or sensor interconnect applications. Research has been conducted on other transition metal silicides $\left(\mathrm{MoSi}_{2}, \mathrm{TiSi}_{2}\right.$ etc.) and silicide-oxide composites $\left(\mathrm{MoSi}_{2}-\mathrm{Al}_{2} \mathrm{O}_{3}, \mathrm{WSi}_{2}-\mathrm{Al}_{2} \mathrm{O}_{3}\right.$ etc.), which showed promising results for electrical applications such as thermocouples and thermistors [15,2831]. Although $\mathrm{NbSi}_{2}$ and $\mathrm{TaSi}_{2}$ are also known as metallic conductors even at elevated temperatures, like most of the transition metal silicides $\left(\mathrm{MoSi}_{2}, \mathrm{WSi}_{2}\right.$ etc.) $[7,8,11]$, the high-temperature electrical properties of the bulk $\mathrm{NbSi}_{2}$ - and $\mathrm{TaSi}_{2}$-based composites have not been investigated for their potential use in advanced sensing applications at hightemperature and harsh-environment conditions. Therefore, this study focuses on the development of $\mathrm{NbSi}_{2}$ - and $\mathrm{TaSi}_{2}$-oxide electroconductive ceramic composites reinforced by alumina and zirconia particles, and extensive investigation of their sintering/densification, phase development and stability, microstructures, and hightemperature oxidation and electrical properties.

\subsection{Experimental}

\subsubsection{Materials and method}

Commercial niobium silicide ( $\mathrm{NbSi}_{2}, 99.85 \%$ metals basis), tantalum silicide ( $\mathrm{TaSi}_{2}, 99.0 \%$ metals basis) and zirconia $\left(\mathrm{ZrO}_{2}, 99+\%\right)$ as starting powders were purchased 

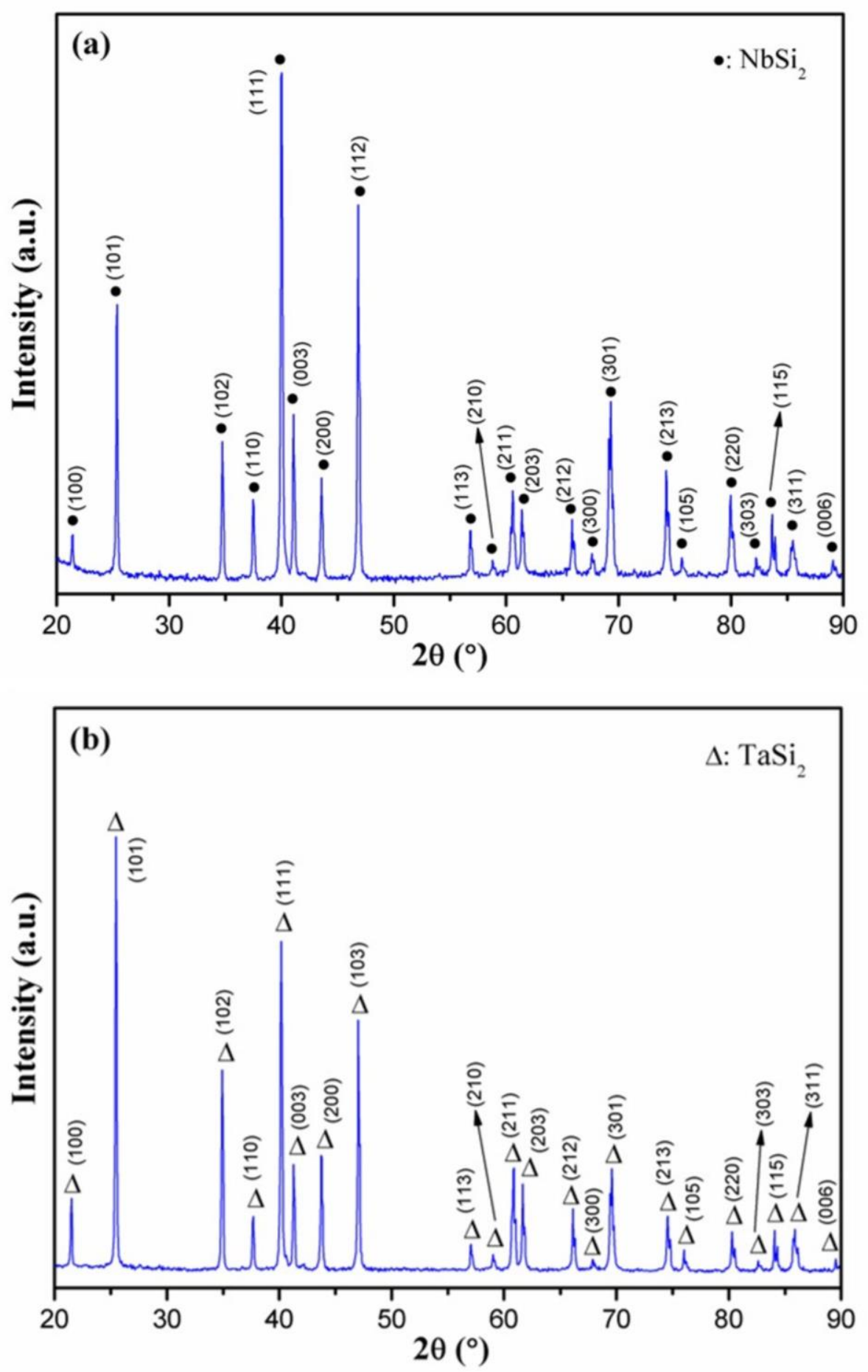

Figure 45. XRD patterns of the commercial (a) niobium disilicide $\left(\mathrm{NbSi}_{2}\right)$, and (b) tantalum disilicide $\left(\mathrm{TaSi}_{2}\right)$ starting powders. 
from Alfa Aesar (Tewksbury, MA). Alumina $\left(\mathrm{Al}_{2} \mathrm{O}_{3}, 99.8 \%\right.$, SSA: $\left.8.6 \mathrm{~m}^{2} / \mathrm{g}\right)$ powders purchased from Almatis (Leetsdale, $\mathrm{PA}$ ) were also used in this study. The $\mathrm{Nb}_{5} \mathrm{Si}_{3}$ powder (99.5\% metals basis, Alfa Aesar) was also used in this study as a reference material system. The close thermal expansion match of $\mathrm{Al}_{2} \mathrm{O}_{3}\left(\sim 8.0 \times 10^{-6} \mathrm{~K}^{-1}\right)$ and $\mathrm{ZrO}_{2}\left(9.6 \times 10^{-6} \mathrm{~K}^{-1}\right)$ with that of $\mathrm{NbSi}_{2}\left(8.4-11.7 \times 10^{-6} \mathrm{~K}^{-1}\right)$ and $\mathrm{TaSi}_{2}\left(\sim 8.9 \times 10^{-6} \mathrm{~K}^{-1}\right)$ in a wide temperature range $\left(20^{\circ}-1070^{\circ} \mathrm{C}\right)$, and the high-temperature capabilities of these refractory oxides, were major reasons of their selection as reinforcement particles [6]. Phase and microstructural analyses of the starting powders were initially conducted by X-ray diffraction (XRD, Panaltyical X'Pert Pro, Westborough, MA) and field-emission scanning electron microscopy (FESEM, Hitachi S-4700F, Tokyo, Japan), respectively. For the phase and crystal structure identification, the X'Pert High Score software (Panalytical Inc., Westborough, MA) was used. The ImageJ software [32] was also used to measure the average particle sizes from the SEM microstructures. The XRD patterns of the starting $\mathrm{NbSi}_{2}$ and $\mathrm{TaSi}_{2}$ powders are shown in Figure 45. The results clearly displayed that the starting powders are highly pure, since only metal disilicide peaks were identified on their XRD patterns. Both $\mathrm{NbSi}_{2}$ (\#03065-3551) and $\mathrm{TaSi}_{2}$ (\#01-089-2941) exhibited the hexagonal C40 crystal structure. Additionally, starting $\mathrm{Al}_{2} \mathrm{O}_{3}$ and $\mathrm{ZrO}_{2}$ powders exhibited the expected phases with rhombohedral symmetry (\#01-078-2427) and monoclinic structure (\#00-024-1165), respectively, based on their XRD results (not shown). Figure 46 presents the SEM microstructures of all the starting powders. The $\mathrm{NbSi}_{2}$ and $\mathrm{TaSi}_{2}$ powders were found to have random morphology with average particle sizes of 1.4 and $6.4 \mu \mathrm{m}$, respectively. Although the $\mathrm{NbSi}_{2}$ powders (Figure 46a) also consisted of some large particles similar to that of the $\mathrm{TaSi}_{2}$ (Figure 46b), it is clear that their average particle size was substantially lower than that of the $\mathrm{TaSi}_{2}$ due to the majority of smaller particles. The $\mathrm{Al}_{2} \mathrm{O}_{3}$ particles displayed equiaxed morphology with an average size of $0.4 \mu \mathrm{m}$ (Fig. 46c), while average size of the $\mathrm{ZrO}_{2}$ particles having equiaxed and elongated morphology was measured to be $\sim 12.1 \mu \mathrm{m}$ (Figure 46d). 

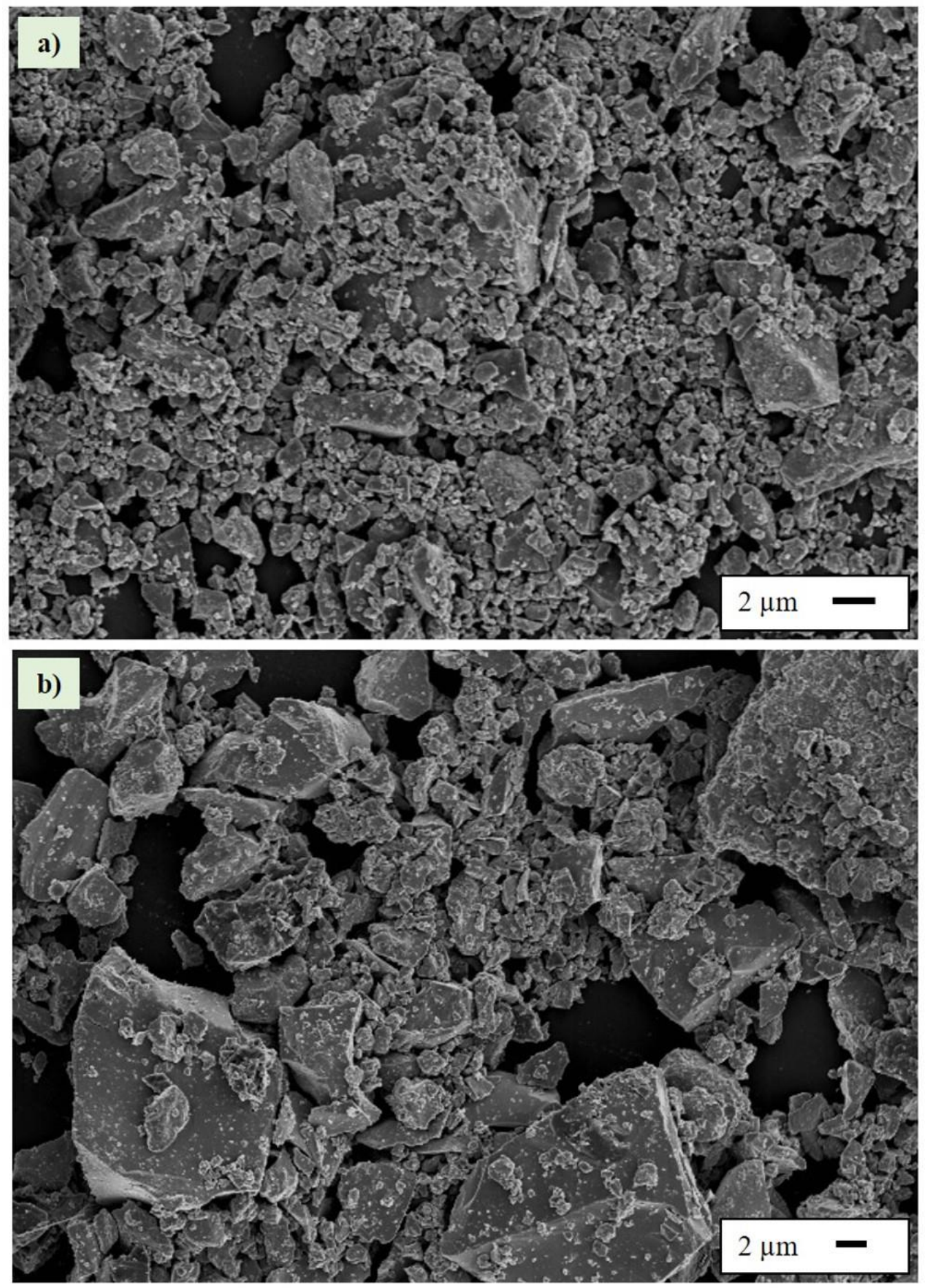

Figure 46. SEM microstructures of the commercial (a) $\mathrm{NbSi}_{2}$, (b) $\mathrm{TaSi}_{2}$, (c) $\mathrm{Al}_{2} \mathrm{O}_{3}$, and (d) $\mathrm{ZrO}_{2}$ starting powders. 

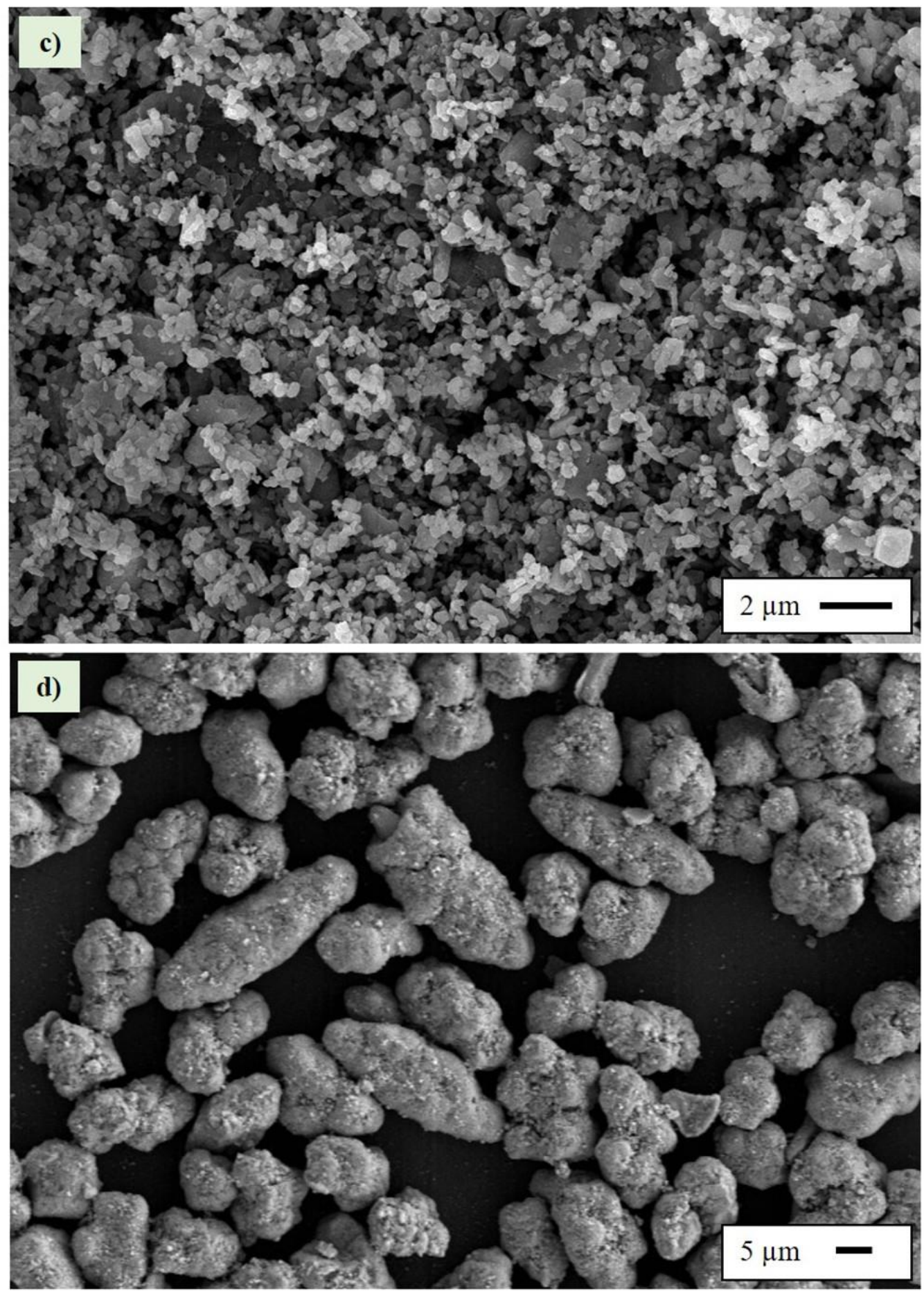

Figure 46. (continued) SEM microstructures of the commercial (a) $\mathrm{NbSi}_{2}$, (b) $\mathrm{TaSi}_{2}$, (c) $\mathrm{Al}_{2} \mathrm{O}_{3}$, and (d) $\mathrm{ZrO}_{2}$ starting powders. 
For preparation of the ceramic composites, $\mathrm{NbSi}_{2}$ and $\mathrm{TaSi}_{2}$ powders were mixed with refractory oxide reinforcement particles $\left(\mathrm{Al}_{2} \mathrm{O}_{3}\right.$ and $\left.\mathrm{ZrO}_{2}\right)$ by ball-milling in ethanol for $24 \mathrm{~h}$, and then dried at $50^{\circ}-60^{\circ} \mathrm{C}$ for $2 \mathrm{~h}$. The $\mathrm{NbSi}_{2}-\mathrm{Al}_{2} \mathrm{O}_{3}, \mathrm{TaSi}_{2}-\mathrm{Al}_{2} \mathrm{O}_{3}, \mathrm{NbSi}_{2}-\mathrm{ZrO}_{2}$ and $\mathrm{TaSi}_{2}-\mathrm{ZrO}_{2}$ are composite compositions prepared in this study. The metal siliciderefractory oxide contents were selected as 30-70 and 60-40 volume percentages (vol\%) to extensively study these composites at near percolation and above percolation regions, respectively. Therefore, for simplicity, the composites were termed as " $30-70$ " and "60-40" throughout the study. After drying, small (13 mm diameter) and large (26 $\mathrm{mm}$ diameter) cylindrical pellets, with $\sim 2-4 \mathrm{~mm}$ thickness, were prepared from the as-prepared composite powders using uniaxial pressing (13.8 MPa as applied pressure). The pressed pellets were sintered at $1400^{\circ}-1600^{\circ} \mathrm{C}$ using an atmosphere-controlled tube furnace in flowing argon gas at heating and cooling rates of $3^{\circ} \mathrm{C} / \mathrm{min}$. To study their short- and long-term thermal stability, secondary phase formation, microstructures and high-temperature stability of electrical properties, $60-40 \mathrm{vol} \%$ composites previously sintered at $1600^{\circ} \mathrm{C}$ were further annealed at $1400^{\circ} \mathrm{C}$ for 24,48 and $96 \mathrm{~h}$, similarly under argon atmosphere.

\subsubsection{Characterization studies}

Archimedes method was utilized using ethanol $\left(0.789 \mathrm{~g} / \mathrm{cm}^{3}\right)$ for measuring the densities of the sintered composite samples. It is important to note that apparent density and apparent porosity values were used for understanding the densification in different composite systems instead of the relative densities. This was due to the formation of the secondary 5-3 metal silicide phases $\left(\mathrm{Nb}_{5} \mathrm{Si}_{3}\right.$ and $\left.\mathrm{Ta}_{5} \mathrm{Si}_{3}\right)$ during sintering and the significant differences between the theoretical densities of metal disilicides and their 5-3 metal silicide forms, which could be misleading due to the error margins in the theoretical density calculations. After sintering and annealing processes, phase analyses of the composite samples were conducted by X-ray diffraction (XRD, Panaltyical X'Pert Pro, Westborough, MA) with $\mathrm{CuK}_{\alpha}$ radiation source. In addition to the XRD analyses, the MAUD software [33] was used to determine the volume percentages of secondary phases within the $\mathrm{NbSi}_{2}-$ $\mathrm{Al}_{2} \mathrm{O}_{3}$ and $\mathrm{NbSi}_{2}-\mathrm{ZrO}_{2}$ composite systems via Rietveld method. However, the TaSi 2 -based 
composites could not be analyzed using the same technique due to lack of a matching $\mathrm{Ta}_{5} \mathrm{Si}_{3}$ crystallographic information file (CIF) required for the Rietveld analysis. For the microstructural analyses of the composite samples, fine polishing was performed using $\mathrm{SiC}$ sanding papers with $600-1200$ grits and then applying the diamond paste $(0.5 \mu \mathrm{m})$ on a polishing cloth (Ted Pella Inc., Redding, CA). Each polishing step was carried out for 5-10 min, followed by ultrasonication in deionized water for $15 \mathrm{~min}$. After the sample preparation, a field-emission scanning electron microscopy (FE-SEM, Hitachi S-4700F, Tokyo, Japan) was used to analyze the cross-sectional microstructures of the as-polished composite samples.

For the oxidation studies, very small rectangular pellets having $0.1-0.3 \mathrm{~cm}^{2}$ surface area were prepared via cutting and polishing processes, and their dimensions (width $\times$ length $\times$ height) were measured before oxidation tests for their surface area calculations. The high-temperature oxidation studies of these composite samples were conducted using a thermogravimetric analyzer (TGA, Pyris 1, PerkinElmer, Shelton, CT) in flowing air $(20 \mathrm{ml} / \mathrm{min})$. The samples were heated from $50^{\circ} \mathrm{C}$ to $800^{\circ} \mathrm{C}$ with a heating rate of $10^{\circ} \mathrm{C} / \mathrm{min}$, and the mass changes $\left(\mathrm{mg} / \mathrm{cm}^{2}\right)$ were calculated using the recorded mass changes and the calculated specific sample surface areas. The high-temperature electrical measurements were completed using a high-purity four-bore alumina tube and platinum (Pt) wires $(99.95 \%$ pure). The rectangular bar samples $(\sim 20 \times 4 \times 4 \mathrm{~mm})$ prepared for the standard electrical measurements (ASTM B193-16) [34] were connected to the test setup, which was then carefully sealed in a high-temperature tube furnace. These measurements were performed up to $900^{\circ}-1000^{\circ} \mathrm{C}$ in argon for avoiding the potential materials degradation. The electrical resistance was measured using a digital multimeter (Keithley 2100, Tektronix, Beaverton, OR), and recorded as a function of temperature by LabVIEW (National Instruments, Austin, TX) and Keithley software. Lastly, the specific sample dimensions were used to calculate the electrical conductivity of the composite samples. 


\subsection{Results and Discussion}

\subsubsection{Densification as a function of composition and temperature}

The $\mathrm{NbSi}_{2}$ - and $\mathrm{TaSi}_{2}$-based composites with the addition of $\mathrm{Al}_{2} \mathrm{O}_{3}$ and $\mathrm{ZrO}_{2}$ particles, all having 30-70 and 60-40 volume percentages, were sintered at three different temperatures ranging from $1400^{\circ} \mathrm{C}$ to $1600^{\circ} \mathrm{C}$. Their apparent densities and porosities were measured to investigate their densification as a function of composition (volume percentage, type of oxide/silicide phase) and increasing sintering temperature. The apparent densities of these composites are listed in Table 8. At the 30-70 volume percentages, the apparent density of the $\mathrm{NbSi}_{2}-\mathrm{Al}_{2} \mathrm{O}_{3}$ and $\mathrm{TaSi}_{2}-\mathrm{Al}_{2} \mathrm{O}_{3}$ composites increased with increasing sintering temperature from $1400^{\circ} \mathrm{C}$ to $1500^{\circ} \mathrm{C}$, but then decreased to the lower values at $1600^{\circ} \mathrm{C}$. A similar trend was also observed for the $\mathrm{NbSi}_{2}-\mathrm{Al}_{2} \mathrm{O}_{3}, \mathrm{TaSi}_{2}-\mathrm{Al}_{2} \mathrm{O}_{3}$ and $\mathrm{TaSi}_{2}-$ $\mathrm{ZrO}_{2}$ composites, which have 60-40 volume percentages. The decreased apparent densities for these composites, particularly from $1500^{\circ} \mathrm{C}$ to $1600^{\circ} \mathrm{C}$, could be attributed to the decreased porosity levels and enhanced densification at high sintering temperature. On the other hand, no significant changes were observed in the apparent densities of all $\mathrm{NbSi}_{2}-$ $\mathrm{ZrO}_{2}$ and $30-70 \mathrm{TaSi}_{2}-\mathrm{ZrO}_{2}$ composites at $1500^{\circ}-1600^{\circ} \mathrm{C}$.

To understand the densification of these composites better, their apparent porosity levels are presented as percentages (\%) in Figure 47 as a function of sintering temperature. At $1400^{\circ} \mathrm{C}$, the apparent porosity levels were found to be above $22.1 \%$ for all the composites except for the $60-40 \mathrm{NbSi}_{2}-\mathrm{Al}_{2} \mathrm{O}_{3}$, since it revealed $\sim 16.1 \%$ porosity at the same temperature. With increasing sintering temperature from $1400^{\circ}$ to $1500^{\circ} \mathrm{C}$, significant reductions in the porosity levels ranging from 3.73 to $8.27 \%$ were achieved for the $\mathrm{NbSi}_{2}$ $\mathrm{Al}_{2} \mathrm{O}_{3}, \mathrm{NbSi}_{2}-\mathrm{ZrO}_{2}$ and $\mathrm{TaSi}_{2}-\mathrm{Al}_{2} \mathrm{O}_{3}$ composites all having 30-70 volume percentages. However, only a $0.19-0.79 \%$ decrease was observed at the same temperature range for the same compositions, but all having the 60-40 volume percentages. The apparent porosity levels were also reduced for all the composites by $2.70-13.5 \%$ with increasing sintering temperature from $1500^{\circ}$ to $1600^{\circ} \mathrm{C}$, but this decrease was drastic (10.3-13.5\%) only for the 30-70 $\mathrm{NbSi}_{2}-\mathrm{Al}_{2} \mathrm{O}_{3}, 30-70 \mathrm{TaSi}_{2}-\mathrm{Al}_{2} \mathrm{O}_{3}$ and 60-40 $\mathrm{TaSi}_{2}-\mathrm{Al}_{2} \mathrm{O}_{3}$ composites. The lowest 
Table 8. Apparent density of the $\mathrm{NbSi}_{2}$ - and $\mathrm{TaSi}_{2}$-based composites with the addition of $\mathrm{Al}_{2} \mathrm{O}_{3}$ and $\mathrm{ZrO}_{2}$ particles, as function of the sintering temperature.

\begin{tabular}{|c|c|c|c|}
\hline \multirow{2}{*}{ Composite } & \multicolumn{3}{|c|}{ Apparent density $\left(\mathrm{g} / \mathrm{cm}^{3}\right)$} \\
\hline & $1400^{\circ} \mathrm{C}$ & $1500^{\circ} \mathrm{C}$ & $1600^{\circ} \mathrm{C}$ \\
\hline $30-70 \mathrm{NbSi}_{2}-\mathrm{Al}_{2} \mathrm{O}_{3}$ & 4.41 & 4.49 & 4.25 \\
\hline $60-40 \mathrm{NbSi}_{2}-\mathrm{Al}_{2} \mathrm{O}_{3}$ & 4.81 & 5.04 & 4.98 \\
\hline $30-70 \mathrm{NbSi}_{2}-\mathrm{ZrO}_{2}$ & 5.74 & 5.84 & 5.83 \\
\hline $60-40 \mathrm{NbSi}_{2}-\mathrm{ZrO}_{2}$ & 5.74 & 5.75 & 5.75 \\
\hline 30-70 $\mathrm{TaSi}_{2}-\mathrm{Al}_{2} \mathrm{O}_{3}$ & 5.38 & 5.53 & 5.28 \\
\hline $60-40 \mathrm{TaSi}_{2}-\mathrm{Al}_{2} \mathrm{O}_{3}$ & 6.85 & 7.02 & 6.66 \\
\hline 30-70 $\mathrm{TaSi}_{2}-\mathrm{ZrO}_{2}$ & 6.78 & 6.92 & 6.88 \\
\hline 60-40 $\mathrm{TaSi}_{2}-\mathrm{ZrO}_{2}$ & 7.64 & 7.94 & 7.60 \\
\hline
\end{tabular}

porosity levels were achieved $(5.15-7.70 \%)$ for the $\mathrm{NbSi}_{2}-\mathrm{Al}_{2} \mathrm{O}_{3}$ and $\mathrm{TaSi}_{2}-\mathrm{Al}_{2} \mathrm{O}_{3}$ composites both with $30-70$ volume percentages at $1600^{\circ} \mathrm{C}$ (Figure $47(\mathrm{a}-\mathrm{b})$ ). It can also be clearly seen that porosity levels of the silicide-alumina composites were significantly lower than that of the silicide-zirconia composites in all cases. The silicide-zirconia composites displayed porosity levels higher than $25.8 \%$ even at $1600^{\circ} \mathrm{C}$.

As a review, these results demonstrated that the particle packing and densification kinetics were highly improved by lowering the metal silicide content (60 to $30 \mathrm{vol} \%$ ) and/or increasing the refractory oxide (40 to $70 \mathrm{vol} \%$ ) content within these composite systems. It is apparent that the particle packing was substantially enhanced with the addition of $70 \mathrm{vol} \%$ alumina particles to the $\mathrm{NbSi}_{2}$ and $\mathrm{TaSi}_{2}$, which acted as reinforcement particles in these cases. This could be directly related to the initial agglomeration of the fine 

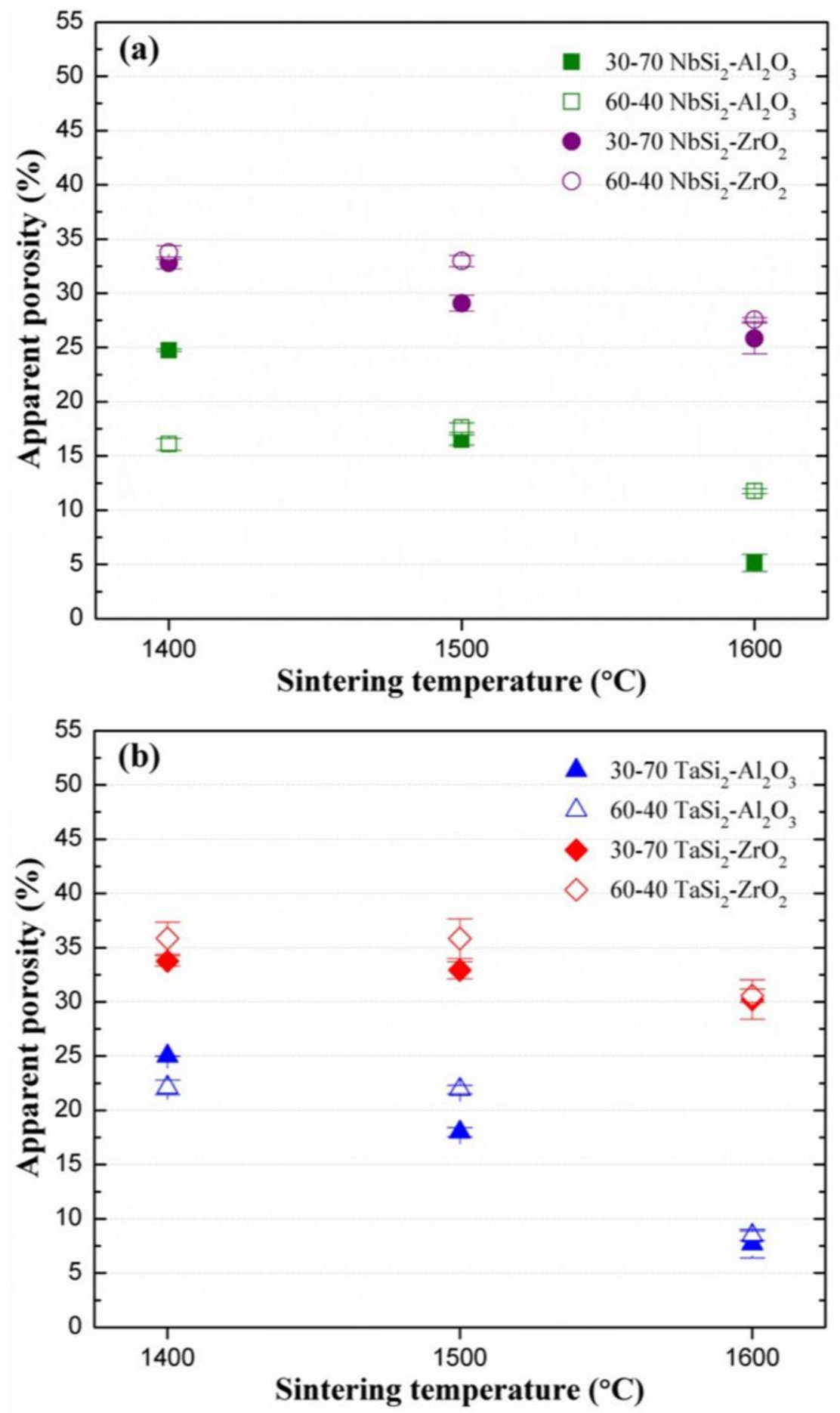

Figure 47. Apparent porosity levels (\%) of the (a) $\mathrm{NbSi}_{2}$-based, and (b) $\mathrm{TaSi}_{2}$-based composites with the addition of the $\mathrm{Al}_{2} \mathrm{O}_{3}$ and $\mathrm{ZrO}_{2}$ particles, as a function of sintering temperature. 
alumina particles $(\sim 0.4 \mu \mathrm{m})$ and high metal silicide/alumina particle size ratios $\left(\mathrm{NbSi}_{2} / \mathrm{Al}_{2} \mathrm{O}_{3} \approx 3.5 ; \mathrm{TaSi}_{2} / \mathrm{Al}_{2} \mathrm{O}_{3} \approx 16.0\right)$. It was reported that reinforcement particle size, reinforcement/matrix particle size ratio and volume percentages could highly affect the densification rate of the composite systems during high-temperature sintering [35-37]. Yan et al. reported that the densification rate of the composites could be positively affected by increasing the reinforcement/matrix particle size ratio and decreasing the volume percentage of the reinforcement particles [38]. They also presented that the retarding effect was lower in the case of second phase particle agglomeration at high volume percentage (20 vol\%), indicating the adverse effect of the homogeneous particle distribution and increased number of dissimilar grain contacts $\left(\mathrm{NbSi}_{2}-\mathrm{Al}_{2} \mathrm{O}_{3}\right.$ and $\left.\mathrm{TaSi}_{2}-\mathrm{Al}_{2} \mathrm{O}_{3}\right)$ within the microstructure on the densification. Since the local densification kinetics were also more favored with the existence of agglomerated alumina grains and related single-phase grain boundary regions, the combination of all these parameters significantly enhanced the densification of the $\mathrm{NbSi}_{2}-\mathrm{Al}_{2} \mathrm{O}_{3}$ and $\mathrm{TaSi}_{2}-\mathrm{Al}_{2} \mathrm{O}_{3}$ composites not only at the 30-70 volume percentages, but also at the 60-40. These results were also found to be highly consistent with our previous study on the $\mathrm{MoSi}_{2}$ - and $\mathrm{WSi}_{2}$-oxide composites [30]. On the other hand, significantly high porosity levels and low densification for the silicide-zirconia composites at all sintering temperatures could be correlated to lower metal silicide/zirconia particle size ratios $\left(\mathrm{NbSi}_{2} / \mathrm{ZrO}_{2} \approx 0.1 ; \mathrm{TaSi}_{2} / \mathrm{ZrO}_{2} \approx 0.5\right)$ and insufficient sintering kinetics for the $\mathrm{ZrO}_{2}$ having the higher melting point. That could be also interrelated with the microcracks that may form within these composite microstructures due to reversible monoclinic-tetragonal phase transformation of zirconia near $1170^{\circ} \mathrm{C}$ [39], since it was reported by Skandan et al. [40] that a $4.5 \%$ strain formed during this martensitic transformation may cause microcracking.

\subsubsection{Phase development and stability at high-temperatures}

The phase development within the $\mathrm{NbSi}_{2}$ - and $\mathrm{TaSi}_{2}$-based composites (60-40 volume percentages) with the addition of $40 \mathrm{vol} \%$ alumina and zirconia particles was examined after sintering at $1600^{\circ} \mathrm{C}$ for $2 \mathrm{~h}$ in argon due to the enhanced densification and 

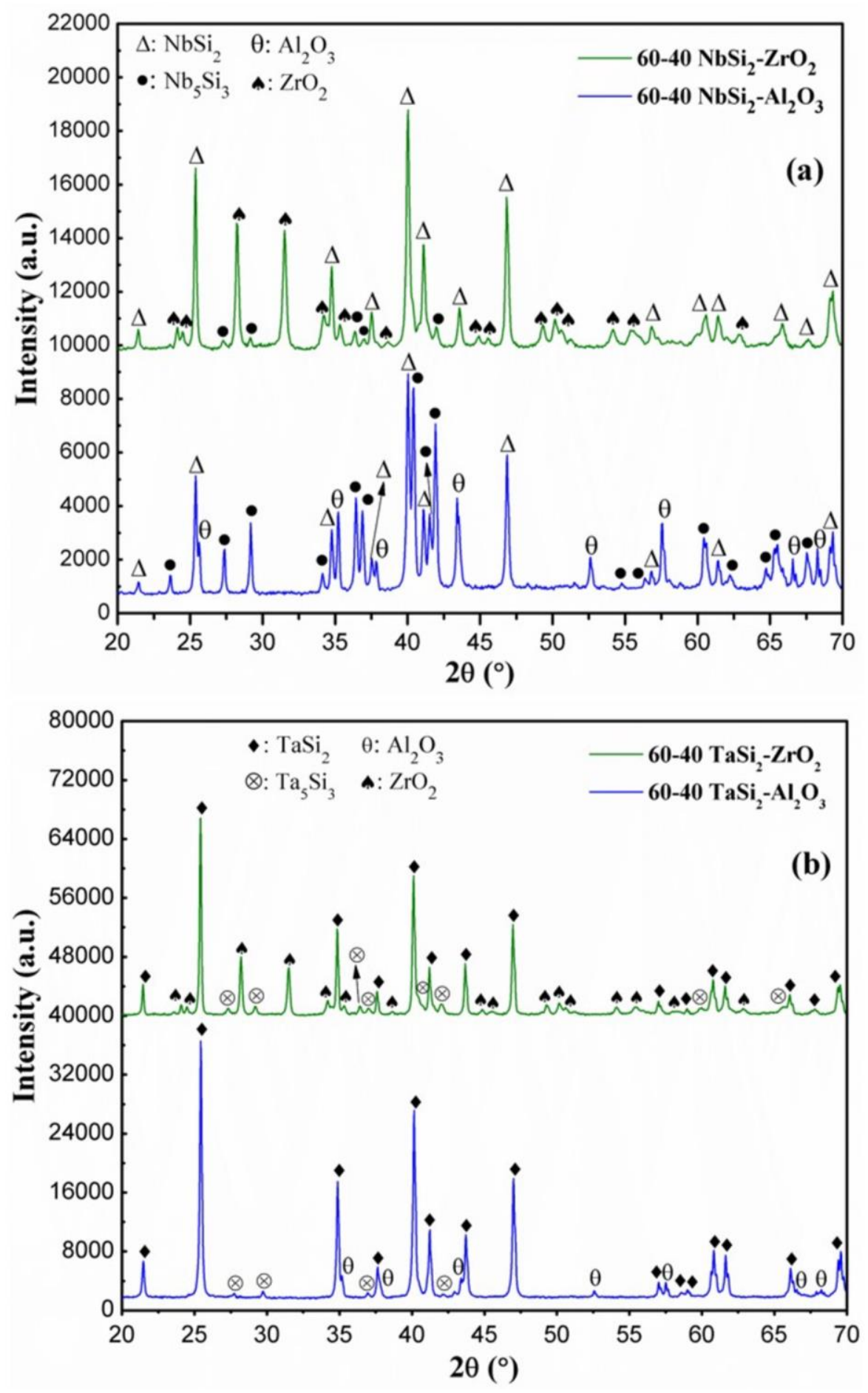

Figure 48. XRD patterns of the (a) 60-40 $\mathrm{NbSi}_{2}$-based, and (b) 60-40 $\mathrm{TaSi}_{2}$-based composites, with the addition of $40 \mathrm{vol} \% \mathrm{Al}_{2} \mathrm{O}_{3}$ and $\mathrm{ZrO}_{2}$ particles, sintered at $1600^{\circ} \mathrm{C}$ for $2 \mathrm{~h}$ in argon. 
lower porosity levels achieved at that temperature. Figure 48 displays the XRD patterns of the (a) $\mathrm{NbSi}_{2}$-based and (b) $\mathrm{TaSi}_{2}$-based composites sintered at $1600^{\circ} \mathrm{C}$. For the $\mathrm{NbSi}_{2}-$ $\mathrm{Al}_{2} \mathrm{O}_{3}$ and $\mathrm{NbSi}_{2}-\mathrm{ZrO}_{2}$ composites, the XRD peaks detected at $2 \theta$ of $25.4^{\circ}, 40.0^{\circ}$ and $46.9^{\circ}$ corresponds to the hexagonal $\mathrm{NbSi}_{2}$ phase, and its major diffraction peaks for the (101), (111) and (112) planes, respectively. The peaks attributed to the $\mathrm{Al}_{2} \mathrm{O}_{3}$ and $\mathrm{ZrO}_{2}$ as refractory oxides can be also seen in Figure 48(a), having the corundum and monoclinic crystal structures, respectively. In addition, these XRD results revealed the formation of an intermediate $\mathrm{Nb}_{5} \mathrm{Si}_{3}$ phase with the hexagonal structure during high-temperature sintering as a result of the diffraction peaks detected at $2 \theta$ of $36.4^{\circ}, 40.4^{\circ}, 41.5^{\circ}$ and $41.9^{\circ}$ corresponding to the (210), (211), (300) and (112) planes, respectively. It is also apparent that $\mathrm{Nb}_{5} \mathrm{Si}_{3}$ peaks are more intense in the $\mathrm{NbSi}_{2}-\mathrm{Al}_{2} \mathrm{O}_{3}$ than the $\mathrm{NbSi}_{2}-\mathrm{ZrO}_{2}$ composite after sintering at $1600^{\circ} \mathrm{C}$, indicating its higher volume percentage within the $\mathrm{NbSi}_{2}-\mathrm{Al}_{2} \mathrm{O}_{3}$. Similarly, the XRD patterns of the $\mathrm{TaSi}_{2}-\mathrm{Al}_{2} \mathrm{O}_{3}$ and $\mathrm{TaSi}_{2}-\mathrm{ZrO}_{2}$ composites exhibited the existence of an intermediate $\mathrm{Ta}_{5} \mathrm{Si}_{3}$ phase with the hexagonal structure, along with the hexagonal-structured $\mathrm{TaSi}_{2}$ and refractory oxides $\left(\mathrm{Al}_{2} \mathrm{O}_{3}, \mathrm{ZrO}_{2}\right)$ (Figure 48(b)). The monoclinic structure was also identified for the zirconia phase. The most intense peaks of the $\mathrm{TaSi}_{2}$ phase were detected at $2 \theta$ of $25.4^{\circ}, 34.9^{\circ}, 40.1^{\circ}$ and $47.0^{\circ}$ reflecting the $(011)$, (012), (111) and (112) planes, respectively. The major diffraction peaks of the hexagonal $\mathrm{Ta}_{5} \mathrm{Si}_{3}$ phase were found to be situated at $2 \theta$ of $29.2^{\circ}, 36.5^{\circ}$ and $42.0^{\circ}$, corresponding to the (111), (120) and (112) planes, respectively. In contrast with the $\mathrm{NbSi}_{2}$-based composites, the intermediate $\mathrm{Ta}_{5} \mathrm{Si}_{3}$ diffraction peaks are relatively more intense in the $\mathrm{TaSi}_{2}-\mathrm{ZrO}_{2}$ compared to the $\mathrm{TaSi}_{2}-\mathrm{Al}_{2} \mathrm{O}_{3}$ composite system after sintering.

It is known that the transition metal disilicides studied for high-temperature applications exhibit two crystal structures, which are $\mathrm{C} 11_{\mathrm{b}}$ body-centered tetragonal $\left(\mathrm{MoSi}_{2}\right.$, $\mathrm{WSi}_{2}$ etc.) and $\mathrm{C} 40$ hexagonal ( $\mathrm{NbSi}_{2}, \mathrm{CrSi}_{2}, \mathrm{TaSi}_{2}$ etc.) $[1,2,17]$. However, some studies reported that the transition metal silicides having the 5-3 stoichiometry, such as $\mathrm{Nb}_{5} \mathrm{Si}_{3}$, $\mathrm{Ta}_{5} \mathrm{Si}_{3}$ and $\mathrm{Mo}_{5} \mathrm{Si}_{3}$, also possess higher melting points $\left(\mathrm{Nb}_{5} \mathrm{Si}_{3}: 2515^{\circ} \mathrm{C}\right.$; $\left.\mathrm{Ta}_{5} \mathrm{Si}_{3}: 2550^{\circ} \mathrm{C}\right)$, good thermal stability, sufficient mechanical properties and high creep resistance at 
elevated temperatures $[5,19,22]$. Based on the $\mathrm{Nb}-\mathrm{Si}$ and Ta-Si binary phase diagrams, both the $\mathrm{Nb}_{5} \mathrm{Si}_{3}$ and $\mathrm{Ta}_{5} \mathrm{Si}_{3}$ intermediate phases can similarly exist in the two tetragonal equilibrium forms $\left(\alpha-\mathrm{Nb}_{5} \mathrm{Si}_{3}, \beta-\mathrm{Nb}_{5} \mathrm{Si}_{3}\right.$, etc.) and one metastable hexagonal form $[21,41-$ 43]. The structure of the intermediate $\mathrm{Nb}_{5} \mathrm{Si}_{3}$ and $\mathrm{Ta}_{5} \mathrm{Si}_{3}$ phases formed during sintering at $1600^{\circ} \mathrm{C}$ was identified as hexagonal in this study. It was demonstrated that these 5-3 metal silicides, having the hexagonal structure, could be observed in the presence of impurities such as carbon, boron, nitrogen and oxygen, which tend to stabilize their hexagonal form instead of the tetragonal $[42,44]$. Therefore, the formation of $\mathrm{Nb}_{5} \mathrm{Si}_{3}$ and $\mathrm{Ta}_{5} \mathrm{Si}_{3}$ phases in the hexagonal form could be an indication of the existence of impurities in small amounts that could not be detected within the $\mathrm{NbSi}_{2}$ - and $\mathrm{TaSi}_{2}$-based composites by XRD. This could be caused by a small degree of impurities that may potentially exist within the starting silicide and/or oxide powders (e.g. Hf in the commercial $\mathrm{ZrO}_{2}$ ), or entrapped oxygen in the pore structures. Similar types of observations regarding the formation of such hexagonal intermediate 5-3 silicide phases both in bulk and thin film samples were reported in several studies $[24,25,42,44,45]$. In the case of their formation mechanism, metal disilicides $\left(\mathrm{NbSi}_{2}, \mathrm{TaSi}_{2}\right)$ could interact with residual oxygen that remained in the starting silicide powders, or was entrapped within the pores during processing of the composites. It is known that $\mathrm{NbSi}_{2}$ and $\mathrm{TaSi}_{2}$, like most of the transition metal disilicides, will react with oxygen at high-temperatures to form their 5-3 metal silicide and $\mathrm{SiO}_{2}$ phases $[18,24,30,46]$.

In addition to the phase development within the $\mathrm{NbSi}_{2}$ - and $\mathrm{TaSi}_{2}$-based composites during high-temperature sintering, their short- and long-term phase (thermal) stability is very crucial for their potential use in high-temperature sensing applications required for long operation with high thermal stability and measurement accuracy [47-49]. Therefore, the high temperature phase stability studies were also performed on the $\mathrm{NbSi}_{2}$ - and $\mathrm{TaSi}_{2}$ based composites after further annealing at $1400^{\circ} \mathrm{C}$ for 24,48 and $96 \mathrm{~h}$ in argon. Their XRD patterns after high-temperature annealing are presented in Figure 49, focusing on the $2 \theta$ region ranging from $20^{\circ}$ to $50^{\circ}$ due to the major diffraction peaks of the disilicides and 5-3 silicides. For all these composites, the most intense peaks were found to be attributed to 

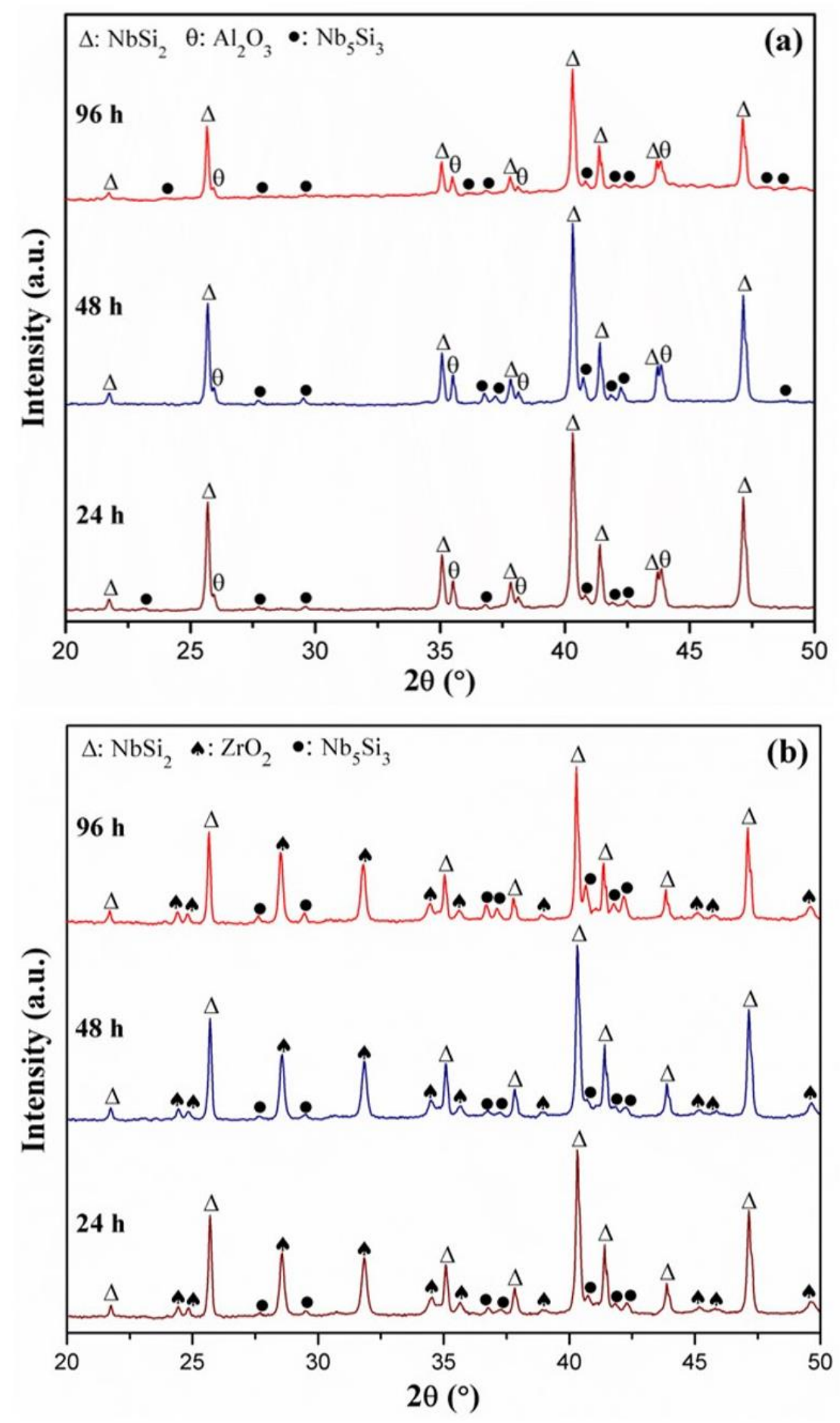

Figure 49. $\mathrm{XRD}$ patterns of the (a) $\mathrm{NbSi}_{2}-\mathrm{Al}_{2} \mathrm{O}_{3}$, (b) $\mathrm{NbSi}_{2}-\mathrm{ZrO}_{2}$, (c) $\mathrm{TaSi}_{2}-\mathrm{Al}_{2} \mathrm{O}_{3}$, and (d) $\mathrm{TaSi}_{2}-\mathrm{ZrO}_{2}$ composites with the addition of $40 \mathrm{vol} \%$ alumina and zirconia particles, all further annealed at $1400^{\circ} \mathrm{C}$ for 24,48 and $96 \mathrm{~h}$ in argon. 

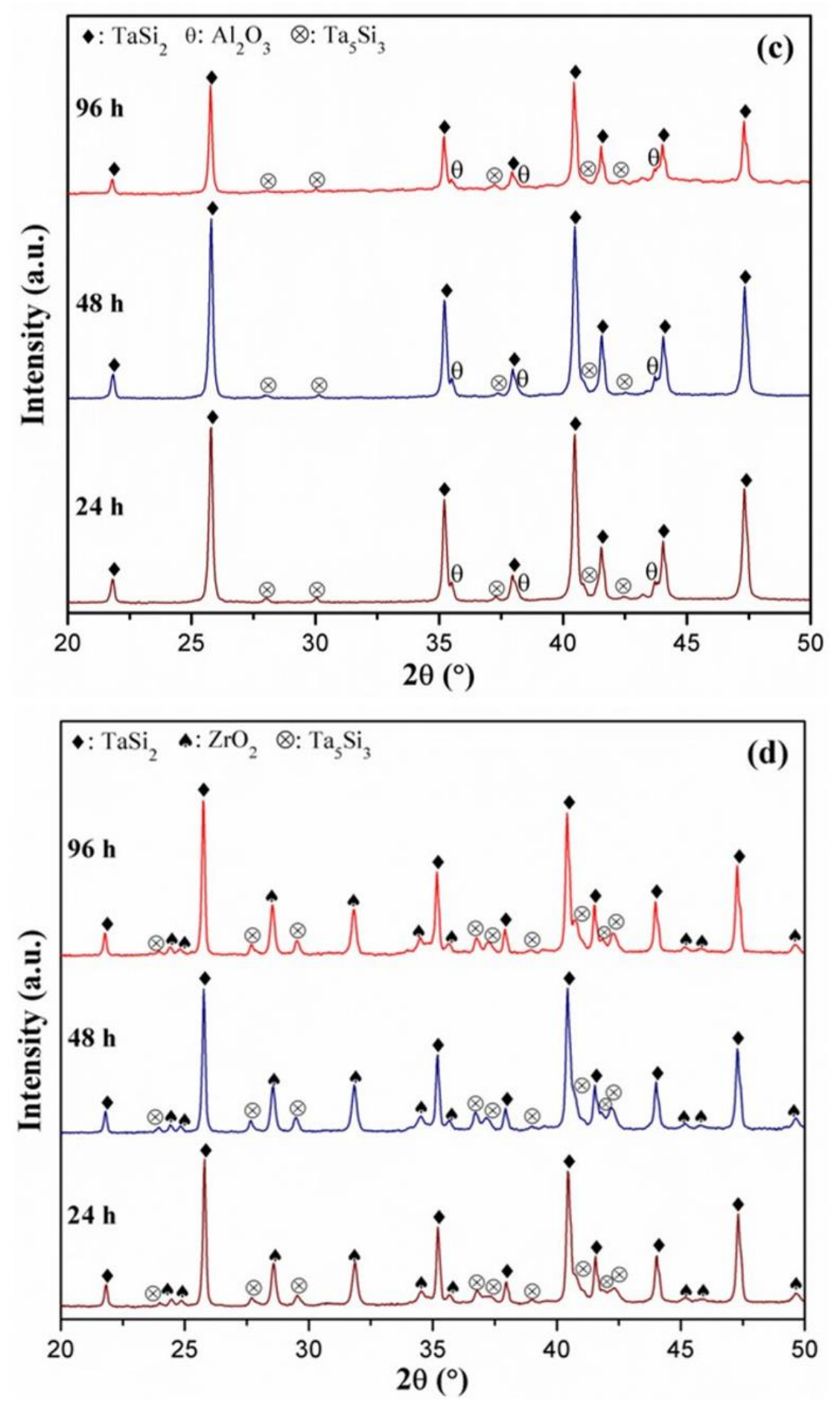

Figure 49. (continued) $\mathrm{XRD}$ patterns of the (a) $\mathrm{NbSi}_{2}-\mathrm{Al}_{2} \mathrm{O}_{3}$, (b) $\mathrm{NbSi}_{2}-\mathrm{ZrO}_{2}$, (c) $\mathrm{TaSi}_{2}$ $\mathrm{Al}_{2} \mathrm{O}_{3}$, and (d) $\mathrm{TaSi}_{2}-\mathrm{ZrO}_{2}$ composites with the addition of $40 \mathrm{vol} \%$ alumina and zirconia particles, all further annealed at $1400^{\circ} \mathrm{C}$ for 24,48 and $96 \mathrm{~h}$ in argon. 
metal disilicides $\left(\mathrm{NbSi}_{2}, \mathrm{TaSi}_{2}\right)$ and refractory oxides $\left(\mathrm{Al}_{2} \mathrm{O}_{3}, \mathrm{ZrO}_{2}\right)$. Additionally, the intermediate 5-3 metal silicide phases $\left(\mathrm{Nb}_{5} \mathrm{Si}_{3}, \mathrm{Ta}_{5} \mathrm{Si}_{3}\right)$ existed within the composite systems after annealing up to $96 \mathrm{~h}$, similar to the XRD results after sintering. An increase in the peak intensities of the 5-3 metal silicide phases was also detected for all these composites as a function of annealing time; however, it was found to be more significant within the $60-40 \mathrm{NbSi}_{2}-\mathrm{ZrO}_{2}$ and $\mathrm{TaSi}_{2}-\mathrm{ZrO}_{2}$ composites (Figure 49(b-d)) compared to the other composite systems consisting of alumina particles (Figure 49(a-c)). These results clearly demonstrated that the $\mathrm{NbSi}_{2}$ - and $\mathrm{TaSi}_{2}$-based composites did not undergo any compositional (thermal) decomposition at $1400^{\circ} \mathrm{C}$ within the time period ranging from 24 to $96 \mathrm{~h}$. The detected peak intensity changes may imply relative increments in the volume percentages of the 5-3 silicide phases as a function of annealing time. In addition, more significant intensity changes for the silicide-zirconia composites may be related to more interaction of these metal disilicides with zirconia particles at high-temperatures due to their coarser grain size. Significantly higher porosity levels (27.6-30.6\%) existing in the silicide-zirconia composites could also possibly lead to further reaction of the $\mathrm{NbSi}_{2}$ and $\mathrm{TaSi}_{2}$ with residual oxygen at high-temperatures resulting in more 5-3 silicide formation with increased annealing time. No study was reported on the thermal stability of the $\mathrm{NbSi}_{2}-$ and $\mathrm{TaSi}_{2}$-oxide composites, and there is only a limited number of papers discussing the solid-state synthesis (e.g. combustion, mechanical alloying) and mechanical characterization of the $\mathrm{NbSi}_{2}$ - and $\mathrm{TaSi}_{2}$-alumina composites [17,20,50].

To understand the change in the amounts of these 5-3 metal silicide phases, 60-40 $\mathrm{NbSi}_{2}$-based composites were examined by applying the Rietveld refinement method on the XRD patterns of the composites after both sintering and annealing processes at high temperatures. It is important to note that the $\mathrm{TaSi}_{2}$-based composites could not be similarly studied here, due to the lack of the crystallographic information file (CIF) for the $\mathrm{Ta}_{5} \mathrm{Si}_{3}$ phase in the related databases. As the main parameters of the Rietveld analysis, the goodness-of-fit (sig) and percentage weighted profile R-factor $\left(\mathrm{R}_{\mathrm{wp}}\right)$ were determined as $1.48-2.06$ and 1.86-4.47, respectively, indicating the high quality of the Rietveld refinement 


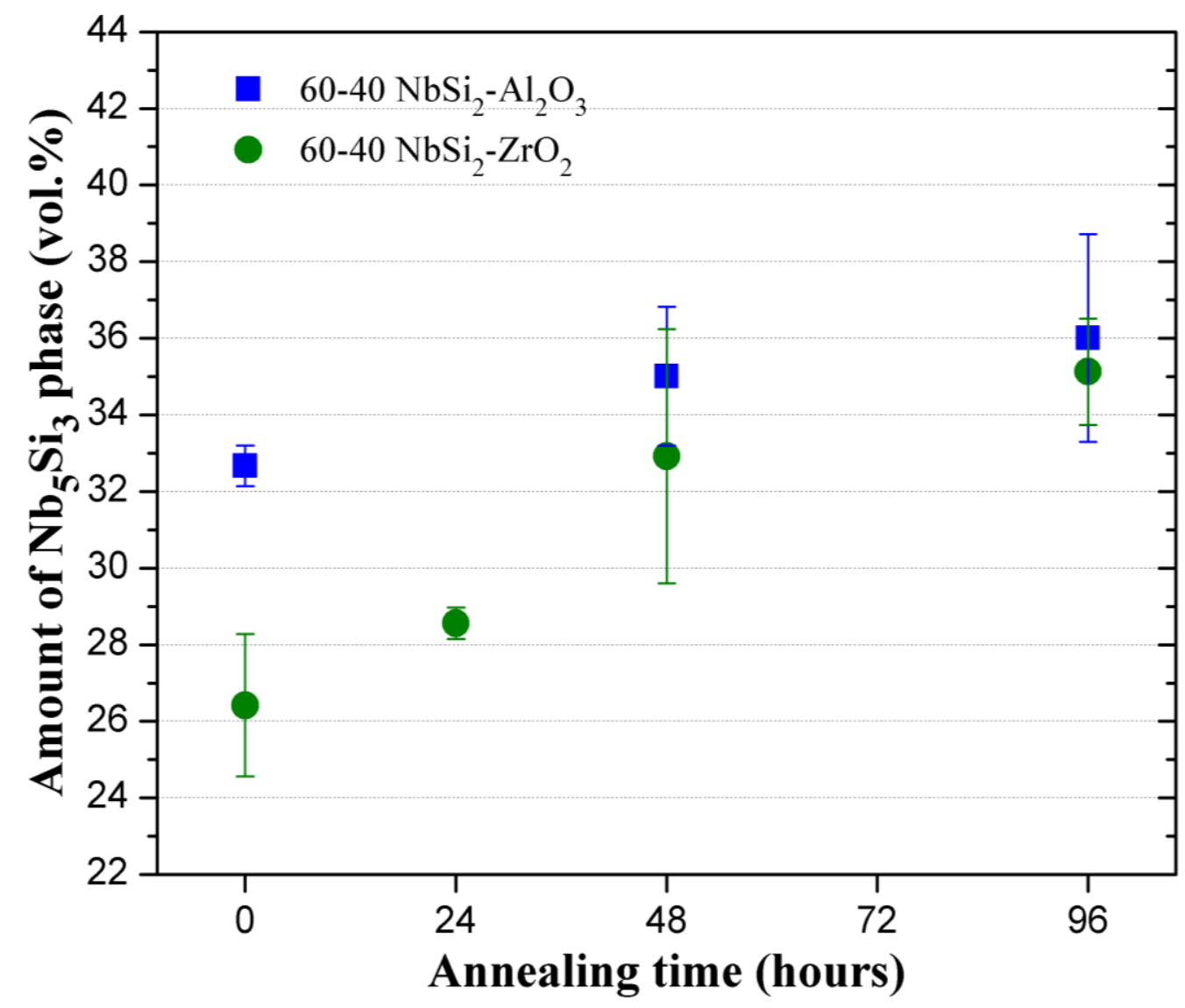

Figure 50. Changes in the volume percentage of the $\mathrm{Nb}_{5} \mathrm{Si}_{3}$ secondary phase within the 60-40 $\mathrm{NbSi}_{2}-\mathrm{Al}_{2} \mathrm{O}_{3}$ and $\mathrm{NbSi}_{2}-\mathrm{ZrO}_{2}$ composites as a function of annealing time.

[33]. Figure 50 shows the changes in the amount of the secondary $\mathrm{Nb}_{5} \mathrm{Si}_{3}$ phase within the $60-40 \mathrm{NbSi}_{2}-\mathrm{Al}_{2} \mathrm{O}_{3}$ and $60-40 \mathrm{NbSi}_{2}-\mathrm{ZrO}_{2}$ composites as a function of annealing time. The refinement parameters were found to be relatively higher than the required values for the 60-40 $\mathrm{NbSi}_{2}-\mathrm{Al}_{2} \mathrm{O}_{3}$ annealed at $1400^{\circ} \mathrm{C}$ for $24 \mathrm{~h}$; therefore, only its quantitative phase analysis data is not presented here. The starting data points represented at "0 hour" annealing time in Figure 50 correspond to the volume percentages of the $\mathrm{Nb}_{5} \mathrm{Si}_{3}$ phase within these composites only after sintering (with no annealing). The amount of the $\mathrm{Nb}_{5} \mathrm{Si}_{3}$ phase in the $\mathrm{NbSi}_{2}-\mathrm{Al}_{2} \mathrm{O}_{3}\left(32.7 \mathrm{vol} \%\right.$ ) was substantially higher than that in the $\mathrm{NbSi}_{2}-\mathrm{ZrO}_{2}$ composite $(26.4 \mathrm{vol} \%)$ after sintering at $1600^{\circ} \mathrm{C}$. It is apparent that the amount of the $\mathrm{Nb}_{5} \mathrm{Si}_{3}$ phase increased with increasing annealing time up to $96 \mathrm{~h}$ for all $\mathrm{NbSi}_{2}$-based 
composites. While its volume percentage increased from 32.7 to 36.0 vol\% within the 60 $40 \mathrm{NbSi}_{2}-\mathrm{Al}_{2} \mathrm{O}_{3}$ composite, this increase was found to be from 26.4 to $35.1 \mathrm{vol} \%$ for the 60-40 $\mathrm{NbSi}_{2}-\mathrm{ZrO}_{2}$ composite. Therefore, the level of increase was significantly higher within the $\mathrm{NbSi}_{2}-\mathrm{ZrO}_{2}$ system, particularly at the annealing period from 0 to $48 \mathrm{~h}$. In addition, it can be clearly seen from Figure 50 that the rate of increase decelerated after 48 $\mathrm{h}$ of annealing. However, the Rietveld results displayed close amounts of the $\mathrm{Nb}_{5} \mathrm{Si}_{3}$ phase for the $\mathrm{NbSi}_{2}-\mathrm{Al}_{2} \mathrm{O}_{3}$ and $\mathrm{NbSi}_{2}-\mathrm{ZrO}_{2}$ composites after annealing at $1400^{\circ} \mathrm{C}$ for $96 \mathrm{~h}$. It should be also noted that the $\mathrm{Nb}_{5} \mathrm{Si}_{3}$ became the major silicide phase within these composites after $48 \mathrm{~h}$ of annealing. As a review, the increase in the amount of the $\mathrm{Nb}_{5} \mathrm{Si}_{3}$

phase within the $\mathrm{NbSi}_{2}-\mathrm{ZrO}_{2}$ composite as a function of time was found to be mostly related to its higher porosity level (27.6\%) compared to the $\mathrm{NbSi}_{2}-\mathrm{Al}_{2} \mathrm{O}_{3}$ composite (11.8\%), since it possibly increased the oxygen diffusion into the composite from residual sources, and thus, more favored the reaction of the $\mathrm{NbSi}_{2}$ phase with oxygen at hightemperatures. The slower kinetics for high-temperature oxidation reactions and related formation of the $\mathrm{Nb}_{5} \mathrm{Si}_{3}$ phase observed after $48 \mathrm{~h}$ could be related to the reduced amount of open surface area of the $\mathrm{NbSi}_{2}$ phase over time due to the initial formation of the $\mathrm{Nb}_{5} \mathrm{Si}_{3}$ phase and silica layer at grain boundaries and surface [46]. Similar trends may be also assumed for the formation of the $\mathrm{Ta}_{5} \mathrm{Si}_{3}$ phase within $\mathrm{TaSi}_{2}-\mathrm{Al}_{2} \mathrm{O}_{3}$ and $\mathrm{TaSi}_{2}-\mathrm{ZrO}_{2}$ composite systems, since our previous study [30] on the $\mathrm{MoSi}_{2}$ - and $\mathrm{WSi}_{2}$-oxide composites also demonstrated such trends for the 5-3 metal silicide phase formation as a function of annealing time at high-temperatures.

\subsubsection{Microstructural evolution at high-temperatures}

The microstructures of the $\mathrm{NbSi}_{2}$ - and $\mathrm{TaSi}_{2}$-based composites were analyzed after sintering and further annealing processes, to investigate the particle distribution, microstructural evolution and secondary phase formation within these systems. Figure 51 presents the backscattered SEM microstructures of these composites with the addition of 40 vol\% refractory oxide after sintering at $1600^{\circ} \mathrm{C}$ for $2 \mathrm{~h}$ in argon at relatively low magnifications. In the $\mathrm{NbSi}_{2}-\mathrm{Al}_{2} \mathrm{O}_{3}$ microstructure, gray and dark regions refer to the $\mathrm{NbSi}_{2}$ 

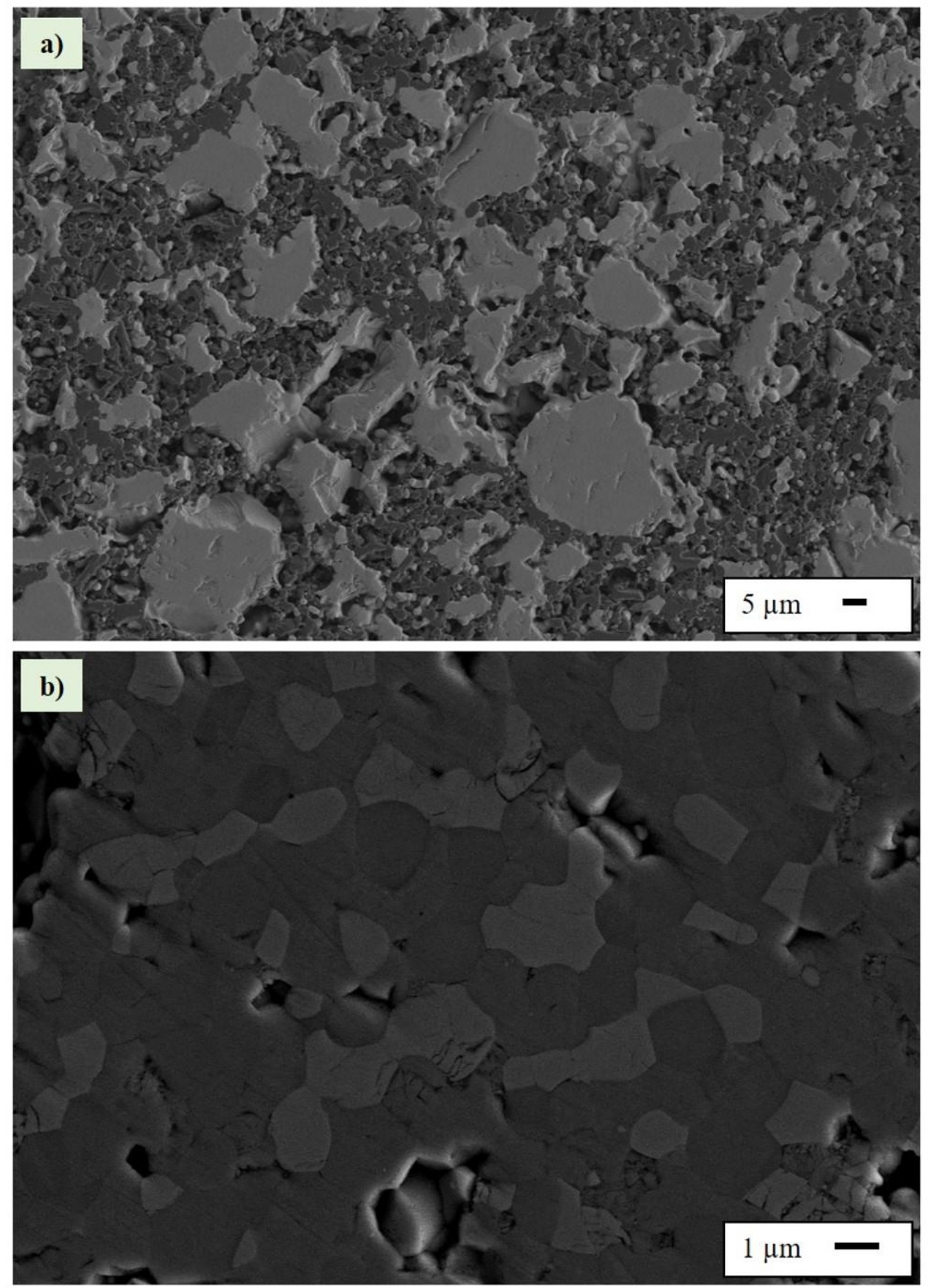

Figure 51. Low magnification backscattered SEM microstructures of the (a) $\mathrm{NbSi}_{2}$ $\mathrm{Al}_{2} \mathrm{O}_{3}$, (b) $\mathrm{NbSi}_{2}-\mathrm{ZrO}_{2}$, (c) $\mathrm{TaSi}_{2}-\mathrm{Al}_{2} \mathrm{O}_{3}$, and (d) $\mathrm{TaSi}_{2}-\mathrm{ZrO}_{2}$ composites with the addition of $40 \mathrm{vol} \% \mathrm{Al}_{2} \mathrm{O}_{3}$ and $\mathrm{ZrO}_{2}$ particles after sintering at $1600^{\circ} \mathrm{C}$ for $2 \mathrm{~h}$ in argon. 

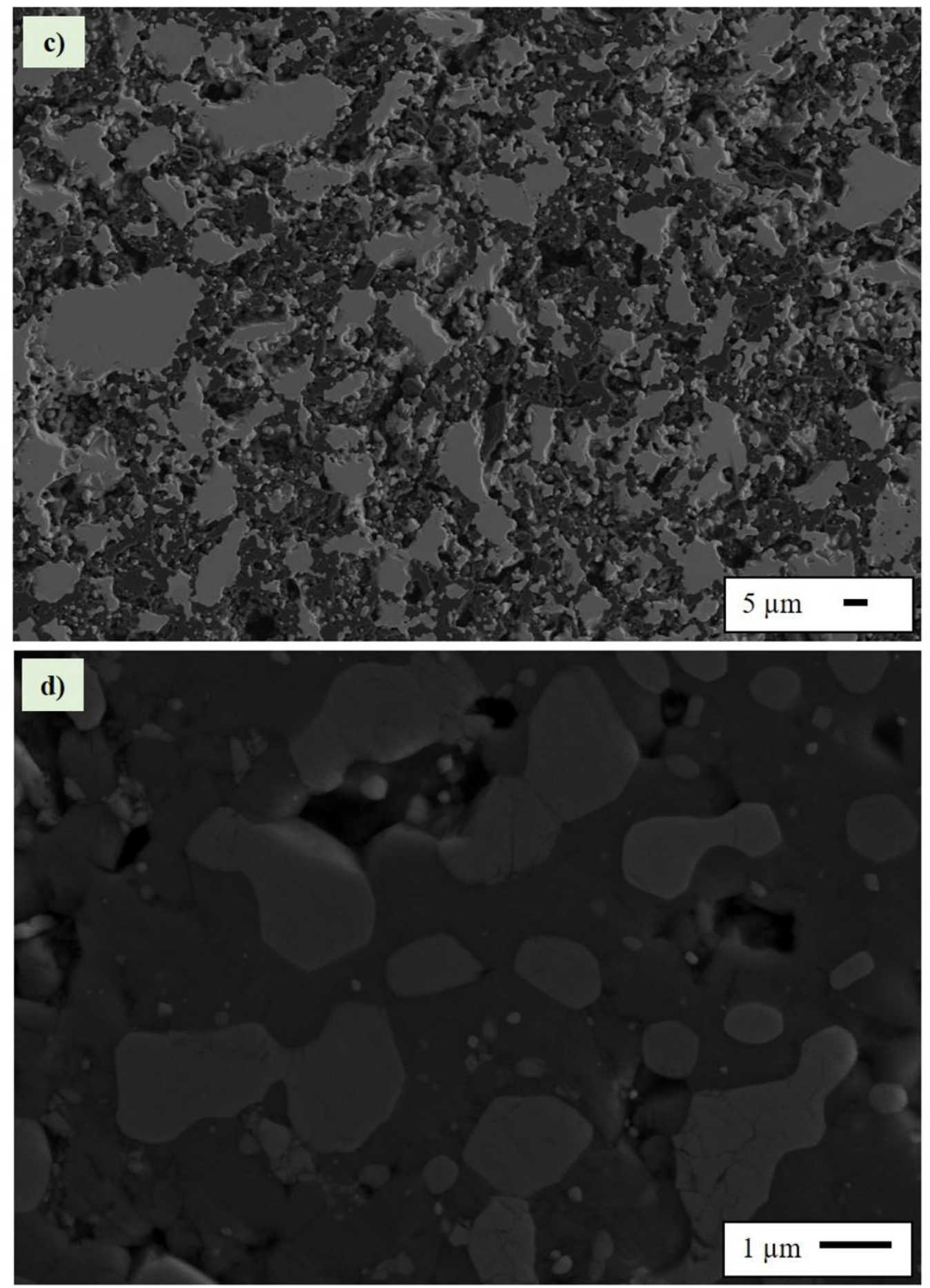

Figure 51. (continued) Low magnification backscattered SEM microstructures of the (a) $\mathrm{NbSi}_{2}-\mathrm{Al}_{2} \mathrm{O}_{3}$, (b) $\mathrm{NbSi}_{2}-\mathrm{ZrO}_{2}$, (c) $\mathrm{TaSi}_{2}-\mathrm{Al}_{2} \mathrm{O}_{3}$, and (d) $\mathrm{TaSi}_{2}-\mathrm{ZrO}_{2}$ composites with the addition of $40 \mathrm{vol} \% \mathrm{Al}_{2} \mathrm{O}_{3}$ and $\mathrm{ZrO}_{2}$ particles after sintering at $1600^{\circ} \mathrm{C}$ for $2 \mathrm{~h}$ in argon. 
and $\mathrm{Al}_{2} \mathrm{O}_{3}$ grains, respectively (Figure 51(a)). It was observed that the micron-sized niobium silicide grains were homogeneously distributed between the insulating alumina grains. However, three different phases can be clearly seen within the microstructure of the as-sintered $\mathrm{NbSi}_{2}-\mathrm{ZrO}_{2}$ composite, where the bright, gray and dark regions indicate $\mathrm{Nb}_{5} \mathrm{Si}_{3}$, $\mathrm{ZrO}_{2}$ and $\mathrm{NbSi}_{2}$ grains, respectively (Figure 51(b)). It was found that the intermediate $\mathrm{Nb}_{5} \mathrm{Si}_{3}$ grains (bright regions) were formed mostly around the $\mathrm{NbSi}_{2}$ grains (dark regions), which resulted in the formation of different interfaces $\left(\mathrm{NbSi}_{2}-\mathrm{Nb}_{5} \mathrm{Si}_{3}\right.$ and $\left.\mathrm{Nb}_{5} \mathrm{Si}_{3}-\mathrm{ZrO}_{2}\right)$ and $\mathrm{NbSi}_{2}-\mathrm{ZrO}_{2}-\mathrm{Nb}_{5} \mathrm{Si}_{3}$ triple phase boundaries. Additionally, it should be noted that the $\mathrm{Nb}_{5} \mathrm{Si}_{3}$ grains and their formation from the $\mathrm{NbSi}_{2}$ grain boundaries could positively affect the percolation and electrical properties within the composite. The SEM microstructure of the $\mathrm{TaSi}_{2}-\mathrm{Al}_{2} \mathrm{O}_{3}$ displayed only two phases with a homogeneous distribution at low magnification (Figure 51(c)). Similar results were also observed for the microstructure of the $\mathrm{TaSi}_{2}-\mathrm{ZrO}_{2}$ composite (Figure 51(d)). In the $\mathrm{TaSi}_{2}$-based composites, the gray and dark regions refer to the $\mathrm{TaSi}_{2}$ and refractory oxide $\left(\mathrm{Al}_{2} \mathrm{O}_{3}, \mathrm{ZrO}_{2}\right)$ grains, respectively. As a review, all these composites generally exhibited homogeneous distribution of the conductive metal silicide phases within the insulating oxides, which could positively affect the electrical percolation and reduce the critical percolation concentration [28,51]. Besides, except for the $\mathrm{NbSi}_{2}-\mathrm{ZrO}_{2}$, intermediate 5-3 metal silicide phases were not detected in the other microstructures by SEM under relatively low magnifications.

Additionally, microstructures of these composites were examined at higher magnifications to better characterize the 5-3 metal silicide formation. Figure 52 shows the high magnification backscattered SEM microstructures of the $\mathrm{NbSi}_{2}$ - and $\mathrm{TaSi}_{2}$-based composites with the addition of $40 \mathrm{vol} \%$ refractory oxides after sintering at $1600^{\circ} \mathrm{C}$. For the $\mathrm{NbSi}_{2}$-based composites, the intermediate $\mathrm{Nb}_{5} \mathrm{Si}_{3}$ phases formed during high temperature sintering can be observed in the bright regions as presented on the microstructures (Figure 52(a-b)). Similarly, the intermediate $\mathrm{Ta}_{5} \mathrm{Si}_{3}$ phases were also detected for the $\mathrm{TaSi}_{2}$-based composites at high magnifications as seen in Figure 52(c-d). The presence of the 5-3 metal silicide phases was additionally identified by utilizing the energy dispersive spectroscopy 

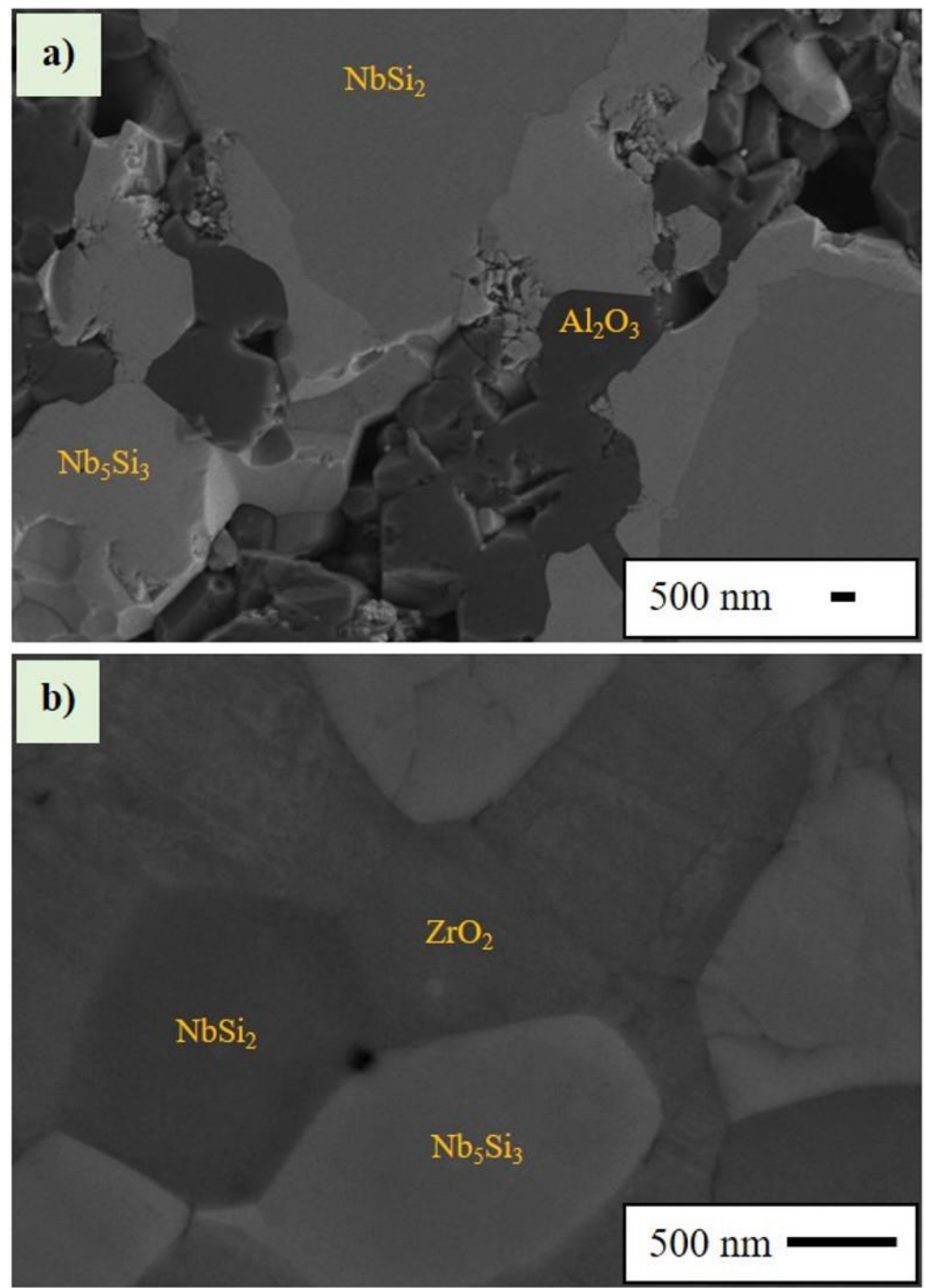

Figure 52. High magnification backscattered SEM microstructures of the (a) $\mathrm{NbSi}_{2}$ $\mathrm{Al}_{2} \mathrm{O}_{3}$, (b) $\mathrm{NbSi}_{2}-\mathrm{ZrO}_{2}$, (c) $\mathrm{TaSi}_{2}-\mathrm{Al}_{2} \mathrm{O}_{3}$, and (d) $\mathrm{TaSi}_{2}-\mathrm{ZrO}_{2}$ composites with the addition of $40 \mathrm{vol} \% \mathrm{Al}_{2} \mathrm{O}_{3}$ and $\mathrm{ZrO}_{2}$ particles after sintering at $1600^{\circ} \mathrm{C}$ for $2 \mathrm{~h}$ in argon. 


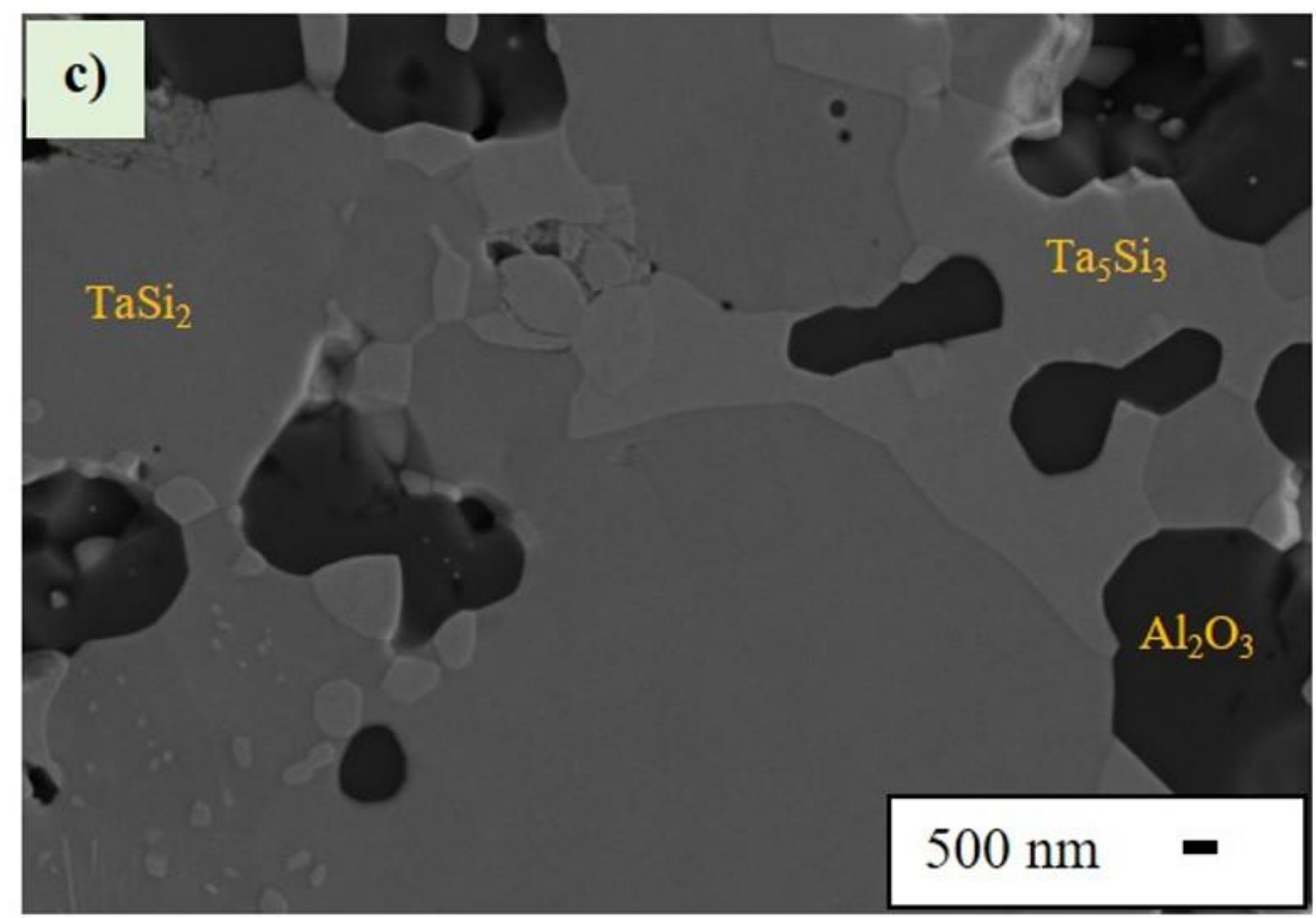

d)

Figure 52. (continued) High magnification backscattered SEM microstructures of the (a) $\mathrm{NbSi}_{2}-\mathrm{Al}_{2} \mathrm{O}_{3}$, (b) $\mathrm{NbSi}_{2}-\mathrm{ZrO}_{2}$, (c) $\mathrm{TaSi}_{2}-\mathrm{Al}_{2} \mathrm{O}_{3}$, and (d) $\mathrm{TaSi}_{2}-\mathrm{ZrO}_{2}$ composites with the addition of $40 \mathrm{vol} \% \mathrm{Al}_{2} \mathrm{O}_{3}$ and $\mathrm{ZrO}_{2}$ particles after sintering at $1600^{\circ} \mathrm{C}$ for $2 \mathrm{~h}$ in argon. 
(EDS) on the related regions of the microstructures. The average weight percentages of niobium $(\mathrm{Nb})$ and silicon $(\mathrm{Si})$ elements in the bright microstructural areas of the $\mathrm{NbSi}_{2}-$ based composites were measured as 82.3 and $17.7 \mathrm{wt} \%$, respectively. For the $\mathrm{TaSi}_{2}$-based composites, the EDS quantification results revealed $91.0 \mathrm{wt} \%$ of tantalum (Ta) and 9.0 $\mathrm{wt} \%$ of Si elements for the related bright regions. These results clearly demonstrated the formation of these intermediate phases in 5-3 stoichiometry, as previously supported with the XRD results. Furthermore, it could be proposed based on the SEM/EDS results that the 5-3 metal silicide phases started to form at the metal disilicide-oxide grain boundaries, and then continued to grow towards the metal disilicide grains. This formation could be attributed to the reaction of the metal disilicides with the entrapped or grain boundary diffused oxygen from environmental sources at high temperatures $[18,24,46]$. These results hereby demonstrated that the intermediate 5-3 silicide phase formation was predominantly controlled by high-temperature oxidation reactions of the metal disilicides. This also resulted in the reduction of the volume percentages of the metal disilicides; and thus, the increase in the amount of the 5-3 metal silicide phases within these composite systems as a function of increasing temperature (above $1000^{\circ} \mathrm{C}$ ) and hold time. This correlates well with the previously discussed $\mathrm{XRD} /$ Rietveld results. The formation of the secondary $\mathrm{Nb}_{5} \mathrm{Si}_{3}$ phase was similarly presented by Binbin et al. [12] within a microstructure of the dense monolithic $\mathrm{NbSi}_{2}$ sample, which was prepared by self-propagating high-temperature synthesis followed by hot pressing. Its formation was explained with the loss of silicon from the $\mathrm{NbSi}_{2}$ phase in that study. The secondary $\mathrm{Ta}_{5} \mathrm{Si}_{3}$ phase was identified within the $\mathrm{HfB}_{2}-\mathrm{TaSi}_{2}$ composite by electron diffraction, which was also correlated to the removal of the oxide phases controlled by the high-temperature oxidation reaction of the $\mathrm{TaSi}_{2}$ [24].

The microstructural evolution and intermediate 5-3 silicide phase formation was further investigated after annealing of the composites at high-temperature up to $96 \mathrm{~h}$. The SEM microstructures of the $\mathrm{NbSi}_{2}$ - and $\mathrm{TaSi}_{2}$-based composites having 40 vol\% oxide additions, which were annealed at $1400^{\circ} \mathrm{C}$ for 48 and $96 \mathrm{~h}$, are presented in Figure 53. The SEM images are denoted by the (a1-b1-c1-d1), representing their microstructures after 

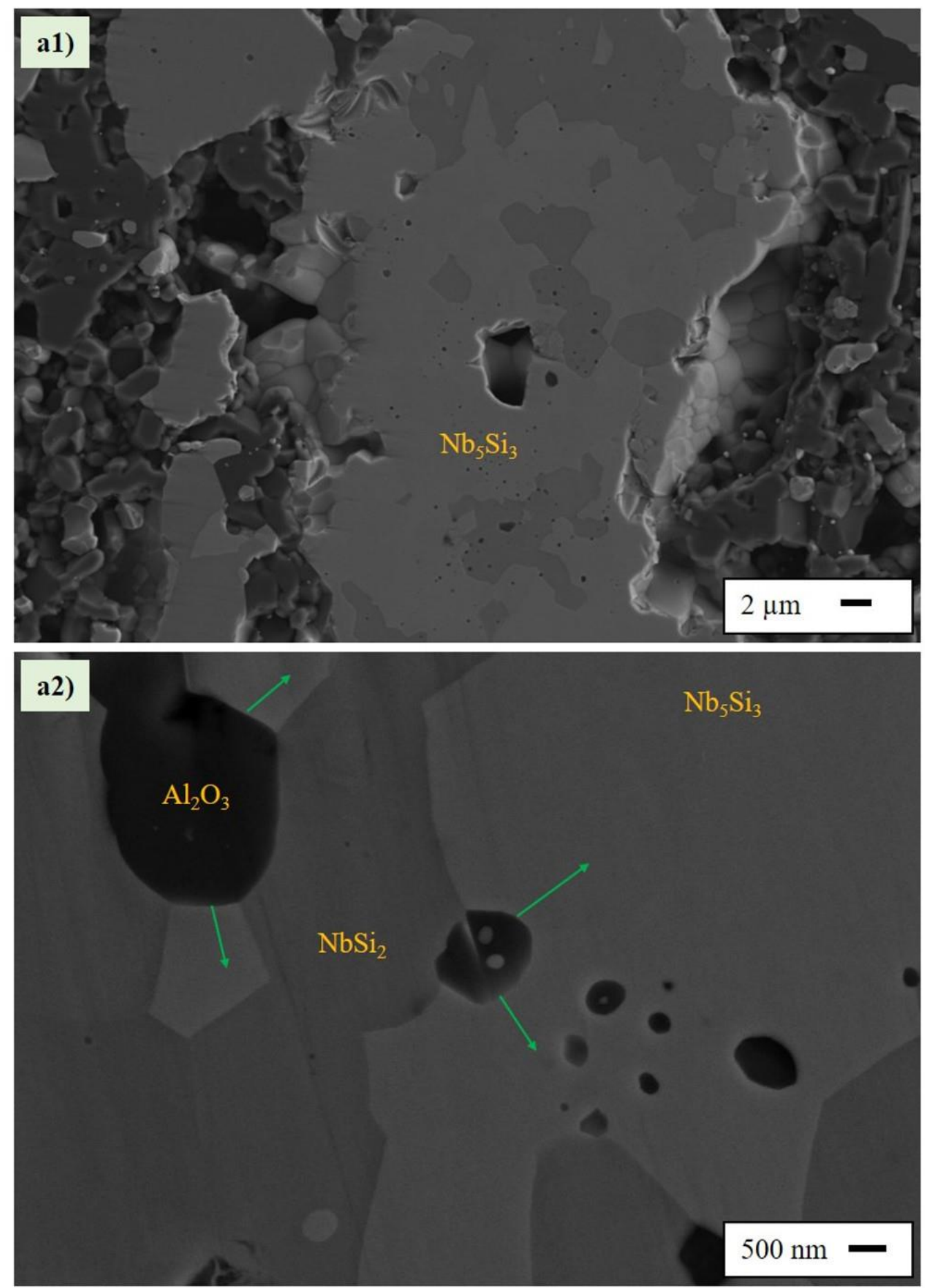

Figure 53. $\mathrm{SEM}$ microstructures of the (a1-a2) $\mathrm{NbSi}_{2}-\mathrm{Al}_{2} \mathrm{O}_{3}$, (b1-b2) $\mathrm{NbSi}_{2}-\mathrm{ZrO}_{2}$, (c1c2) $\mathrm{TaSi}_{2}-\mathrm{Al}_{2} \mathrm{O}_{3}$, and (d1-d2) $\mathrm{TaSi}_{2}-\mathrm{ZrO}_{2}$ composites with addition of $40 \mathrm{vol} \% \mathrm{Al}_{2} \mathrm{O}_{3}$ and $\mathrm{ZrO}_{2}$ particles after annealing at $1400^{\circ} \mathrm{C}$ for 48 and $96 \mathrm{~h}$ in argon, respectively. (a1-b1c1-d1: after annealing for 48 ; a2-b2-c2-d2: after annealing for $96 \mathrm{~h}$ ). 


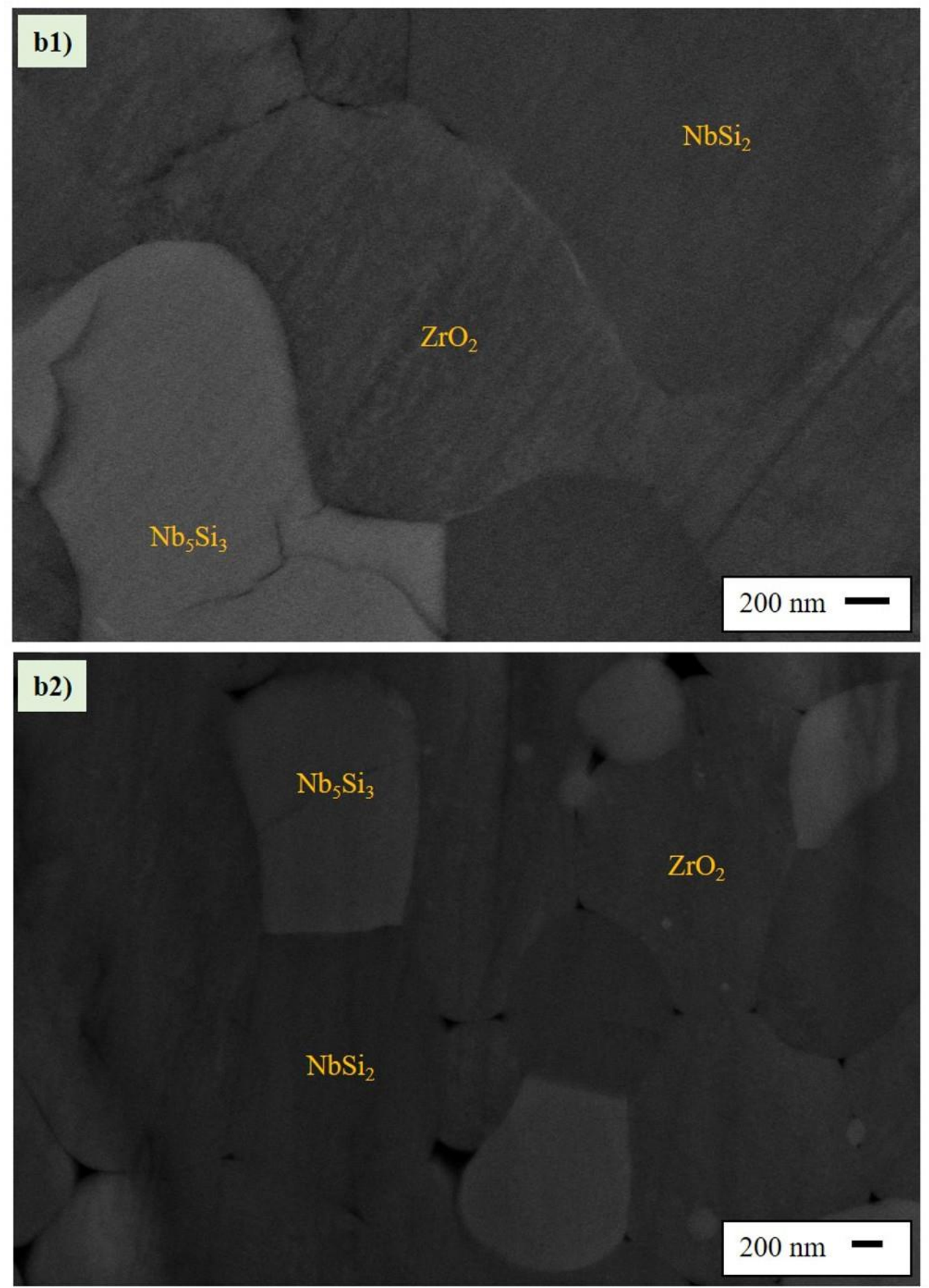

Figure 53. (continued) $\mathrm{SEM}$ microstructures of the (a1-a2) $\mathrm{NbSi}_{2}-\mathrm{Al}_{2} \mathrm{O}_{3}$, (b1-b2) $\mathrm{NbSi}_{2}$ $\mathrm{ZrO}_{2}$, (c1-c2) $\mathrm{TaSi}_{2}-\mathrm{Al}_{2} \mathrm{O}_{3}$, and (d1-d2) $\mathrm{TaSi}_{2}-\mathrm{ZrO}_{2}$ composites with addition of $40 \mathrm{vol} \%$ $\mathrm{Al}_{2} \mathrm{O}_{3}$ and $\mathrm{ZrO}_{2}$ particles after annealing at $1400^{\circ} \mathrm{C}$ for 48 and $96 \mathrm{~h}$ in argon, respectively. (a1-b1-c1-d1: after annealing for $48 \mathrm{~h}$; a2-b2-c2-d2: after annealing for $96 \mathrm{~h}$ ). 


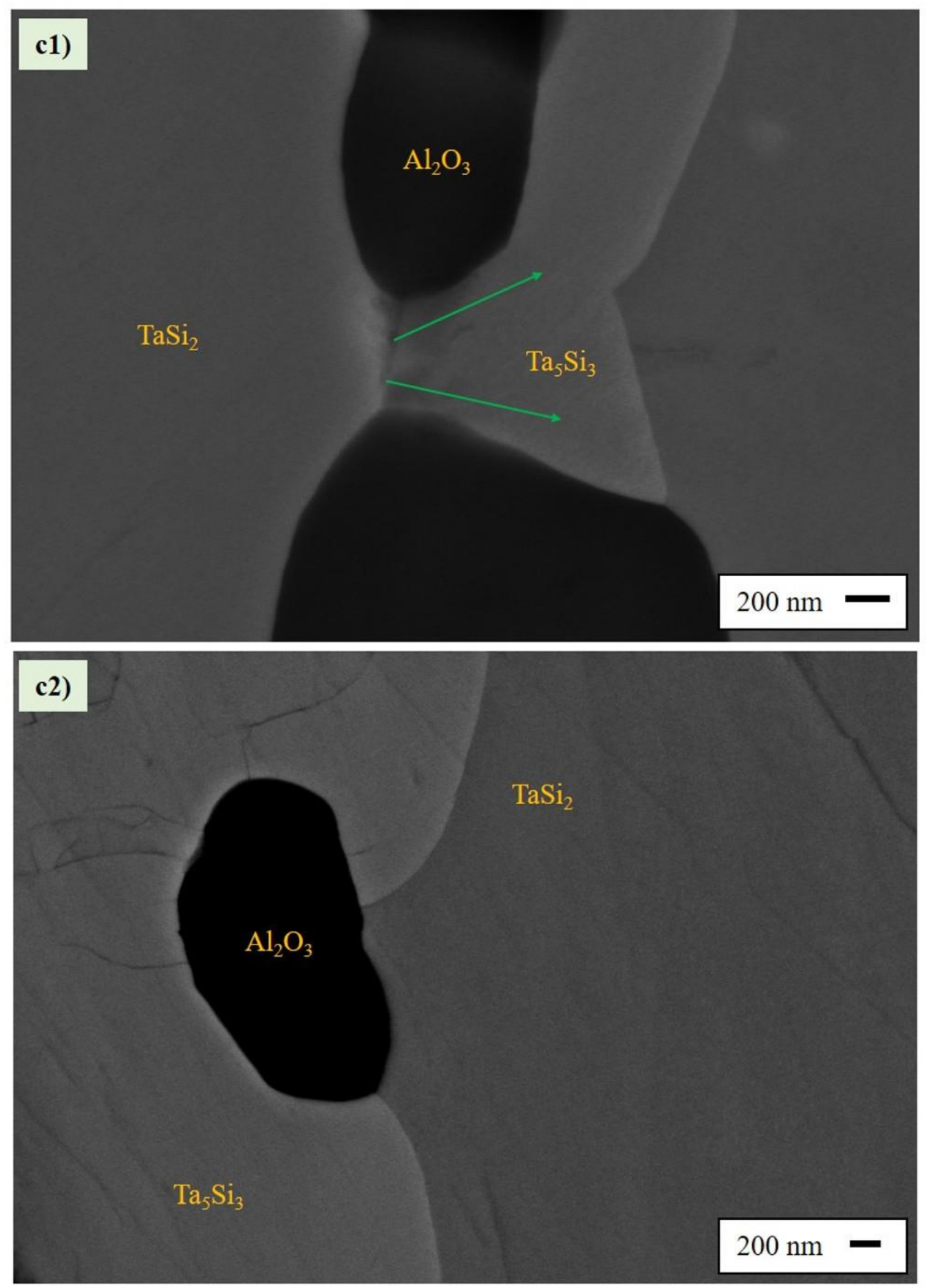

Figure 53. (continued) $\mathrm{SEM}$ microstructures of the (a1-a2) $\mathrm{NbSi}_{2}-\mathrm{Al}_{2} \mathrm{O}_{3}$, (b1-b2) $\mathrm{NbSi}_{2}$ $\mathrm{ZrO}_{2}$, (c1-c2) $\mathrm{TaSi}_{2}-\mathrm{Al}_{2} \mathrm{O}_{3}$, and (d1-d2) $\mathrm{TaSi}_{2}-\mathrm{ZrO}_{2}$ composites with addition of $40 \mathrm{vol} \%$ $\mathrm{Al}_{2} \mathrm{O}_{3}$ and $\mathrm{ZrO}_{2}$ particles after annealing at $1400^{\circ} \mathrm{C}$ for 48 and $96 \mathrm{~h}$ in argon, respectively. (a1-b1-c1-d1: after annealing for $48 \mathrm{~h}$; a2-b2-c2-d2: after annealing for $96 \mathrm{~h}$ ). 

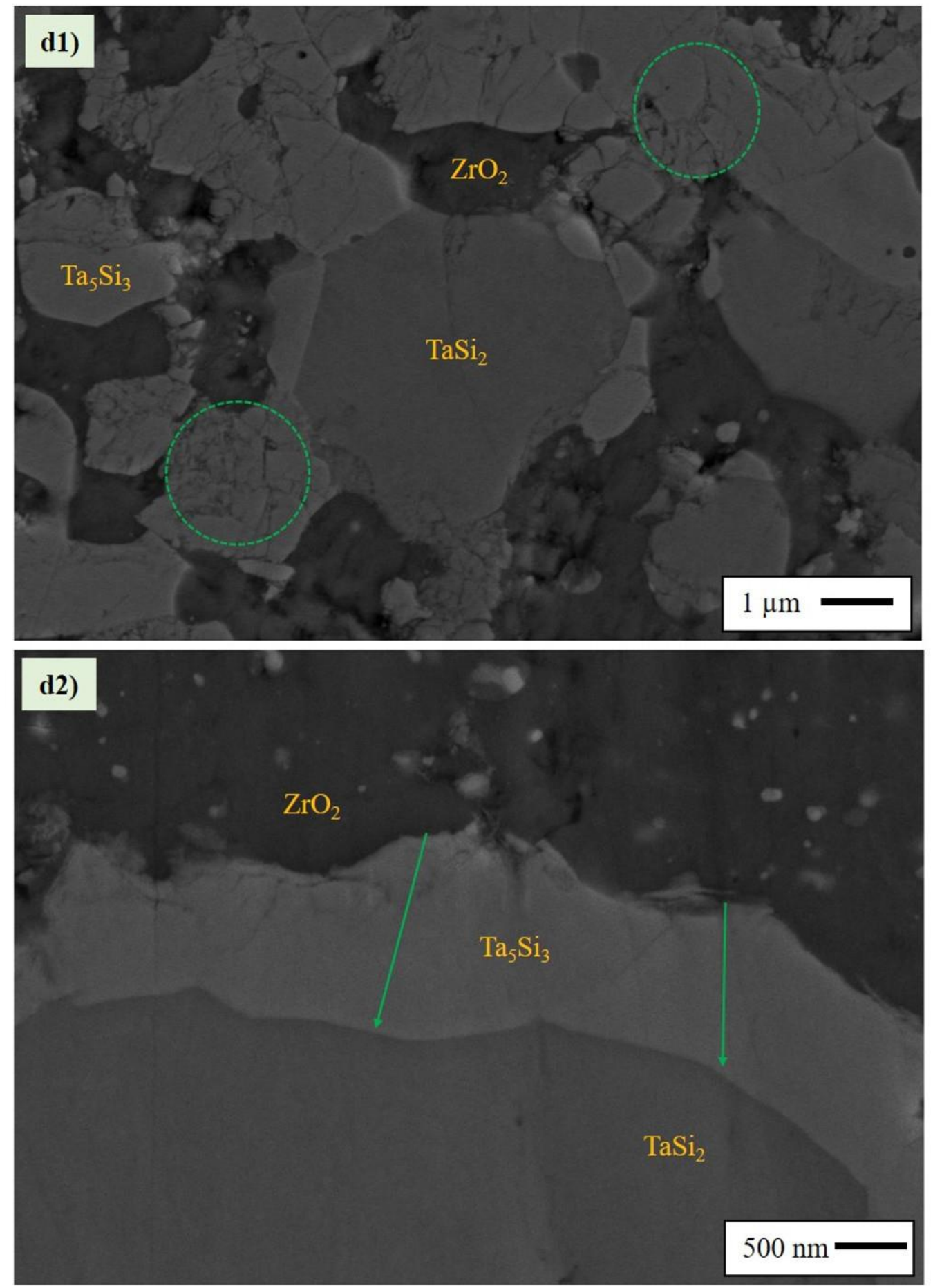

Figure 53. (continued) $\mathrm{SEM}$ microstructures of the (a1-a2) $\mathrm{NbSi}_{2}-\mathrm{Al}_{2} \mathrm{O}_{3}$, (b1-b2) $\mathrm{NbSi}_{2}$ $\mathrm{ZrO}_{2}$, (c1-c2) $\mathrm{TaSi}_{2}-\mathrm{Al}_{2} \mathrm{O}_{3}$, and (d1-d2) $\mathrm{TaSi}_{2}-\mathrm{ZrO}_{2}$ composites with addition of $40 \mathrm{vol} \%$ $\mathrm{Al}_{2} \mathrm{O}_{3}$ and $\mathrm{ZrO}_{2}$ particles after annealing at $1400^{\circ} \mathrm{C}$ for 48 and $96 \mathrm{~h}$ in argon, respectively. (a1-b1-c1-d1: after annealing for $48 \mathrm{~h}$; a2-b2-c2-d2: after annealing for $96 \mathrm{~h}$ ). 
annealing for $48 \mathrm{~h}$, while the (a2-b2-c2-d2) images refer to the microstructures after annealing for $96 \mathrm{~h}$. The presence of the $\mathrm{Nb}_{5} \mathrm{Si}_{3}$ phase can be seen within the microstructures of the $\mathrm{NbSi}_{2}$-based composites after annealing for 48 and $96 \mathrm{~h}$ (a1-a2-b1b2 in the Figure 53). The significant formation of the $\mathrm{Nb}_{5} \mathrm{Si}_{3}$ phase was clearly observed within the $\mathrm{NbSi}_{2}-\mathrm{Al}_{2} \mathrm{O}_{3}$ composite after annealing for $48 \mathrm{~h}$ (Figure 53(a1)), indicating the substantial amount present within the composite systems. As seen in Figure 53(a2), the $\mathrm{Nb}_{5} \mathrm{Si}_{3}$ phase started to form at the $\mathrm{NbSi}_{2}-\mathrm{Al}_{2} \mathrm{O}_{3}$ grain boundaries and around the pores (shown with arrows), and continued to grow as a function of time as the niobium disilicide reacted with residual oxygen sources at high-temperature conditions. Similarly, it was observed that after annealing for $48-96 \mathrm{~h}$, the $\mathrm{Ta}_{5} \mathrm{Si}_{3}$ phase formed and started to grow from the tantalum disilicide-alumina and tantalum disilicide-zirconia grain boundaries (c1-c2-d1$\mathrm{d} 2$ in the Figure 53). The $\mathrm{Ta}_{5} \mathrm{Si}_{3}$ layer can be seen between the tantalum disilicide and zirconia grains after annealing for $96 \mathrm{~h}$ (Figure 53(d2)), where it formed due to the hightemperature oxidation of the tantalum disilicide phase. Furthermore, the SEM studies displayed the presence of some microcracks within the $\mathrm{Nb}_{5} \mathrm{Si}_{3}$ and $\mathrm{Ta}_{5} \mathrm{Si}_{3}$ grains for $\mathrm{NbSi}_{2}-$ $\mathrm{ZrO}_{2}$ and $\mathrm{TaSi}_{2}-\mathrm{Al}_{2} \mathrm{O}_{3}$ composites after annealing (b1-c2 in the Figure 53). However, the level of microcracking within the $\mathrm{Ta}_{5} \mathrm{Si}_{3}$ grains was detected to be substantial for the $\mathrm{TaSi}_{2}$ $\mathrm{ZrO}_{2}$ composite, particularly after annealing at $1400^{\circ} \mathrm{C}$ for $48 \mathrm{~h}$ as denoted by the dashed circles in Figure 53(d1). It may be proposed that these cracks were due to the thermal expansion mismatch of the intermediate 5-3 silicide phases with metal disilicides and oxides, and related to the thermal stresses generated during long-term, high-temperature annealing $[52,53]$. This could be a serious issue for the $\mathrm{TaSi}_{2}-\mathrm{ZrO}_{2}$ composites owing to the extent of the thermal stress-induced microcracking. Due to the formation of these intermediate 5-3 metal silicide phases, different interfaces $\left(\mathrm{NbSi}_{2}-\mathrm{Nb}_{5} \mathrm{Si}_{3}, \mathrm{Nb}_{5} \mathrm{Si}_{3}-\mathrm{ZrO}_{2}\right.$, $\mathrm{TaSi}_{2}-\mathrm{Ta}_{5} \mathrm{Si}_{3}, \mathrm{Ta}_{5} \mathrm{Si}_{3}-\mathrm{Al}_{2} \mathrm{O}_{3}$ etc.) and triple phase boundaries (e.g. $\mathrm{TaSi}_{2}-\mathrm{Al}_{2} \mathrm{O}_{3}-\mathrm{Ta}_{5} \mathrm{Si}_{3}$ ) can be also seen within these composite microstructures. Such microstructural changes should be carefully taken into consideration for further discussions, since high-temperature properties of these composites can be highly influenced by these grain boundaries. 


\subsubsection{High-temperature oxidation behavior}

Most of the transition metal silicides (e.g. $\mathrm{MoSi}_{2}$ ) are known for their excellent oxidation resistance at very high-temperatures (above $\sim 1000^{\circ} \mathrm{C}$ ). However, at relatively low temperatures $\left(\sim 450^{\circ}-900^{\circ} \mathrm{C}\right)$ most of the silicides $\left(\mathrm{MoSi}_{2}, \mathrm{WSi}_{2}, \mathrm{NbSi}_{2}\right.$ etc.) undergo pest oxidation, which is commonly described as an accelerated internal oxidation resulting in a dramatic structural disintegration from the dense solid monolith into a powder form after being exposed to an air atmosphere for a short period of time [54,55]. The presence of defects, microcracks, internal stresses and pores was found to be the major factors affecting the pest oxidation. Since a majority of the studies were focused on the pesting phenomenon within the molybdenum disilicide system, similar oxidation studies for the $\mathrm{NbSi}_{2}$ and $\mathrm{TaSi}_{2}$ have received less attention. It was reported that the pest oxidation occurs at $700^{\circ}-750^{\circ} \mathrm{C}$ and $\sim 800^{\circ}-950^{\circ} \mathrm{C}$ for the $\mathrm{NbSi}_{2}$ and $\mathrm{TaSi}_{2}$, respectively [12,56,57]. However, it should be noted that no clear information was found in the literature for the temperatures, where the pest oxidation initially starts for these silicides. To overcome these oxidation issues, alloying with different materials ( $\mathrm{Al}, \mathrm{Ti}, \mathrm{Cr}$ etc.) for forming a protective oxide layer, and applying oxidation resistant coatings have been extensively investigated as the main approaches for high-temperature structural applications over the years [58-60]. In addition, fabricating these silicide bulk materials with a less number of defects, such as pores and microcracks, is known as another way of controlling their pest oxidation.

To understand the influence of the processing parameters and the addition of the refractory oxide phases on the pest oxidation, the thermogravimetric analyses (TGA) were conducted in ambient air atmosphere at the temperatures reaching $800^{\circ} \mathrm{C}$ on the as-sintered $\mathrm{NbSi}_{2}$ - and $\mathrm{TaSi}_{2}$-based composites, as well as, the as-sintered metal silicides $\left(\mathrm{NbSi}_{2}\right.$, $\mathrm{Nb}_{5} \mathrm{Si}_{3}, \mathrm{TaSi}_{2}$ ). The composition, volume percentage of oxide phase (40 and 70 vol\%) and sintering temperature $\left(1400^{\circ}-1600^{\circ} \mathrm{C}\right)$ were extensively studied. Figure 54 shows the mass change per unit surface area $\left(\mathrm{mg} / \mathrm{cm}^{2}\right)$ of the various $\mathrm{NbSi}_{2}$ - and $\mathrm{TaSi}_{2}$-based composites as a function of oxidation temperature. The temperature axes were all kept in the temperature range of $500^{\circ}-800^{\circ} \mathrm{C}$, since an insignificant oxidation $\left(<0.18 \mathrm{mg} / \mathrm{cm}^{2}\right)$ was detected at the 

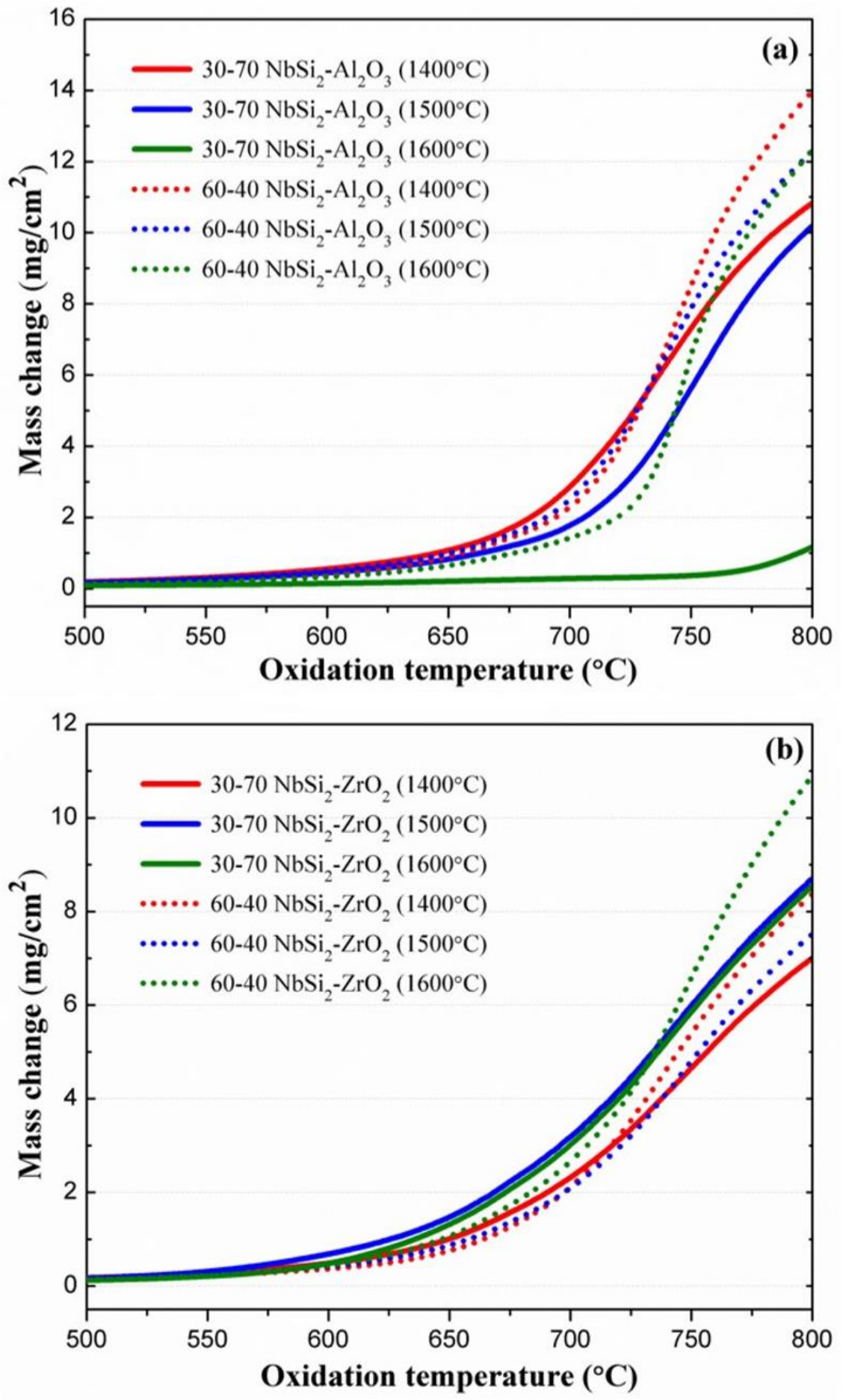

Figure 54. Oxidation-induced mass change per unit surface area $\left(\mathrm{mg} / \mathrm{cm}^{2}\right)$ of the various $\mathrm{NbSi}_{2}$ - and $\mathrm{TaSi}_{2}$-based composites in air as a function of oxidation temperature, sintering temperature (denoted in parenthesis) and silicide-oxide volume ratio. 

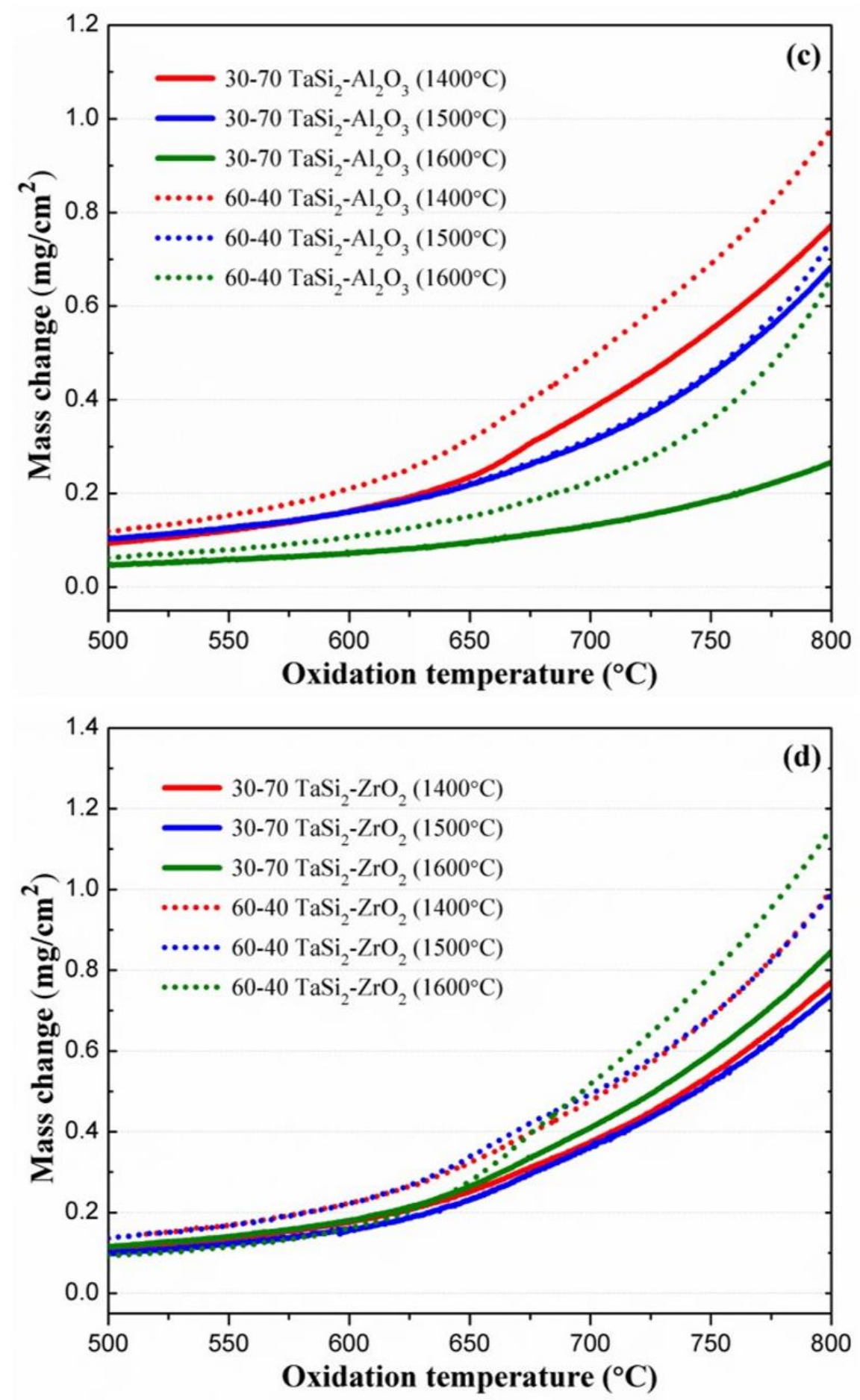

Figure 54. (continued) Oxidation-induced mass change per unit surface area $\left(\mathrm{mg} / \mathrm{cm}^{2}\right)$ of the various $\mathrm{NbSi}_{2}$ and $\mathrm{TaSi}_{2}$-based composites in air as a function of oxidation temperature, sintering temperature (denoted in parenthesis) and silicide-oxide volume ratio. 
temperatures below $500^{\circ} \mathrm{C}$ for all the composites presented. For all the $\mathrm{NbSi}_{2}-\mathrm{Al}_{2} \mathrm{O}_{3}$ and $\mathrm{NbSi}_{2}-\mathrm{ZrO}_{2}$ composites, the mass changes were found to less than $1.0 \mathrm{mg} / \mathrm{cm}^{2}$ at the temperatures below $625^{\circ}-645^{\circ} \mathrm{C}$ (Figure 54(a-b)). It demonstrated that the oxidation rates for the $\mathrm{NbSi}_{2}$-based composites were significantly low below these temperatures, indicating that their pest oxidation slowly started at around $550^{\circ}-600^{\circ} \mathrm{C}$. The mass changes of these $\mathrm{NbSi}_{2}$-based composites relatively increased up to $\sim 700^{\circ} \mathrm{C}$; however, drastic increments were observed at the oxidation temperatures ranging from $700^{\circ}$ to $800^{\circ} \mathrm{C}$, only except for the $30-70 \mathrm{NbSi}_{2}-\mathrm{Al}_{2} \mathrm{O}_{3}$ composite sintered at $1600^{\circ} \mathrm{C}$ (solid green curve in Figure 54(a)). Furthermore, it is apparent for the $\mathrm{NbSi}_{2}-\mathrm{Al}_{2} \mathrm{O}_{3}$ composites that the increasing sintering temperature (from $1400^{\circ} \mathrm{C}$ to $1600^{\circ} \mathrm{C}$ ) and volume percentage of the alumina phase (from 40 to $70 \mathrm{vol} \%$ ) reduced the overall mass change and pest oxidation at $750^{\circ}-800^{\circ} \mathrm{C}$. This effect was determined to be more significant for the $\mathrm{NbSi}_{2}-\mathrm{Al}_{2} \mathrm{O}_{3}$ composites sintered at $1600^{\circ} \mathrm{C}$, since the overall mass change at $800^{\circ} \mathrm{C}$ decreased from 12.3 to $1.2 \mathrm{mg} / \mathrm{cm}^{2}$ (by $90.2 \%$ ) with increasing the alumina content from 40 to 70 vol\% (Figure 54(a)). No pest oxidation was observed until $\sim 770^{\circ} \mathrm{C}$ for the $30-70 \mathrm{NbSi}_{2}-\mathrm{Al}_{2} \mathrm{O}_{3}$ composite sintered at $1600^{\circ} \mathrm{C}$. On the other hand, similar improvements were not achieved for the pest oxidation of the $\mathrm{NbSi}_{2}-\mathrm{ZrO}_{2}$ composites, as seen in Figure 54(b). Due to the higher pest oxidation temperature of the tantalum silicide system, substantially lower mass changes $(\leq 1.15$ $\mathrm{mg} / \mathrm{cm}^{2}$ ) were detected for the $\mathrm{TaSi}_{2}$-based composites throughout the oxidation temperature range (Figure 54(c-d)). The oxidation-induced mass changes of the $\mathrm{TaSi}_{2}-$ $\mathrm{Al}_{2} \mathrm{O}_{3}$ composites were relatively lower with increasing sintering temperature and alumina content, but only at the sintering temperatures of $1400^{\circ} \mathrm{C}$ and $1600^{\circ} \mathrm{C}$. These composites sintered at $1500^{\circ} \mathrm{C}$ exhibited similar oxidation behavior, as clearly presented in Figure 54(c). Similar to the $30-70 \mathrm{NbSi}_{2}-\mathrm{Al}_{2} \mathrm{O}_{3}$, a significant decrease in the overall mass change from 0.66 to $0.27 \mathrm{mg} / \mathrm{cm}^{2}$ (by $59.1 \%$ ) was observed at $800^{\circ} \mathrm{C}$ for the $\mathrm{TaSi}_{2}-\mathrm{Al}_{2} \mathrm{O}_{3}$ composite with increasing the volume percentage of alumina phase (green curves in the Figure 54(c)). These changes were found to be less significant for the $\mathrm{TaSi}_{2}-\mathrm{ZrO}_{2}$ composites. Also, surprisingly for the individual silicide-zirconia systems, their 60-40 
composites that were sintered at $1600^{\circ} \mathrm{C}$ oxidized relatively more at $750^{\circ}-800^{\circ} \mathrm{C}$ than their other composites even sintered at lower temperatures (Figure 54(b-d)).

Additionally, highly pure $\mathrm{NbSi}_{2}, \mathrm{Nb}_{5} \mathrm{Si}_{3}$ and $\mathrm{TaSi}_{2}$ pellets were similarly sintered at $1600^{\circ} \mathrm{C}$ in argon, and their pest oxidation behavior was then compared with the composites sintered at the same temperature. Their mass changes per unit surface area $\left(\mathrm{mg} / \mathrm{cm}^{2}\right)$ are presented in Figure 55, similarly as a function of the oxidation temperature. The pest oxidation of the $\mathrm{NbSi}_{2}$ and $\mathrm{Nb}_{5} \mathrm{Si}_{3}$ was observed particularly at the temperatures ranging from $700^{\circ}$ to $800^{\circ} \mathrm{C}$. However, it was determined that the pest oxidation of the $\mathrm{Nb}_{5} \mathrm{Si}_{3}$ was more drastic than that of the $\mathrm{NbSi}_{2}$. The oxidation-induced mass changes for the $\mathrm{NbSi}_{2}$ and $\mathrm{Nb}_{5} \mathrm{Si}_{3}$ were measured at $800^{\circ} \mathrm{C}$ as 8.3 and $17.3 \mathrm{mg} / \mathrm{cm}^{2}$, respectively, implying the negative influence of the $\mathrm{Nb}_{5} \mathrm{Si}_{3}$ phase formation on the pest oxidation of the composites. In addition, in the pest oxidation region, all $\mathrm{NbSi}_{2}-\mathrm{ZrO}_{2}$ composites and $60-40 \mathrm{NbSi}-\mathrm{Al}_{2} \mathrm{O}_{3}$ displayed lower mass changes than the $\mathrm{Nb}_{5} \mathrm{Si}_{3}$, but relatively higher than the $\mathrm{NbSi}_{2}$ (Figure 55(a)). The pest oxidation of the niobium silicide phases was highly eliminated by the 30$70 \mathrm{NbSi}_{2}-\mathrm{Al}_{2} \mathrm{O}_{3}$ composite, proving the positive influence of the refractory alumina addition on their oxidation behavior. In comparison to the $\mathrm{NbSi}_{2}$ and $\mathrm{Nb}_{5} \mathrm{Si}_{3}$, the oxidationinduced mass change at $800^{\circ} \mathrm{C}$ was reduced by 85.8 and $93.2 \%$, respectively, with the addition of 70 vol\% alumina phase. Similarly, all the TaSiz-based composites except for the 30-70 $\mathrm{TaSi}_{2}-\mathrm{Al}_{2} \mathrm{O}_{3}$ oxidized relatively higher than the $\mathrm{TaSi}_{2}$ at the temperatures ranging from $650^{\circ}-800^{\circ} \mathrm{C}$ (Figure $55(\mathrm{~b})$ ). There was also a $24.4 \%$ reduction in the overall mass change at $800^{\circ} \mathrm{C}$ for the $30-70 \mathrm{TaSi}_{2}-\mathrm{Al}_{2} \mathrm{O}_{3}$ composite compared to the $\mathrm{TaSi}_{2}$.

As a review of the oxidation studies, increasing sintering temperature and volume percentage of the refractory oxide phase reduced the pest oxidation of the $\mathrm{NbSi}_{2}-\mathrm{Al}_{2} \mathrm{O}_{3}$ and $\mathrm{TaSi}_{2}-\mathrm{Al}_{2} \mathrm{O}_{3}$ composites. The lowest oxidation-induced mass changes were achieved by these composites sintered at $1600^{\circ} \mathrm{C}$ with 70 vol\% alumina. The pest oxidation of these composites was also found to be lower than their dense monolithic metal silicides. This could be correlated to the lower porosity levels identified for these composites $(5.2-7.7 \%)$ 

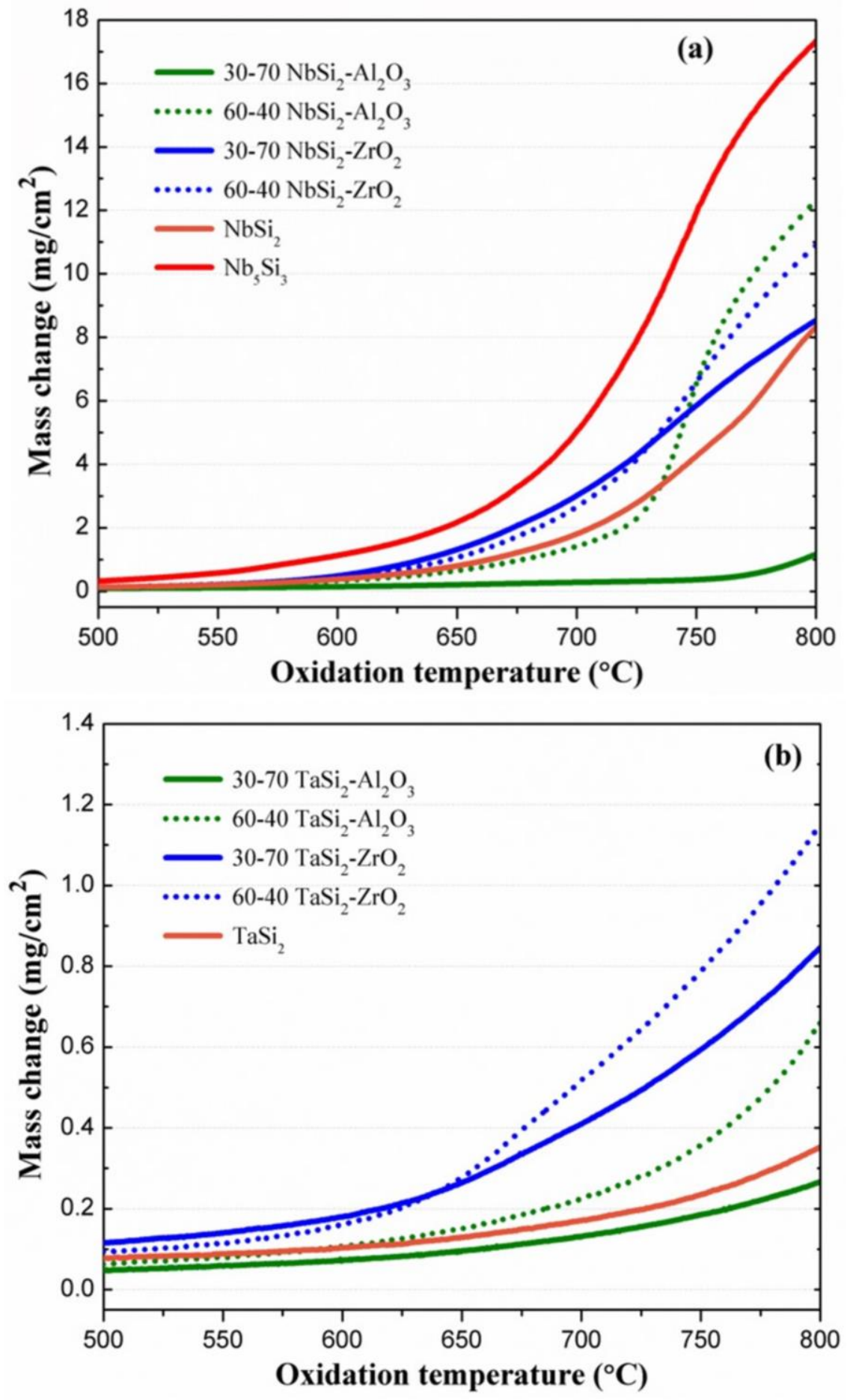

Figure 55. Comparison of the oxidation-induced mass changes $\left(\mathrm{mg} / \mathrm{cm}^{2}\right)$ of the (a) $\mathrm{NbSi}_{2}$-based composites with $\mathrm{NbSi}_{2}$ and $\mathrm{Nb}_{5} \mathrm{Si}_{3}$, and (b) $\mathrm{TaSi}_{2}$-based composites with $\mathrm{TaSi}_{2}$, all sintered at $1600^{\circ} \mathrm{C}$ in argon, as a function of the oxidation temperature. 
and reduced oxygen diffusion rates due to the refractory oxide addition. The increase in the sintering temperature reduced the amount of porosity at different levels, and thus, relatively lowered the pest oxidation. However, this effect was more significant in the silicidealumina composites, particularly at 30-70 volume percentages. Significant changes in the pest oxidation behavior of the silicide-zirconia composites were not similarly observed by adjusting the processing parameters. This could be explained with significantly higher porosity levels within these composites, since they all exhibited above $25.8 \%$ porosity at all sintering temperatures. When the porosity levels were above $8.4 \%$, the positive effect of refractory oxide phase addition was also not observed. These results clearly show that the key factor for reducing the pest oxidation rates is low porosity levels and improved densification, since it is apparent that the accelerated oxygen diffusion through the pores and/or across the pore surfaces is the main mechanism of the pest oxidation. The preexisting microcracks and grain boundaries were additionally described as major oxidation sites within the microstructures causing the pest oxidation of these silicide systems $[12,54,56,61]$. It is important to note that volume percentages of the intermediate 5-3 metal silicide phases should be also considered due to their different oxidation rates compared to their disilicide forms. Since the $\mathrm{Nb}_{5} \mathrm{Si}_{3}$ oxidizes faster than $\mathrm{NbSi}_{2}$, oxidation rates of the composites could drastically increase over time when the diffusing oxygen reaches the $\mathrm{Nb}_{5} \mathrm{Si}_{3}$ grains and $\mathrm{NbSi}_{2}-\mathrm{Nb}_{5} \mathrm{Si}_{3}$ grain boundaries. The relatively high level of oxidation of the $\mathrm{TaSi}_{2}$-based composites (except for the 30-70 $\mathrm{TaSi}_{2}-\mathrm{Al}_{2} \mathrm{O}_{3}$ ) compared to the $\mathrm{TaSi}_{2}$ may be also correlated to the presence of the intermediate $\mathrm{Ta}_{5} \mathrm{Si}_{3}$ phase possibly having poorer oxidation resistance. In conclusion, even though the pest oxidation of the metal silicides was highly reduced by fabricating the $\mathrm{NbSi}_{2}$ - and $\mathrm{TaSi}_{2}$-based composites with the addition of 70 vol\% alumina phase, further studies need to be performed since surface oxide layers formed $\left(\mathrm{Nb}_{2} \mathrm{O}_{5}, \mathrm{Ta}_{2} \mathrm{O}_{5}\right.$ etc.) did not completely eliminate further oxidation over time $[55,57,62]$. Strategies for controlled pest formation (pre-oxidation) to produce a more stable and dense protective surface layer should be further investigated to improve the chemical stability at high-temperatures. 


\subsubsection{High-temperature electrical properties}

The electrical properties of these composites were also investigated at high temperatures in this study. It should be noted that the electrical conductivity data is presented in the temperature ranges of $400^{\circ}-900^{\circ} \mathrm{C}$ for the metal silicides and the $60-40$ composites, and $100^{\circ}-900^{\circ} \mathrm{C}$ for the $30-70$ composites in this study. The reason is that the very low resistance, and thus high electrical conductivity values above $\sim 2100 \mathrm{~S} / \mathrm{cm}$, limited the accurate measurements at lower temperatures. In addition, the Pt-wire/ink electrical connections were lost at around $900^{\circ}-950^{\circ} \mathrm{C}$, which may be related to the local reactions between metal disilicides and platinum resulting in the formation of a low-melting point platinum silicide phase (e.g. PtSi) on the surface of the bulk sample [30,63]. Prior to the electrical measurements of the $\mathrm{NbSi}_{2}$ and $\mathrm{TaSi}_{2}$-based composites, the electrical conductivities of the monolithic $\mathrm{NbSi}_{2}, \mathrm{Nb}_{5} \mathrm{Si}_{3}$ and $\mathrm{TaSi}_{2}$ samples, that were sintered at $1600^{\circ} \mathrm{C}$ without addition of any refractory oxide phase, are presented in Figure 56 as a reference data. The electrical conductivity of the composites decreased with increasing temperature with a metallic-type trend for all compositions [11,64]. The results demonstrated that the electrical conductivity of the $\mathrm{NbSi}_{2}$ decreased from 163.3 to 42.3 $\mathrm{S} / \mathrm{cm}$ with increasing temperature from $500^{\circ} \mathrm{C}$ to $900^{\circ} \mathrm{C}$, whereas this decrease was from 353.8 to $41.5 \mathrm{~S} / \mathrm{cm}$ for the $\mathrm{TaSi}_{2}$ at the same temperature range. The room-temperature bulk resistivities of the $\mathrm{NbSi}_{2}(24.5-50.4 \mu \Omega . \mathrm{cm})$ and $\mathrm{TaSi}_{2}(38-46 \mu \Omega . \mathrm{cm})$ were also reported similar to each other by Chow and Steckl [9]. On the other hand, the $\mathrm{Nb}_{5} \mathrm{Si}_{3}$ displayed a linear trend as a function of temperature, since its electrical conductivity decreased from 233.6 to $152.1 \mathrm{~S} / \mathrm{cm}$ with increasing temperature from $500^{\circ} \mathrm{C}$ to $900^{\circ} \mathrm{C}$. It can be concluded that the $\mathrm{Nb}_{5} \mathrm{Si}_{3}$ has substantially higher electrical conductivity than the $\mathrm{NbSi}_{2}$ and $\mathrm{TaSi}_{2}$ at the elevated temperatures above $\sim 530^{\circ} \mathrm{C}$. Therefore, the continued formation of the intermediate 5-3 metal silicide phases within the disilicide composition may lead to a complex electrical network that evolves with high-temperature oxidation. The conductivity may decrease (or increase) depending upon the change in percolation of the 5-3 metal silicide phases within the microstructure over time. 


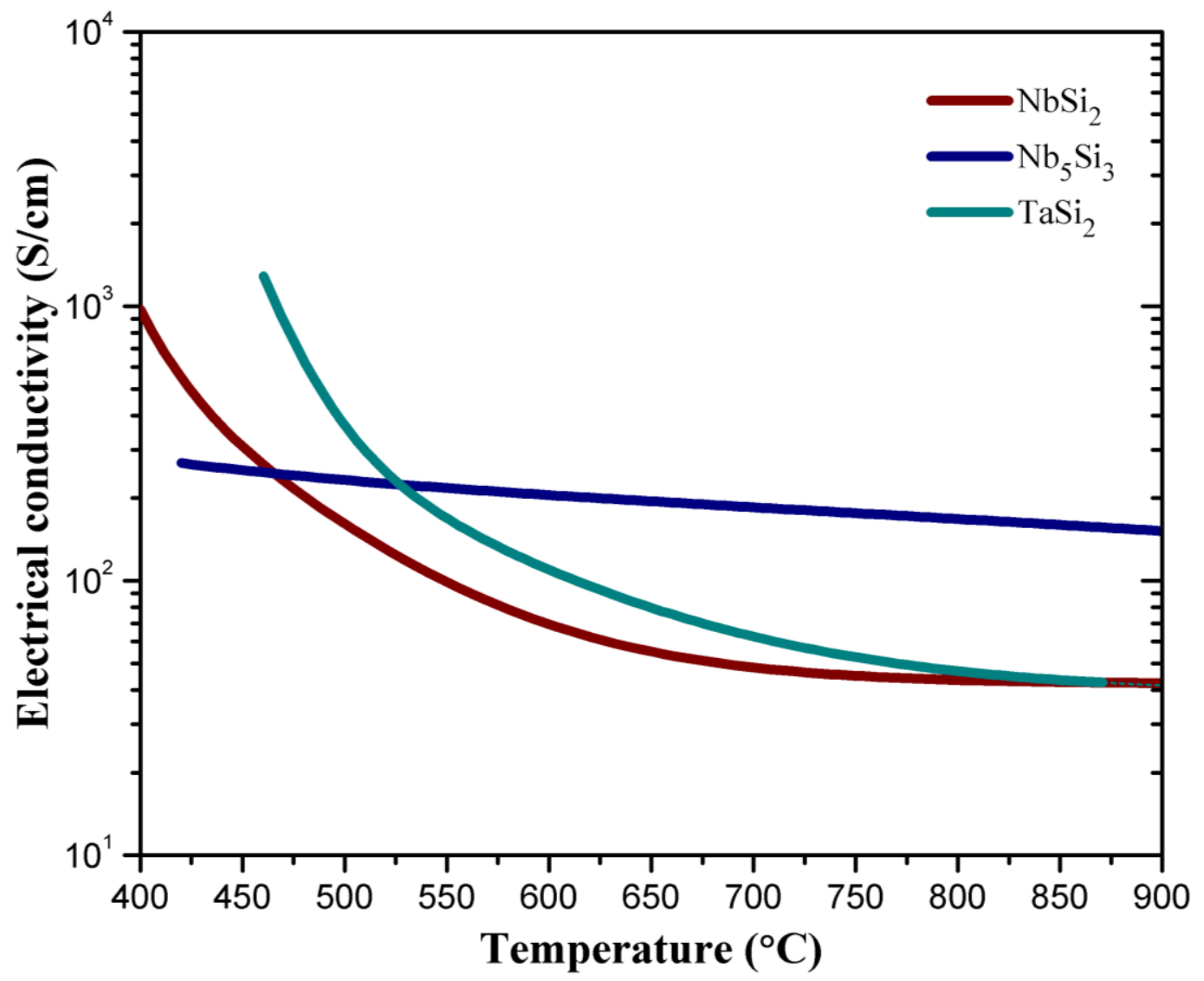

Figure 56. Electrical conductivity of the dense monolithic $\mathrm{NbSi}_{2}, \mathrm{Nb}_{5} \mathrm{Si}_{3}$ and $\mathrm{TaSi}_{2}$ as a reference data, all sintered at $1600^{\circ} \mathrm{C}$ in argon, as a function of the temperature (Electrical conductivity data is shown on the logarithmic scale).

The electrical conductivity results of the $\mathrm{NbSi}_{2}$ - and $\mathrm{TaSi}_{2}$-based composites, that were sintered at $1600^{\circ} \mathrm{C}$, are presented in Figure 57 as a function of temperature. At the 6040 volume percentages, $\mathrm{NbSi}_{2}-\mathrm{Al}_{2} \mathrm{O}_{3}$ and $\mathrm{NbSi}_{2}-\mathrm{ZrO}_{2}$ composites showed similar electrical conductivities at the temperatures ranging from $450^{\circ}$ to $900^{\circ} \mathrm{C}$ (Figure $57(\mathrm{a})$ ). The electrical conductivities of the $60-40 \mathrm{NbSi}_{2}-\mathrm{Al}_{2} \mathrm{O}_{3}$ and $\mathrm{NbSi}_{2}-\mathrm{ZrO}_{2}$ composites at $900^{\circ} \mathrm{C}$ were found as 107.3 and $111.3 \mathrm{~S} / \mathrm{cm}$, respectively. However, 60-40 $\mathrm{TaSi}_{2}-\mathrm{ZrO}_{2}$ composite exhibited significantly lower electrical conductivity than all of the other 60-40 composites throughout the same temperature range. At $900^{\circ} \mathrm{C}$, the $\mathrm{TaSi}_{2}-\mathrm{Al}_{2} \mathrm{O}_{3}$ and $\mathrm{TaSi}_{2}-\mathrm{ZrO}_{2}$ composites with the 60-40 volume percentages revealed 87.3 and $25.9 \mathrm{~S} / \mathrm{cm}$, respectively. Furthermore, at the 30-70 volume percentages, the $\mathrm{TaSi}_{2}-\mathrm{Al}_{2} \mathrm{O}_{3}$ composite showed higher 

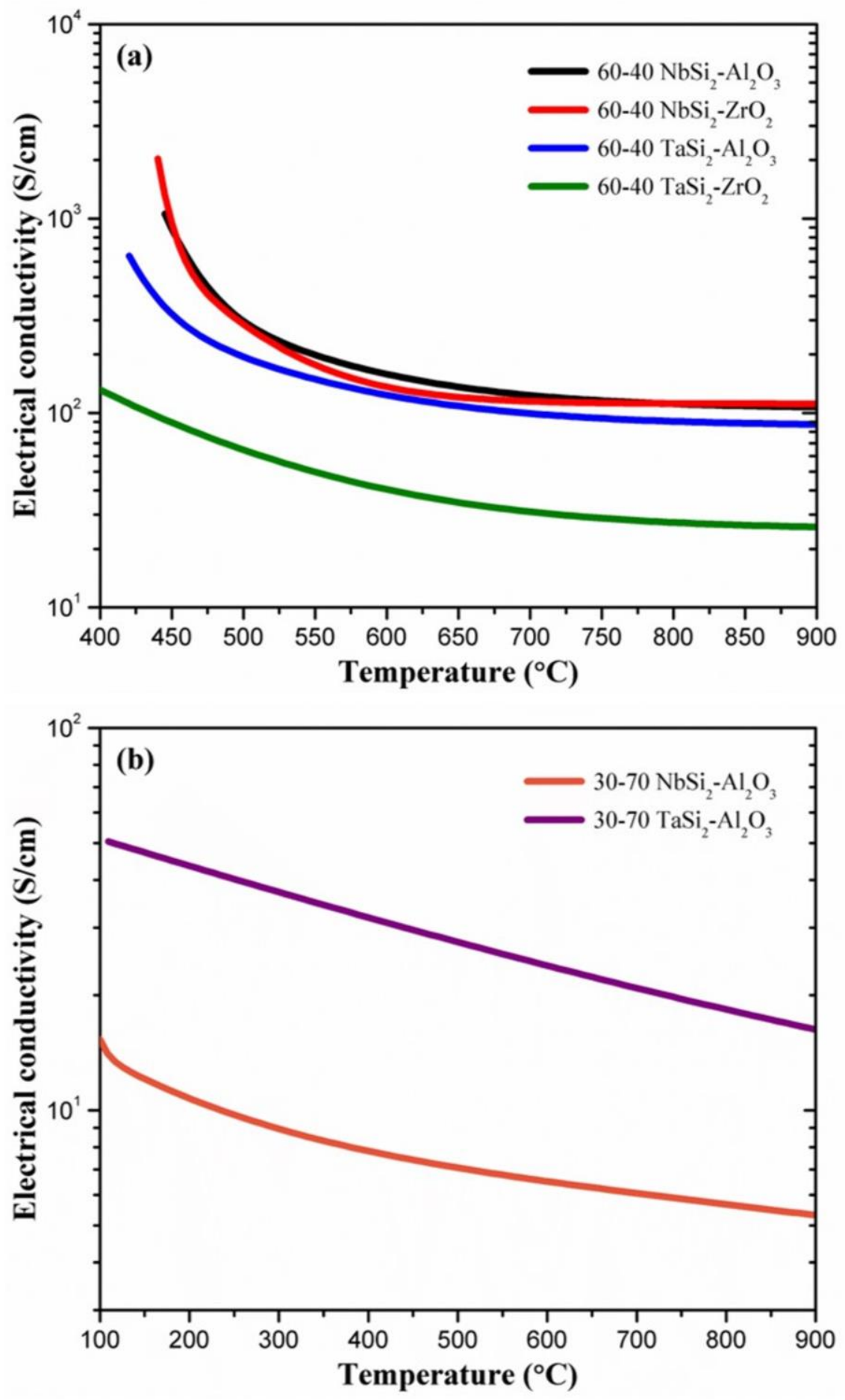

Figure 57. Electrical conductivity of the $\mathrm{NbSi}_{2}$ - and $\mathrm{TaSi}_{2}$-based composites having (a) 60-40 and (b) 30-70 metal silicide-refractory oxide volume percentages, all sintered at $1600^{\circ} \mathrm{C}$ in argon, as a function of the temperature (Electrical conductivity data is shown on the logarithmic scale). 
electrical conductivity than the $\mathrm{NbSi}_{2}-\mathrm{Al}_{2} \mathrm{O}_{3}$ at the temperature range of $100^{\circ}-900^{\circ} \mathrm{C}$, as clearly seen in Figure 57(b). The electrical conductivities of the 30-70 $\mathrm{NbSi}_{2}-\mathrm{Al}_{2} \mathrm{O}_{3}$ and $\mathrm{TaSi}_{2}-\mathrm{Al}_{2} \mathrm{O}_{3}$ composites were measured at $900^{\circ} \mathrm{C}$ as 5.3 and $16.3 \mathrm{~S} / \mathrm{cm}$, respectively. It is important to note that the electrical conductivities of the $30-70 \mathrm{NbSi}_{2}-\mathrm{ZrO}_{2}$ and $\mathrm{TaSi}_{2}-\mathrm{ZrO}_{2}$ composites are not presented here, since their electrical conductivity data could not be recorded at the temperatures above $450^{\circ}-500^{\circ} \mathrm{C}$ due to their high brittleness and related sample cracking during measurements at elevated temperatures.

As a review, it was demonstrated that the 60-40 $\mathrm{NbSi}_{2}-\mathrm{Al}_{2} \mathrm{O}_{3}$ and $\mathrm{NbSi}_{2}-\mathrm{ZrO}_{2}$ composites revealed significantly higher electrical conductivities $(107.3-111.3 \mathrm{~S} / \mathrm{cm})$ than the monolithic $\mathrm{NbSi}_{2}(42.3 \mathrm{~S} / \mathrm{cm})$ at $900^{\circ} \mathrm{C}$. This result clearly indicated the positive influence of the intrinsic electrical conductivity of the intermediate $\mathrm{Nb}_{5} \mathrm{Si}_{3}$ phase $(152.1$ $\mathrm{S} / \mathrm{cm}$ at $900^{\circ} \mathrm{C}$ ) on the electrical properties of these composites, which included 26.4-32.7 vol\% $\mathrm{Nb}_{5} \mathrm{Si}_{3}$ phase based on the Rietveld data. Although the $60-40 \mathrm{NbSi}_{2}-\mathrm{ZrO}_{2}$ composite had higher level of porosity (27.6\%), it still displayed a slightly higher electrical conductivity than the $60-40 \mathrm{NbSi}_{2}-\mathrm{Al}_{2} \mathrm{O}_{3}$ at high temperatures. For the $\mathrm{TaSi}_{2}$-based composites with 60-40 volume percentages, $\mathrm{TaSi}_{2}-\mathrm{Al}_{2} \mathrm{O}_{3}$ exhibited substantially higher electrical conductivity $(87.3 \mathrm{~S} / \mathrm{cm})$ than the $\mathrm{TaSi}_{2}-\mathrm{ZrO}_{2}(25.9 \mathrm{~S} / \mathrm{cm})$ and monolithic $\mathrm{TaSi}_{2}$ $(41.5 \mathrm{~S} / \mathrm{cm})$ at $900^{\circ} \mathrm{C}$. It was found that the high porosity level $(30.6 \%)$ within the $60-40$ $\mathrm{TaSi}_{2}-\mathrm{ZrO}_{2}$ composite adversely affected its electrical properties at high-temperatures. It should be noted that these results may also be influenced by the unknown intrinsic electrical conductivity of the intermediate $\mathrm{Ta}_{5} \mathrm{Si}_{3}$ phase and microstructural homogeneity. The distribution of the silicide phases will drastically affect the three-dimensional electrical network that controls electron movement through the composite [28,51]. Due to the low porosity levels (5.2-7.7\%), the electrical percolation was achieved even at 30-70 metal silicide-oxide volume percentages. The electrical conductivities of the $30-70 \mathrm{NbSi}_{2}-\mathrm{Al}_{2} \mathrm{O}_{3}$ and $\mathrm{TaSi}_{2}-\mathrm{Al}_{2} \mathrm{O}_{3}$ were found to be relatively lower than that of the monolithic metal silicides at high-temperatures. The higher electrical conductivity achieved by the 30-70 $\mathrm{TaSi}_{2}-\mathrm{Al}_{2} \mathrm{O}_{3}$ composite could be an indication of a higher level of percolation formed 
within this composite system. Therefore, these $\mathrm{NbSi}_{2-}$ and $\mathrm{TaSi}_{2}$-based composites displayed promising high-temperature electrical properties at low and high metal silicide volume percentages. As discussed, the physical properties of the composites at high temperatures were found to be highly influenced by porosity levels, volume percentages of the intermediate 5-3 metal silicide phases $\left(\mathrm{Nb}_{5} \mathrm{Si}_{3}, \mathrm{Ta}_{5} \mathrm{Si}_{3}\right)$ and microstructural homogeneity or percolation.

\subsection{Conclusions}

The $\mathrm{NbSi}_{2}$ - and $\mathrm{TaSi}_{2}$-based electroconductive ceramic composites were fabricated with the addition of 40 and 70 vol\% refractory oxides $\left(\mathrm{Al}_{2} \mathrm{O}_{3}, \mathrm{ZrO}_{2}\right)$. The particle packing and densification of the composites were enhanced by lowering the metal silicide and/or increasing the oxide phase, as well as, increasing the sintering temperature. Significant improvements were particularly achieved for the silicide-alumina composites due to the higher silicide/alumina particle size ratios and local densification kinetics favored by the single-phase grain boundary regions such as silicide-silicide and oxide-oxide. The insufficient sintering kinetics and phase transformation-induced microcracking adversely affected the densification of the silicide-zirconia composites. The formation of the intermediate $\mathrm{Nb}_{5} \mathrm{Si}_{3}$ and $\mathrm{Ta}_{5} \mathrm{Si}_{3}$ phases during high-temperature sintering and annealing processes was found to be related to the interaction of starting metal disilicides with residual oxygen that remained in the starting silicide powders, and was entrapped within the pores or diffused from environmental sources. It was proposed that these 5-3 silicide phases were initially formed at the metal disilicide-oxide grain boundaries, and predominantly controlled by their high-temperature oxidation reactions. Furthermore, the presence of microcracks was detected particularly within the silicide-zirconia composites after long-term (48-96 h) high-temperature annealing, which was attributed to the thermal expansion mismatch of the 5-3 silicide phases with that of the metal disilicides and oxides and thermal stresses generated at high-temperatures. The increasing sintering temperature and volume percentage of the oxide phase highly reduced the pest oxidation, particularly for the silicide-alumina composites, which exhibited even lower mass changes than their 
monolithic metal silicides. It was determined that the oxygen diffusion through the pores, grain boundaries and microcracks resulted in an increase of the internal oxidation. Due to the metallic conducting behavior of these transition metal silicides, the electrical conductivities of these composites decreased with increasing temperature. In addition, the high-temperature electrical conductivities of these composites at $900^{\circ} \mathrm{C}$ ranged from 5.3 to 111.3 S/cm depending on the silicide-oxide volume percentages, which were highly affected by porosity levels, volume percentages of the conductive silicide phases and microstructural homogeneity (percolation). In conclusion, particularly the $\mathrm{NbSi}_{2}-\mathrm{Al}_{2} \mathrm{O}_{3}$ and $\mathrm{TaSi}_{2}-\mathrm{Al}_{2} \mathrm{O}_{3}$ ceramic composites exhibited very promising results for their use in high temperature advanced electronic and sensing applications owing to their phase and microstructural stability, reduced oxidation rates and high electrical conductivities at elevated temperatures. However, further studies are needed to investigate the influence of the intermediate 5-3 metal silicide phases on the properties of the composites, and to further improve their high-temperature oxidation resistance by enhancing the densification and/or the quality of the protective surface oxide layer.

\section{References}

[1] F. Chu, M. Lei, S.A. Maloy, J.J. Petrovic, T.E. Mitchell, Elastic properties of C40 transition metal disilicides, Acta Mater. 44 (1996) 3035-3048.

[2] N. Xu, Y. Xu, J. Ma, Investigations on the structural, electronic, elastic and thermodynamic properties of niobium silicide under high temperature and pressure, Materials Science in Semiconductor Processing 30 (2015) 636-644.

[3] N.M. Ravindra, L. Jin, D. Ivanov, V.R. Mehta, L.M. Dieng, G. Popov, O.H. Gokce, J. Grow, A.T. Fiory, Electrical and compositional properties of $\mathrm{TaSi}_{2}$ films, Journal of Electronic Materials 31 (2002) 1074-1079.

[4] I-J. Shon, H-K. Park, H-C. Kim, J-K. Yoon, I-Y. Ko, Simultaneous pulsed current activated combustion synthesis and densification of $\mathrm{NbSi}_{2}-\mathrm{SiC}$ composite, Ceram. Inter. 34 (2008) 615-619. 
[5] B. Wan, F. Xiao, Y. Zhang, Y. Zhao, L. Wu, J. Zhang, H. Gou, Theoretical study of structural characteristics, mechanical properties and electronic structure of metal $(\mathrm{TM}=\mathrm{V}$, $\mathrm{Nb}$ and Ta) silicides, Journal of Alloys and Compounds 681 (2016) 412-420.

[6] M. Ostling, C. Zaring, Thermal properties of TM silicides, in: K. Maex, M.V. Rossum (Eds.), Properties of Metal Silicides, Inspec/Iee, London, 1995, pp. 31-44.

[7] F. Nava, K.N. Tu, E. Mazzega, M. Michelini, G. Queirolo, Electrical transport properties of transition-metal disilicides films, J. Appl. Phys. 61 (1987) 1085-1093.

[8] K. Pomoni, C. Krontiras, J. Salmi, Electrical transport properties of $\mathrm{NbSi}_{2}$ thin films, J. Phys. D: Appl. Phys. 23 (1990) 354-357.

[9] T.P. Chow, A.J. Steckl, Refractory metal silicides: Thin-film properties and processing technology, IEEE Transactions on Electron Devices ED-30 (1983) 1480-1497.

[10] S.P. Murarka, M.H. Read, C.J. Doherty, D.B. Fraser, Resistivities of thin film transition metal silicides, J. Electrochem. Soc.: Electrochemical Science and Technology 129 (1982) 293-301.

[11] M.T. Huang, T.L. Martin, V. Malhotra, J.E. Mahan, Electron transport properties of tantalum disilicide thin films, J. Vac. Sci. Technol. B 3 (1985) 836-845.

[12] S. Binbin, F. Peizhong, W. Jianzhong, G. Yuan, W. Guangzhi, W. Xiaohong, A. Farid, Oxidation properties of self-propagating high temperature synthesized niobium disilicide, Corrosion Science 85 (2014) 311-317.

[13] C.Y. Li, Z.H. Yu, H.Z. Liu, T.Q. Lu, High pressure and high temperature in situ X-ray diffraction study on the structural stability of tantalum disilicide, Solid State Communications 157 (2013) 1-5.

[14] K. Kurokawa, H. Matsuoka, T. Nagai, High temperature oxidation of some $\mathrm{MSi}_{2}$-type silicides, In Advanced Materials '93, Elsevier (1994) 255-258.

[15] K.G. Kreider, Thin film high temperature silicide thermocouples, U.S. Patent, No. 5474619 (1995).

[16] D.A. Berztiss, R.R. Cerchiara, E.A. Gulbransen, F.S. Pettit, G.H. Meier, Oxidation of $\mathrm{MoSi}_{2}$ and comparison with other silicide materials, Materials Science and Engineering: A 155 (1992) 165-181. 
[17] C-L. Yeh, Y-S. Huang, Thermite-based combustion synthesis of niobium silicides $/ \mathrm{Al}_{2} \mathrm{O}_{3}$ composites, High Temperature Materials Processes 16 (2012) 57-69.

[18] H-G. Jo, I-J. Shon, Simultaneous synthesis and consolidation of nanostructured $\mathrm{WSi}_{2}-$ $\mathrm{NbSi}_{2}$ composite by pulsed current activated heating and its mechanical properties, Journal of Ceramic Processing Research 15 (2014) 371-375.

[19] W. Li, H. Yang, A. Shan, L. Zhang, W. Jiansheng, Microstructure and properties of directionally solidified $\mathrm{NbSi}_{2} / \mathrm{Nb}_{5} \mathrm{Si}_{3}$ composites, Materials Science Forum 475-479 (2005) 733-736.

[20] Z. Yazdani, F. Karimzadeh, M.H. Abbasi, Formation mechanism of $\mathrm{NbSi}_{2}-\mathrm{Al}_{2} \mathrm{O}_{3}$ nanocomposite subject to mechanical alloying, Advanced Powder Technology 25 (2014) 1357-1361.

[21] E.M. Carrillo-Heian, C. Unuvar, J.C. Gibeling, G.H. Paulino, Z.A. Munir, Simultaneous synthesis and densification of niobium silicide/niobium composites, Scripta Materialia 45 (2001) 405-412.

[22] J.D. Rigney, J.J. Lewandowski, Loading rate and test temperature effects on fracture of in situ niobium silicide-niobium composites, Metallurgical and Materials Transactions A 27A (1996) 3292-3306.

[23] H-G. Jo, I-J. Shon, Pulsed current activated synthesis and consolidation of nanostructured $\mathrm{MoSi}_{2}-\mathrm{NbSi}_{2}$ composite and its mechanical properties, Materials Transactions 55 (2014) 391-394.

[24] L. Silvestroni, D. Sciti, Densification of $\mathrm{ZrB}_{2}-\mathrm{TaSi}_{2}$ and $\mathrm{HfB}_{2}-\mathrm{TaSi}_{2}$ ultra-hightemperature ceramic composites, J. Am. Ceram. Soc. 94 (2011) 1920-1930.

[25] I.G. Talmy, J.A. Zaykoski, M.M. Opeka, High-temperature chemistry and oxidation of $\mathrm{ZrB}_{2}$ ceramics containing $\mathrm{SiC}, \mathrm{Si}_{3} \mathrm{~N}_{4}, \mathrm{Ta}_{5} \mathrm{Si}_{3}$, and $\mathrm{TaSi}_{2}$, J. Am. Ceram. Soc. 91 (2008) 2250-2257.

[26] S. Wang, C. Xu, Y. Ding, X. Zhang, Thermal shock behavior of $\mathrm{ZrB}_{2}-\mathrm{SiC}$ composite ceramics with added $\mathrm{TaSi}_{2}$, Int. Journal of Refractory Metals and Hard Materials 41 (2013) 507-516. 
[27] D. Sciti, L. Silvestroni, S. Guicciardi, D.D. Fabbriche, A. Bellosi, Processing, mechanical properties and oxidation behavior of $\mathrm{TaC}$ and $\mathrm{HfC}$ composites containing 15 vol\% $\mathrm{TaSi}_{2}$ or $\mathrm{MoSi}_{2}$, J. Mater. Res. 24 (2009) 2056-2065

[28] S. Kobel, J. Pluschke, U. Vogt, T.J. Graule, $\mathrm{MoSi}_{2}-\mathrm{Al}_{2} \mathrm{O}_{3}$ electroconductive ceramic composites, Ceram. Int. 30 (2004) 2105-2110.

[29] H. Yamamoto, S. Sendai, Study on high temperature thermistor made of $\mathrm{MoSi}_{2}-$ granular $\mathrm{Al}_{2} \mathrm{O}_{3}$ composite, J. Ceram. Soc. Jpn. 97 (1989) 783-786.

[30] G.A. Yakaboylu, R.C. Pillai, K. Sabolsky, E.M. Sabolsky, Stability and electrical properties of $\mathrm{MoSi}_{2}$ - and $\mathrm{WSi}_{2}$-oxide electroconductive composites, J. Am. Ceram. Soc. 100 (2017) 4461-4475.

[31] G.A. Yakaboylu, R.C. Pillai, K. Sabolsky, E.M. Sabolsky, MoSiz- and $\mathrm{WSi}_{2}$-based embedded ceramic composite thermocouples for high-temperature and harsh-environment sensing, Sensors and Actuators A: Physical (2018) in-press.

[32] C.A. Schneider, W.S. Rasband, K.W. Eliceiri, NIH image to ImageJ: 25 years of image analysis. Nat. Methods 9 (2012) 671-675.

[33] L. Lutterotti, S. Matthies, H-R. Wenk, MAUD: a friendly Java program for material analysis using diffraction, IUCr: Newsletter of the CPD 21 (1999) 14-15.

[34] ASTM B193-16 Standard test method for resistivity of electrical conductor materials, ASTM International, West Conshohocken, PA.

[35] S.S. Razavi-Tousi, R. Yazdani-Rad, S.A. Manafi, Effect of volume fraction and particle size of alumina reinforcement on compaction and densification behavior of Al$\mathrm{Al}_{2} \mathrm{O}_{3}$ nanocomposites, Mater. Sci Eng. A 528 (2011) 1105-1110.

[36] M.N. Rahaman, Ceramic Processing and Sintering, Marcel Dekker, New York, NY (2003).

[37] S-Q. Guo, Densification of $\mathrm{ZrB}_{2}$-based composites and their mechanical and physical properties: a review, Journal of the European Ceramic Society 29 (2009) 995-1011.

[38] Z. Yan, C.L. Martin, O. Guillon, D. Bouvard, Effect of size and homogeneity of rigid inclusions on the sintering of composites, Scripta Materialia 69 (2013) 327-330. 
[39] J.T. Bauer, A. Scholz, C. Berger, L. Weiler, M. Achtermann, Influence of metastable tetragonal $\mathrm{ZrO}_{2}$-reinforcements on the properties of $\mathrm{MoSi}_{2}$-composites, Int. J. Mater. Res. 99 (2008) 352-258.

[40] G. Skandan, H. Hahn, M. Roddy, W.R. Cannon, Ultrafine-grained dense monoclinic and tetragonal zirconia, J. Am. Ceram. Soc. 77 (1994) 1706-1710.

[41] S. Okada, K. Okita, K. Hamano, T. Lundstrom, Growth conditions of $\mathrm{Nb}_{3} \mathrm{Si}, \alpha-\mathrm{Nb}_{5} \mathrm{Si}_{3}$ and $\mathrm{NbSi}_{2}$ single crystals from high-temperature metal solutions and properties of the crystals, High Temperature Materials and Processes, 13 (2011) 311-318.

[42] I.G. Talmy, J.A. Zaykoski, M.M. Opeka, A.H. Smith, Properties of ceramics in the system $\mathrm{ZrB}_{2}-\mathrm{Ta}_{5} \mathrm{Si}_{3}$, Journal of Materials Research 21 (2006) 2593-2599.

[43] M.E. Schlesinger, The Si-Ta (silicon-tantalum) system, Journal of Phase Equilibria 15 (1994) 90-95.

[44] T.P. Chow, W.J. Lu, A.J. Steckl, B.J. Baliga, Thin film properties of sputtered niobium silicide on $\mathrm{SiO}_{2}, \mathrm{Si}_{3} \mathrm{~N}_{4}$ and $\mathrm{N}^{+}$poly-Si, J. Electrochem. Soc. 133 (1986) 175-178.

[45] C.U. Pinnow, M. Bicker, U. Geyer, S. Schneider, G. Goerigk, Decomposition and nanocrystallization in reactively sputtered amorphous Ta-Si-N thin films, Journal of Applied Physics 90 (2001) 1986-1991.

[46] Y-J. Choi, J-K. Yoon, G-H. Kim, W-Y. Yoon, J-M. Doh, K-T. Hong, High temperature isothermal oxidation behavior of $\mathrm{NbSi}_{2}$ coating at $1000-1450^{\circ} \mathrm{C}$, Corrosion Science 129 (2017) 102-114.

[47] I.M. Tougas, M. Amani, O.J. Gregory, Metallic and ceramic thin film thermocouples for gas turbine engines, Sensors 13 (2013) 15324-15347.

[48] D. Grobnic, C.W. Smelser, S.J. Mihailov, R.B. Walker, Long-term thermal stability tests at $1000^{\circ} \mathrm{C}$ of silica fibre Bragg gratings made with ultrafast laser radiation, Meas. Sci. Technol. 17 (2006) 1009-1013.

[49] W.H. Bennethum, L.T. Sherwood, Sensors for ceramic components in advanced propulsion systems, NASA Contractor Report 180900 (1988) August. 
[50] C.L. Yeh, Y.S. Huang, Thermite reduction of $\mathrm{Ta}_{2} \mathrm{O}_{5} / \mathrm{SiO}_{2}$ powder mixtures for combustion synthesis of Ta-based silicides, Journal of Alloys and Compounds 509 (2011) 6302-6306.

[51] F. Lux, Models proposed to explain the electrical conductivity of mixtures made of conductive and insulating materials, J. Mater. Sci. 28 (1993) 285-301.

[52] J.J. Petrovic, M.I Pena, I.E. Reimanis, M.S. Sandlin, S.D. Conzone, H.H. Kung, D.P. Butt, Mechanical behavior of $\mathrm{MoSi}_{2}$ reinforced-Si $\mathrm{N}_{4}$ matrix composites, J. Am. Ceram. Soc. 80 (1997) 3070-3076.

[53] J. Lemus-Ruiz, C.A. Leon-Patino, E.A. Aguilar-Reyes, Interface behavior during the self-joining of $\mathrm{Si}_{3} \mathrm{~N}_{4}$ using a Nb-foil interlayer, Scripta Materialia 54 (2006) 1339-1343.

[54] F. Zhang, L.T. Zhang, A.D. Shan, J.S. Wu, In situ observations of the pest oxidation process of $\mathrm{NbSi}_{2}$ at $1023 \mathrm{~K}$, Scripta Materialia 53 (2005) 653-656.

[55] R. Mitra, Mechanical behaviour and oxidation resistance of structural silicides, International Materials Reviews 51 (2006) 13-64.

[56] F. Zhang, L.T. Zhang, A.D. Shan, J.S. Wu, Microstructural effect on oxidation kinetics of $\mathrm{NbSi}_{2}$ at $1023 \mathrm{~K}$, Journal of Alloys and Compounds 422 (2006) 308-312.

[57] Y. Niu, L. Huang, C. Zhai, Y. Zeng, X. Zheng, C. Ding, Microstructure and thermal stability of $\mathrm{TaSi}_{2}$ coating fabricated by vacuum plasma spray, Surface \& Coatings Technology 279 (2015) 1-8.

[58] B. Voglewede, V.R. Rangel, S.K. Varma, The effects of uncommon silicides on the oxidation behavior of alloys from the Nb-Cr-Si system, Corrosion Science 61 (2012) 123133.

[59] K. Kurokawa, A. Yamauchi, S. Matsushita, Improvement of oxidation resistance of $\mathrm{NbSi}_{2}$ by addition of boron, Mater. Sci. Forum 502 (2005) 243-248.

[60] W. Wang, B. Yuan, C. Zhou, Formation and oxidation resistance of germanium modified silicide coating on $\mathrm{Nb}$ based in situ composites, Corrosion Science 80 (2014) 164-168.

[61] A. Stergiou, P. Tsakiropoulos, The intermediate and high-temperature oxidation behaviour of $(\mathrm{Mo}, \mathrm{X}) \mathrm{Si}_{2}(\mathrm{X}=\mathrm{W}, \mathrm{Ta})$ intermetallic alloys, Intermetallics 5 (1997) 117-126. 
[62] K.S. Chan, Cyclic oxidation response of multiphase niobium-based alloys, Metallurgical and Materials Transactions A 35A (2004) 589-597.

[63] Y. Ito, M. Sato, K. Wakisaka, S. Yoshikado, Improvement of heating characteristics of molybdenum silicide thin film electric heaters, Electr. Eng. Jpn. 168 (2009) 452-458.

[64] U. Gottlieb, F. Nava, M. Affronte, O. Laborde, R. Madar, Electrical transport in metallic TM silicides, in: K. Maex, M.V. Rossum (Eds.), Properties of Metal Silicides, Inspec/Iee, London, 1995, pp. 189-204. 


\section{CHAPTER 4: PROCESSING AND PROPERTIES OF CHROM I U S IL I C I D E-B A S E D C OM POS I T E S}

\subsection{Introduction}

The various transition metal silicides show both metallic and covalent bonding within their structures, resulting in a variety of physical properties [1,2]; thus, they exhibit different electrical properties ranging from semiconducting to metallic, which makes them interesting materials for electronic applications. The chromium-silicon $(\mathrm{Cr}-\mathrm{Si})$ material system displays great potential for high-temperature electrical applications, such as thermoelectrics and interconnects, due to the promising electrical properties, high melting points $\left(>1410^{\circ} \mathrm{C}\right)$, and structural and thermal stability of the binary chromium silicide compounds $[3,4]$. The binary phases of the $\mathrm{Cr}-\mathrm{Si}$ system are listed as $\mathrm{CrSi}_{2}, \mathrm{Cr}_{3} \mathrm{Si}_{2} \mathrm{Cr}_{5} \mathrm{Si}_{3}$ and $\mathrm{CrSi}$; previous research studies primarily focused on the former three silicides.

Among these binary compounds, chromium disilicide $\left(\mathrm{CrSi}_{2}\right)$ is the most extensively studied phase for high-temperature thermoelectric applications. Like some of the other disilicides (e.g. $\mathrm{MnSi}_{2}$ ), this phase demonstrates chemical/thermal stability, high melting temperature $\left(1490^{\circ} \mathrm{C}\right)$, semiconducting nature, large power factor and low toxicity [4-6]. It is known as a p-type degenerate semiconductor with a narrow band gap of $\sim 0.30$ $\mathrm{eV}$ and a relatively high Seebeck coefficient (S) of $\sim 90 \mu \mathrm{V} / \mathrm{K}[4,7,8]$. Although its high $\mathrm{S}$ and low electrical resistivity are advantageous for thermoelectric applications, it was intensively reported that the thermal conductivity of the $\mathrm{CrSi}_{2}$ should be reduced to increase its thermoelectric figure-of-merit (ZT) and performance $[6,9,10]$. Therefore, many attempts have been made using different approaches such as grain size reduction, stoichiometry adjustment and doping over the years. In addition, several studies presented that the $\mathrm{CrSi}_{2}$ exhibits a high oxidation resistance in oxygen-rich atmospheres at temperatures up to $725^{\circ}-1000^{\circ} \mathrm{C}$ with a very low mass gain owing to the formation of chromium oxide $\left(\mathrm{Cr}_{2} \mathrm{O}_{3}\right)$ and amorphous silica $\left(\mathrm{SiO}_{2}\right)$ phases as a protective surface layer 
$[8,11,12]$. Its sufficient mechanical properties and high creep resistance at elevated temperatures were also noted as advantages for their potential use in thermoelectrics, as well as, high temperature structural applications in aggressive environments.

The $\mathrm{Cr}_{3} \mathrm{Si}$ and $\mathrm{Cr}_{5} \mathrm{Si}_{3}$ compounds are classified as metallic conductors, with relatively higher melting temperatures $\left(1680^{\circ}-1770^{\circ} \mathrm{C}\right)$ than chromium monosilicide and disilicide $[3,13,14]$. These chromium silicides have been mainly described as promising candidates for the high temperature structural applications, such as aircraft engines and aerospace gas turbines, due to their higher melting points, high stiffness, excellent hightemperature oxidation and corrosion resistance [15-18]. However, their low fracture toughness and ductility at room- and moderately high-temperatures were identified as major issues that needed to be addressed before their use in such industrial applications. Therefore, several methods such as secondary ductile phase addition (e.g. chromium), solid solution alloying and impurity reduction were applied only to the $\mathrm{Cr}_{3} \mathrm{Si}$ system $[17,19]$. It was also determined that the $\mathrm{Cr}_{3} \mathrm{Si}$ compound exhibits an excellent oxidation resistance at temperatures up to $1000^{\circ} \mathrm{C}$ with a very low specific mass change $\leq 0.5 \mathrm{mg} / \mathrm{cm}^{2}$ even after $100 \mathrm{~h}$ exposure to air [16,20]. Unfortunately, high-temperature oxidation behavior of the $\mathrm{Cr}_{5} \mathrm{Si}_{3}$ compound has not been reported yet, since the limited studies for this compound typically focus on the synthesis, mechanical and electrical properties of the single crystal and thin film forms $[2,18,21]$. The electrical properties of the $\mathrm{Cr}_{3} \mathrm{Si}$ and $\mathrm{Cr}_{5} \mathrm{Si}_{3}$ compounds were only reported using the thin films by Mazzega et al. [2]. They studied their electrical properties at temperatures up to $827^{\circ} \mathrm{C}$; they reported the electrical resistivities for the $\mathrm{Cr}_{3} \mathrm{Si}$ and $\mathrm{Cr}_{5} \mathrm{Si}_{3}$ thin films to be $\sim 95.0$ and $\sim 170.0 \mu \Omega \cdot \mathrm{cm}$, respectively. However, no study reported the electrical properties of the bulk forms of these two chromium silicides. This is surprising, since these compositions display substantially high electrical conductivity values at elevated temperatures, and thus, great potential for the hightemperature electrical applications, such as interconnects and advanced sensors. $\mathrm{The}^{\mathrm{Cr}} \mathrm{Si}_{3}$ and $\mathrm{Cr}_{5} \mathrm{Si}_{3}$ phases were reportedly synthesized by a variety of methods from chromium $(\mathrm{Cr})$ and silicon $(\mathrm{Si})$ metals or powders using arc melting, double-cathode glow discharge 
and electron beam evaporation techniques [2,16,22,23]. Unlike the $\mathrm{CrSi}_{2}$ compound, the $\mathrm{Cr}_{3} \mathrm{Si}$ and $\mathrm{Cr}_{5} \mathrm{Si}_{3}$ powders are not commercially available to the authors' knowledge.

In summary, different chromium silicide compounds present a unique combination of properties and electrical characteristics, which make them highly useful for a broad range of high-temperature electrical applications ranging from thermoelectric devices to advanced physical sensors. However, there are very limited studies conducted on their electrical properties, oxidation behavior and stability at high-temperatures, particularly for the $\mathrm{Cr}_{3} \mathrm{Si}, \mathrm{Cr}_{5} \mathrm{Si}_{3}$ and $\mathrm{CrSi}$ compounds, since the main attention has been given to the $\mathrm{CrSi}_{2}$ phase and related thermoelectric applications. Therefore, in this study, various composite materials were fabricated by solid-state sintering of chromium silicide and chromium oxide powders at high temperature. The main purpose was to achieve highly stable, oxidation resistant and electrically conductive composites, which are composed of conductive chromium silicide phases and high-temperature refractory phases (e.g. chromia, silica), for their particular use in high-temperature applications. The phase development and stability, microstructure, oxidation behavior and electrical properties of the composites were extensively investigated at elevated temperatures.

\subsection{Experimental}

\subsubsection{Materials and method}

Commercial chromium silicide $\left(\mathrm{CrSi}_{2}, 99+\%\right)$ and chromium (III) oxide $\left(\mathrm{Cr}_{2} \mathrm{O}_{3}\right.$, $98+\%$ ) powders were selected as precursor materials, which were purchased from Alfa Aesar (Tewksbury, MA). The starting powders were initially characterized by $\mathrm{x}$-ray diffraction (XRD, Panalytical X'Pert Pro, Westborough, MA). Figure 58 displays the XRD pattern of the chromium silicide powder. X'Pert High Score software (Panalytical Inc., Westborough, MA) was used for phase and crystal structure identification. It was determined that starting chromium silicide powder consisted of two different silicide phases, which are hexagonal-structured $\mathrm{CrSi}_{2}$ (\#98-062-6776, P6222) and cubic CrSi (\#98001-6837, P2 3 ). In addition, the XRD result (not shown) of the starting chromium oxide 


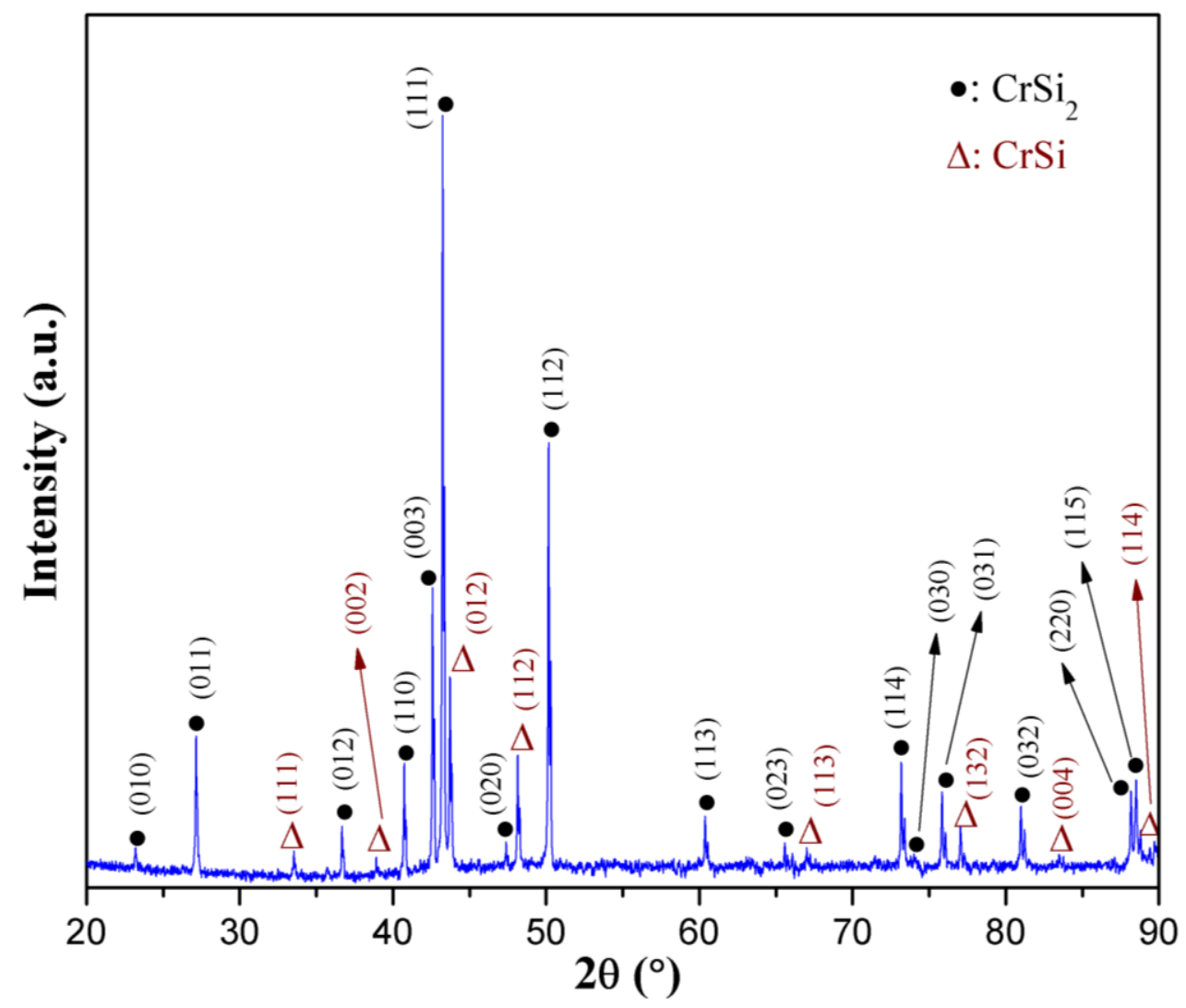

Figure 58. XRD pattern of the commercial chromium silicide starting powder.

powder displayed the expected $\mathrm{Cr}_{2} \mathrm{O}_{3}$ phase with a rhombohedral structure (\#01-084-0312, $\mathrm{R}-3 \mathrm{c})$.

The composite powder mixtures were prepared by ball-milling the appropriate amounts of the chromium silicide and oxide starting powders in ethanol (200 proof) for 24 $\mathrm{h}$, followed by a drying step at around $60^{\circ} \mathrm{C}$ for $4 \mathrm{~h}$. The amounts of the powders were all determined based on volume percentage (vol\%), and the volume percentages of the chromium silicide phase ranged from 40 to 90 vol\% within the composites. For simplicity, the composites were described by abbreviations including the first letters and initial volume percentages of the powders throughout the paper, as presented in Table 9. For example, a (40-60) vol\% chromium silicide-chromium oxide (CC) composite was labeled as "CC$4060 "$ ". The as-prepared powder mixtures were uniaxially pressed ( $13.8 \mathrm{MPa})$ into 
Table 9. Compositions and denotations of the chromium silicide-based composites.

\begin{tabular}{|c|c|c|}
\hline $\begin{array}{c}\text { Amount of starting } \\
\text { chromium silicide powder } \\
(\text { vol\%) }\end{array}$ & $\begin{array}{c}\text { Amount of starting } \\
\text { chromium oxide powder } \\
(\text { vol\%) }\end{array}$ & $\begin{array}{c}\text { Composite sample } \\
\text { denotation }\end{array}$ \\
\hline $\mathbf{4 0}$ & 60 & CC-4060 \\
\hline $\mathbf{5 0}$ & 50 & CC-5050 \\
\hline $\mathbf{5 5}$ & 45 & CC-5545 \\
\hline $\mathbf{6 0}$ & 40 & CC-6040 \\
\hline $\mathbf{6 5}$ & 35 & CC-6535 \\
\hline $\mathbf{7 0}$ & 30 & CC-7030 \\
\hline $\mathbf{8 0}$ & 20 & CC-8020 \\
\hline $\mathbf{9 0}$ & 10 & CC-9010 \\
\hline
\end{tabular}

cylindrical pellets with 13-26 mm diameter and 2-4 mm thickness by using a stainless-steel die. The pellets were then placed in an alumina crucible and sintered at $1370^{\circ} \mathrm{C}$ for $2 \mathrm{~h}$ in a tube furnace under flowing argon gas $(50 \mathrm{sccm})$. The heating and cooling rates were kept constant at $3{ }^{\circ} \mathrm{C} / \mathrm{min}$ for all sintering experiments. Also, several $\mathrm{CrSi}_{2}$ pellets were sintered under similar conditions as baseline samples for comparison. After sintering, selected composite samples were additionally annealed at $1350^{\circ} \mathrm{C}$ for $24-96 \mathrm{~h}$ to further study the phase stability, microstructural changes, oxidation behavior and electrical properties at elevated temperatures.

\subsubsection{Characterization}

The phase analyses of the composite samples were performed after sintering and annealing by X-ray diffraction (Panaltyical X'Pert Pro, Westborough, MA) with a $\mathrm{CuK}_{\alpha}$ radiation source. Prior to the microstructural analyses, the composite samples were 
prepared by fine polishing with silicon carbide ( $\mathrm{SiC}$ ) polishing sheets (600-1200 grits) and lastly diamond paste $(0.5 \mu \mathrm{m})$. After each polishing step, the as-polished sample surfaces were cleaned by $10 \mathrm{~min}$ of ultrasonication in deionized water and ethanol, respectively. The cross-sectional microstructure and elemental analyses were conducted using a fieldemission scanning electron microscopy (FE-SEM, Hitachi S-4700F, Tokyo, Japan). For the high-temperature oxidation studies, very small square or rectangular pellets with a surface area ranging from 0.09 to $0.20 \mathrm{~cm}^{2}$ were prepared by cutting and fine polishing with a 600 grit $\mathrm{SiC}$ polishing sheet, followed by sample cleaning in ethanol by ultrasonication. The dimensions of the as-prepared composite samples were measured before oxidation experiments to calculate their surface areas, which are required to determine the oxidationinduced specific mass changes. The non-isothermal oxidation tests of the chromium silicide-based composite samples were performed in air atmosphere at temperatures from $50^{\circ} \mathrm{C}$ to $870^{\circ} \mathrm{C}$ using a thermogravimetric analyzer (TGA, Pyris 1, PerkinElmer, Shelton, CT) with a heating rate of $10^{\circ} \mathrm{C} / \mathrm{min}$. In addition, the isothermal oxidation studies were conducted at $850^{\circ} \mathrm{C}$ in air, but the samples were heated to that temperature in an argon atmosphere. The volumetric flow rates of the air and argon were kept constant at $20 \mathrm{ml} / \mathrm{min}$ during the oxidation tests. For the standard electrical measurements (ASTM B193-16) [24], rectangular bar samples with dimensions of $\sim 20 \times 4 \times 4 \mathrm{~mm}$ were prepared, and then attached to the test setup made from a high-purity four-bore alumina tube and platinum (Pt) wires (99.95\% pure, $0.28 \mathrm{~mm}$ diameter, Surepure Chemetals, Florham Park, NJ). The test setup was then sealed in a high-temperature tube furnace to perform the high-temperature electrical measurements up to $870^{\circ}-1000^{\circ} \mathrm{C}$ in argon atmosphere. Additionally, a B-type thermocouple was inserted into the furnace to record the testing temperature during the experiments. The electrical resistance of the samples was measured as a function of temperature using a digital multimeter (Keithley 2100, Tektronix, Beaverton, OR) directly connected to the LabVIEW (National Instruments, Austin, TX) and Keithley software. Their electrical conductivities were lastly calculated using the recorded resistance data and specific sample dimensions. 


\subsection{Results and Discussion}

\subsubsection{Phase development via solid-state reactions}

The phase development within the chromium silicide-based composites was investigated after sintering of the various particulate mixtures at $1370^{\circ} \mathrm{C}$ leading to the solid-state reactions between starting chromium silicide and chromium oxide phases. Figure 59(a-b) present the XRD patterns of the as-sintered chromium silicide-based composites, which are all entitled by volume percentages of the starting powders (e.g. CC4060, CC-5545) as described in the experimental section. The XRD result of the CC-4060 composite revealed that $\mathrm{Cr}_{0.91} \mathrm{Si}_{0.09}$ and silica $\left(\mathrm{SiO}_{2}\right)$ phases were formed as a result of the solid-state reactions between $40 \mathrm{vol} \%$ chromium silicides $\left(\mathrm{CrSi}, \mathrm{CrSi}_{2}\right)$ and $60 \mathrm{vol} \%$ chromium oxide $\left(\mathrm{Cr}_{2} \mathrm{O}_{3}\right)$. The diffraction peaks of the cubic-structured $\mathrm{Cr}_{0.91} \mathrm{Si}_{0.09}$ phase (\#98-010-8354, space group: $\operatorname{Im} 3 \mathrm{~m}$ ) were detected at $2 \theta$ of $44.5^{\circ}, 64.7^{\circ}$ and $81.9^{\circ}$ corresponding to the (011), (002) and (112) planes, respectively. It should be noted that the $\mathrm{Cr}_{0.91} \mathrm{Si}_{0.09}$ is not a common silicide phase, since it was reported only by studies on the chromium-silicon phase relations [13] and the high-temperature corrosion of nickel alloy including chromium [25]. Additionally, it was found that the diffraction peaks at the $2 \theta$ of $22.0^{\circ}, 31.5^{\circ}$ and $36.1^{\circ}$ displayed the formation of the $\mathrm{SiO}_{2}$ phase in the low-cristobalite (or $\alpha$-cristobalite) form with a tetragonal structure and space group of $\mathrm{P}_{1}{ }_{1}{ }_{1} 2$, which is known as the low temperature phase of the cristobalite structure [26]. For the CC-5050 composite, the XRD peaks detected at $2 \theta$ of $39.4^{\circ}, 44.3^{\circ}$ and $48.8^{\circ}$ corresponded to the cubic $\mathrm{Cr}_{3} \mathrm{Si}$ phase (\#98-062-6771, space group: Pm3n), and its major diffraction peaks for the (002), (012) and (112) planes, respectively. The low-cristobalite $\mathrm{SiO}_{2}$ phase was also observed within the CC-5050 composite after sintering. Therefore, it is apparent that the chromium silicide phase completely changed from $\mathrm{Cr}_{0.91} \mathrm{Si}_{0.09}$ to $\mathrm{Cr}_{3} \mathrm{Si}$ with increasing volume percentage of starting chromium silicide by $10 \mathrm{vol} \%$ (from 40 to $50 \mathrm{vol} \%$ ), as expected due to the increased silicon $(\mathrm{Si})$ amount reacting with the $\mathrm{Cr}_{2} \mathrm{O}_{3}$. The XRD pattern of the CC5545 composite revealed a similar result with the CC-5050 composite, since the major diffractions peaks of $\mathrm{Cr}_{3} \mathrm{Si}$ and low-cristobalite $\mathrm{SiO}_{2}$ phases were observed. However, the presence of $\mathrm{Cr}_{5} \mathrm{Si}_{3}$ and $\mathrm{CrSi}_{2}$ phases was additionally detected for the CC-5545 composite 

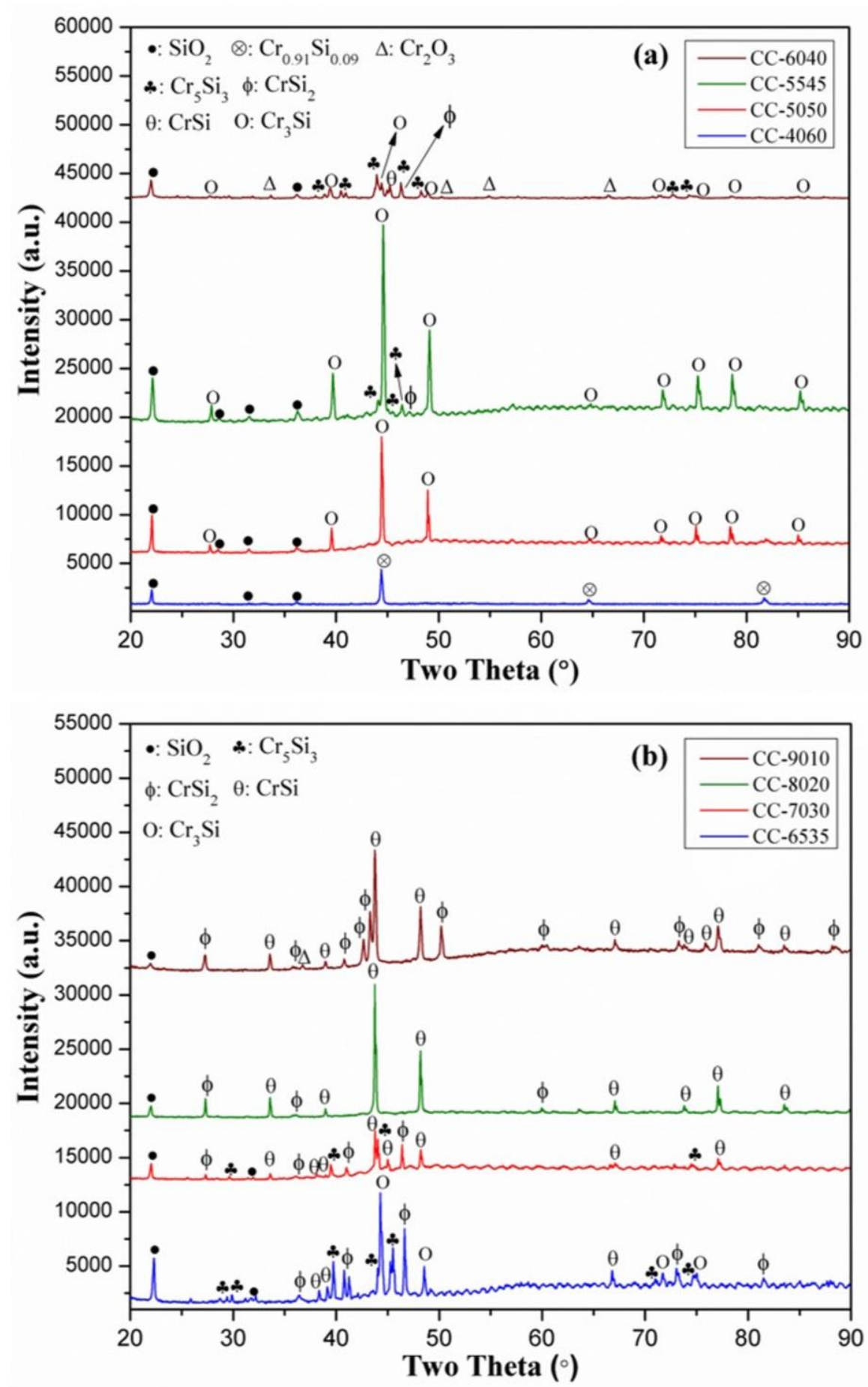

Figure 59. XRD patterns of the (a) CC-4060, CC-5050, CC-5545 and CC-6040, and (b) CC-6535, CC-7030, CC-8020 and CC-9010 chromium silicides-based composites, which were all sintered at $1370^{\circ} \mathrm{C}$ for $2 \mathrm{~h}$ in argon. 
with the additional 5 vol\% increase in starting chromium silicide powder. The XRD peaks detected at $2 \theta$ of $43.7^{\circ}, 44.2^{\circ}$ and $45.3^{\circ}$ were attributed to the tetragonal-structured $\mathrm{Cr}_{5} \mathrm{Si}_{3}$ (\#98-062-6793, space group: I4/mcm), and its (022), (240) and (141) planes, respectively. The CC-6040 composite exhibited a more complex structure, where four different chromium silicide phases $\left(\mathrm{Cr}_{3} \mathrm{Si}_{2} \mathrm{Cr}_{5} \mathrm{Si}_{3}, \mathrm{CrSi}, \mathrm{CrSi}_{2}\right)$ were detected along with the lowcristobalite $\mathrm{SiO}_{2}$ and initial phases. The presence of starting chromium silicide phases (cubic-CrSi, hexagonal-CrSi 2$)$ and chromium oxide $\left(\mathrm{Cr}_{2} \mathrm{O}_{3}\right)$ within the CC-6040 composite implied a partial solid-state reaction during sintering resulting in the formation of new metal silicide phases $\left(\mathrm{Cr}_{3} \mathrm{Si}_{1}, \mathrm{Cr}_{5} \mathrm{Si}_{3}\right)$ and unreacted phases. The increased peak intensities of the $\mathrm{Cr}_{5} \mathrm{Si}_{3}$ compared to that of the CC-5545 composite imply that there is a concentration increase of this phase in the CC-6040 composite (Figure 59a). The XRD results of the CC6040 and CC-6535 composites were found to be quite similar, since they both displayed structures consisting of four different silicide phases $\left(\mathrm{Cr}_{5} \mathrm{Si}_{3}, \mathrm{Cr}_{3} \mathrm{Si}, \mathrm{CrSi}, \mathrm{CrSi}_{2}\right)$ and the low-cristobalite $\mathrm{SiO}_{2}$ phase. However, no remaining $\mathrm{Cr}_{2} \mathrm{O}_{3}$ phase was observed for the $\mathrm{CC}$ 6535 composite after sintering. For the CC-7030 composite, $\mathrm{Cr}_{5} \mathrm{Si}_{3}$ and low-cristobalite $\mathrm{SiO}_{2}$ phases were detected along with the unreacted $\mathrm{CrSi}$ and $\mathrm{CrSi}_{2}$ phases. It is clear that no $\mathrm{Cr}_{3} \mathrm{Si}$ phase was formed within the composites when starting with a metal silicide content above $65 \mathrm{vol} \%$. On the other hand, for the CC-8020 and CC-9010 composites, solid-state reactions resulted only in the formation of low-cristobalite silica minor phase due to the small amount of $\mathrm{Cr}_{2} \mathrm{O}_{3}$ to be reacted with the starting silicides. The major phases within these composites were similarly identified as $\mathrm{CrSi}$ and $\mathrm{CrSi}_{2}$ after sintering (Figure 59b). In addition, a small amount of unreacted $\mathrm{Cr}_{2} \mathrm{O}_{3}$ was detected in the CC-9010 composite.

As a review of the $\mathrm{XRD}$ results, high-temperature solid-state reactions between the initial $\mathrm{Cr}_{2} \mathrm{O}_{3}$ and $\mathrm{CrSi}_{2}$ (with the presence of $\mathrm{CrSi}$ phase) mixed phases resulted in the formation of different chromium silicides $\left(\mathrm{Cr}_{3} \mathrm{Si}_{2}, \mathrm{Cr}_{5} \mathrm{Si}_{3}, \mathrm{Cr}_{0.91} \mathrm{Si}_{0.09}\right)$ and the lowcristobalite phase depending on the volume percentages of the starting metal silicide and oxide powders. For all initial compositions, the $\mathrm{Cr}_{2} \mathrm{O}_{3}$ phase completely disappeared after 
thermal processing. In the CC-4060 composite with a 40 vol\% initial silicide content, the major silicide phase was found to be $\mathrm{Cr}_{0.91} \mathrm{Si}_{0.09}$. For the composites with the initial silicide contents ranging from 50 to $65 \mathrm{vol} \%, \mathrm{Cr}_{3} \mathrm{Si}$ and $\mathrm{Cr}_{5} \mathrm{Si}_{3}$ phases were formed. The homogeneity ranges (nonstoichiometry range or difference between maximum and minimum concentration of Si in a Cr-silicide phase) for the $\mathrm{Cr}_{3} \mathrm{Si}$ and $\mathrm{Cr}_{5} \mathrm{Si}_{3}$ phases were reported based on the atomic percentage of silicon ( $\mathrm{Si}$ ) as 22.5-26.4 and 36.0-41.0 at.\% Si, respectively $[3,13]$. This indicated that the starting silicon content within the CC-5050 was in the homogeneity range of $\mathrm{Cr}_{3} \mathrm{Si}$ phase, since initial chromium silicides reacted with $\mathrm{Cr}_{2} \mathrm{O}_{3}$ to form $\mathrm{Cr}_{3} \mathrm{Si}$ and $\mathrm{SiO}_{2}$. However, the increased volume percentage of the starting metal silicide from 50 to $65 \mathrm{vol} \%$ resulted in a sufficient increase in the at $\%$ of Si within the composite, which caused a shift towards the right side of the $\mathrm{Cr}-\mathrm{Si}$ phase diagram from the homogeneity range of $\mathrm{Cr}_{3} \mathrm{Si}$ (22.5-26.4 at.\% Si). Since the $\mathrm{Cr}_{3} \mathrm{Si}$ and $\mathrm{Cr}_{5} \mathrm{Si}_{3}$ phases coexisted within the CC-5545, CC-6040 and CC-6535 composites, the amount of reacted silicon within these composites ranged from 26.4 to 36.0 at.\%. There was no formation of $\mathrm{Cr}_{3} \mathrm{Si}$ and $\mathrm{Cr}_{5} \mathrm{Si}_{3}$ phases when the starting silicide content was above 70 vol\%, as expected based on the $\mathrm{Cr}-\mathrm{Si}$ phase diagram and the homogeneity ranges of these two equilibrium phases ( $\geq 50$ at.\% Si) [3]. These results clearly demonstrated that the type of chromium silicide phases and their amounts within the composites could be controlled via hightemperature solid-state reaction by adjusting the volume percentages of starting chromium silicide and chromium oxide powders. It should be noted that this knowledge is very beneficial for producing composite materials composed of different chromium silicides, silica and chromium oxide in a controlled manner, which could provide a variety of physical properties depending on the major silicide phases formed via solid-state reactions.

\subsubsection{Composite microstructures after solid-state reactions}

The microstructural development within the chromium silicide-based composites was examined after the solid-state reactions occurred during high-temperature sintering at $1370^{\circ} \mathrm{C}$. The SEM microstructures of the CC-4060, CC-5050, CC-5545 and CC-6040 composites are shown in Figure 60. The homogeneous distribution of the $\mathrm{Cr}_{0.91} \mathrm{Si}_{0.09}$ phase 

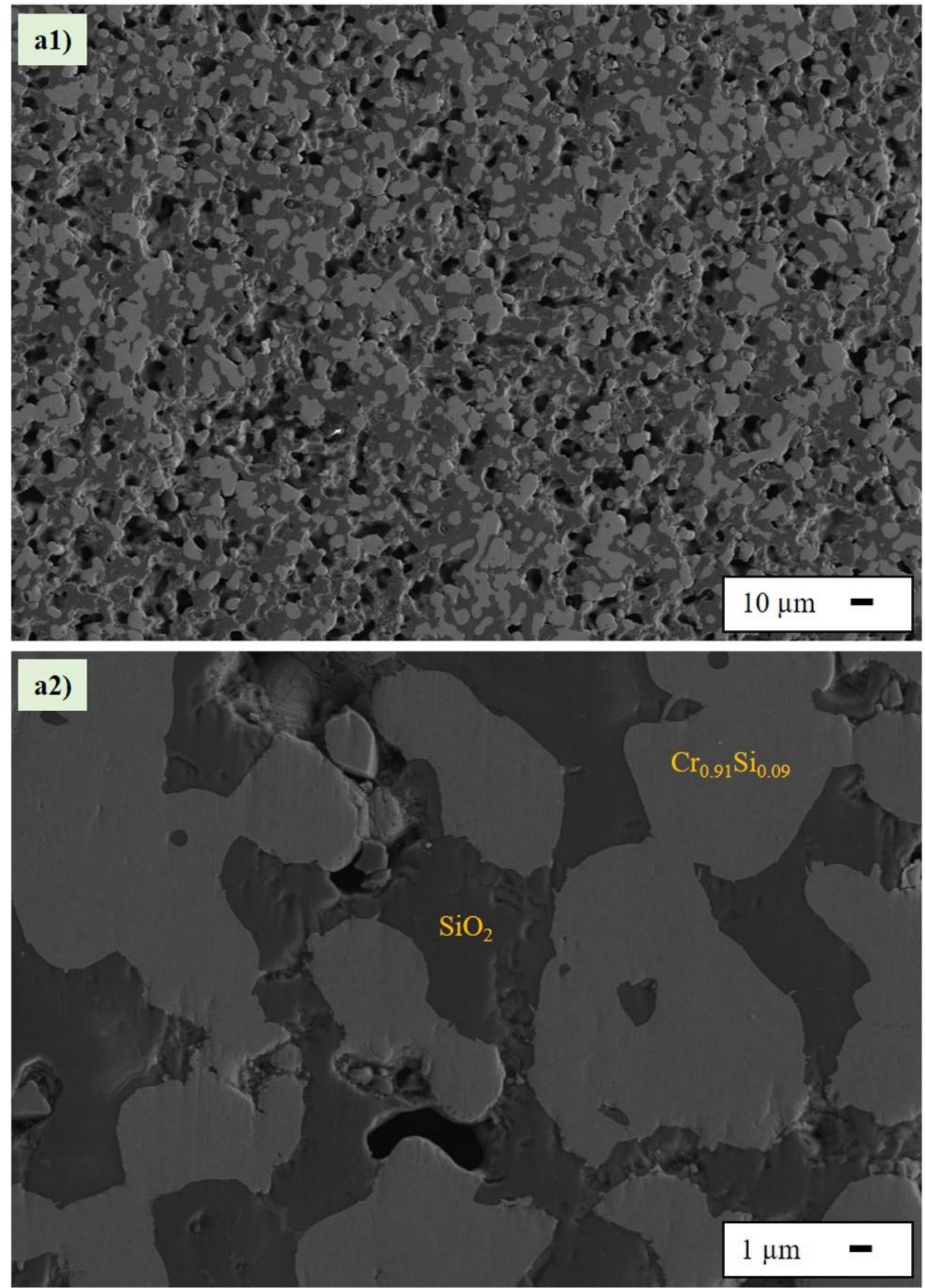

Figure 60. SEM microstructures of the (a1-a2) CC-4060, (b1) CC-5050, (c1-c2) CC5545 and (d1-d2) CC-6040 chromium silicides-based composites after sintering at $1370^{\circ} \mathrm{C}$ for $2 \mathrm{~h}$ in argon. 

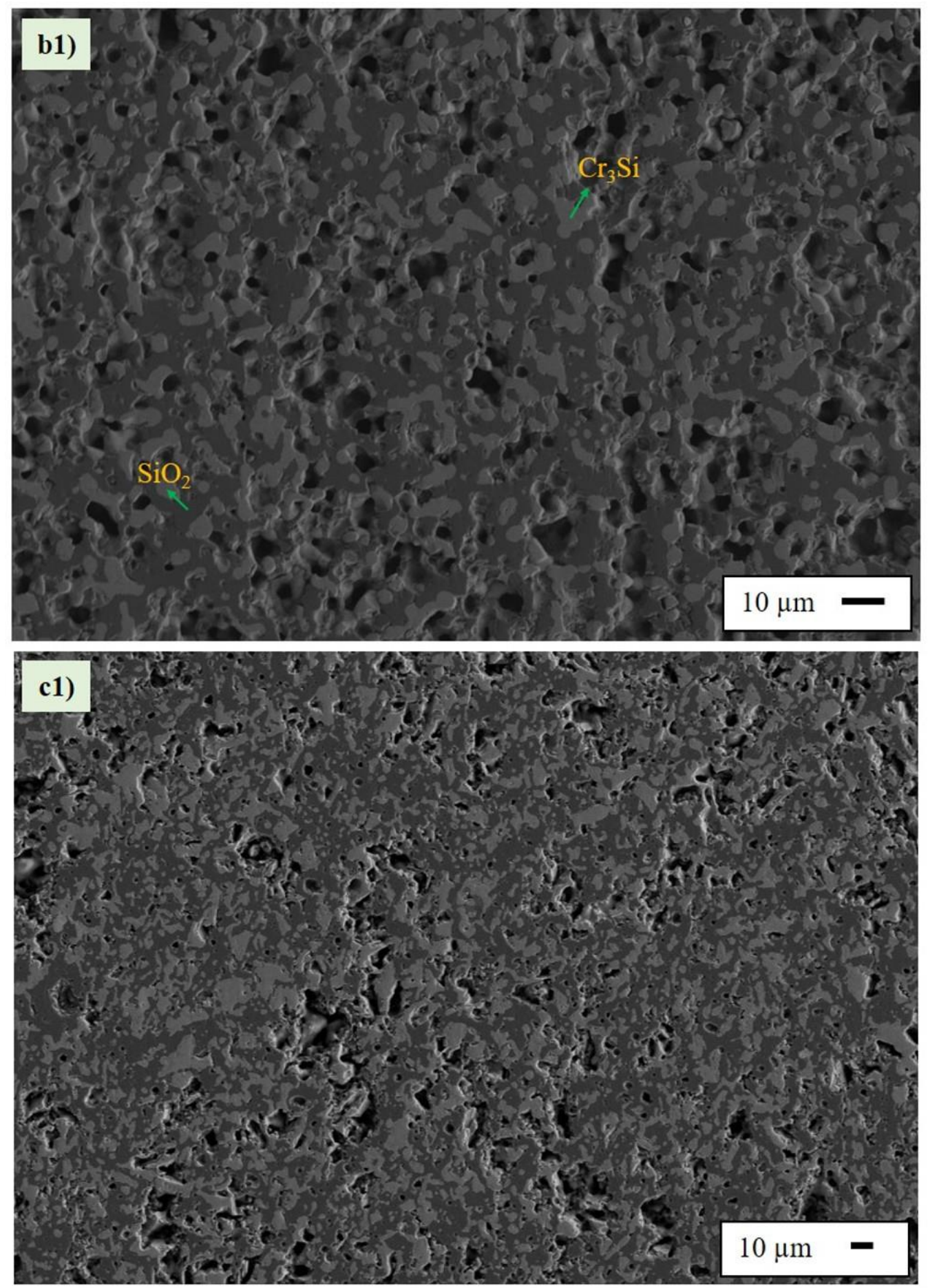

Figure 60. (continued) SEM microstructures of the (a1-a2) CC-4060, (b1) CC-5050, (c1c2) CC-5545 and (d1-d2) CC-6040 chromium silicides-based composites after sintering at $1370^{\circ} \mathrm{C}$ for $2 \mathrm{~h}$ in argon. 

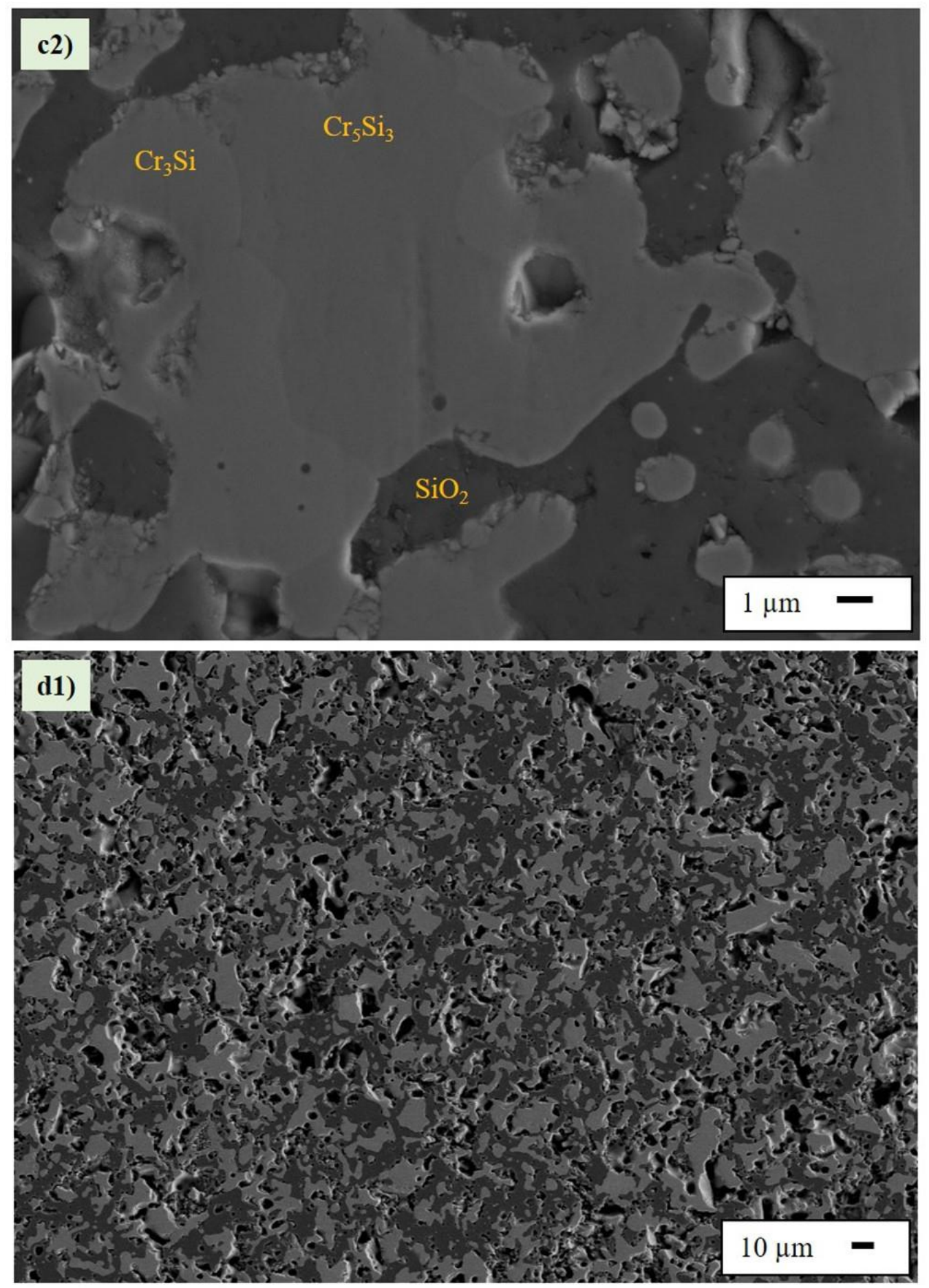

Figure 60. (continued) SEM microstructures of the (a1-a2) CC-4060, (b1) CC-5050, (c1c2) CC-5545 and (d1-d2) CC-6040 chromium silicides-based composites after sintering at $1370^{\circ} \mathrm{C}$ for $2 \mathrm{~h}$ in argon. 


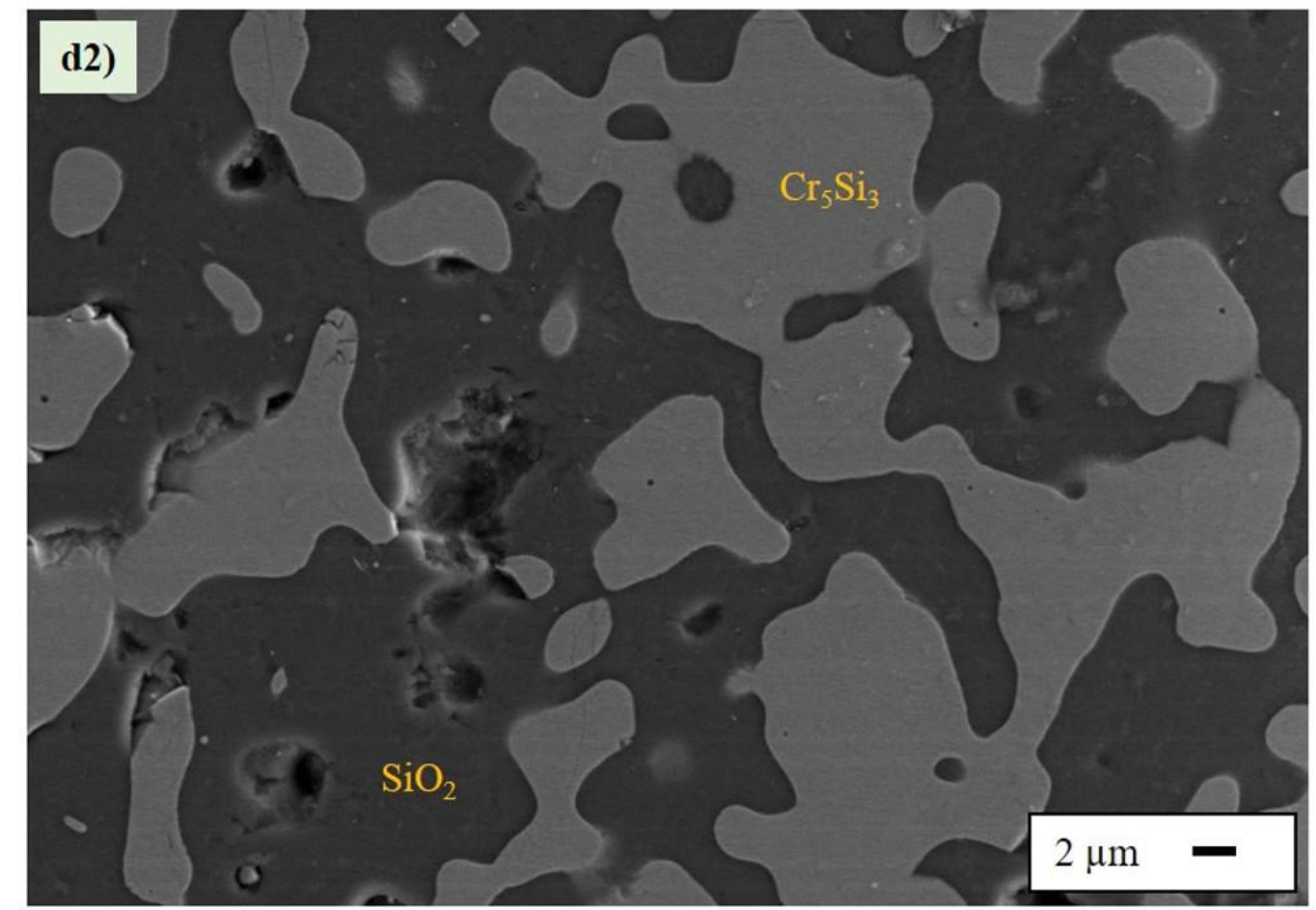

Figure 60. (continued) SEM microstructures of the (a1-a2) CC-4060, (b1) CC-5050, (c1c2) CC-5545 and (d1-d2) CC-6040 chromium silicides-based composites after sintering at $1370^{\circ} \mathrm{C}$ for $2 \mathrm{~h}$ in argon.

(bright regions) within the low-cristobalite $\mathrm{SiO}_{2}$ grains (dark regions) was clearly observed for the CC-4060 composite, as displayed in Figure 60(a1-a2). Similarly, CC-5050, CC5545 and CC-6040 composites all revealed highly homogeneous microstructures, where the bright and dark regions refer to chromium silicide phases and low-cristobalite $\mathrm{SiO}_{2}$, respectively (Figure 60(b1-c1-d1)). The $\mathrm{Cr}_{3} \mathrm{Si}$ and $\mathrm{SiO}_{2}$ phases were detected for the CC5050 composite (Figure 60(b1)), which was found to be consistent with the previously discussed XRD data. The composition of the chromium silicide phase was also identified as $\mathrm{Cr}_{3} \mathrm{Si}(86.0 \mathrm{wt} \% \mathrm{Cr}+14.0 \mathrm{wt} \% \mathrm{Si}$ ) based on the quantitative EDS analysis (not shown). Although the CC-5545 composite seemed to be a two-phase system based on its low magnification SEM image (Figure 60(c1)), it is apparent that chromium silicide grains were composed of two different phases as detected at a higher magnification. As also supported with the EDS analyses, the brighter, gray and dark regions corresponded to $\mathrm{Cr}_{3} \mathrm{Si}_{1} \mathrm{Cr}_{5} \mathrm{Si}_{3}$ 
and $\mathrm{SiO}_{2}$ grains, respectively (Figure 60(c2)). These results are in good correlation with the XRD data of the CC-5545 composite; however, unreacted $\mathrm{CrSi}_{2}$ phase, which was detected by XRD, was not observed in the SEM microstructures, indicating its very low concentration remained after sintering. Two major phases $\left(\mathrm{Cr}_{5} \mathrm{Si}_{3}, \mathrm{SiO}_{2}\right)$ can be clearly seen within the microstructures of the CC-6040 composite after sintering as shown in Figure 60(d1-d2). Although the XRD analysis also demonstrated the presence of $\mathrm{Cr}_{3} \mathrm{Si}, \mathrm{CrSi}_{2}$, $\mathrm{CrSi}$ and $\mathrm{Cr}_{2} \mathrm{O}_{3}$ as minor phases, they could not be observed in their microstructures probably due to their small amounts and lack of color contrast between different chromium silicide grains. In addition, Figure 61 presents the SEM microstructures of the CC-6535, CC-7030, CC-8020 and CC-9010 composites after sintering at $1370^{\circ} \mathrm{C}$. The homogeneous distribution of the chromium silicide phases within the grain boundary silica phase can be similarly seen for all these composites. However, the reduced amount of the silica phase was observed particularly within the microstructures of the composites (CC-8020, CC9010) including the high amount of starting metal silicide content ( $\geq 80 \mathrm{vol} \%$ ) due to their solid-state reaction only with low chromia content (Figure 61(c1-d1)). Although the XRD data demonstrated the presence of $\mathrm{Cr}_{5} \mathrm{Si}_{3}, \mathrm{Cr}_{3} \mathrm{Si}, \mathrm{CrSi}, \mathrm{CrSi}_{2}$ and $\mathrm{SiO}_{2}$, only two phases were observed within the microstructures of the CC-6535 composite (Figure 61(a1-a2)). For the CC-7030 composite, the SEM microstructure displayed three different phases $\left(\mathrm{CrSi}, \mathrm{Cr}_{5} \mathrm{Si}_{3}, \mathrm{SiO}_{2}\right)$ as shown in Figure 61(b1). This was found to be consistent with the XRD data; however, unreacted $\mathrm{CrSi}_{2}$ phase was not detected by SEM due to its small concentration that remained after sintering. The SEM microstructures of the CC-9010 composite clearly revealed three different phases $\left(\mathrm{CrSi}, \mathrm{CrSi}_{2}, \mathrm{SiO}_{2}\right)$, as supported with the XRD and EDS analyses (Figure 61(d1-d2)). These results indicated that a small portion of starting chromium silicides $\left(\mathrm{CrSi}, \mathrm{CrSi}_{2}\right)$ partially reacted with $10-20$ vol\% $\mathrm{Cr}_{2} \mathrm{O}_{3}$ phase only to form silica in low-cristobalite structure as a grain boundary phase.

As a review of the composite microstructures achieved after solid-state reaction, it can be concluded that different chromium silicide phases were homogeneously distributed within the grain boundary silica phase for all the composite systems. This could be highly 

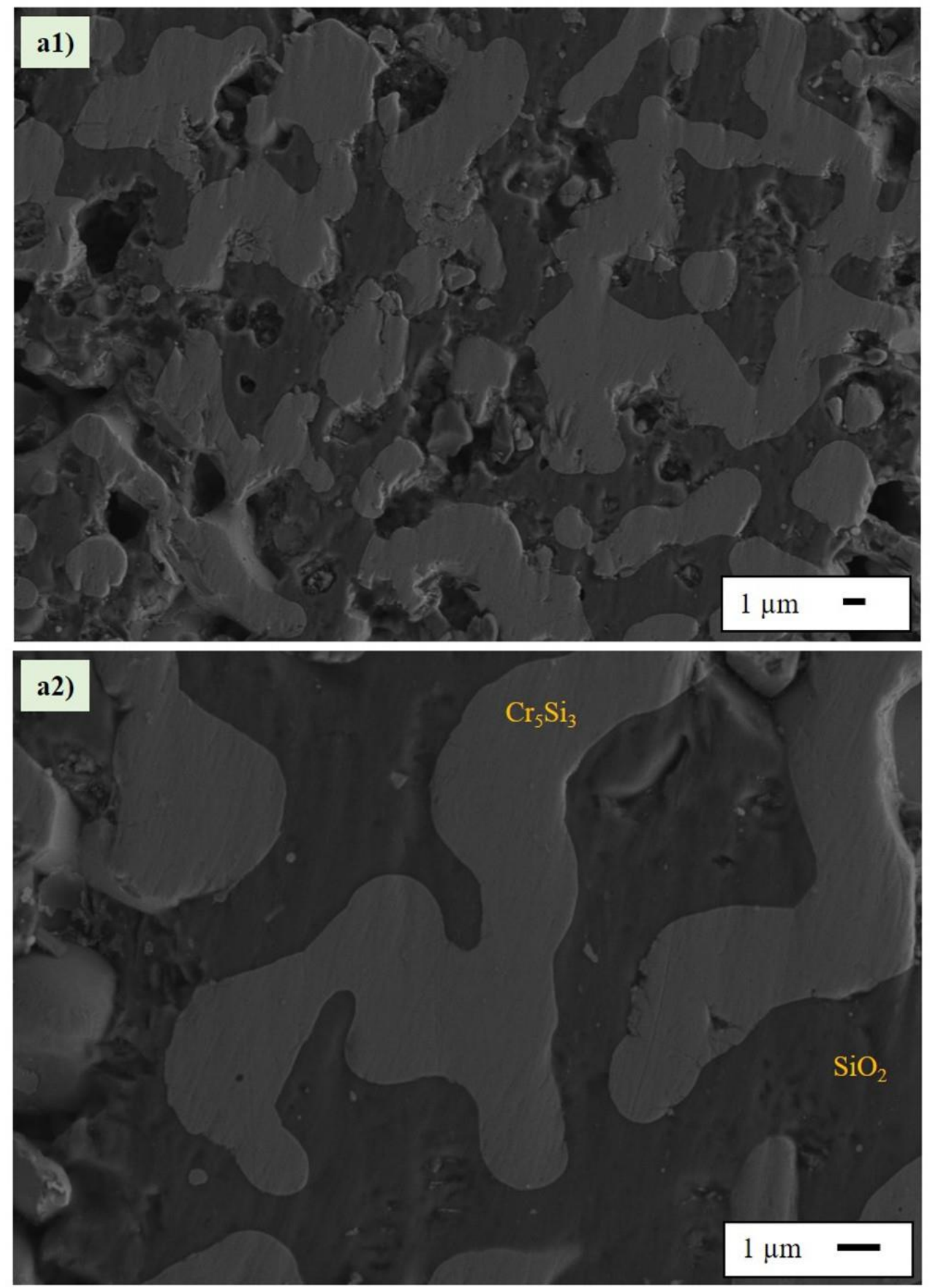

Figure 61. SEM microstructures of the (a1-a2) CC-6535, (b1) CC-7030, (c1) CC-8020 and (d1-d2) CC-9010 chromium silicides-based composites after sintering at $1370^{\circ} \mathrm{C}$ for $2 \mathrm{~h}$ in argon. 

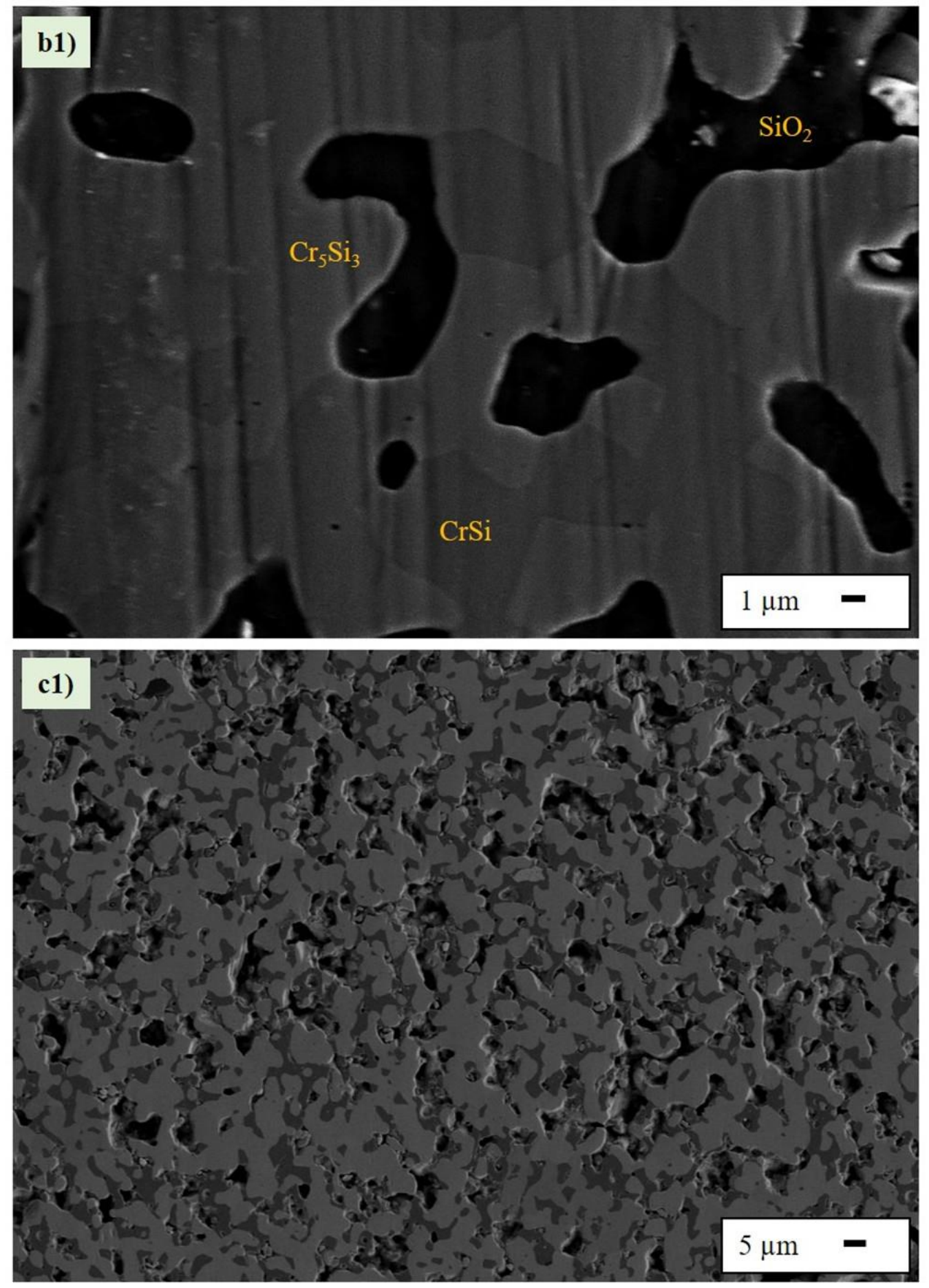

Figure 61. (continued) SEM microstructures of the (a1-a2) CC-6535, (b1) CC-7030, (c1) CC-8020 and (d1-d2) CC-9010 chromium silicides-based composites after sintering at $1370^{\circ} \mathrm{C}$ for $2 \mathrm{~h}$ in argon. 

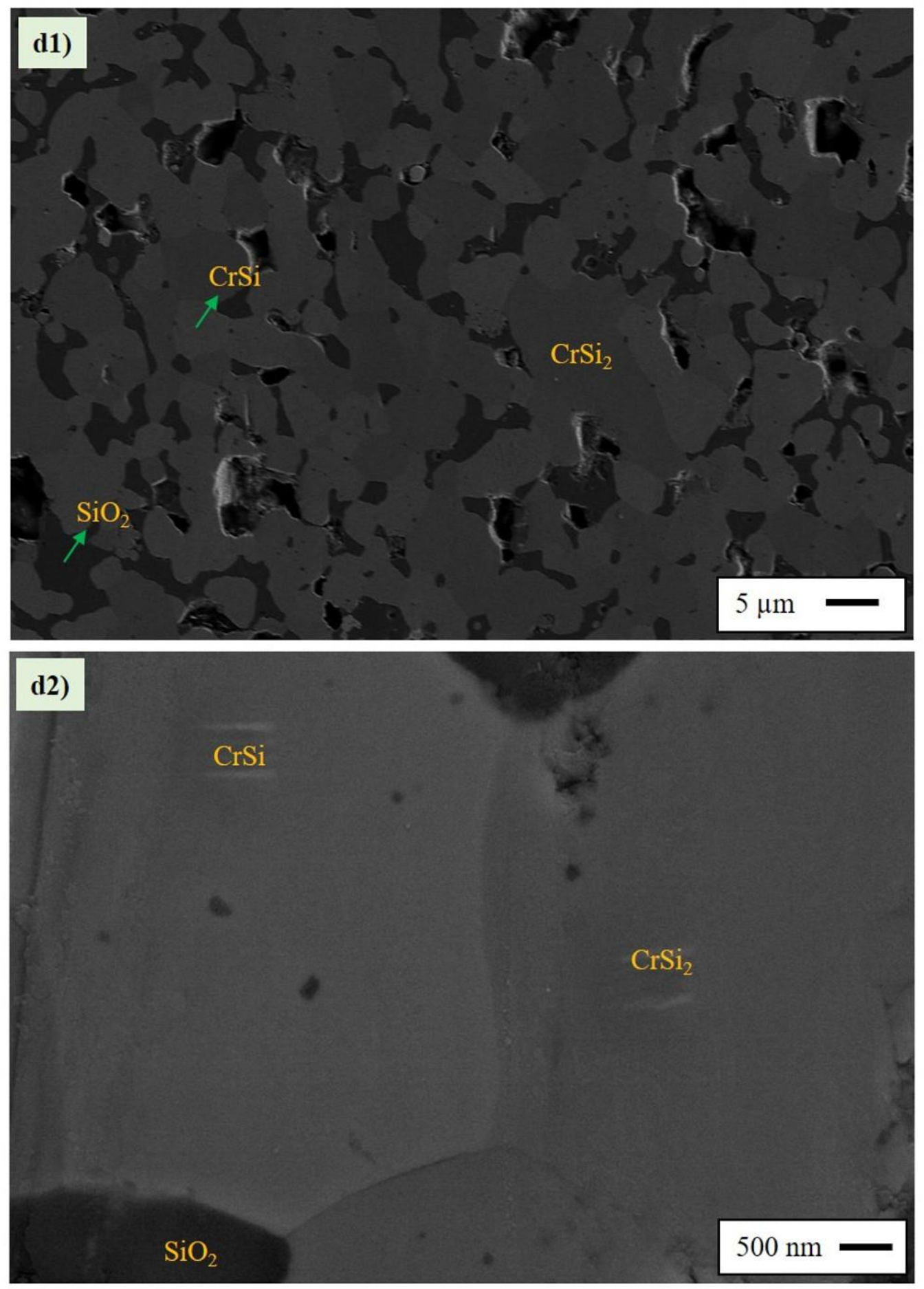

Figure 61. (continued) SEM microstructures of the (a1-a2) CC-6535, (b1) CC-7030, (c1) CC-8020 and (d1-d2) CC-9010 chromium silicides-based composites after sintering at $1370^{\circ} \mathrm{C}$ for $2 \mathrm{~h}$ in argon. 
advantageous for achieving a better electrical network (percolation) and consistent electrical properties within the electroconductive composite systems composed of both conductive and insulating materials [27,28]. It was demonstrated that CC-4060 and CC5050 composites are two-phase systems consisting of a single chromium silicide phase $\left(\mathrm{Cr}_{0.91} \mathrm{Si}_{0.09}, \mathrm{Cr}_{3} \mathrm{Si}\right)$ and a silica grain boundary phase. However, other composite systems displayed more complex microstructures owing to the presence of at least two different chromium silicide phases (e.g. $\mathrm{Cr}_{5} \mathrm{Si}_{3}, \mathrm{CrSi}$ ) along with the silica and some unreacted phases. Therefore, the formation of different grain boundary structures within these composites (e.g. $\mathrm{CrSi}-\mathrm{CrSi}_{2}, \mathrm{Cr}_{5} \mathrm{Si}_{3}-\mathrm{CrSi}, \mathrm{Cr}_{3} \mathrm{Si}_{-}-\mathrm{Cr}_{5} \mathrm{Si}_{3}$ ) could significantly influence their physical properties. It is also clear that all chromium silicide-based composites had a certain amount of porosity within their microstructures after sintering. In addition, grain boundaries of the chromium silicide grains were found to be highly smooth (not angular), particularly at the regions where the chromium silicide grains were in contact with the silica phase. The presence of highly rounded silicide grains can be clearly seen. This result implied the presence of an additional amorphous (glassy) silica phase at the grain boundaries, which highly wetted the chromium silicide grains and provided the formation of rounded grains by lowering the silicide-silica interfacial energy. Similar observation was reported for the rounded zirconia grains due to the presence of glassy silica phase at grain boundaries [29]. This could be also attributed to the formation of the silica phase in cristobalite form, its metastable nature and related phase transitions. It is known that the cristobalite structure undergoes phase transformations during both cooling and heating at around $275^{\circ} \mathrm{C}$ (low-cristobalite $\leftrightarrow$ high-cristobalite or $\alpha$-cristobalite $\leftrightarrow \beta$-cristobalite) $[26,30,31]$. This tetragonal-cubic transition was reported to be rapid and reversible, but it could create up to $\sim 2.8 \%$ change in volume (contraction or expansion), which may affect the microstructures.

\subsubsection{High-temperature non-isothermal oxidation of the composites}

The thermogravimetric analyses (TGA) were performed in ambient air at the temperatures ranging from $50^{\circ} \mathrm{C}$ to $870^{\circ} \mathrm{C}$ on the as-sintered chromium silicide-based 
composites, as well as, the as-sintered starting chromium silicide (mixture of $\mathrm{CrSi}_{2}$ and $\mathrm{CrSi})$. Figure 62(a-c) present their specific mass changes per unit surface areas $\left(\mathrm{mg} / \mathrm{cm}^{2}\right)$ as a function of oxidation temperature. The oxidation-induced mass change for the CC-4060 composite, which is a mixture of $\mathrm{Cr}_{0.91} \mathrm{Si}_{0.09}$ and $\mathrm{SiO}_{2}$, was less than $0.10 \mathrm{mg} / \mathrm{cm}^{2}$ up to $\sim 450^{\circ} \mathrm{C}$, but starting from this point, it relatively increased to the level of $0.63 \mathrm{mg} / \mathrm{cm}^{2}$ with increasing temperature to $870^{\circ} \mathrm{C}$. This implied that the $\mathrm{Cr}_{0.91} \mathrm{Si}_{0.09}$ phase could oxidize at relatively higher rate at temperatures above $450^{\circ} \mathrm{C}$, since the specific mass change at $\sim 855^{\circ} \mathrm{C}$ was found to be six times higher than that at $450^{\circ} \mathrm{C}$ (Figure 62(a)). The CC-5050, CC-5545 and CC-6040 composites displayed a similar type of oxidation behavior, since their specific mass changes were measured to be less than $0.24 \mathrm{mg} / \mathrm{cm}^{2}$ at the temperatures below $700^{\circ} \mathrm{C}$ (Figure $62(\mathrm{a}-\mathrm{b})$ ). However, a notable increase $\left(+0.25-0.34 \mathrm{mg} / \mathrm{cm}^{2}\right)$ was observed in their oxidation at the temperatures ranging from $700^{\circ} \mathrm{C}$ to $870^{\circ} \mathrm{C}$. The oxidation-induced mass changes at $870^{\circ} \mathrm{C}$ for the CC-5050, CC-5545 and CC-6040 composites were $0.47,0.58$ and $0.40 \mathrm{mg} / \mathrm{cm}^{2}$, respectively, indicating their relatively lower oxidation kinetics compared to the CC-4060 composite. Similarly, a negligible oxidation with mass changes less than $0.18 \mathrm{mg} / \mathrm{cm}^{2}$ was detected for the CC-6535 and CC-7030 composites at the temperatures below $700^{\circ} \mathrm{C}$ as shown in Figure 62(b). Their specific mass changes increased at higher temperatures; however, the level of increase was two times higher in the CC-7030 composite $\left(+0.38 \mathrm{mg} / \mathrm{cm}^{2}\right)$ compared to the CC-6535 composite $\left(+0.19 \mathrm{mg} / \mathrm{cm}^{2}\right)$. The oxidation-induced mass changes at $870^{\circ} \mathrm{C}$ for the CC-6535 and CC7030 composites were 0.35 and $0.56 \mathrm{mg} / \mathrm{cm}^{2}$, respectively. The non-isothermal oxidation behavior of the CC-8020 and CC-9010 composites was different compared to the abovementioned composites, but quite similar to the as-sintered chromium silicide reference sample (mixture of $\mathrm{CrSi}_{2}+\mathrm{CrSi}$ as denoted) as presented in Figure 62(c). The specific mass changes were similarly found to be negligible $\left(<+0.1 \mathrm{mg} / \mathrm{cm}^{2}\right)$ at the temperatures up to around $550^{\circ} \mathrm{C}$. However, differently, a slight reduction in the mass change was observed in these composites at the temperatures ranging from $550^{\circ} \mathrm{C}$ to around $650^{\circ}-750^{\circ} \mathrm{C}$, probably due to the evaporation of a small amount of a volatile surface oxide phase (e.g. $\mathrm{CrO}_{3}$ ) formed at the lower temperatures. At higher temperatures, the specific mass changes 

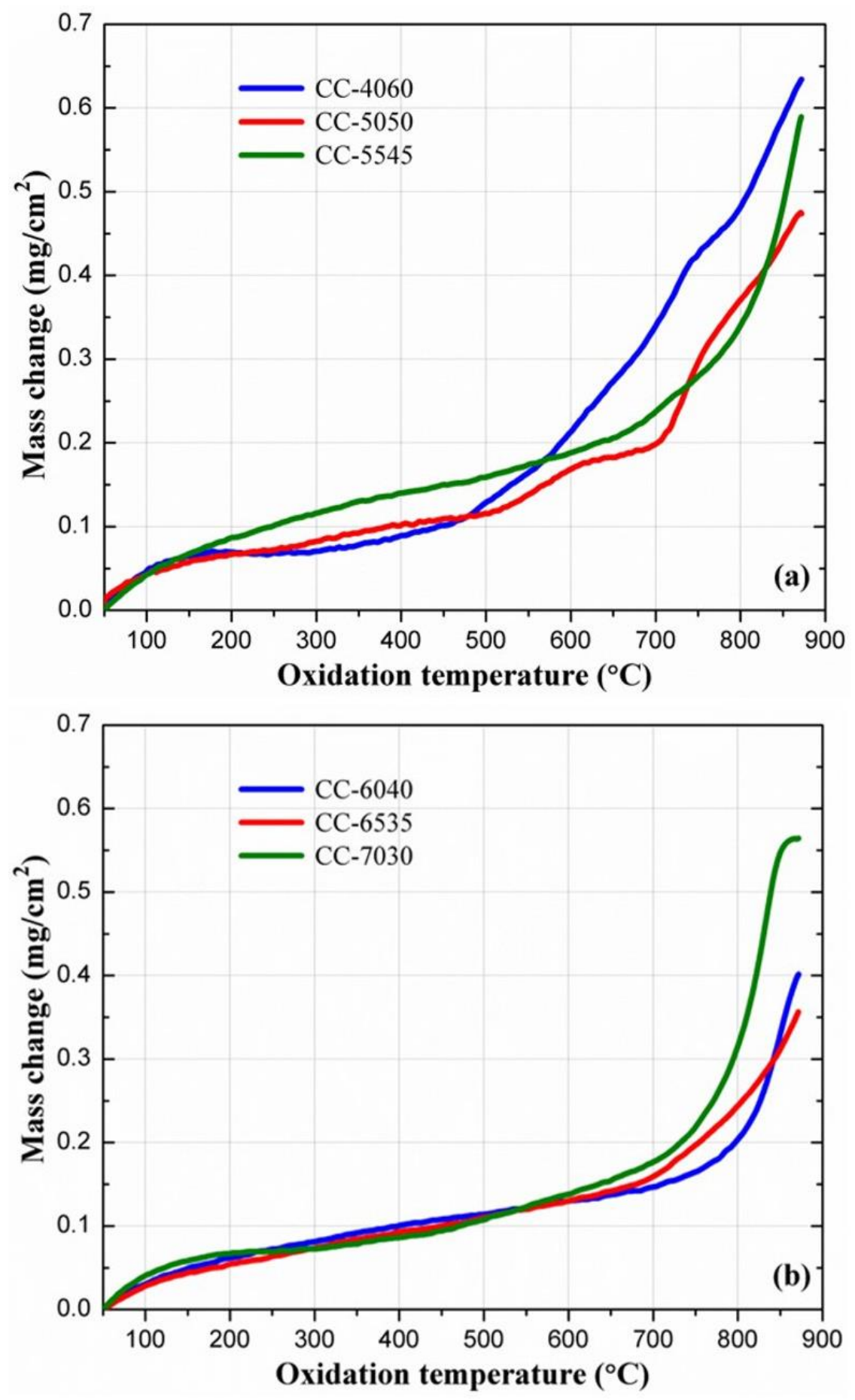

Figure 62. Mass change per unit surface area as a function of oxidation temperature for the (a) CC-4060, CC-5050, CC-5545, (b) CC-6040, CC-6535, CC-7030, and (c) CC8020, CC-9010, reference $\mathrm{CrSi}_{2}+\mathrm{CrSi}$ sample during non-isothermal oxidation from $50^{\circ} \mathrm{C}$ to $870^{\circ} \mathrm{C}$ in air. 


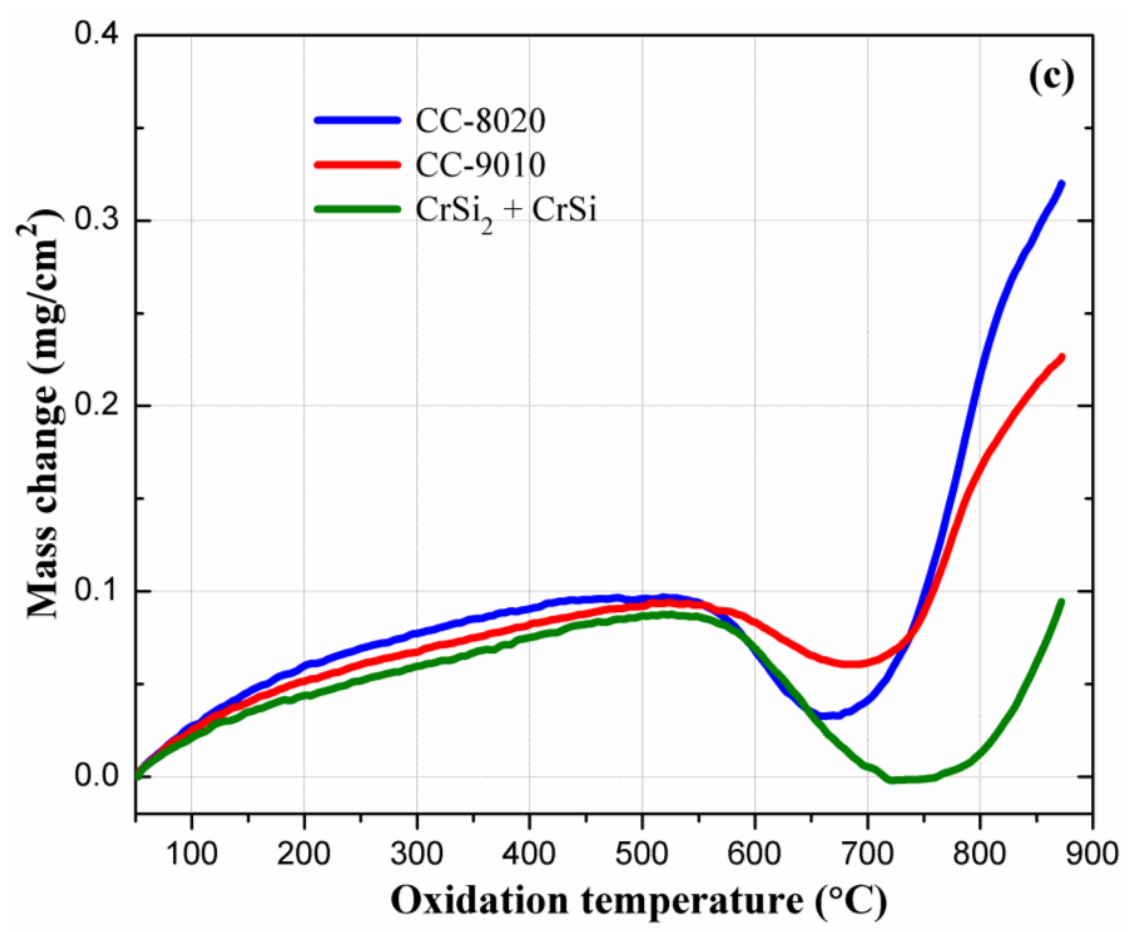

Figure 62. (continued) Mass change per unit surface area as a function of oxidation temperature for the (a) CC-4060, CC-5050, CC-5545, (b) CC-6040, CC-6535, CC-7030, and (c) $\mathrm{CC}-8020$, CC-9010, reference $\mathrm{CrSi}_{2}+\mathrm{CrSi}$ sample during non-isothermal oxidation from $50^{\circ} \mathrm{C}$ to $870^{\circ} \mathrm{C}$ in air.

increased in the CC-8020 and CC-9010 composites, as well as, in the as-sintered $\mathrm{CrSi}_{2}+$ $\mathrm{CrSi}$ reference bulk sample. The oxidation-induced mass changes at $870^{\circ} \mathrm{C}$ for the $\mathrm{CC}$ 8020 and CC-9010 composites were 0.32 and $0.22 \mathrm{mg} / \mathrm{cm}^{2}$, respectively. The as-sintered $\mathrm{CrSi}_{2}+\mathrm{CrSi}$ sample exhibited relatively lower oxidation rates $\left(<0.095 \mathrm{mg} / \mathrm{cm}^{2}\right)$ at high temperatures compared to all chromium silicide-based composite systems.

Based on the non-isothermal oxidation studies, the chromium silicide-based composites, which are composed of different silicide phases $\left(\mathrm{Cr}_{3} \mathrm{Si}_{1}, \mathrm{Cr}_{5} \mathrm{Si}_{3}, \mathrm{CrSi}, \mathrm{CrSi}_{2}\right.$, $\mathrm{Cr}_{0.91} \mathrm{Si}_{0.09}$ ) did not show any pest oxidation (structural disintegration due to cracking or extreme spallation) behavior at the temperatures ranging from $50^{\circ} \mathrm{C}$ to $870^{\circ} \mathrm{C}$; therefore, no accelerated internal oxidation and related structural disintegration was observed. The CC4060 composite was composed of $\mathrm{Cr}_{0.91} \mathrm{Si}_{0.09}$ and $\mathrm{SiO}_{2}$ phases, which displayed a negligible 
oxidation below $450^{\circ} \mathrm{C}$ and $0.63 \mathrm{mg} / \mathrm{cm}^{2}$ specific mass change at $870^{\circ} \mathrm{C}$. Its oxidation was determined to be relatively higher than the other composites at high temperatures, which was an indication of the lower oxidation resistance of the $\mathrm{Cr}_{0.91} \mathrm{Si}_{0.09}$ phase compared to the other chromium silicide phases. The major silicide phases were $\mathrm{Cr}_{3} \mathrm{Si}$ and $\mathrm{Cr}_{5} \mathrm{Si}_{3}$ for the CC-5050, CC-5545 and CC-6040 composites, which revealed specific mass changes ranging from 0.40 to $0.58 \mathrm{mg} / \mathrm{cm}^{2}$ at $870^{\circ} \mathrm{C}$. These results demonstrated that the presence of the $\mathrm{Cr}_{5} \mathrm{Si}_{3}$ phase within the CC-5545 adversely affected its oxidation resistance, since it oxidized relatively higher than the CC-5050 composite including only $\mathrm{Cr}_{3} \mathrm{Si}$ as a silicide phase. It was reported that the sputter-deposited $\mathrm{Cr}_{3} \mathrm{Si}$ film exhibited substantially high oxidation resistance at $700^{\circ} \mathrm{C}$ and $800^{\circ} \mathrm{C}$ with very low mass changes $\left(\sim 0.15-0.32 \mathrm{mg} / \mathrm{cm}^{2}\right)$ after cyclic oxidation in air for $100 \mathrm{~h} \mathrm{[16].} \mathrm{Its} \mathrm{oxidation} \mathrm{behavior} \mathrm{was} \mathrm{due} \mathrm{to} \mathrm{the} \mathrm{formation}$ of a protective surface layer composed of $\mathrm{Cr}_{2} \mathrm{O}_{3}$ and amorphous $\mathrm{SiO}_{2}$ phases, and its good adhesion on the $\mathrm{Cr}_{3} \mathrm{Si}$ phase. The chromium silicide-based composites consisting of $\mathrm{Cr}_{3} \mathrm{Si}$ as a major phase also showed negligible mass gain at temperatures below $500^{\circ}-650^{\circ} \mathrm{C}$. This was found to be in good correlation with the previous studies [15,32]. Shah and Anton [33] reported that the $\mathrm{Cr}_{3} \mathrm{Si}$ displayed an initial weight loss saturating around $3.12 \mathrm{mg} / \mathrm{cm}^{2}$ after

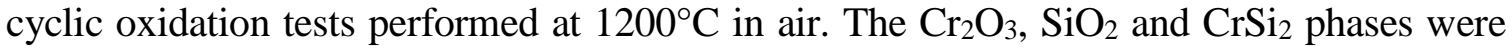
identified as the oxidation products in this study. The oxidation resistance of the $\mathrm{Cr}_{3} \mathrm{Si}$ phase was hereby reported to be sufficiently high up to around $1150^{\circ}-1200^{\circ} \mathrm{C}$, which makes it a good candidate material for a broad range of high temperature structural and electrical applications $[20,34]$. However, due to the faster oxidation rate of chromium than silicon, it was described that protective silica layer could not be formed on the $\mathrm{Cr}_{3} \mathrm{Si}$ surface at the temperatures of $1200^{\circ}-1500^{\circ} \mathrm{C}$, which needs to be further studied (e.g. alloying with molybdenum) [23]. Additionally, it should be pointed out that no study has been conducted yet on the oxidation of the $\mathrm{Cr}_{0.91} \mathrm{Si}_{0.09}$ and $\mathrm{Cr}_{5} \mathrm{Si}_{3}$ silicide phases. The relatively lower oxidation of the CC-6040 and CC-6535 composites compared to the other composites composed of similar silicide phases could be attributed to the presence of unreacted silicide $\left(\mathrm{CrSi}, \mathrm{CrSi}_{2}\right)$ and $\mathrm{Cr}_{2} \mathrm{O}_{3}$ phases. The composites with only $\mathrm{CrSi}$ and $\mathrm{CrSi}_{2}$ major phases (CC-8020, CC-9010) exhibited significantly lower mass changes, and thus, 
lower oxidation at high temperatures. The non-isothermal oxidation studies were similarly conducted on the $\mathrm{CrSi}_{2}$ sample from room temperature to $1000^{\circ} \mathrm{C}$ in a $50 \mathrm{ml} / \mathrm{min}$ flowing air with a heating rate of $10^{\circ} \mathrm{C} / \mathrm{min}$ by Stathokostopoulos et al. [4]. The results showed that specific mass gain for the $\mathrm{CrSi}_{2}$ was around $0.03 \mathrm{mg} / \mathrm{cm}^{2}$, and then increased to $\sim 0.08$ $\mathrm{mg} / \mathrm{cm}^{2}$ with increasing temperature up to $1000^{\circ} \mathrm{C}$. The excellent oxidation resistance of the $\mathrm{CrSi}_{2}$ phase was mainly attributed to the formation of a protective surface layer consisting of $\mathrm{Cr}_{2} \mathrm{O}_{3}$ and amorphous $\mathrm{SiO}_{2}$ [5,8,11]. These results were determined to be in good correlation with the oxidation behavior of the as-sintered $\mathrm{CrSi}+\mathrm{CrSi}_{2}$ baseline samples studied. The relatively higher oxidation of the CC-8020 and CC-9010 composites compared to the as-sintered reference sample could be correlated to the reduced amount of $\mathrm{CrSi}_{2}$ and relatively poor oxidation resistance of the $\mathrm{CrSi}$ phase. However, it should be noted that the oxidation behavior of the $\mathrm{CrSi}$ phase has not been investigated to date. Additionally, a slight specific mass loss was detected at the temperatures between $550^{\circ} \mathrm{C}$ and $750^{\circ} \mathrm{C}$ for the $\mathrm{CC}-8020$ and $\mathrm{CC}-9010$ composites, as well as, the as-sintered reference sample. A similar type of oxidation behavior was also reported for the $\mathrm{CrSi}_{2}$ material at a similar temperature range, but was not explained [5]. This could be correlated to the different oxidation behavior of the $\mathrm{CrSi}_{2}$ and $\mathrm{CrSi}$ phases at the temperatures below $700^{\circ}-$ $750^{\circ} \mathrm{C}$ and possible formation of volatile chromium oxide species (e.g. $\mathrm{CrO}_{3}$ ) in small amounts [22].

\subsubsection{High-temperature electrical properties of the composites}

The high-temperature electrical conductivities of the chromium silicide-based composites were measured at the temperatures up to $1000^{\circ} \mathrm{C}$ in argon, and their electrical properties are presented as a function of temperature in Figure 63. The electrical data was recorded at the temperatures of $\sim 200^{\circ}-1000^{\circ} \mathrm{C}$, since very low resistance values for the tested sample dimensions caused relatively inaccurate measurements at lower temperatures. The electrical connections made by platinum were lost at $\sim 896^{\circ}-998^{\circ} \mathrm{C}$ depending on the composite samples; therefore, exponential decay fitting $\left(1^{\text {st }}-3^{\text {rd }}\right.$ degree, R-square: 0.98 0.99) was applied to extrapolate the electrical data up to $1000^{\circ} \mathrm{C}$ (dotted lines) for a better 

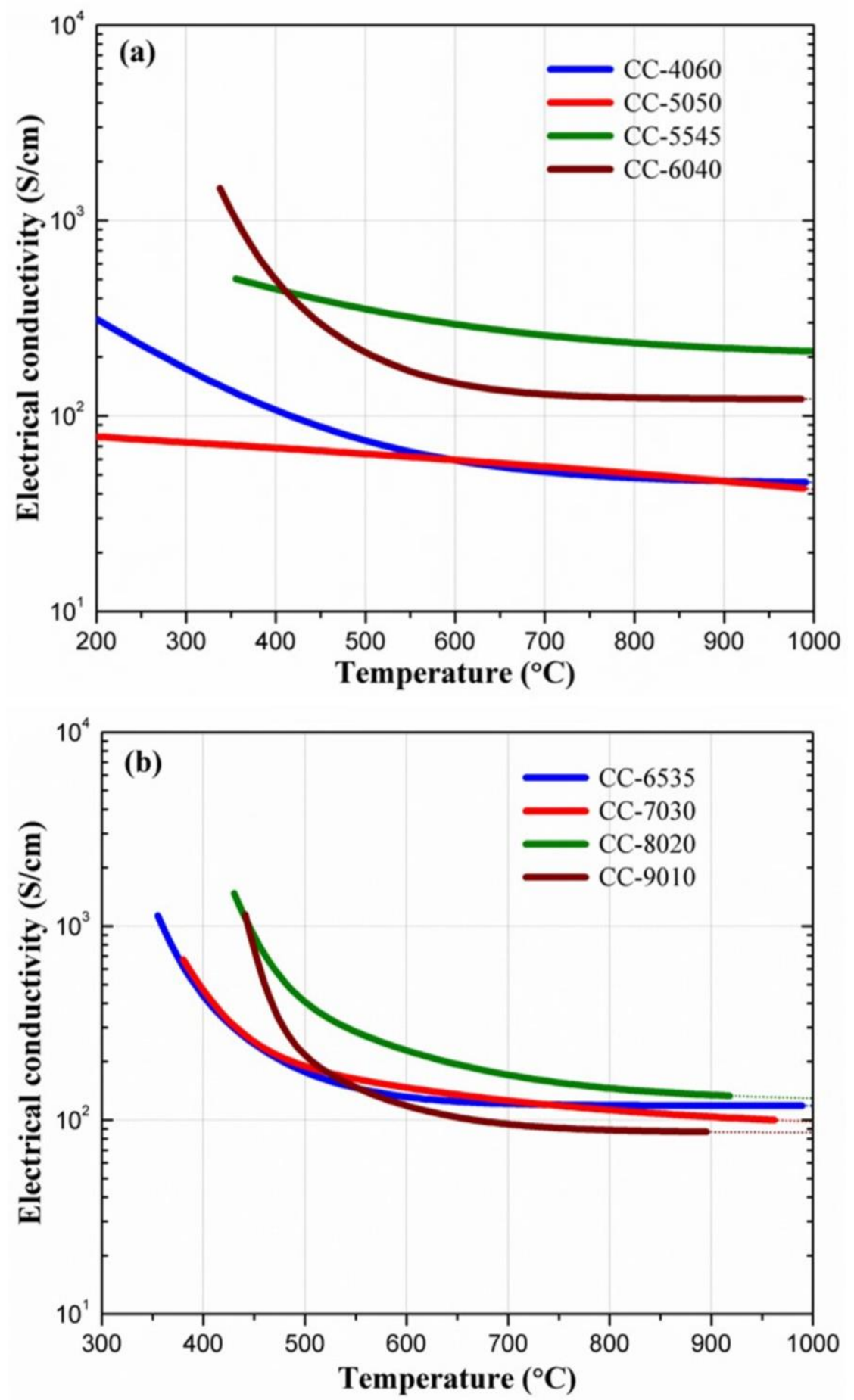

Figure 63. Electrical conductivity as a function of the temperature for the (a) $\mathrm{CC}-4060$, CC-5050, CC-5545 and CC-6040, and (b) CC-6535, CC-7030, CC-8020 and CC-9010 chromium silicide-based composites, which were all sintered at $1370^{\circ} \mathrm{C}$ in $\operatorname{argon}$ (Electrical conductivity data is shown on the logarithmic scale). 
comparison. It is apparent from Figure 63(a-b) that the electrical conductivity of all the chromium silicide-based composites decreased with increasing temperature. These results demonstrated that all composites exhibited a metallic-type electrical behavior due to the presence of different chromium silicide phases. As presented in Figure 63a, the electrical conductivities of the CC-4060 and CC-5050 composites were found at $1000^{\circ} \mathrm{C}$ as 45.7 and 42.1 S/cm, respectively. These results may imply that the $\mathrm{Cr}_{0.91} \mathrm{Si}_{0.09}$ and $\mathrm{Cr}_{3} \mathrm{Si}$ silicides have a similar intrinsic electrical conductivity at high temperatures $\left(>550^{\circ} \mathrm{C}\right)$, since these two composites were two-phase systems composed of a single chromium silicide phase along with silica. At $1000^{\circ} \mathrm{C}$, the electrical conductivities of the CC-5545 and CC-6040 composites were 213.7 and $122.1 \mathrm{~S} / \mathrm{cm}$, respectively. It is clear that these composites displayed substantially higher electrical conductivity values compared to the CC-4060 and CC-5050 composites, which could be related to the increased fraction of the $\mathrm{Cr}_{3} \mathrm{Si}$ phase and presence of the $\mathrm{Cr}_{5} \mathrm{Si}_{3}$ phase. Mazzega et al. [2] reported that the pure $\mathrm{Cr}_{3} \mathrm{Si}_{\text {and }} \mathrm{Cr}_{5} \mathrm{Si}_{3}$ films possessed the electrical conductivities of $\sim 10500$ and $\sim 5900 \mathrm{~S} / \mathrm{cm}$ at around $827^{\circ} \mathrm{C}$, respectively. The electrical conductivity of the CC-6040 composite was found to be lower than that of the CC-5545 composite at the temperatures above $\sim 420^{\circ} \mathrm{C}$, even though the major silicide phases were identified as $\mathrm{Cr}_{3} \mathrm{Si}_{3}$ and $\mathrm{Cr}_{5} \mathrm{Si}_{3}$ within both composites. This could be attributed to the presence of the remaining $\mathrm{CrSi}$ and $\mathrm{CrSi}_{2}$ phases within the $\mathrm{CC}$ 6040 composite, since their electrical conductivities were shown to be significantly lower compared to the $\mathrm{Cr}_{3} \mathrm{Si}$ and $\mathrm{Cr}_{5} \mathrm{Si}_{3}$ [4]. Based on the previous studies, electrical conductivities at $\sim 500^{\circ} \mathrm{C}$ for the $\mathrm{CrSi}, \mathrm{CrSi}_{2}, \mathrm{Cr}_{5} \mathrm{Si}_{3}$ and $\mathrm{Cr}_{3} \mathrm{Si}$ compounds are around 500, 725, 6700 and $14300 \mathrm{~S} / \mathrm{cm}$, respectively [2,4,5]. As shown in Figure 63b, the electrical conductivity of the CC-6535 composite was $118.4 \mathrm{~S} / \mathrm{cm}$ at $1000^{\circ} \mathrm{C}$, which was found to be very close to that of the CC-6040 composite $(122.1 \mathrm{~S} / \mathrm{cm})$ due to the same silicide phases $\left(\mathrm{Cr}_{3} \mathrm{Si}_{1} \mathrm{Cr}_{5} \mathrm{Si}_{3}, \mathrm{CrSi}, \mathrm{CrSi}_{2}\right)$ existing within these composites. The electrical conductivities of the CC-7030, CC-8020 and CC-9010 composites at $1000^{\circ} \mathrm{C}$ were $98.1,129.6$ and 86.3 $\mathrm{S} / \mathrm{cm}$, respectively. These results point out that the higher concentration of the $\mathrm{CrSi}_{2}$ phase within the CC-7030 and CC-9010 composites lowered their electrical conductivity, particularly compared to the CC-6040, CC-6535 and CC-8020 composites. 
The metallic-type of electrical conduction behavior is expected for the chromium silicide-based composites including $\mathrm{Cr}_{3} \mathrm{Si}_{2}, \mathrm{Cr}_{5} \mathrm{Si}_{3}$ and $\mathrm{CrSi}$ as major silicide phases, since $\mathrm{Cr}_{3} \mathrm{Si}$ and $\mathrm{Cr}_{5} \mathrm{Si}_{3}$ compounds are known to display a temperature-dependent electrical resistivity like a metal $[2,14]$. It was reported that the electrical conductivity of the $\mathrm{CrSi}$ decreased with increasing temperature $\left(\sim 50^{\circ}-400^{\circ} \mathrm{C}\right)$ [4]; however, it should be noted that its electrical properties and behavior have not been reported for high temperatures. The electrical data of the CC-8020 and CC-9010 composites with a CrSi major silicide phase (Figure 63b) demonstrated that the CrSi could have a metallic conductivity similar to the $\mathrm{Cr}_{3} \mathrm{Si}$ and $\mathrm{Cr}_{5} \mathrm{Si}_{3}$. Several studies also demonstrated that the electrical conductivity of the $\mathrm{CrSi}_{2}$, which is known as a p-type degenerate semiconducting material, initially decreased with increasing temperature to $\sim 300^{\circ}-430^{\circ} \mathrm{C}$, and then started to increase as a function of temperature $[5,8,35,36]$. This behavior of the $\mathrm{CrSi}_{2}$ was explained with its degenerated semiconducting nature and related transition from extrinsic to intrinsic conduction regime at that temperature range. However, this type of electrical behavior was not detected in any chromium silicide-based composites throughout the temperature range, even though some composites (e.g. CC-8020, CC-9010) contained the $\mathrm{CrSi}_{2}$ phase within their structure. This could be highly related to the small amount that remained as a minor phase after solid-state reaction. Additionally, the CC-5545 composite composed of $\mathrm{Cr}_{3} \mathrm{Si}_{2}, \mathrm{Cr}_{5} \mathrm{Si}_{3}$ as major conductive silicide phases displayed higher electrical conductivity values than the other composites at the temperatures above $\sim 550^{\circ} \mathrm{C}$, which is in consistent with the higher electrical conductivities of these phases compared to the other chromium silicides [4]. The relatively low electrical conductivities of the CC-4060 and CC-5050 composites could be correlated to the low volume percentage of the silicide phases and high content of the insulating grain boundary silica phase formed via solid-state reaction.

As schematically reviewed in the Figure 64 with a spline diagram, the electrical conductivities of the chromium silicide-based composites ranged from 42.1 to $213.7 \mathrm{~S} / \mathrm{cm}$ at $1000^{\circ} \mathrm{C}$ depending on the major silicide phases $\left(\mathrm{Cr}_{3} \mathrm{Si}, \mathrm{Cr}_{5} \mathrm{Si}_{3}, \mathrm{CrSi}, \mathrm{CrSi}_{2}, \mathrm{Cr}_{0.91} \mathrm{Si}_{0.09}\right)$ and their amounts. Thus, it should be noted that their electrical properties can be controlled 


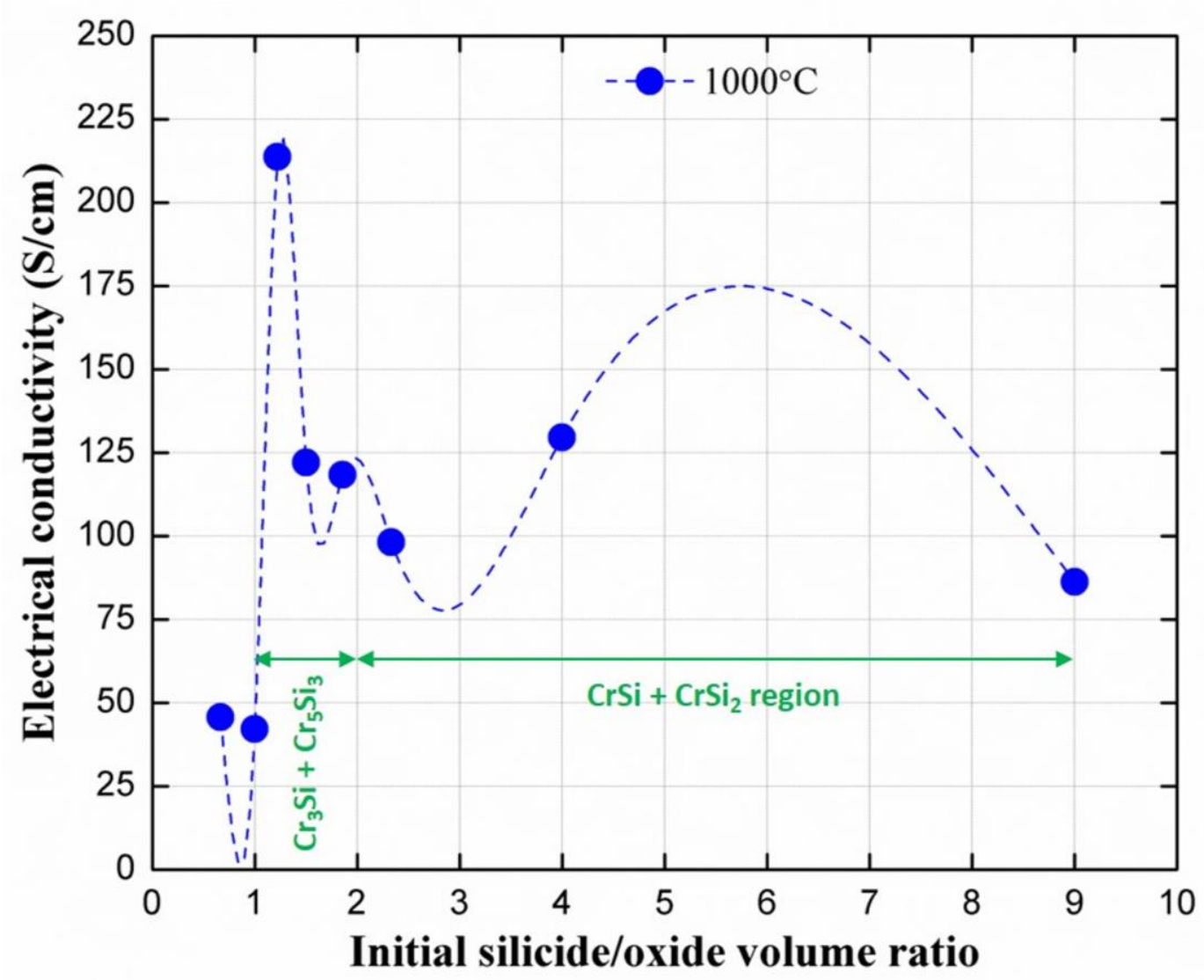

Figure 64. Schematic review (spline diagram) of changes in the electrical conductivities of the chromium silicide-based composites at $1000^{\circ} \mathrm{C}$ as a function of the initial chromium silicide/oxide ratios.

by adjusting the initial chromium silicide/oxide volume ratio. As a review of the studies conducted on the chromium silicide-based composites fabricated via solid-state reactions, their compositions (major/minor phases) and high temperature oxidation/electrical properties are additionally summarized in Table 10. All composites exhibited high oxidation resistance at the temperatures up to $870^{\circ} \mathrm{C}$, since their oxidation-induced specific mass changes were $0.09-0.16 \mathrm{mg} / \mathrm{cm}^{2}$ and $0.22-0.63 \mathrm{mg} / \mathrm{cm}^{2}$ at $500^{\circ} \mathrm{C}$ and $870^{\circ} \mathrm{C}$, respectively. They also showed metallic-type conductivity throughout the temperature range, and their electrical conductivities ranged from 64.1 to $409.5 \mathrm{~S} / \mathrm{cm}$ at $500^{\circ} \mathrm{C}$, and from 42.1 to $213.7 \mathrm{~S} / \mathrm{cm}$ at $1000^{\circ} \mathrm{C}$, depending on the chromium silicide phases present and their volume percentages. 
Table 10. Summary of the composite compositions, and high-temperature oxidation and electrical properties of the chromium silicide-based composites.

\begin{tabular}{|c|c|c|c|c|c|}
\hline \multirow{2}{*}{$\begin{array}{l}\text { Composite } \\
\text { samples }\end{array}$} & \multirow{2}{*}{$\begin{array}{c}\text { Major/minor } \\
\text { phases present }\end{array}$} & \multicolumn{2}{|c|}{$\begin{array}{l}\text { Oxidation-induced mass } \\
\text { change/gain }\left(\mathrm{mg} / \mathrm{cm}^{2}\right)\end{array}$} & \multicolumn{2}{|c|}{$\begin{array}{l}\text { Electrical conductivity } \\
(\mathrm{S} / \mathrm{cm})\end{array}$} \\
\hline & & $500^{\circ} \mathrm{C}$ & $870^{\circ} \mathrm{C}$ & $500^{\circ} \mathrm{C}$ & $1000^{\circ} \mathrm{C}$ \\
\hline CC-4060 & $\mathrm{Cr}_{0.91} \mathrm{Si}_{0.09}, \mathrm{SiO}_{2}$ & +0.13 & +0.63 & 74.9 & 45.7 \\
\hline CC-5050 & $\mathrm{Cr}_{3} \mathrm{Si}, \mathrm{SiO}_{2}$ & +0.12 & +0.47 & 64.1 & 42.1 \\
\hline CC-5545 & $\begin{array}{c}\mathrm{Cr}_{3} \mathrm{Si}, \mathrm{Cr}_{5} \mathrm{Si}_{3}, \mathrm{CrSi}_{2} \\
\mathrm{SiO}_{2}\end{array}$ & +0.16 & +0.58 & 351.9 & 213.7 \\
\hline CC-6040 & $\begin{array}{l}\mathrm{Cr}_{3} \mathrm{Si}_{1} \mathrm{Cr}_{5} \mathrm{Si}_{3}, \mathrm{CrSi} \\
\mathrm{CrSi}_{2}, \mathrm{SiO}_{2}, \mathrm{Cr}_{2} \mathrm{O}_{3}\end{array}$ & +0.11 & +0.40 & 208.0 & 122.1 \\
\hline CC-6535 & $\begin{array}{c}\mathrm{Cr}_{5} \mathrm{Si}_{3}, \mathrm{Cr}_{3} \mathrm{Si}_{1} \mathrm{CrSi}_{2} \\
\mathrm{CrSi}, \mathrm{SiO}_{2}\end{array}$ & +0.11 & +0.35 & 177.2 & 118.4 \\
\hline CC-7030 & $\begin{array}{c}\mathrm{CrSi}, \mathrm{Cr}_{5} \mathrm{Si}_{3}, \mathrm{CrSi}_{2} \\
\mathrm{SiO}_{2}\end{array}$ & +0.11 & +0.56 & 189.1 & 98.1 \\
\hline CC-8020 & $\mathrm{CrSi}, \mathrm{CrSi}_{2}, \mathrm{SiO}_{2}$ & +0.09 & +0.32 & 409.5 & 129.6 \\
\hline CC-9010 & $\begin{array}{c}\mathrm{CrSi}, \underset{\mathrm{CrSi}}{2}, \mathrm{SiO}_{2} \\
\mathrm{Cr}_{2} \mathrm{O}_{3}\end{array}$ & +0.09 & +0.22 & 216.0 & 86.3 \\
\hline
\end{tabular}

\subsubsection{High-temperature stability of the selected $\mathrm{Cr} 3 \mathrm{Si}$ - and $\mathrm{Cr}_{5} \mathrm{Si}$-based composites}

It was presented that the major chromium silicide phases were $\mathrm{Cr}_{3} \mathrm{Si}$ and $\mathrm{Cr}_{5} \mathrm{Si}_{3}$ within the CC-5050, CC-5545 and CC-6040 composites after solid-state reactions. Due to the higher melting temperatures of the $\mathrm{Cr}_{3} \mathrm{Si}$ and $\mathrm{Cr}_{5} \mathrm{Si}_{3}$ compounds $\left(1680^{\circ}-1770^{\circ} \mathrm{C}\right)$ in the $\mathrm{Cr}-\mathrm{Si}$ binary system, these three composites were further annealed at $1350^{\circ} \mathrm{C}$ for $24-96 \mathrm{~h}$ in argon to better understand their thermal stability and microstructural evolution, as well as, the stability of their high-temperature oxidation and electrical properties. 


\subsubsection{Thermal stability and microstructural evolution}

The XRD patterns of the CC-5050, CC-5545 and CC-6040 composites, which were further annealed at $1350^{\circ} \mathrm{C}$ for 24,48 and $96 \mathrm{~h}$, are shown in Figure 65 . The XRD data of these composites after sintering was also included to compare the possible phase changes, and thus, they are described with " $0 \mathrm{~h}$ " implying non-annealed composites as reference samples. No phase changes were observed for the CC-5050 composite, since only $\mathrm{Cr}_{3} \mathrm{Si}$ and low-cristobalite $\mathrm{SiO}_{2}$ phases were detected after annealing for 24-96 h (Figure 65a). However, it is apparent that the $\mathrm{SiO}_{2}$ peak intensities increased as a function of annealing time, particularly after $24 \mathrm{~h}$ of annealing compared to the as-sintered sample $(0 \mathrm{~h})$. For the as-sintered CC-5545 composite, the phases detected were $\mathrm{Cr}_{3} \mathrm{Si}_{2}, \mathrm{Cr}_{5} \mathrm{Si}_{3}, \mathrm{CrSi}_{2}$ and $\mathrm{SiO}_{2}$ as previously discussed. Similarly, no thermal decomposition was identified for the CC-5545 composite system after annealing at $1350^{\circ} \mathrm{C}$ up to $96 \mathrm{~h}$, as presented in Figure $65 \mathrm{~b}$. Unlike the CC-5050 composite system, the peak intensities of the $\mathrm{SiO}_{2}$ phase remained almost the same for the CC-5545 composite. However, it should be noted that the presence of the remaining $\mathrm{CrSi}_{2}$ phase was observed only within the as-sintered and $24 \mathrm{~h}$ annealed CC5545 samples, but not after 48 and $96 \mathrm{~h}$ of annealing. After $24 \mathrm{~h}$ annealing, there was also an increase in the peak intensities of the $\mathrm{Cr}_{5} \mathrm{Si}_{3}$ phase, but a decrease in the peak intensities of the $\mathrm{Cr}_{3} \mathrm{Si}$ phase. Therefore, these results indicate that further solid-state reactions took place between the chromium silicides (e.g. $\mathrm{Cr}_{3} \mathrm{Si}$ ) and the remaining $\mathrm{CrSi}_{2}$ phase to form more $\mathrm{Cr}_{5} \mathrm{Si}_{3}$ phase within the $\mathrm{CC}-5545$ composite during high-temperature annealing. For the CC-6040 composite, there was a more complex structure due to the presence of multiple silicides $\left(\mathrm{Cr}_{3} \mathrm{Si}_{1}, \mathrm{Cr}_{5} \mathrm{Si}_{3}, \mathrm{CrSi}, \mathrm{CrSi}_{2}\right)$ and oxides $\left(\mathrm{SiO}_{2}, \mathrm{Cr}_{2} \mathrm{O}_{3}\right)$ after sintering. All these phases were also identified after annealing for $24 \mathrm{~h}$ (Figure 65c). However, there was a significant increase in the peak intensities of the $\mathrm{SiO}_{2}, \mathrm{Cr}_{3} \mathrm{Si}_{2}, \mathrm{Cr}_{5} \mathrm{Si}_{3}$, and a decrease in that of the remaining phases $\left(\mathrm{CrSi}, \mathrm{CrSi}_{2}, \mathrm{Cr}_{2} \mathrm{O}_{3}\right)$. After $96 \mathrm{~h}$ of annealing, a similar structure to the annealed CC-5545 composite was achieved, since the phases detected were $\mathrm{Cr}_{3} \mathrm{Si}_{2} \mathrm{Cr}_{5} \mathrm{Si}_{3}$ and $\mathrm{SiO}_{2}$. It should be noted that the $\mathrm{Cr}_{5} \mathrm{Si}_{3}$ phases were found to be more intense within the CC-6040 composite, indicating the higher volume percentage of the $\mathrm{Cr}_{5} \mathrm{Si}_{3}$ after high-temperature annealing. As a review of these annealing studies, it can be 

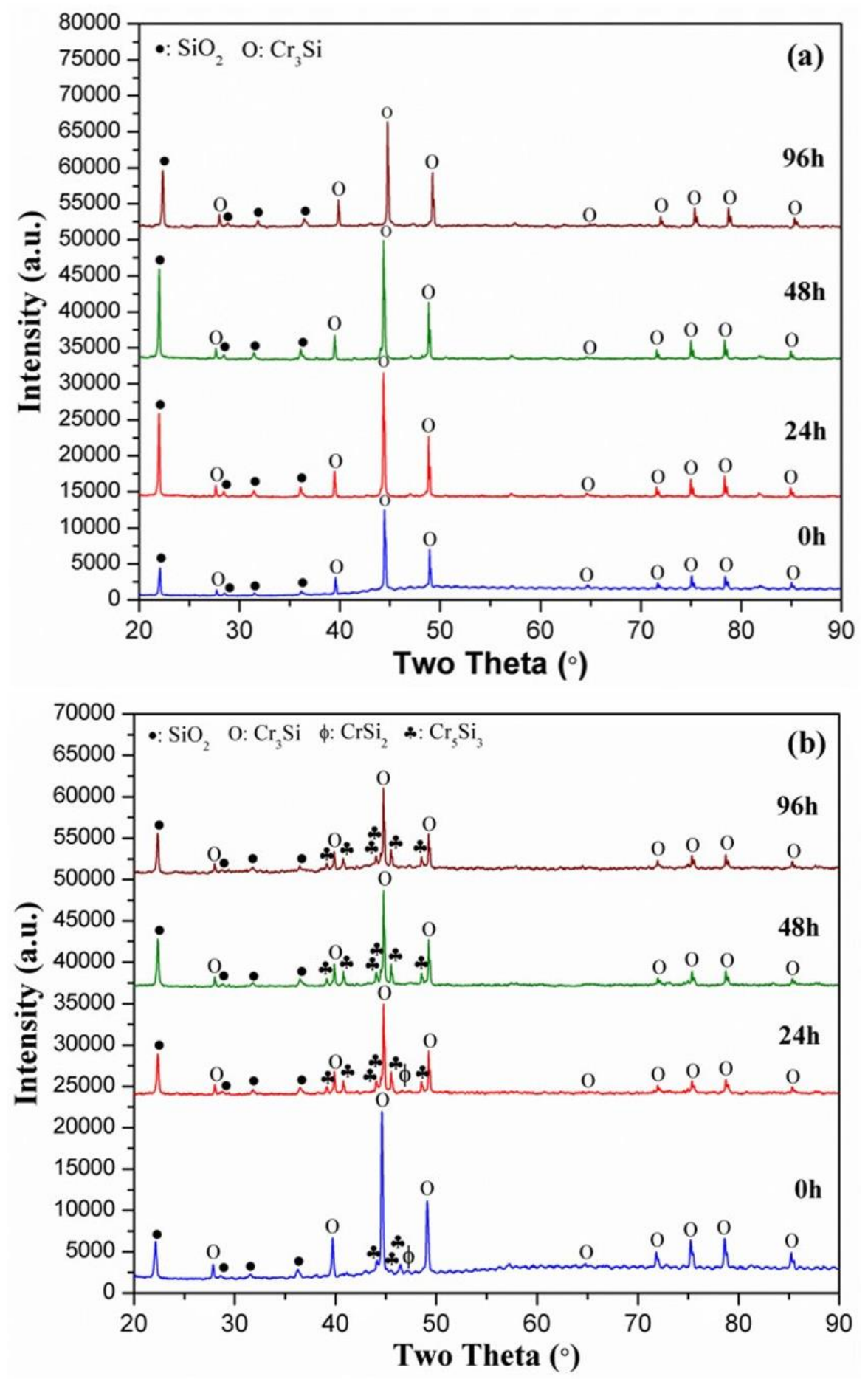

Figure 65. XRD patterns of the (a) CC-5050, (b) CC-5545, and (c) CC-6040 composites after sintering (denoted as " $0 \mathrm{~h}$ " annealing), and after further annealing at $1350^{\circ} \mathrm{C}$ for 24 , 48 and $96 \mathrm{~h}$ in argon. 


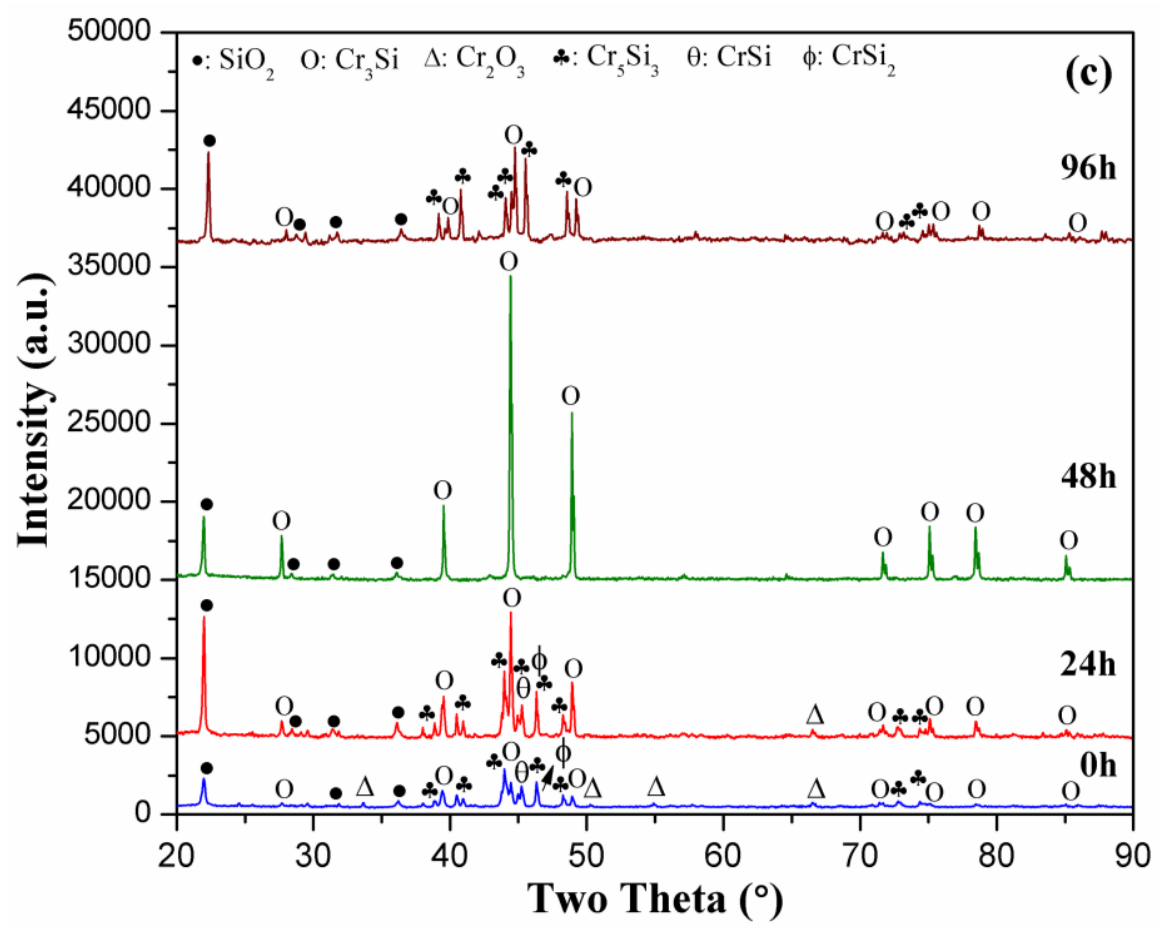

Figure 65. (continued) XRD patterns of the (a) CC-5050, (b) CC-5545, and (c) CC-6040 composites after sintering (denoted as " $0 \mathrm{~h}$ " annealing), and after further annealing at $1350^{\circ} \mathrm{C}$ for 24,48 and $96 \mathrm{~h}$ in argon.

concluded that the CC-5050 composite, which consisted of the $\mathrm{Cr}_{3} \mathrm{Si}$ and $\mathrm{SiO}_{2}$ phases, displayed higher thermal stability compared to the CC-5545 and CC-6040 composite. The lower thermal stability of the CC-5545 and CC-6040 composites could be attributed to the presence of the remaining initial phases $\left(\mathrm{CrSi}, \mathrm{CrSi}_{2}, \mathrm{Cr}_{2} \mathrm{O}_{3}\right)$ within their structure after sintering, which resulted in further solid-state reactions taking place during annealing at $1350^{\circ} \mathrm{C}$ for 24-96 $\mathrm{h}$. In addition, peak intensities of the $\mathrm{SiO}_{2}$ phase increased as a function of annealing time, which may also be related to the metastable nature of the cristobalite structure and related phase transition (low-cristobalite $\leftrightarrow$ high-cristobalite) [26,30]. After $96 \mathrm{~h}$ of annealing, the CC-5050 composite revealed a two-phase system $\left(\mathrm{Cr}_{3} \mathrm{Si}+\mathrm{SiO}_{2}\right)$, while a similar three-phase system $\left(\mathrm{Cr}_{3} \mathrm{Si}+\mathrm{Cr}_{5} \mathrm{Si}_{3}+\mathrm{SiO}_{2}\right)$ was achieved for the CC-5545 and CC-6040 composites. 
The microstructural changes within these composites were also examined as a function of the annealing time. Figure 66 presents the SEM microstructures of the CC5050, CC-5545 and CC-6040 composites after annealing at $1350^{\circ} \mathrm{C}$ for 24,48 and $96 \mathrm{~h}$. It is apparent that the similar microstructures were observed after annealing. The highly homogeneous distribution of the chromium silicide phases (bright regions: $\mathrm{Cr}_{3} \mathrm{Si}_{1} \mathrm{Cr}_{5} \mathrm{Si}_{3}$ ) within the silica grain boundary phase (dark regions) can be seen from Figure 66(a1-c3). The presence of the pores within the microstructures was observed after annealing. To better understand the changes in the degree of porosity, the apparent porosity levels were additionally measured by Archimedes method. The results displayed that there was $\sim 0.7-$ $3.5 \%$ decrease in porosity within the CC-5050 and CC-5545 composites as a function of annealing time. However, the degree of porosity increased by $6.6 \%$ in the CC- 6040 composite after annealing, which is directly related to the extent of the continued solid-state reaction during the initial $48 \mathrm{~h}$ of annealing period. Furthermore, the chromium silicide grains became smoother and more round with increasing annealing time, since the presence of nearly round chromium silicide grains were clearly observed within the composite microstructures, particularly after 48 and $96 \mathrm{~h}$ of annealing at $1350^{\circ} \mathrm{C}$ (Figure 66(a2,a3,b3,c2,c3)). These observations were found to be more apparent when the silicide grains were in contact with the silica phase, which may indicate the occurrence of a solidphase grain boundary wetting by the amorphous glass phase. It should be noted that the phenomenon of grain boundary wetting is well-known by the presence of a liquid phase, but wetting of grains by a solid phase was also reported for ceramic composites (e.g. $\mathrm{ZrO}_{2}-$ $\mathrm{SiO}_{2}$ ) [29] and binary alloy systems (e.g. Al-Mg, Al-Zn) [37,38]. However, further studies are needed to better understand this wetting mechanism within these intermetallic composites. In addition, the formation of a highly-dense surface layer with an average thickness of $31.8 \mu \mathrm{m}( \pm 2.2 \mu \mathrm{m})$ was observed within the microstructure of the CC-5545 composite after $48 \mathrm{~h}$ of annealing at $1350^{\circ} \mathrm{C}$, as shown in Figure 67 . The EDS analysis revealed that the composition of the surface layer is silica based on the quantitative elemental data $(47.0 \mathrm{wt} \% \mathrm{Si}+53.0 \mathrm{wt} \% \mathrm{O})$. As a review, the above-discussed phase and microstructural changes during high-temperature annealing could highly influence the high 

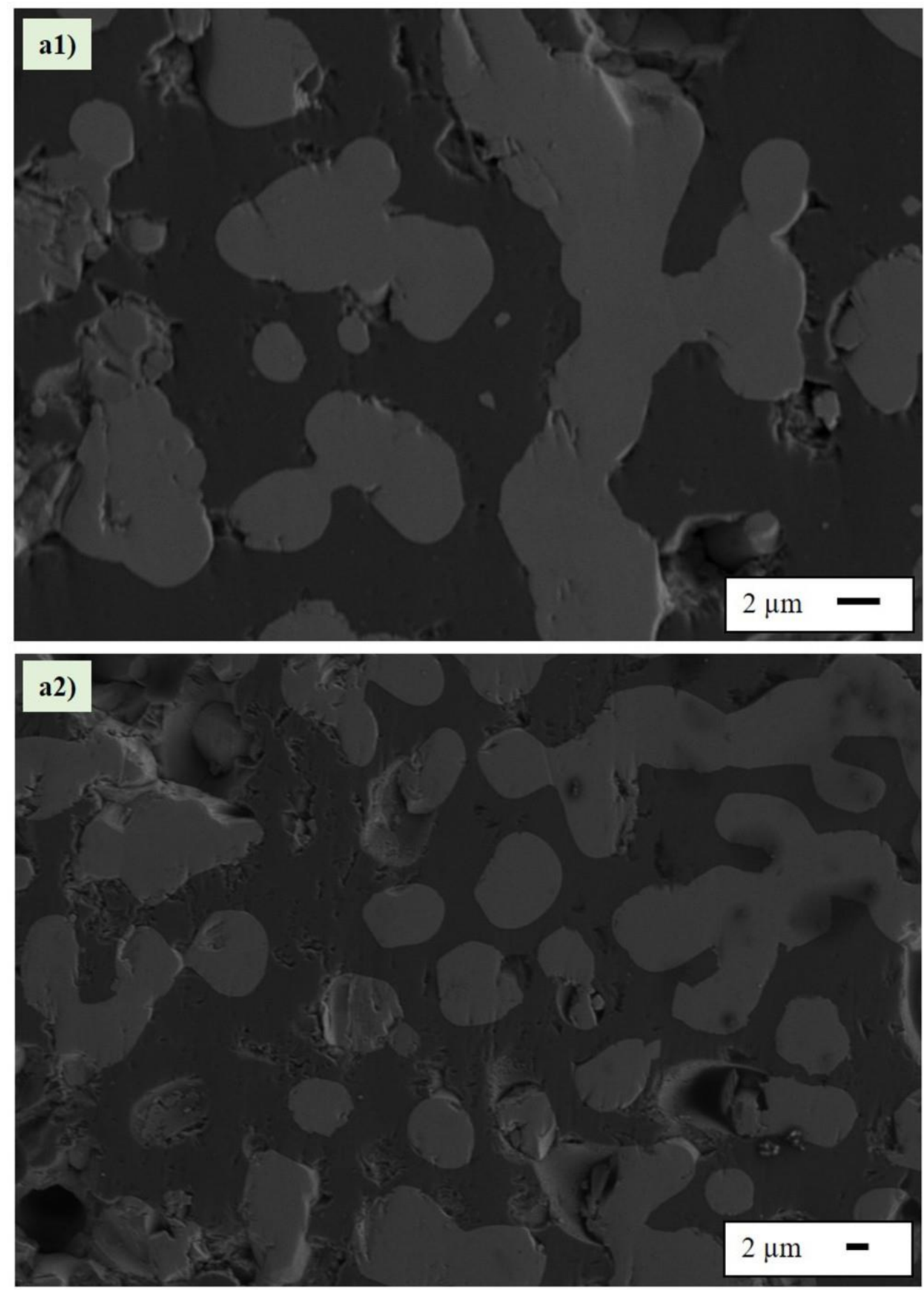

Figure 66. SEM microstructures of the (a1-a2-a3) CC-5050, (b1-b2-b3) CC-5545, and (c1-c2-c3) CC-6040 composites after further annealing at $1350^{\circ} \mathrm{C}$ for 24,48 and $96 \mathrm{~h}$ in argon (a1-b1-c1: after annealing for $24 \mathrm{~h}$; a2-b2-c2: after annealing for $48 \mathrm{~h}$; a3-b3-c3: after annealing for $96 \mathrm{~h}$ ). 

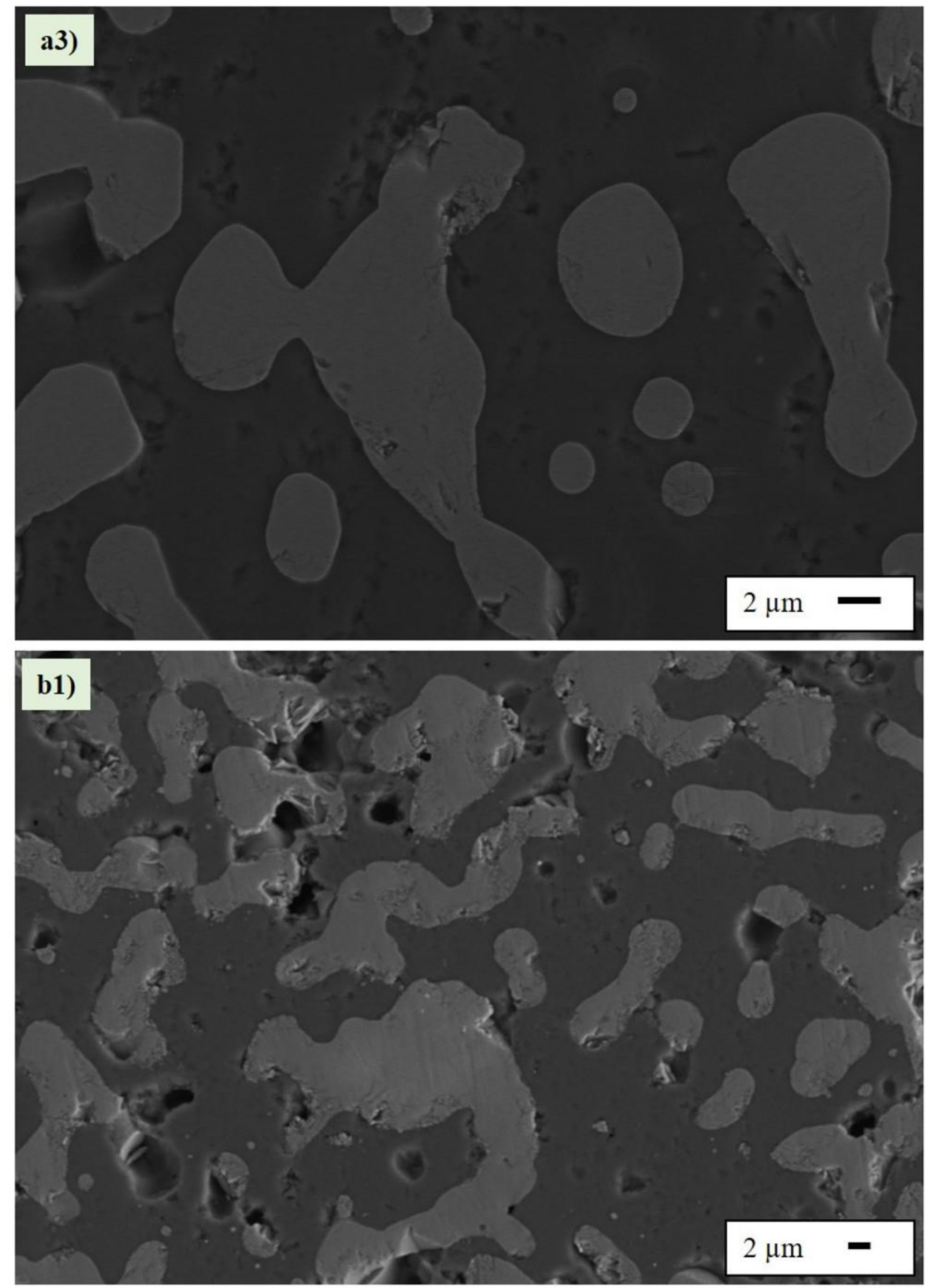

Figure 66. (continued) SEM microstructures of the (a1-a2-a3) CC-5050, (b1-b2-b3) CC5545 , and (c1-c2-c3) CC-6040 composites after further annealing at $1350^{\circ} \mathrm{C}$ for 24,48 and $96 \mathrm{~h}$ in argon (a1-b1-c1: after annealing for $24 \mathrm{~h}$; a2-b2-c2: after annealing for $48 \mathrm{~h}$; a3b3-c3: after annealing for $96 \mathrm{~h}$ ). 

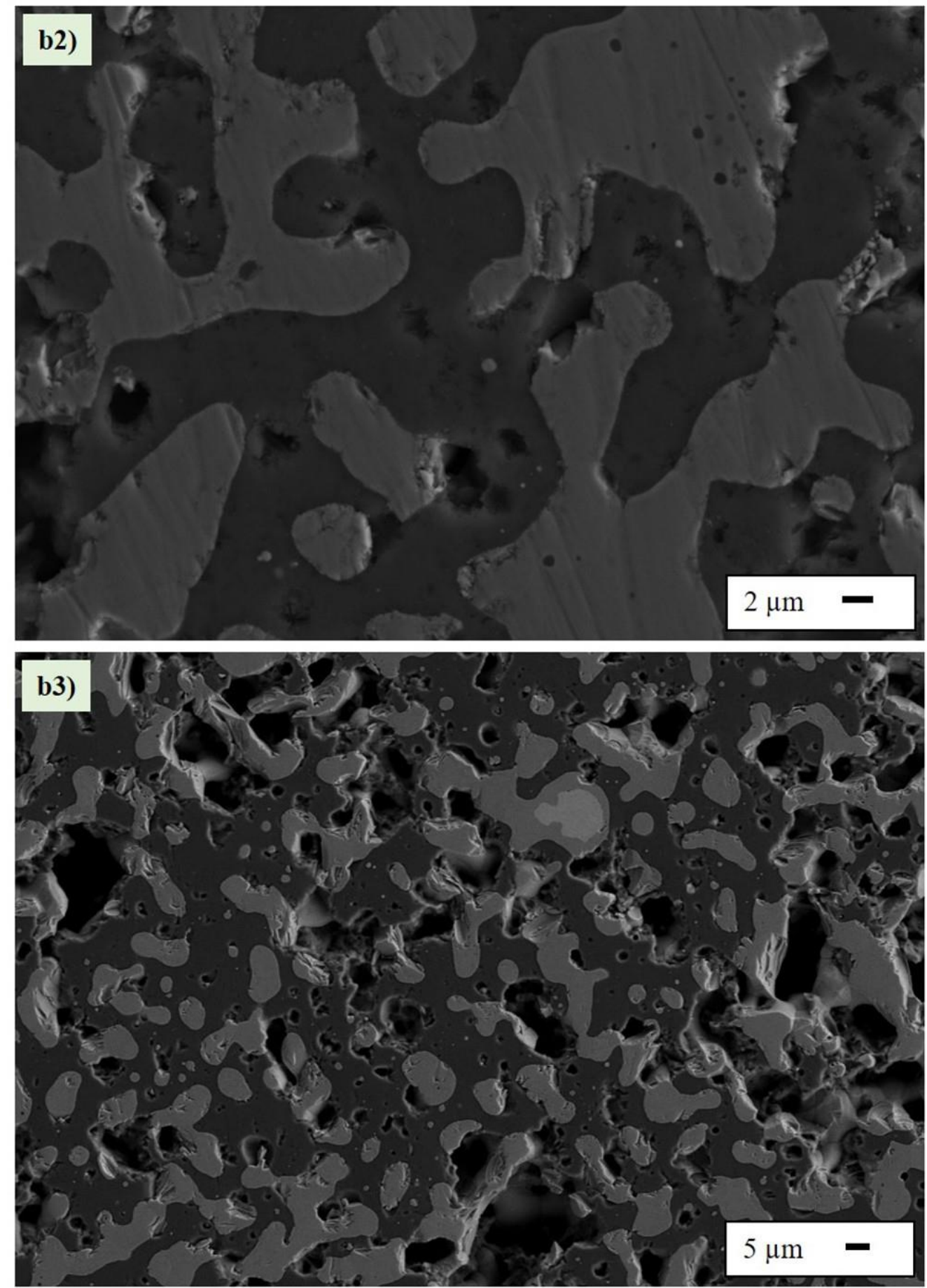

Figure 66. (continued) SEM microstructures of the (a1-a2-a3) CC-5050, (b1-b2-b3) CC5545, and (c1-c2-c3) CC-6040 composites after further annealing at $1350^{\circ} \mathrm{C}$ for 24,48 and $96 \mathrm{~h}$ in argon (a1-b1-c1: after annealing for $24 \mathrm{~h}$; a2-b2-c2: after annealing for $48 \mathrm{~h}$; a3b3-c3: after annealing for $96 \mathrm{~h}$ ). 

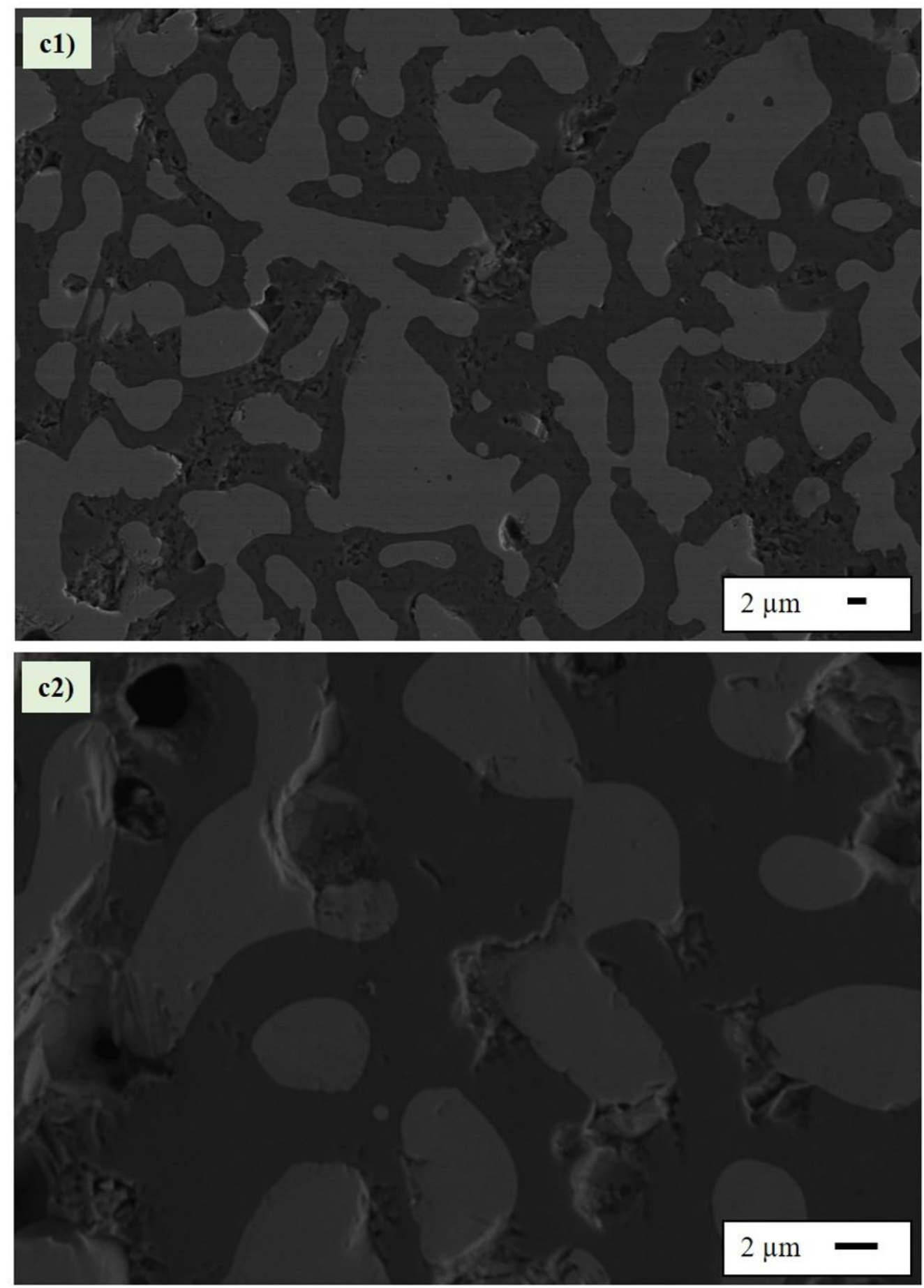

Figure 66. (continued) SEM microstructures of the (a1-a2-a3) CC-5050, (b1-b2-b3) CC5545 , and (c1-c2-c3) CC-6040 composites after further annealing at $1350^{\circ} \mathrm{C}$ for 24,48 and $96 \mathrm{~h}$ in argon (a1-b1-c1: after annealing for $24 \mathrm{~h}$; a2-b2-c2: after annealing for $48 \mathrm{~h}$; a3b3-c3: after annealing for $96 \mathrm{~h}$ ). 


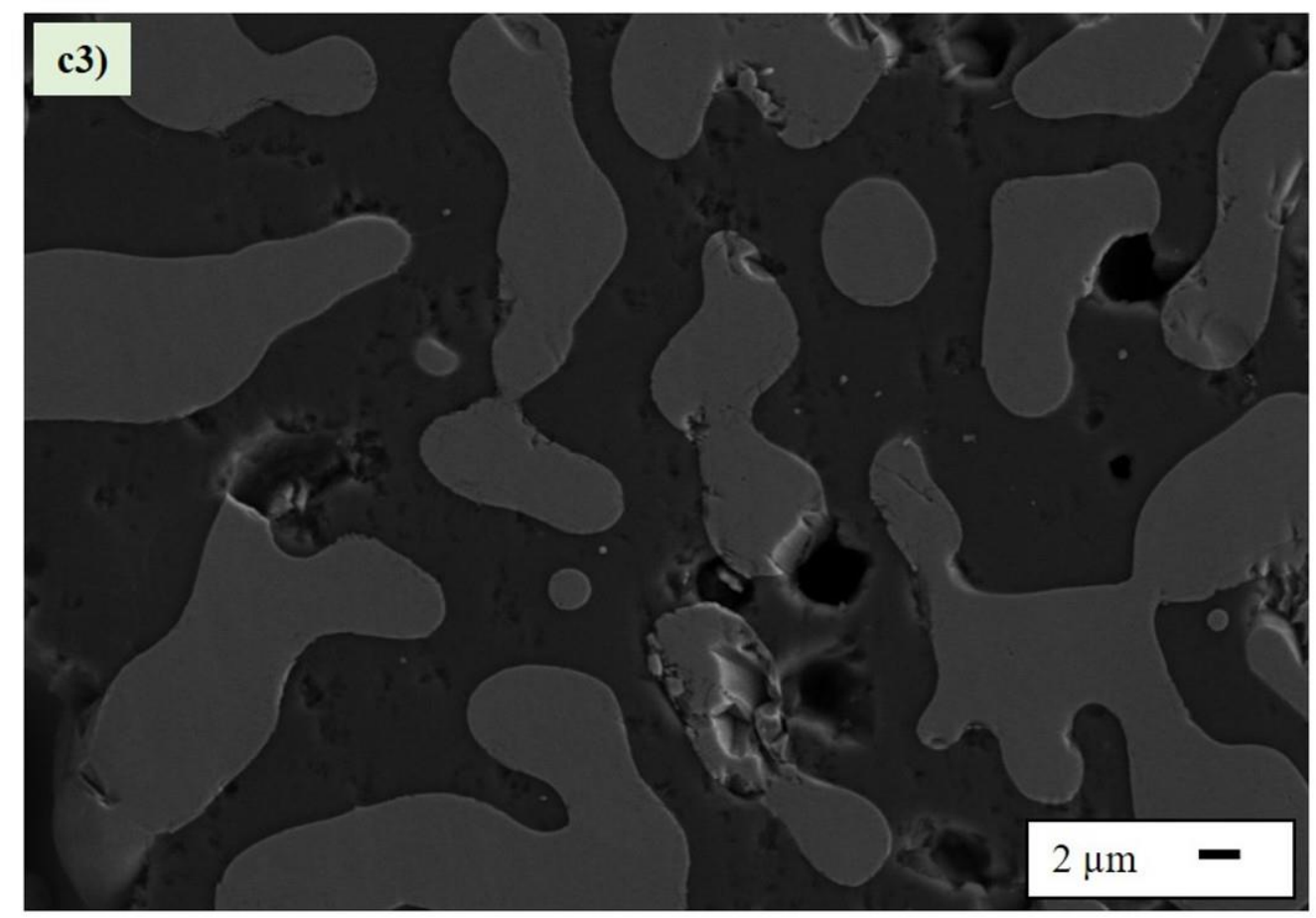

Figure 66. (continued) SEM microstructures of the (a1-a2-a3) CC-5050, (b1-b2-b3) CC5545, and (c1-c2-c3) CC-6040 composites after further annealing at $1350^{\circ} \mathrm{C}$ for 24,48 and $96 \mathrm{~h}$ in argon (a1-b1-c1: after annealing for $24 \mathrm{~h}$; a2-b2-c2: after annealing for $48 \mathrm{~h}$; a3b3-c3: after annealing for $96 \mathrm{~h}$ ).

temperature physical properties of these chromium silicide-based composites, and therefore, they may need to be sintered longer or pre-heat treated before use in real applications to complete the solid-state reactions (if any unreacted phases exist) and achieve a more stable structure.

\subsubsection{High-temperature oxidation and electrical properties after annealing}

The non-isothermal and isothermal oxidation tests were additionally performed in an air atmosphere using the as-sintered and as-annealed CC-5050, CC-5545 and CC-6040 composites. Figure 68 displays the specific mass changes per unit surface areas $\left(\mathrm{mg} / \mathrm{cm}^{2}\right)$ as a function of time during isothermal oxidation of the as-sintered composites at $850^{\circ} \mathrm{C}$. The CC-5545 composite oxidized substantially higher compared to other composites, since the mass changes after $12 \mathrm{~h}$ exposure to air were $0.78,1.98$ and $0.75 \mathrm{mg} / \mathrm{cm}^{2}$ for CC-5050, 


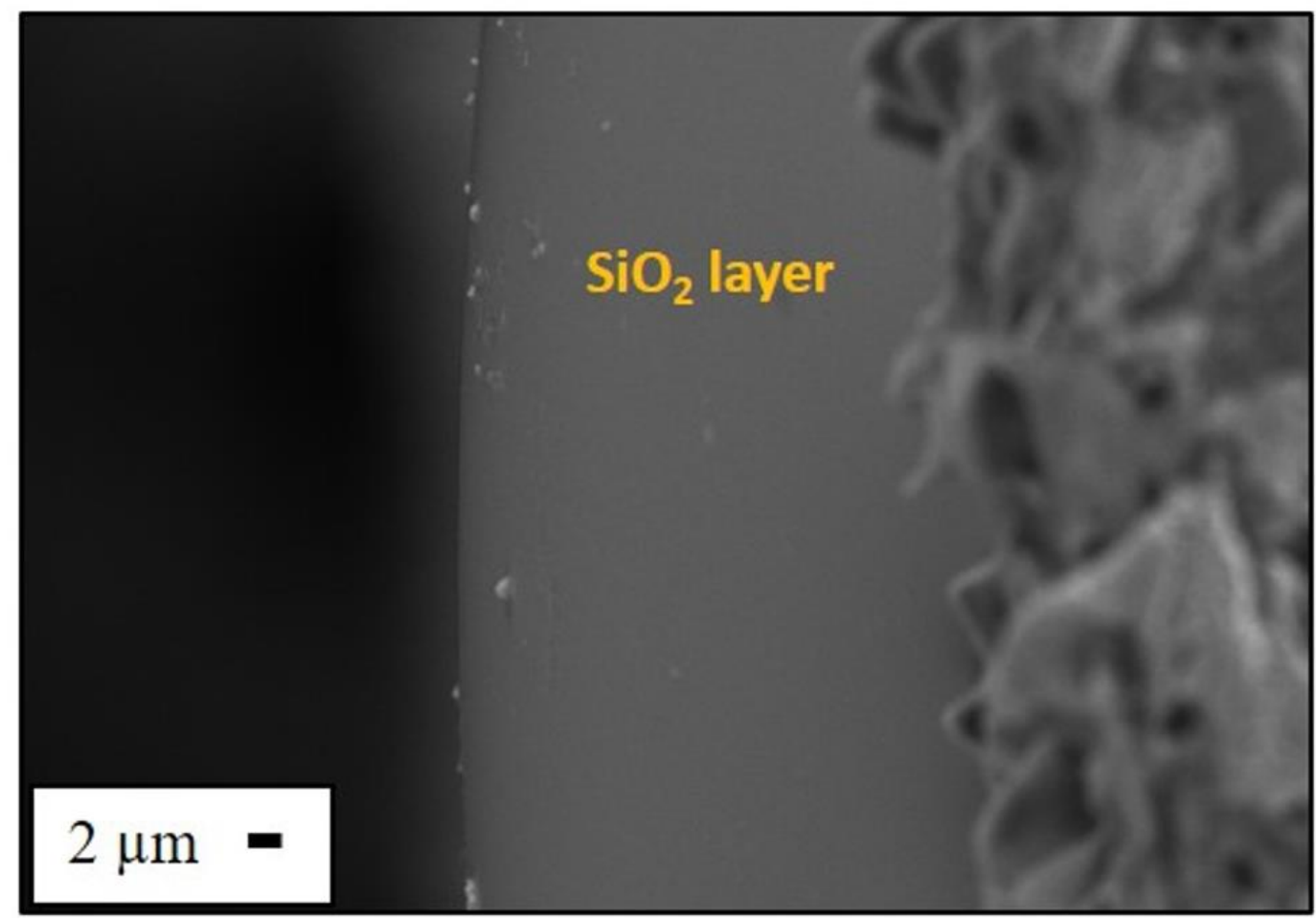

Figure 67. SEM microstructure of the highly dense silica surface layer formed within the $\mathrm{CC}-5545$ composite after annealing at $1350^{\circ} \mathrm{C}$ for $48 \mathrm{~h}$ in argon.

CC-5545 and CC-6040 composites, respectively. The CC-5050 and CC-6040 composites revealed a similar isothermal oxidation behavior at $850^{\circ} \mathrm{C}$. However, the isothermal oxidation of these composites could be divided into two regions as (i) 0-2 h and (ii) 2-12 h due to the different rates of oxidation observed (Figure 68). The specific mass gain drastically increased in the initial $2 \mathrm{~h}$ of oxidation, but then their oxidation was slower following a more linear trend from 2 to $12 \mathrm{~h}$ of oxidation. These results demonstrated that there was a formation of a protective surface oxide layer in the initial stage, which lowered the oxidation rates afterwards. Similar trends were also presented for the isothermal oxidation of the sputter-deposited nanocrystalline $\mathrm{Cr}_{3} \mathrm{Si}$ film at $700^{\circ} \mathrm{C}$ and $800^{\circ} \mathrm{C}$ [16]. Due to relatively lower oxidation rates at $700^{\circ}-800^{\circ} \mathrm{C}$, a linear trend was observed in that study after exposed to air for $\sim 30-40 \mathrm{~h}$. After $12 \mathrm{~h}$ of oxidation, the mass changes were $\sim 0.07$ and $\sim 0.16 \mathrm{mg} / \mathrm{cm}^{2}$ at $700^{\circ} \mathrm{C}$ and $800^{\circ} \mathrm{C}$, respectively. The surface layer formed on the CC5050, CC-5545 and CC-6040 composites is assumed to be composed of $\mathrm{Cr}_{2} \mathrm{O}_{3}$ and $\mathrm{SiO}_{2}$, 


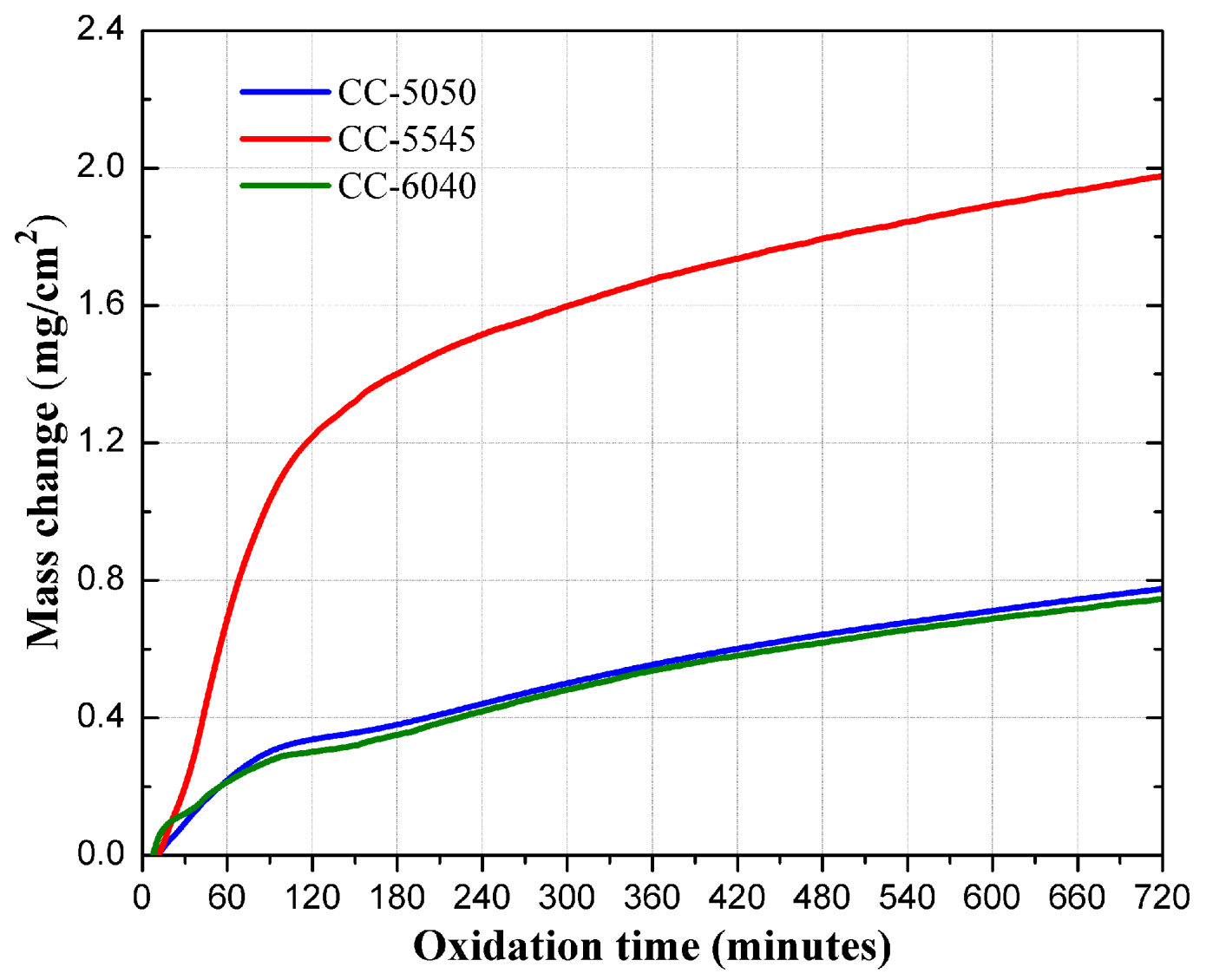

Figure 68. Isothermal oxidation of the CC-5050, CC-5545 and CC-6040 composites in air at $850^{\circ} \mathrm{C}$ for $12 \mathrm{~h}$.

where it was previously reported as the major surface oxide species in correlation with the oxidation mechanisms of the chromium silicide systems (particularly $\mathrm{Cr}_{3} \mathrm{Si}$ ) [16,32,33].

To understand the stability of their high-temperature oxidation behavior, nonisothermal oxidation of these chromium silicide-based composites was examined after annealing at $1350^{\circ} \mathrm{C}$ for $24-96 \mathrm{~h}$. Figure 69 (a-c) present the specific mass changes within the as-annealed CC-5050, CC-5545 and CC-6040 composites as a function of oxidation temperature. For comparison, the oxidation data of the as-sintered composites is also shown. The mass changes decreased for the as-annealed CC-5050 and CC-5545 composites (Figure 69(a-b)). For the CC-5050 composite system, the specific mass gain at $870^{\circ} \mathrm{C}$ reduced from 0.47 to $\sim 0.24 \mathrm{mg} / \mathrm{cm}^{2}$ after annealing for $24-48 \mathrm{~h}$, but then there was 

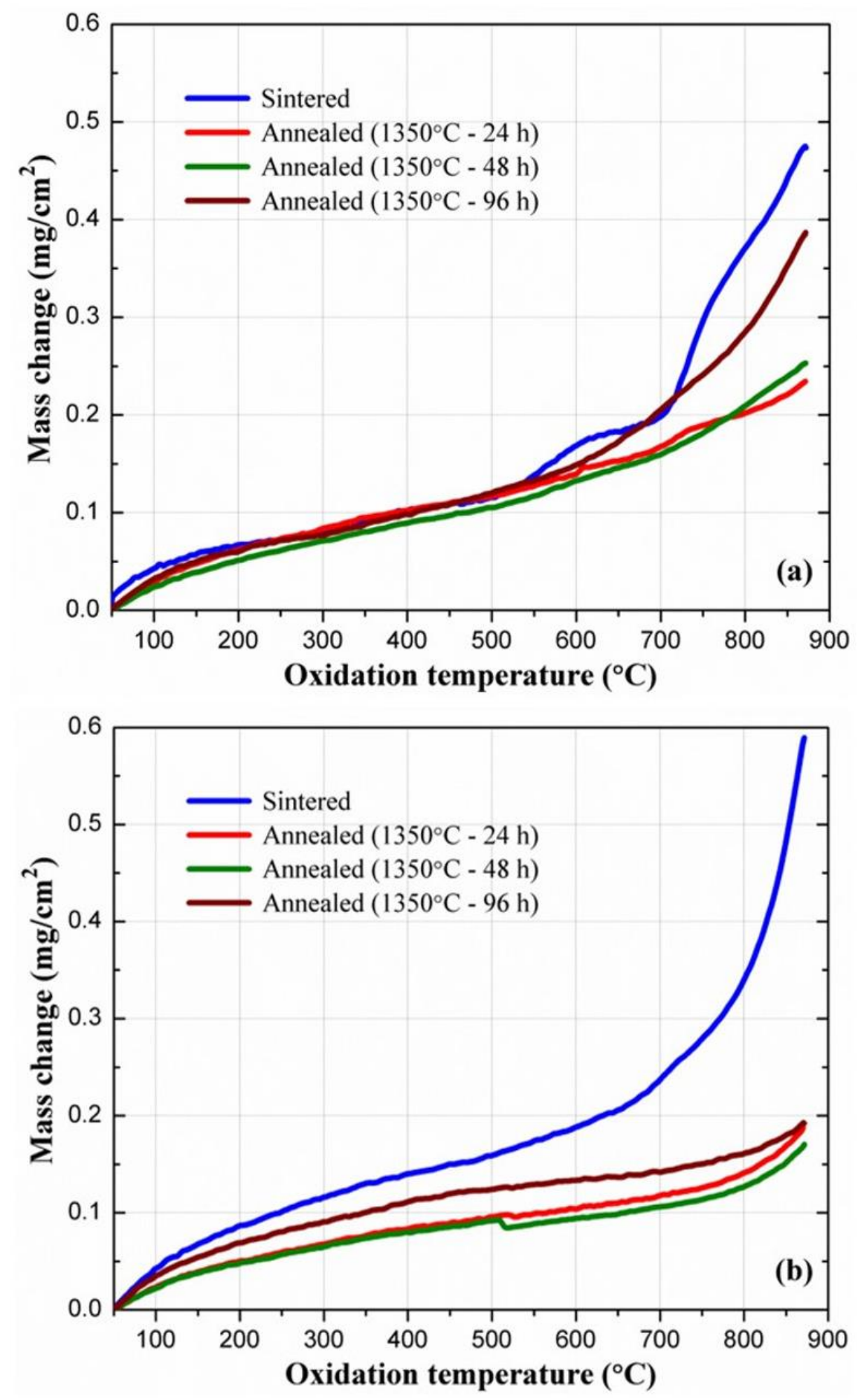

Figure 69. Mass change per unit surface area as a function of oxidation temperature for the as-sintered and as-annealed (a) CC-5050, (b) CC-5545, and (c) CC-6040 composites during non-isothermal oxidation from $50^{\circ} \mathrm{C}$ to $870^{\circ} \mathrm{C}$ in air. 


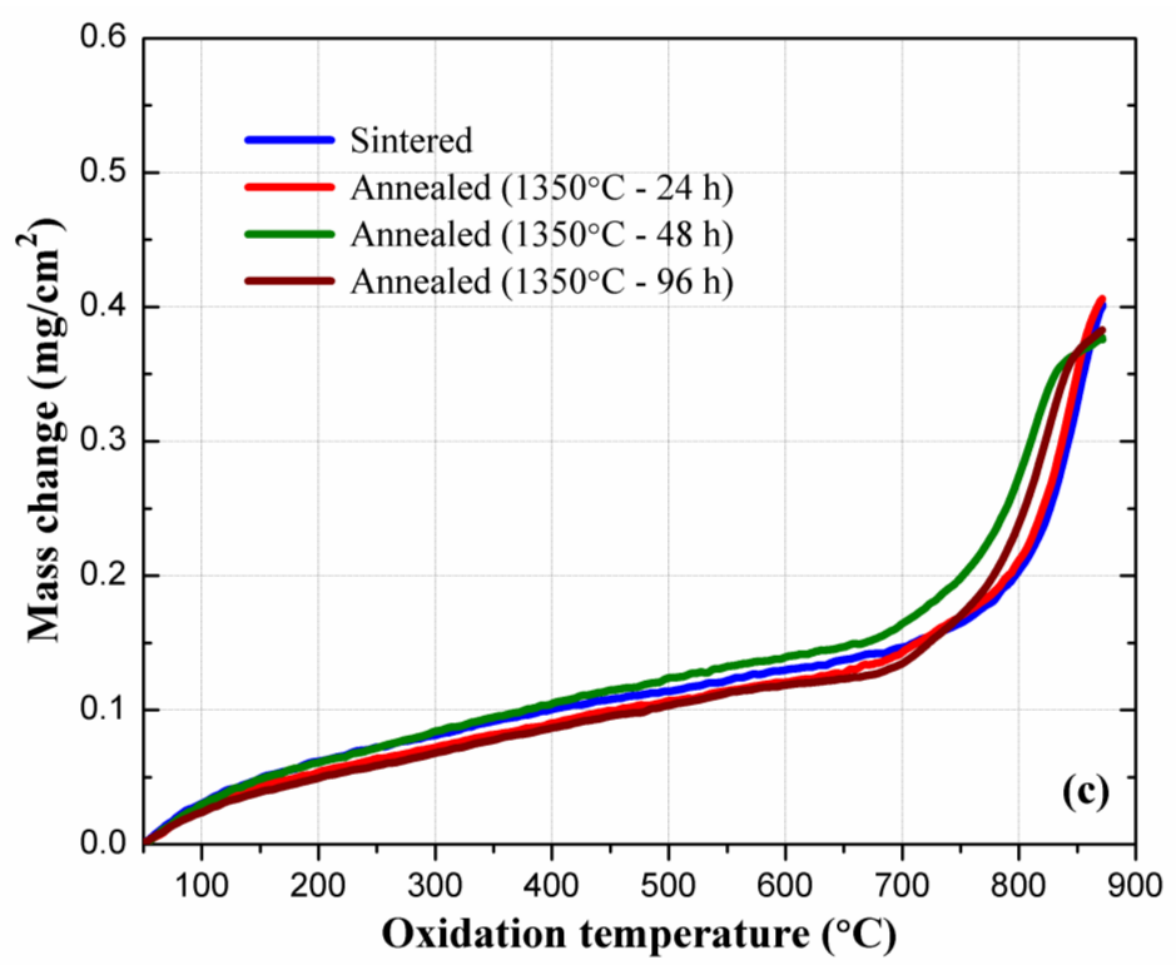

Figure 69. (continued) Mass change per unit surface area as a function of oxidation temperature for the as-sintered and as-annealed (a) CC-5050, (b) CC-5545, and (c) CC6040 composites during non-isothermal oxidation from $50^{\circ} \mathrm{C}$ to $870^{\circ} \mathrm{C}$ in air.

an increase to $0.38 \mathrm{mg} / \mathrm{cm}^{2}$ after $96 \mathrm{~h}$ of annealing. The non-isothermal oxidation of the CC-5545 composite was substantially reduced after annealing, where the specific mass gain at $870^{\circ} \mathrm{C}$ decreased from 0.58 to $\sim 0.18 \mathrm{mg} / \mathrm{cm}^{2}$, as presented in Figure $69 \mathrm{~b}$. There was a drastic increase in the oxidation rate of the as-sintered CC-5545 composite above $\sim 650^{\circ} \mathrm{C}$, but this behavior was not observed after high-temperature annealing. No significant changes were observed in the non-isothermal oxidation behavior of the CC6040 composite after annealing (Figure 69c). The specific mass changes were all in the range of $0.38-0.40 \mathrm{mg} / \mathrm{cm}^{2}$ for the CC-6040 composite system. The reduced oxidation rates for the CC-5050 and CC-5545 composites could be correlated to the formation of a dense protective silica layer on their surfaces, as observed by SEM analysis (Figure 67), and the reduced porosity levels (by $\sim 0.7-3.5 \%$ ) after annealing. It is known that the oxidation rates of the transition metal silicides are highly affected by the type of surface layer formed, 
degree of porosity and microcracks $[32,39,40]$. It can be concluded that all these $\mathrm{Cr}_{3} \mathrm{Si}$ - and $\mathrm{Cr}_{5} \mathrm{Si}_{3}$-based composites exhibited sufficiently high oxidation resistance in air during both non-isothermal and isothermal conditions.

The electrical conductivities of the CC-5050, CC-5545 and CC-6040 composites after annealing for 24-96 h are presented as a function of temperature in Figure 70 . Similarly, the electrical data of the as-sintered composites is also displayed here to observe the changes after high-temperature annealing. As shown in Figure 70a, the electrical conductivities of the as-annealed CC-5050 composite samples were substantially higher than that of its as-sintered sample throughout the temperature range. At $1000^{\circ} \mathrm{C}$, the electrical conductivities of the CC-5050 samples after annealing for 24, 48 and $96 \mathrm{~h}$ were 214.2, 232.7 and $355.2 \mathrm{~S} / \mathrm{cm}$, respectively. The electrical conductivity drastically increased from 42.1 to $355.2 \mathrm{~S} / \mathrm{cm}$ after $96 \mathrm{~h}$ of annealing at $1350^{\circ} \mathrm{C}$. For the CC-5545 composite, similar trends were observed after annealing for 24 and $96 \mathrm{~h}$, where the electrical conductivity increased from 213.7 to 261.0, and then to $540.1 \mathrm{~S} / \mathrm{cm}$, respectively (Figure 70b). However, there was a slight decrease in its electrical conductivity at the temperatures above $\sim 600^{\circ} \mathrm{C}$ only after $48 \mathrm{~h}$ of annealing (green curve). The electrical conductivities of the CC-6040 composite samples were also found to increase as a function of annealing time as displayed in Figure 70c. The CC-6040 composite samples revealed quite similar electrical conductivity data at all temperatures $\left(350^{\circ}-1000^{\circ} \mathrm{C}\right)$ after annealing for 24 and 48 $\mathrm{h}$ (red-green curves), with conductivities of 138.0 and $144.5 \mathrm{~S} / \mathrm{cm}$ at $1000^{\circ} \mathrm{C}$, respectively. Therefore, a slight increase was identified compared to the as-sintered CC-6040 sample. However, the level of increase was significantly higher after $96 \mathrm{~h}$ of annealing, since the electrical conductivity increased to $244.2 \mathrm{~S} / \mathrm{cm}$ at $1000^{\circ} \mathrm{C}$.

As a review, the high-temperature electrical conductivities of the CC-5050, CC5545 and CC-6040 composites were highly influenced by annealing processes at $1350^{\circ} \mathrm{C}$ for 24-96 h. After $96 \mathrm{~h}$ of annealing, their electrical conductivities drastically increased (+ 122.1-326.4 S/cm). This increase was found to be much higher for CC-5545 and CC-5050 

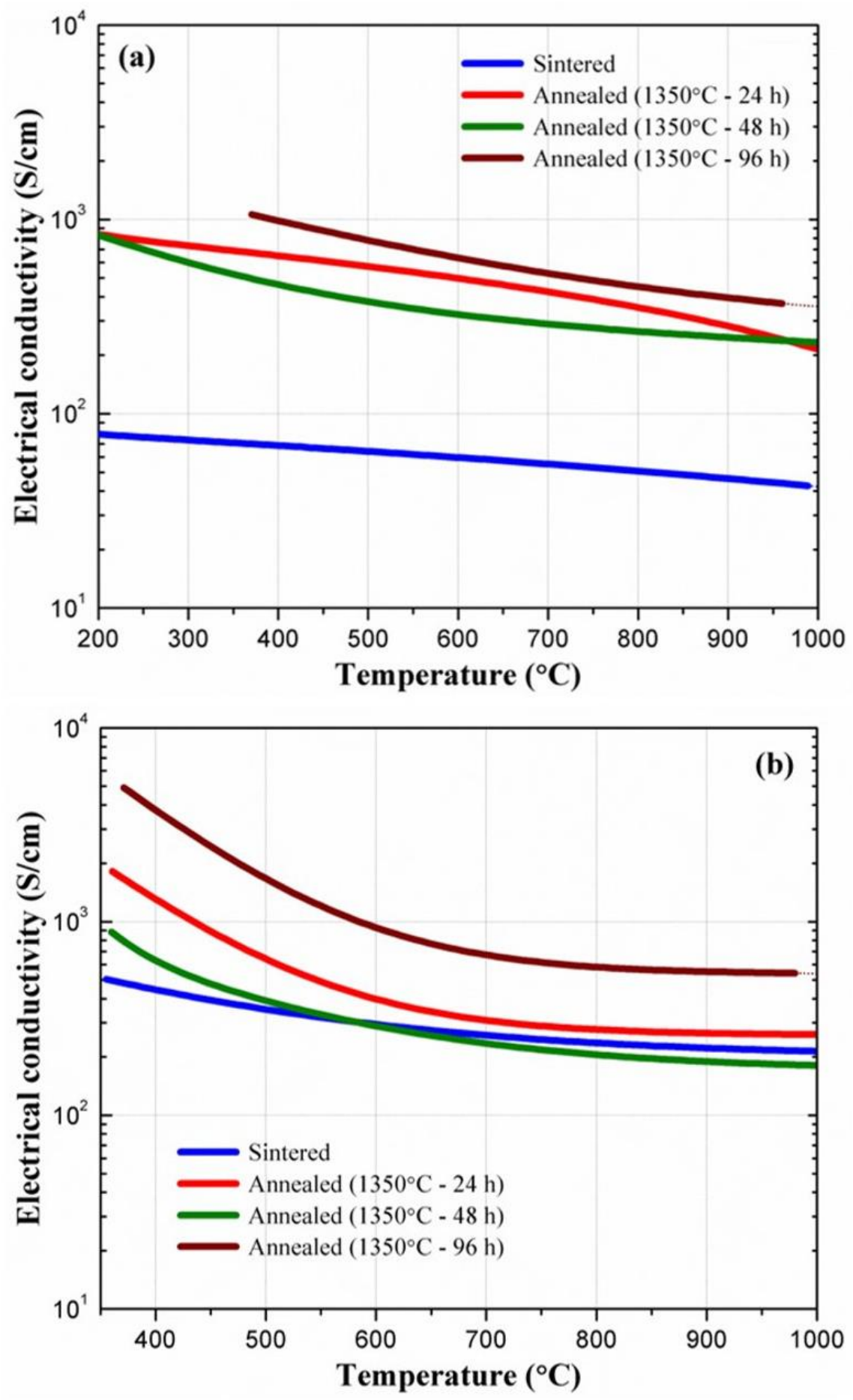

Figure 70. Electrical conductivity as a function of temperature for the as-sintered and asannealed (a) CC-5050, (b) CC-5545, and (c) CC-6040 composites (Electrical conductivity data is shown on the logarithmic scale). 


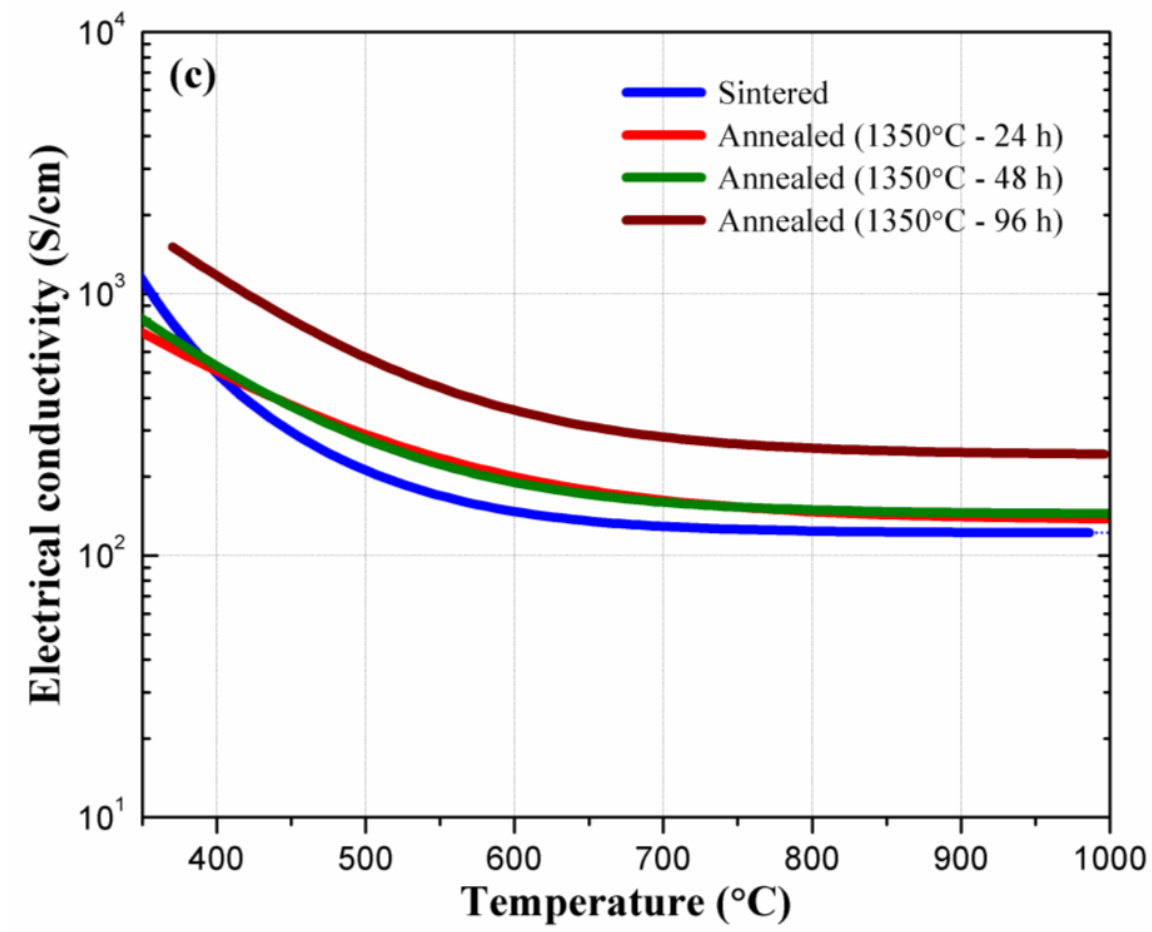

Figure 70. (continued) Electrical conductivity as a function of temperature for the assintered and as-annealed (a) CC-5050, (b) CC-5545, and (c) CC-6040 composites (Electrical conductivity data is shown on the logarithmic scale).

composites compared to the CC-6040. The positive influence of the annealing on their high-temperature electrical properties could be correlated to the above-mentioned phase and microstructural changes observed after high-temperature annealing. The presence of the remaining initial phases (e.g. $\mathrm{CrSi}, \mathrm{CrSi}_{2}$ ) within the structures of the $\mathrm{CC}-5545$ and $\mathrm{CC}$ 6040 composites after sintering resulted in further solid-state reactions and the formation of three-phase system $\left(\mathrm{Cr}_{3} \mathrm{Si}+\mathrm{Cr}_{5} \mathrm{Si}_{3}+\mathrm{SiO}_{2}\right)$ after annealing. Therefore, the removal of the remaining phases via solid-state reactions and increased amount of the $\mathrm{Cr}_{3} \mathrm{Si}$ and $\mathrm{Cr}_{5} \mathrm{Si}_{3}$ phases enhanced their electrical conductivities. The $\mathrm{CrSi}$ and $\mathrm{CrSi}_{2}$ phases are known to exhibit lower electrical conductivities compared to the $\mathrm{Cr}_{3} \mathrm{Si}$ and $\mathrm{Cr}_{5} \mathrm{Si}_{3}$ [2,4,5]. Although these two composites had the same three-phase structure after $96 \mathrm{~h}$ of annealing, the CC5545 composite exhibited substantially higher electrical conductivity than the CC-6040. This could be related to the major $\mathrm{Cr}_{3} \mathrm{Si}$ and minor $\mathrm{Cr}_{5} \mathrm{Si}_{3}$ phases within the $\mathrm{CC}-5545$ composite, and higher intrinsic electrical conductivity of the $\mathrm{Cr}_{3} \mathrm{Si}$. The $\mathrm{Cr}_{5} \mathrm{Si}_{3} \mathrm{XRD}$ peaks 
became more intense for the CC-6040 composite indicating the higher content, which possibly reduced its overall electrical conductivity compared to the $\mathrm{Cr}_{3} \mathrm{Si}$-dominant $\mathrm{CC}$ 5545 composite. On the other hand, the increase in the electrical conductivity of the CC5050 composite after annealing could be attributed to the slight changes in the volume percentages of the $\mathrm{Cr}_{3} \mathrm{Si}$ and $\mathrm{SiO}_{2}$ phases, but no major phase changes were observed within this composite system. Therefore, it should be noted that the percolation and electrical transport could also be positively influenced by the microstructural changes and formation of more rounded grains via solid-phase grain boundary wetting by a metastable and/or amorphous silica phase. It is known that the electrical percolation of the mixtures of conductive and insulating materials are highly influenced by several factors including grain size and morphology, microstructural homogeneity, particle interactions and wetting behavior $[28,41,42]$. The importance of wetting behavior (connectivity of two phases) on the electrical conductivity and critical percolation threshold is commonly discussed for conductive polymer composites (e.g. wetting of a polymer by a filler material) $[43,44]$, but a similar relation may be of importance for these intermetallic composites.

\subsection{Conclusions}

The chromium silicide-based electroconductive composites were fabricated by solid-state reactions between chromium silicide and oxide compounds, and their phase stability, microstructural evolution, oxidation behavior and electrical properties were studied at high temperatures. By adjusting the starting silicide/oxide volume ratio, different chromium silicide phases (e.g. $\mathrm{Cr}_{0.91} \mathrm{Si}_{0.09}, \mathrm{Cr}_{3} \mathrm{Si}_{1}, \mathrm{Cr}_{5} \mathrm{Si}_{3}$ ) were formed along with a metastable and/or amorphous grain boundary silica phase. The distribution of the silicide phases within the silica was determined to be homogeneous for all the composite systems. No pest oxidation (structural disintegration) were observed during both non-isothermal and isothermal conditions. Their excellent oxidation resistance was attributed to the formation of a protective surface layer composed of chromium oxide and amorphous silica. All of the composites exhibited a metallic-type conduction behavior, and their electrical conductivities ranged from 42.1 to $213.7 \mathrm{~S} / \mathrm{cm}$ at $1000^{\circ} \mathrm{C}$ depending on the major silicide 
phases present and their amount. In addition, further phase and microstructural changes were identified after high-temperature annealing, which mostly enhanced their oxidation resistance and electrical conductivities at high-temperatures. Further studies are needed to better understand the effects of the silica grain boundary phase and the high-temperature heat treatment on their phase stability, microstructures (e.g. solid-phase grain boundary wetting), oxidation behavior and electrical properties.

\section{References}

[1] I. Nishida, T. Sakata, Semiconducting properties of pure and Mn-doped chromium disilicides, J. Phys. Chem. Solids 39 (1978) 499-505.

[2] E. Mazzega, M. Michelini, F. Nava, Electrical properties of chromium silicide films: $\mathrm{Cr}_{3} \mathrm{Si}$ and $\mathrm{Cr}_{5} \mathrm{Si}_{3}$, J. Phys. F: Met. Phys. 17 (1987) 1135-1142.

[3] A.B. Gokhale, G.J. Abbaschian, The Cr-Si (chromium-silicon) system, Bulletin of Alloy Phase Diagram 8 (1987) 474-484.

[4] D. Stathokostopoulos, D. Chaliampalias, E. Tarani, A. Theodorakakos, V. Giannoulatou, G.S. Polymeris, E. Pavlidou, K. Chrissafis, E. Hatzikraniotis, K.M. Paraskevopoulos, G. Vourlias, Formation of the thermoelectric candidate chromium silicide by use of a pack-cementation process, Journal of Electronic Materials 43 (2014) 3733-3739.

[5] T. Dasgupta, J. Etourneau, B. Chevalier, S.F. Matar, A.M. Umarji, Structural, thermal and electrical properties of $\mathrm{CrSi}_{2}$, Journal of Applied Physics 103 (2008) 113516-1-7.

[6] H. Nagai, T. Takamatsu, Y. Iijima, K. Hayashi, Y. Miyazaki, Effects of Nb substitution on thermoelectric properties of $\mathrm{CrSi}_{2}$, Journal of Alloys and Compounds 687 (2016) 37-41. [7] S.F. Gong, X-H. Li, H.T.G. Hentzell, J. Strandberg, Electrical and structural properties of thin films of sputtered $\mathrm{CrSi}_{2}$, Thin Solid Films 208 (1992) 91-95.

[8] T. Dasgupta, A.M. Umarji, Role of milling parameters and impurity on the thermoelectric properties of mechanically alloyed chromium silicide, Journal of Alloys and Compounds 461 (2008) 292-297. 
[9] M. Mikami, Y. Kinemuchi, Microstructure and thermoelectric properties of $\mathrm{WSi}_{2}$-added $\mathrm{CrSi}_{2}$ composite, Journal of Alloys and Compounds 690 (2017) 652-657.

[10] A. Nozariasbmarz, A. Agarwal, Z.A. Coutant, M.J. Hall, J. Liu, R. Liu, A. Malhotra, P. Norouzzadeh, M.C. Ozturk, V.P. Ramesh, Y. Sargolzaeiaval, F. Suarez, D. Vashaee, Thermoelectric silicides: A review, Japanese Journal of Applied Physics 56 (2017) 05DA04-1-27.

[11] T.S.R.Ch. Murthy, J.K. Sonber, C. Subramanian, R.K. Fotedar, S. Kumar, M.R. Gonal, A.K. Suri, A new $\mathrm{TiB}_{2}+\mathrm{CrSi}_{2}$ composite - Densification, characterization and oxidation studies, Int. Journal of Refractory Metals \& Hard Materials 28 (2010) 529-540.

[12] G.V. Samsonov, V.A. Lavrenko, L.A. Glebov, Oxidation of chromium disilicide in oxygen, Soviet Powder Metallurgy and Metal Ceramics 13 (1974) 36-38.

[13] Y.A. Chang, Phase relationships in the system chromium-silicon, Transactions of the Metallurgical Society of AIME 242 (1968) 1509-1515.

[14] U. Gottlieb, F. Nava, M. Affronte, O. Laborde, R. Madar, Electrical transport in metallic TM silicides, in: K. Maex, M.V. Rossum (Eds.), Properties of Metal Silicides, Inspec/Iee, London, 1995, pp. 189-204.

[15] J. Ma, Y. Gu, L. Shi, L. Chen, Z. Yang, Y. Qian, Synthesis and oxidation behavior of chromium silicide $\left(\mathrm{Cr}_{3} \mathrm{Si}\right)$ nanorods, Journal of Alloys and Compounds 375 (2004) 249252.

[16] J. $\mathrm{Xu}$, Investigation on the behaviour of sputter-deposited nanocrystalline $\mathrm{Cr}_{3} \mathrm{Si}$ film by double cathode glow discharge, Current Nanoscience 5 (2009) 493-502.

[17] H.M. Wang, G. Duan, Microstructure and wear resistance of a laser clad reinforced $\mathrm{Cr}_{3} \mathrm{Si}$ metal silicide composite coating, Mater. Sci. Eng. A 336 (2002) 117-123.

[18] Y. Ochiai, K. Kishida, K. Tanaka, H. Inui, Mechanical properties of $\mathrm{Cr}_{5} \mathrm{Si}_{3}$ with the D8 ${ }_{m}$ structure, Mater. Res. Soc. Symp. Proc. 1295 (2011) 213-218.

[19] T.A. Cruse, J.W. Newkirk, Evaluation of methods to produce tough $\mathrm{Cr}_{3} \mathrm{Si}$ based composites, Mater. Sci. Eng. A 239 (1997) 410-418.

[20] S.V. Raj, An evaluation of the properties of $\mathrm{Cr}_{3} \mathrm{Si}$ alloyed with Mo, Mater. Sci. Eng. A 201 (1995) 229-241. 
[21] S. Motojima, K. Sugiyama, Chemical vapor growth of $\mathrm{Cr}_{5} \mathrm{Si}_{3}$ whiskers and hollow crystals, Journal of Crystal Growth 55 (1981) 611-613.

[22] D.W. McKee, R.L. Fleischer, Oxidation behavior of advanced intermetallic compounds, Mater. Res. Soc. Symp. Proc. 213 (1991) 969-974.

[23] S.V. Raj, High temperature creep and oxidation resistant chromium silicide matrix alloy containing molybdenum, U.S. Patent, No. 5,330,590, 1994.

[24] ASTM B193-16 Standard test method for resistivity of electrical conductor materials, ASTM International, West Conshohocken, PA.

[25] A.M. Smyslov, R.R. Nev'yantseva, A.A. Bybin, E.V. Parfenov, High-temperature corrosion of nickel alloy TsNK7P with a protective aluminide coating, Protection of Metals 40 (2004), 497-500.

[26] W. Pabst, E. Gregorova, Elastic properties of silica polymorphs - a review, Ceramics Silikaty 57 (2013) 167-184.

[27] S. Kobel, J. Pluschke, U. Vogt, T.J. Graule, $\mathrm{MoSi}_{2}-\mathrm{Al}_{2} \mathrm{O}_{3}$ electroconductive ceramic composites, Ceram. Int. 30 (2004) 2105-2110.

[28] F. Lux, Models proposed to explain the electrical conductivity of mixtures made of conductive and insulating materials, J. Mater. Sci. 28 (1993) 285-301.

[29] S. Tekeli, T. Boyacioglu, A. Gural, The effect of silica doping on the microstructure and mechanical properties of $\mathrm{c}-\mathrm{ZrO}_{2} / \mathrm{SiO}_{2}$ composites, Ceramics International 34 (2008) 1959-1964.

[30] D.M. Hatch, S. Ghose, The $\alpha-\beta$ phase transition in cristobalite, $\mathrm{SiO}_{2}$ : Symmetry analysis, domain structure, and the dynamical nature of the $\beta$-phase, Phys. Chem. Minerals 17 (1991) 554-562.

[31] F. Ren, G. Zhai, Z. Ma, X. Chen, A.A. Volinsky, Microstructure and quality of SiC foam filters for casting, Journal of Ceramic Processing Research 12 (2011) 691-694.

[32] R. Mitra, Mechanical behavior and oxidation resistance of structural silicides, International Materials Reviews 51 (2006) 13-64.

[33] D.M. Shah, D.L. Anton, Evaluation of refractory intermetallics with A15 structure for high temperature structural applications, Mater. Sci. Eng. A 153 (1992) 402-409. 
[34] D.L. Anton, D.M. Shah, High temperature properties of refractory intermetallics, Mat. Res. Soc. Symp. Proc. 213 (1991) 733-738.

[35] D. Shinoda, S. Asanabe, Y. Sasaki, Semiconducting properties of chromium disilicide, J. Phys. Soc. Jpn. 19 (1964) 269-272.

[36] S. Karuppaiah, M. Beaudhuin, R. Viennois, Investigation of the thermoelectric properties of nanostructured $\mathrm{Cr}_{1-\mathrm{x}} \mathrm{Ti}_{\mathrm{x}} \mathrm{Si}_{2}$, Journal of Solid State Chemistry 199 (2013) 9095.

[37] B.B. Straumal, B. Baretzky, O.A. Kogtenkova, A.B. Straumal, A.S. Sidorenko, Wetting of grain boundaries in $\mathrm{Al}$ by the solid $\mathrm{Al}_{3} \mathrm{Mg}_{2}$ phase, J. Mater. Sci. 45 (2010) 2057-2061.

[38] S.G. Protasova, O.A. Kogtenkova, B.B. Straumal, P. Zieba, B. Baretzky, Inversed solid-phase grain boundary wetting in the Al-Zn system, J. Mater. Sci. 46 (2011) 43494353.

[39] M. Bartur, Thermal oxidation of transition metal silicides: the role of mass transport, Thin Solid Films 107 (1983) 55-65.

[40] K. Kurokawa, A. Shibayama, A. Kobayashi, Formation of $\mathrm{SiO}_{2}$ scale in hightemperature oxidation of $\mathrm{WSi}_{2}$, Transactions of JWRI 36 (2007) 51-55.

[41] R.A. Gerhardt, J. Runyan, C. Sana, D.S. McLachlan, R. Ruh, Electrical properties of boron nitride matrix composites: III, Observations near the percolation threshold in BN$\mathrm{B}_{4} \mathrm{C}$ composites, J. Am. Ceram. Soc. 84 (2001) 2335-2342.

[42] T.L. Pruyn, R.A. Gerhardt, Percolation in borosilicate glass matrix composites containing antimony-doped tin oxide segregated networks. Part II: examination of electrical behavior using impedance spectroscopy, J. Am. Ceram. Soc. 97 (2014) 2082-2090.

[43] R. Tchoudakov, O. Breuer, M. Narkis, A. Siegmann, Conductive polymer blends with low carbon black loading: polypropylene/polyamide, Polymer Engineering and Science 36 (1996) 1336-1346.

[44] M.L. Clingerman, J.A. King, K.H. Schulz, J.D. Meyers, Evaluation of electrical conductivity models for conductive polymer composites, Journal of Applied Polymer Science 83 (2002) 1341-1356. 


\begin{tabular}{lccccr} 
CHA P T R & $5:$ & DETERM INATION & OF & A \\
\hline H OMOGENEITY & FACTOR & FOR & C OMPOS TE
\end{tabular}
M A T E R I A L S

\subsection{Introduction}

Composites are a prominent class of material systems that consist of a combination of at least two constituent materials typically with distinctively different property characteristics. Over the past half century, composite materials with advanced material properties were achieved by using various matrix and reinforcement (or additive) materials. Work continues on the development of these unique materials in many industrial fields including electronics, aerospace, and automotive [1-3]. It is well known that the distribution of the additive phase within a matrix material has a major effect on the constitutive properties of composite material (e.g. electrical, mechanical, thermal), and this distribution is dependent upon the concentration, particle size and morphology of the additive phase [1-5]. Various quantitative microscopy methods have been developed in different fields such as ecology and materials science to characterize the microstructure of composites, but methods to describe the spatial distribution of the phases within the matrix have been limited. A simple method and index to quantify the degree of distribution, dispersion and/or mixedness of the composite microstructures would be beneficial to correlate processing and microstructure to the final properties of the materials. Quantitative analysis of the degree of distribution is crucial for understanding and controlling the process parameters for improving the microstructural homogeneity and composite properties. It is known that qualitative methods such as visual observation of composite microstructures do not provide objective and numeric results as needed [1,6]. For the quantification of the additive distribution within a matrix material, characteristics such as relative particle size [7,8], local concentration [2,9], number of particles [3,10,11,12], and distance between neighboring particles [4,5,13-15] have been selected as measures for the distribution in various methods. The method based on the relative particle size (RPS) is the 
simplest technique used to quantify the level of clustering and/or agglomeration by calculating the particle size ratio of matrix to the additive material $[1,8]$. Therefore, the RPS method is mostly used for metal matrix composites (MMCs) prepared by dry mixing and sintering/hot-pressing due to high level of clustering.

As discussed above, the most common methods to quantify the degree of distribution or homogeneity are based upon microstructural parameters such as local concentration, number of particles, and distance between neighboring particles. These parameters are usually further analyzed by mathematical equations and distribution models including various statistical measures of distribution and variability such as standard deviation, coefficient of variation, and variance. The homogeneity of a multi-phased material is typically defined through these statistical analyses by a degree of distribution or homogeneity index, and often correlated with local concentration of the additive material and concentration ratio [2,9]. The degree of distribution was shown to be dependent on the local concentration of the dispersed phase by Ondracek \& Renz (1989) [9]. They utilized the coefficient of variation, where the standard deviation is divided by the mean, to statistically quantify the degree of distribution; this paper used this coefficient to determine the homogeneity within metal-polymer composite structures. Kalyon et al. (2002) [2] developed a similar method using concentration variations, which are characterized by a wide-angle X-ray diffraction (WAXD)-based quantitative phase analysis route. The degree of mixedness was quantitatively assessed in that study by a mixing index developed using the statistical variance in order to provide a relationship between electrical properties of the composites and mixing homogeneity. The quadrat method is known as the most commonly used technique for quantification of the distribution due to its simplicity among all methods developed. In the quadrat method, a micrograph to be studied is simply divided into quadrats, and then the number of particles in each quadrat is measured. Using the quadrat method, a Skewness index $(\beta)$ is calculated as the degree of asymmetry of a statistical distribution around its mean based on the number of particles, the standard deviation of the particle population, and the number of quadrats studied $[12,16]$. Therefore, high $\beta$ values 
are accepted as an indication of poor distribution, and this index is only used to compare the reinforcement distribution within different specimens. This technique is mostly used for MMCs and nanocomposites with highly clustered particle distributions and high level of agglomeration due to the principle of the quadrat method [3,10-12,14-16].

In addition to the parameters of local concentration and number of particles that are utilized by the methods discussed above, distance between neighboring particles is also considered as an important microstructural parameter to quantify the degree of distribution. The mean free-path and nearest-neighbor distance techniques, which are both based on the average distance between neighboring particles or features, have been frequently used. Although they have similar principles, distances between particle surfaces (interfaces), and distances between centroids of the nearest neighboring particles are measured for mean free-path and nearest-neighbor distance methods, respectively [15,17]. In the mean freepath method proposed by Luo \& Koo (2008) [4] for the quantification of nanoparticle dispersions, the free-path spacing between fillers were measured by dividing a representative micrograph into multiple grid lines. Since the distribution of the free-path distance exhibits a lognormal distribution model, a dispersion parameter was calculated as the probability of this distribution. A modified version of this method was developed by considering the combination of the percentage of distribution (free-path spacing) and agglomeration size in order to analyze the dispersion of nanoparticles in composite materials [5]. The mean free-path was also calculated by using the volume fraction of particles, sum of the perimeter length and total test area in several studies on MMCs [15,17]. The nearest-neighbor distance method proposed by Clark \& Evans (1954) [13] measured the distance from each individual to its nearest-neighbor, and then they correlated the population by the mean distance, which is expected for a random distribution, for quantitative measurement of distribution. Furthermore, several other methods on the basis of the amount of work (dispersive work), relative entropy, radial distribution function, and Voronoi tessellation are alternatively developed, and particularly used for characterization 
of nanoparticle/inclusion dispersion and particle clustering in composite structures $[1,18$ 21].

All of the methods reviewed above were developed for the quantitative characterization of particle distribution and clustering/agglomeration in different composite materials by considering different microstructural parameters. However, it is known that most methods have several shortcomings which limits their accuracy, scalability and practical use in different types of composite structures; the prime limits include the selection of the number of quadrats, quadrat size/shape, and the relation of these factors to the relative size and distribution of the agglomerated particles. The quantitative measure of the distribution should consider these limiting factors, while also being simple and applicable to different types of composite microstructures. In this paper, an image analysis method and a new index is presented for quantifying the distribution (homogeneity) efficiently in binary composite materials. The proposed method is based on the free-path spacing between the particles, which considers the method developed by Luo \& Koo (2008) [4] in principle, but the present study distinctly takes the coefficient of variation into account as a measure of the degree of distribution instead of an equation based on the lognormal distribution model.

\subsection{Materials and methods}

\subsubsection{Homogeneity analysis method}

The proposed method is a microstructural image analysis technique for the quantification of the phase or granular distribution (homogeneity) in composite materials based upon the free-path spacing, which can be also defined as the distance between two neighboring particles on a micrograph as a basic measure of the distribution. Therefore, multiple straight lines (total $2 N$ lines) are drawn both horizontally ( $N$ lines) and vertically ( $N$ lines) on a cross-sectional microstructure of a composite, which only consists of the particles of its one constituent after making the microstructure image binary by using the ImageJ software [22], as schematically illustrated in the Figure 71. The free-path spacing 


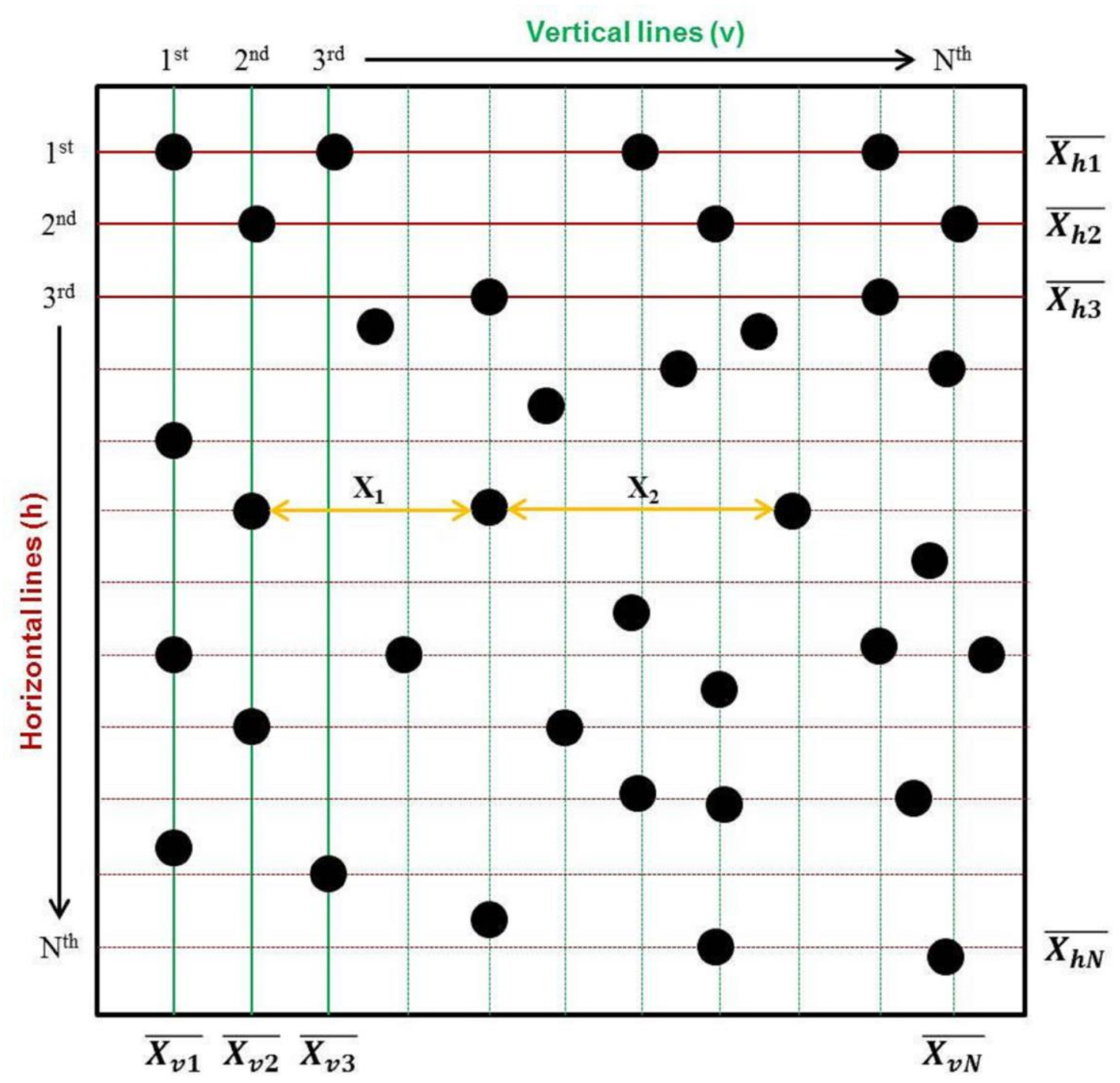

Figure 71. Schematic illustration of the proposed image analysis method for quantifying the degree of distribution (homogeneity) in composite materials on a representative microstructure. (Black circles represent the particles on the image).

$\left(X_{1}, X_{2}, \ldots ., X_{n}\right)$ data between all the neighboring particles are recorded as profile plots as a function of distance, and then measured by processing the data in the Microsoft Excel. The free-path spacing values can be used as pixels or microns after setting the scale. The arithmetic mean of the free-path spacing values on each line $\left(\overline{X_{h 1}}, \overline{X_{h 2}}, \ldots, \overline{X_{h N}}\right.$ $\left.; \overline{X_{v 1}}, \overline{X_{v 2}}, \ldots, \overline{X_{v N}}\right)$ are separately calculated as: 


$$
\overline{X_{h 1}}=\frac{1}{n} \sum_{i=1}^{n} X_{i} ; \overline{X_{v 1}}=\frac{1}{n} \sum_{i=1}^{n} X_{i} ; \ldots \ldots \ldots
$$

where $n$ is defined as the total number of free-path spacing on a specific line drawn, and $h$ and $v$ are abbreviations of horizontal and vertical lines, respectively. Afterwards, the arithmetic mean $(\bar{X})$ and the standard deviation $(s)$ of the all free-path spacing values obtained for total $2 N$ lines are calculated by using the equation (2) and (3), respectively.

$$
\begin{gathered}
\bar{X}=\frac{\left(\overline{X_{h 1}}+\overline{X_{h 2}}+\cdots \cdots+\overline{X_{h N}}\right)+\left(\overline{X_{v 1}}+\overline{X_{v 2}}+\cdots \cdots+\overline{X_{v N}}\right)}{2 N} \\
s=\sqrt{\frac{\left[\sum_{i=1}^{N}\left(\overline{X_{h l}}-\bar{X}\right)^{2}\right]+\left[\sum_{i=1}^{N}\left(\overline{X_{v l}}-\bar{X}\right)^{2}\right]}{2 N-1}}
\end{gathered}
$$

The degree of distribution or homogeneity can be identified as maximum, if all the arithmetic mean values of the free-path spacing are the same on each line analyzed, and also the same with the mean $(\bar{X})$ value. But in the case of an inhomogeneity or inhomogeneous distribution of particles, these mean values $\left(\overline{X_{h 1}}, \overline{X_{h 2}}\right.$, etc. $)$ differ from each other, and also from the mean $(\bar{X})$ of all free-path spacing values obtained for the total $2 N$ lines. Since the mean free-path spacing values are different for each line analyzed, and the standard deviation value is also depending on $\bar{X}$ value in that case, the coefficient of variation $\left(\mathrm{C}_{\mathrm{V}}\right)$ was selected to be used for assessing the relative variability of the mean freepath spacing at a total $2 N$ lines. Thus, the $\mathrm{C}_{\mathrm{V}}$ can be efficiently used to determine the degree of variation (distribution) for one variable having different mean values among multiple lines. Therefore, $\mathrm{C}_{V}$ is accepted as the distribution index (D index) in the proposed homogeneity analysis method, and presented as:

$$
D \text { index }=C_{V}=\left(\frac{s}{\bar{X}}\right)
$$

The $\mathrm{D}$ index exhibits a zero value $\left(\mathrm{C}_{V}=0\right)$ for a perfectly homogeneous composite material and its representative microstructure, since all free-path spacing values between particles (additive or reinforcement particles) and their arithmetic mean values on each line are the same. If the particles are agglomerated or clustered in a composite material at a certain 
level, then the D index diverges from zero, and thus tends to increase up to 1 and/or above 1. If the D index is found to be above 1.0 at some regions with low number of analyzed lines (e.g. $\mathrm{N} \leq 10$ ), this means that the standard deviation is higher than the mean value, which clearly indicates that the agglomeration level of particles is extremely high. Thus, the proposed method can also provide important information regarding the high level of agglomeration of the individual particles. As a review, when the $\mathrm{D}$ index equals 0 , then this indicates a maximum homogeneity and degree of distribution; a higher D index presents a minimum homogeneity and poorer distribution. Therefore, the proposed method based on the free-path spacing and its outcome, the D index, can be efficiently used to quantify the degree of distribution and to compare the distribution levels of different composite samples.

\subsubsection{Description of the data and experimental method}

To test the accuracy and potential limitations of the proposed homogeneity analysis method, six binary images representing the reference composite microstructures were created. The calculations based on the free-path spacing were performed on each image to determine the $\mathrm{D}$ index values as a function of the number of lines analyzed for comparison. In addition to the reference images, actual microstructures of ceramic-matrix composites were also analyzed. Metal silicide-refractory oxide composites were fabricated using molybdenum disilicide ( $\left.\mathrm{MoSi}_{2}, 99.5 \%\right)$, tungsten disilicide $\left(\mathrm{WSi}_{2}, 99.5 \%\right)$, aluminum oxide $\left(\mathrm{Al}_{2} \mathrm{O}_{3}, 8.6 \mathrm{~m}^{2} / \mathrm{g}\right)$, zirconium oxide $\left(\mathrm{ZrO}_{2}, 99+\%\right)$, and yttrium oxide $\left(\mathrm{Y}_{2} \mathrm{O}_{3}, 99.99 \%\right)$ powders, all purchased from a commercial vendor (Alfa Aesar). The three composite compositions that will be discussed in this work were (60-40) vol\% $\mathrm{MoSi}_{2}-\mathrm{Al}_{2} \mathrm{O}_{3},(60-40)$ vol\% $\mathrm{WSi}_{2}-\mathrm{Y}_{2} \mathrm{O}_{3}$, and (60-40) vol\% $\mathrm{WSi}_{2}-\mathrm{ZrO}_{2}$. These composites were synthesized by ball-milling in ethanol for $24 \mathrm{~h}$, followed by drying at room temperature in a fume hood. The synthesized composite powders were uniaxially pressed into pellets $(1 \mathrm{~cm}$ diameter, 2 mm thickness) by using a stainless steel die. Afterwards, these pellets were placed in an alumina crucible and sintered in a tube furnace in flowing argon gas $(50 \mathrm{sccm})$ to a temperature of $1600^{\circ} \mathrm{C}$. This was followed by the cutting of the sintered samples with a 
diamond saw, and fine polishing with $\mathrm{SiC}$ grit papers and also diamond paste. The microstructural analysis of the cross-sectional areas of the metal silicide-refractory oxide composites were performed by scanning electron microscope (SEM, Hitachi S-4700F, Japan). To prepare these micrographs for quantitative image analysis, the micrographs were converted into binary images consisting of only metal silicide grains by using ImageJ [22]. The proposed image analysis method and related calculations were similarly applied to these composite microstructures in order to determine the degree of distribution (homogeneity) of transition metal silicides (D index values) within the refractory oxide matrix materials quantitatively. In addition, the quadrat method, which is known as the most commonly used technique described in literature for homogeneity analysis, was applied to the same composite microstructures for comparison of the D index values obtained by the proposed analysis method.

\subsection{Results and Discussion}

\subsubsection{Homogeneity analysis of generated binary images}

In this study, six binary patterns (P1-P6) were generated in order to act as representative composite microstructures presenting the distribution of reinforcement particles within a matrix. These generated microstructures were used to demonstrate the accuracy, and also show the potential limitations of the proposed homogeneity analysis method. Figure 72 displays these generated composite microstructures, all including $19 \times$ 19 units, a hundred identical reinforcement particles, and thus, the same reinforcement volume fraction as a standard measurement. These patterns represent different degrees of distribution of reinforcement particles, from a perfectly homogeneous microstructure (P1) to an extremely agglomerated or poorly homogeneous microstructure (P6).

In order to investigate how well the proposed method quantifies the degree of distribution and homogeneity, 20 horizontal and 20 vertical lines were projected on each pattern, and then the arithmetic mean of the free-path spacing values on each line $\left(\overline{X_{h 1}}, \overline{X_{v 1}}\right.$ etc.) were measured to calculate the $\mathrm{D}$ index values based on the coefficient of variation. 

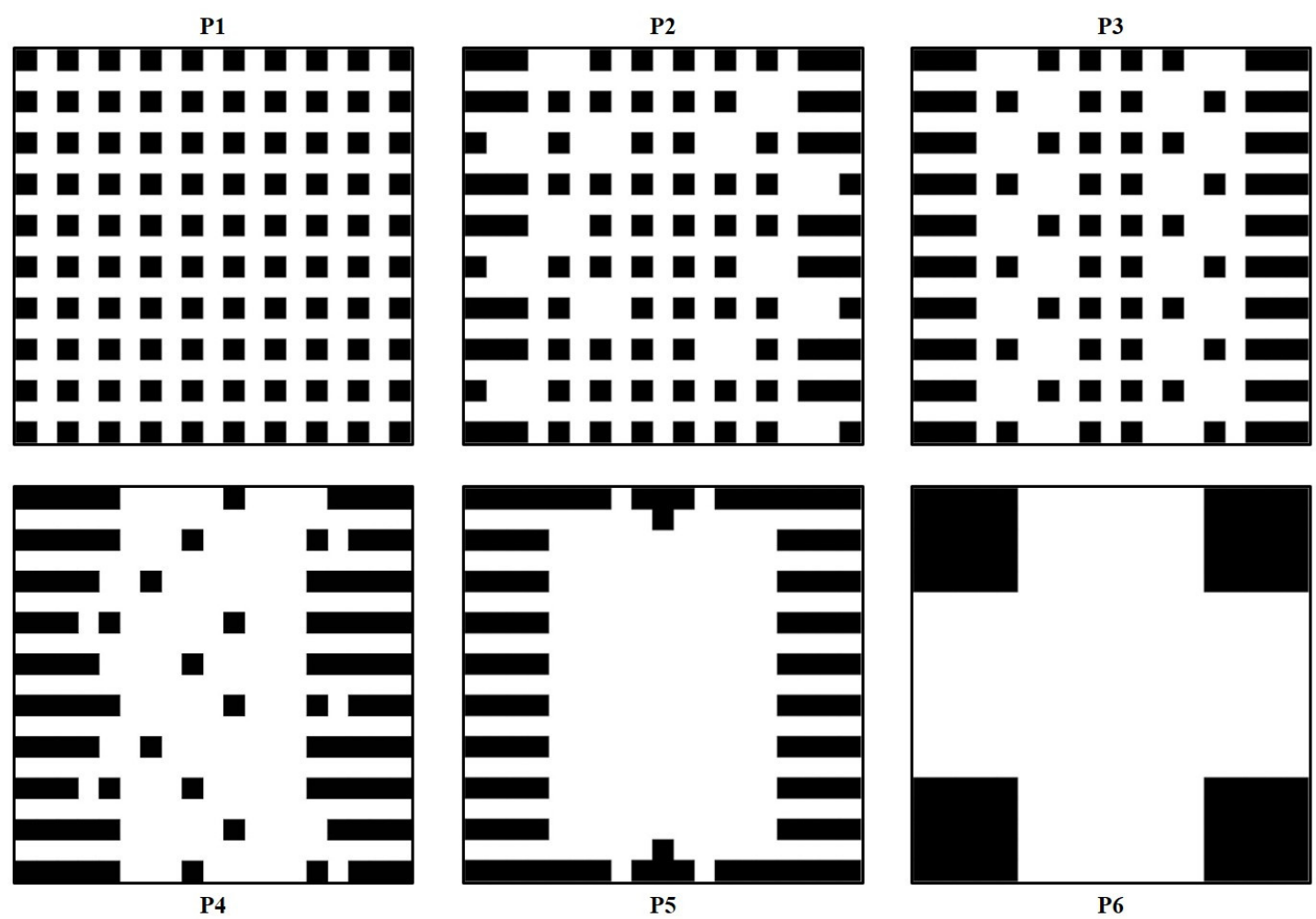

Figure 72. Images of six 19x19 reference patterns (P1-P6) which act as representative composite microstructures with different degrees of distribution of identical reinforcement particles. (Black squares represent the particles on the binary images).

Figure 73 presents the calculated D index values for six reference patterns from P1 to P6 as a function of total number of lines analyzed $(2 \mathrm{~N})$. It is clear that the D index value is zero for the P1 pattern representing a perfectly homogeneous microstructure, since all free-path spacing values, and their arithmetic means on all 40 lines, are the same indicating that there is no variance. In the Figure 73, the curve composed of D index values for the P1 (blue triangles) is beneath the P6 curve (orange triangles) due to the same D index values measured. In the case of the P2 pattern, the measured D index values range from 0.257 to 0.226 with increasing total number of lines analyzed from 5 to 40 . It is important to note that the total number of lines analyzed should be high enough to cover all the free-path spacing between particles and thus to achieve more accurate results. Therefore, the $\mathrm{D}$ index value for the P2 pattern representing a microstructure with high level of homogeneity is considered as 0.226 , which slightly diverges from zero due to the existence of small 


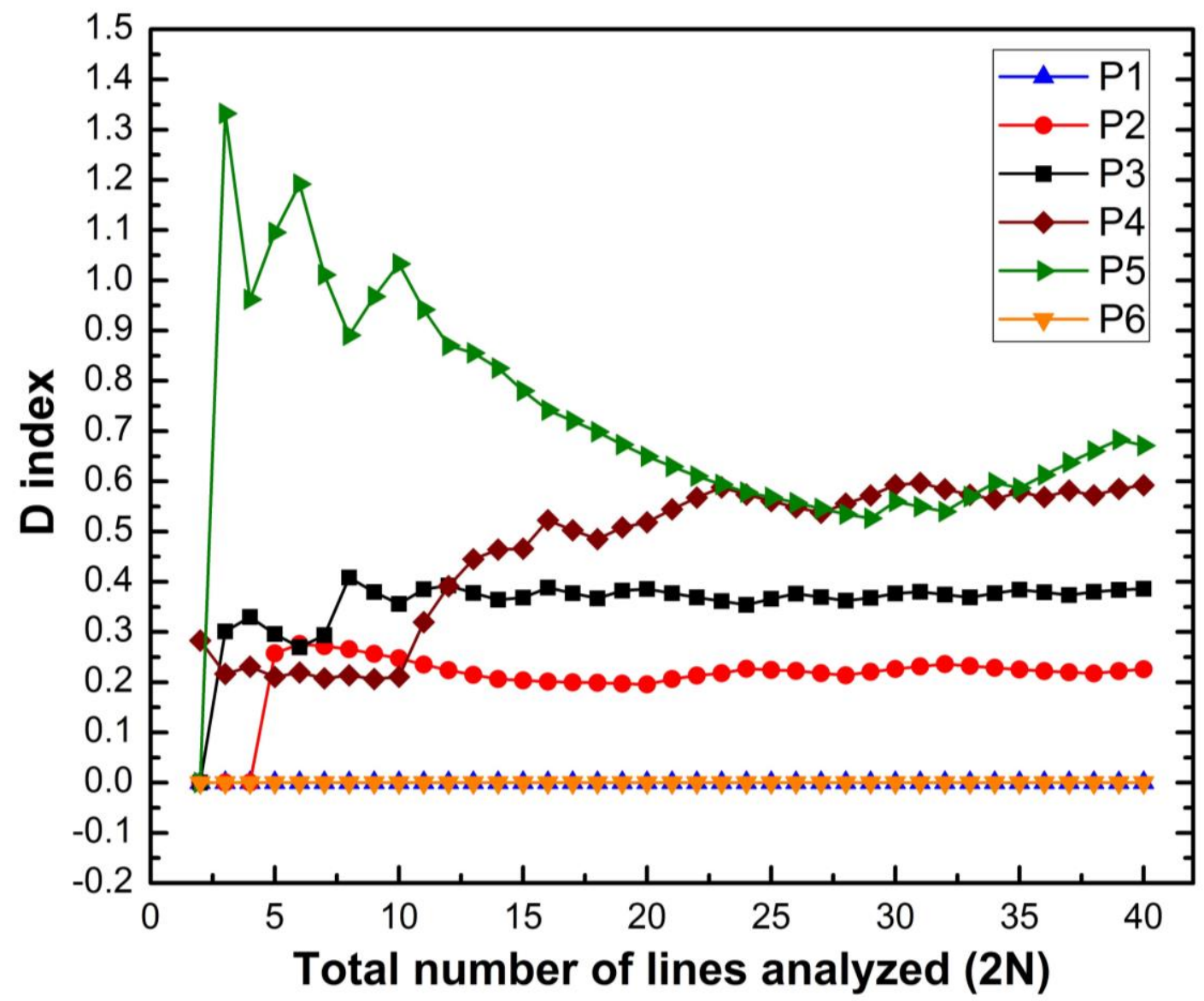

Figure 73. D index values calculated for six reference patterns (microstructures) from P1 to P6 as a function of total number of lines analyzed $(2 \mathrm{~N})$ by using the proposed method. (Blue triangles of the $\mathrm{P} 1$ are under the orange triangles of the P6).

agglomerates only at the left and right edges of the pattern (Figure 72). Since the majority of the particles are well distributed and the variance is low, the P2 pattern presents a highly homogeneous microstructure as expected. In addition, it is obvious that the number of these small agglomerates, and the free-path spacing values, increase from P2 to P3, which results in an increase of the variance and $\mathrm{D}$ index for the $\mathrm{P} 3$ pattern. The results present $\mathrm{D}$ index values for the $\mathrm{P} 3$ pattern range between 0.408 and 0.386 with an increasing total number of lines analyzed from 8 to 40 , which is reasonable for the pattern representing a moderate level of homogeneity (distribution). In addition to the P1, P2 and P3 patterns, P4 and P5 patterns were also studied by the proposed method for representing low and very low levels 
of homogeneity, respectively. The D index values measured for P4 and P5 patterns based on total 40 lines are 0.592 and 0.671 , respectively. It is clear that the D index values for P4 and P5 highly diverge from zero, and tend to get close to a value of one, indicating a low level of homogeneity and poor distribution. These results are directly related to the high level of particle agglomeration on these reference patterns and representative composite microstructures. Although the agglomeration level is very high, and this is similar for P4 and P5, the proposed method is found to be able to differentiate their degree of distribution and homogeneity levels efficiently from free-path spacing and $\mathrm{C}_{V}$ values. In addition, it is observed that the D index values are above 1.0 at some points for P5, which may be an indication of a high level of agglomeration. It can also be seen from Figure 73 that the D index values for P1, P2 and P3 patterns are all very stable after roughly 8 lines analyzed, while the values for P4 and P5 are mostly stable above 23 lines. This result indicates that more lines should be carefully analyzed in the case of a high level of agglomeration and low levels of homogeneity, in order to obtain a more accurate analysis by covering all agglomerated regions of a microstructure. Lastly, for the P6 pattern representing the extreme level of agglomeration, the D index is measured as zero, which is similar to the P1 pattern, since all free-path spacing values are same. In that case, it is important to note that the $\mathrm{D}$ index is measured inaccurately, because it is not possible to measure most of the freepath spacing values between individual particles due to such a high level of agglomeration, which can be stated as the main limitation of the proposed method. As a review of all the reference patterns, it is demonstrated that the $\mathrm{D}$ index values increase from 0.0 to 0.671 depending on the degree of distribution or homogeneity level, from maximum (perfect) to very low homogeneity. Therefore, the degrees of distribution or homogeneity levels for composites are classified based on the $\mathrm{D}$ index values for the proposed method as i) perfect (maximum) homogeneity ( $\mathrm{D}=0.00)$, ii) high level of homogeneity $(0.00<\mathrm{D} \leq 0.25)$, iii) moderate level of homogeneity $(0.25<\mathrm{D} \leq 0.40)$, iv) low level of homogeneity $(0.40<\mathrm{D}$ $\leq 0.60$ ), and v) very low level of homogeneity ( $\mathrm{D}>0.60)$, which is also schematically illustrated in Figure 74 . These boundary values $(0.25,0.40$ and 0.60$)$ for classifying the levels of homogeneity were determined based on the level of increase in free-path spacing 


\section{Homogeneity Levels of the Composites}

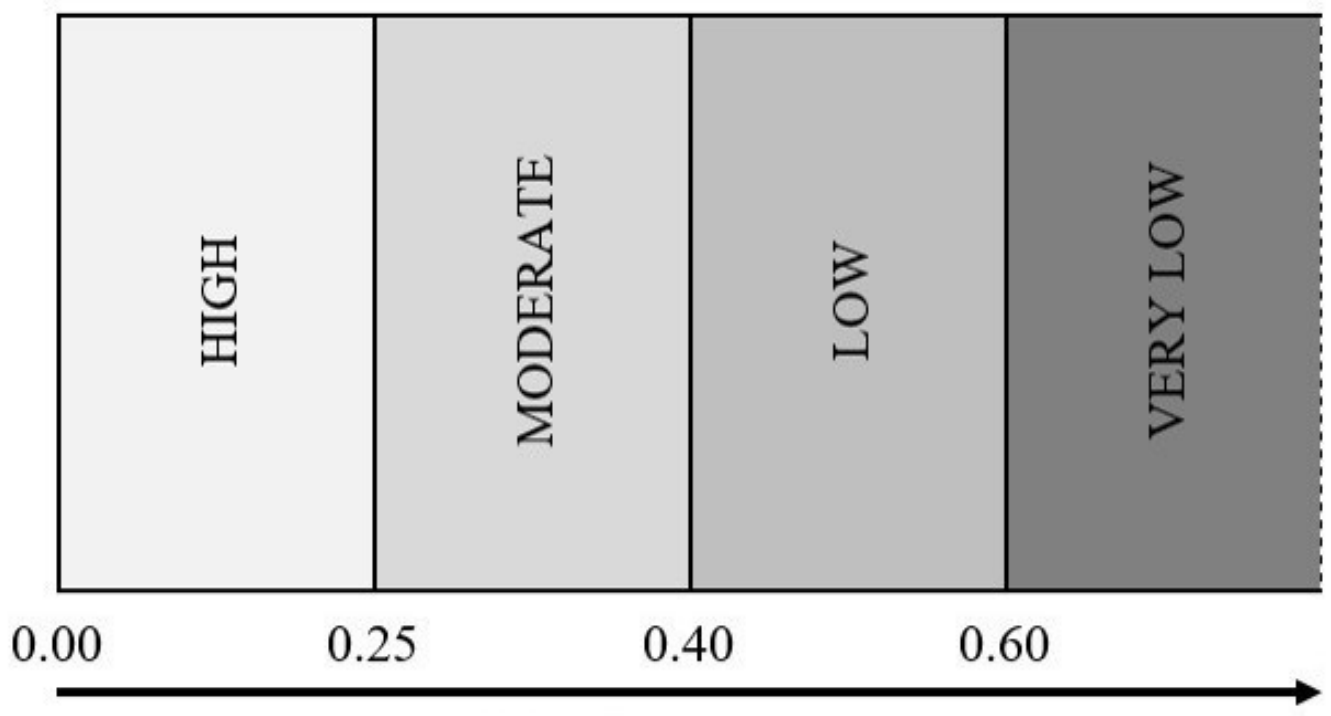

\section{Index Increases}

Figure 74. Classification of the homogeneity (degree of distribution) levels for composites based on D index ranges in the proposed method.

values, level of decrease in reference number of particles measured (agglomeration level), and corresponding D index values obtained for the five reference patterns (P1-P5).

The quantification of the degree of distribution and homogeneity can be efficiently performed for the proposed microstructure using the $\mathrm{D}$ index simply by increasing the total number of lines for horizontal and vertical axes, since the distance between two individual particles (free-path spacing) is of prime importance in for calculating homogeneity. By simply tracking this variable, the use of any quadrats becomes unnecessary, and thus, eliminates any effects produced by quadrat size selection on the distribution data, as expressed by Clark \& Evans (1954) [13]. Therefore, the proposed method has a significant advantage compared to the popular quadrat method, which produces the $\beta$ index as its major outcome from the number of particles. The selection of the optimum quadrat size and total number of quadrats is reported as the major downside of the quadrat method, since the distribution results are highly dependent on them, and thus not objective $[6,12,17]$. For example, many particle-free regions can be analyzed with a very small selected quadrat 
size, which may incorrectly result in clustering [15]. In addition, the RPS method does not provide direct information regarding the arrangement and distribution of particles, because it is only a measure of particle clustering, so a higher RPS is accepted as an indication of higher clustering [1]. In the proposed method, the microstructure should be carefully selected as a representative of the composite sample. If we assume that there are only four large individual particles on P6 pattern (Figure 72), then the D index would be measured as zero, and this value would not be representative of the microstructure for the composite sample due to a very high image magnification. Therefore, it is very crucial to select a composite microstructure at the correct magnification that can cover enough particles and represent the composite sample for the proposed method, and likewise, for the previously developed methods such as quadrat, mean free-path, and nearest-neighbor distance. The main limitation of the proposed method can be defined when inaccurate $\mathrm{D}$ index values are obtained as a result of homogeneously distributed agglomerates existing at the same size level (which usually occurs at high agglomeration levels). It is known that the quadrat method may also give incorrect $\beta$ values in that case. For the mean free-path method, it is reported by Karnezis et al. (1998) [15] that the perimeter length of the cluster could be falsely measured if a cluster of particles is analyzed as one particle. Therefore, incorrect distribution data may be obtained by the mean free-path method in the case of agglomeration. The similar problem is identified for the nearest-neighbor distance method in the same study, since the related distance may be measured inaccurately when a particle diameter falsely refers to a high level of agglomeration. In addition, it was demonstrated by Cetin \& Kalkanli (2009) [19] on their study for quantitative characterization of particle clustering, that the practical use of their cumulative radial distribution function is limited particularly in discontinuously reinforced composites which include well-separated clusters of reinforcement particles that may falsely change the measured data. In the study performed by Tyson et al. (2011) [5], it was reported that the free-path spacing and particle size values can be utilized to assess the dispersion and agglomeration quantities, respectively. However, the selection of the lognormal distribution function was found as one of the shortcomings for that modified free-path spacing technique, because inaccurate 
Original Image

a)

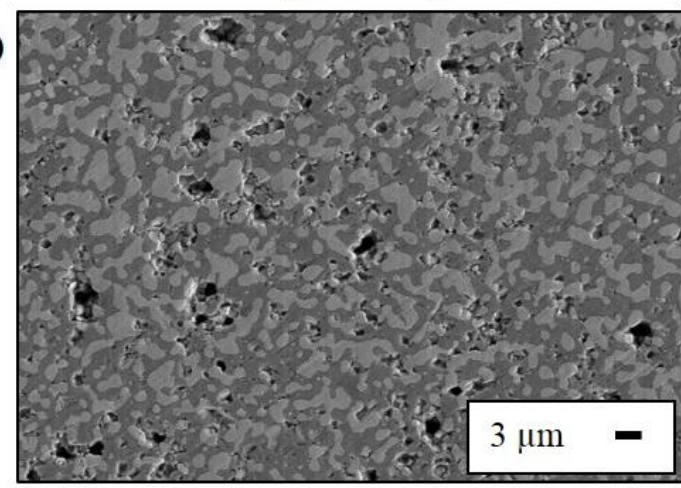

b)

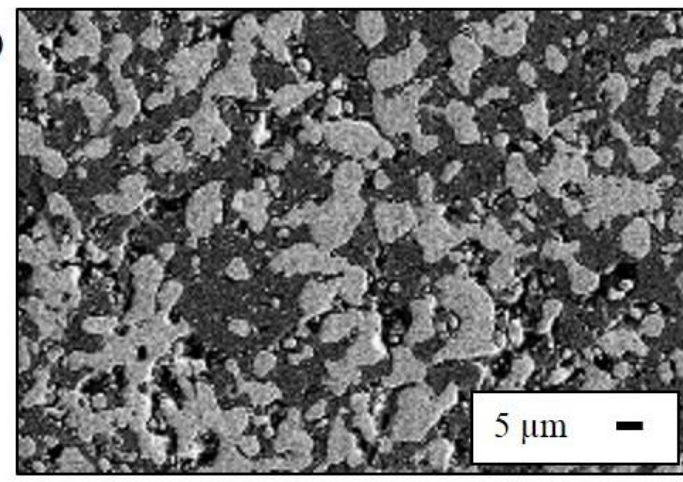

c)

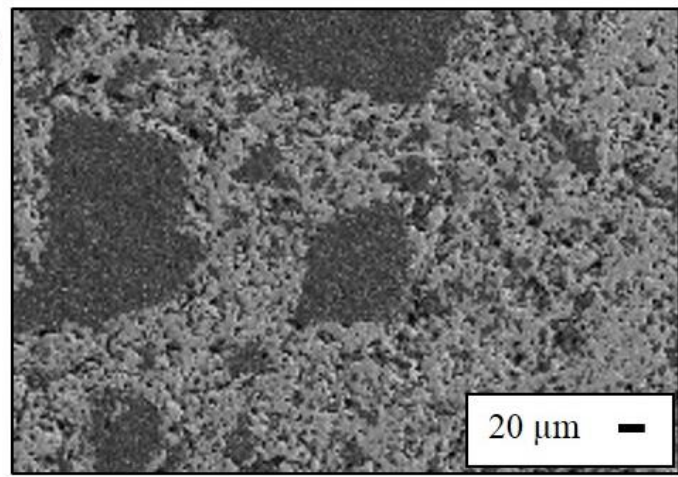

Binary Image
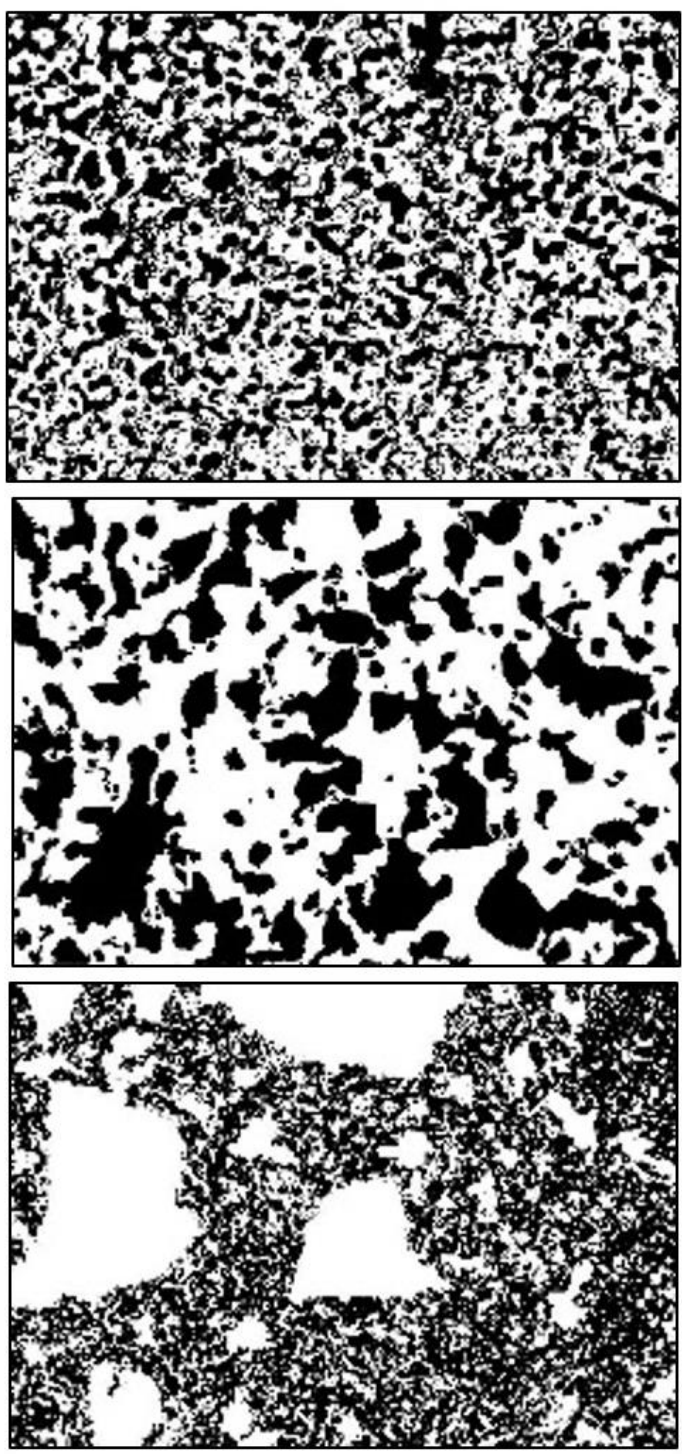

Figure 75. Original cross-sectional SEM images of the metal silicide-refractory oxide composites and their converted binary images showing individual metal silicide grains as black regions: a) (60-40) vol\% $\mathrm{WSi}_{2}-\mathrm{ZrO}_{2}$, b) (60-40) vol\% $\mathrm{WSi}_{2}-\mathrm{Y}_{2} \mathrm{O}_{3}$, and c) (60-40) vol\% $\mathrm{MoSi}_{2}-\mathrm{Al}_{2} \mathrm{O}_{3}$.

data may be obtained if the selected function is not suitable for that state of partial dispersion. As a review, it was demonstrated by using the reference patterns that the proposed homogeneity analysis method works with high accuracy to quantify the degree of distribution in composite materials by considering the coefficient of variation as a measure 
of the distribution and also eliminating the problematic quadrat effect. But similar to other previously developed methods, it was presented that the existence of well-distributed large agglomerates limits its use for some composite microstructures due to lack of the free-path spacing values to be measured.

\subsubsection{Homogeneity analysis of actual composite microstructures}

In addition to the analysis of six reference patterns, the proposed homogeneity analysis method was applied to actual ceramic-matrix composite microstructures. Figure 75 presents the original cross-sectional SEM microstructures of the metal silicide-refractory oxide composites and also their converted binary images showing individual metal silicide grains as black regions. The selected composite compositions are (60-40) vol\% $\mathrm{WSi}_{2}-\mathrm{ZrO}_{2}$, (60-40) vol\% $\mathrm{WSi}_{2}-\mathrm{Y}_{2} \mathrm{O}_{3}$, and (60-40) vol\% $\mathrm{MoSi}_{2}-\mathrm{Al}_{2} \mathrm{O}_{3}$, which all represent different degrees of distribution of metal silicide grains within a refractory oxide matrix. In order to quantify the degree of distribution and homogeneity of these composites using the D index, the free-path spacing and their arithmetic mean values were similarly measured on a total of 40 lines drawn both in the horizontal and vertical direction. The free-path spacing and all calculated values are measured in microns, not pixels after setting the conversion.

Figure 76 shows the calculated D index values for three different metal siliciderefractory oxide composites' SEM microstructures as a function of total number of lines analyzed $(2 \mathrm{~N})$. The measured $\mathrm{D}$ index values for the (60-40) vol\% $\mathrm{WSi}_{2}-\mathrm{ZrO}_{2}$ composite range from 0.189 to 0.142 with increasing total number of lines analyzed from 2 to 40 . For high accuracy, its D index is accepted as 0.142 based on the results obtained with 40 lines, since the arithmetic mean $(\bar{X})$ and standard deviation (s) of the all free-path spacing values are found as 1.043 and $0.148 \mu \mathrm{m}$, respectively (Table 11). These results show that the D index of (60-40) vol\% $\mathrm{WSi}_{2}-\mathrm{ZrO}_{2}$ composite slightly diverges from zero, and thus the distribution of the $\mathrm{WSi}_{2}$ grains within $\mathrm{ZrO}_{2}$ ceramic matrix is highly homogeneous. It is important to note that there may be a low level of error for the calculated D index values due to the existence of pores in small quantities within the microstructure to be analyzed, as 


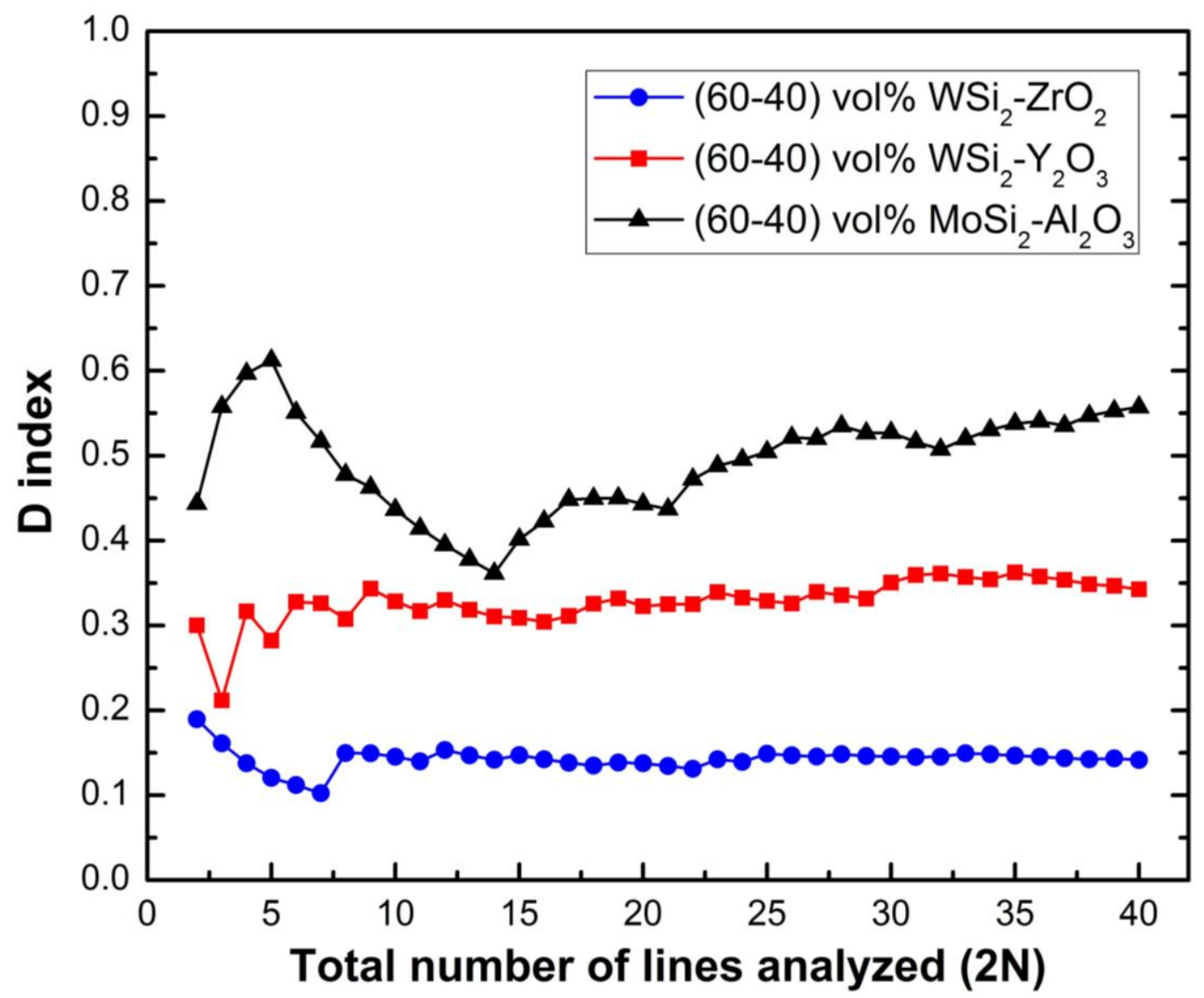

Figure 76. The D index values calculated for three different metal silicide-refractory oxide composite SEM microstructures as a function of total number of lines analyzed $(2 \mathrm{~N})$ by using the proposed method.

seen in the original SEM images of the composites (Figure 75). For the (60-40) vol\% $\mathrm{WSi}_{2}-\mathrm{Y}_{2} \mathrm{O}_{3}$ composite, the arithmetic mean and standard deviation of the all free-path spacing values obtained on 40 lines was measured as 4.817 and $1.651 \mu \mathrm{m}$, respectively. Therefore, the $\mathrm{D}$ index value for $\mathrm{WSi}_{2}-\mathrm{Y}_{2} \mathrm{O}_{3}$ composite was found as 0.343 , which represents a moderate level of homogeneity and distribution of $\mathrm{WSi}_{2}$ grains within $\mathrm{Y}_{2} \mathrm{O}_{3}$ ceramic matrix due to agglomeration at certain regions. In comparison of $\mathrm{WSi}_{2}-\mathrm{ZrO}_{2}$ and $\mathrm{WSi}_{2}-\mathrm{Y}_{2} \mathrm{O}_{3}$ composites, it is clear that the $\mathrm{D}$ index increases from 0.142 to 0.343 due to particle agglomeration and related change in the free-path spacing values. It can also be seen that the $\mathrm{D}$ index values for these two composites are highly stable after 8 lines were 
Table 11. Review of the results obtained for three different metal silicide-refractory oxide composites after 40 lines analyzed by using the proposed method.

\begin{tabular}{|c|c|c|c|}
\hline Composites & $\overline{\boldsymbol{X}}$ & $\mathbf{s}$ & $\begin{array}{c}\text { D index } \\
\text { (Cv) }\end{array}$ \\
\hline$(60-40) \mathrm{vol} \% \mathrm{WSi}_{2}-\mathrm{ZrO}_{2}$ & $1.043 \mu \mathrm{m}$ & $0.148 \mu \mathrm{m}$ & 0.142 \\
\hline$(60-40) \mathrm{vol} \% \mathrm{WSi}_{2}-\mathrm{Y}_{2} \mathrm{O}_{3}$ & $4.817 \mu \mathrm{m}$ & $1.651 \mu \mathrm{m}$ & 0.343 \\
\hline$(60-40) \mathrm{vol} \% \mathrm{MoSi}_{2}-\mathrm{Al}_{2} \mathrm{O}_{3}$ & $7.935 \mu \mathrm{m}$ & $4.423 \mu \mathrm{m}$ & 0.557 \\
\hline
\end{tabular}

$* \bar{X}$ : arithmetic mean of the all free-path spacing values

$*$ s: standard deviation of the all free-path spacing values

analyzed, which proves that accurate results for these kinds of microstructures can be simply achieved by analyzing several lines on both axes (Figure 76). In addition, it was found that the $\mathrm{D}$ index values for the (60-40) vol\% $\mathrm{MoSi}_{2}-\mathrm{Al}_{2} \mathrm{O}_{3}$ composite range from 0.444 to 0.557 with increasing total number of lines. However, its D index is considered as 0.557 based on the results obtained with 40 lines as presented in Table 11. Since the standard deviation $(4.423 \mu \mathrm{m})$ is relatively high compared to its arithmetic mean (7.935 $\mu \mathrm{m})$ due to high variations in the free-path spacing values, the $\mathrm{MoSi}_{2}-\mathrm{Al}_{2} \mathrm{O}_{3}$ composite exhibits a low level of homogeneity. These results are directly related with particle agglomeration and also poor distribution of $\mathrm{MoSi}_{2}$ grains within $\mathrm{Al}_{2} \mathrm{O}_{3}$ matrix. Therefore, it can be clearly seen that D index values are not stable until 28 lines are analyzed (Figure 76).

Lastly, the quadrat method was applied to the same binary images of the SEM microstructures of the metal silicide-refractory oxide composites for comparison of the $\mathrm{D}$ index values with the Skewness index $(\beta)$ values, since it is known as the most commonly used and simple method in literature for quantification of the particle distribution. In order to calculate $\beta$ index values, the binary images were divided into a number of square quadrats, and then, number of particles in each quadrat were determined by using ImageJ 
Table 12. Review of the Skewness index $(\beta)$ values as a function of the number of quadrats, and their comparison with the $\mathrm{D}$ index values for the metal silicide-refractory oxide composites.

\begin{tabular}{|c|c|c|c|c|}
\hline \multirow{2}{*}{ Composites } & \multicolumn{3}{|c|}{$\beta$ index } & \multirow{2}{*}{ D index } \\
\cline { 2 - 4 } & 4-quadrats & 16-quadrats & 64-quadrats & \\
\hline$(60-40)$ vol\% $\mathrm{WSi}_{2}-\mathrm{ZrO}_{2}$ & -0.772 & 0.211 & 0.168 & 0.142 \\
\hline$(60-40)$ vol\% $\mathrm{WSi}_{2}-\mathrm{Y}_{2} \mathrm{O}_{3}$ & -0.779 & 0.318 & 0.518 & 0.343 \\
\hline$(60-40)$ vol\% $\mathrm{MoSi}_{2}-\mathrm{Al}_{2} \mathrm{O}_{3}$ & 1.954 & 0.828 & 0.839 & 0.557 \\
\hline
\end{tabular}

software $[12,3,22]$. The $\beta$ index values were calculated by using three different cell systems: (i) 4-quadrats, (ii) 16-quadrats, and (iii) 64-quadrats, since the main limitation of the quadrat method is known as the selection of the number of quadrats. Table 12 presents the review of the calculated $\beta$ index values as a function of the number of quadrats, and also $D$ index values for a better comparison of different index values. It was found that the $\beta$ index values changed depending on the number of quadrats selected, ant it even became negative in the 4-quadrats system. The $\beta$ index values obtained for three different composites ranged between 0.168 and 0.839 in the 16- and 64-quadrats system. However, the $\beta$ index obtained for the $\mathrm{WSi}_{2}-\mathrm{Y}_{2} \mathrm{O}_{3}$ composite increased from 0.318 to 0.518 with increasing number of quadrats, which indicates that it is not clear which data is more accurate, and thus the selection of the number of quadrats is very difficult. In comparison, it is clear that the $\mathrm{D}$ index and the Skewness index $(\beta)$ both increases from $\mathrm{WSi}_{2}-\mathrm{ZrO}_{2}$ to $\mathrm{MoSi}_{2}-\mathrm{Al}_{2} \mathrm{O}_{3}$ composite, but at different intervals. Therefore, both index values can be used to understand which composite sample is more homogeneous than others. However, the D index provides a relatively stable description of the degree of distribution and also level of particle agglomeration for an individual composite based on the proximity of the $\mathrm{D}$ index to zero and/or one, since it is measured by using the ratio of standard deviation to the arithmetic mean. Instead, the $\beta$ index utilizes the difference between the number of particles in each cell and mean number of particles per cell, and thus, quite a large 
distribution of $\beta$ index values (38.9, 52.7 etc.) can be obtained depending on the number of quadrats and representative microstructures [12]. Therefore, it is important to note that the $\beta$ index can be generally used for comparison.

As a review, it was presented that the $\mathrm{D}$ index values measured for metal siliciderefractory oxide composite microstructures increase from 0.142 to 0.557 depending on the free-path spacing, coefficient of variation, and degree of distribution. It was found that the (60-40) vol\% $\mathrm{WSi}_{2}-\mathrm{ZrO}_{2}$ composite displayed a high homogeneity, while the (60-40) vol\% WSi2 $-\mathrm{Y}_{2} \mathrm{O}_{3}$ and (60-40) vol\% $\mathrm{MoSi}_{2}-\mathrm{Al}_{2} \mathrm{O}_{3}$ composites exhibited moderate and low level of homogeneity, respectively. It was demonstrated that the measured D index values and related degrees of distribution are quite reasonable based on the visual observation of the microstructures and their converted binary images. Furthermore, it was shown that accurate results for the composite microstructures having high or moderate level of homogeneity can be obtained by analyzing several lines $(\leq 10)$, while there is a need to analyze more lines ( $\geq 28)$ for microstructures presenting low or very low level of homogeneity. These results clearly indicate that the proposed homogeneity analysis method works very accurately on different kinds of binary composite microstructures by considering the coefficient of variation and related $\mathrm{D}$ index value as a measure of the degree of distribution.

\subsection{Conclusions}

An image analysis method based on measuring free-path spacing was presented for the quantification of the degree of distribution or homogeneity in composite materials. It was presented that the proposed method is a useful tool for quantifying the degree of distribution with high accuracy by considering the coefficient of variation and related distribution (D) index as measures of the distribution, and also by eliminating the problematic quadrat effect. Since a high value of $\mathrm{D}$ index indicates a poor distribution, the homogeneity levels for composites are classified from perfect (maximum) to very low level based on increasing D index values. However, it was found that analysis of more lines may be needed in the case of a high level of agglomeration and low levels of homogeneity in 
order to achieve more accurate data by covering all regions within a binary composite microstructure. In the case that homogeneously distributed, similar-sized agglomerates or clusters exist, then the proposed method may provide incorrect D index values due to lack of the free-path spacing values to be measured, which limits its use only for these specific kinds of composite microstructures. But in general, it was clearly shown that the proposed method can be efficiently applied to different types of binary composite microstructures for characterizing the degree of distribution. The presentation of this index will help in the correlation of microstructures and properties, and thus, assist in presenting a direction for controlling processing parameters for improved homogeneity and the associated physical properties of the composites. Continued studies are needed for improving its accuracy and practical use, and also transferring it to a computing environment for faster quantitative image analysis on more complex composite microstructures. Further advancement in this area can be quickly achieved through the collaboration of the materials science community with maturing computational areas such as mathematical morphology, computer/machine vision, and biometrics.

\section{References}

[1] A. Yazdanbakhsh, Z. Grasley, B. Tyson, R.K.A. Al-Rub, Dispersion quantification of inclusions in composites, Composites: Part A 42, 75-83 (2011).

[2] D.M. Kalyon, E. Birinci, R. Yazici, B. Karuv, S. Walsh, Electrical properties of composites as affected by the degree of mixedness of the conductive filler in the polymer matrix, Polymer Engineering and Science 42, 1609-1617 (2002).

[3] S. Tzamtzis, N.S. Barekar, N.H. Babu, J. Patel, B.K. Dhindaw, Z. Fan, Processing of advanced $\mathrm{Al} / \mathrm{SiC}$ particulate metal matrix composites under intensive shearing - A novel Rheo-process, Composites: Part A 40, 144-151 (2009).

[4] Z.P. Luo, J.H. Koo, Quantitative study of the dispersion degree in carbon nanofiber/polymer and carbon nanotube/polymer nanocomposites, Materials Letters 62, 3493-3496 (2008). 
[5] B.M. Tyson, R.K.A. Al-Rub, A. Yazdanbakhsh, Z. Grasley, A quantitative method for analyzing the dispersion and agglomeration of nano-particles in composite materials, Composites: Part B 42, 1395-1403 (2011).

[6] M.D. Haslam, B. Raeymaekers, A composite index to quantify dispersion of carbon nanotubes in polymer-based composite materials, Composites: Part B 55, 16-21 (2013).

[7] V.V.B. Prasad, B.V.R. Bhat, P. Ramakrishnan, Y.R. Mahajan, Clustering probability maps for private metal matrix composites, Scripta Materialia 43, 835-840 (2000).

[8] A. Slipenyuk, V. Kuprin, Y. Milman, J.E. Spowart, D.B. Miracle, The effect of matrix to reinforcement particle size ratio (PSR) on the microstructure and mechanical properties of a P/M processed AlCuMn/SiCp MMC, Materials Science and Engineering A 381, 165170 (2004).

[9] G. Ondracek, R. Renz, The quantitative evaluation of homogeneity (phase distribution) in multi-phased materials (composites), Praktische Metallographie 26, 368-374 (1989).

[10] I. Sabirov, O. Kolednik, R.Z. Valiev, R. Pippan, Equal channel angular pressing of metal matrix composites: effect of particle distribution and fracture toughness, Acta Materialia 53, 4919-4930 (2005).

[11] M. Jahedi, M.H. Paydar, M. Knezevic, Enhanced microstructural homogeneity in metal-matrix composites developed under high-pressure-double-torsion, Materials Characterization 104, 92-100 (2015).

[12] D. Kim, J.S. Lee, C.M.F. Barry, J.L. Mead, Microscopic measurement of the degree of mixing for nanoparticles in polymer nanocomposites by TEM images, Microscopy Research and Technique 70, 539-546 (2007).

[13] P.J. Clark, F.C. Evans, Distance to nearest neighbor as a measure of spatial relationships in populations, Ecology 35, 445-453 (1954).

[14] F.J. Carrion, A. Arribas, M.D. Bermudez, A. Guillamon, Physical and tribological properties of a new polycarbonate-organoclay nanocomposite. European Polymer Journal 44, 968-977 (2008).

[15] P.A. Karnezis, G. Durrant, B. Cantor, Characterization of reinforcement distribution in cast Al-alloy/SiCp composites, Materials Characterization 40, 97-109 (1998). 
[16] N. Barekar, S. Tzamtzis, B.K. Dhindaw, J. Patel, N.H. Babu, Z. Fan, Processing of aluminum-graphite particulate metal matrix composites by advanced shear technology, Journal of Materials Engineering and Performance 18, 1230-1240 (2009).

[17] G. Sundberg, P. Paul, C. Sung, T. Vasilos, Fabrication of CuSiC metal matrix composites, Journal of Materials Science 41, 485-504 (2006).

[18] S. Pfeifer, P.R. Bandaru, A methodology for quantitatively characterizing the dispersion of nanostructures in polymers and composites, Materials Research Letters 2, 166-175 (2014).

[19] A. Cetin, A. Kalkanli, Multi-scale characterization of particle clustering in discontinuously reinforced composites, Materials Characterization 60, 568-572 (2009).

[20] Q. Zhou, L. Zeng, M. DeCicco, X. Li, S. Zhou, A comparative study on clustering indices for distribution uniformity of nanoparticles in metal matrix nanocomposites, CIRP Journal of Manufacturing Science and Technology 5, 348-356 (2012).

[21] T. Konegger, Image-analytical evaluation of the spatial distribution of particulate fillers in ceramic composites prepared via the polymer-derived ceramics route, Materials Characterization 86, 9-20 (2013).

[22] C.A. Schneider, W.S. Rasband, K.W. Eliceiri, NIH image to ImageJ: 25 years of image analysis, Nature Methods 9, 671-675 (2012). 


THERM OELECTRIC PROPERTIES OF EMBEDDED

\section{CERAM IC COMPOSITE THERMOCOUPLES}

\subsection{Introduction}

Thermocouples are extensively used to measure the temperature of kilns, gas turbines, diesel engines and many other industrial processes and scientific applications due to their ability to cover a wide range of temperatures and their relative low cost [1]. However, the state of the art high temperature thermocouples based on noble metals are not stable for the applications demanding multiple atmospheres, as well as, extreme harsh environments for long duration [2]. Recently, thick- and thin-film thermocouples are preferred over conventional thermocouples due to their advantages of excellent spatial resolution, low cost, and capability of direct deposition on any surface without adhesives and surface preparation [3]. Budhani et al. [4] reviewed the problems and prospects of noble metal thin-film thermocouples for the application of blades and vanes of a hightemperature gas turbine jet engines. One of the issues with the most commonly used platinum-rhodium $(\mathrm{Pt} / / \mathrm{Rh})$ alloy thin-film thermocouples is their poor oxidation resistance above $800^{\circ} \mathrm{C}$ [4]. Ceramic-based oxides, carbides and silicides are suggested as alternative materials for thermocouples used in high-temperature and harsh-environment applications due to their unique features of oxidation resistance, corrosion resistance, high melting points and relative thermodynamic stability on both oxidizing and reducing environments [5]. Chen et al. [6] developed thin film Pt- $\operatorname{In}_{2} \mathrm{O}_{3}$ and $\mathrm{In}_{2} \mathrm{O}_{3}-\mathrm{In}_{2} \mathrm{O}_{3}: \mathrm{SnO}_{2}$ thermocouples for monitoring the surface temperature of components used in hot sections of gas turbine engines. The $\mathrm{Pt} / / \mathrm{In}_{2} \mathrm{O}_{3}$ thermocouple showed an average Seebeck coefficient of $224 \mu \mathrm{V} /{ }^{\circ} \mathrm{C}$ and thermoelectric voltage of $238 \mathrm{mV}$ at $1273^{\circ} \mathrm{C}$, whereas $\mathrm{In}_{2} \mathrm{O}_{3} / / \mathrm{In}_{2} \mathrm{O}_{3}: \mathrm{SnO}_{2}$ [95:05] wt\% thermocouple displayed an average Seebeck coefficient of $162 \mu \mathrm{V} /{ }^{\circ} \mathrm{C}$ and thermoelectric voltage of $179 \mathrm{mV}$ at $1273^{\circ} \mathrm{C}$ in air. These thermocouples exhibited higher stability and reproducibility compared to conventional $\mathrm{Pt} / \mathrm{Rh}$ thermocouples from room temperature to $1300^{\circ} \mathrm{C}$ in air. However, the authors did not study the performance of these thermocouples 
at lower partial pressures of oxygen $\left(p \mathrm{O}_{2}\right)$ where $\mathrm{In}_{2} \mathrm{O}_{3}$ and $\mathrm{SnO}_{2}$ typically reduce. Wrbanek et al. [7] demonstrated TiC-and TaC-based thermocouples at very low pressure, but their performance degraded above $1000^{\circ} \mathrm{C}$. They also reported the performance of the $\mathrm{CrSi} 2 / / \mathrm{Pt}$ and $\mathrm{TaC} / / \mathrm{Pt}$ thermocouples in air up to $600^{\circ}$ and $400^{\circ} \mathrm{C}$, respectively. However, thermoelectric data is found to be very limited on non-metallic thin-film and thick-film thermocouples above $1000^{\circ} \mathrm{C}[8]$.

Transition metal silicides $\left(\mathrm{MoSi}_{2}, \mathrm{WSi}_{2}\right.$ etc.) are known for their excellent hightemperature oxidation resistance due to the formation of a passive oxide layer on their surface [9]. They may also form solid solutions with other oxides and exhibit stability on both high and low $\mathrm{pO}_{2}$. Metal silicides such as $\mathrm{MoSi}_{2}$ and $\mathrm{WSi}_{2}$, and their composites, are widely used in heating applications including high-performance gas igniters and diesel glow plugs. The $\mathrm{MoSi}_{2}-\mathrm{Al}_{2} \mathrm{O}_{3}$ composite-based igniter is known for its capability of heating to $1450^{\circ} \mathrm{C}$ in less than ten seconds in both oxidizing and reducing atmospheres [9]. Thin-films of $\mathrm{MoSi}_{2}$ also show excellent corrosion and erosion resistance at temperatures below $1500^{\circ} \mathrm{C}$ due to formation of the $\mathrm{Mo}_{5} \mathrm{Si}_{3}$ and $\mathrm{Mo}_{3} \mathrm{Si}$ passivation layers $[10,11]$. In the present work, $\mathrm{MoSi}_{2}-\mathrm{Al}_{2} \mathrm{O}_{3} / / \mathrm{WSi}_{2}-\mathrm{Al}_{2} \mathrm{O}_{3}, \quad \mathrm{MoSi}_{2}-\mathrm{Al}_{2} \mathrm{O}_{3} / / \mathrm{Pt}, \quad \mathrm{WSi}_{2}-\mathrm{Al}_{2} \mathrm{O}_{3} / / \mathrm{Pt}$ and $\mathrm{MoSi}_{2} / / \mathrm{WSi}_{2}$ thick-film ceramic composite thermocouples were fabricated by screen printing and lamination techniques using particulate mixtures of $\mathrm{MoSi}_{2}-\mathrm{Al}_{2} \mathrm{O}_{3}$ and $\mathrm{WSi}_{2}-$ $\mathrm{Al}_{2} \mathrm{O}_{3}$, and $\mathrm{Pt}$. The $\mathrm{Al}_{2} \mathrm{O}_{3}$ was added to the metal silicides in order to limit the grain growth/sintering mechanisms and oxidation reactions potentially during the extended use at the temperatures above $500^{\circ} \mathrm{C}$. A set of thermocouples were fabricated by screen printing the silicide-oxide composite mixtures and platinum on alumina substrates, and by incorporating that design within the alumina microstructure via tape lamination processing. The phase development, microstructure and high-temperature thermoelectric performance of the sintered thermocouples were investigated. After optimization of the silicide-oxide composite composition, $22.9 \mathrm{~cm}$ long ceramic composite thermocouples with $400 \mu \mathrm{m}$ thickness were fabricated, and the thermoelectric performance was subsequently evaluated up to $1350^{\circ} \mathrm{C}$ in $\operatorname{argon}$. 


\subsection{Materials and Method}

Commercial $\mathrm{MoSi}_{2}(99.5 \%)$ and $\mathrm{WSi}_{2}(99.5 \%)$ powders (Alfa Aesar, Tewksbury, MA), and $\mathrm{Al}_{2} \mathrm{O}_{3}$ powder $\left(99.8 \%, 8.6 \mathrm{~m}^{2} / \mathrm{g} \mathrm{SSA}\right.$; Almatis, Leetsdale, PA) were used as starting materials for preparation of the particulate composite mixtures in this study. The initial X-ray diffraction (XRD, X'Pert Pro Panalytical, Westborough, MA) results of the starting powders (not shown) showed that the starting $\mathrm{MoSi}_{2}$ powder consists of $\mathrm{MoSi}_{2}$ (tetragonal, \#98-064-4400) Mo5Si3 (tetragonal, \#98-064-4413) and Mo (cubic, \#01-0895023) phases. Similar to the $\mathrm{MoSi}_{2}$ starting powder, it was also found that $\mathrm{WSi}_{2}$ (tetragonal, \#98-065-2553), $\mathrm{W}_{5} \mathrm{Si}_{3}$ (tetragonal, \#98-007-3331) and $\mathrm{W}$ (cubic) phases exist within the $\mathrm{WSi}_{2}$ starting powder. Furthermore, the XRD result of the alumina powder (not shown) revealed that it had the corundum structure with the rhombohedral symmetry (\#01-0782427).

\subsubsection{Formulation of ink and screen printing on alumina substrates}

The thick-film thermocouple elements were deposited on alumina substrates by a screen printing technique. The details of the compositions of thermocouple elements are presented on the Table 13. The $\mathrm{MoSi}_{2}-\mathrm{Al}_{2} \mathrm{O}_{3}$ and $\mathrm{WSi}_{2}-\mathrm{Al}_{2} \mathrm{O}_{3}$ composite powders with volume percentages of $\mathrm{MoSi}_{2}$ and $\mathrm{WSi}_{2}$ ranging from 50 to 90 vol\% were synthesized by roll-milling. For simplicity, only the volume percentages were used to identify the composite compositions such as [50-50] and [90-10], since all amounts for the composites were determined based on volume percentages. The appropriate amounts of metal silicide $\left(\mathrm{MoSi}_{2}, \mathrm{WSi}_{2}\right)$ powders (Alfa Aesar, Tewksbury, MA) were mixed with fine alumina $\left(\mathrm{Al}_{2} \mathrm{O}_{3}\right)$ powder $\left(99.8 \%\right.$, SSA: $8.6 \mathrm{~m}^{2} / \mathrm{g}$, Alfa Aesar) and ball-milled in ethanol for 24 hours in a high-density polyethylene (HDPE) jar using $5 \mathrm{~mm}$ diameter yttria-stabilized zirconia milling media (Tosoh Corporation, Japan). The well-mixed powders were dried at $80^{\circ} \mathrm{C}$ in a vacuum oven and subsequently screened through a sieve having $44 \mu \mathrm{m}$ size openings (325 mesh). Metal silicide-alumina composite inks required for the screen printing were prepared by mixing as-prepared silicide-oxide composite powders with an organic vehicle 
Table 13. Configurations and compositions of the various metal silicide-oxide//Pt, metal silicide//metal silicide and metal silicide-oxide//metal silicide-oxide thermocouples studied (volume percentages are represented by [ ]).

\begin{tabular}{|c|c|c|}
\hline Thermocouple & Leg 1 & Leg 2 \\
\hline$[50-50] \mathrm{MoSi}_{2}-\mathrm{Al}_{2} \mathrm{O}_{3} / / \mathrm{Pt}$ & {$[50-50] \mathrm{MoSi}_{2}-\mathrm{Al}_{2} \mathrm{O}_{3}$} & $\mathrm{Pt}$ \\
\hline$[60-40] \mathrm{MoSi}_{2}-\mathrm{Al}_{2} \mathrm{O}_{3} / / \mathrm{Pt}$ & {$[60-40] \mathrm{MoSi}_{2}-\mathrm{Al}_{2} \mathrm{O}_{3}$} & $\mathrm{Pt}$ \\
\hline$[90-10] \mathrm{MoSi}_{2}-\mathrm{Al}_{2} \mathrm{O}_{3} / / \mathrm{Pt}$ & {$[90-10] \mathrm{MoSi}_{2}-\mathrm{Al}_{2} \mathrm{O}_{3}$} & $\mathrm{Pt}$ \\
\hline$[50-50] \mathrm{WSi}_{2}-\mathrm{Al}_{2} \mathrm{O}_{3} / / \mathrm{Pt}$ & {$[50-50] \mathrm{WSi}_{2}-\mathrm{Al}_{2} \mathrm{O}_{3}$} & $\mathrm{Pt}$ \\
\hline$[60-40] \mathrm{WSi}_{2}-\mathrm{Al}_{2} \mathrm{O}_{3} / / \mathrm{Pt}$ & {$[60-40] \mathrm{WSi}_{2}-\mathrm{Al}_{2} \mathrm{O}_{3}$} & $\mathrm{Pt}$ \\
\hline$[75-25] \mathrm{WSi}_{2}-\mathrm{Al}_{2} \mathrm{O}_{3} / / \mathrm{Pt}$ & {$[75-25] \mathrm{WSi}_{2}-\mathrm{Al}_{2} \mathrm{O}_{3}$} & $\mathrm{Pt}$ \\
\hline$[90-10] \mathrm{WSi}_{2}-\mathrm{Al}_{2} \mathrm{O}_{3} / / \mathrm{Pt}$ & {$[90-10] \mathrm{WSi}_{2}-\mathrm{Al}_{2} \mathrm{O}_{3}$} & $\mathrm{Pt}$ \\
\hline$[50-50] \mathrm{MoSi}_{2}-\mathrm{Al}_{2} \mathrm{O}_{3} / /[50-50] \mathrm{WSi}_{2}-\mathrm{Al}_{2} \mathrm{O}_{3}$ & [50-50] $\mathrm{MoSi}_{2}-\mathrm{Al}_{2} \mathrm{O}_{3}$ & {$[50-50] \mathrm{WSi}_{2}-\mathrm{Al}_{2} \mathrm{O}_{3}$} \\
\hline$[60-40] \mathrm{MoSi}_{2}-\mathrm{Al}_{2} \mathrm{O}_{3} / /[60-40] \mathrm{WSi}_{2}-\mathrm{Al}_{2} \mathrm{O}_{3}$ & {$[60-40] \mathrm{MoSi}_{2}-\mathrm{Al}_{2} \mathrm{O}_{3}$} & {$[60-40] \mathrm{WSi}_{2}-\mathrm{Al}_{2} \mathrm{O}_{3}$} \\
\hline$[75-25] \mathrm{MoSi}_{2}-\mathrm{Al}_{2} \mathrm{O}_{3} / /[75-25] \mathrm{WSi}_{2}-\mathrm{Al}_{2} \mathrm{O}_{3}$ & {$[75-25] \mathrm{MoSi}_{2}-\mathrm{Al}_{2} \mathrm{O}_{3}$} & {$[75-25] \mathrm{WSi}_{2}-\mathrm{Al}_{2} \mathrm{O}_{3}$} \\
\hline$[90-10] \mathrm{MoSi}_{2}-\mathrm{Al}_{2} \mathrm{O}_{3} / /[90-10] \mathrm{WSi}_{2}-\mathrm{Al}_{2} \mathrm{O}_{3}$ & {$[90-10] \mathrm{MoSi}_{2}-\mathrm{Al}_{2} \mathrm{O}_{3}$} & {$[90-10] \mathrm{WSi}_{2}-\mathrm{Al}_{2} \mathrm{O}_{3}$} \\
\hline $\mathrm{MoSi}_{2} / / \mathrm{WSi}_{2}$ & $\mathrm{MoSi}_{2}$ & $\mathrm{WSi}_{2}$ \\
\hline
\end{tabular}

(63-2 vehicle, Johnson Matthey, USA) followed by ultra-sonication. The ratio of composite powders to organic vehicle was fixed as 70:30 by wt\% in all ink formulations.

The alumina substrates required for the thermocouples were fabricated by a tape casting process. The alumina tapes were prepared by using deflocculated alumina powders (SG20, SSA: $2.6 \mathrm{~m}^{2} / \mathrm{g}$ ) mixed with the polyvinyl butyral binder, poly-alkaline glycol and benzyl butyl phthalate plasticizers/modifiers (Tape Casting Warehouse, Morrisville, PA). The slurries were casted into thin sheets with thickness of $\sim 200 \mu \mathrm{m}$. The casted tapes were 
cut into $175 \mathrm{~mm} \times 175 \mathrm{~mm}$ thin sheets, vacuum packed and laminated at $90^{\circ} \mathrm{C}$ under 10 $\mathrm{MPa}$ pressure to form $\sim 800 \mu \mathrm{m}$ thick tape laminates. The as-prepared alumina tapes were laser cut into $30 \mathrm{~mm}$ × $15 \mathrm{~mm}$ substrates. The thermocouples were screen printed on alumina substrates with dimensions of $30 \mathrm{~mm}$ x $15 \mathrm{~mm}$ x $0.8 \mathrm{~mm}$ using an Aremco's Accu-Coat ${ }^{\mathrm{TM}}$ screen printer using a nylon screen (250 mesh). Initially, the left leg of the thermocouple was printed with the $\mathrm{MoSi}_{2}-\mathrm{Al}_{2} \mathrm{O}_{3}$ composite ink followed by a heat treatment for $5 \mathrm{~min}$ at $50^{\circ} \mathrm{C}$ in an oven to dry the ink. The screen printing and drying processes were repeated four times to achieve a $400 \mu \mathrm{m}$ thick thermocouple leg. After screen printing and drying of the left leg of the thermocouple, the right leg was similarly printed with the $\mathrm{WSi}_{2}-\mathrm{Al}_{2} \mathrm{O}_{3}$ composite ink or Pt ink. The screen printing of two legs of the thermocouples was completed separately only due to the ease of processing the multiple repeat sensor samples. All these thermocouples were lastly sintered at $1500^{\circ} \mathrm{C}$ for $2 \mathrm{~h}$ under argon atmosphere. Figure 77 shows an optical photograph of a $\mathrm{MoSi}_{2}-\mathrm{Al}_{2} \mathrm{O}_{3} / / \mathrm{WSi}_{2}-\mathrm{Al}_{2} \mathrm{O}_{3}$ thermocouple screen printed on an alumina substrate and sintered at $1500^{\circ} \mathrm{C}$ for $2 \mathrm{~h}$ in argon. The // symbol represented in the paper denotes a couple being formed with the compositions preceding and following the symbol. Figure 77 also displays the SEM micrographs of the post-annealed ceramic composite thermocouple legs made by [75-25] $\mathrm{MoSi}_{2}-\mathrm{Al}_{2} \mathrm{O}_{3}$ and [75-25] $\mathrm{WSi}_{2}-\mathrm{Al}_{2} \mathrm{O}_{3}$. After optimization of the metal silicide-oxide composition, both 5.1 and $22.9 \mathrm{~cm}$ long thermocouples were fabricated and subsequently embedded into the as-prepared alumina preforms.

\subsubsection{Structural and thermoelectric characterization of thermocouples}

An X'Pert Pro Panalytical X-ray diffractometer (Westborough, MA) with $\mathrm{CuK}_{\alpha}$ radiation source was used to investigate the phase development of the sintered thick-film thermocouples. Data was collected from $16^{\circ}$ to $110^{\circ}$ angles $(2 \theta)$ with a step size of 0.02 increments at a rate of $1 \% \mathrm{~min}$. An X'Pert High Score software was used to identify the phases, lattice parameters and crystal structure. The microstructures of the sintered thermocouples were examined by a scanning electron microscopy (SEM, JEOL 7600F, Peabody, MA; FE-SEM, Hitachi S-4700F, Tokyo, Japan). In addition to the XRD analyses, 


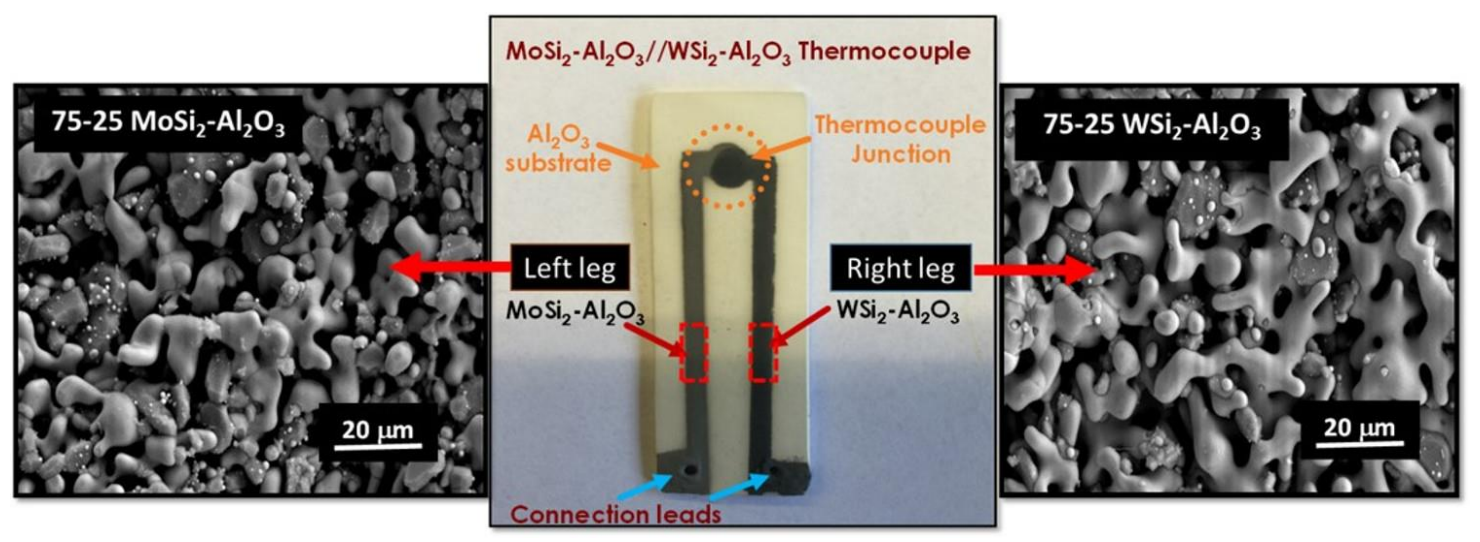

Figure 77. Optical photograph and SEM micrographs of the [75-25] $\mathrm{MoSi}_{2}-\mathrm{Al}_{2} \mathrm{O}_{3} / / \mathrm{WSi}_{2}$ $\mathrm{Al}_{2} \mathrm{O}_{3}$ composite thermocouple screen printed on an alumina substrate and then sintered at $1500^{\circ} \mathrm{C}$ for $2 \mathrm{~h}$.

quantitative phase analysis studies via Rietveld method were performed by using the MAUD software [12] to determine the volume percentages of secondary phases formed after sintering. X-ray photoelectron spectroscopy (XPS) measurements were also carried out using a Physical Electronics, PHI 5000 Versa Probe spectrometer with a monochromatic $\mathrm{AlK}_{\alpha}$ source operated at $300 \mathrm{~W}$ and a base pressure of $5 \times 10^{-8}$ Torr. The XPS analysis was performed to understand the changes in the valence state and binding energy of the constituent elements present in the samples. Furthermore, thermoelectric properties of the ceramic composite thermocouples were measured using an atmospheric controlled high-temperature furnace, where K- and S-type thermocouples were used to monitor the cold and hot junction temperatures, and a National Instruments thermocouple reader was digitally connected to the computer through a LabVIEW software. The electrical contacts to thermocouples were made using platinum $(\mathrm{Pt})$ paste and $\mathrm{Pt}$ wires at the cold junction held at the same temperature back to the digital multimeter.

\subsection{Results and Discussion}

\subsubsection{Phase development in the composite thermocouples}

XPS analyses were carried out to obtain information regarding chemical bonding and chemical state of the elements presented in the silicide-oxide composites. Figure 78a shows the XPS wide range survey spectra of all the $\mathrm{MoSi}_{2}-\mathrm{Al}_{2} \mathrm{O}_{3}$ composites with volume 


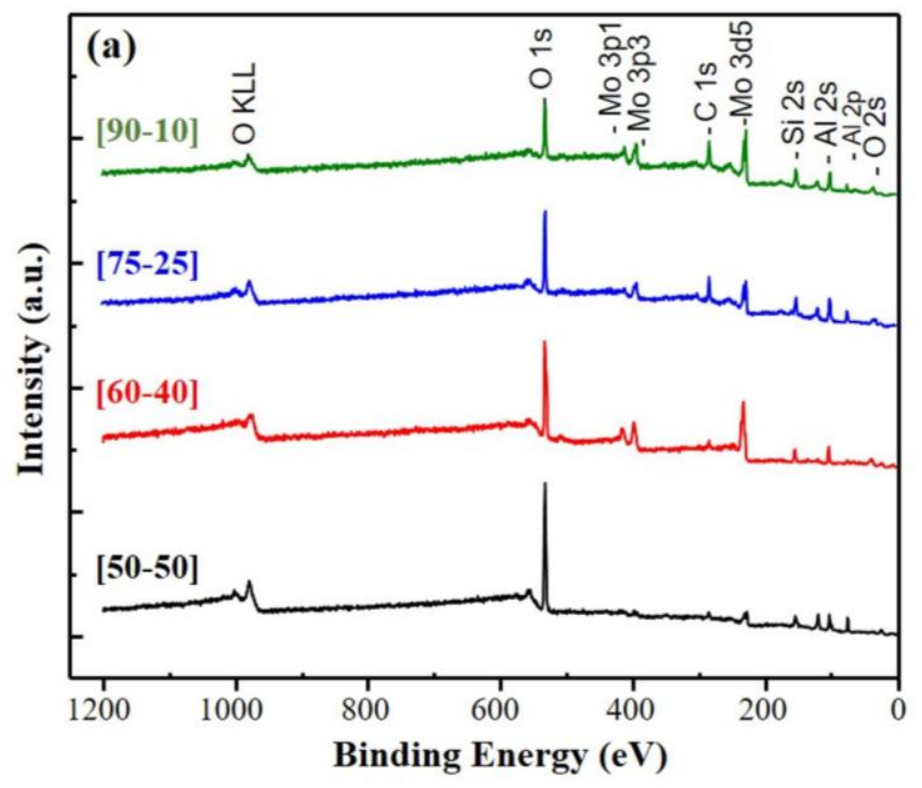

(b)

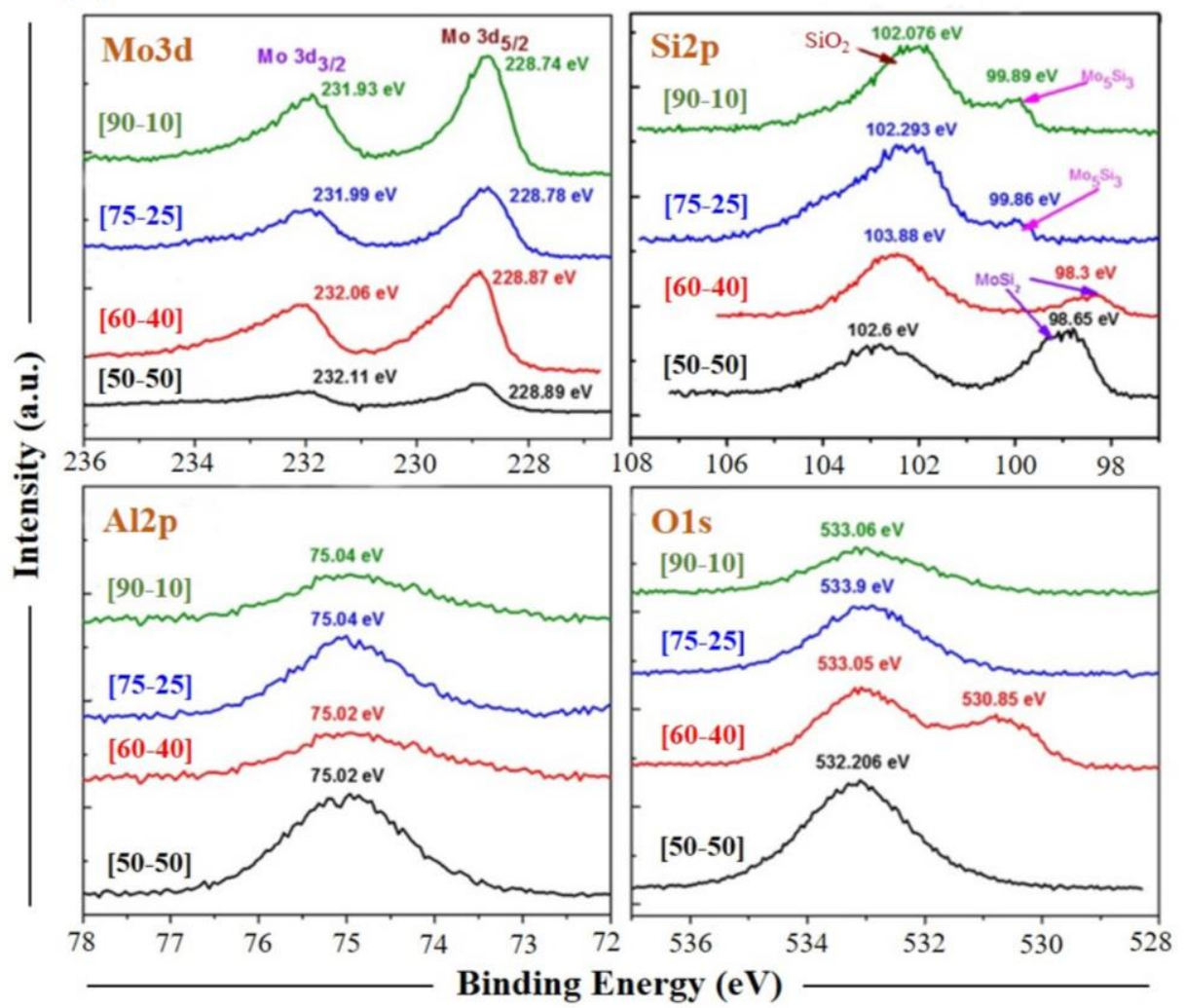

Figure 78. (a) XPS wide range survey spectra and (b) high-resolution XPS spectra (Mo3d, Si2p, Al2p, O1s) of the various $\mathrm{MoSi}_{2}-\mathrm{Al}_{2} \mathrm{O}_{3}$ composites after sintering at $1500^{\circ} \mathrm{C}$ for $2 \mathrm{~h}$. 
percentages of $\mathrm{MoSi}_{2}$ varying from 50 to $90 \mathrm{vol} \%$ that were sintered at $1500^{\circ} \mathrm{C}$ for $2 \mathrm{~h}$. The similar spectra and peaks corresponding to $\mathrm{Mo}, \mathrm{Si}, \mathrm{Al}$, and $\mathrm{O}$ elements can be clearly seen for all the composites. In addition, high-resolution XPS spectra for the Mo3d, Si2p, A12p and $\mathrm{O} 1 \mathrm{~s}$ collected from the $\mathrm{MoSi}_{2}-\mathrm{Al}_{2} \mathrm{O}_{3}$ composite samples are presented in the Figure 78b. The Mo3d spectra consists of two doublet peaks arising from Mo3d $\mathrm{d}_{5 / 2}$ and $\mathrm{Mo}_{3 / 2}$ at the binding energies of 227.9 and $231.1 \mathrm{eV}$, respectively, corresponding to $\mathrm{Mo}^{4}$ [13]. It is clearly evident that both $\mathrm{Mo}_{5 / 2}$ and $\mathrm{Mo}_{5} \mathrm{~d}_{3 / 2}$ peaks shifted towards lower binding energies with increasing $\mathrm{MoSi}_{2}$ content in the composite. The peak observed at $98.7 \mathrm{eV}$, that is characteristic for the $\mathrm{Si} 2 \mathrm{p}$ high-resolution spectra, refers to the $\mathrm{MoSi}_{2}$ phase [14]. Another high-intensity peak observed at $102.6 \mathrm{eV}$ corresponds to $\mathrm{SiO}_{2}$ phase, which indicated that the $\mathrm{MoSi}_{2}$ was oxidized to form the $\mathrm{SiO}_{2}$ and $\mathrm{Mo}_{5} \mathrm{Si}_{3}$ secondary phases based on its thermodynamically feasible oxidation reaction. In addition, the peaks appeared at $99.9 \mathrm{eV}$ in the $\mathrm{Si} 2 \mathrm{p}$ spectra were found to be a supportive data for the formation of $\mathrm{Mo}_{5} \mathrm{Si}_{3}$ phase in significant amounts particularly at the [75-25] and [90-10] $\mathrm{MoSi}_{2}-\mathrm{Al}_{2} \mathrm{O}_{3}$ composites. For the $\mathrm{Al} 2 \mathrm{p}$ spectra, the peaks observed at $75.0 \mathrm{eV}$ presents the existence of $\mathrm{Al}_{2} \mathrm{O}_{3}$ phase in the composites after sintering [15]. It is important to note that several peak shifts observed in the high-resolution XPS spectra may be related to the changes in Fermi energy levels caused by variations in defect concentrations and changes in electron charge density [16]. The peaks observed at $532.2 \mathrm{eV}$ in the $\mathrm{O} 1 \mathrm{~s}$ spectra indicate that $\mathrm{SiO}_{2}$ may be in its amorphous state. In addition to the $\mathrm{MoSi}_{2}-\mathrm{Al}_{2} \mathrm{O}_{3}$ composites, XPS survey spectra of the $\mathrm{WSi}_{2}-\mathrm{Al}_{2} \mathrm{O}_{3}$ composites sintered at $1500^{\circ} \mathrm{C}$ for $2 \mathrm{~h}$ are shown in the Figure $79 \mathrm{a}$. In the XPS spectra, the peaks corresponding to $\mathrm{W}, \mathrm{Al}, \mathrm{Si}$ and $\mathrm{O}$ were detected as expected for all the $\mathrm{WSi}_{2}-\mathrm{Al}_{2} \mathrm{O}_{3}$ composite samples. Also, the high-resolution XPS spectra for the W4f, Si2p, $\mathrm{A} 12 \mathrm{p}$ and $\mathrm{O} 1 \mathrm{~s}$ peaks collected for these composites are presented in the Figure 79b. In the W4f spectra, two doublet peaks at the binding energies of $31.1 \mathrm{eV}\left(\mathrm{W}_{4} \mathrm{f}_{7 / 2}\right)$ and $33.5 \mathrm{eV}$ $\left(\mathrm{W}_{4} \mathrm{f}_{5 / 2}\right)$ and a peak at $29.16 \mathrm{eV}$ imply the presence of the $\mathrm{WSi}_{2}$ phase. However, another single peak appeared at $35.4 \mathrm{eV}$, which represents $\mathrm{WO}_{3}$ phase that might form on the surface in a very small amount due to high-temperature oxidation of the $\mathrm{WSi}_{2}$ phase [17]. It is also found that $\mathrm{Si} 2 \mathrm{p}$ spectrum of the $[50-50] \mathrm{WSi}_{2}-\mathrm{Al}_{2} \mathrm{O}_{3}$ composite displayed two peaks 


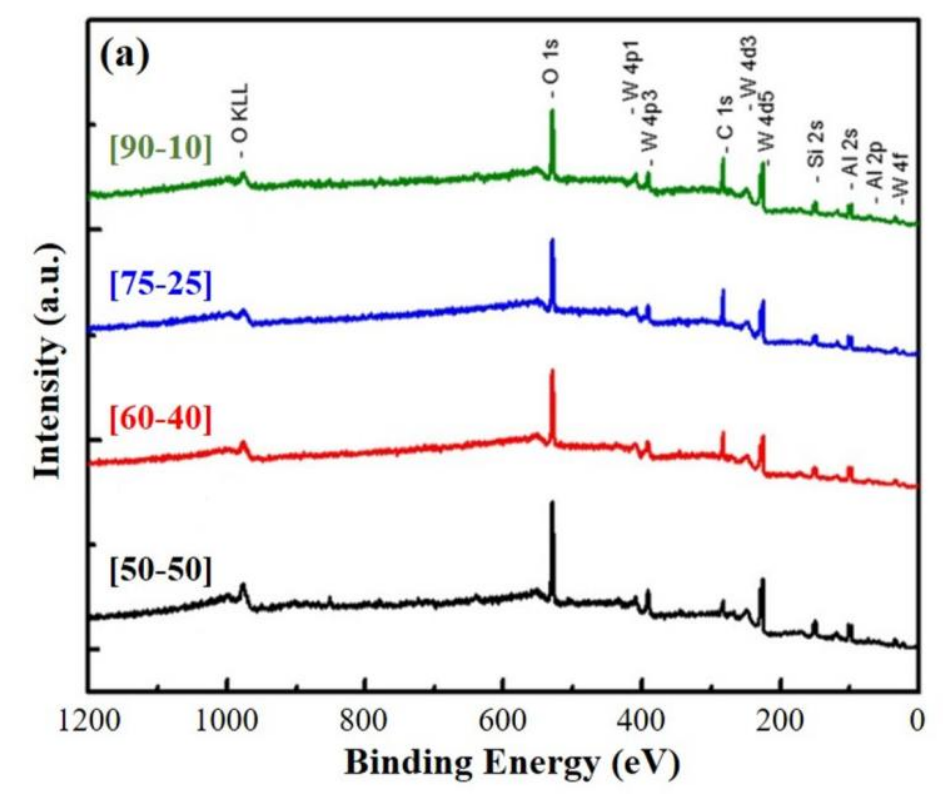

(b)

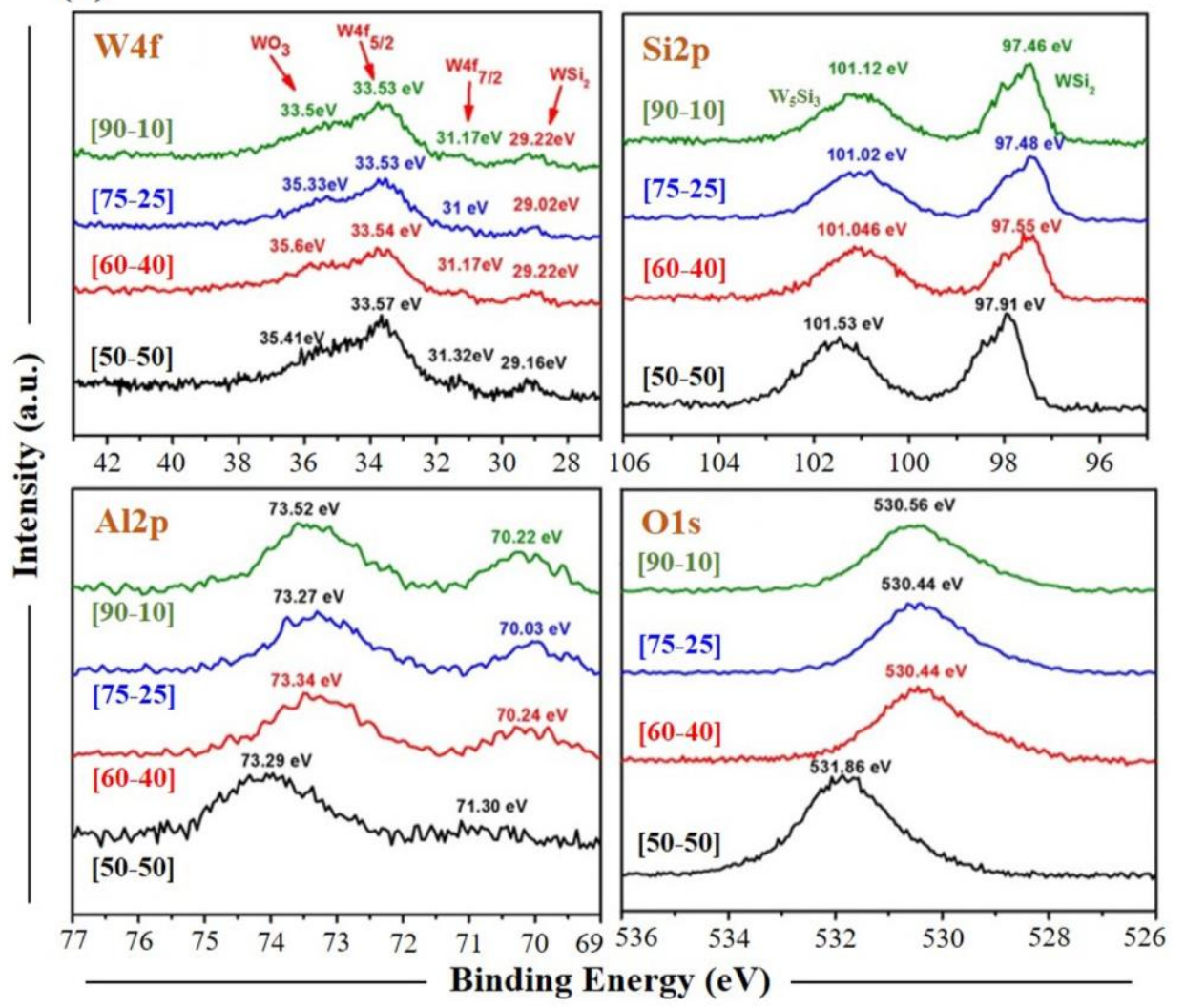

Figure 79. (a) XPS wide range survey spectra and (b) high-resolution XPS spectra (W4f, $\mathrm{Si} 2 \mathrm{p}, \mathrm{Al} 2 \mathrm{p}, \mathrm{O} 1 \mathrm{~s}$ ) of the various $\mathrm{WSi}_{2}-\mathrm{Al}_{2} \mathrm{O}_{3}$ composites after sintering at $1500^{\circ} \mathrm{C}$ for $2 \mathrm{~h}$. 
at 97.9 and $101.5 \mathrm{eV}$, which represent $\mathrm{WSi}_{2}$ and $\mathrm{W}_{5} \mathrm{Si}_{3}$ phases, respectively [18]. The peak shifts to lower binding energy levels were clearly observed with increasing metal silicide content from 50 to $90 \mathrm{vol} \%$. The peak detected at $73.3 \mathrm{eV}$ in the Al2p spectra shows the presence of the $\mathrm{Al}_{2} \mathrm{O}_{3}$ phase. In addition, similar to the $\mathrm{MoSi}_{2}-\mathrm{Al}_{2} \mathrm{O}_{3}$ composites, peaks detected at $530.4 \mathrm{eV}$ in the $\mathrm{O} 1 \mathrm{~s}$ spectra reveal the presence of $\mathrm{SiO}_{2}$ phase and its potential amorphous state [19]. The peak shifts to lower binding energy levels were also clear in $\mathrm{Si} 2 \mathrm{p}, \mathrm{Al} 2 \mathrm{p}$ and $\mathrm{O} 1 \mathrm{~s}$ spectra with increasing $\mathrm{WSi}_{2}$ content from 50 to $90 \mathrm{vol} \%$. As a review of the XPS results, it was demonstrated that $\mathrm{MoSi}_{2}-\mathrm{Al}_{2} \mathrm{O}_{3}$ composites having different volume percentages of metal silicide (50 to $90 \mathrm{vol} \%$ ) consist of $\mathrm{MoSi}_{2}$ and $\mathrm{Al}_{2} \mathrm{O}_{3}$ initial phases with $\mathrm{Mo}_{5} \mathrm{Si}_{3}$ and $\mathrm{SiO}_{2}$ secondary phases formed during sintering. For all the $\mathrm{WSi}_{2}-$ $\mathrm{Al}_{2} \mathrm{O}_{3}$ composites, presence of $\mathrm{WSi}_{2}, \mathrm{~W}_{5} \mathrm{Si}_{3}, \mathrm{Al}_{2} \mathrm{O}_{3}$ and $\mathrm{SiO}_{2}$ phases was similarly determined. However, the XPS results for the $\mathrm{WSi}_{2}-\mathrm{Al}_{2} \mathrm{O}_{3}$ composite samples also revealed that there may be a formation of $\mathrm{WO}_{3}$ phase in a small amount on the sample surface due to the high-temperature oxidation of $\mathrm{WSi}_{2}$. The formation of the 5-3 metal silicides $\left(\mathrm{Mo}_{5} \mathrm{Si}_{3}\right.$, $\left.\mathrm{W}_{5} \mathrm{Si}_{3}\right)$ and $\mathrm{SiO}_{2}$ as secondary phases could be related to the high-temperature oxidation of starting metal silicide phases and metal silicide-oxide interactions at high-temperatures [2022].

The phase analysis studies were additionally performed by XRD to understand the phase development and secondary phase formation in the composite systems during sintering better. Therefore, two representative samples with the lowest and highest metal silicide content, which are [50-50] and [90-10] $\mathrm{MoSi}_{2}-\mathrm{Al}_{2} \mathrm{O}_{3}$ composites, were selected for this study. Figure 80a shows the XRD patterns of these $\mathrm{MoSi}_{2}-\mathrm{Al}_{2} \mathrm{O}_{3}$ composites after sintering at $1500^{\circ} \mathrm{C}$ for $2 \mathrm{~h}$. $\mathrm{MoSi}_{2}, \mathrm{Mo}_{5} \mathrm{Si}_{3}$ and $\mathrm{Al}_{2} \mathrm{O}_{3}$ phases were detected for these composites, since they revealed similar XRD patterns after sintering. The crystal structure of $\mathrm{MoSi}_{2}$ is a body-centered tetragonal with a space group of $\mathrm{I} / \mathrm{mmm}$ and $\mathrm{C} 11_{\mathrm{b}}$ type characterized by ABAB-type stacking along the c-axis, while $\mathrm{Mo}_{5} \mathrm{Si}_{3}$ has a tetragonal crystal structure with a space group of I-42m [14]. However, the silica phase could not be detected by XRD due to its very small amount on the surface and possibly its amorphous 

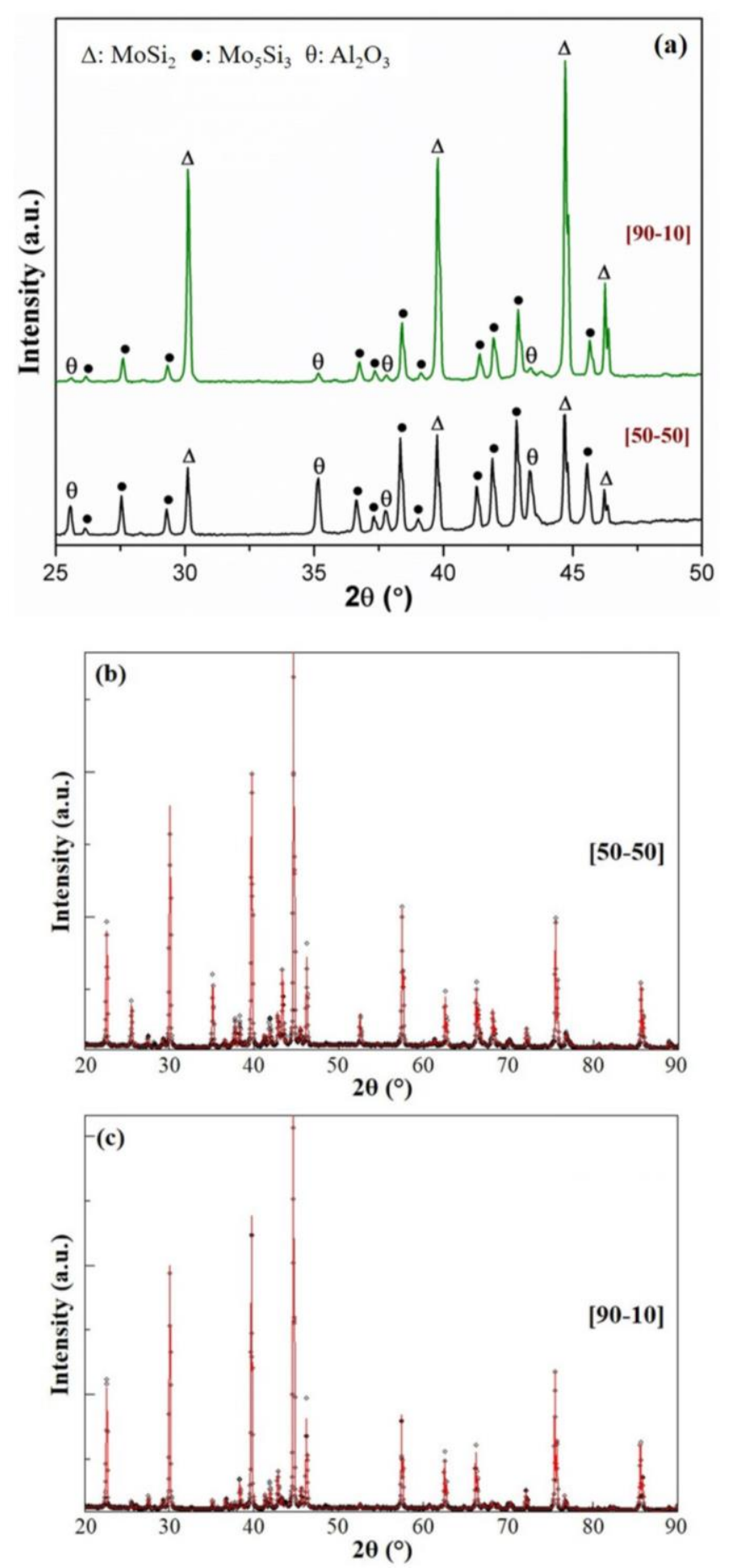

Figure 80. (a) XRD patterns of the [50-50] and [90-10] $\mathrm{MoSi}_{2}-\mathrm{Al}_{2} \mathrm{O}_{3}$ composites after sintering at $1500^{\circ} \mathrm{C}$ for $2 \mathrm{~h}$; (b-c) Rietveld refinement results of the [50-50] and [90-10] $\mathrm{MoSi}_{2}-\mathrm{Al}_{2} \mathrm{O}_{3}$ composites, respectively [solid red lines = fitting curves; black dots = experimental XRD data]. 
state based on the XPS data. The presence of $\mathrm{Mo}_{5} \mathrm{Si}_{3}$ as a secondary phase may not be disadvantageous, since it has a higher melting point, improved creep resistance and relatively low oxidation resistance $[9,23]$. Lin and Speyer also studied surface oxidation mechanisms of $\mathrm{MoSi}_{2}$ in the high-temperature combustion environments, and their studies revealed that material stability could be reestablished after a transient period under oxidizing and reducing environments due to the formation of a stable $\mathrm{Mo}_{5} \mathrm{Si}_{3}$ layer [24]. It is important to point out that alumina addition as an oxidation-resistant refractory oxide could substantially lower the oxygen diffusion into the composite systems. Therefore, it may significantly lower the amount of $\mathrm{Mo}_{5} \mathrm{Si}_{3}$ secondary phase in the composite systems, particularly at [50-50] and [60-40] volume percentages due to a significant amount of alumina phase ( $\geq 40 \mathrm{vol} \%$ ). To determine the volume percentages of $\mathrm{Mo}_{5} \mathrm{Si}_{3}$ secondary phase and the changes in its amount as a function of increasing metal silicide content, quantitative phase analysis studies were additionally performed by utilizing the Rietveld method on the XRD patterns of the [50-50] and [90-10] $\mathrm{MoSi}_{2}-\mathrm{Al}_{2} \mathrm{O}_{3}$ composites. Figure 80(b-c) present the Rietveld refinement results of the [50-50] and [90-10] $\mathrm{MoSi}_{2}-\mathrm{Al}_{2} \mathrm{O}_{3}$ composites, where solid red lines and black dots represent fitting curves and experimental XRD data, respectively. It is important to note that the quality of the Rietveld refinement was sufficient enough, since the goodness of fit (sig) and weighted profile R-factor $\left(\mathrm{R}_{\mathrm{wp}}\right)$ values were 2.7-3.0 and 5.1-5.8, respectively. The amounts of $\mathrm{Mo}_{5} \mathrm{Si}_{3}$ phase for the [50-50] and [90-10] $\mathrm{MoSi}_{2}-\mathrm{Al}_{2} \mathrm{O}_{3}$ composite samples were determined as 4.6 and $20.2 \mathrm{vol} \%$, respectively. This result demonstrated that there was a 15.6 vol\% increase in the volume percentage of $\mathrm{Mo}_{5} \mathrm{Si}_{3}$ secondary phase with increasing metal silicide content in the composite from 50 to 90 vol\%. It was similarly reported in our previous study on the bulk $\mathrm{MoSi}_{2}$ - and $\mathrm{WSi}_{2}$-oxide composites that amount of the $\mathrm{Mo}_{5} \mathrm{Si}_{3}$ and $\mathrm{W}_{5} \mathrm{Si}_{3}$ secondary phases substantially increased as a function of the refractory oxide material (fine/coarse $\mathrm{Al}_{2} \mathrm{O}_{3}$, $\left.\mathrm{ZrO}_{2}\right)$ and the annealing time at $1400^{\circ} \mathrm{C}$ [25]. The XPS and XRD data in the current work shows that the $\mathrm{MoSi}_{2}$ - and $\mathrm{WSi}_{2}$-based thick-film composites also undergo a similar transformation to the 5-3 metal silicide phase as shown for the bulk samples; further work 

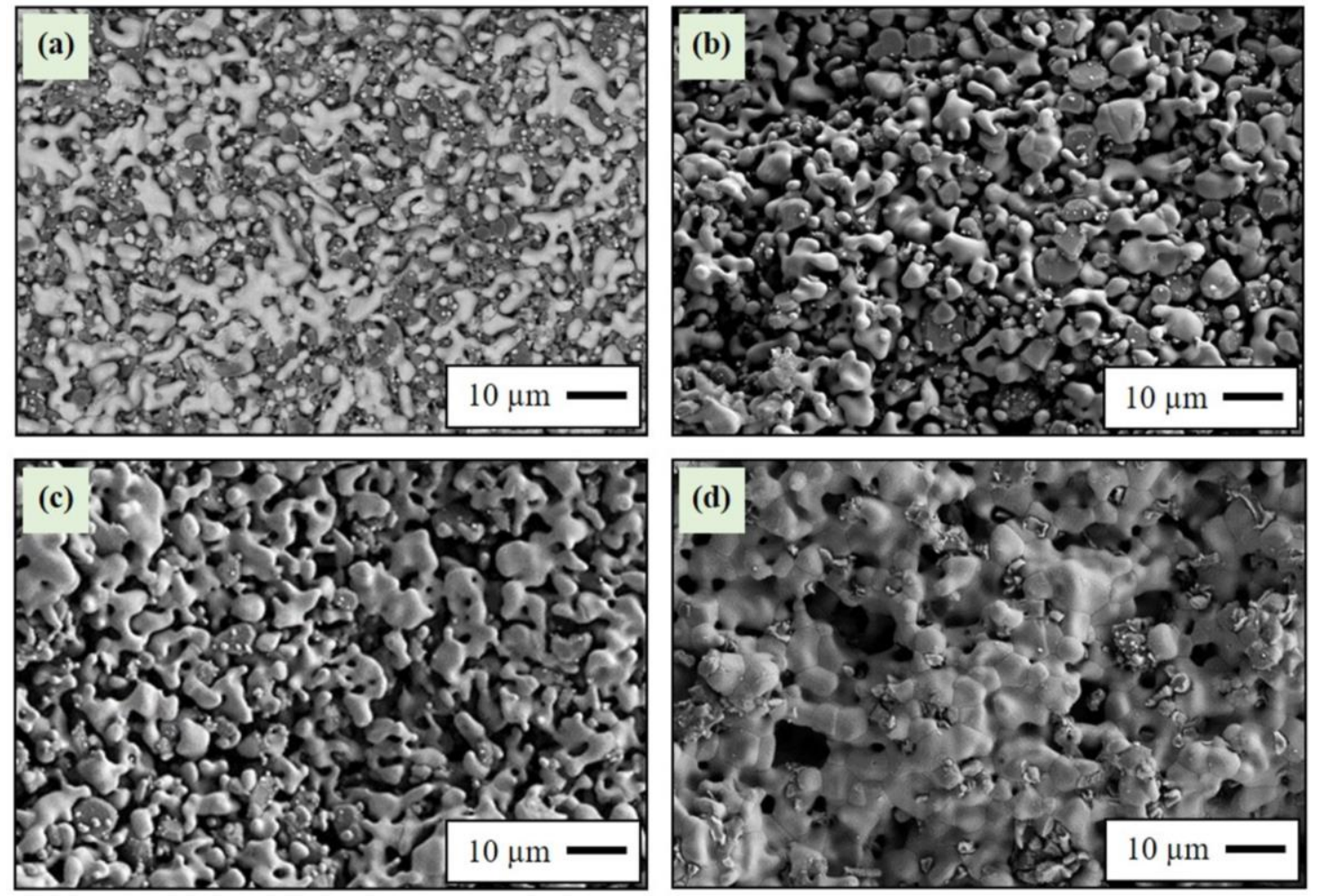

Figure 81. SEM micrographs of the (a) [50-50], (b) [60-40], (c) [75-25] and (d) [90-10] $\mathrm{MoSi}_{2}-\mathrm{Al}_{2} \mathrm{O}_{3}$ composites after sintering at $1500^{\circ} \mathrm{C}$ for $2 \mathrm{~h}$.

is currently being completed to better understand the effect of sample density, oxygen partial pressure, and metal silicide-alumina grain boundaries on the transformation kinetics.

\subsubsection{Microstructures of the composite thermocouples}

Figure 81(a-d) displays the SEM micrographs of the $\mathrm{MoSi}_{2}-\mathrm{Al}_{2} \mathrm{O}_{3}$ composites after sintering at $1500^{\circ} \mathrm{C}$ for $2 \mathrm{~h}$. The bright and dark regions within all microstructures correspond to the $\mathrm{MoSi}_{2}$ and $\mathrm{Al}_{2} \mathrm{O}_{3}$ particles, respectively. It is clear that distribution of $\mathrm{MoSi}_{2}$ and $\mathrm{Al}_{2} \mathrm{O}_{3}$ grains are relatively homogeneous within the composites. These results also demonstrated that the degree of percolation and $\mathrm{MoSi}_{2}$ grain size increased by increasing $\mathrm{MoSi}_{2}$ volume percentage from 50 to $90 \mathrm{vol} \%$. Another feature observed in the microstructures of [60-40] and [75-25] $\mathrm{MoSi}_{2}-\mathrm{Al}_{2} \mathrm{O}_{3}$ composites was agglomeration of the $\mathrm{MoSi}_{2}$ grains in some regions. This may be due to the difference in wetting behavior and 

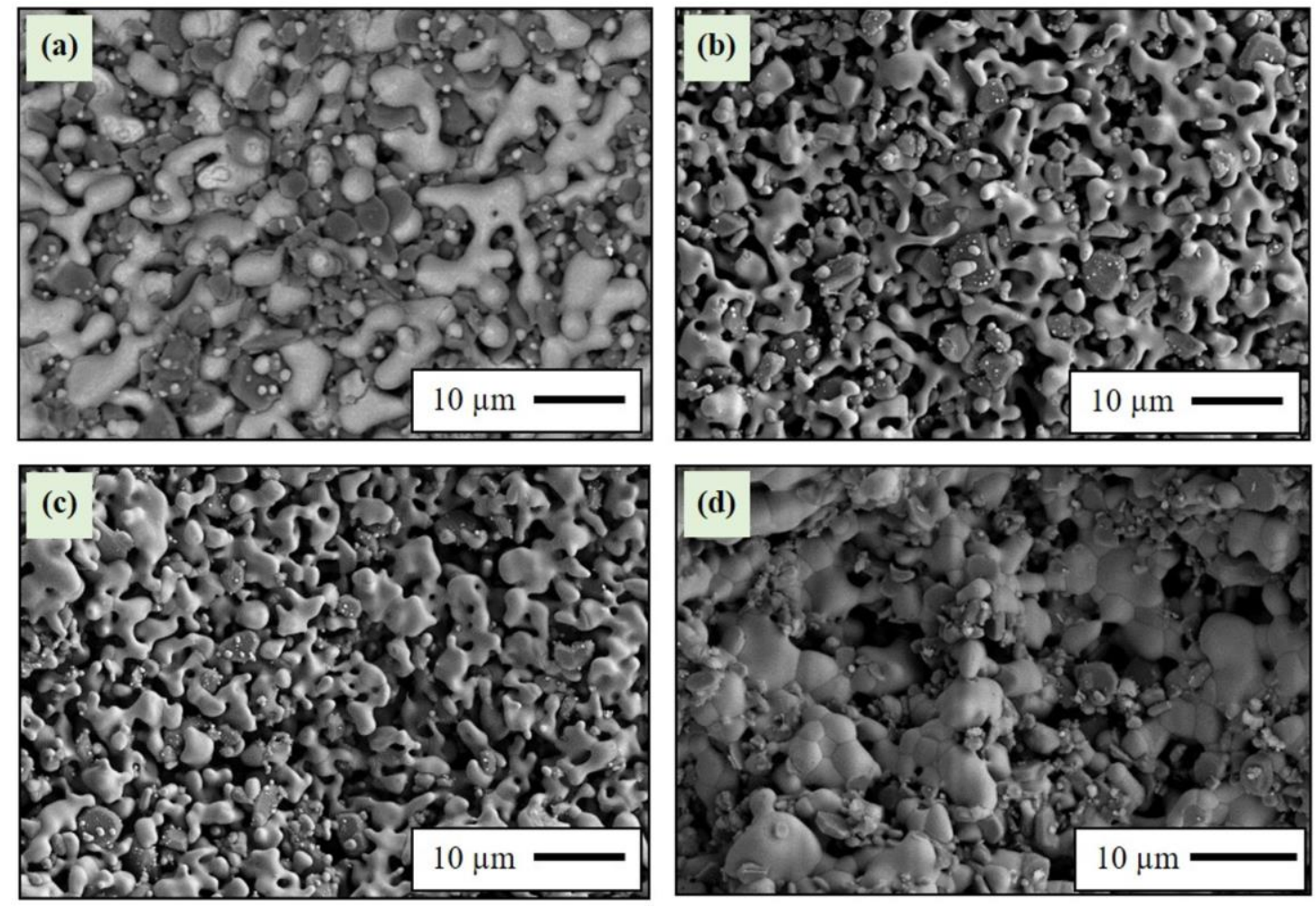

Figure 82. SEM micrographs of the (a) [50-50], (b) [60-40], (c) [75-25] and (d) [90-10] $\mathrm{WSi}_{2}-\mathrm{Al}_{2} \mathrm{O}_{3}$ composites after sintering at $1500^{\circ} \mathrm{C}$ for $2 \mathrm{~h}$.

surface free energies of $\mathrm{Al}_{2} \mathrm{O}_{3}$ and $\mathrm{MoSi}_{2}$ influencing the driving forces for sintering and grain growth. Further kinetic studies are currently being completed to understand the mechanisms of grain growth within the metal silicide-oxide composites. The SEM micrographs of the $\mathrm{WSi}_{2}-\mathrm{Al}_{2} \mathrm{O}_{3}$ composites sintered at $1500^{\circ} \mathrm{C}$ are presented in the Figure 82(a-d). The bright and dark regions within these microstructures refer to the $\mathrm{WSi}_{2}$ and $\mathrm{Al}_{2} \mathrm{O}_{3}$ particles, respectively. The microstructures were found to be highly similar to that of the $\mathrm{MoSi}_{2}-\mathrm{Al}_{2} \mathrm{O}_{3}$ composites based on the homogeneity and grain sizes. The welldeveloped percolation paths of the conductive $\mathrm{WSi}_{2}$ phase can be clearly seen for all $\mathrm{WSi}_{2}$ $\mathrm{Al}_{2} \mathrm{O}_{3}$ composites. However, it is important to note that 5-3 metal silicide ( $\left.\mathrm{Mo}_{5} \mathrm{Si}_{3}, \mathrm{~W}_{5} \mathrm{Si}_{3}\right)$ secondary phases formed during sintering were not observable in the composite microstructures. 
Figure 83 presents optical photographs and SEM micrographs of the [75-25] $\mathrm{MoSi}_{2}-\mathrm{Al}_{2} \mathrm{O}_{3} / / \mathrm{Pt}$ thermocouple screen printed on an alumina substrate and sintered at $1500^{\circ} \mathrm{C}$ for $2 \mathrm{~h}$ in argon. The microstructures of the alumina substrate, left leg ( $\mathrm{MoSi}_{2}-$ $\mathrm{Al}_{2} \mathrm{O}_{3}$ ), right leg $(\mathrm{Pt})$ and thermocouple junction can be seen in detail. The average size of the $\mathrm{MoSi}_{2}$ grains were measured as 3-5 $\mu \mathrm{m}$, and they were found to be well-connected in such a way that the percolation path of $\mathrm{MoSi}_{2}$ grains on the left leg of the thermocouple was continuous without any cracks or voids. However, Pt right leg, as well as, the thermocouple junction revealed a porous structure. Also, as-sintered alumina substrate showed a few large grains within a fine grain matrix. No cracks or voids were observed on the alumina substrate after sintering. In addition, the Pt right leg revealed a very fine grain microstructure having slightly more porosity than the $\mathrm{MoSi}_{2}-\mathrm{Al}_{2} \mathrm{O}_{3}$ composite (left leg). As a review, all thermocouple lines made of $\mathrm{MoSi}_{2}-\mathrm{Al}_{2} \mathrm{O}_{3}$ and $\mathrm{WSi}_{2}-\mathrm{Al}_{2} \mathrm{O}_{3}$ composites in the present study showed a good adhesion on the alumina substrate. No evidence of degradation, blisters or coalesce was observed on the composite and platinum thermocouple lines even after high-temperature sintering in argon. It is well known for fabrication of the ceramic composites that occurrence of interfacial microcracks due to thermal expansion and sintering mismatch between substrate and composite films is an important issue that needs to be addressed $[9,25,26]$. However, there was no evidence of interfacial microcracking in the presented composite microstructures. It must be noted that there is a close match between the coefficients of thermal expansion (CTEs) of metal silicides $\left(\mathrm{MoSi}_{2}, \mathrm{WSi}_{2}\right)$ and alumina. Kobel et al. [27] studied thermal expansion behavior of the $\mathrm{MoSi}_{2}-\mathrm{Al}_{2} \mathrm{O}_{3}$ composites with varying volume percentages of the $\mathrm{MoSi}_{2}$ in a wide temperature range. They reported that CTEs of the pure $\mathrm{Al}_{2} \mathrm{O}_{3}$ and $\mathrm{MoSi}_{2}$ only differ by $4 \%$, and CTE of the [75-25] $\mathrm{MoSi}_{2}-\mathrm{Al}_{2} \mathrm{O}_{3}$ composite matches with that of the pure $\mathrm{Al}_{2} \mathrm{O}_{3}$ from room temperature to $900^{\circ} \mathrm{C}$. Therefore, it can be pointed out that the possibility of interfacial cracking within the $\mathrm{MoSi}_{2}-\mathrm{Al}_{2} \mathrm{O}_{3}$ and $\mathrm{WSi}_{2}-\mathrm{Al}_{2} \mathrm{O}_{3}$ composites is expected to be very low after repeated thermal cycling. Lu et al. [28] also investigated the $\mathrm{MoSi}_{2}$-based composites reinforced by alumina fibers and platelets, and they similarly reported that both types of reinforcement did not create any interfacial cracks between the fillers and matrix, 


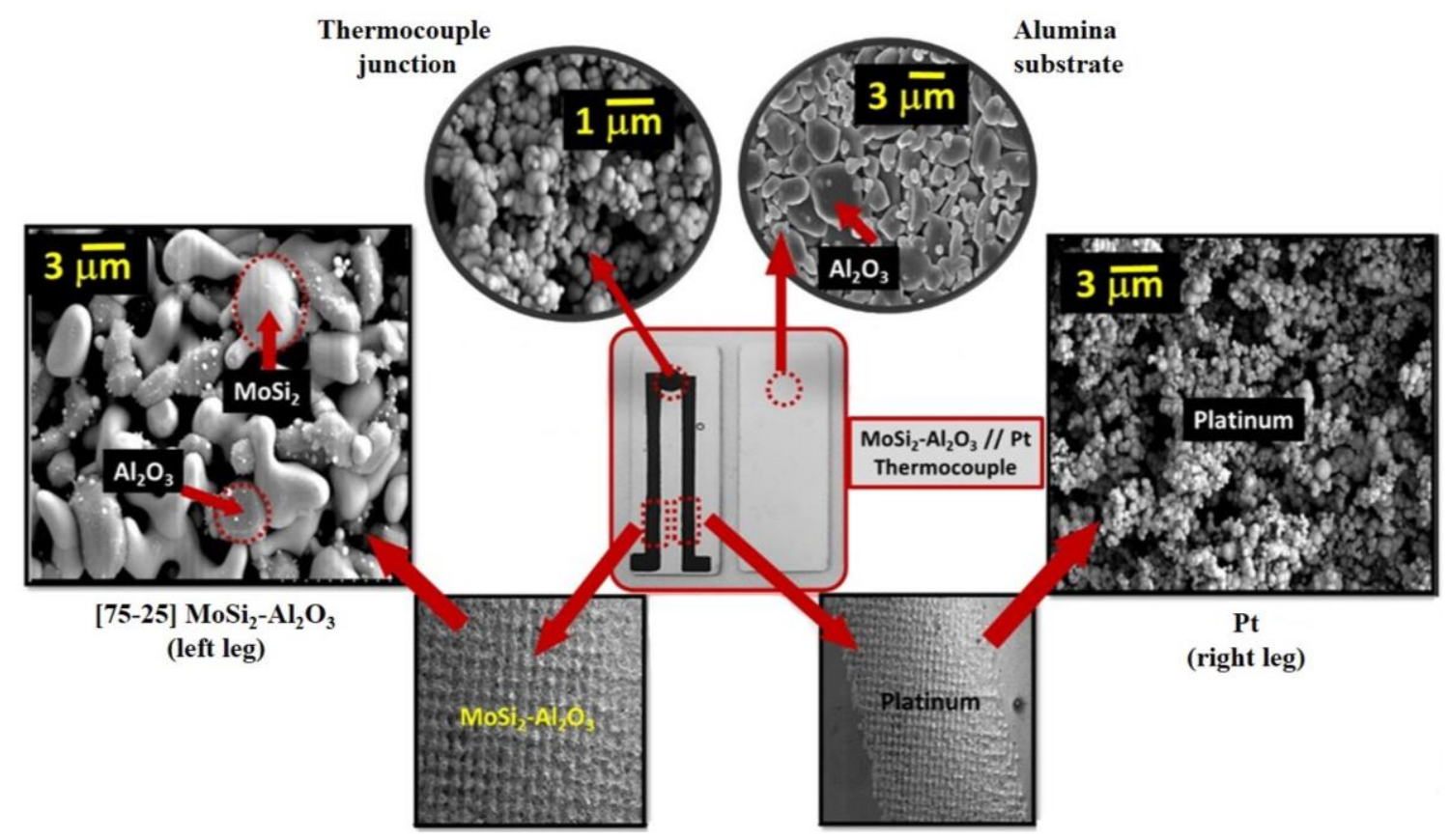

Figure 83. Optical photograph and SEM micrographs (alumina substrate, left leg, right leg, junction) of the [75-25] $\mathrm{MoSi}_{2}-\mathrm{Al}_{2} \mathrm{O}_{3} / / \mathrm{Pt}$ thermocouple screen printed on an alumina substrate and then sintered at $1500^{\circ} \mathrm{C}$ for $2 \mathrm{~h}$.

which is highly beneficial for these silicide-oxide composite thermocouples screen printed on the alumina substrates.

\subsubsection{Thermoelectric characterization of the composite thermocouples}

The Seebeck coefficient is a material property that dictates the thermally-derived voltage generated within a material. This property may be measured for a material by evaluating the slope of thermoelectric voltage $(\mathrm{E})$-temperature difference $(\Delta \mathrm{T})$ graph. Thermocouple sensors are based upon the junction of two electrically dissimilar materials having dissimilar Seebeck coefficients $\left(S_{A}\right.$ and $\left.S_{B}\right)$. The generated thermoelectric voltage is defined by the difference in their Seebeck coefficients $\left(S_{A B}=S_{A}-S_{B}\right)$, and this can be written as [29]:

$$
S_{A B}=\lim _{\Delta T \rightarrow 0} \frac{\Delta V_{A B}}{\Delta T}
$$


where $\Delta V_{A B}$ is the electric potential across the interface of two dissimilar conductors within a thermal gradient, $\Delta \mathrm{T}$. In the present study, intrinsic Seebeck coefficients of the MoSiz$\mathrm{Al}_{2} \mathrm{O}_{3}\left(S_{M A}\right)$ and $\mathrm{WSi}_{2}-\mathrm{Al}_{2} \mathrm{O}_{3}\left(S_{W A}\right)$ composites were estimated from the effective Seebeck coefficients of the $\mathrm{MoSi}_{2}-\mathrm{Al}_{2} \mathrm{O}_{3} / / \mathrm{Pt}\left(S_{M A P t}\right)$ and $\mathrm{WSi}_{2}-\mathrm{Al}_{2} \mathrm{O}_{3} / / \mathrm{Pt}\left(S_{W A P t}\right)$ thermocouples tested up to $1000^{\circ} \mathrm{C}$ in argon. According to the equation (1), difference in the effective Seebeck coefficients of the thermocouples with configurations of the $\mathrm{MoSi}_{2}-\mathrm{Al}_{2} \mathrm{O}_{3} / / \mathrm{Pt}$ and $\mathrm{WSi}_{2}-\mathrm{Al}_{2} \mathrm{O}_{3} / / \mathrm{Pt}$ can be written as:

$$
\begin{aligned}
& S_{\text {MAPt }}=S_{M A}-S_{P t} \\
& S_{W A P t}=S_{W A}-S_{P t}
\end{aligned}
$$

where $S_{M A P t}$ is the difference in the intrinsic Seebeck coefficients of the $\mathrm{MoSi}_{2}-\mathrm{Al}_{2} \mathrm{O}_{3}$ $\left(S_{M A}\right)$ and Pt $\left(S_{P t}\right)$ legs of the thermocouple; and $S_{W A P t}$ is the difference in the intrinsic Seebeck coefficients of the $\mathrm{WSi}_{2}-\mathrm{Al}_{2} \mathrm{O}_{3} / / \mathrm{Pt}\left(S_{W A}\right)$ and $\mathrm{Pt}\left(S_{P t}\right)$ legs of the thermocouple. By using the equations (2-3), the effective Seebeck coefficient of a composite thermocouple with a configuration of the $\mathrm{MoSi}_{2}-\mathrm{Al}_{2} \mathrm{O}_{3} / / \mathrm{WSi}_{2}-\mathrm{Al}_{2} \mathrm{O}_{3}\left(S_{\text {MAWA }}\right)$ could be estimated as:

$$
S_{M A W A}=S_{M A}-S_{W A}
$$

where $\triangle \mathrm{S}_{\text {MAWA }}$ denotes the estimated effective Seebeck coefficient of the $\mathrm{MoSi}_{2}-$ $\mathrm{Al}_{2} \mathrm{O}_{3} / / \mathrm{WSi}_{2}-\mathrm{Al}_{2} \mathrm{O}_{3}$ thermocouple by using the data obtained from the thermocouples made of $\mathrm{MoSi}_{2}-\mathrm{Al}_{2} \mathrm{O}_{3} / / \mathrm{Pt}$ and $\mathrm{WSi}_{2}-\mathrm{Al}_{2} \mathrm{O}_{3} / / \mathrm{Pt}$.

To evaluate this experimentally, standard thermocouples with configurations of [50-50], [60-40], [75-25] and [90-10] $\mathrm{MoSi}_{2}-\mathrm{Al}_{2} \mathrm{O}_{3} / / \mathrm{Pt}$, and [50-50], [60-40], [75-25] and [90-10] $\mathrm{WSi}_{2}-\mathrm{Al}_{2} \mathrm{O}_{3} / / \mathrm{Pt}$ were fabricated, and their thermoelectric responses were recorded as a function of temperature difference. It was reported that a $\mathrm{Pt} / / \mathrm{Pd}$ wire thermocouple (Pt-67 reference standard maintained by NIST) exhibited a Seebeck coefficient of $18.2 \mu \mathrm{V} / \mathrm{K}$ at $900^{\circ} \mathrm{C}$ [30]. In the present study, thermocouples were tested by recording the voltage drop across the device with an acquisition system (DAQ, National Instruments) associated with a computer-based LabView software. The 
estimated Seebeck coefficients of the $\mathrm{MoSi}_{2}-\mathrm{Al}_{2} \mathrm{O}_{3}$ and $\mathrm{WSi}_{2}-\mathrm{Al}_{2} \mathrm{O}_{3}$ composites were determined by using the intrinsic Seebeck coefficient of Pt and effective Seebeck coefficients of $\mathrm{MoSi}_{2}-\mathrm{Al}_{2} \mathrm{O}_{3} / / \mathrm{Pt}$ and $\mathrm{WSi}_{2}-\mathrm{Al}_{2} \mathrm{O}_{3} / / \mathrm{Pt}$ thermocouples in the equations (23). Figure 84(a-d) presents the thermoelectric voltage and effective Seebeck coefficients of the various $\mathrm{MoSi}_{2}-\mathrm{Al}_{2} \mathrm{O}_{3} / / \mathrm{Pt}$ and $\mathrm{WSi}_{2}-\mathrm{Al}_{2} \mathrm{O}_{3} / / \mathrm{Pt}$ thermocouples as a function of temperature difference. The error margin in the thermoelectric characterization of [75-25] $\mathrm{MoSi}_{2}-\mathrm{Al}_{2} \mathrm{O}_{3} / / \mathrm{Pt}$ thermocouple was very high; therefore, the related data is not presented and not included in further Seebeck coefficient calculations. The thermoelectric voltages of the [50-50], [60-40], and [90-10] $\mathrm{MoSi}_{2}-\mathrm{Al}_{2} \mathrm{O}_{3} / / \mathrm{Pt}$ thermocouples were measured at $1000^{\circ} \mathrm{C}$ as $15.4,21.9$ and $36.2 \mathrm{mV}$, respectively. In addition, thermoelectric voltages of [50-50], [60-40], [75-25] and [90-10] $\mathrm{WSi}_{2}-\mathrm{Al}_{2} \mathrm{O}_{3} / / \mathrm{Pt}$ thermocouples measured at $1000^{\circ} \mathrm{C}$ were $12.8,11.5,14.8$ and $30.5 \mathrm{mV}$, respectively. The thermoelectric voltage increased with increasing temperature, as well as, increasing metal silicide content (from 50 to 90 vol\%) in the $\mathrm{MoSi}_{2}-\mathrm{Al}_{2} \mathrm{O}_{3} / / \mathrm{Pt}$ and $\mathrm{WSi}_{2}-\mathrm{Al}_{2} \mathrm{O}_{3} / / \mathrm{Pt}$ thermocouples. However, [50-50] $\mathrm{WSi}_{2}-\mathrm{Al}_{2} \mathrm{O}_{3} / / \mathrm{Pt}$ showed relatively higher thermoelectric voltage than [60-40] $\mathrm{WSi}_{2}$ $\mathrm{Al}_{2} \mathrm{O}_{3} / / \mathrm{Pt}$ only at the temperature gradients above $570^{\circ} \mathrm{C}$, which could be related to the differences in percolation, volume percentage of secondary $\mathrm{W}_{5} \mathrm{Si}_{3}$ phase and its overall effect on thermoelectric output with respect to platinum. At lower temperature differences up to $\sim 200^{\circ} \mathrm{C}$, the thermoelectric voltages of all the $\mathrm{MoSi}_{2}-\mathrm{Al}_{2} \mathrm{O}_{3} / / \mathrm{Pt}$ and $\mathrm{WSi}_{2}-\mathrm{Al}_{2} \mathrm{O}_{3} / / \mathrm{Pt}$ thermocouples were found to be relatively low ( $<3 \mathrm{mV}$ ) (Figure 84a-c). It is also clear that the $\mathrm{MoSi}_{2}-\mathrm{Al}_{2} \mathrm{O}_{3} / / \mathrm{Pt}$ thermocouples exhibited higher thermoelectric voltages than the $\mathrm{WSi}_{2}-\mathrm{Al}_{2} \mathrm{O}_{3} / / \mathrm{Pt}$ thermocouples at [50-50] and [60-40] volume percentages. In addition, at [90-10] volume percentage, they displayed relatively similar thermoelectric performance $\left(>12 \mathrm{mV}\right.$ ) at the temperature gradient above $600^{\circ} \mathrm{C}$. As presented in the Figure 84c, [5050] and [60-40] $\mathrm{WSi}_{2}-\mathrm{Al}_{2} \mathrm{O}_{3} / / \mathrm{Pt}$ thermocouples also exhibited a very similar thermoelectric performance. However, a significant increase in the thermoelectric voltage was achieved by the [90-10] $\mathrm{WSi}_{2}-\mathrm{Al}_{2} \mathrm{O}_{3} / / \mathrm{Pt}$ thermocouple. 

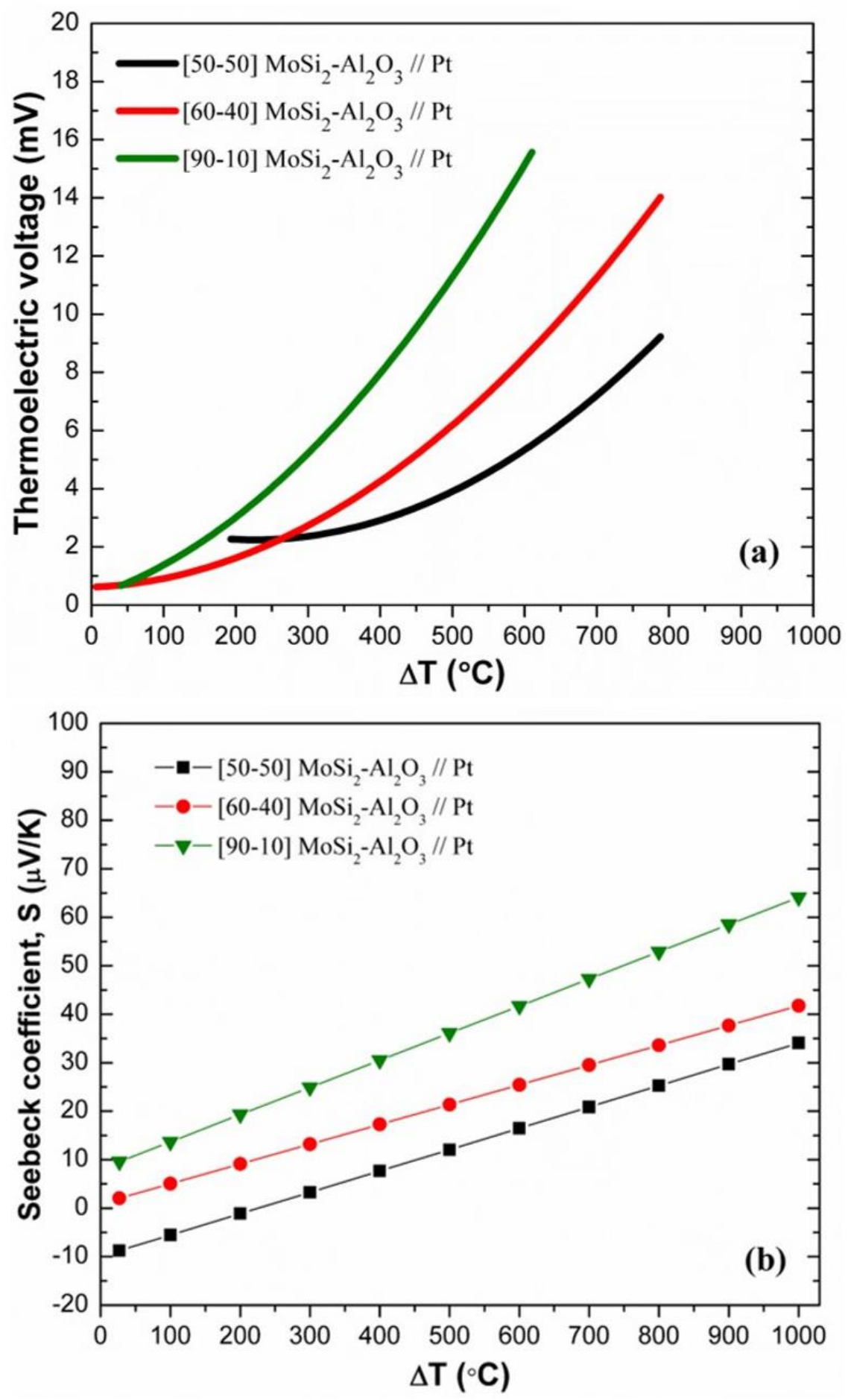

Figure 84. (a-c) Thermoelectric voltages (E) and (b-d) effective Seebeck coefficients (S) measured for the various $\mathrm{MoSi}_{2}-\mathrm{Al}_{2} \mathrm{O}_{3} / / \mathrm{Pt}$ and $\mathrm{WSi}_{2}-\mathrm{Al}_{2} \mathrm{O}_{3} / / \mathrm{Pt}$ thermocouples as a function of temperature difference. 

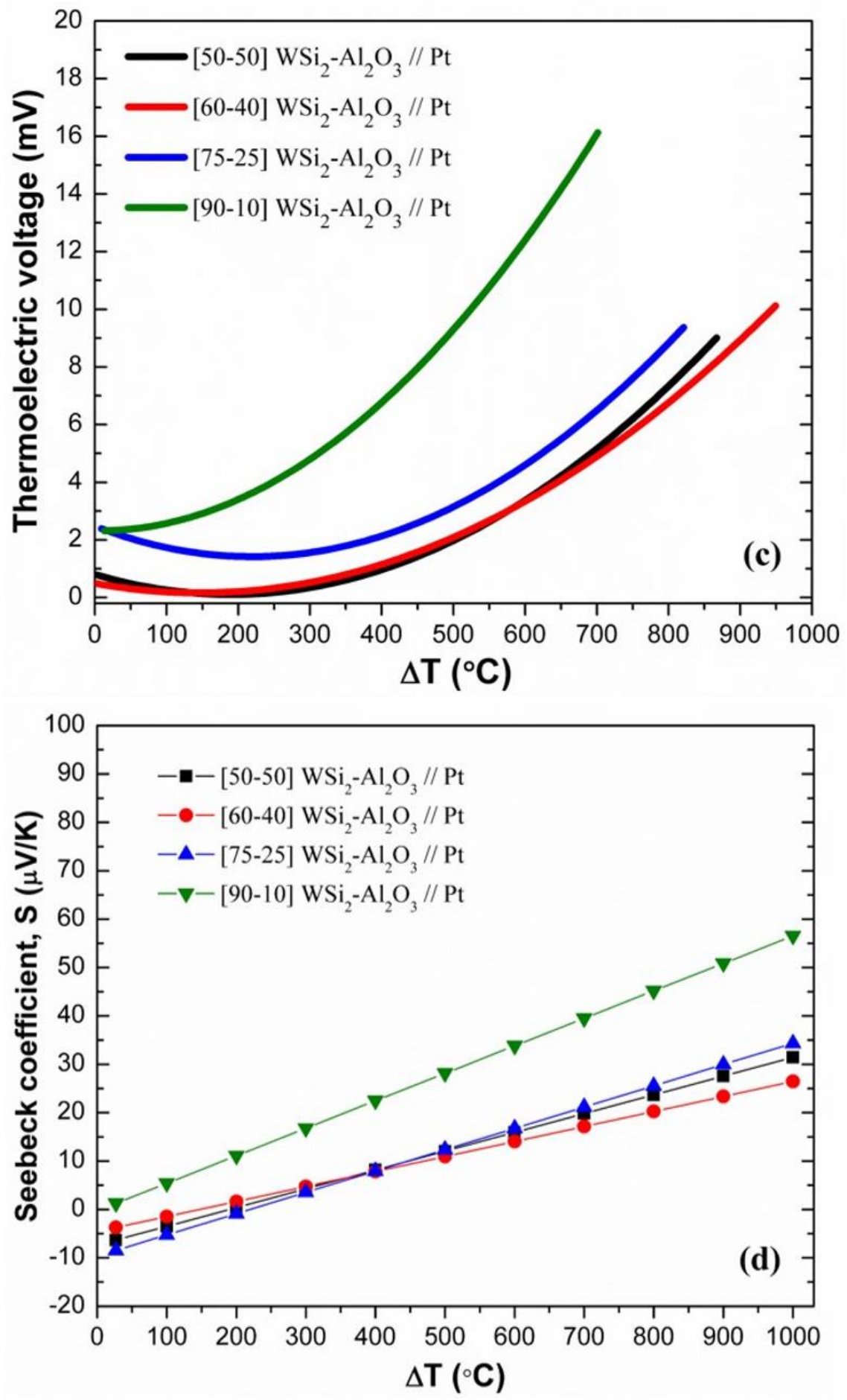

Figure 84. (continued) (a-c) Thermoelectric voltages (E) and (b-d) effective Seebeck coefficients ( $\mathrm{S}$ ) measured for the various $\mathrm{MoSi}_{2}-\mathrm{Al}_{2} \mathrm{O}_{3} / / \mathrm{Pt}$ and $\mathrm{WSi}_{2}-\mathrm{Al}_{2} \mathrm{O}_{3} / / \mathrm{Pt}$ thermocouples as a function of temperature difference. 
To determine the effective Seebeck coefficients of these thermocouples, thermoelectric responses were fit to a second-order or a third-order polynomial using a least square method. Based on the theory [31], thermoelectric voltage (E) and Seebeck coefficient (S) can be expressed as:

$$
\begin{array}{ccc}
2^{\text {nd }} \text { order: } & E=A \Delta T+B \Delta T^{2}+C & S=A+2 B \Delta T \\
3^{\text {rd }} \text { order: } & E=A \Delta T+B \Delta T^{2}+D \Delta T^{3}+C & S=A+2 B \Delta T+3 D \Delta T^{2}
\end{array}
$$

where $\mathrm{A}, \mathrm{B}, \mathrm{C}$ and $\mathrm{D}$ are fitting coefficients, and $\Delta \mathrm{T}$ is temperature gradient. In order to calculate the Seebeck coefficient in $\mu \mathrm{V} / \mathrm{K}$, the units of fitting coefficients were converted prior to these calculations. The effective Seebeck coefficients of the $\mathrm{MoSi}_{2}-\mathrm{Al}_{2} \mathrm{O}_{3} / / \mathrm{Pt}$ and $\mathrm{WSi}_{2}-\mathrm{Al}_{2} \mathrm{O}_{3} / / \mathrm{Pt}$ thermocouples are presented in the Figure $84(\mathrm{~b}-\mathrm{d})$ as a function of temperature difference $(\Delta \mathrm{T})$. Their thermoelectric properties and related fitting coefficients are additionally reviewed in the Table 14 and Table 15 . At $500^{\circ} \mathrm{C}$, the effective Seebeck coefficients $\left(\mathrm{S}_{500}\right)$ of [50-50], [60-40] and [90-10] $\mathrm{MoSi}_{2}-\mathrm{Al}_{2} \mathrm{O}_{3} / / \mathrm{Pt}$ thermocouples were measured as 12.1, 21.4 and $36.1 \mu \mathrm{V} / \mathrm{K}$, respectively; while [50-50], [60-40], [75-25] and [90-10] $\mathrm{WSi}_{2}-\mathrm{Al}_{2} \mathrm{O}_{3} / \mathrm{Pt}$ exhibited effective Seebeck coefficients of 12.0, 11.0, 12.4 and $28.2 \mu \mathrm{V} / \mathrm{K}$, respectively. The effective Seebeck coefficients of all thermocouples increased with increasing temperature difference up to $1000^{\circ} \mathrm{C}$. The [50-50] and [60-40] $\mathrm{MoSi}_{2}$ $\mathrm{Al}_{2} \mathrm{O}_{3} / / \mathrm{Pt}$ thermocouples exhibited similar behavior up to $200^{\circ} \mathrm{C}$; however, [60-40] $\mathrm{MoSi}_{2}-$ $\mathrm{Al}_{2} \mathrm{O}_{3} / / \mathrm{Pt}$ revealed higher effective Seebeck coefficients than [50-50] above that temperature. In the case of $\mathrm{WSi}_{2}-\mathrm{Al}_{2} \mathrm{O}_{3} / / \mathrm{Pt}$ thermocouples, relatively higher Seebeck coefficients were observed for the [75-25] composition at the temperatures above $600^{\circ} \mathrm{C}$, compared to the [50-50] and [60-40] thermocouples. Similar to their thermoelectric voltage data, [50-50] $\mathrm{WSi}_{2}-\mathrm{Al}_{2} \mathrm{O}_{3} / / \mathrm{Pt}$ thermocouple showed relatively higher Seebeck coefficient than [60-40] only at higher temperature gradients. However, a substantial increase in the Seebeck coefficient was observed at the 90 vol\% metal silicide content both for $\mathrm{MoSi}_{2}$ $\mathrm{Al}_{2} \mathrm{O}_{3} / / \mathrm{Pt}$ and $\mathrm{WSi}_{2}-\mathrm{Al}_{2} \mathrm{O}_{3} / / \mathrm{Pt}$ thermocouples (Figure 84b-d). These drastic increases in the effective Seebeck coefficients may be attributed to the interaction of charge carriers with non-equilibrium portion of the phonon distribution and spatial redistribution of the charge 
Table 14. Summary of the fitting parameters (A, B and D) and $R^{2}$ values calculated, and then, used in thermoelectric calculations.

\begin{tabular}{|c|c|c|c|c|}
\hline Thermocouple composition & $\underset{(\mu \mathbf{V} / \mathbf{K})}{\mathbf{A}}$ & $\frac{B}{\left(\mu \mathbf{V} / \mathbf{K}^{2}\right)}$ & $\underset{\left(\mu \mathbf{V} / \mathbf{K}^{3}\right)}{\mathbf{D}}$ & $\mathbf{R}^{2}$ \\
\hline$[50-50] \mathrm{MoSi}_{2}-\mathrm{Al}_{2} \mathrm{O}_{3} / / \mathrm{Pt}$ & -9.93 & 0.0220 & - & 1.0 \\
\hline$[60-40] \mathrm{MoSi}_{2}-\mathrm{Al}_{2} \mathrm{O}_{3} / / \mathrm{Pt}$ & 0.96 & 0.0204 & - & 1.0 \\
\hline$[90-10] \mathrm{MoSi}_{2}-\mathrm{Al}_{2} \mathrm{O}_{3} / / \mathrm{Pt}$ & 8.09 & 0.0280 & - & 1.0 \\
\hline$[50-50] \mathrm{WSi}_{2}-\mathrm{Al}_{2} \mathrm{O}_{3} / / \mathrm{Pt}$ & -7.36 & 0.0194 & - & 1.0 \\
\hline$[60-40] \mathrm{WSi}_{2}-\mathrm{Al}_{2} \mathrm{O}_{3} / / \mathrm{Pt}$ & -4.55 & 0.0155 & - & 1.0 \\
\hline$[75-25] \mathrm{WSi}_{2}-\mathrm{Al}_{2} \mathrm{O}_{3} / / \mathrm{Pt}$ & -9.65 & 0.0220 & - & 1.0 \\
\hline$[90-10] \mathrm{WSi}_{2}-\mathrm{Al}_{2} \mathrm{O}_{3} / / \mathrm{Pt}$ & -0.25 & 0.0284 & - & 1.0 \\
\hline $\begin{array}{c}{[50-50] \mathrm{MoSi}_{2}-\mathrm{Al}_{2} \mathrm{O}_{3} / /[50-50] \mathrm{WSi}_{2}-} \\
\mathrm{Al}_{2} \mathrm{O}_{3}\end{array}$ & 3.93 & 0.0085 & $3.4 \times 10^{-6}$ & 0.999 \\
\hline $\begin{array}{c}{[60-40] \mathrm{MoSi}_{2}-\mathrm{Al}_{2} \mathrm{O}_{3} / /[60-40] \mathrm{WSi}_{2}-} \\
\mathrm{Al}_{2} \mathrm{O}_{3}\end{array}$ & -25.33 & 0.0657 & $-3.0 \times 10^{-5}$ & 0.999 \\
\hline $\begin{array}{c}{[75-25] \mathrm{MoSi}_{2}-\mathrm{Al}_{2} \mathrm{O}_{3} / /[75-25] \mathrm{WSi}_{2}-} \\
\mathrm{Al}_{2} \mathrm{O}_{3}\end{array}$ & 6.38 & 0.0195 & $-1.2 \times 10^{-5}$ & 0.999 \\
\hline $\begin{array}{c}{[90-10] \mathrm{MoSi}_{2}-\mathrm{Al}_{2} \mathrm{O}_{3} / /[90-10] \mathrm{WSi}_{2}-} \\
\mathrm{Al}_{2} \mathrm{O}_{3}\end{array}$ & 14.17 & 0.0033 & - & 0.999 \\
\hline $\mathrm{MoSi}_{2} / / \mathrm{WSi}_{2}$ & 25.03 & 0.0003 & - & 0.999 \\
\hline
\end{tabular}

carriers in the composite matrix that promotes the average energy of the charge carrier [6]. In addition, it can be seen that [50-50] $\mathrm{MoSi}_{2}-\mathrm{Al}_{2} \mathrm{O}_{3} / / \mathrm{Pt}$ and [50-50] $\mathrm{WSi}_{2}-\mathrm{Al}_{2} \mathrm{O}_{3} / / \mathrm{Pt}$ thermocouples revealed a similar trend for their effective Seebeck coefficients, whereas $\mathrm{MoSi}_{2}-\mathrm{Al}_{2} \mathrm{O}_{3} / / \mathrm{Pt}$ thermocouples always exhibited higher Seebeck coefficients than the $\mathrm{WSi}_{2}-\mathrm{Al}_{2} \mathrm{O}_{3} / \mathrm{Pt}$ thermocouples with [60-40] and [90-10] compositions in a wide temperature range. 
Table 15. Summary of the measured thermoelectric voltage $\left(\mathrm{E}_{1000}\right)$ and effective Seebeck coefficients $\left(\mathrm{S}_{500}, \mathrm{~S}_{1000}\right)$ of all thermocouples at $500^{\circ} \mathrm{C}$ and $1000^{\circ} \mathrm{C}$.

\begin{tabular}{|c|c|c|c|}
\hline Thermocouple composition & $\begin{array}{l}\mathbf{E}_{1000} \\
(\mathrm{mV})\end{array}$ & $\begin{array}{c}\mathbf{S}_{500} \\
(\boldsymbol{\mu V} / \mathbf{K})\end{array}$ & $\begin{array}{c}\mathbf{S}_{1000} \\
(\boldsymbol{\mu V} / \mathbf{K})\end{array}$ \\
\hline$[50-50] \mathrm{MoSi}_{2}-\mathrm{Al}_{2} \mathrm{O}_{3} / / \mathrm{Pt}$ & 15.43 & 12.07 & 34.07 \\
\hline$[60-40] \mathrm{MoSi}_{2}-\mathrm{Al}_{2} \mathrm{O}_{3} / / \mathrm{Pt}$ & 21.97 & 21.36 & 41.76 \\
\hline$[90-10] \mathrm{MoSi}_{2}-\mathrm{Al}_{2} \mathrm{O}_{3} / / \mathrm{Pt}$ & 36.18 & 36.09 & 64.09 \\
\hline$[50-50] \mathrm{WSi}_{2}-\mathrm{Al}_{2} \mathrm{O}_{3} / / \mathrm{Pt}$ & 12.84 & 12.04 & 31.44 \\
\hline$[60-40] \mathrm{WSi}_{2}-\mathrm{Al}_{2} \mathrm{O}_{3} / / \mathrm{Pt}$ & 11.45 & 10.95 & 26.45 \\
\hline$[75-25] \mathrm{WSi}_{2}-\mathrm{Al}_{2} \mathrm{O}_{3} / / \mathrm{Pt}$ & 14.81 & 12.35 & 34.35 \\
\hline$[90-10] \mathrm{WSi}_{2}-\mathrm{Al}_{2} \mathrm{O}_{3} / / \mathrm{Pt}$ & 30.47 & 28.15 & 56.55 \\
\hline$[50-50] \mathrm{MoSi}_{2}-\mathrm{Al}_{2} \mathrm{O}_{3} / /[50-50] \mathrm{WSi}_{2}-\mathrm{Al}_{2} \mathrm{O}_{3}$ & 15.21 & 15.04 & 31.29 \\
\hline$[60-40] \mathrm{MoSi}_{2}-\mathrm{Al}_{2} \mathrm{O}_{3} / /[60-40] \mathrm{WSi}_{2}-\mathrm{Al}_{2} \mathrm{O}_{3}$ & 16.03 & 18.09 & 16.97 \\
\hline [75-25] $\mathrm{MoSi}_{2}-\mathrm{Al}_{2} \mathrm{O}_{3} / /$ [75-25] $\mathrm{WSi}_{2}-\mathrm{Al}_{2} \mathrm{O}_{3}$ & 14.11 & 17.11 & 10.28 \\
\hline$[90-10] \mathrm{MoSi}_{2}-\mathrm{Al}_{2} \mathrm{O}_{3} / /[90-10] \mathrm{WSi}_{2}-\mathrm{Al}_{2} \mathrm{O}_{3}$ & 17.49 & 17.52 & 20.87 \\
\hline $\mathrm{MoSi}_{2} / / \mathrm{WSi}_{2}$ & 25.67 & 25.35 & 25.67 \\
\hline
\end{tabular}

The experimental results of the $\mathrm{MoSi}_{2}-\mathrm{Al}_{2} \mathrm{O}_{3} / / \mathrm{Pt}$ and $\mathrm{WSi}_{2}-\mathrm{Al}_{2} \mathrm{O}_{3} / / \mathrm{Pt}$ thermocouples were initially used in this study to determine the estimated intrinsic Seebeck coefficients of the $\mathrm{MoSi}_{2}-\mathrm{Al}_{2} \mathrm{O}_{3}$ and $\mathrm{WSi}_{2}-\mathrm{Al}_{2} \mathrm{O}_{3}$ composites. Afterwards, these estimated values were utilized to calculate the estimated Seebeck coefficients of the various $\mathrm{MoSi}_{2}-\mathrm{Al}_{2} \mathrm{O}_{3} / / \mathrm{WSi}_{2}-$ $\mathrm{Al}_{2} \mathrm{O}_{3}$ composite thermocouples, which were then compared with the measured effective Seebeck coefficients of equivalent $\mathrm{MoSi}_{2}-\mathrm{Al}_{2} \mathrm{O}_{3} / / \mathrm{WSi}_{2}-\mathrm{Al}_{2} \mathrm{O}_{3}$ composite thermocouples. 


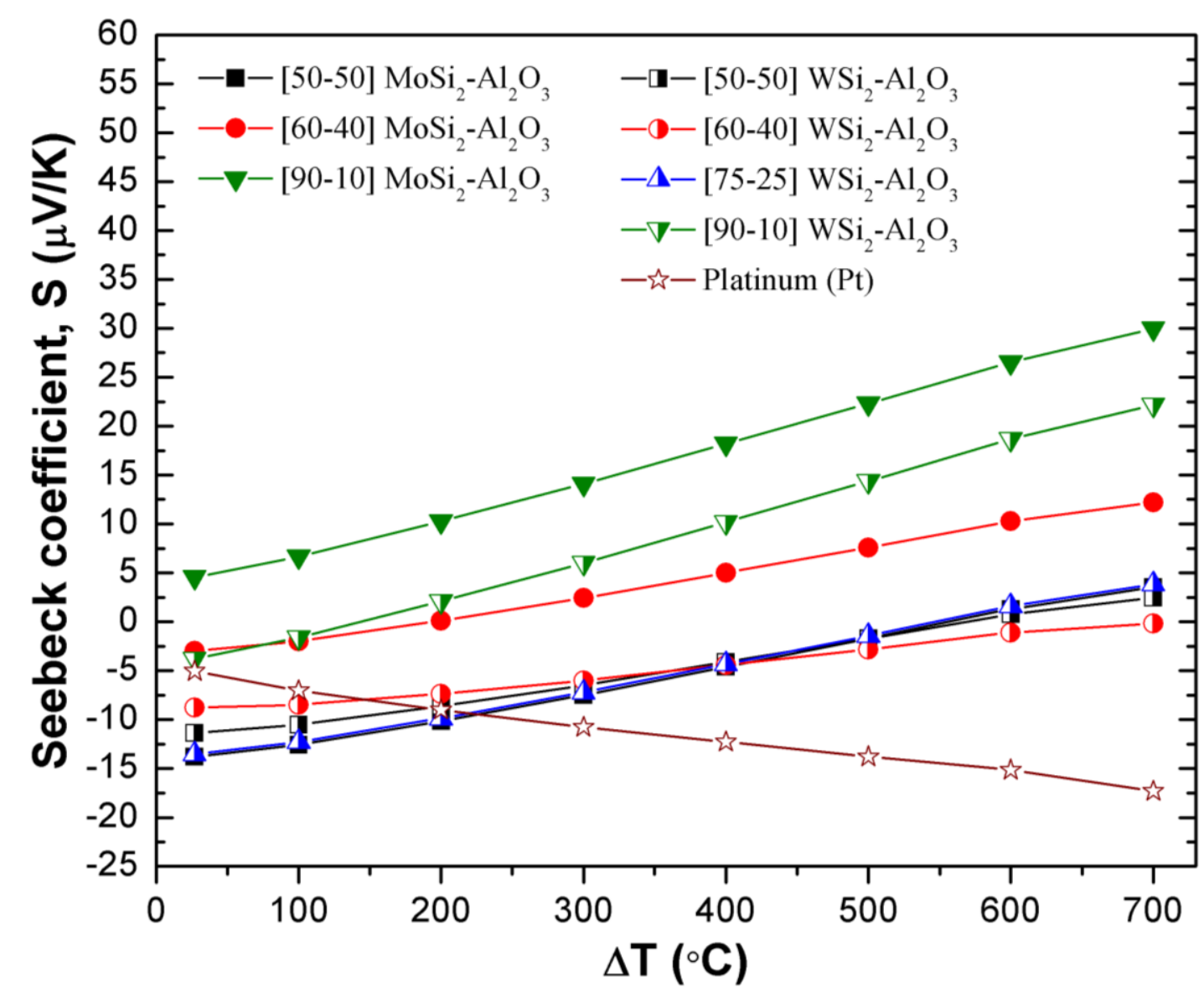

Figure 85. Estimated Seebeck coefficients $(\mathrm{S})$ of the various $\mathrm{MoSi}_{2}-\mathrm{Al}_{2} \mathrm{O}_{3}$ and $\mathrm{WSi}_{2}$ $\mathrm{Al}_{2} \mathrm{O}_{3}$ composites as a function of temperature difference ( $\mathrm{S}_{\mathrm{Pt}}$ is also presented).

Figure 85 presents the estimated intrinsic Seebeck coefficients of various $\mathrm{MoSi}_{2}-\mathrm{Al}_{2} \mathrm{O}_{3}$ and $\mathrm{WSi}_{2}-\mathrm{Al}_{2} \mathrm{O}_{3}$ composites that were calculated by using the measured effective Seebeck coefficients of metal silicide-oxide//Pt thermocouples and reference intrinsic Seebeck coefficients of $\mathrm{Pt}$ [32] within the equations (2-3). At $500^{\circ} \mathrm{C}$, the intrinsic Seebeck coefficients of the [50-50], [60-40] and [90-10] $\mathrm{MoSi}_{2}-\mathrm{Al}_{2} \mathrm{O}_{3}$ composites were calculated as $-1.70,7.59$ and $22.3 \mu \mathrm{V} / \mathrm{K}$, respectively. The intrinsic Seebeck coefficients of [50-50], [6040], [75-25] and [90-10] $\mathrm{WSi}_{2}-\mathrm{Al}_{2} \mathrm{O}_{3}$ composites were also determined at $500^{\circ} \mathrm{C}$ as -1.73 , 2.82, -1.42 and $14.4 \mu \mathrm{V} / \mathrm{K}$, respectively. Interestingly, the [60-40] $\mathrm{MoSi}_{2}-\mathrm{Al}_{2} \mathrm{O}_{3},[90-10]$ $\mathrm{MoSi}_{2}-\mathrm{Al}_{2} \mathrm{O}_{3}$ and [90-10] $\mathrm{WSi}_{2}-\mathrm{Al}_{2} \mathrm{O}_{3}$ composites revealed mostly positive estimated Seebeck coefficients, all other composites displayed negative estimated Seebeck 
coefficients. In addition, the intrinsic Seebeck coefficients of the [50-50] $\mathrm{MoSi}_{2}-\mathrm{Al}_{2} \mathrm{O}_{3}$ and [50-50], [60-40] and [75-25] $\mathrm{WSi}_{2}-\mathrm{Al}_{2} \mathrm{O}_{3}$ composites decreased with increasing temperature gradient, since their intrinsic Seebeck coefficients were all higher as negative values ( -13.8 to $-4.11 \mu \mathrm{V} / \mathrm{K})$ at the temperatures below $400^{\circ} \mathrm{C}$. These composites displayed very low intrinsic Seebeck coefficients at the temperatures above that temperature. Also, [50-50] $\mathrm{MoSi}_{2}-\mathrm{Al}_{2} \mathrm{O}_{3}$ and [75-25] $\mathrm{WSi}_{2}-\mathrm{Al}_{2} \mathrm{O}_{3}$ composites showed almost identical intrinsic Seebeck coefficients at all temperatures (Figure 85). However, the intrinsic Seebeck coefficients of [90-10] $\mathrm{MoSi}_{2}-\mathrm{Al}_{2} \mathrm{O}_{3}$ and [90-10] $\mathrm{WSi}_{2}-\mathrm{Al}_{2} \mathrm{O}_{3}$ significantly increased with increasing temperature gradient, particularly above $200^{\circ} \mathrm{C}$. These results indicated that the $\mathrm{MoSi}_{2}-\mathrm{Al}_{2} \mathrm{O}_{3}$ and $\mathrm{WSi}_{2}-\mathrm{Al}_{2} \mathrm{O}_{3}$ composites could have higher intrinsic Seebeck coefficients at [90-10] composition based on the estimation using the data obtained by metal silicide-oxide//Pt thermocouples.

As previously described, $\mathrm{MoSi}_{2}-\mathrm{Al}_{2} \mathrm{O}_{3} / / \mathrm{WSi}_{2}-\mathrm{Al}_{2} \mathrm{O}_{3}$ composite thermocouples were fabricated by screen printing on tape-casted alumina substrates and sintered at $1500^{\circ} \mathrm{C}$. Their thermoelectric performance was analyzed under argon atmosphere and compared with the estimated values. Pure $\mathrm{MoSi}_{2} / \mathrm{WSi}_{2}$ thermocouples were also fabricated to investigate the effect of alumina content on their thermoelectric performance. The thermoelectric voltages and effective Seebeck coefficients of these thermocouples are presented in the Figure 86(a-b) as a function of temperature difference $(\Delta \mathrm{T})$. These results are additionally summarized in the Table 15 for a better review of their thermoelectric performance. The thermoelectric voltage of all $\mathrm{MoSi}_{2}-\mathrm{Al}_{2} \mathrm{O}_{3} / / \mathrm{WSi}_{2}-\mathrm{Al}_{2} \mathrm{O}_{3}$ and $\mathrm{MoSi}_{2} / / \mathrm{WSi}_{2}$ thermocouples increased significantly with increasing temperature up to $600^{\circ}-1000^{\circ} \mathrm{C}$. At $500^{\circ} \mathrm{C}, \mathrm{MoSi}_{2} / / \mathrm{WSi}_{2}$ thermocouple displayed a thermoelectric voltage of $12.9 \mathrm{mV}$; whereas, the [50-50], [60-40], [75-25], [90-10] $\mathrm{MoSi}_{2}-\mathrm{Al}_{2} \mathrm{O}_{3} / /[50-50]$, [60-40], [75-25], [90-10] $\mathrm{WSi}_{2}-\mathrm{Al}_{2} \mathrm{O}_{3}$ thermocouples showed 3.85, 5.41, 6.53 and $7.89 \mathrm{mV}$, respectively, at the same temperature. The thermoelectric voltage relatively increased with increasing metal silicide $\left(\mathrm{MoSi}_{2}, \mathrm{WSi}_{2}\right)$ content on both legs of the thermocouple from 50 to $90 \mathrm{vol} \%$. It was also demonstrated that the thermoelectric voltage decreased from 12.9 to 

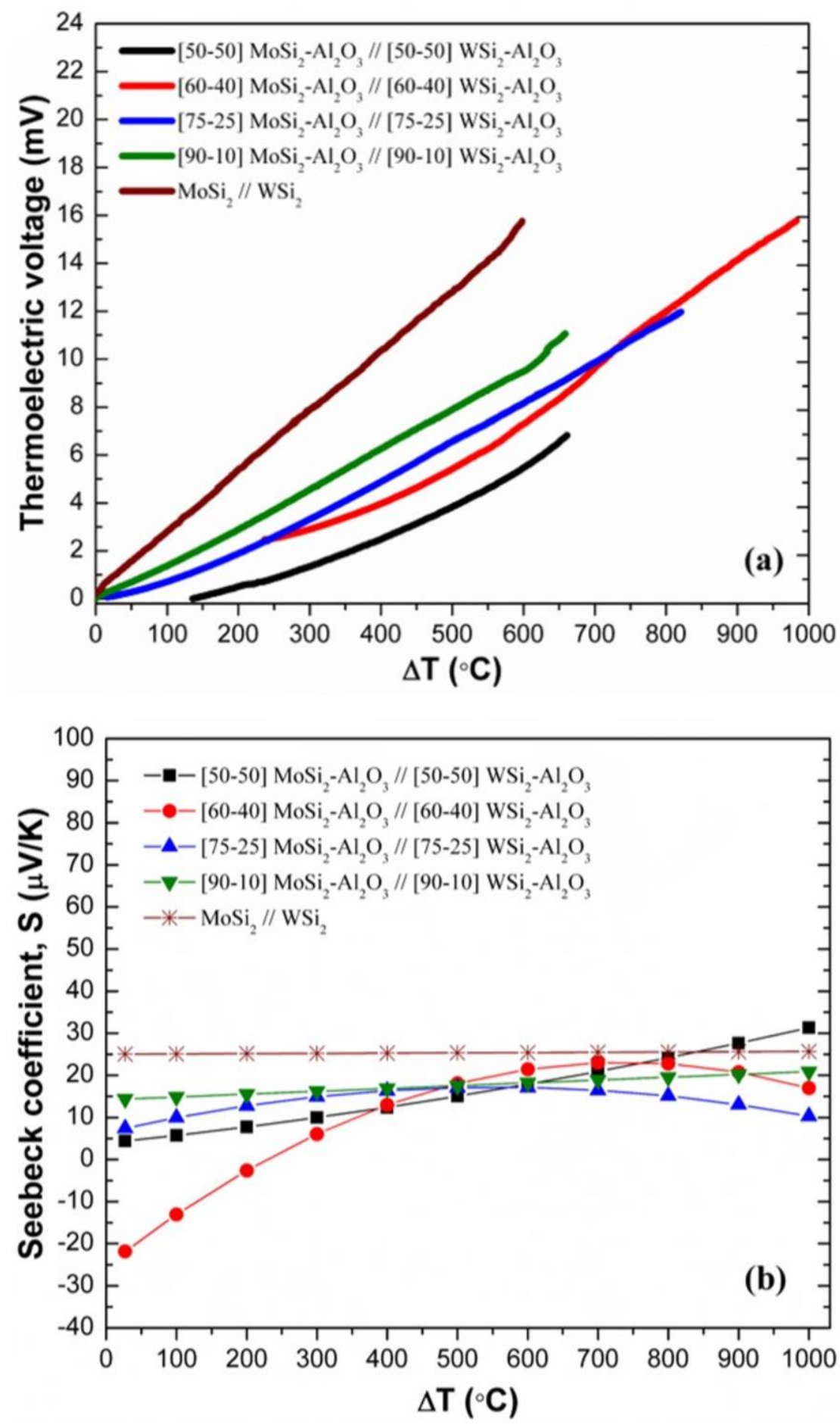

Figure 86. (a) Thermoelectric voltage (E) and (b) effective Seebeck coefficients (S) measured for the $\mathrm{MoSi}_{2} / / \mathrm{WSi}_{2}$ and various $\mathrm{MoSi}_{2}-\mathrm{Al}_{2} \mathrm{O}_{3} / / \mathrm{WSi}_{2}-\mathrm{Al}_{2} \mathrm{O}_{3}$ thermocouples as a function of temperature difference. 
$7.89 \mathrm{mV}$ at $500^{\circ} \mathrm{C}$ with the addition of $10 \mathrm{vol} \% \mathrm{Al}_{2} \mathrm{O}_{3}$ into both legs of the thermocouple. At $1000^{\circ} \mathrm{C}$, [50-50], [60-40], [75-25], [90-10] $\mathrm{MoSi}_{2}-\mathrm{Al}_{2} \mathrm{O}_{3} / /[50-50]$, [60-40], [75-25], [9010] $\mathrm{WSi}_{2}-\mathrm{Al}_{2} \mathrm{O}_{3}$ thermocouples exhibited $15.2,16.0,14.1$ and $17.5 \mathrm{mV}$, respectively. It is clear that the [60-40] $\mathrm{MoSi}_{2}-\mathrm{Al}_{2} \mathrm{O}_{3} / /[60-40] \mathrm{WSi}_{2}-\mathrm{Al}_{2} \mathrm{O}_{3}$ thermocouple could have relatively higher thermoelectric voltage than [50-50] and [75-25] at $1000^{\circ} \mathrm{C}$ based on the calculations. The [90-10] $\mathrm{MoSi}_{2}-\mathrm{Al}_{2} \mathrm{O}_{3} / /[90-10] \mathrm{WSi}_{2}-\mathrm{Al}_{2} \mathrm{O}_{3}$ thermocouple performed better than the other composite thermocouples throughout the temperature range.

The effective Seebeck coefficients as a function of temperature difference for the composite thermocouples are presented in Figure 86(b). The $\mathrm{MoSi}_{2} / / \mathrm{WSi}_{2}$ thermocouple showed 25.4 and $25.7 \mu \mathrm{V} / \mathrm{K}$ at $500^{\circ} \mathrm{C}$ and $1000^{\circ} \mathrm{C}$, respectively. The effective Seebeck coefficients of the [50-50], [60-40], [75-25], [90-10] $\mathrm{MoSi}_{2}-\mathrm{Al}_{2} \mathrm{O}_{3} / /[50-50]$, [60-40], [7525], [90-10] $\mathrm{WSi}_{2}-\mathrm{Al}_{2} \mathrm{O}_{3}$ thermocouples measured at $500^{\circ} \mathrm{C}$ were $15.0,18.1,17.1$ and 17.5 $\mu \mathrm{V} / \mathrm{K}$, respectively. Therefore, the [60-40] and [90-10] revealed slightly higher Seebeck coefficients than the other composite thermocouples at $500^{\circ} \mathrm{C}$. In addition, the effective Seebeck coefficients of all the composite thermocouples were relatively lower than the pure $\mathrm{MoSi}_{2} / / \mathrm{WSi}_{2}$ thermocouple at the same temperature. At $1000^{\circ} \mathrm{C}$, the effective Seebeck coefficients of the [50-50], [60-40], [75-25], [90-10] $\mathrm{MoSi}_{2}-\mathrm{Al}_{2} \mathrm{O}_{3} / /[50-50]$, [60-40], [7525], [90-10] $\mathrm{WSi}_{2}-\mathrm{Al}_{2} \mathrm{O}_{3}$ thermocouples were measured as $31.3,17.0,10.3$ and $20.9 \mu \mathrm{V} / \mathrm{K}$, respectively. It is important to point out that [50-50] $\mathrm{MoSi}_{2}-\mathrm{Al}_{2} \mathrm{O}_{3} / /[50-50] \mathrm{WSi}_{2}-\mathrm{Al}_{2} \mathrm{O}_{3}$ thermocouple exhibited relatively higher Seebeck coefficient than $\mathrm{MoSi}_{2} / \mathrm{WSi}_{2}$ and other composite thermocouples at $900^{\circ} \mathrm{C}$ and $1000^{\circ} \mathrm{C}$; although, it showed lower Seebeck coefficients than those thermocouples at the temperatures below $\sim 200^{\circ} \mathrm{C}$. This result may be related to the local compositional changes at the junction of the two composite legs of the [50-50] $\mathrm{MoSi}_{2}-\mathrm{Al}_{2} \mathrm{O}_{3} / /[50-50] \mathrm{WSi}_{2}-\mathrm{Al}_{2} \mathrm{O}_{3}$ thermocouples. Furthermore, a non-linear thermoelectric response was observed for the [60-40] $\mathrm{MoSi}_{2}-\mathrm{Al}_{2} \mathrm{O}_{3} / /[60-40] \mathrm{WSi}_{2}-\mathrm{Al}_{2} \mathrm{O}_{3}$ composite thermocouple as seen in Figure 86(a-b). Multiple samples of this composition showed similar responses, and from the characterization previously presented, a significant difference in chemistry was not identified. This data was included in the paper to 
emphasize that there are some effects of phase formation and transformation at the junction that still require further characterization and understanding. Bhatt et al. [3] reported a similar non-linear behavior for the $\mathrm{TiC} / \mathrm{TaC}$ thin-film thermocouples even after several cycles of heating and cooling, which was attributed to the lack of control over the temperature difference between the hot and cold junctions of the thin films resulting in noise, drift and voltage spikes in the thermoelectric response. In addition, the [90-10] $\mathrm{MoSi}_{2}-\mathrm{Al}_{2} \mathrm{O}_{3} / /[90-10] \quad \mathrm{WSi}_{2}-\mathrm{Al}_{2} \mathrm{O}_{3}$ composite thermocouple displayed a Seebeck coefficient of $20.9 \mu \mathrm{V} / \mathrm{K}$ at $1000^{\circ} \mathrm{C}$, which is found to be highly comparable to that of the $\mathrm{MoSi}_{2} / / \mathrm{WSi}_{2}$ thermocouple $(25.7 \mu \mathrm{V} / \mathrm{K})$ and also significantly higher than that of the high alumina containing composite thermocouples $(10.3-17.0 \mu \mathrm{V} / \mathrm{K})$. This result may be related to the high content of the 5-3 metal silicide $\left(\mathrm{Mo}_{5} \mathrm{Si}_{3}, \mathrm{~W}_{5} \mathrm{Si}_{3}\right)$ phases formed during sintering, since the XRD/Rietveld results proved that there was 15.6 vol\% increase in the volume percentage of the $\mathrm{Mo}_{5} \mathrm{Si}_{3}$ secondary phase with increasing metal silicide content in the composite from 50 to $90 \mathrm{vol} \%$. Therefore, a significant increase in the thermoelectric voltage and Seebeck coefficient of the [90-10] $\mathrm{MoSi}_{2}-\mathrm{Al}_{2} \mathrm{O}_{3} / /[90-10] \mathrm{WSi}_{2}-\mathrm{Al}_{2} \mathrm{O}_{3}$ thermocouple can be clearly seen at all temperatures, particularly at $1000^{\circ} \mathrm{C}$. It also showed the most stable thermoelectric response in a wide temperature range in comparison to the other composite thermocouples, since its effective Seebeck coefficient increased only from 14.4 to $20.9 \mu \mathrm{V} / \mathrm{K}$ with increasing temperature gradient from $27^{\circ} \mathrm{C}$ to $1000^{\circ} \mathrm{C}$. In addition, both $\mathrm{MoSi}_{2} / / \mathrm{WSi}_{2}$ and [90-10] $\mathrm{MoSi}_{2}-\mathrm{Al}_{2} \mathrm{O}_{3} / /[90-10] \mathrm{WSi}_{2}-\mathrm{Al}_{2} \mathrm{O}_{3}$ thermocouples revealed higher sensitivity $(14.4-25.7 \mu \mathrm{V} / \mathrm{K})$ than the mostly used $\mathrm{Pt}-\mathrm{Rh} / \mathrm{Pt}$ high-temperature thermocouples; since it was reported that S-type (90\% Pt-10\% Rh//Pt) and R-type $(87 \% \mathrm{Pt}-$ $13 \% \mathrm{Rh} / \mathrm{Pt}$ ) thermocouples have sensitivity ranging from 5.5 to $13.0 \mu \mathrm{V} / \mathrm{K}$ throughout the temperature range from room temperature to $1000^{\circ} \mathrm{C}[33]$.

As a review, the above results indicated that higher silicide content positively affects thermoelectric response of the composite thermocouples in general, where the measured Seebeck coefficient was shown to generally increase with decreased alumina content. Also, the results demonstrated that $\mathrm{MoSi}_{2} / / \mathrm{WSi}_{2}$ thermocouple $(25.1-25.7 \mu \mathrm{V} / \mathrm{K})$ 


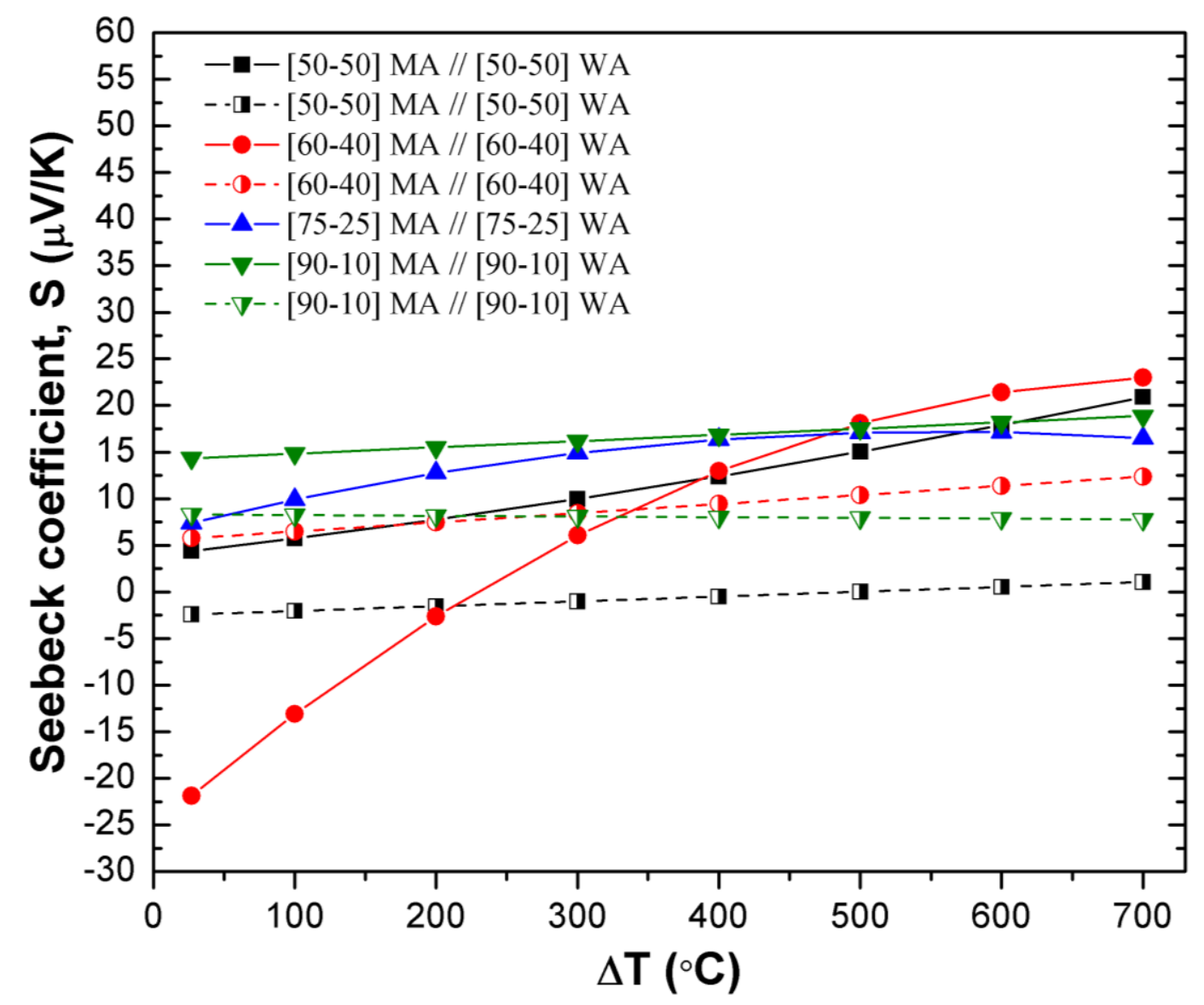

Figure 87. Comparison of the estimated (dashed lines) and measured effective (solid lines) Seebeck coefficients of the various $\mathrm{MoSi}_{2}-\mathrm{Al}_{2} \mathrm{O}_{3} / / \mathrm{WSi}_{2}-\mathrm{Al}_{2} \mathrm{O}_{3}$ (abbreviated as $M A / / W A$ ) composite thermocouples as a function of temperature difference.

showed nearly nine times higher performance compared to that predicted for the pure $\mathrm{MoSi}_{2} / / \mathrm{WSi}_{2}$ couples estimated from previously reported Seebeck coefficient data. For example; the effective Seebeck coefficient for a $\mathrm{MoSi}_{2} / / \mathrm{WSi}_{2}$ couple should be near 2.8 $\mu \mathrm{V} /{ }^{\circ} \mathrm{C}$, estimated from the data presented by Bennethum and Sherwood [34]. As briefly discussed above, the raw precursors and sintered composites used in the current study showed the additional 5-3 metal silicide phases (within both Mo and W compositions), as characterized by both XPS and XRD. It is believed that the addition of the 5-3 metal silicide phases within the thermocouple is enhancing the thermoelectric effect for the sensors above that predicted for the pure $\mathrm{MoSi}_{2} / / \mathrm{WSi}_{2}$ compositions. As shown in this 
work, the amount of 5-3 metal silicide phase increases in both the $\mathrm{MoSi}_{2}$ and $\mathrm{WSi}_{2}$ compositions as the alumina content is decreased, resulting in a significant increase in the Seebeck coefficient of the [90-10] $\mathrm{MoSi}_{2}-\mathrm{Al}_{2} \mathrm{O}_{3} / /[90-10] \mathrm{WSi}_{2}-\mathrm{Al}_{2} \mathrm{O}_{3}$ thermocouple at $1000^{\circ} \mathrm{C}$. Unfortunately, the Seebeck data for pure $\mathrm{Mo}_{5} \mathrm{Si}_{3}$ and $\mathrm{W}_{5} \mathrm{Si}_{3}$ phases are not available in literature, and further work is being completed by the current authors to investigate the intrinsic thermoelectric characteristics of various 5-3 metal silicide phases.

In addition, Figure 87 presents both estimated (dashed lines) and measured (solid lines) Seebeck coefficients of the various $\mathrm{MoSi}_{2}-\mathrm{Al}_{2} \mathrm{O}_{3} / / \mathrm{WSi}_{2}-\mathrm{Al}_{2} \mathrm{O}_{3}$ composite thermocouples. The measured Seebeck coefficients of the $\mathrm{MoSi}_{2}-\mathrm{Al}_{2} \mathrm{O}_{3} / / \mathrm{WSi}_{2}-\mathrm{Al}_{2} \mathrm{O}_{3}$ composite thermocouples were acquired directly from the experiments of the composite thermocouples. The estimated Seebeck coefficients were calculated by using the data obtained with the metal silicide-oxide//Pt thermocouples and utilizing the equations (2-4). It was demonstrated that the measured Seebeck coefficients from the actual $\mathrm{MoSi}_{2}$ $\mathrm{Al}_{2} \mathrm{O}_{3} / / \mathrm{WSi}_{2}-\mathrm{Al}_{2} \mathrm{O}_{3}$ composite thermocouples were higher than those estimated from the data of metal silicide-oxide//Pt thermocouples and Pt reference. It can be also seen that the [50-50], [60-40] $\mathrm{MoSi}_{2}-\mathrm{Al}_{2} \mathrm{O}_{3} / /[50-50]$, [60-40] $\mathrm{WSi}_{2}-\mathrm{Al}_{2} \mathrm{O}_{3}$ thermocouples exhibited relatively higher effective Seebeck coefficients than the [75-25] and [90-10] compositions only at $700^{\circ} \mathrm{C}$; while they exhibited lower effective Seebeck coefficients at the temperatures ranging from $27^{\circ} \mathrm{C}$ to $\sim 480^{\circ} \mathrm{C}$ (solid lines in the Figure 87). In addition, the [60-40] $\mathrm{MoSi}_{2}-\mathrm{Al}_{2} \mathrm{O}_{3} / /[60-40] \mathrm{WSi}_{2}-\mathrm{Al}_{2} \mathrm{O}_{3}$ thermocouple could display relatively higher Seebeck coefficients than the [90-10] at the temperatures above $400^{\circ} \mathrm{C}$ based on the estimated Seebeck coefficients (dashed lines). This estimated trend was clearly observed in the measured effective Seebeck coefficients of these composite thermocouples at the temperatures above $500^{\circ} \mathrm{C}$, as seen in Figure 87. As a review, these results indicated that a difference in 5-3 metal silicide content may not be the only aspect influencing the thermocouple performance; local compositional changes at the junction of the two composite legs may also be enhancing the thermoelectric behavior. Further work must be 


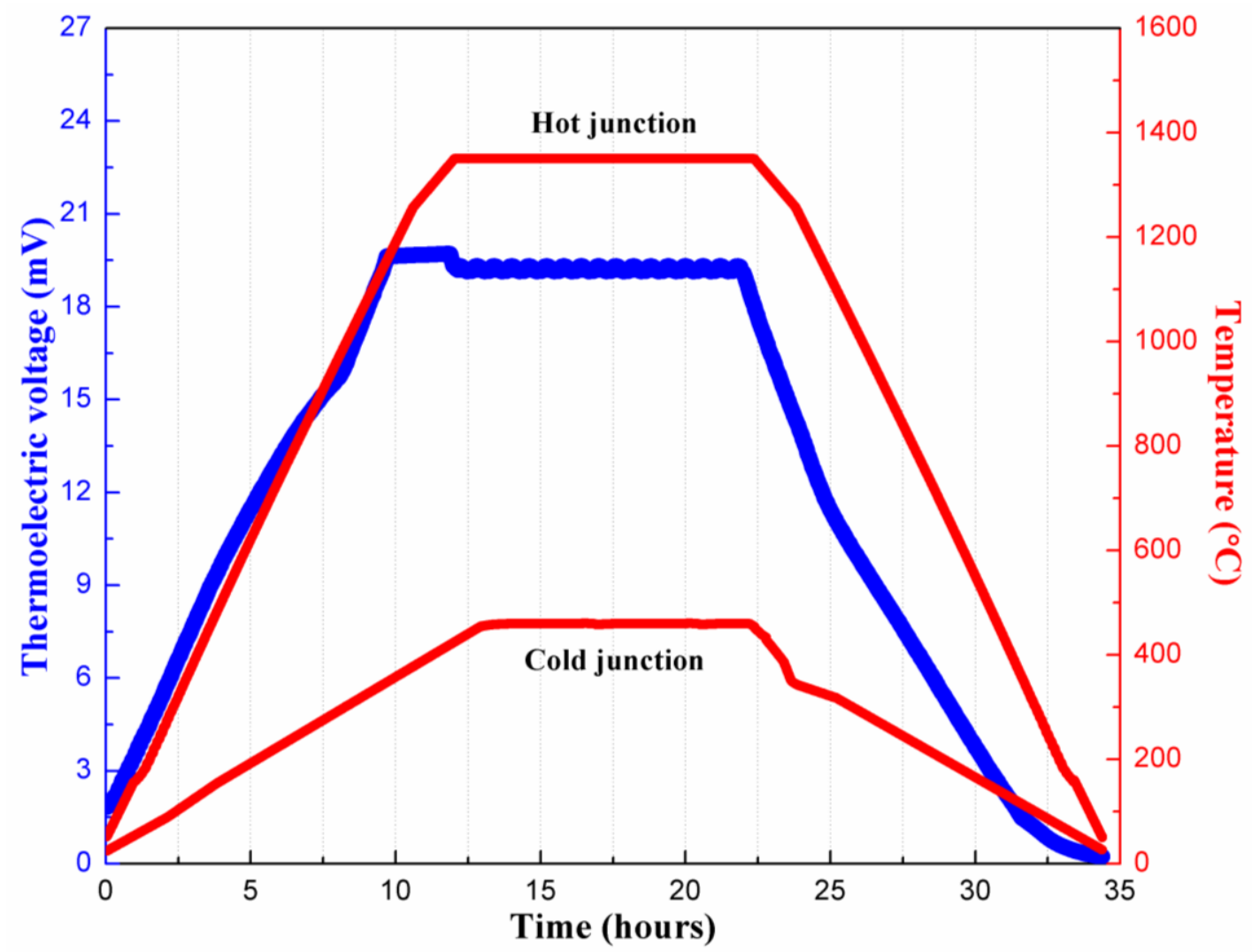

Figure 88. Thermoelectric performance of the [90-10] $\mathrm{MoSi}_{2}-\mathrm{Al}_{2} \mathrm{O}_{3} / /[90-10] \mathrm{WSi}_{2}-\mathrm{Al}_{2} \mathrm{O}_{3}$ long composite thermocouple $\left(22.9 \mathrm{~cm}\right.$ length, $0.6 \mathrm{~cm}$ width) up to $1350^{\circ} \mathrm{C}$, as a function of cold- and hot-junction temperature, and time.

completed in order to isolate the influence at this location, possibly through more compositionally controlled thin-film experiments.

To investigate the thermoelectric performance of a long thermocouple $(22.9 \mathrm{~cm}$ length, $0.6 \mathrm{~cm}$ width, $\sim 400 \mu \mathrm{m}$ thickness) at higher temperatures, a composite thermocouple with a configuration of [90-10] $\mathrm{MoSi}_{2}-\mathrm{Al}_{2} \mathrm{O}_{3} / /[90-10] \mathrm{WSi}_{2}-\mathrm{Al}_{2} \mathrm{O}_{3}$ was selected for an extended demonstration of the thermoelectric performance at higher temperatures and durations $\left(1350^{\circ} \mathrm{C}\right.$ for $10 \mathrm{~h}$ in argon). The thermoelectric performance of a long [90-10] $\mathrm{MoSi}_{2}-\mathrm{Al}_{2} \mathrm{O}_{3} / /[90-10] \mathrm{WSi}_{2}-\mathrm{Al}_{2} \mathrm{O}_{3}$ composite thermocouple is presented as a function of temperature and time in the Figure 88. A reference thermocouple was placed near the cold and hot junction of the sensor sample; the temperature versus measurement 
time data collected from both reference thermocouples was also included in the Figure 88. A slightly different testing configuration (compared to the smaller thermocouples discussed in this work) was needed for testing at the higher operation temperatures. The longer thermocouple was measured within a high-temperature tube furnace with alumina fiberinsulation placed around the cold-junction. Even with this insulation, the cold-junction reached a temperature of $\sim 460^{\circ} \mathrm{C}$ when the $1350^{\circ} \mathrm{C}$ maximum isothermal was achieved. The thermoelectric voltage linearly increased with increasing temperature, and it exhibited a maximum thermoelectric voltage of $19.3 \mathrm{mV}$ at $1350^{\circ} \mathrm{C}$. It is also clear that its thermoelectric performance was adequately stable during the isothermal hold for $10 \mathrm{~h}$. The slight changes in the thermoelectric voltage data during the isothermal hold were found to be caused by small temperature fluctuations $\left(\sim 0.02^{\circ} \mathrm{C}\right)$ of the high-temperature furnace; and therefore, it does not indicate any stability issue of the composite thermocouple. As a result, this thermoelectric response shows promise for future high-temperature applications for replacement of precious metal-based sensors.

\subsection{Conclusions}

Various thermocouples were fabricated by using two metal silicides ( $\left.\mathrm{MoSi}_{2}, \mathrm{WSi}_{2}\right)$, $\mathrm{MoSi}_{2}-\mathrm{Al}_{2} \mathrm{O}_{3}$ and $\mathrm{WSi}_{2}-\mathrm{Al}_{2} \mathrm{O}_{3}$ composites, and platinum. The phase development, microstructural analysis and thermoelectric characterization studies were performed on various combinations of these materials. It was determined that 5-3 metal silicides $\left(\mathrm{Mo}_{5} \mathrm{Si}_{3}\right.$, $\mathrm{W}_{5} \mathrm{Si}_{3}$ ) were formed in the composite thermocouples as secondary phases during sintering. Small amounts of silica and tungsten oxide $\left(\mathrm{WO}_{3}\right)$ phases were also found to be formed on the surface of the thermocouples. In addition, an increase in the concentration of secondary 5-3 silicides with increasing metal silicide content in the composites was shown for the composites. Thermoelectric voltage and Seebeck coefficients of the thermocouples mostly increased with increasing temperature and metal silicide content. Significant improvements in the thermoelectric performance of the composite thermocouples $\left(\mathrm{MoSi}_{2}-\mathrm{Al}_{2} \mathrm{O}_{3} / \mathrm{Pt}\right.$, $\mathrm{WSi}_{2}-\mathrm{Al}_{2} \mathrm{O}_{3} / / \mathrm{Pt}$ and $\mathrm{MoSi}_{2}-\mathrm{Al}_{2} \mathrm{O}_{3} / / \mathrm{WSi}_{2}-\mathrm{Al}_{2} \mathrm{O}_{3}$ ) were achieved particularly at the [90-10] volume percentage. It was proposed that the increased presence of the 5-3 metal silicide 
$\left(\mathrm{Mo}_{5} \mathrm{Si}_{3}, \mathrm{~W}_{5} \mathrm{Si}_{3}\right)$ phases formed within the composite systems having high metal silicide content (75-90 vol\%) may be influencing the increased thermoelectric performance. In addition, the measured effective Seebeck coefficients of the $\mathrm{MoSi}_{2}-\mathrm{Al}_{2} \mathrm{O}_{3} / / \mathrm{WSi}_{2}-\mathrm{Al}_{2} \mathrm{O}_{3}$ thermocouples were significantly higher than their estimated Seebeck coefficients from the Pt reference measurements, possibly indicating further compositional effects at the thermocouple junction. A long composite thermocouple with a configuration of [90-10] $\mathrm{MoSi}_{2}-\mathrm{Al}_{2} \mathrm{O}_{3} / /[90-10] \mathrm{WSi}_{2}-\mathrm{Al}_{2} \mathrm{O}_{3}$ embedded within an alumina preform displayed stable thermoelectric performance at $1350^{\circ} \mathrm{C}$ with a maximum thermoelectric voltage of $19.3 \mathrm{mV}$. This study presented that the $\mathrm{MoSi}_{2}-\mathrm{Al}_{2} \mathrm{O}_{3} / / \mathrm{WSi}_{2}-\mathrm{Al}_{2} \mathrm{O}_{3}$ thick-film ceramic composite thermocouples have great potential for high-temperature measurements, and the ceramicbased composite thermocouples are relatively robust and stable, and substantially less costly compared to the mostly used precious metal-based thermocouples.

\section{References}

[1] T.M. McGee, Principles and Methods of Temperature Measurement, Wiley, New York, (1988).

[2] E.M. Sabolsky, R.C. Pillai, K. Sabolsky, G.A. Yakaboylu, B. Armour, A. Teter, M. Palmisiano, T. Close, Refractory ceramic sensors for process and health monitoring of slagging gasifiers, ECS Trans. 66, 43-53 (2015).

[3] H.D. Bhatt, R. Vedula, S.B. Desu, G.C. Fralick, Thin film TiC/TaC thermocouples, Thin Solid Films. 342, 214-220 (1999).

[4] R.C. Budhani, S. Prakash, R.F. Bunshah, Thin film temperature sensors for gas turbine engines: Problems and prospects, J. Vac. Sci. Technol. A. 4, 2609-2617 (1986).

[5] O.J. Gregory, T. You, Ceramic temperature sensors for harsh environments, IEEE Sensors. 5, 833-838 (2005).

[6] X. Chen, O.J. Gregory, M. Amani, Thin film thermocouples based on the system $\mathrm{In}_{2} \mathrm{O}_{3}$ $\mathrm{SnO}_{2}$, J. Am. Ceram. Soc. 94, 854-860 (2011). 
[7] J.D. Wrbanek, G.C. Fralick, S.C. Farmer, A. Sayir, C.A. Blaha, J.M. Gonzalez, Development of thin film ceramic thermocouples for high temperature environments, NASA Contractor Report. NASA/TM-2004-213211, August (2004).

[8] M. Kohl, G. Veltl, M. Busse, Printed sensors produced via thick film technology for the use in monitoring applications, Procedia Technology. 15, 107-113 (2014).

[9] A.K. Vasudevan, J.J. Petrovic, A comparative overview of molybdenum disilicide composites, Mater. Sci. Eng. A. 155, 1-17 (1992).

[10] S.K. Sundaram, R.F. Speyer, Electrochemical corrosion and protection of molybdenum and molybdenum disilicide in a molten soda-lime silicate glass environment, J. Am. Ceram. Soc. 79, 1851-1856 (1996).

[11] H. Yamamoto, S. Sendai, Study on high temperature thermistor made of $\mathrm{MoSi}_{2}$ granular $\mathrm{Al}_{2} \mathrm{O}_{3}$ composite, J. Ceram. Soc. Jpn. 97, 783-786 (1989).

[12] L. Lutterotti, S. Matthies, H.R. Wenk, MAUD: a friendly Java program for material analysis using diffraction, IUCr Newsletter CPD. 21, 14-15 (1999).

[13] T. Tabaru, K. Shobu, M. Sakamoto, S. Hanada, Effects of substitution of Al for Si on the lattice variations and thermal expansion of $\mathrm{Mo}(\mathrm{Si}, \mathrm{Al})_{2}$, Intermetallics. 12, 33-41 (2004).

[14] J. Xu, Z.Y. Li, P. Munroe, Z.H. Xie, Oxidation resistance of $\mathrm{Mo}\left(\mathrm{Si}_{1-\mathrm{X}} \mathrm{Al}_{\mathrm{x}}\right)_{2}$ nanocrystalline films and characterization of their oxide scales by electrochemical impedance spectroscopy, RSC Adv. 4, 55696-55708 (2014).

[15] J. Xua, Z. Li, Z.H. Xiec, P. Munroed, X.L. Lua, X.F. Lana, Novel high damagetolerant, wear resistant $\mathrm{MoSi}_{2}$ based nanocomposite coatings, Applied Surface Science. 270, 418-427 (2013).

[16] E.N. Kaufmann, Characterization of Materials, vol. 2, John Wiley \& Sons, Hoboken, New Jersey (2003).

[17] Z. Liu, Y. Kawashima, A. Komatsu, T. Hamada, H. Kawano, K. Shiotani, Formation mechanism of metal-oxides on plasma-exposed WSix/ poly Si gate stacks, Jpn. J. Appl. Phys. 38, 209-211 (1999). 
[18] J.K. Yoon, K.W. Lee, S.J. Chung, I.J. Shon, J.M. Doh, G.H. Kim, Growth kinetics and oxidation behavior of $\mathrm{WSi}_{2}$ coating formed by chemical vapor deposition of $\mathrm{Si}$ on $\mathrm{W}$ substrate, Journal of Alloys and Compounds. 420, 199-206 (2006).

[19] T.M. Christensen, Surface studies of amorphous $\mathrm{W}_{75} \mathrm{Si}_{25}$ oxidation, J. Vac. Sci. Technol. A. 7, 1689-1693 (1989).

[20] Z. Yao, J. Stiglich, T.S. Sudarshan, Molybdenum silicide based materials and their properties, J. Mater. Eng. Perform. 8, 291-304 (1999).

[21] G. Jiang, S. Bai, L. Chen, W. Li, H. Zhuang, Fabrication and microstructure of $\mathrm{MoSi}_{2} / \mathrm{Al}_{2} \mathrm{O}_{3}$ functionally graded material, Mater. Sci. Forum. 423-425, 195-198 (2003).

[22] C.D. Wirkus, D.R. Wilder, High-temperature oxidation of molybdenum disilicide, J. Am. Ceram. Soc. 49, 173-177 (1966).

[23] J.J. Petrovic, A.K. Vasudevan, Key developments in high temperature structural silicides, Mater. Sci. Eng. A. 261, 1-5 (1999).

[24] W-Y. Lin, R.F. Speyer, Stability of molybdenum disilicide in combustion gas environments, J. Am. Ceram. Soc. 77, 1162-1168 (1994).

[25] G.A. Yakaboylu, R.C. Pillai, K. Sabolsky, E.M. Sabolsky, Stability and electrical properties of $\mathrm{MoSi}_{2}$ - and $\mathrm{WSi}_{2}$-oxide electroconductive composites, J. Am. Ceram. Soc. 100, 4461-4475 (2017).

[26] A. Chakraborty, S.V. Kamat, R. Mitra, K.K. Ray, Effect of $\mathrm{MoSi}_{2}$ and $\mathrm{Nb}$ reinforcements on mechanical properties of $\mathrm{Al}_{2} \mathrm{O}_{3}$ matrix composites, J. Mater. Sci. 35, 3827-3835 (2000).

[27] S. Kobel, J. Pluschke, U. Vogt, T.J. Graule, $\mathrm{MoSi}_{2}-\mathrm{Al}_{2} \mathrm{O}_{3}$ electroconductive ceramic composites, Ceram. Int. 30, 2105-2110 (2004).

[28] T.C. Lu, J. Yang, Z. Suo, A.G. Evans, R. Hecht, R. Mehrabian, Matrix cracking in intermetallic composites caused by thermal-expansion mismatch, Acta Metall. Mater. 39, 1883-1890 (1991).

[29] J. Martin, T. Tritt, C. Uher, High temperature Seebeck coefficient metrology, J. Appl. Phys. 108, 121101-1-12 (2010). 
[30] K.G. Kreider, G. Gillen, High temperature materials for thin-film thermocouples on silicon wafers, Thin Solid Films. 376, 32-37 (2000).

[31] K.G. Kreider, Thin film high temperature silicide thermocouples, U.S. Patent, No. 5474619 (1995).

[32] M. Gunes, M. Parlak, M. Ozenbas, An instrument for the high temperature measurement of the Seebeck coefficient and electrical resistivity, Meas. Sci. Technol. 25, 055901 (2014).

[33] E. Committee, Ed., Manual on the use of thermocouples in temperature measurement, STP470B-EB, ASTM International, West Conshohocken, PA (1981).

[34] W.H. Bennethum, L.T. Sherwood, Sensors for ceramic components in advanced propulsion systems, NASA Contractor Report. NASA-CR-180900, August (1988). 
CHA P T ER 7: EFFECT OF ALUMINA PHASE AND HIGH - TEMPERATURE PREOXIDATION TREATMENT ON OXIDATION BEHAVIOR OF COMPOSITES

\subsection{Introduction}

Molybdenum silicide $\left(\mathrm{MoSi}_{2}\right)$ and tungsten silicide ( $\left.\mathrm{WSi}_{2}\right)$ were extensively studied due to their great potential for use in a broad range of structural and electrical applications subjected to elevated temperatures and harsh conditions such as gas turbine blades, heating elements and gate electrodes. Their high melting points $\left(>2000^{\circ} \mathrm{C}\right)$, good mechanical strength/hardness, excellent high-temperature oxidation resistance above $1000^{\circ} \mathrm{C}$, and high electrical conductivity are described as their major advantages [1-6]. However, at relatively lower temperatures $\left(\sim 400^{\circ}-800^{\circ} \mathrm{C}\right)$, these silicides undergo catastrophic oxidation, as commonly referred as pest oxidation or pesting, resulting in dramatic structural disintegration from the bulk into a powder [7-10]. This accelerated internal oxidation phenomenon is found to be caused by simultaneous oxidation of metals (Mo, W) and silicon to form highly volatile molybdenum oxide $\left(\mathrm{MoO}_{3}\right)$ and tungsten oxide $\left(\mathrm{WO}_{3}\right)$ phases, which inhibit the formation of a protective and highly dense silica $\left(\mathrm{SiO}_{2}\right)$ layer on the surface [10-12]. The $\mathrm{MoSi}_{2}$ - and $\mathrm{WSi}_{2}$-based materials are also known to be more prone to pest oxidation in the presence of high porosity, microcracks and internal stresses $[13,14]$.

For greater application, these metal silicides need to be capable of operating under cyclic oxidation conditions in a wide temperature range $\left(\sim 400^{\circ}-1600^{\circ} \mathrm{C}\right)$ for long operation hours, and thus, it is crucial to improve their low-temperature (pest) oxidation resistance for enhancing their lifetime, reliability and performance. Therefore, different engineering approaches have been applied over the years to improve their oxidation resistance by controlling their oxidation kinetics. The substitutional alloying with metals and reinforcing with ceramic materials (composite approach) are the most widely used techniques in this 
field $[3,7,15]$. The most common alloying elements for these silicide systems are aluminum, boron, chromium and vanadium, while carbides (e.g. $\mathrm{SiC}, \mathrm{TiC}$ ), borides (e.g. $\mathrm{TiB}_{2}, \mathrm{MoB}$ ) and $\mathrm{Si}_{3} \mathrm{~N}_{4}$ are commonly used as a secondary reinforcing phase with these silicides. Some improvements on their low-temperature oxidation resistance were achieved mostly by the addition of different carbides and borides [12,16-18]. These achievements were attributed to the reduced oxygen diffusion rates owing to selective oxidation of the additive phases and the formation of relatively dense surface silica layers along with different oxide phases (e.g. $\mathrm{TiO}_{2}, \mathrm{Mo}_{9} \mathrm{O}_{26}$ ). In addition, it was reported that the addition of 10-30 vol\% $\mathrm{Al}_{2} \mathrm{O}_{3}$ phase could relatively lower the pest oxidation of $\mathrm{MoSi}_{2}$ coatings at $500^{\circ} \mathrm{C}$, but the molybdenum oxide $\left(\mathrm{MoO}_{3}\right)$ phase was still detected after exposure to air for $16 \mathrm{~h}$ [19]. However, it should be noted that the high-temperature oxidation of the $\mathrm{MoSi}_{2}$ coatings was adversely influenced by the increased alumina content due to the formation of the mullite phase and pores within the surface $[19,20]$. There are limited studies conducted on the effect of alumina addition for the metal silicide-based $\left(\mathrm{MoSi}_{2}, \mathrm{WSi}_{2}\right)$ material systems, and thus, further oxidation studies are highly needed.

Another approach to enhance the low-temperature oxidation of the metal silicides is through a high-temperature preoxidation treatment, which aims to form a protective surface layer without any reinforcement. To the author's knowledge, this alternative approach was first reported in open literature on hot isostatically pressed $\mathrm{MoSi}_{2}$ samples by Berztiss et al. [21]. They preoxidized the $\mathrm{MoSi}_{2}$ samples at $1000^{\circ} \mathrm{C}$ for 26 and $54 \mathrm{~h}$, and directly cooled the samples to $500^{\circ} \mathrm{C}$ for performing the oxidation tests in an oxygen atmosphere. The results showed that the preoxidized $\mathrm{MoSi}_{2}$ samples still oxidized after $\sim 75-110 \mathrm{~h}$ of isothermal oxidation period at $500^{\circ} \mathrm{C}$, but the process highly limited the internal oxidation. The clay-bonded $\mathrm{MoSi}_{2}$-based composite samples were preoxidized at $1400^{\circ} \mathrm{C}$ for an hour in another study [22]. Their isothermal oxidation experiments at $500^{\circ} \mathrm{C}$ for $288 \mathrm{~h}$ showed that the specific mass change could be reduced from +0.466 to $-0.007 \mathrm{mg} / \mathrm{cm}^{2}$ by forming the protective surface silica (low-cristobalite) layer via the preoxidation treatment. This result demonstrated that the structural disintegration and pest oxidation of the $\mathrm{MoSi}_{2}$ could 
be highly restrained using this approach. However surprisingly, there are very limited studies investigating the effect of a high-temperature preoxidation treatment on the pest oxidation of the transition metal silicides (e.g. $\mathrm{MoSi}_{2}, \mathrm{TiSi}_{2}$ ) [21-23], and no study was found on the $\mathrm{WSi}_{2}$ system to the best of our knowledge. Therefore, the conceptual understanding of the high-temperature preoxidation treatment is very limited. Further studies are essential to better understand the mechanism and kinetics of the hightemperature preoxidation treatment, formation of surface oxide layers (surface characterization), and their effect on the low-temperature oxidation behavior of the transition metal silicides and their composites.

The high-temperature preoxidation treatment is a very promising approach for enhancing the low-temperature oxidation resistance of the transition metal silicides and their performance for high-temperature structural and electrical applications. This could be highly beneficial particularly for the high-temperature electrical applications (e.g. interconnects, sensors), since the intrinsic electrical properties of the transition metal silicides could be theoretically preserved at the same time, unlike the common alloying approaches which focus on structural applications. Therefore, in this study, $\mathrm{MoSi}_{2}-\mathrm{Al}_{2} \mathrm{O}_{3}$ and $\mathrm{WSi}_{2}-\mathrm{Al}_{2} \mathrm{O}_{3}$ composites were preoxidized at $1000^{\circ}-1200^{\circ} \mathrm{C}$ to understand the combined effect of the alumina addition and high-temperature preoxidation on surface oxide formation and their low-temperature oxidation behavior. Their electrical properties were additionally characterized to examine the influence of the preoxidation treatment on their high-temperature electrical performance.

\subsection{Materials and Method}

\subsubsection{Processing of the $\mathrm{MoSi}_{2}$ - and $\mathrm{WSi}_{2}-\mathrm{Al}_{2} \mathrm{O}_{3}$ composites}

Commercial $\mathrm{MoSi}_{2}(99.5 \%)$ and $\mathrm{WSi}_{2}(99.5 \%)$ powders were purchased from Alfa Aesar (Tewksbury, MA) as starting metal silicide powders, while the starting corundum $\mathrm{Al}_{2} \mathrm{O}_{3}$ powder $(99.8 \%)$ was provided by Almatis (Leetsdale, PA). These powders were initially characterized by X-ray diffraction (XRD, Panalytical X'Pert Pro, Westborough, MA) and field emission scanning electron microscopy (FE-SEM, Hitachi S-4700F, Tokyo, 
Japan). The results (not shown) displayed that starting metal silicide powders consisted of metal disilicides $\left(\mathrm{MoSi}_{2}, \mathrm{WSi}_{2}\right)$ and 5-3 metal silicides $\left(\mathrm{Mo}_{5} \mathrm{Si}_{3}, \mathrm{~W}_{5} \mathrm{Si}_{3}\right)$, all with a tetragonal structure, and remaining metal phases (Mo, W). The average grain sizes of the starting $\mathrm{MoSi}_{2}, \mathrm{WSi}_{2}$ and $\mathrm{Al}_{2} \mathrm{O}_{3}$ powders were 4.2, 5.3 and $0.4 \mu \mathrm{m}$, respectively, as measured using the ImageJ software [24]. The metal silicide powders had random morphology, while the equiaxed morphology was identified for the alumina powder as presented in our previous publication [25]. The $\mathrm{MoSi}_{2}-\mathrm{Al}_{2} \mathrm{O}_{3}$ and $\mathrm{WSi}_{2}-\mathrm{Al}_{2} \mathrm{O}_{3}$ composite powders were prepared by the addition of 70 vol\% of alumina phase via ball-milling in ethanol for $24 \mathrm{~h}$. Since the metal silicide-oxide volume percentages kept constant at 30-70 vol\%, only composite compositions $\left(\mathrm{MoSi}_{2}-\mathrm{Al}_{2} \mathrm{O}_{3}\right.$ and $\left.\mathrm{WSi}_{2}-\mathrm{Al}_{2} \mathrm{O}_{3}\right)$ were used throughout the paper. After the drying process at around $50^{\circ} \mathrm{C}$, the cylindrical pellets with $13-26 \mathrm{~mm}$ diameter were pressed using a uniaxial press, followed by sintering at $1600^{\circ} \mathrm{C}$ for $2 \mathrm{~h}$ under $50 \mathrm{sccm}$ of argon flow. The heating and cooling rates were kept constant at $3^{\circ} \mathrm{C} / \mathrm{min}$ during sintering processes. In addition, baseline $\mathrm{MoSi}_{2}$ and $\mathrm{WSi}_{2}$ pellets were sintered under similar conditions without the addition of the alumina phase for initial comparison.

\subsubsection{High-temperature preoxidation treatment}

Prior to the preoxidation treatment, very small square/rectangular specimens having $0.10-0.19 \mathrm{~cm}^{2}$ surface area were prepared from the as-sintered composites by cutting and fine polishing with a 600 grit $\mathrm{SiC}$ polishing paper. Larger rectangular bar samples $(\sim 15 \times 4 \times 2 \mathrm{~mm})$ were also prepared from the selected samples for further high-temperature electrical measurements. This was followed by cleaning of the samples in ethanol under ultrasonication for 10 minutes. The as-prepared specimens were placed in a tube furnace within an alumina crucible. They were all preoxidized isothermally at $1000^{\circ}-1200^{\circ} \mathrm{C}$ under $10 \mathrm{sccm}$ of air flow for different time periods ranging from 10 to 120 minutes. After the preoxidation treatment was completed, they were further heated to $1300^{\circ} \mathrm{C}$ by $2^{\circ} \mathrm{C} / \mathrm{min}$ and held there for $2 \mathrm{~h}$ to densify the surface oxide layer formed. It should be noted that all steps (heating, cooling and isothermal hold at $1300^{\circ} \mathrm{C}$ ), except for the isothermal preoxidation treatments, were conducted in argon $(50 \mathrm{sccm})$ to avoid any other oxidation reactions. 
Table 16. High-temperature preoxidation (PO) treatment conditions and sample denotations.

\begin{tabular}{|c|c|c|}
\hline $\begin{array}{l}\text { Preoxidation } \\
\text { temperature }\end{array}$ & $\begin{array}{l}\text { Preoxidation } \\
\text { time (minutes) }\end{array}$ & $\begin{array}{l}\text { PO sample } \\
\text { denotation }\end{array}$ \\
\hline \multirow{4}{*}{$1000^{\circ} \mathrm{C}$} & 10 & PO-1000-10 \\
\hline & 30 & PO-1000-30 \\
\hline & 60 & PO-1000-60 \\
\hline & 120 & PO-1000-120 \\
\hline \multirow{4}{*}{$1100^{\circ} \mathrm{C}$} & 10 & PO-1100-10 \\
\hline & 30 & PO-1100-30 \\
\hline & 60 & PO-1100-60 \\
\hline & 120 & PO-1100-120 \\
\hline \multirow{4}{*}{$1200^{\circ} \mathrm{C}$} & 10 & PO-1200-10 \\
\hline & 30 & PO-1200-30 \\
\hline & 60 & PO-1200-60 \\
\hline & 120 & PO-1200-120 \\
\hline
\end{tabular}

The air and argon volumetric flow rates were controlled by a LabVIEW program (National Instruments, Austin, TX) as a function of time and temperature. For simplicity, the preoxidized composite samples (abbreviated as $\boldsymbol{P O}$ ) were labeled in this paper based on the preoxidation conditions; for example, a composite sample preoxidized at $1000^{\circ} \mathrm{C}$ for 30 minutes was termed as "PO-1000-30". All preoxidation conditions and sample denotations are additionally listed in Table 16. The optical macrographs of the samples were recorded before/after preoxidation treatments using a digital microscope (Dino-Lite, New Taipei City, Taiwan). 


\subsubsection{Oxidation tests and material characterization}

A thermogravimetric analyzer (TGA, Pyris 1, PerkinElmer, Shelton, CT) was used to perform the non-isothermal oxidation tests in an ambient air atmosphere $(20 \mathrm{ml} / \mathrm{min})$ at the temperatures ranging from $50^{\circ} \mathrm{C}$ to $870^{\circ} \mathrm{C}$. The heating rate was kept constant at $10^{\circ} \mathrm{C} / \mathrm{min}$ for all oxidation experiments conducted on the reference silicide samples $\left(\mathrm{MoSi}_{2}, \mathrm{WSi}_{2}\right)$, as-sintered composites (without preoxidation, termed as w/o PO) and preoxidized composites (termed as $\boldsymbol{w} / \boldsymbol{P O}$ ). The optical images of the samples were also taken after the non-isothermal oxidation tests. The densities of the as-sintered composites were measured by applying the Archimedes technique using ethanol as the immersion liquid. The apparent porosity levels of the non-preoxidized $\mathrm{MoSi}_{2}-\mathrm{Al}_{2} \mathrm{O}_{3}$ and $\mathrm{WSi}_{2}-\mathrm{Al}_{2} \mathrm{O}_{3}$ composites were then calculated as $10.4( \pm 0.81)$ and $8.3 \%( \pm 2.10)$, respectively. The bright-field optical images of the composite surfaces were taken by a light microscope (Axio Lab.A1, Zeiss, Jena, Germany) using a contrast enhancing blue color filter. For microstructural analyses, the cross-sectional areas of the composite samples were polished using SiC polishing sheets (600-1200 grits) followed by a diamond paste $(0.5 \mu \mathrm{m})$. After 10 minutes of overall polishing process, the as-polished samples were subsequently ultrasonicated in deionized water and ethanol, each for 10-15 minutes. The cross-sectional microstructural analysis of the samples was performed using a field-emission scanning electron microscope (FE-SEM, Hitachi S-4700F, Tokyo, Japan).

The phase analysis of the composite samples was initially conducted by X-ray diffraction (XRD, Panaltyical X'Pert Pro, Westborough, MA) with $\mathrm{CuK}_{\alpha}$ radiation source. The surface characterization of the composite samples before/after high-temperature preoxidation treatments were performed by X-ray photoelectron spectroscopy (XPS, Physical Electronics, PHI 5000 VersaProbe, Chanhassen, MN) and Raman microscope (Renishaw InVia Raman, New Mills, UK). The XPS analyses were conducted using a focused monochromatized Al-Ka radiation $(1486.6 \mathrm{eV})$, and the peaks were recorded with a constant pass energy of $0.5 \mathrm{eV}$ in the 0 to $1400 \mathrm{eV}$ spectral range. Raman spectra of the composites were measured with $532 \mathrm{~nm}$ Ar laser excitation, where the laser beam was 
focused on the sample with a $50 \times$ microscope objective with a $100 \%$ laser power. Standard 4-point DC electrical conductivity measurements were conducted at the temperatures up to $950^{\circ} \mathrm{C}$ using the as-prepared rectangular bar samples, which were attached to the test setup made of a four-bore alumina tube and platinum $(\mathrm{Pt})$ wires $(99.95 \%$ pure, Surepure Chemetals, Florham Park, NJ). The electrical measurements were carried out in argon atmosphere for a better comparison of the electrical data of the composite samples with (and without) subjected to the high-temperature preoxidation treatment. It should be also noted that the surface oxide layers formed after preoxidation were removed via fine polishing using 1200 grit SiC polishing paper for 30-40 seconds before electrical tests due to the insulating characteristics of the surface layers and difficulty of making continuous $\mathrm{Pt}$ electrical connections. A digital multimeter (Keithley 2100, Tektronix, Beaverton, OR) was controlled by LabVIEW (National Instruments, Austin, TX) and Keithley software to measure the electrical resistance of the composite samples as a function of temperature, which was simultaneously recorded by a B-type of thermocouple.

\subsection{Results}

\subsubsection{Non-isothermal low-temperature oxidation}

The oxidation-induced mass changes for the as-sintered (non-preoxidized) silicides $\left(\mathrm{MoSi}_{2}, \mathrm{WSi}_{2}\right)$ and their composites with the addition of 70 vol\% alumina phase are presented in Figure 89 as a function of oxidation temperature ranging from $50^{\circ} \mathrm{C}$ to $870^{\circ} \mathrm{C}$. A negligible mass gain $\left(\leq 0.12 \mathrm{mg} / \mathrm{cm}^{2}\right)$ was observed for the $\mathrm{MoSi}_{2}$ and $\mathrm{MoSi}_{2}-\mathrm{Al}_{2} \mathrm{O}_{3}$ composite samples up to around $400^{\circ} \mathrm{C}$. It is apparent that there was a notable mass gain at the temperature region of $400^{\circ}-780^{\circ} \mathrm{C}$ due to low-temperature oxidation of $\mathrm{MoSi}_{2}$ leading to the formation of $\mathrm{MoO}_{3}$ and $\mathrm{SiO}_{2}$ as oxidation products [21,26,27]. The overall mass gain at $780^{\circ} \mathrm{C}$ for the $\mathrm{MoSi}_{2}-\mathrm{Al}_{2} \mathrm{O}_{3}$ composite $\left(0.44 \mathrm{mg} / \mathrm{cm}^{2}\right)$ was relatively lower than that for the $\mathrm{MoSi}_{2}\left(0.72 \mathrm{mg} / \mathrm{cm}^{2}\right)$. The mass loss was detected above this temperature, which is related to the evaporation of the volatile $\mathrm{MoO}_{3}$ phase [12]. However, no pest oxidation was observed for both $\mathrm{MoSi}_{2}$-based samples during non-isothermal oxidation, since pesting usually refers to the formation of volatile oxide species, followed by a structural disintegration of the bulk samples into powders [28]. Similar to the $\mathrm{MoSi}_{2}$-based materials, 

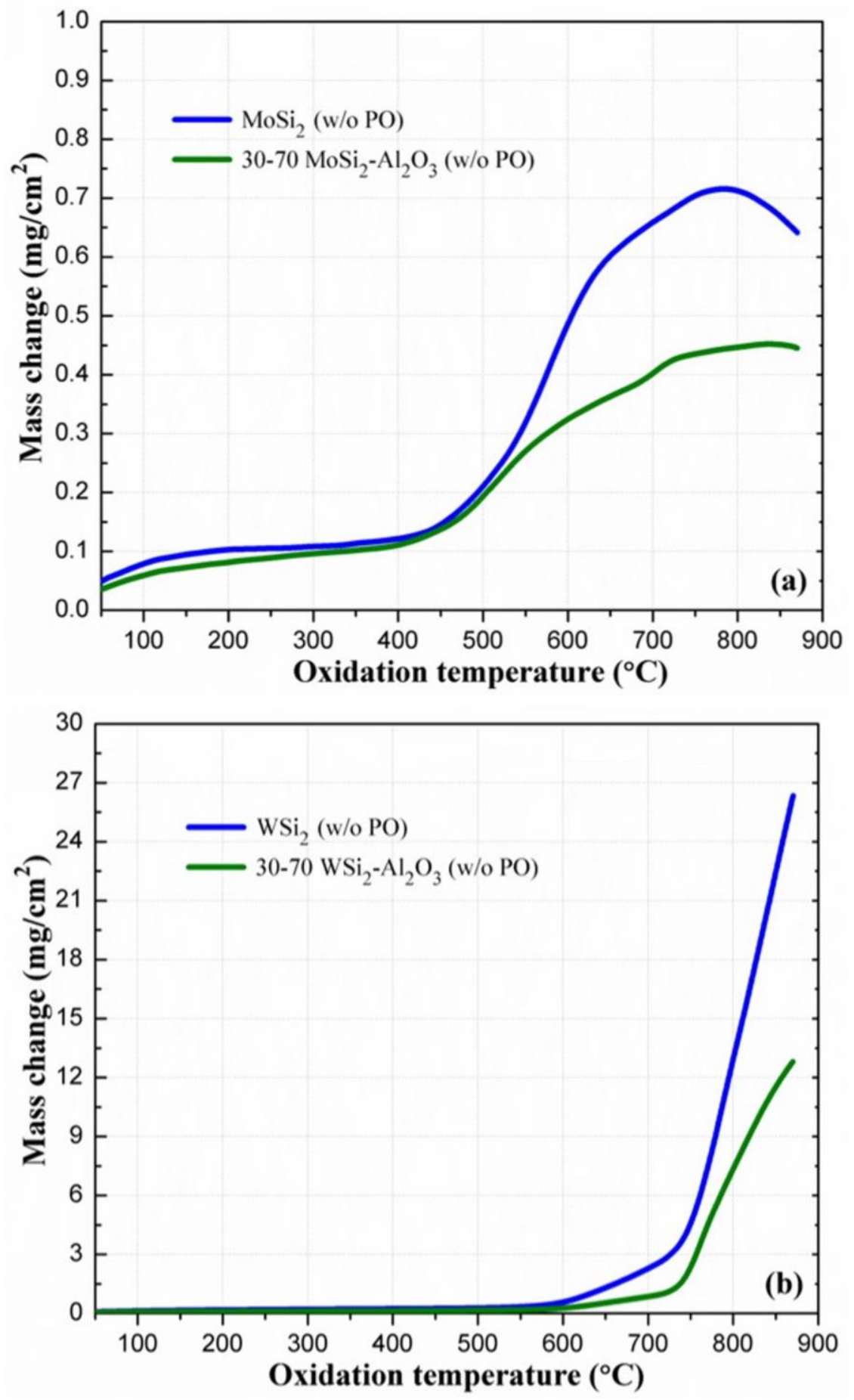

Figure 89. Mass change per unit surface area of the as-sintered (non-preoxidized) (a) $\mathrm{MoSi}_{2}$ and 30-70 vol\% $\mathrm{MoSi}_{2}-\mathrm{Al}_{2} \mathrm{O}_{3}$, and (b) $\mathrm{WSi}_{2}$ and 30-70 vol\% $\mathrm{WSi}_{2}-\mathrm{Al}_{2} \mathrm{O}_{3}$ samples as a function of oxidation temperature in air (" $w / o$ " term refers to non-preoxidized samples). 
there was a very low mass gain $\left(<0.27 \mathrm{mg} / \mathrm{cm}^{2}\right)$ for the as-sintered $\mathrm{WSi}_{2}$ and $\mathrm{WSi}_{2}-\mathrm{Al}_{2} \mathrm{O}_{3}$ composite samples at the temperature region of $50^{\circ}-500^{\circ} \mathrm{C}$ (Figure $89 \mathrm{~b}$ ). The significant mass gain for both samples is apparent starting from $500^{\circ} \mathrm{C}$, but it was found to be more drastic at the temperatures ranging from $\sim 730^{\circ} \mathrm{C}$ to $870^{\circ} \mathrm{C}$. However, the overall mass gain at $870^{\circ} \mathrm{C}$ for the $\mathrm{WSi}_{2}-\mathrm{Al}_{2} \mathrm{O}_{3}$ composite $\left(12.81 \mathrm{mg} / \mathrm{cm}^{2}\right)$ was substantially lower than that of the $\mathrm{WSi}_{2}\left(26.34 \mathrm{mg} / \mathrm{cm}^{2}\right)$. Unlike the $\mathrm{MoSi}_{2}$-based samples, these bulk samples completely disintegrated into a powder form owing to the poorer oxidation resistance of the $\mathrm{WSi}_{2}$, which resulted in the formation of $\mathrm{WO}_{3}$ and $\mathrm{SiO}_{2}$ as oxidation products leading to their pest oxidation $[6,10]$. In brief, the addition of the 70 vol\% alumina highly reduced the mass gain, which could be attributed to the less interaction of the metal silicide phases with open environment owing to their coverage with the oxide phase. However, the level of decrease in mass gain $(\sim 38.9-51.4 \%)$ was not proportional to the decrease in the silicide content (70 vol\%), which implied possible differences in porosity levels between the samples, and heterogeneous composite microstructures.

After examining the influence of the alumina addition on the oxidation behavior, the high-temperature preoxidation treatment was applied to the $\mathrm{MoSi}_{2}-\mathrm{Al}_{2} \mathrm{O}_{3}$ and $\mathrm{WSi}_{2}$ $\mathrm{Al}_{2} \mathrm{O}_{3}$ composites in order to understand the kinetics and to further improve their oxidation resistance by lowering or eliminating their pest oxidation behavior. Figure 90 displays the oxidation-induced mass change for (a-c) $\mathrm{MoSi}_{2}-\mathrm{Al}_{2} \mathrm{O}_{3}$ and (d-f) $\mathrm{WSi}_{2}-\mathrm{Al}_{2} \mathrm{O}_{3}$ composites, which were all preoxidized (termed as $\boldsymbol{w} / \boldsymbol{P O}$ ) at $1000^{\circ}-1200^{\circ} \mathrm{C}$ for a period of time ranging from 10 to 120 minutes. The non-isothermal oxidation data of the non-preoxidized (without preoxidation, termed as w/o $\boldsymbol{P O}$ ) composite samples was also included here for a better comparison. For the $\mathrm{MoSi}_{2}-\mathrm{Al}_{2} \mathrm{O}_{3}$ composites, the overall mass gain significantly increased after preoxidation at $1000^{\circ} \mathrm{C}$ for $10-30 \mathrm{~min}$, in comparison with the nonpreoxidized sample (Figure 90a). The formation and evaporation curves of a volatile phase were clearly observed for these two samples. At the peak points around $700^{\circ} \mathrm{C}$ (before evaporation or mass loss), the mass gain increased from 0.40 to $1.31-2.39 \mathrm{mg} / \mathrm{cm}^{2}$, which could be due to the formation of a porous surface layer with a remaining volatile oxide 

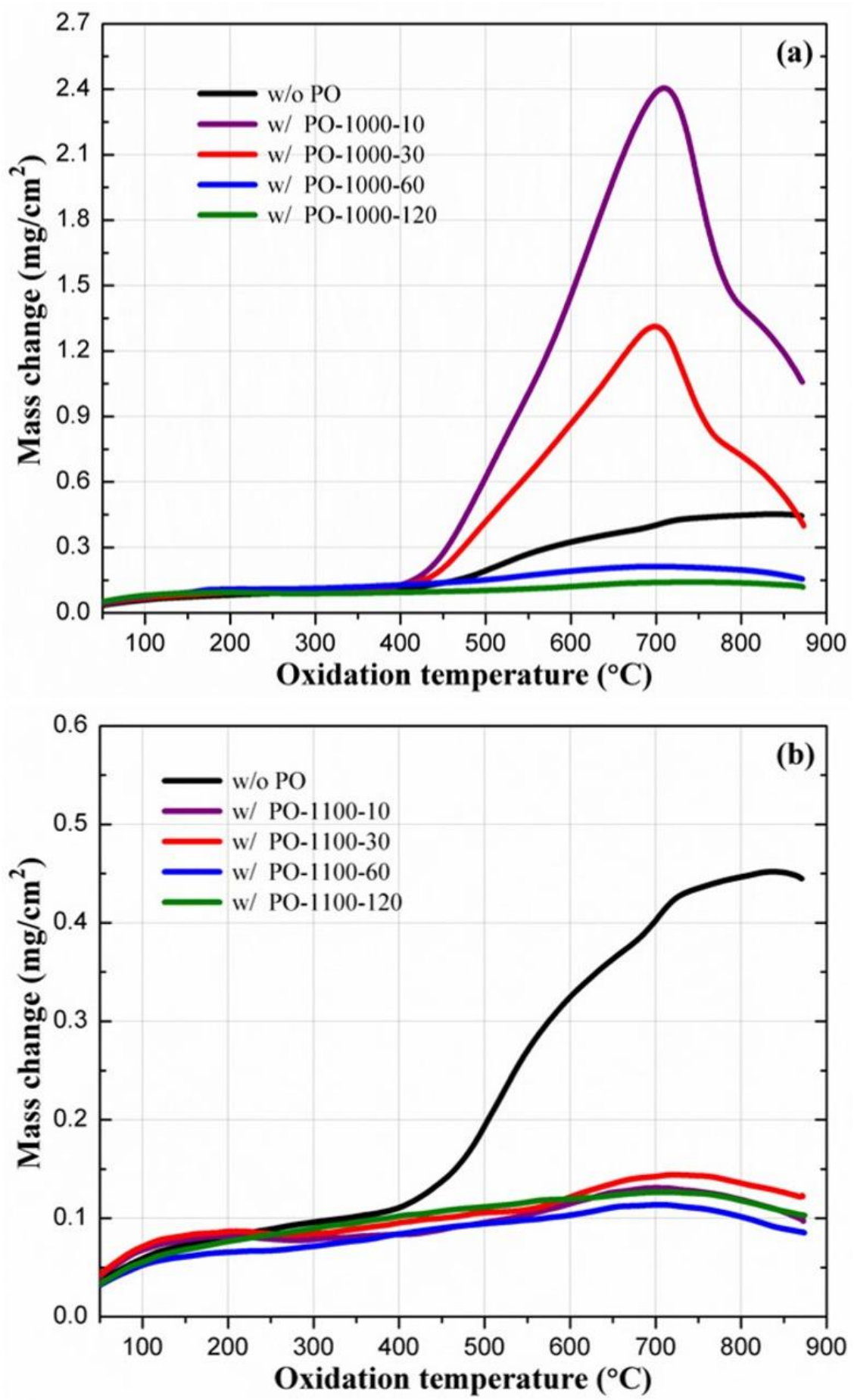

Figure 90. Mass change per unit surface area of the non-preoxidized $(w / o)$ and preoxidized (w/) (a-b-c) 30-70 vol\% $\mathrm{MoSi}_{2}-\mathrm{Al}_{2} \mathrm{O}_{3}$, and (d-e-f) 30-70 vol\% $\mathrm{WSi}_{2}-\mathrm{Al}_{2} \mathrm{O}_{3}$ composites as a function of oxidation temperature in air ( $a-d, b-e, c-f$ presents the samples preoxidized at $1000^{\circ} \mathrm{C}, 1100^{\circ} \mathrm{C}$ and $1200^{\circ} \mathrm{C}$, respectively). 

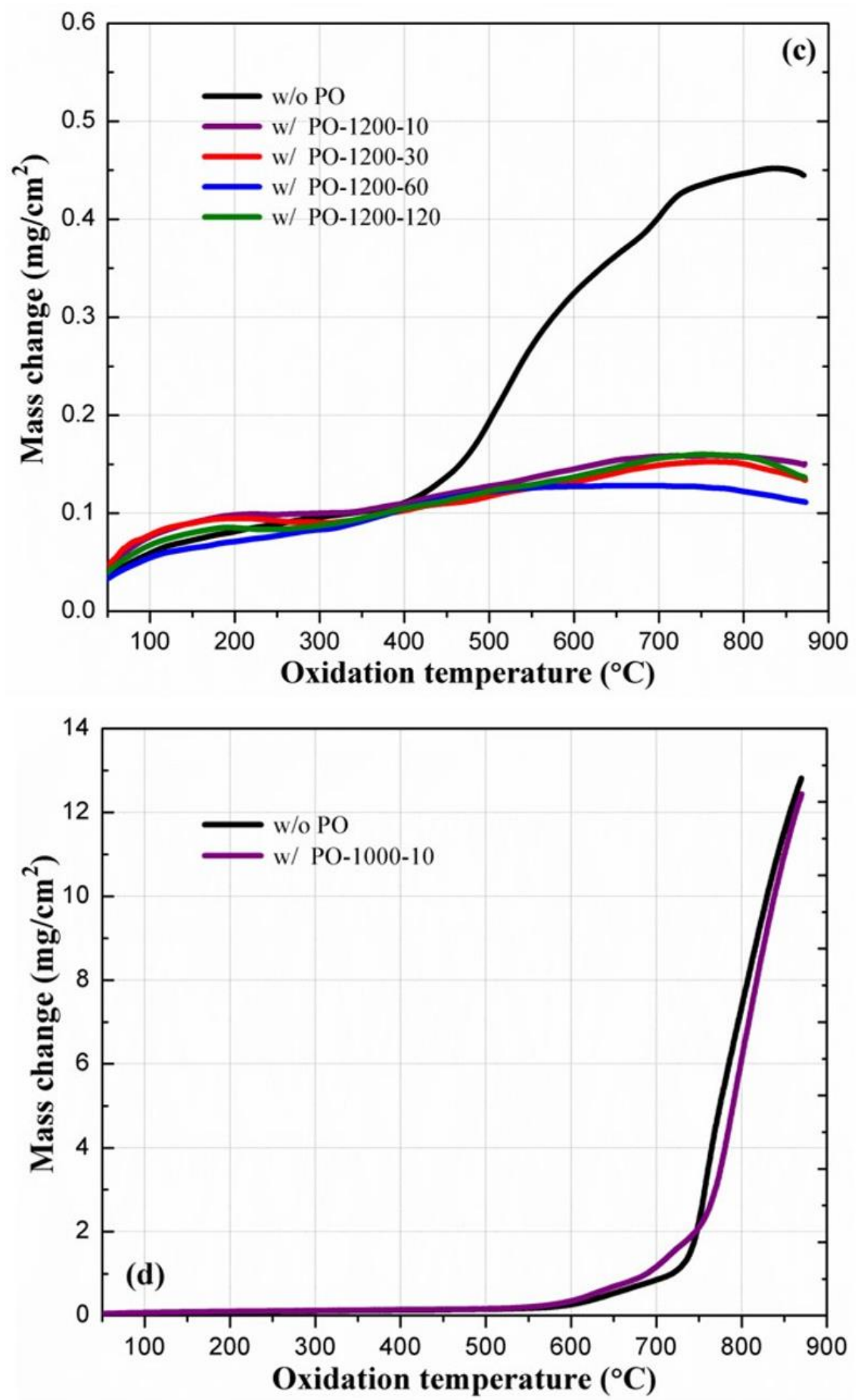

Figure 90. (continued) Mass change per unit surface area of the non-preoxidized (w/o) and preoxidized (w/) (a-b-c) 30-70 vol\% $\mathrm{MoSi}_{2}-\mathrm{Al}_{2} \mathrm{O}_{3}$, and (d-e-f) 30-70 vol\% $\mathrm{WSi}_{2}-\mathrm{Al}_{2} \mathrm{O}_{3}$ composites as a function of oxidation temperature in air $(a-d, b-e, c-f$ presents the samples preoxidized at $1000^{\circ} \mathrm{C}, 1100^{\circ} \mathrm{C}$ and $1200^{\circ} \mathrm{C}$, respectively). 

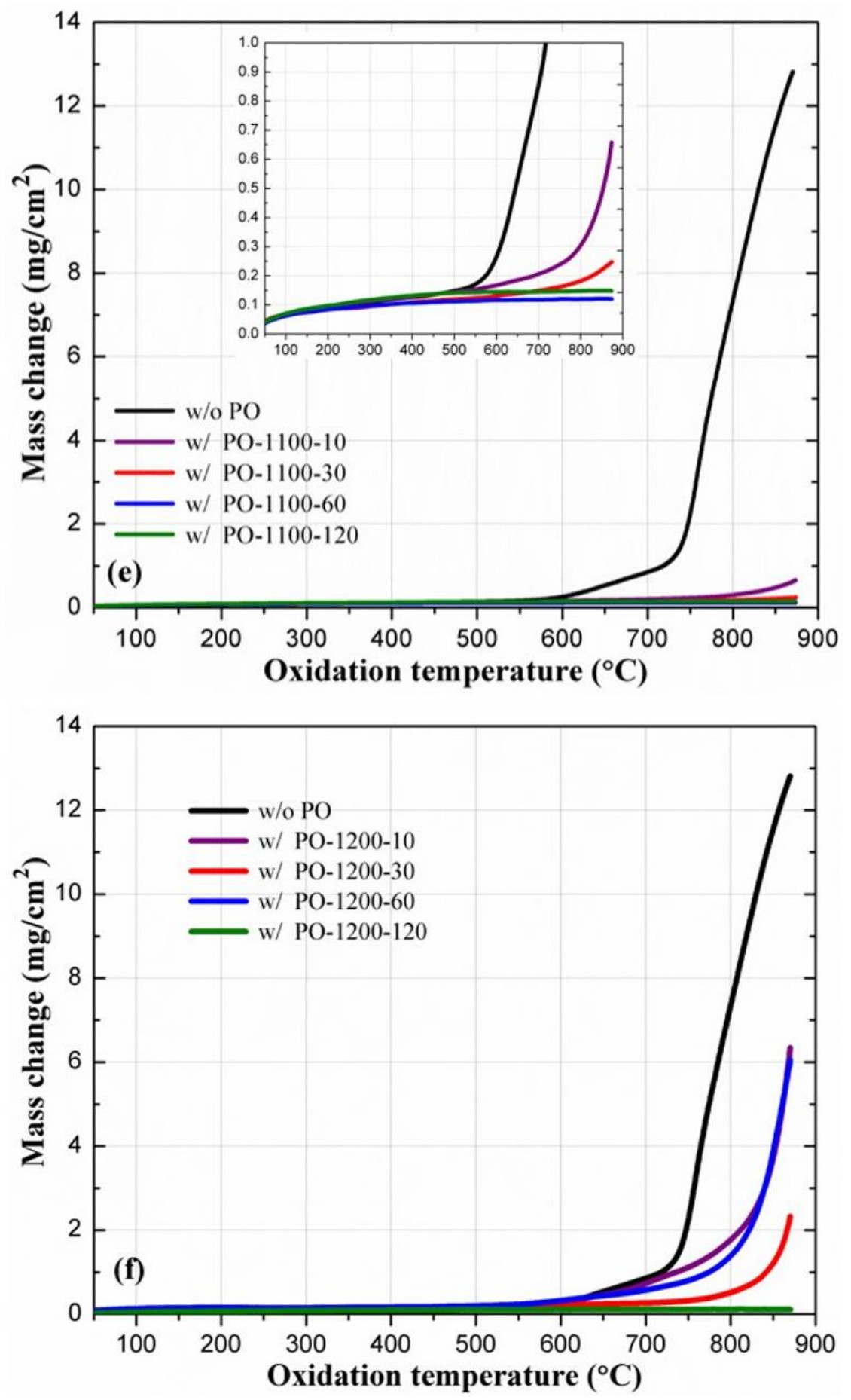

Figure 90. (continued) Mass change per unit surface area of the non-preoxidized (w/o) and preoxidized (w/) (a-b-c) 30-70 vol\% $\mathrm{MoSi}_{2}-\mathrm{Al}_{2} \mathrm{O}_{3}$, and (d-e-f) 30-70 vol\% $\mathrm{WSi}_{2}-\mathrm{Al}_{2} \mathrm{O}_{3}$ composites as a function of oxidation temperature in air $(a-d, b-e, c-f$ presents the samples preoxidized at $1000^{\circ} \mathrm{C}, 1100^{\circ} \mathrm{C}$ and $1200^{\circ} \mathrm{C}$, respectively). 
species during preoxidation treatment at $1000^{\circ} \mathrm{C}$ for a short period. Therefore, a partial pest oxidation was observed for these samples. However, it is evident that the overall mass gain was highly reduced by preoxidizing the composites for $60-120 \mathrm{~min}$ at the same temperature. At higher preoxidation temperatures $\left(1100^{\circ}-1200^{\circ} \mathrm{C}\right)$, the critical preoxidation time was much shorter for the $\mathrm{MoSi}_{2}-\mathrm{Al}_{2} \mathrm{O}_{3}$ composites, as seen in Figure 90b-c. The overall mass gain at $870^{\circ} \mathrm{C}$ was significantly lowered from 0.45 to $0.09-0.15 \mathrm{mg} / \mathrm{cm}^{2}$ by preoxidizing the samples, even only for $10 \mathrm{~min}$. For the $\mathrm{WSi}_{2}-\mathrm{Al}_{2} \mathrm{O}_{3}$ composites, preoxidation treatment at $1000^{\circ} \mathrm{C}$ for $10 \mathrm{~min}$ did not affect the low-temperature oxidation behavior, since the overall mass gain of the preoxidized sample at $870^{\circ} \mathrm{C}\left(12.42 \mathrm{mg} / \mathrm{cm}^{2}\right)$ was quite similar to that of the non-preoxidized sample $\left(12.81 \mathrm{mg} / \mathrm{cm}^{2}\right)$. It should be noted that further preoxidation studies at $1000^{\circ} \mathrm{C}$ were not conducted for the $\mathrm{WSi}_{2}-\mathrm{Al}_{2} \mathrm{O}_{3}$ samples due to the formation of porous surface layers and pest oxidation during preoxidation treatment. However, significant reductions in the overall mass gain were clearly observed as a function of increasing preoxidation time at $1100^{\circ}-1200^{\circ} \mathrm{C}$ (Figure $90 \mathrm{e}-\mathrm{f}$ ), indicating the requirement of longer preoxidation time periods ( $\geq 60 \mathrm{~min}$ ) for the $\mathrm{WSi}_{2}-\mathrm{Al}_{2} \mathrm{O}_{3}$ composites. The overall mass gain at $870^{\circ} \mathrm{C}$ was decreased from 12.81 to $0.11-0.15 \mathrm{mg} / \mathrm{cm}^{2}$ by preoxidizing the composite samples at $1100^{\circ} \mathrm{C}$ for $60-120 \mathrm{~min}$ and at $1200^{\circ} \mathrm{C}$ for $120 \mathrm{~min}$.

After non-isothermal oxidation tests, the overall mass gain values recorded at $870^{\circ} \mathrm{C}$ for the preoxidized composite samples are summarized as a function of preoxidation time in Figure 91a-b to understand the kinetics of the high-temperature preoxidation treatment at three different temperatures. It is apparent that there is a critical preoxidation time at different temperatures, which is necessary to achieve a protective layer on the composite surfaces and to highly improve their low-temperature oxidation resistance. As additionally reviewed in Figure 91c, the oxidation-induced mass gains in their specific pest oxidation regions $\left(\sim 400^{\circ}-750^{\circ} \mathrm{C}\right.$ for the $\mathrm{MoSi}_{2}-\mathrm{Al}_{2} \mathrm{O}_{3} ; \sim 400^{\circ}-870^{\circ} \mathrm{C}$ for the $\left.\mathrm{WSi}_{2}-\mathrm{Al}_{2} \mathrm{O}_{3}\right)$ were determined to be $\sim 0.02-0.05 \mathrm{mg} / \mathrm{cm}^{2}$ after high-temperature preoxidation treatment for $120 \mathrm{~min}$. Therefore, further studies (e.g. microstructure, surface chemistry) were only performed on the selected preoxidized composite samples (at $1000^{\circ}-1200^{\circ} \mathrm{C}$ for $120 \mathrm{~min}$ ), 

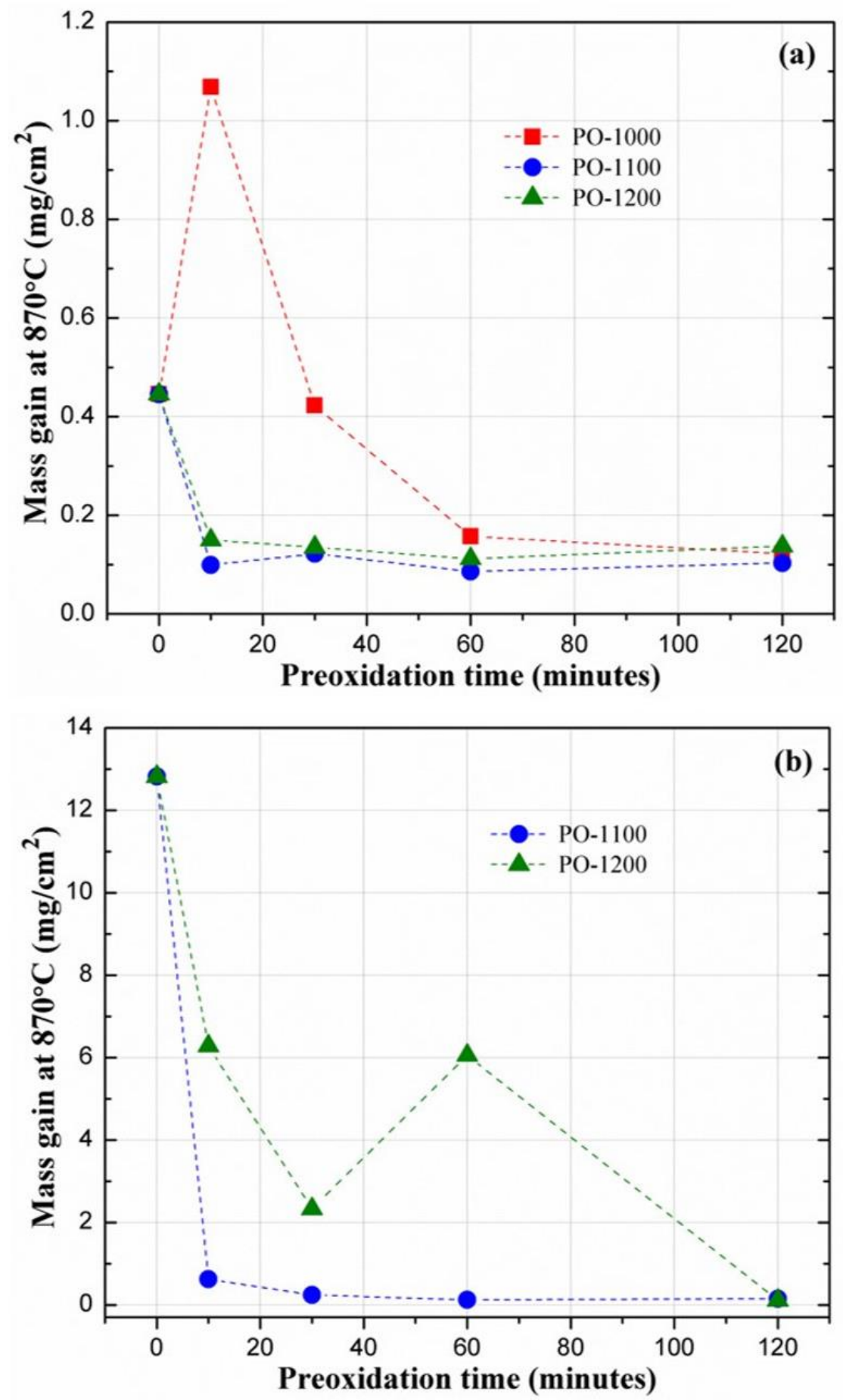

Figure 91. Effect of preoxidation time and temperature on the overall mass gain at $870^{\circ} \mathrm{C}$ for the (a) 30-70 vol\% $\mathrm{MoSi}_{2}-\mathrm{Al}_{2} \mathrm{O}_{3}$, (b) 30-70 vol\% $\mathrm{WSi}_{2}-\mathrm{Al}_{2} \mathrm{O}_{3}$ composites, and (c) mass change per unit surface area in the pest oxidation temperature regime for the composites preoxidized at $1000^{\circ}-1200^{\circ} \mathrm{C}$ for $120 \mathrm{~min}$. 


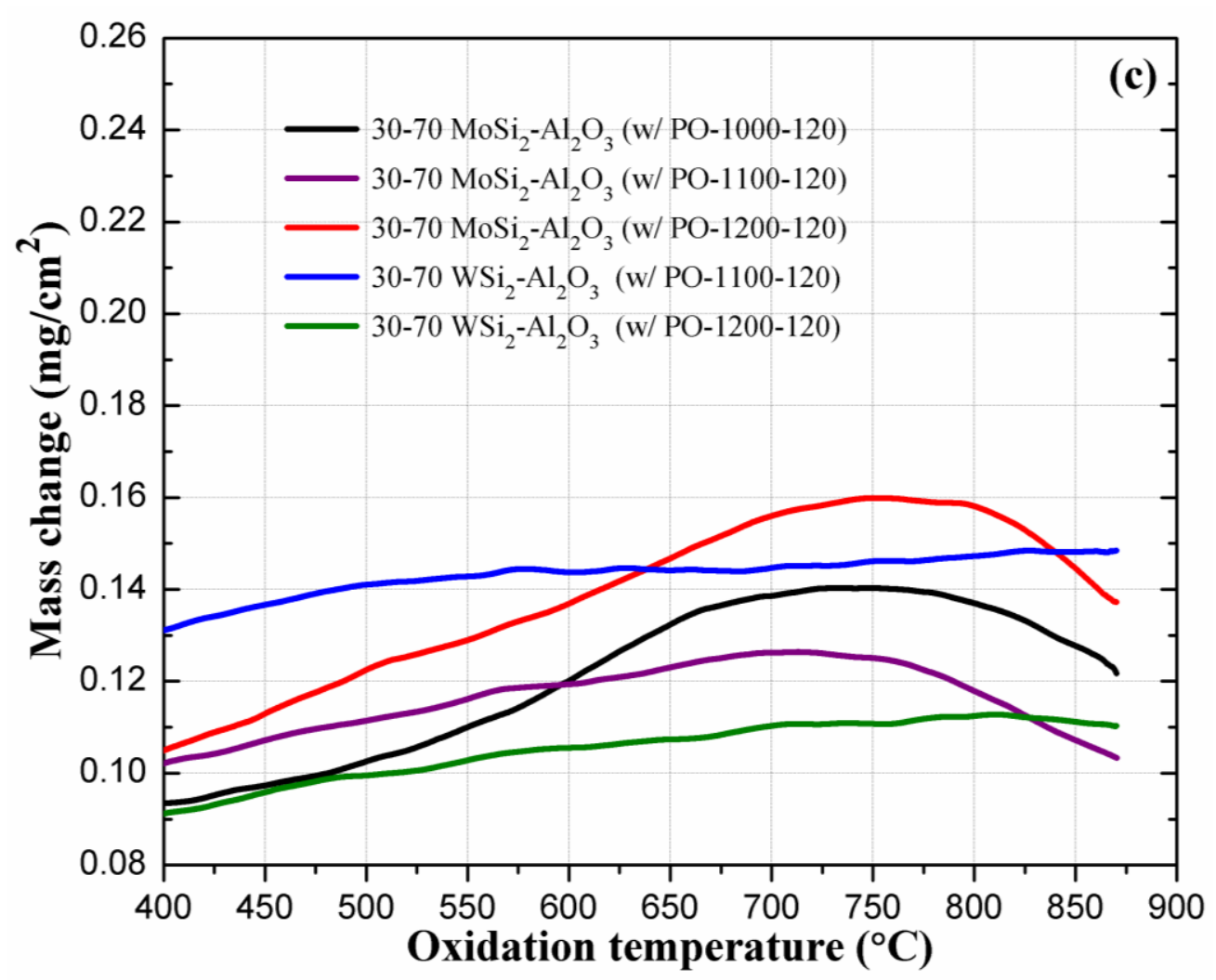

Figure 91. (continued) Effect of preoxidation time and temperature on the overall mass gain at $870^{\circ} \mathrm{C}$ for the (a) $30-70 \mathrm{vol} \% \mathrm{MoSi}_{2}-\mathrm{Al}_{2} \mathrm{O}_{3}$, (b) $30-70$ vol $\% \mathrm{WSi}_{2}-\mathrm{Al}_{2} \mathrm{O}_{3}$ composites, and (c) mass change per unit surface area in the pest oxidation temperature regime for the composites preoxidized at $1000^{\circ}-1200^{\circ} \mathrm{C}$ for $120 \mathrm{~min}$.

along with the non-preoxidized samples, to better understand how high-temperature preoxidation treatment improved their oxidation resistance.

\subsubsection{Optical micrographs and SEM microstructures of surface layer morphologies}

The optical micrographs of the protective surface features of the preoxidized $\mathrm{MoSi}_{2}$ - and $\mathrm{WSi}_{2}-\mathrm{Al}_{2} \mathrm{O}_{3}$ composites are shown in Figure 92. For baseline, the surface images of the non-preoxidized samples are also included. It is evident that different surface morphologies with glassy type of features were formed on the surface of the composite samples during high-temperature preoxidation treatment conducted at $1000^{\circ}-1200^{\circ} \mathrm{C}$ for 120 min. For $\mathrm{MoSi}_{2}-\mathrm{Al}_{2} \mathrm{O}_{3}$ system, the surface features were identified to be very similar 


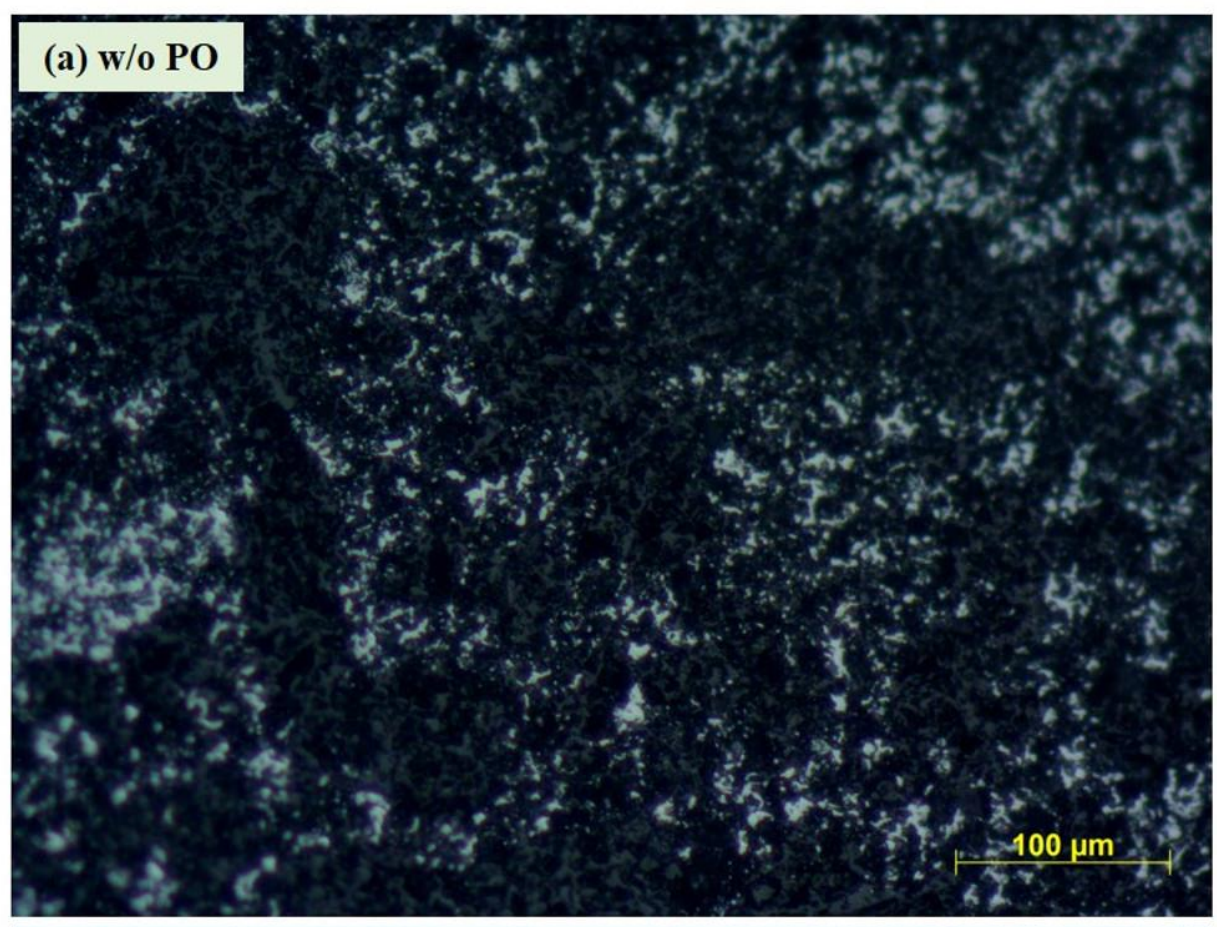

(b) w/ PO-1000-120

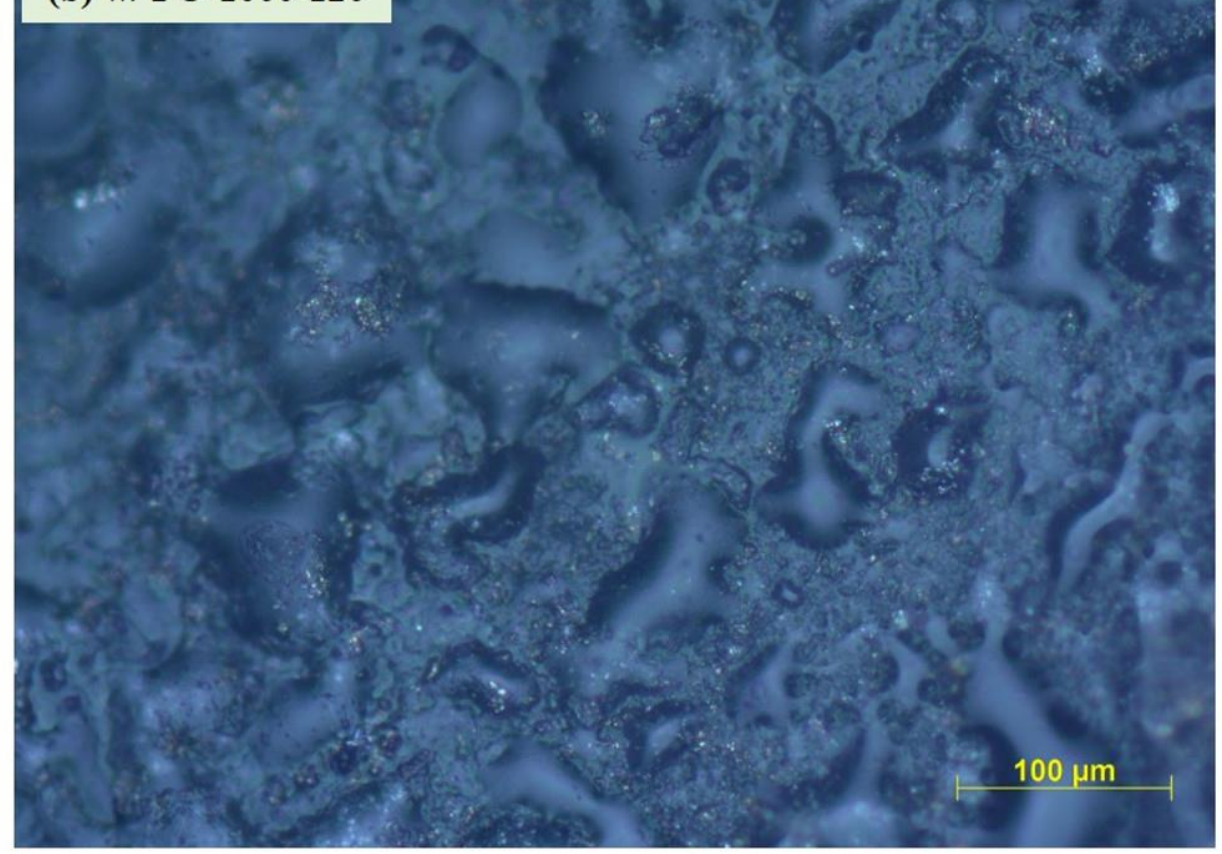

Figure 92. Optical micrographs of the surface of the non-preoxidized (w/o PO) and preoxidized ( $w / P O$ ) (a-b-c-d) 30-70 $\mathrm{MoSi}_{2}-\mathrm{Al}_{2} \mathrm{O}_{3}$ and (e-f-g-h) 30-70 $\mathrm{WSi}_{2}-\mathrm{Al}_{2} \mathrm{O}_{3}$ composites (non-preoxidized sample surfaces are presented as baseline). 

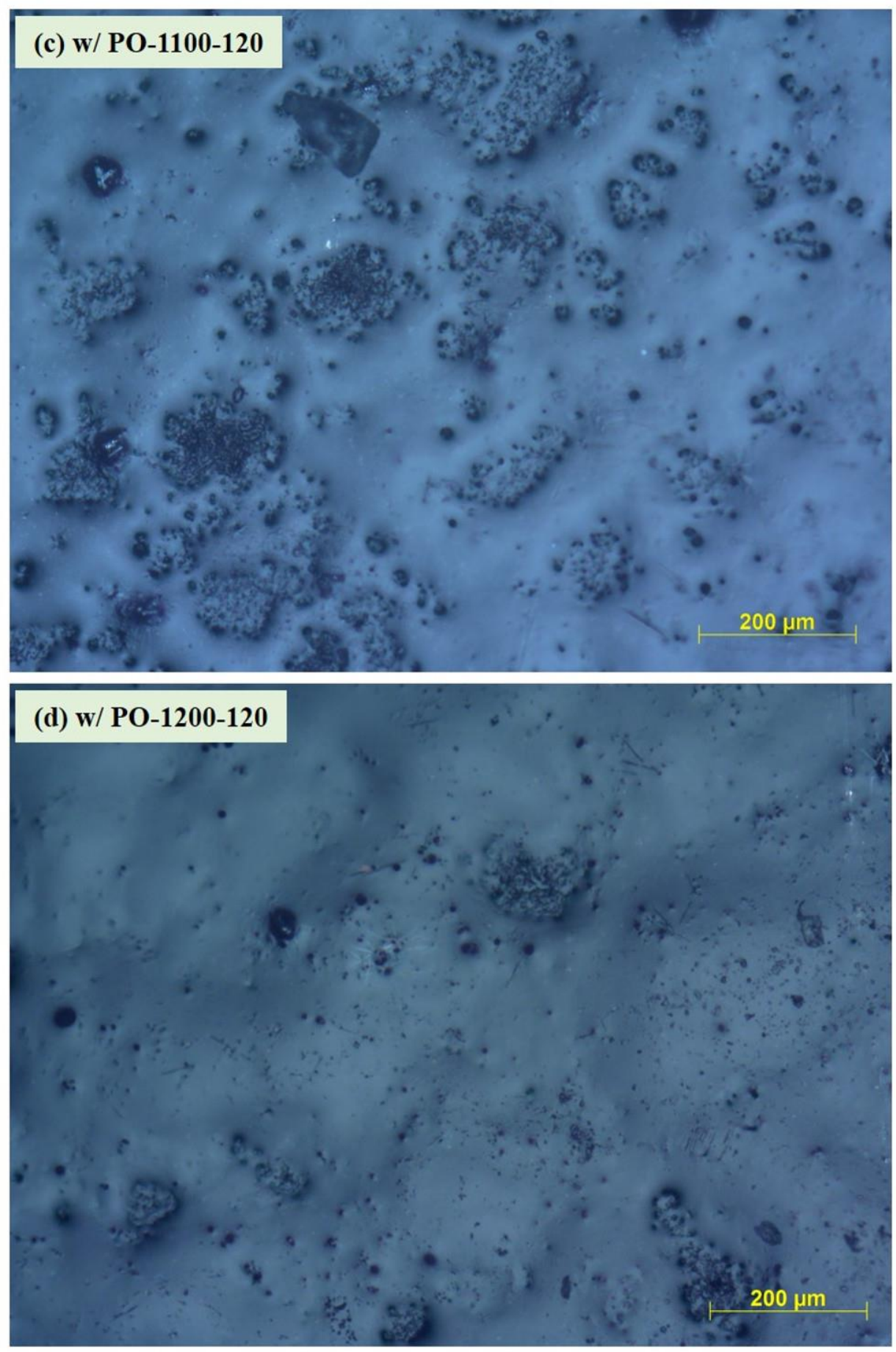

Figure 92. (continued) Optical micrographs of the surface of the non-preoxidized ( $w / o$ $P O$ ) and preoxidized ( $w / P O$ ) (a-b-c-d) 30-70 $\mathrm{MoSi}_{2}-\mathrm{Al}_{2} \mathrm{O}_{3}$ and (e-f-g-h) 30-70 $\mathrm{WSi}_{2}-$ $\mathrm{Al}_{2} \mathrm{O}_{3}$ composites (non-preoxidized sample surfaces are presented as baseline). 


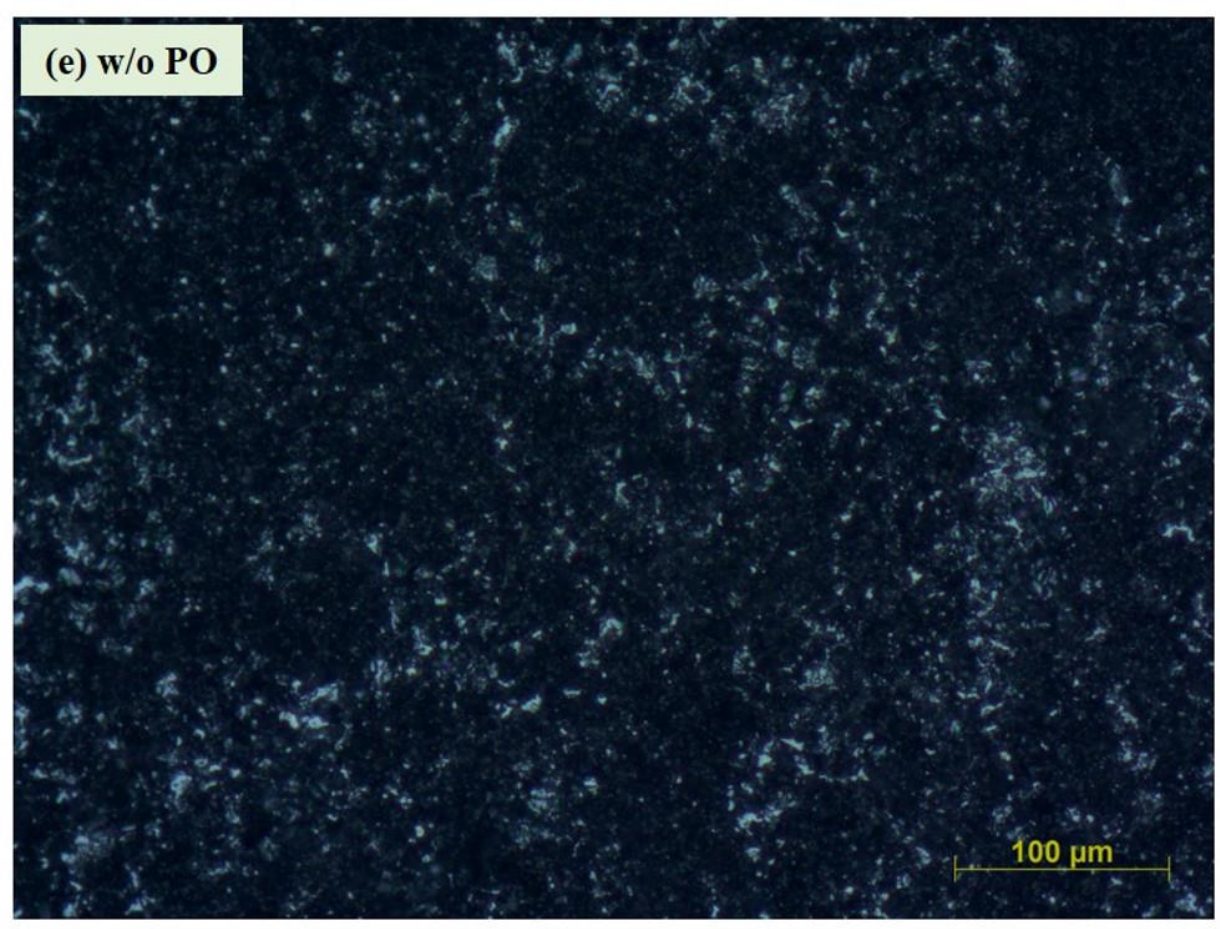

(f) Pest oxidation during PO-1000-30

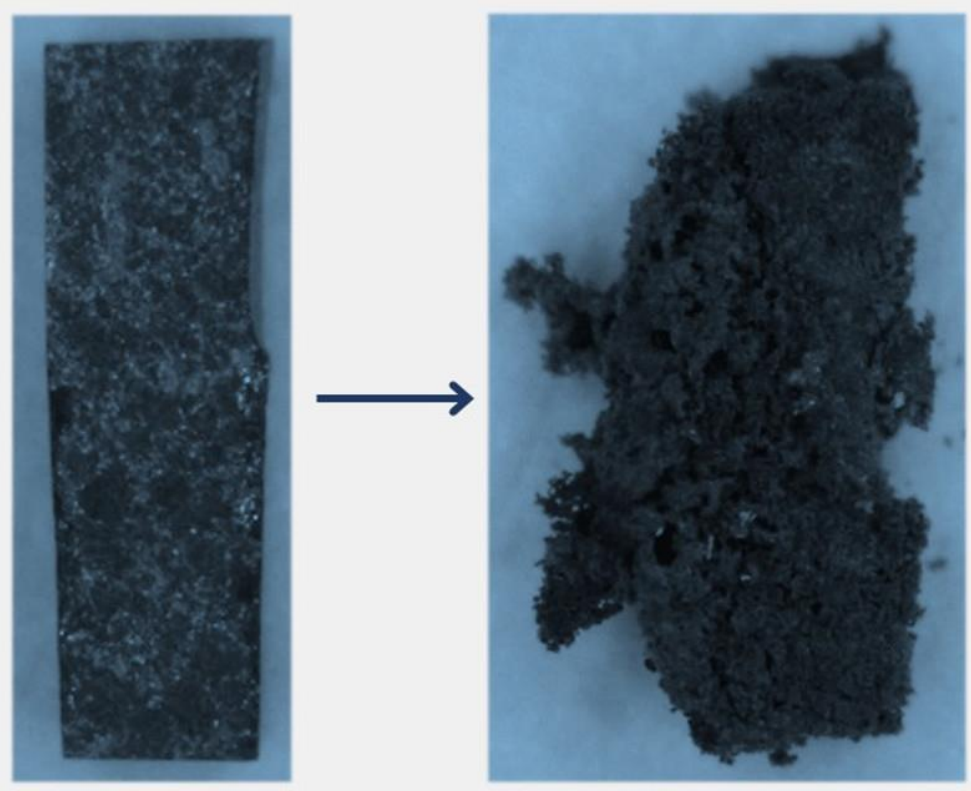

Figure 92. (continued) Optical micrographs of the surface of the non-preoxidized (w/o $P O$ ) and preoxidized ( $w / P O$ ) (a-b-c-d) 30-70 $\mathrm{MoSi}_{2}-\mathrm{Al}_{2} \mathrm{O}_{3}$ and (e-f-g-h) 30-70 $\mathrm{WSi}_{2}-$ $\mathrm{Al}_{2} \mathrm{O}_{3}$ composites (non-preoxidized sample surfaces are presented as baseline). 

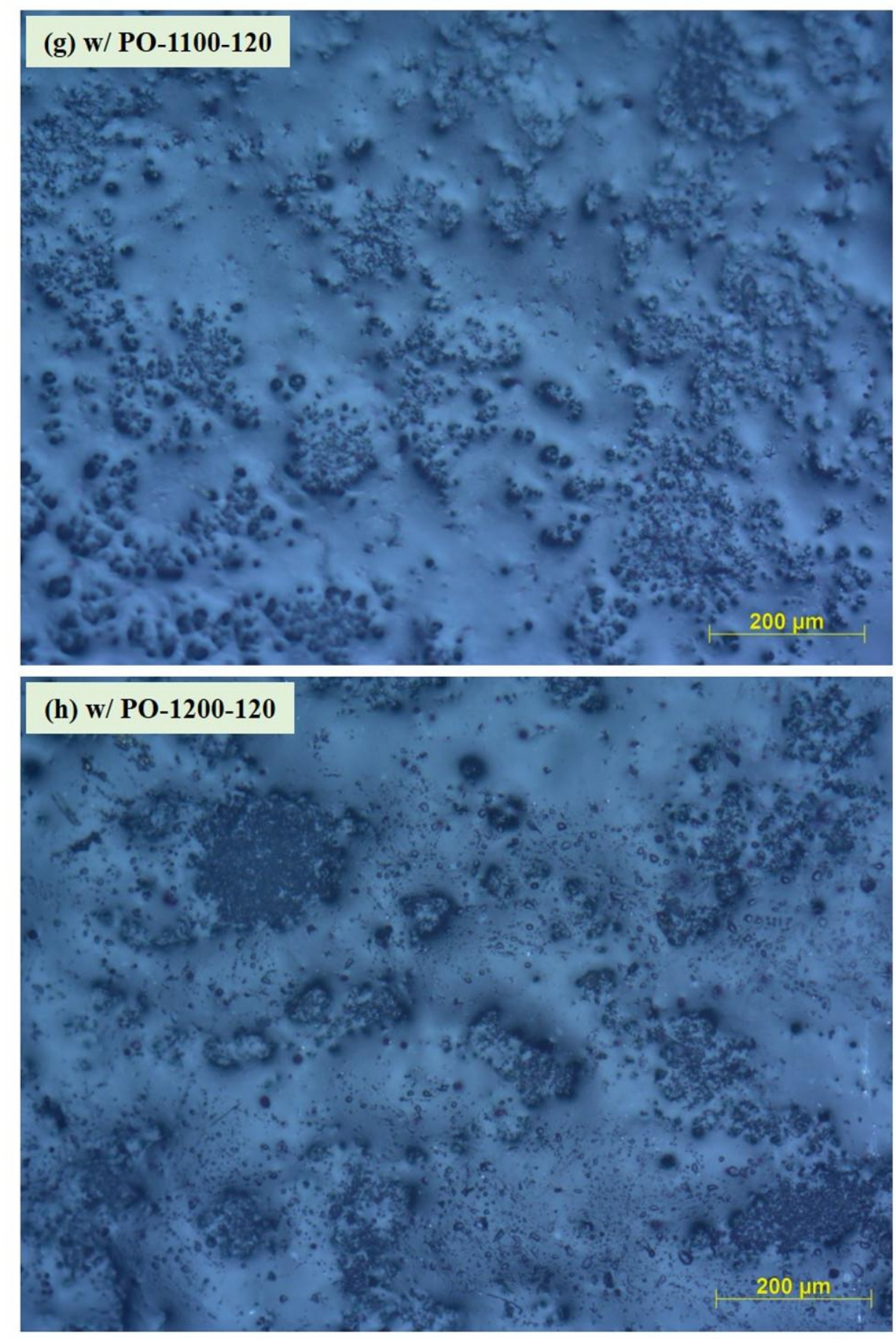

Figure 92. (continued) Optical micrographs of the surface of the non-preoxidized (w/o $P O$ ) and preoxidized ( $w / P O$ ) (a-b-c-d) 30-70 $\mathrm{MoSi}_{2}-\mathrm{Al}_{2} \mathrm{O}_{3}$ and (e-f-g-h) 30-70 $\mathrm{WSi}_{2}-$ $\mathrm{Al}_{2} \mathrm{O}_{3}$ composites (non-preoxidized sample surfaces are presented as baseline). 
after preoxidation at $1100^{\circ}-1200^{\circ} \mathrm{C}$, but glassy regions seemed to be different and more clear after preoxidation at $1000^{\circ} \mathrm{C}$. Significant differences on the surface features formed can be similarly seen for the $\mathrm{WSi}_{2}-\mathrm{Al}_{2} \mathrm{O}_{3}$ composites preoxidized at different temperatures. As also described in the previous section, the preoxidation treatment at $1000^{\circ} \mathrm{C}$ was found to be not applicable for the $\mathrm{WSi}_{2}-\mathrm{Al}_{2} \mathrm{O}_{3}$ composites due to the pest oxidation and structural disintegration of the samples during preoxidation process, as shown by the optical images.

Figure 93 presents the cross-sectional SEM microstructures of the $\mathrm{MoSi}_{2}-\mathrm{Al}_{2} \mathrm{O}_{3}$ and $\mathrm{WSi}_{2}-\mathrm{Al}_{2} \mathrm{O}_{3}$ composites after high-temperature preoxidation treatment at $1000^{\circ}-1200^{\circ} \mathrm{C}$ for $120 \mathrm{~min}$. The highly dense protective surface layers were clearly observed on the surfaces of the preoxidized composite samples. The average thicknesses of the protective surface layers after preoxidation of the $\mathrm{MoSi}_{2}-\mathrm{Al}_{2} \mathrm{O}_{3}$ composite samples at $1000^{\circ} \mathrm{C}, 1100^{\circ} \mathrm{C}$ and $1200^{\circ} \mathrm{C}$ were $4.94 \mu \mathrm{m}( \pm 1.008), 14.16 \mu \mathrm{m}( \pm 0.605)$ and $6.45 \mu \mathrm{m}( \pm 0.900)$, respectively. For the $\mathrm{WSi}_{2}-\mathrm{Al}_{2} \mathrm{O}_{3}$ composites, the average thickness of the surface layer decreased from $4.81( \pm 1.013)$ to $3.05 \mu \mathrm{m}( \pm 0.147)$ with increasing preoxidation temperature from $1100^{\circ} \mathrm{C}$ to $1200^{\circ} \mathrm{C}$. The protective surface layers formed more homogeneously on the $\mathrm{MoSi}_{2}-\mathrm{Al}_{2} \mathrm{O}_{3}$ (w/ PO-1100-120) and $\mathrm{WSi}_{2}-\mathrm{Al}_{2} \mathrm{O}_{3}$ (w/ PO-1200-120) composite samples, since the thicknesses of the surface layers were found to be more similar at different regions. In addition, different features were detected on the outer surface (bright regions) of the $\mathrm{MoSi}_{2}-$ $\mathrm{Al}_{2} \mathrm{O}_{3}$ composite preoxidized at $1000^{\circ} \mathrm{C}$, as similarly identified on its optical micrograph. The metal disilicide $\left(\mathrm{MoSi}_{2}, \mathrm{WSi}_{2}\right)$ and 5-3 metal silicide $\left(\mathrm{Mo}_{5} \mathrm{Si}_{3}, \mathrm{~W}_{5} \mathrm{Si}_{3}\right)$ grains were identified within the composite microstructures, as marked in Figure 93. The secondary 5-3 metal silicide phases were formed at the regions closer to the surface layer during the preoxidation processes, as dictated by the thermodynamics of the high-temperature (above $\sim 1000^{\circ} \mathrm{C}$ ) oxidation reactions of the starting metal disilicides [6,28,29]. These results are in good agreement with the reported research studies, since it is known that these metal silicides react with oxygen at high temperatures to form 5-3 metal silicide phases mostly underneath the surface layer $[25,30]$. 


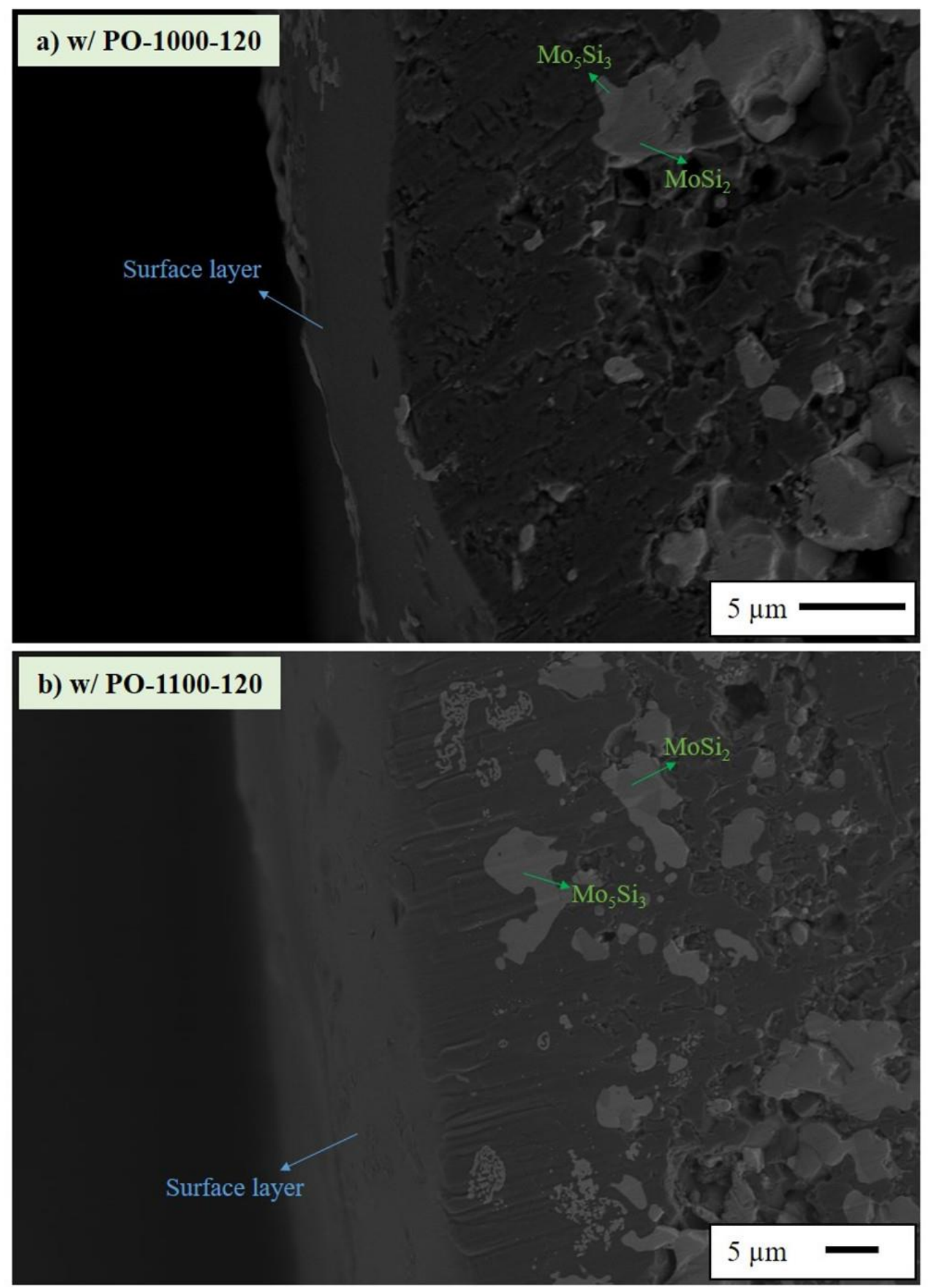

Figure 93. Cross-sectional SEM microstructures of the (a-b-c-d-e) 30-70 $\mathrm{MoSi}_{2}-\mathrm{Al}_{2} \mathrm{O}_{3}$ and (f-g-h-i) $30-70 \mathrm{WSi}_{2}-\mathrm{Al}_{2} \mathrm{O}_{3}$ composites after preoxidation at $1000^{\circ}-1200^{\circ} \mathrm{C}$ for 120 $\min$. 


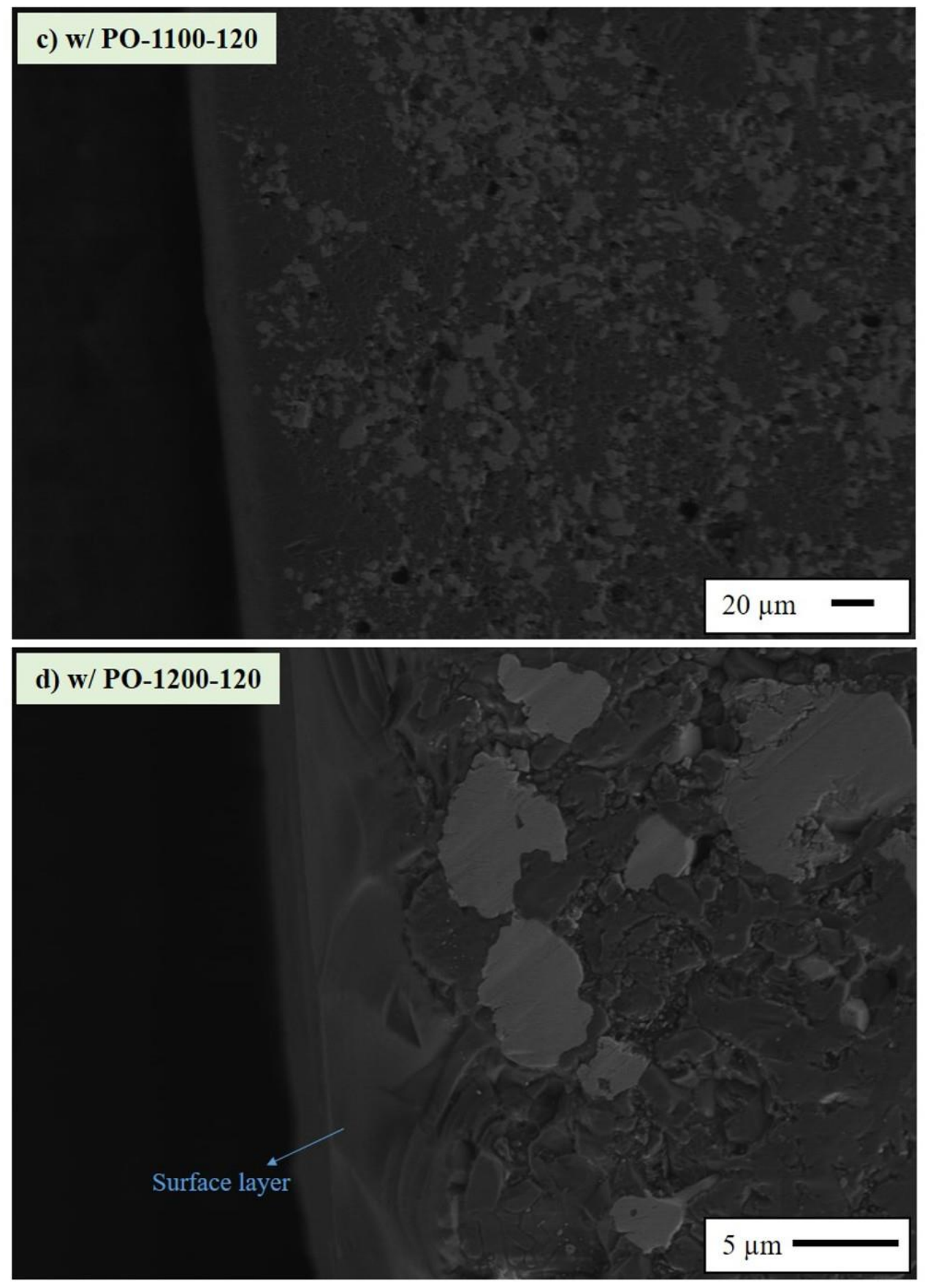

Figure 93. (continued) Cross-sectional SEM microstructures of the (a-b-c-d-e) 30-70 $\mathrm{MoSi}_{2}-\mathrm{Al}_{2} \mathrm{O}_{3}$ and (f-g-h-i) $30-70 \mathrm{WSi}_{2}-\mathrm{Al}_{2} \mathrm{O}_{3}$ composites after preoxidation at $1000^{\circ}-$ $1200^{\circ} \mathrm{C}$ for $120 \mathrm{~min}$. 


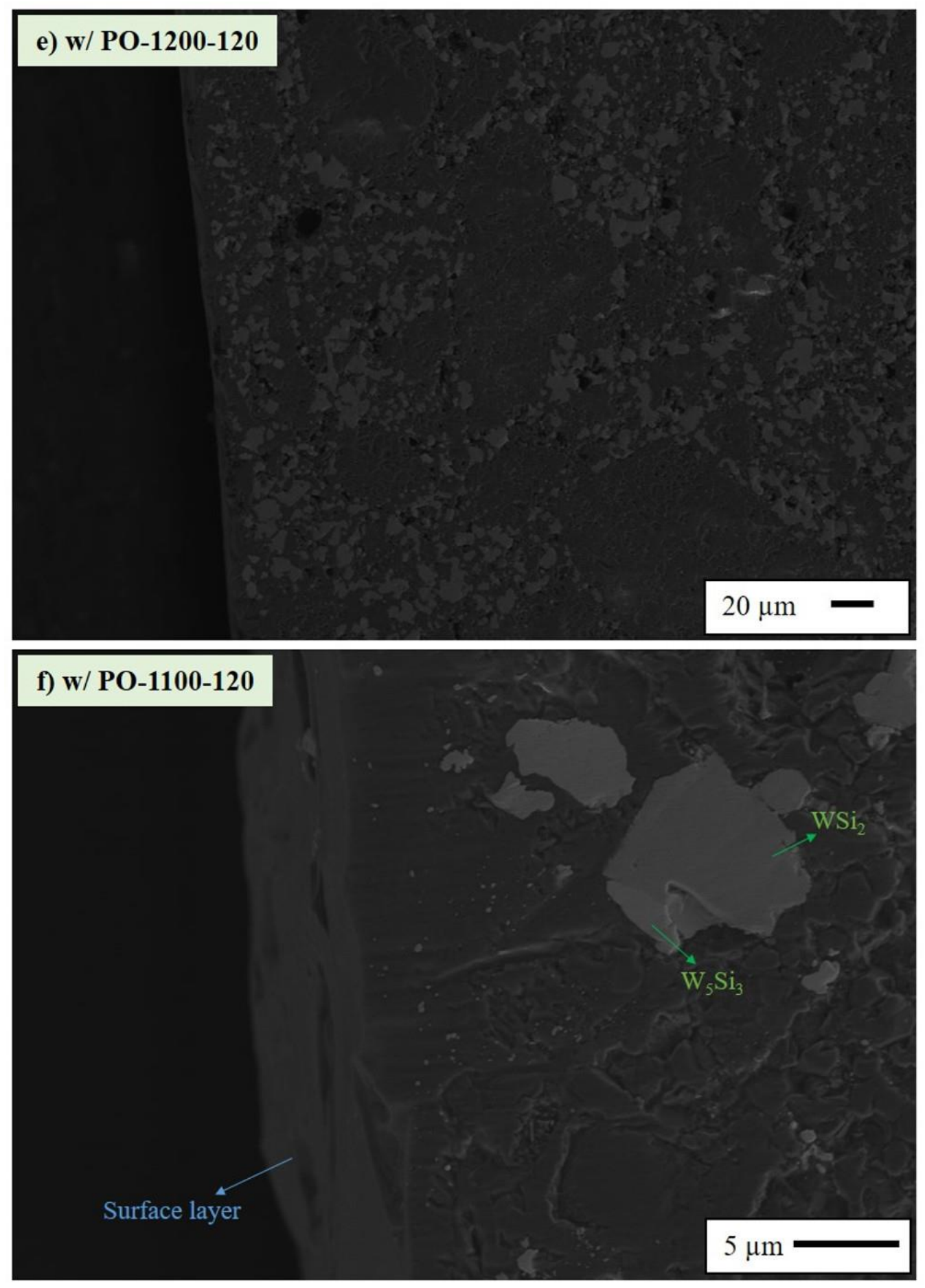

Figure 93. (continued) Cross-sectional SEM microstructures of the (a-b-c-d-e) 30-70 $\mathrm{MoSi}_{2}-\mathrm{Al}_{2} \mathrm{O}_{3}$ and (f-g-h-i) $30-70 \mathrm{WSi}_{2}-\mathrm{Al}_{2} \mathrm{O}_{3}$ composites after preoxidation at $1000^{\circ}-$ $1200^{\circ} \mathrm{C}$ for $120 \mathrm{~min}$. 

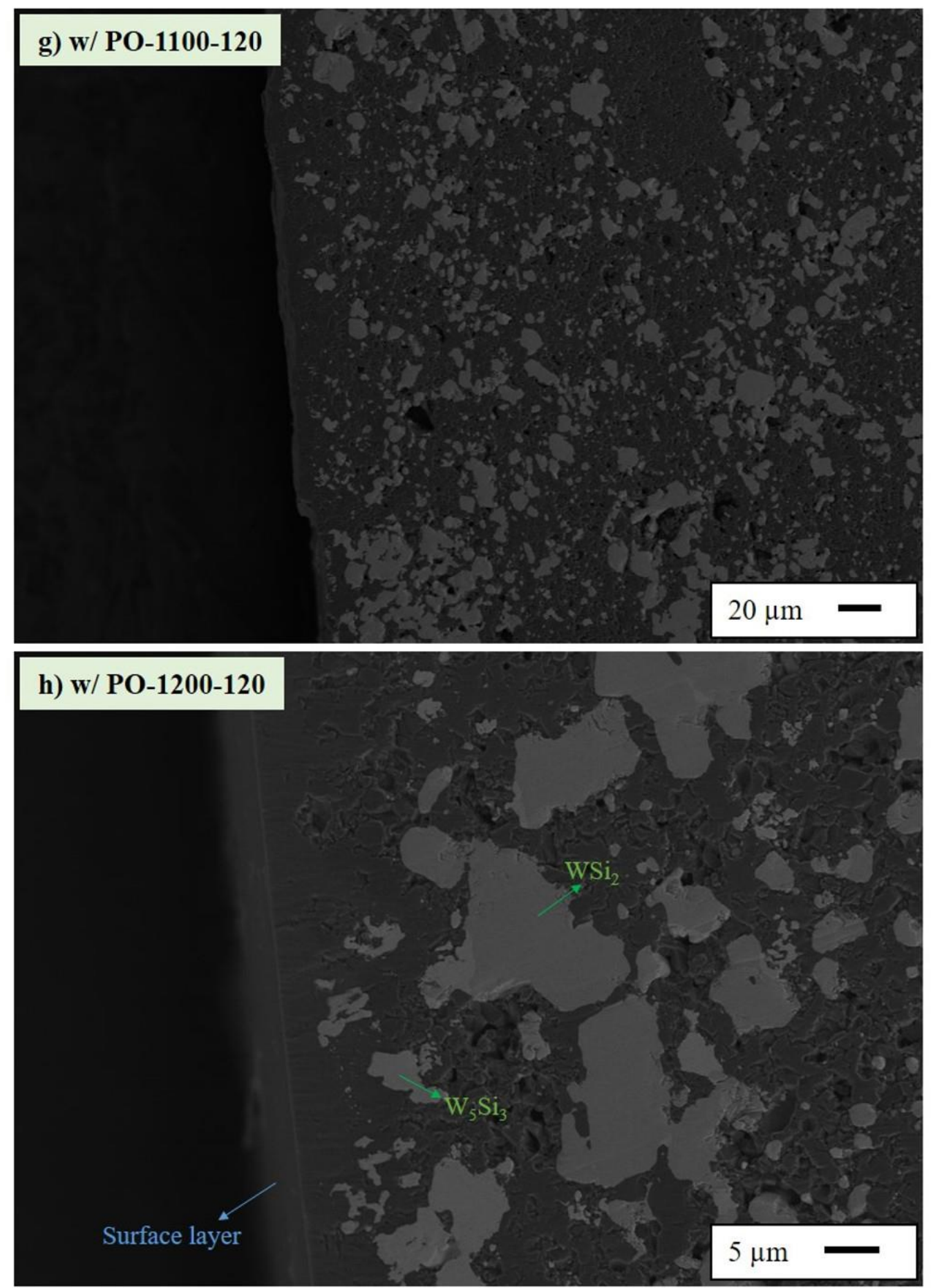

Figure 93. (continued) Cross-sectional SEM microstructures of the (a-b-c-d-e) 30-70 $\mathrm{MoSi}_{2}-\mathrm{Al}_{2} \mathrm{O}_{3}$ and (f-g-h-i) $30-70 \mathrm{WSi}_{2}-\mathrm{Al}_{2} \mathrm{O}_{3}$ composites after preoxidation at $1000^{\circ}-$ $1200^{\circ} \mathrm{C}$ for $120 \mathrm{~min}$. 


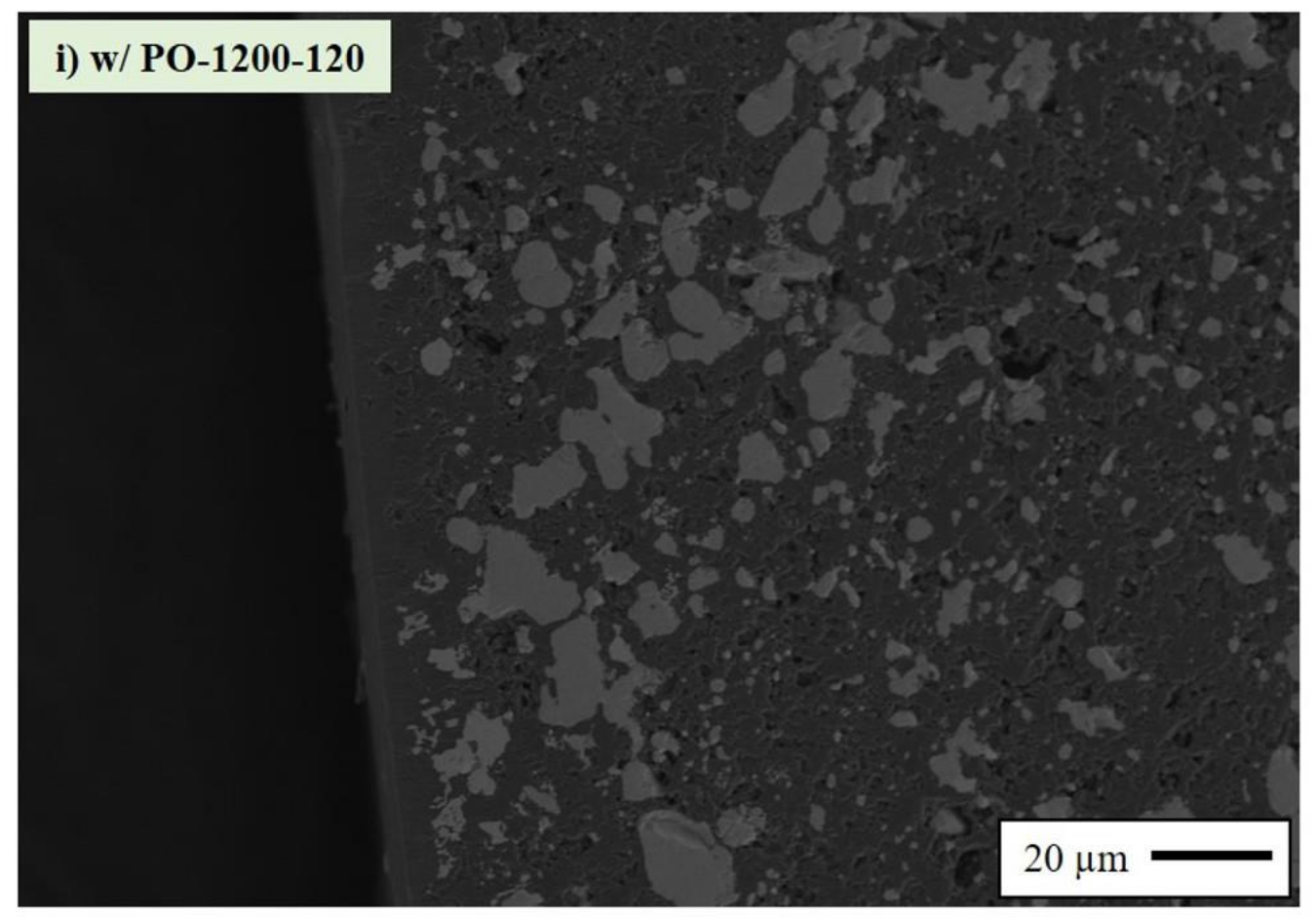

Figure 93. (continued) Cross-sectional SEM microstructures of the (a-b-c-d-e) 30-70 $\mathrm{MoSi}_{2}-\mathrm{Al}_{2} \mathrm{O}_{3}$ and (f-g-h-i) $30-70 \mathrm{WSi}_{2}-\mathrm{Al}_{2} \mathrm{O}_{3}$ composites after preoxidation at $1000^{\circ}$ $1200^{\circ} \mathrm{C}$ for $120 \mathrm{~min}$.

\subsubsection{Structural analysis of the composites}

The structural analysis of the non-preoxidized (w/o PO) and preoxidized (w/PO) $\mathrm{MoSi}_{2}-\mathrm{Al}_{2} \mathrm{O}_{3}$ and $\mathrm{WSi}_{2}-\mathrm{Al}_{2} \mathrm{O}_{3}$ composites was initially performed using XRD to identify the possible phase changes after the high-temperature preoxidation treatment. Figure 94 presents the XRD patterns taken from the surfaces of the composite samples. As baseline data, the XRD patterns of the non-preoxidized composites revealed the presence of the starting metal disilicide (tetragonal-structured $\mathrm{MoSi}_{2}, \mathrm{WSi}_{2}$ ) and alumina. In addition to their high intensity peaks, low intensity peaks were also detected mostly at the $2 \theta$ range of $36-46^{\circ}$, referring to the tetragonal-structured $\mathrm{Mo}_{5} \mathrm{Si}_{3}$ and $\mathrm{W}_{5} \mathrm{Si}_{3}$ phases existing within the composites even before preoxidation treatments. After preoxidation of the composites at $1000^{\circ}-1200^{\circ} \mathrm{C}$ for $120 \mathrm{~min}$, significant structural changes were observed. The peak intensities for the $\mathrm{Mo}_{5} \mathrm{Si}_{3}$ phase increased as a function of preoxidation temperature $\left(1000^{\circ}\right.$ $1200^{\circ} \mathrm{C}$ ), which implies an increase in its amount within the preoxidized $\mathrm{MoSi}_{2}-\mathrm{Al}_{2} \mathrm{O}_{3}$ 

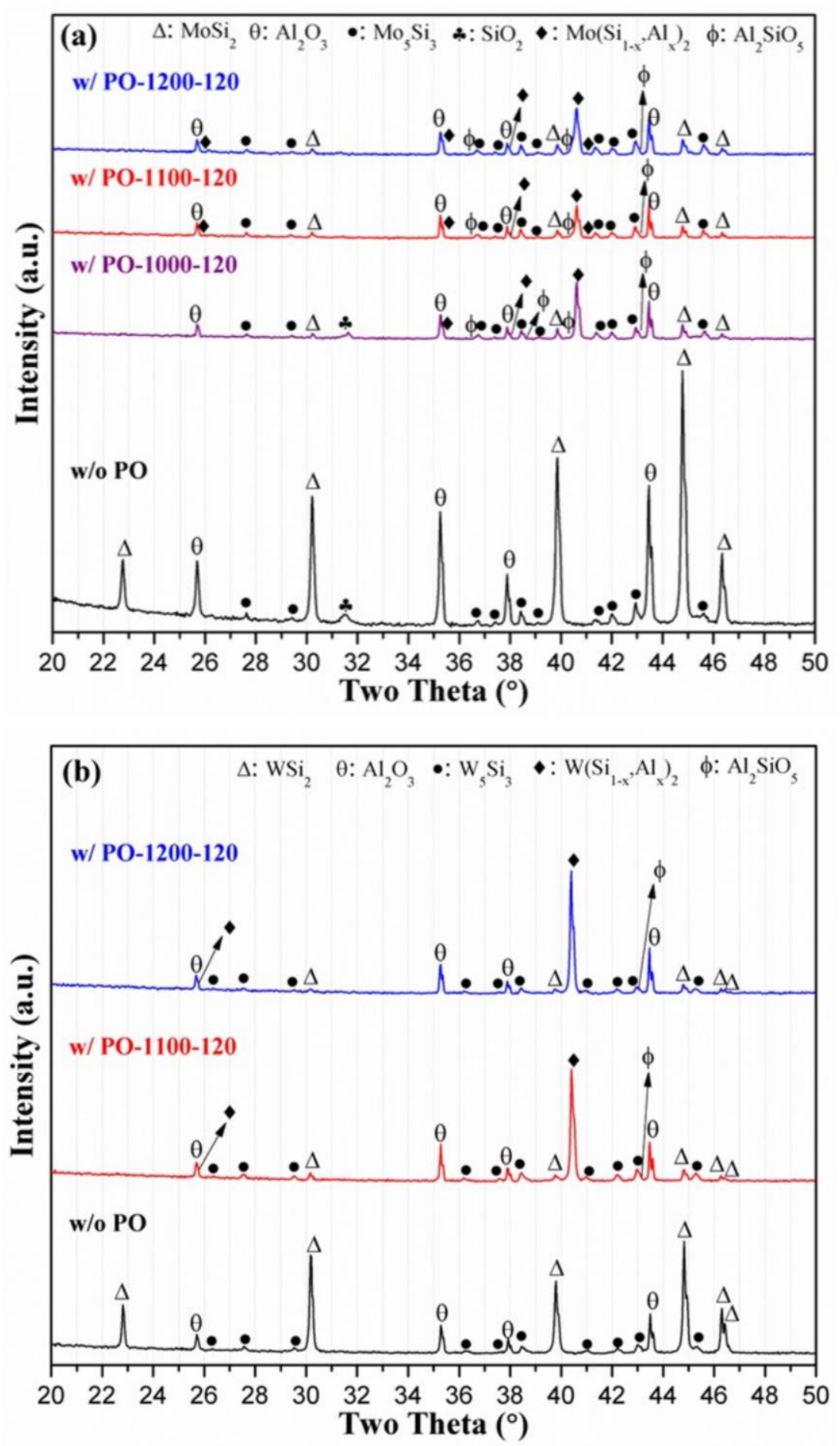

Figure 94. $\mathrm{XRD}$ patterns of the $30-70 \mathrm{vol} \%$ (a) $\mathrm{MoSi}_{2}-\mathrm{Al}_{2} \mathrm{O}_{3}$ and (b) $\mathrm{WSi}_{2}-\mathrm{Al}_{2} \mathrm{O}_{3}$ composites after preoxidation at $1000^{\circ}-1200^{\circ} \mathrm{C}$ for $120 \mathrm{~min}$ (XRD results of the nonpreoxidized samples are used as baseline). 
composites. In addition, the peak intensities for the $\mathrm{MoSi}_{2}$ decreased significantly, while $\mathrm{Mo}\left(\mathrm{Si}_{1-\mathrm{x}}, \mathrm{Al}_{\mathrm{x}}\right)_{2}$ as a ternary intermetallic phase and $\mathrm{Al}_{2} \mathrm{SiO}_{5}$ (a mullite polymorph) phases were formed (Figure 94a). Similar structural changes were also detected within the preoxidized $\mathrm{WSi}_{2}-\mathrm{Al}_{2} \mathrm{O}_{3}$ composites, since $\mathrm{W}\left(\mathrm{Si}_{1-\mathrm{x}}, \mathrm{Al}_{\mathrm{x}}\right)_{2}$ and $\mathrm{Al}_{2} \mathrm{SiO}_{5}$ were identified after high-temperature preoxidation treatment at $1100^{\circ}-1200^{\circ} \mathrm{C}$. However, the $\mathrm{W}_{5} \mathrm{Si}_{3}$ peaks were found to be more intense after preoxidation at $1100^{\circ} \mathrm{C}$ for $120 \mathrm{~min}$ (Figure 94b). The notable reduction in the peak intensities of the starting metal silicides $\left(\mathrm{MoSi}_{2}, \mathrm{WSi}_{2}\right)$ could be related to the significant thickness of the protective surface layers, and also, the presence of alumina, mullite and 5-3 metal silicide $\left(\mathrm{Mo}_{5} \mathrm{Si}_{3}, \mathrm{~W}_{5} \mathrm{Si}_{3}\right)$ as major phases beneath the surface layers. These results indicate that different reactions took place simultaneously during high-temperature preoxidation treatments, referring to the formation of the complex surface structures.

\subsubsection{Surface chemistry of the protective surface layers}

The Raman spectra of the surfaces of the non-preoxidized (w/o PO) and preoxidized $(\boldsymbol{w} / \boldsymbol{P O}) \mathrm{MoSi}_{2}-\mathrm{Al}_{2} \mathrm{O}_{3}$ and $\mathrm{WSi}_{2}-\mathrm{Al}_{2} \mathrm{O}_{3}$ composites are shown in Figure 95. The Raman spectrum of the non-preoxidized $\mathrm{MoSi}_{2}-\mathrm{Al}_{2} \mathrm{O}_{3}$ baseline sample revealed two sharp strong peaks located at 326 and $441 \mathrm{~cm}^{-1}$, which were attributed to the $A_{1 \mathrm{~g}}$ and $\mathrm{E}_{\mathrm{g}}$ Raman active lattice modes of the tetragonal $\mathrm{MoSi}_{2}$ [31]. Similarly, two sharp strong peaks located at 331 and $453 \mathrm{~cm}^{-1}$ for the non-preoxidized $\mathrm{WSi}_{2}-\mathrm{Al}_{2} \mathrm{O}_{3}$ were assigned to the tetragonal $\mathrm{WSi}_{2}$, and the related vibration of silicon atoms in $\mathrm{x}-\mathrm{y}$ planes and along $\mathrm{z}$ direction [32,33]. Significant changes in the surface chemistry of the composite structures were clearly observed after high-temperature preoxidation treatments. Four weak Raman peaks were detected at 154, 170, 215 and $292 \mathrm{~cm}^{-1}$ for the $\mathrm{MoSi}_{2}-\mathrm{Al}_{2} \mathrm{O}_{3}$ sample preoxidized at $1000^{\circ} \mathrm{C}$. These peaks imply the presence of remaining molybdenum oxide species (e.g. $\mathrm{MoO}_{3}$ ) and/or a silica polymorph (tridymite or cristobalite) on the surface layer in small amounts [34-37]. These peaks were not observed after preoxidation at $1100^{\circ}-1200^{\circ} \mathrm{C}$, possibly indicating the formation of molybdenum oxide-free surface layers at higher temperatures. After the preoxidation of the $\mathrm{MoSi}_{2}-\mathrm{Al}_{2} \mathrm{O}_{3}$ at $1100^{\circ} \mathrm{C}$, four very small peaks 

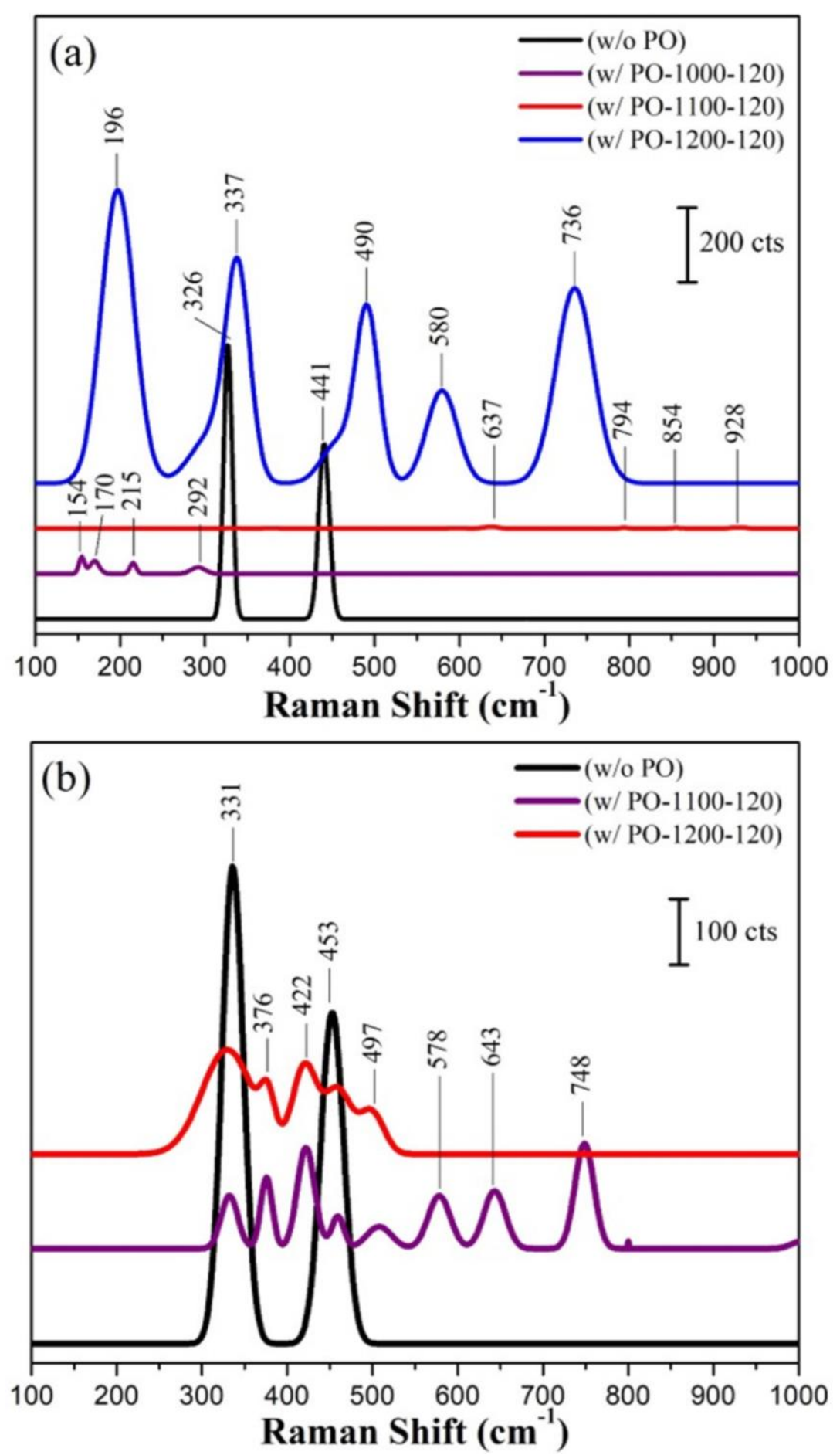

Figure 95. Raman spectra taken from the surfaces of the $30-70 \mathrm{vol} \%$ (a) $\mathrm{MoSi}_{2}-\mathrm{Al}_{2} \mathrm{O}_{3}$ and (b) $\mathrm{WSi}_{2}-\mathrm{Al}_{2} \mathrm{O}_{3}$ composites after preoxidation at $1000^{\circ}-1200^{\circ} \mathrm{C}$ for $120 \mathrm{~min}$ (Raman spectra of the non-preoxidized samples are presented as baseline). 
were detected at $637,794,854$ and $928 \mathrm{~cm}^{-1}$, which may be due to the presence of a mullite polymorph or $\mathrm{Mo}\left(\mathrm{Si}_{1-\mathrm{x}}, \mathrm{Al}_{\mathrm{x}}\right)_{2}$ phase. However, after preoxidation of the $\mathrm{MoSi}_{2}-\mathrm{Al}_{2} \mathrm{O}_{3}$ at $1200^{\circ} \mathrm{C}$, five highly broad and strong peaks were identified at 196, 337, 490, 580 and 736 $\mathrm{cm}^{-1}$. It was determined from the peaks located at 337 and $490 \mathrm{~cm}^{-1}$ that there was a significant Raman peak broadening and shifting to higher energy levels compared to the baseline $\mathrm{MoSi}_{2}$ peaks. This could be due to the $\mathrm{Al}$ substitution into the $\mathrm{MoSi}_{2}$ lattice to form the ternary intermetallic phase, $\operatorname{Mo}\left(\mathrm{Si}_{1-\mathrm{x}}, \mathrm{Al}_{\mathrm{x}}\right)_{2}$, on the surface layer during preoxidation, since the Raman spectroscopy is well-known as an important tool to study the solid solution and ternary phase formations. The peak located at $196 \mathrm{~cm}^{-1}$ could be attributed to a silica polymorph (tridymite or quartz) [36,37]. Similar peak shifts were also observed for the other two peaks (580 and $736 \mathrm{~cm}^{-1}$ ), which were close to the Raman modes of the bulk $\mathrm{Al}_{2} \mathrm{O}_{3}$ [38]. For the $\mathrm{WSi}_{2}-\mathrm{Al}_{2} \mathrm{O}_{3}$ system, similar peaks located at 331, $376,442,453$ and $497 \mathrm{~cm}^{-1}$ were identified after preoxidation at $1100^{\circ} \mathrm{C}$ and $1200^{\circ} \mathrm{C}$ (Figure 95b). The broadening of the two peaks (331 and $453 \mathrm{~cm}^{-1}$ ) could be similarly correlated to the formation of the ternary intermetallic phase $\left(\mathrm{W}\left(\mathrm{Si}_{1-\mathrm{x}}, \mathrm{Al}_{\mathrm{x}}\right)_{2}\right)$ within the surface layer. The close three peaks located at 376, 422 and $497 \mathrm{~cm}^{-1}$ implied the presence of an amorphous silica layer along with a cristobalite- $\mathrm{SiO}_{2}$ [37,39]. Also, after preoxidation at $1100^{\circ} \mathrm{C}$, three different peaks were observed at 578, 643 and $748 \mathrm{~cm}^{-1}$, which may indicate the presence of $\mathrm{Al}_{2} \mathrm{O}_{3}$ and remaining tungsten oxide species (e.g. $\mathrm{WO}_{3}$ ) within the surface layer [38,40,41]. It should be noted that the Raman modes of $\mathrm{W}_{5} \mathrm{Si}_{3}$ at 117, 170 and $270 \mathrm{~cm}^{-1}$ were not detected [42], referring to the formation of 5-3 metal silicide phases beneath the protective surface layer, not within that layer.

The surface chemical characteristics of the composite samples were comprehensively examined by X-ray photoelectron spectroscopy (XPS). It should be noted that these results only represent the surface composition of the protective layers due to the high surface sensitivity of the XPS instrument, which is only a few nanometer of penetration depth [43]. Figure 96 presents the XPS survey spectra of the surface features of the non-preoxidized and preoxidized $\mathrm{MoSi}_{2}-\mathrm{Al}_{2} \mathrm{O}_{3}$ and $\mathrm{WSi}-\mathrm{Al}_{2} \mathrm{O}_{3}$ composite samples. 

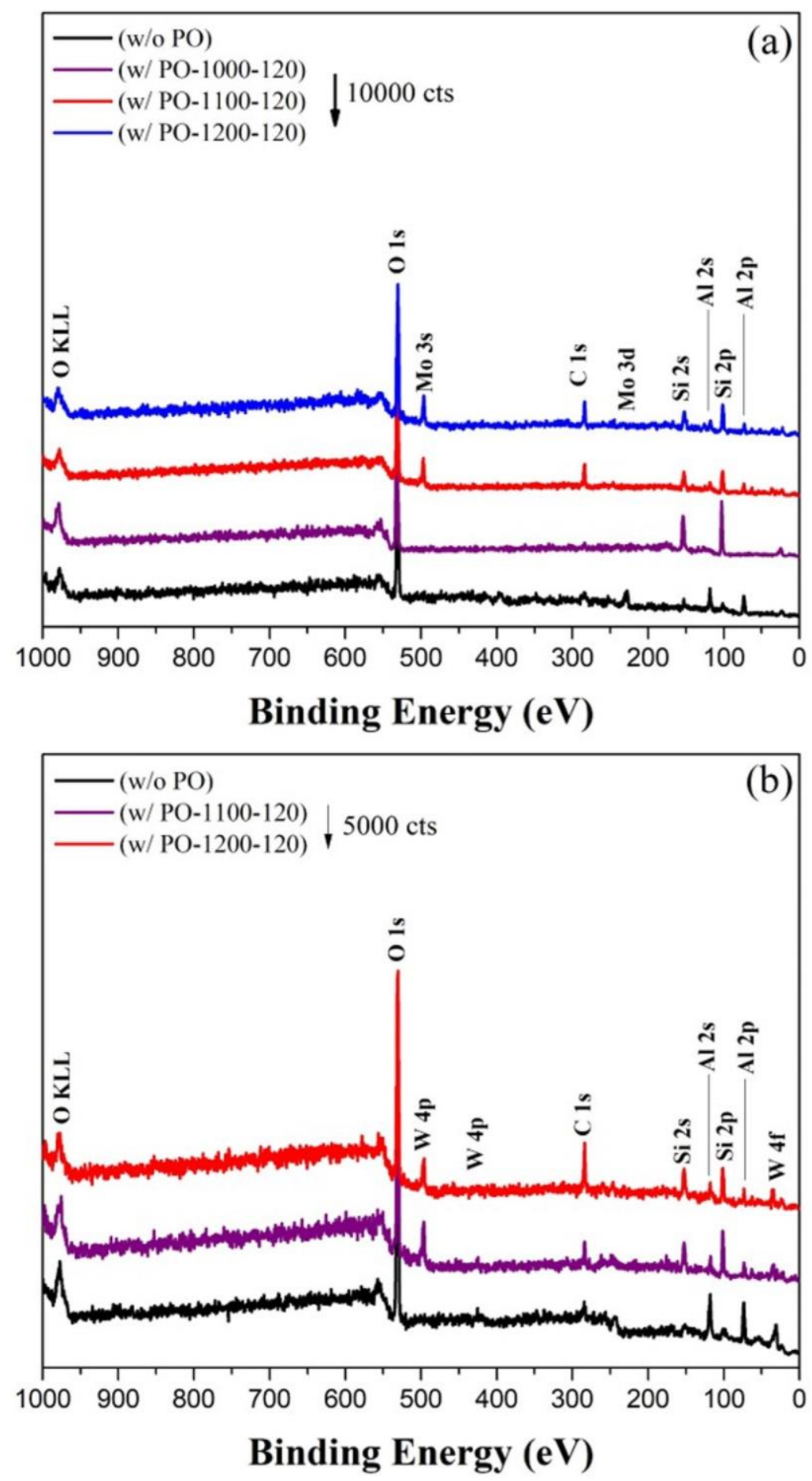

Figure 96. XPS survey spectra taken from the surfaces of the $30-70$ vol\% (a) $\mathrm{MoSi}_{2}$ $\mathrm{Al}_{2} \mathrm{O}_{3}$ and (b) $\mathrm{WSi}_{2}-\mathrm{Al}_{2} \mathrm{O}_{3}$ composites after preoxidation at $1000^{\circ}-1200^{\circ} \mathrm{C}$ for $120 \mathrm{~min}$ (XPS spectra of the non-preoxidized samples are used as baseline). 
The existence of the $\mathrm{C}$ 1s peaks detected could be due to the phenomenon of the adventitious carbon layer formation [44]. For the baseline non-preoxidized $\mathrm{MoSi}_{2}-\mathrm{Al}_{2} \mathrm{O}_{3}$ composite sample, the Mo 3d, Al 2p and Si $2 p$ peaks indicate the presence of the $\mathrm{MoSi}_{2}$, $\mathrm{Al}_{2} \mathrm{O}_{3}$ and $\mathrm{SiO}_{2}$ phases, respectively (Figure 96a). The Mo $3 \mathrm{~d}$ and $\mathrm{Al} 2 \mathrm{p}$ peaks were not observed after its preoxidation at $1000^{\circ} \mathrm{C}$, and the $\mathrm{Si} 2 \mathrm{p}$ peaks also became more intense. This indicated the predominant existence of the silica phase on the surface. At higher preoxidation temperatures $\left(1100^{\circ}-1200^{\circ} \mathrm{C}\right)$, the Mo $3 \mathrm{~s}$ peak at around $500 \mathrm{eV}$ and $\mathrm{Al} 2 \mathrm{p}$ peaks were clearly identified. In addition, a decrease in the intensity of the Si 2 p peaks, as well as, a significant change in the peak shapes were observed, which could be attributed to the formation of an intermetallic phase containing Mo, Al and Si elements. Moreover, increasing the preoxidation temperature from $1100^{\circ} \mathrm{C}$ to $1200^{\circ} \mathrm{C}$ resulted in peak shifts of the Mo 3s, Si 2p and Al 2p, which may be interrelated with the possible compositional changes within the ternary (Mo-Si-Al) intermetallic phase. As displayed in Figure 96b, a similar trend was also observed for the $\mathrm{WSi}_{2}-\mathrm{Al}_{2} \mathrm{O}_{3}$ composite system. The presence of the $\mathrm{WSi}{ }_{2}, \mathrm{Al}_{2} \mathrm{O}_{3}$ and $\mathrm{SiO}_{2}$ phases within the baseline non-preoxidized $\mathrm{WSi}_{2}-\mathrm{Al}_{2} \mathrm{O}_{3}$ composite sample was determined by the detected $\mathrm{W} 4 \mathrm{f}, \mathrm{Al} 2 \mathrm{p}$ and $\mathrm{Si} 2 \mathrm{p}$ peaks. The $\mathrm{W} 4 \mathrm{p}_{3 / 2}$ peak became less intense after preoxidation at $1100^{\circ} \mathrm{C}$, but completely disappeared after preoxidation at $1200^{\circ} \mathrm{C}$. On the other hand, the $\mathrm{W} 4 \mathrm{p}_{1 / 2}$ peaks were detected only after preoxidation treatments, along with shifting of the $\mathrm{Al} 2 \mathrm{p}$ and $\mathrm{Si} 2 \mathrm{p}$ peaks. These changes could be an indication of the formation of an intermetallic phase (W-Al-Si) on the surface of the composites.

To better understand the influence of the high-temperature preoxidation treatments on the formation of protective surface layers and their chemistry, it is necessary to determine the chemical composition and chemical state of the elements. Therefore, for all these composite samples, deconvolution of the Si 2p and Al 2p XPS peaks was carried out by a peak-fitting method to determine the peak positions precisely from their high resolution XPS spectra. The deconvoluted peaks of the Si 2p are presented in Figure 97. The non-preoxidized $\mathrm{MoSi}_{2}-\mathrm{Al}_{2} \mathrm{O}_{3}$ composite revealed two different oxidation states of 

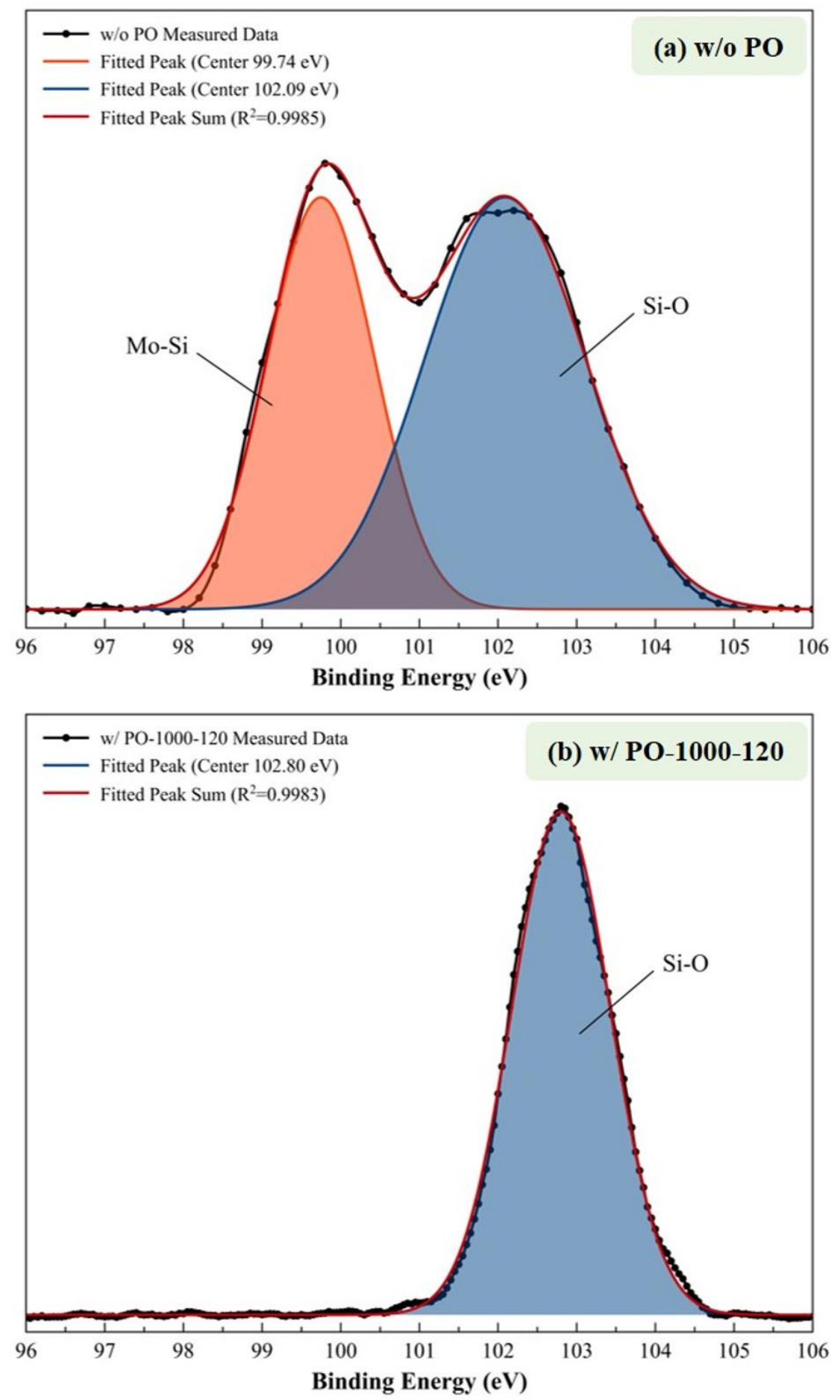

Figure 97. Deconvoluted high-resolution XPS peaks of the Si 2p for the non-preoxidized and preoxidized (a-b-c-d) 30-70 vol\% $\mathrm{MoSi}_{2}-\mathrm{Al}_{2} \mathrm{O}_{3}$ and (e-f-g) 30-70 vol\% $\mathrm{WSi}_{2}-\mathrm{Al}_{2} \mathrm{O}_{3}$ composites. 

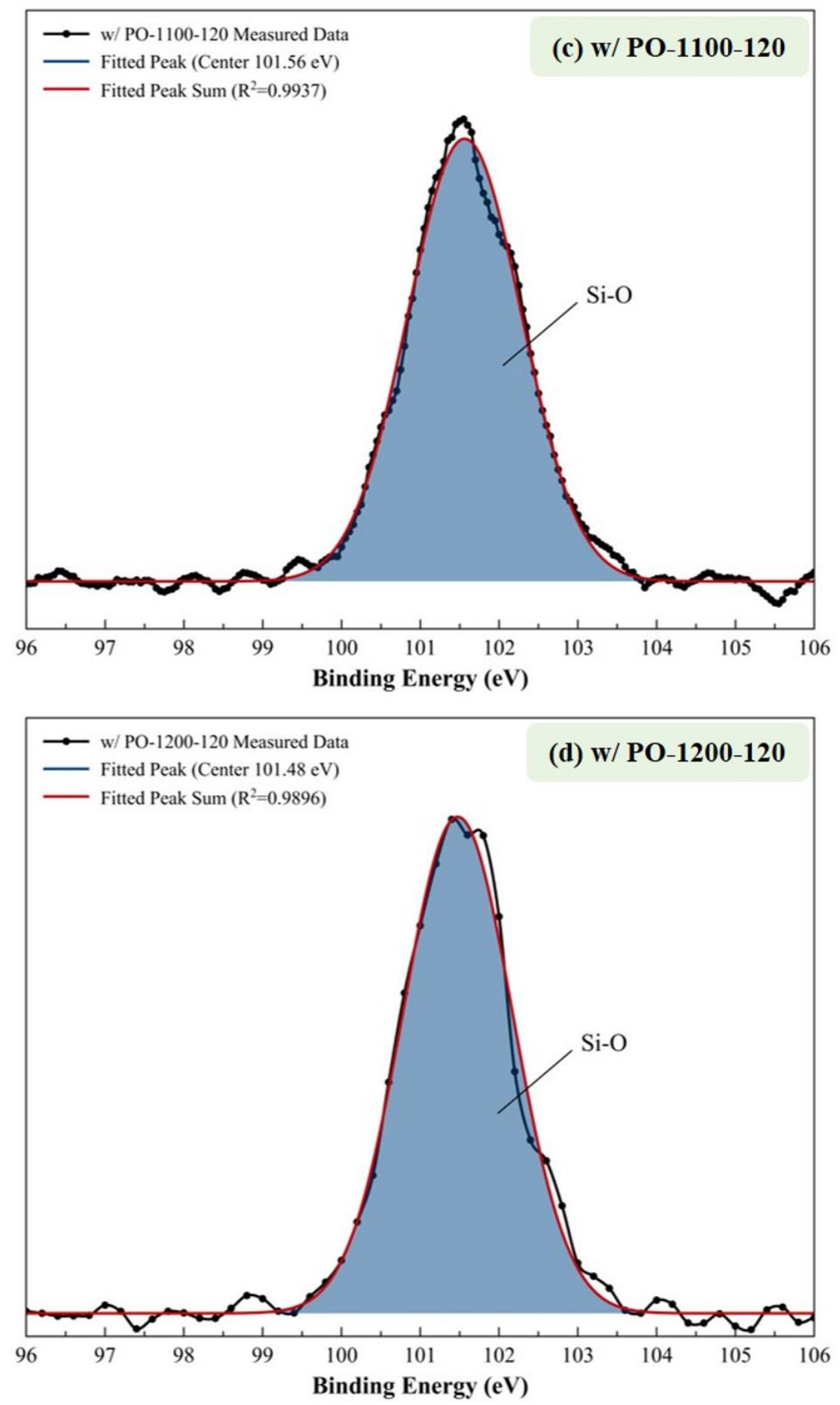

Figure 97. (continued) Deconvoluted high-resolution XPS peaks of the Si $2 p$ for the nonpreoxidized and preoxidized (a-b-c-d) 30-70 vol\% $\mathrm{MoSi}_{2}-\mathrm{Al}_{2} \mathrm{O}_{3}$ and (e-f-g) 30-70 vol\% $\mathrm{WSi}_{2}-\mathrm{Al}_{2} \mathrm{O}_{3}$ composites. 

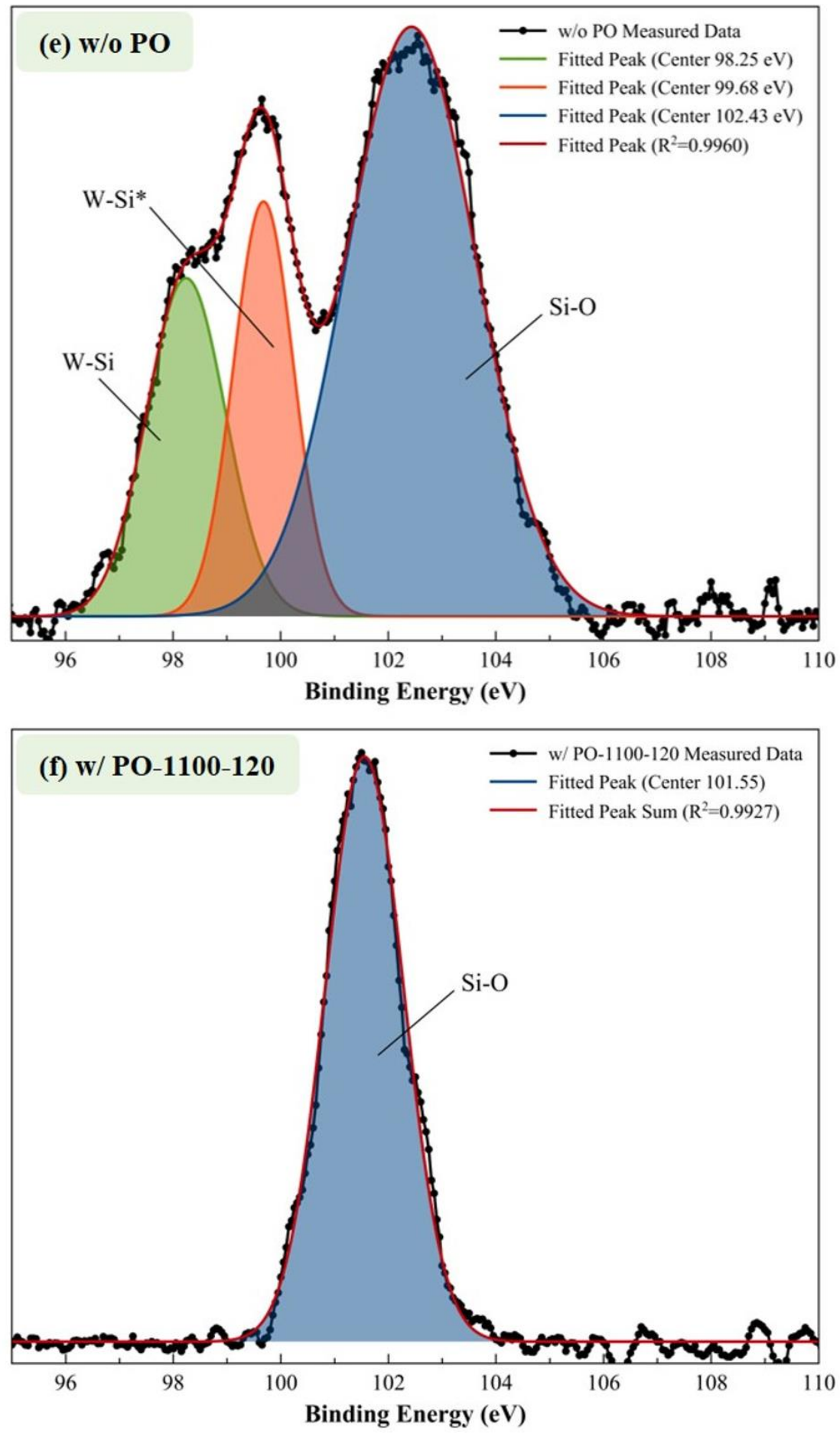

Figure 97. (continued) Deconvoluted high-resolution XPS peaks of the Si $2 p$ for the nonpreoxidized and preoxidized (a-b-c-d) 30-70 vol\% $\mathrm{MoSi}_{2}-\mathrm{Al}_{2} \mathrm{O}_{3}$ and (e-f-g) 30-70 vol\% $\mathrm{WSi}_{2}-\mathrm{Al}_{2} \mathrm{O}_{3}$ composites. 


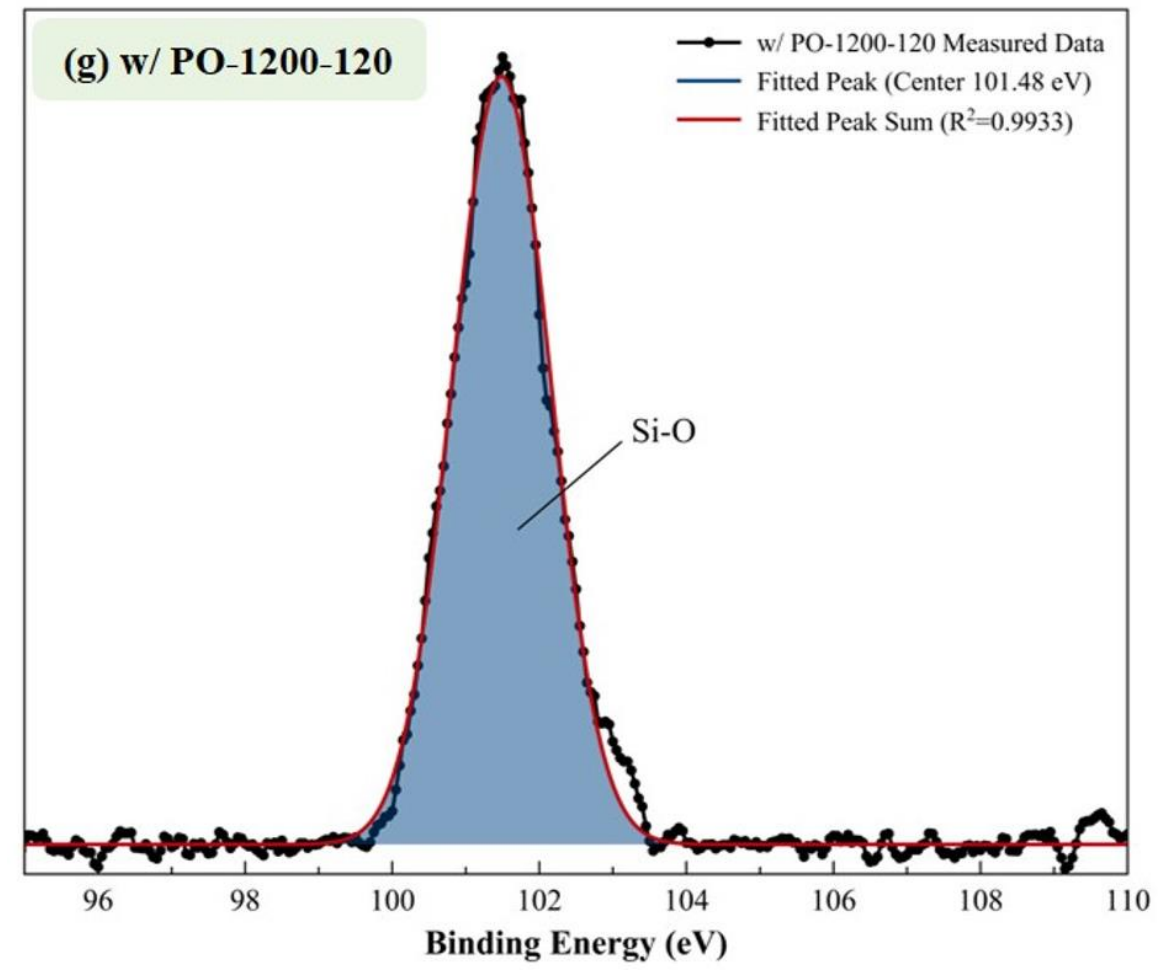

Figure 97. (continued) Deconvoluted high-resolution XPS peaks of the $\mathrm{Si} 2 \mathrm{p}$ for the nonpreoxidized and preoxidized (a-b-c-d) 30-70 vol\% $\mathrm{MoSi}_{2}-\mathrm{Al}_{2} \mathrm{O}_{3}$ and (e-f-g) 30-70 vol\% $\mathrm{WSi}_{2}-\mathrm{Al}_{2} \mathrm{O}_{3}$ composites.

silicon, where Mo-Si and Si-O bonding were identified from the binding energies of 99.74 and $102.09 \mathrm{eV}$, respectively [45,46]. After preoxidation of the $\mathrm{MoSi}_{2}-\mathrm{Al}_{2} \mathrm{O}_{3}$ composite samples at $1000^{\circ}-1200^{\circ} \mathrm{C}$, only a single peak was observed at around $\sim 102 \mathrm{eV}$, corresponding to the $\mathrm{Si}-\mathrm{O}$ bonding. The $\mathrm{Si} 2 \mathrm{p}$ spectrum of the non-preoxidized $\mathrm{WSi}_{2}-\mathrm{Al}_{2} \mathrm{O}_{3}$ composite sample exhibited three peaks at the binding energies of 98.25, 99.68 and 102.43 $\mathrm{eV}$. The former two peaks were found to belong to the W-Si bonding $[47,48]$, which could be assessed as evidence of two different $\mathrm{W}-\mathrm{Si}$ phases $\left(\mathrm{WSi}_{2}, \mathrm{~W}_{5} \mathrm{Si}_{3}\right)$. The Si-O bonding was identified from the single peak located at $102.43 \mathrm{eV}$. After high-temperature preoxidation treatment at $1100^{\circ}-1200^{\circ} \mathrm{C}$, only one peak at $\sim 101.5 \mathrm{eV}$ remained, which belongs to the $\mathrm{Si}-\mathrm{O}$ bonding, similar to the preoxidized $\mathrm{MoSi}_{2}-\mathrm{Al}_{2} \mathrm{O}_{3}$ composites. These results clearly prove the presence of the silica phase on the outer surface of the protective layers. Figure 98 displays the deconvolution of the $\mathrm{Al} 2 \mathrm{p}$ peaks for the composite samples. 

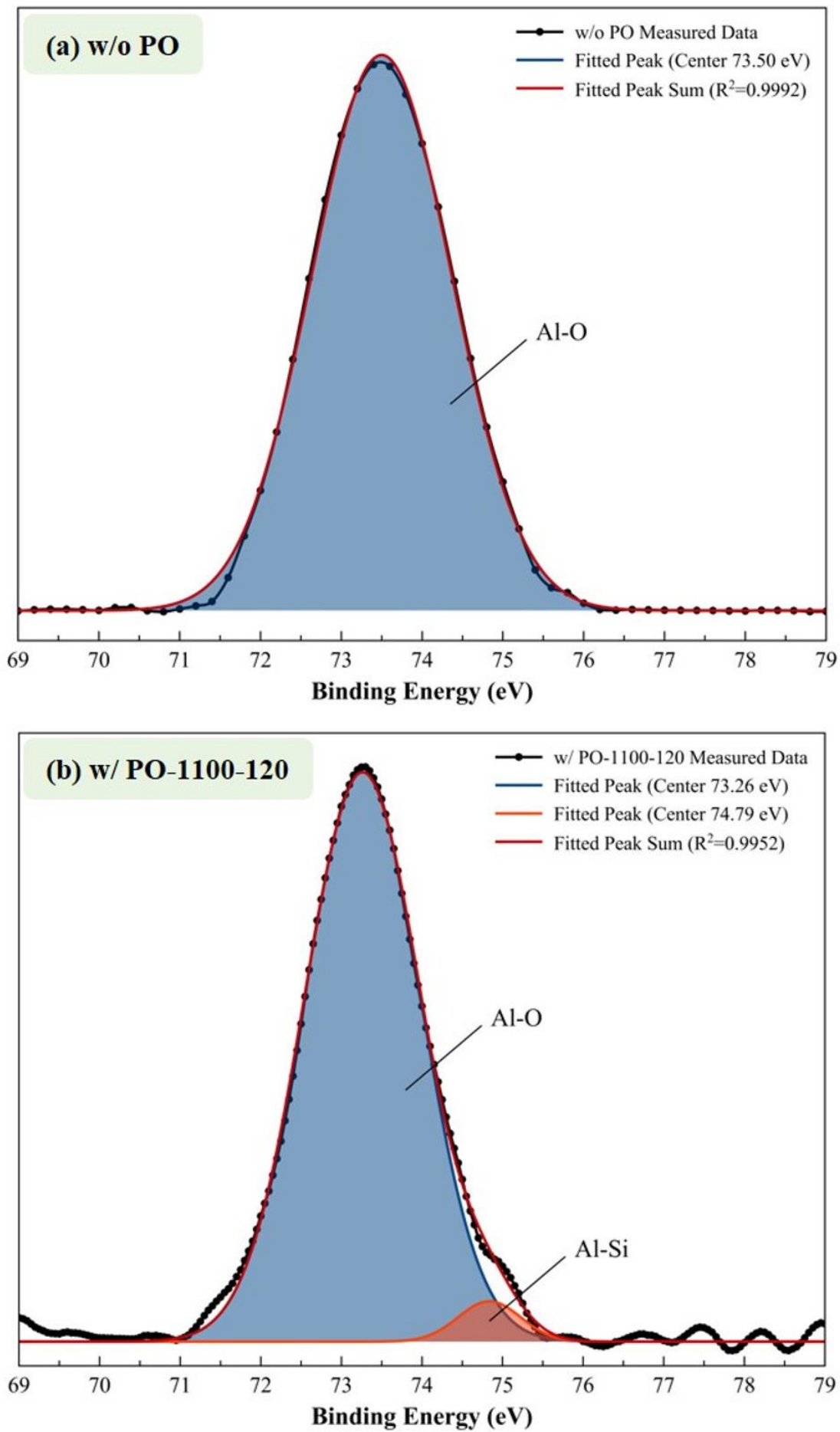

Figure 98. Deconvoluted high-resolution XPS peaks of the $\mathrm{Al} 2 \mathrm{p}$ for the non-preoxidized and preoxidized (a-b-c) 30-70 vol\% $\mathrm{MoSi}_{2}-\mathrm{Al}_{2} \mathrm{O}_{3}$ and (d-e-f) 30-70 vol\% $\mathrm{WSi}_{2}-\mathrm{Al}_{2} \mathrm{O}_{3}$ composites. 

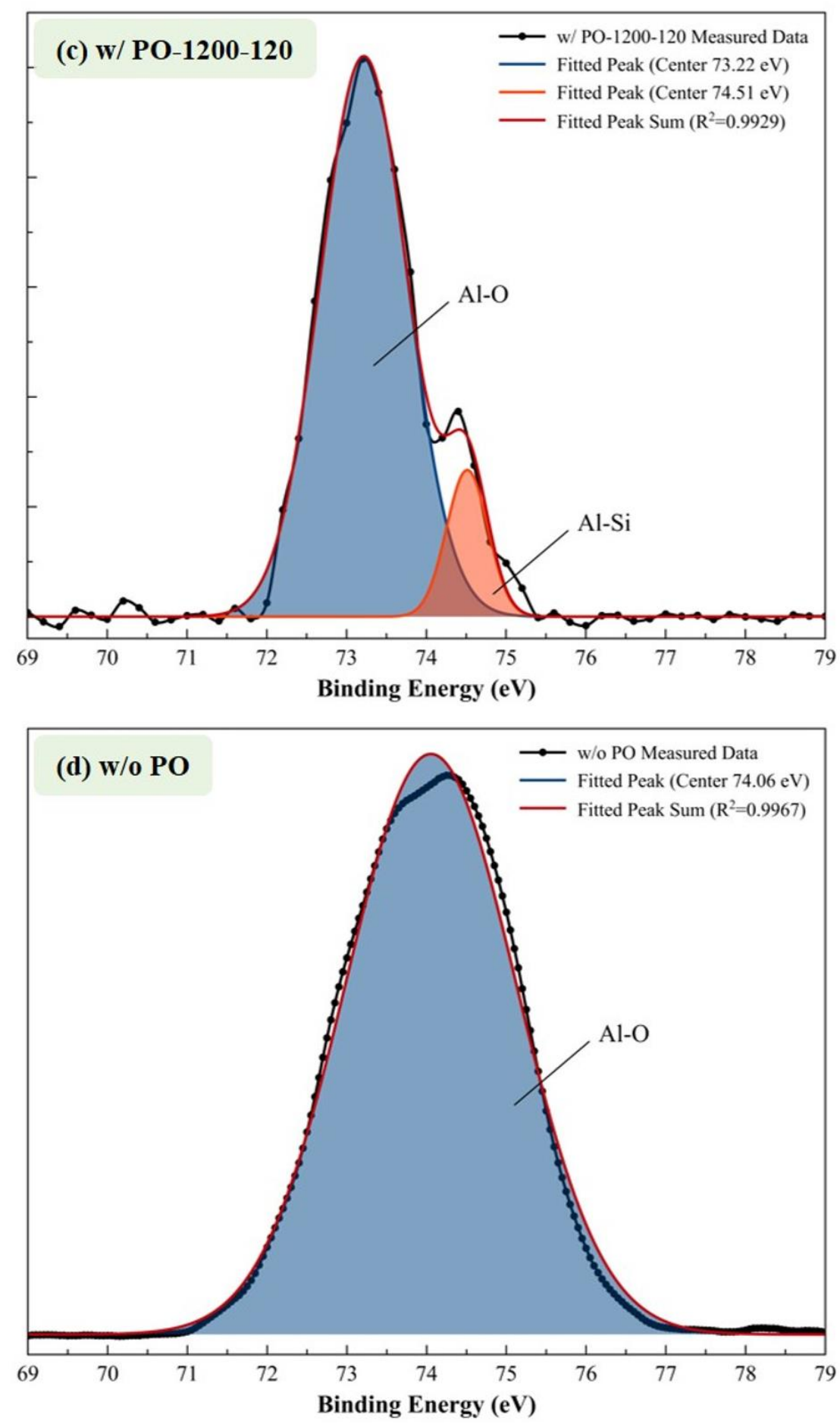

Figure 98. (continued) Deconvoluted high-resolution XPS peaks of the Al $2 p$ for the nonpreoxidized and preoxidized (a-b-c) 30-70 vol\% $\mathrm{MoSi}_{2}-\mathrm{Al}_{2} \mathrm{O}_{3}$ and (d-e-f) 30-70 vol\% $\mathrm{WSi}_{2}-\mathrm{Al}_{2} \mathrm{O}_{3}$ composites. 

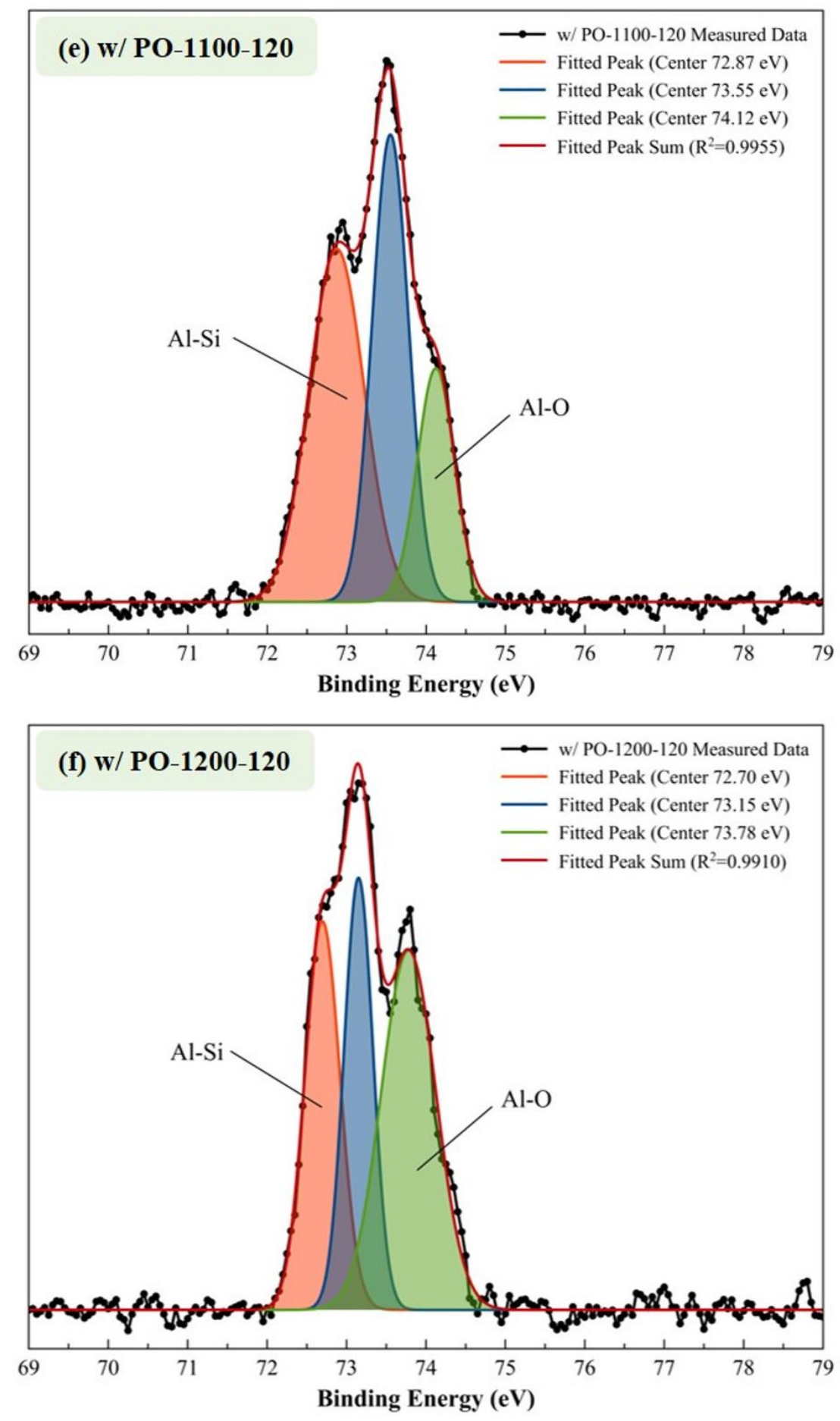

Figure 98. (continued) Deconvoluted high-resolution XPS peaks of the Al $2 p$ for the nonpreoxidized and preoxidized (a-b-c) 30-70 vol\% $\mathrm{MoSi}_{2}-\mathrm{Al}_{2} \mathrm{O}_{3}$ and (d-e-f) 30-70 vol\% $\mathrm{WSi}_{2}-\mathrm{Al}_{2} \mathrm{O}_{3}$ composites. 
The non-preoxidized $\mathrm{MoSi}_{2}-\mathrm{Al}_{2} \mathrm{O}_{3}$ and $\mathrm{WSi}_{2}-\mathrm{Al}_{2} \mathrm{O}_{3}$ composites revealed a single peak centered at $\sim 74 \mathrm{eV}$, representing the $\mathrm{Al}-\mathrm{O}$ bonding. After preoxidation of the $\mathrm{MoSi}_{2}-\mathrm{Al}_{2} \mathrm{O}_{3}$ composites at $1100^{\circ}-1200^{\circ} \mathrm{C}$, two deconvolution peaks at around 73.2 and 74.5 were identified, which are related to the Al-O and Al-Si bonding, respectively [49,50]. The preoxidized $\mathrm{WSi}_{2}-\mathrm{Al}_{2} \mathrm{O}_{3}$ samples displayed three peaks in the $\mathrm{Al} 2 \mathrm{p}$ spectra at the binding energies around 72.8 (Al-Si), 73.3 and $74.0 \mathrm{eV}(\mathrm{Al}-\mathrm{O})$. The unidentified third peak located at around 73.3 may be related to the Al-W bonding.

\subsubsection{High-temperature electrical properties of the composites}

The electrical conductivities of the composites were measured up to $\sim 950^{\circ} \mathrm{C}$ in argon atmosphere for better comparison of the high-temperature electrical properties of the non-preoxidized and preoxidized samples. The electrical data was measured at temperatures above $300^{\circ} \mathrm{C}$, since their significantly higher electrical conductivities caused relatively inaccurate measurements for the low resistances acquired in the lower temperature region. Figure 99 presents the electrical conductivities of the non-preoxidized and preoxidized $\mathrm{MoSi}_{2}-\mathrm{Al}_{2} \mathrm{O}_{3}$ and $\mathrm{WSi}_{2}-\mathrm{Al}_{2} \mathrm{O}_{3}$ composite samples as a function of temperature. It is evident that the electrical conductivity of all the composites decreased with increasing temperature, showing their metallic-type electrical conduction behavior due to the presence of the metallic transition metal silicides within the composite structures [51]. As a baseline, the electrical conductivities of the non-preoxidized $\mathrm{MoSi}_{2}-\mathrm{Al}_{2} \mathrm{O}_{3}$ composite at $800^{\circ} \mathrm{C}$ and $900^{\circ} \mathrm{C}$ were measured as 58.9 and $52.1 \mathrm{~S} / \mathrm{cm}$, respectively (Figure $99 \mathrm{a})$. At the low temperature region $\left(\leq 500^{\circ} \mathrm{C}\right)$, all preoxidized samples exhibited relatively higher electrical conductivities. However, the electrical conductivities of the $\mathrm{MoSi}_{2}-\mathrm{Al}_{2} \mathrm{O}_{3}$ samples were relatively lower $\left(45.1-55.3 \mathrm{~S} / \mathrm{cm}\right.$ at $800^{\circ} \mathrm{C} ; 40.1-47.3 \mathrm{~S} / \mathrm{cm}$ at $\left.900^{\circ} \mathrm{C}\right)$ after preoxidation at $1000^{\circ} \mathrm{C}$ and $1200^{\circ} \mathrm{C}$. In addition, the electrical conductivity significantly increased after preoxidation at $1100^{\circ} \mathrm{C}$, where the electrical conductivities at $800^{\circ} \mathrm{C}$ and $900^{\circ} \mathrm{C}$ were 78.6 and $69.1 \mathrm{~S} / \mathrm{cm}$, respectively. Similar trend in the low temperature region can be also seen for the $\mathrm{WSi}_{2}-\mathrm{Al}_{2} \mathrm{O}_{3}$ composites (Figure 99b). At high temperatures, the preoxidized samples displayed slightly lower electrical conductivity values with respect to 

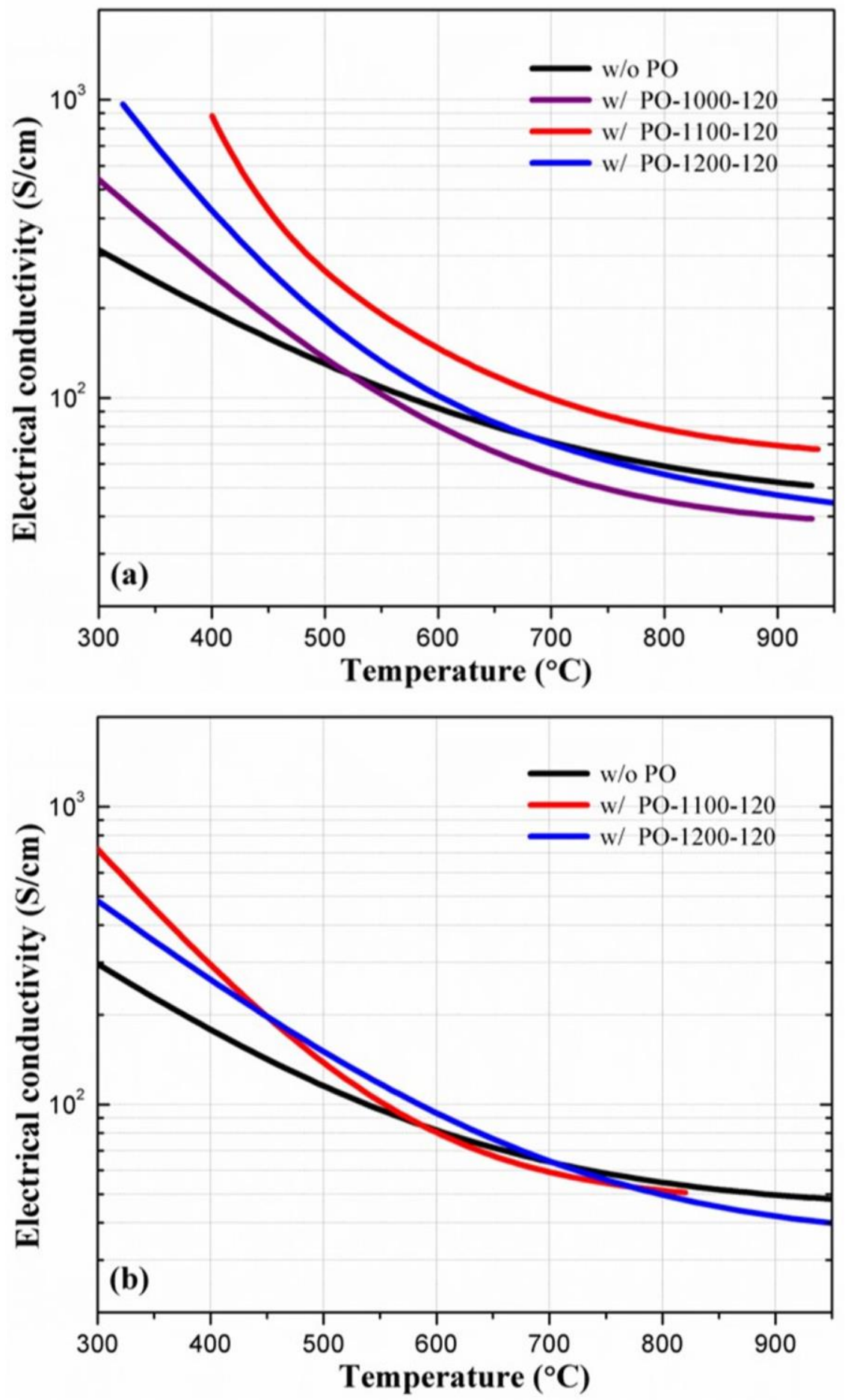

Figure 99. Electrical conductivity of the 30-70 vol\% (a) $\mathrm{MoSi}_{2}-\mathrm{Al}_{2} \mathrm{O}_{3}$ and (b) $\mathrm{WSi}_{2}$ $\mathrm{Al}_{2} \mathrm{O}_{3}$ composites after preoxidation at $1000^{\circ}-1200^{\circ} \mathrm{C}$ for $120 \mathrm{~min}$ (Electrical data of the non-preoxidized samples are also presented as baseline). 
the non-preoxidized sample. The electrical conductivity at $800^{\circ} \mathrm{C}$ decreased from 54.7 to 49.7 $\mathrm{S} / \mathrm{cm}$ with preoxidation process and increasing preoxidation temperature. These results demonstrated that the high-temperature intrinsic electrical properties of the bulk composites could be highly preserved. It is evident that the internal oxidation process was limited to the surfaces of the metal silicides in the porosities, which implied that the oxygen diffusion into the silicide-silicide grain boundaries may be highly inhibited by the alumina phase. Thus, the preoxidation process did not suppress the electrical percolation network between the silicide grains $\left(\mathrm{MoSi}_{2}-\mathrm{MoSi}_{2}\right.$ and $\left.\mathrm{WSi}_{2}-\mathrm{WSi}_{2}\right)$. Small changes in the electrical conductivities could be attributed to the structural changes, particularly to the formation 5-3 metal silicide phases beneath the protective surface layers.

\subsection{Discussion}

The non-isothermal oxidation tests revealed that the oxidation-induced mass gain of the transition metal silicides $\left(\mathrm{MoSi}_{2}, \mathrm{WSi}_{2}\right)$ at the low-temperature region $\left(\sim 400^{\circ}-850^{\circ} \mathrm{C}\right)$ could be reduced up to a certain level $(\sim 38.9-51.4 \%)$ by addition of 70 vol\% alumina phase. This mass gain is due to the characteristic low-temperature (pest) oxidation behavior of these metal silicides and simultaneous formation of highly volatile oxide species along with a silica phase as dictated by the following oxidation reactions (1-2) thermodynamically favored in this temperature regime [6,12,26,28,52]:

$$
\begin{array}{r}
2 \cdot \mathrm{MoSi}_{2}+7 \cdot \mathrm{O}_{2} \rightarrow 2 \cdot \mathrm{MoO}_{3}+4 \cdot \mathrm{SiO}_{2} \\
2 \cdot \mathrm{WSi}_{2}+7 \cdot \mathrm{O}_{2} \rightarrow 2 \cdot \mathrm{WO}_{3}+4 \cdot \mathrm{SiO}_{2}
\end{array}
$$

Their high-temperature structural and electrical applications require a safe and reliable operation under cyclic oxidation conditions for extended hours in a broad temperature range $[19,22,25,53]$. However, it is evident that the addition of the alumina phase could only be a partial solution for improving their low-temperature oxidation resistance, based on the evidence of the oxidation-induced mass gain for both composites and complete structural disintegration for the $\mathrm{WSi}_{2}-\mathrm{Al}_{2} \mathrm{O}_{3}$ composite. Therefore, the non-preoxidized $\mathrm{MoSi}_{2}-\mathrm{Al}_{2} \mathrm{O}_{3}$ and $\mathrm{WSi}_{2}-\mathrm{Al}_{2} \mathrm{O}_{3}$ composites cannot fulfill all the requirements for high- 
temperature applications due to their projected short lifetime particularly under cyclic oxidation.

The preoxidation treatment at $1000^{\circ} \mathrm{C}$ for $10-30$ min was found to be not effective, which could be due to the formation of molybdenum and tungsten oxide species (e.g. $\mathrm{MoO}_{3}$ ). Studies on the $\mathrm{MoSi}_{2}$-based material systems reported that the temperature range of $600^{\circ}-1000^{\circ} \mathrm{C}$ is where the transition from non-protective to protective surface layer formation occurs $[21,27]$. This transition is known to be at relatively higher temperatures $\left(\sim 800^{\circ}-1200^{\circ} \mathrm{C}\right)$ for the $\mathrm{WSi}_{2}$-based materials $[6,18]$. Therefore, initial reactions (1-2) still took place during short-term preoxidation at $1000^{\circ} \mathrm{C}$, possibly causing to the formation of non-protective, porous surface layer including Mo- and W-oxide species in a silica phase $[21,54]$. For the $\mathrm{WSi}_{2}-\mathrm{Al}_{2} \mathrm{O}_{3}$ composites, it is apparent that the reaction (2) predominantly controls their preoxidation at $1000^{\circ} \mathrm{C}$, since pest oxidation was still observed. However, low-temperature (pest) oxidation of the $\mathrm{MoSi}_{2}-\mathrm{Al}_{2} \mathrm{O}_{3}$ composite was highly hindered by preoxidizing at $1000^{\circ} \mathrm{C}$ for longer times (60-120 min), since the preoxidation time was enough for the evaporation of the molybdenum oxide species and formation of the glassytype protective surface layer with a $\sim 4.94 \mu \mathrm{m}$ thickness. Furthermore, the preoxidation treatments, which were conducted at higher temperatures $\left(1100^{\circ}-1200^{\circ} \mathrm{C}\right)$, revealed significant improvements on the low-temperature oxidation resistance of the $\mathrm{MoSi}_{2}-\mathrm{Al}_{2} \mathrm{O}_{3}$ and $\mathrm{WSi}_{2}-\mathrm{Al}_{2} \mathrm{O}_{3}$ composites. At these temperatures, the critical preoxidation time for the $\mathrm{MoSi}_{2}-\mathrm{Al}_{2} \mathrm{O}_{3}$ composites was determined to be relatively lower (10 $\mathrm{min}$ ), particularly compared to that of the $\mathrm{WSi}_{2}-\mathrm{Al}_{2} \mathrm{O}_{3}$ composites $(\geq 60 \mathrm{~min}$ ), which indicated different kinetics and thermodynamics controlling the preoxidation processes of two composite systems. In the specific pest oxidation regions, the oxidation-induced mass gains were substantially lower in the range of $0.02-0.05 \mathrm{mg} / \mathrm{cm}^{2}$ after high-temperature preoxidation treatment. This indicates $\sim 82.1-99.8 \%$ reduction in the mass gain during non-isothermal oxidation owing to the formation of highly dense, protective surface layers with average thicknesses ranging from 3.05 to $14.16 \mu \mathrm{m}$. It should be noted that it is difficult to compare these data with the earlier research studies, where nearly all of them reported isothermal 
(a)

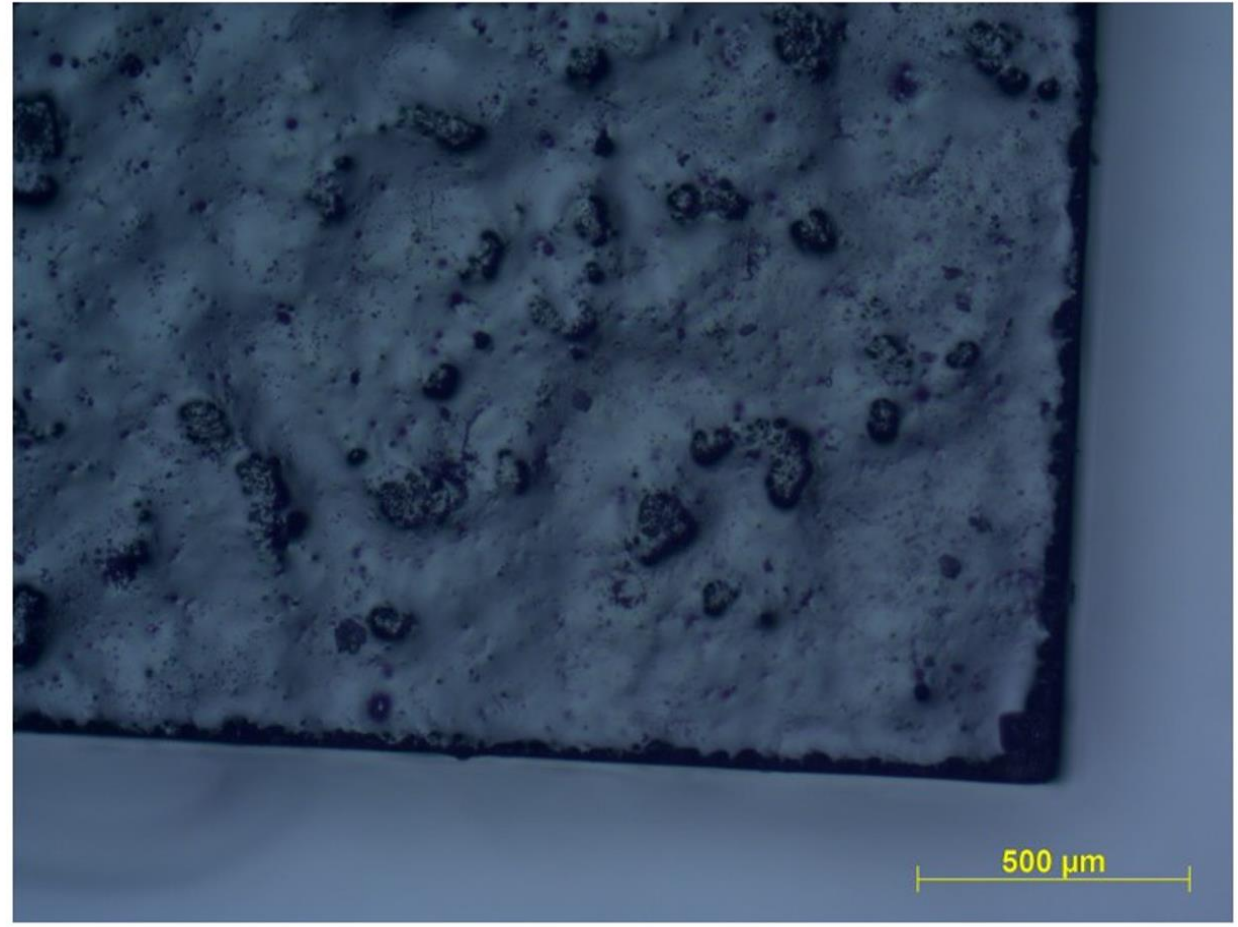

(b)

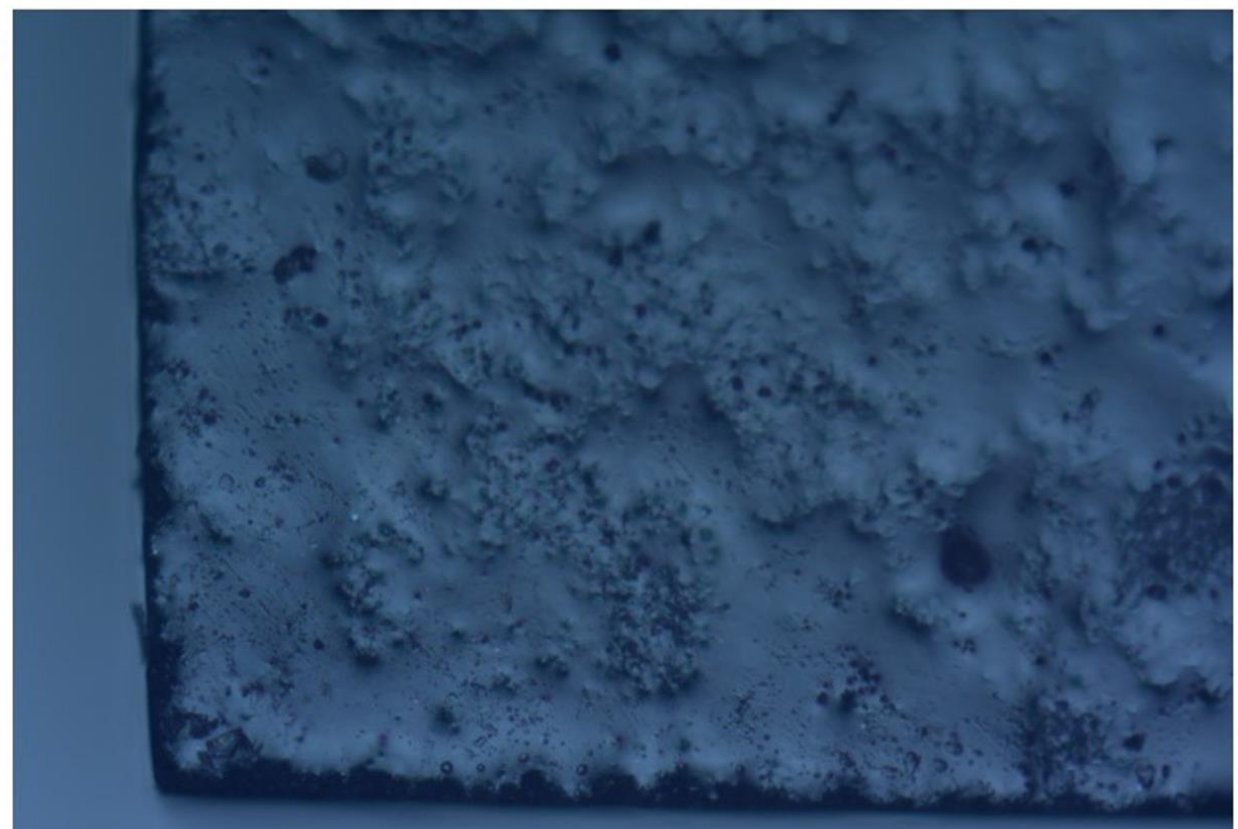

$200 \mu \mathrm{m}$

Figure 100. Optical micrographs of the edges of the composite samples (top surfaces): (a) $\mathrm{MoSi}_{2}-\mathrm{Al}_{2} \mathrm{O}_{3}$ preoxidized at $1200^{\circ} \mathrm{C}$ for $120 \mathrm{~min}$, and (b) $\mathrm{WSi}_{2}-\mathrm{Al}_{2} \mathrm{O}_{3}$ preoxidized at $1100^{\circ} \mathrm{C}$ for $120 \mathrm{~min}$. 
oxidation data. However, in the same temperature region, the mass gain for the $\mathrm{MoSi}_{2}$ sample was measured as $\sim 0.55 \mathrm{mg} / \mathrm{cm}^{2}$ after non-isothermal exposure to air [23]. This is substantially higher than the values achieved after high-temperature preoxidation treatment. Additionally, it is important to point out that the slight oxidation of the preoxidized composites could be attributed to the small gaps, which remained on the edges of the composite surfaces after preoxidation (Figure 100 for example optical images). This could be explained with structural changes on the surface of the composites, which may lead to changes in volume and dewetting of the protective surface layers or volumetric shrinkage during high temperature heat treatment following the preoxidation processes [55].

The highly protective nature of the surface layers formed via high-temperature preoxidation treatments was determined to be due to the very complex structures and surface chemistries, as identified by XRD, XPS and Raman spectroscopy. The presence of ternary intermetallic phases $\left(\mathrm{Mo}\left(\mathrm{Si}_{1-\mathrm{x}}, \mathrm{Al}_{\mathrm{x}}\right)_{2}, \mathrm{~W}\left(\mathrm{Si}_{1-\mathrm{x}}, \mathrm{Al}_{\mathrm{x}}\right)_{2}\right)$ and a mullite polymorph $\left(\mathrm{Al}_{2} \mathrm{SiO}_{5}\right)$, along with starting metal disilicides and alumina, were determined within the composite structures by XRD. As supporting data, identification of different Raman active modes and peak broadening/shifting for the $\mathrm{MoSi}_{2}$ and $\mathrm{WSi}_{2}$ modes implied the presence of mullite, silica (e.g. tridymite, cristobalite), alumina and ternary intermetallic phases within the protective surface layers (inner/outer layers), due to the lower penetration depth of the Raman spectroscopy. It is related to its better surface sensitivity and the lower penetration of the excitation energy, particularly compared to the X-rays [56,57]. Additionally, the XPS results displayed the disappearance of some peaks (e.g. Mo 3d), appearance of new peaks (e.g. Mo 3s, W 4p), increments in the peak intensities of Si 2p and $\mathrm{Si} 2 \mathrm{~s}$ and peak shifts after high-temperature preoxidation treatments. The deconvolution of the Si $2 \mathrm{p}$ and Al 2p XPS peaks also revealed the presence of Si-O, Al-O and Al-Si bonding. These results supported the existence of ternary intermetallic phases, silica, alumina and mullite within the outer surface layers formed via high-temperature preoxidation, due to the greater surface sensitivity of the XPS (less than $10 \mathrm{~nm}$ in depth) [58]. The structural and surface characterization studies demonstrated the complex 
structures of the protective surface layers, implying the possible occurrence of the following reactions (3-8), along with the above-mentioned reaction (2), simultaneously during preoxidation treatments at high-temperatures [6,9,19,20,59-62]:

$$
\begin{gathered}
5 \cdot \mathrm{MoSi}_{2}+7 \cdot \mathrm{O}_{2} \rightarrow \mathrm{Mo}_{5} \mathrm{Si}_{3}+7 \cdot \mathrm{SiO}_{2} \\
2 \cdot \mathrm{MoSi}_{2}+(\mathrm{x}+1) \cdot \mathrm{Al}_{2} \mathrm{O}_{3}+(\mathrm{x} / 2+2) \cdot \mathrm{O}_{2} \rightarrow \mathrm{Mo}\left(\mathrm{Si}_{1-\mathrm{x}}, \mathrm{Al}_{\mathrm{x}}\right)_{2}+(2 \mathrm{x}+1) \cdot \mathrm{SiO}_{2}+\mathrm{Al}_{2} \mathrm{SiO}_{5} \\
2 \cdot \mathrm{Mo}_{5} \mathrm{Si}_{3}+21 \cdot \mathrm{O}_{2} \rightarrow 10 \cdot \mathrm{MoO}_{3}+6 \cdot \mathrm{SiO}_{2} \\
5 \cdot \mathrm{WSi}_{2}+7 \cdot \mathrm{O}_{2} \rightarrow \mathrm{W}_{5} \mathrm{Si}_{3}+7 \cdot \mathrm{SiO}_{2} \\
2 \cdot \mathrm{WSi}_{2}+(\mathrm{x}+1) \cdot \mathrm{Al}_{2} \mathrm{O}_{3}+(\mathrm{x} / 2+2) \cdot \mathrm{O}_{2} \rightarrow \mathrm{W}\left(\mathrm{Si}_{1-\mathrm{x}}, \mathrm{Al}_{\mathrm{x}}\right)_{2}+(2 \mathrm{x}+1) \cdot \mathrm{SiO}_{2}+\mathrm{Al}_{2} \mathrm{SiO}_{5} \\
2 \cdot \mathrm{W}_{5} \mathrm{Si}_{3}+21 \cdot \mathrm{O}_{2} \rightarrow 10 \cdot \mathrm{WO}_{3}+6 \cdot \mathrm{SiO}_{2}
\end{gathered}
$$

Therefore, it is apparent that the alumina phase has a significant effect on the preoxidation process and surface reactions, since it caused side reactions taking place at elevated temperatures; and thus, modified the surface layer features (e.g. wetting) and their composition. This could be explained with the limited solubility of aluminum (Al) in $\mathrm{MoSi}_{2}$, and hence, partial substitution of $\mathrm{Al}$ with silicon $[15,56]$. It is important to point out that the formation of the Mo-Al-Si and W-Al-Si ternary intermetallic phases (aluminosilicides) on the surface of the $\mathrm{MoSi}_{2}-\mathrm{Al}_{2} \mathrm{O}_{3}$ and $\mathrm{WSi}_{2}-\mathrm{Al}_{2} \mathrm{O}_{3}$ composites could also positively influence their oxidation resistance at elevated temperatures. These intermetallic phases are considered to be promising alternative high-temperature heating elements and protective coatings [15,63]. The studies reported that they could exhibit a better oxidation resistance at both low- and high-temperature regimes compared to the metal disilicides due to the formation of a highly dense, protective oxide surface layer composed of alumina and mullite, instead of silica [15,64-66].

The high-temperature electrical conductivities of the composites relatively changed after preoxidation treatments, which is most likely related to the structural changes leading to the reduction in metal disilicide $\left(\mathrm{MoSi}_{2}, \mathrm{WSi}_{2}\right)$ content and increment in 5-3 metal silicide $\left(\mathrm{Mo}_{5} \mathrm{Si}_{3}, \mathrm{~W}_{5} \mathrm{Si}_{3}\right)$ amount within the composite structures. However, the results demonstrate that the alumina phase blocked the oxygen diffusion into silicide-silicide grain boundaries, which highly protected the percolation and electrical conductivity of the 
composites. Kobel et al. (2004) reported that the electrical conductivity of the $25 \mathrm{vol} \%$ $\mathrm{MoSi}_{2}-75 \mathrm{vol} \% \mathrm{Al}_{2} \mathrm{O}_{3}$ composite was to be $\sim 25 \mathrm{~S} / \mathrm{cm}$ at $700^{\circ} \mathrm{C}$ [67]. Therefore, the electrical results achieved for the preoxidized $\mathrm{MoSi}_{2}-\mathrm{Al}_{2} \mathrm{O}_{3}$ composites $(\sim 55.9-99.6 \mathrm{~S} / \mathrm{cm}$ at $700^{\circ} \mathrm{C}$ ) are comparable. No electrical data for the $\mathrm{WSi}_{2}-\mathrm{Al}_{2} \mathrm{O}_{3}$ composites was found in the literature for comparison. In brief, these results are highly promising for high-temperature structural and electrical applications, since their high-temperature electrical properties could be highly preserved, along with their metallic conduction behavior, while substantially improving their oxidation resistance, and also lowering the grain growth rates of the metal silicides by using the alumina phase as a grain growth inhibitor [25].

\subsection{Conclusions}

The influence of the alumina phase and high-temperature preoxidation treatment on the low-temperature (pest) oxidation behavior was studied using the fabricated 30-70 vol\% $\mathrm{MoSi}_{2}-\mathrm{Al}_{2} \mathrm{O}_{3}$ and $\mathrm{WSi}_{2}-\mathrm{Al}_{2} \mathrm{O}_{3}$ composites. The results demonstrated that the lowtemperature oxidation resistance of the composites could be highly enhanced in the presence of alumina and particularly after preoxidation treatment at elevated temperatures $\left(1000^{\circ}-1200^{\circ} \mathrm{C}\right)$ for a certain period of time. The SEM microstructures displayed the formation of highly dense and protective surface layers with average thicknesses ranging from 3.1 to $14.2 \mu \mathrm{m}$. The protective nature of the complex surface structures was due to the presence of the ternary intermetallic phases (Mo-Al-Si, W-Al-Si), alumina, silica and mullite phases, as identified by a series of structural and surface analyses performed via XRD, XPS and Raman spectroscopy. The preoxidized composites still exhibited a metallictype of conduction behavior with highly preserved electrical conductivities of 45.1-78.6 $\mathrm{S} / \mathrm{cm}$ at $800^{\circ} \mathrm{C}$ and $40.1-69.1 \mathrm{~S} / \mathrm{cm}$ at $900^{\circ} \mathrm{C}$. These results are highly promising for an improved performance, lifetime and reliability of metal silicide-based materials in a broad range of high-temperature structural and electrical applications. The high-temperature preoxidation treatment was shown to be a very efficient and practical method, and thus, could be successfully applied to other transition metal silicides and different material systems. Further studies are essential to study and understand the influence of different 
parameters (e.g. alumina content, preoxidation atmosphere, gas flow rate) on controlling the surface layer formation, and the kinetics of the preoxidation treatment (e.g. change in thickness as a function of time).

\section{References}

[1] A.K. Vasudevan, J.J. Petrovic, A comparative overview of molybdenum disilicide composites, Mater. Sci. Eng. A 155 (1992) 1-17.

[2] J.J. Petrovic, A.K. Vasudevan, Key developments in high temperature structural silicides, Mater. Sci. Eng. A 261 (1999) 1-5.

[3] P.R. Taleghani, S.R. Bakhshi, M. Erfanmanesh, G.H. Borhani, R. Vafaei, Improvement of $\mathrm{MoSi}_{2}$ oxidation resistance via boron addition: fabrication of $\mathrm{MoB} / \mathrm{MoSi}_{2}$ composite by mechanical alloying and subsequent reactive sintering, Powder Technology 254 (2014) 241-247.

[4] R.J. Miller, Resistivity and oxidation of tungsten silicide thin films, Thin Solid Films 72 (1980) 427-432.

[5] S. Zirinsky, W. Hammer, F. d'Heurle, J. Baglin, Oxidation mechanisms in $\mathrm{WSi}_{2}$ thin films, Appl. Phys. Lett. 33 (1978) 76-78.

[6] H-S. Kim, J-K. Yoon, G-H. Kim, J-M. Doh, S-I. Kwun, K-T. Hong, Growth behavior and microstructure of oxide scales grown on $\mathrm{WSi}_{2}$ coating, Intermetallics 16 (2008) 360372.

[7] J. Wu, S. Jiang, Y. Wang, Influence of chromium alloying on the cyclic oxidation behavior of nanocrystalline $\left(\mathrm{Mo}_{\mathrm{x}} \mathrm{Cr}_{1-\mathrm{x}}\right)_{5} \mathrm{Si}_{3}$ films at $800^{\circ} \mathrm{C}$ in air, ACS Appl. Mater. Interfaces 2 (2010) 301-311.

[8] T.C. Chou, T.G. Nieh, Kinetics of $\mathrm{MoSi}_{2}$ pest during low-temperature oxidation, J. Mater. Res. 8 (1993) 1605-1610.

[9] C. Zhai, Y. Niu, L. Huang, H. Pan, H. Li, X. Zheng, J. Sun, Microstructure characteristics and oxidation behavior of vacuum plasma sprayed tungsten disilicide coating, Ceramics International 42 (2016) 18798-18805.

[10] R. Mitra, Mechanical behavior and oxidation resistance of structural silicides, International Materials Reviews 51 (2006) 13-64. 
[11] K. Kurokawa, H. Houzumi, I. Saeki, H. Takahashi, Low temperature oxidation of fully dense and porous $\mathrm{MoSi}_{2}$, Mater. Sci. Eng. A 261 (1999) 292-299.

[12] J-K. Yoon, K-H. Lee, G-H. Kim, J-H. Han, J-M. Doh, K-T. Hong, Low-temperature cyclic oxidation behavior of $\mathrm{MoSi}_{2} / \mathrm{SiC}$ nanocomposite coating formed on Mo substrate, Materials Transactions 45 (2004) 2435-2442.

[13] H. Yokota, T. Kudoh, T. Suzuki, Oxidation resistance of boronized $\mathrm{MoSi}_{2}$, Surface and Coatings Technology 169-170 (2003) 171-173.

[14] J. Kuchino, K. Kurokawa, T. Shibayama, H. Takahashi, Effect of microstructure on oxidation resistance of $\mathrm{MoSi}_{2}$ fabricated by spark plasma sintering, Vacuum 73 (2004) 623628.

[15] S-X. Hou, Z-D. Liu, D-Y. Liu, B-R. Li, Effect of alloying with Al on oxidation behavior of $\mathrm{MoSi}_{2}$ coatings at $1100^{\circ} \mathrm{C}$, Surface \& Coatings Technology 206 (2012) 44664470.

[16] A.Y. Potanin, Y.S. Pogozhev, E.A. Levashov, A.V. Novikov, N.V. Shvindina, T.A. Sviridova, Kinetics and oxidation mechanism of $\mathrm{MoSi}_{2}-\mathrm{MoB}$ ceramics in the $600-1200^{\circ} \mathrm{C}$ temperature range, Ceramics International 43 (2017) 10478-10486.

[17] Q. Zhu, K. Shobu, Y. Zeng, T. Watanabe, Oxidation behavior of hot-pressed $\mathrm{MoSi}_{2}-$ TiC composite, Journal of Materials Science 36 (2001) 313-319.

[18] A. Yamauchi, T. Sasaki, A. Kobayashi, K. Kurokawa, Microstructure and oxidation behavior of boron-added WSi $i_{2}$ compact, Materials Transactions 49 (2008) 2047-2053.

[19] X. Fei, Y. Niu, H. Ji, L. Huang, X. Zheng, Oxidation behavior of $\mathrm{Al}_{2} \mathrm{O}_{3}$ reinforced $\mathrm{MoSi}_{2}$ composite coating fabricated by vacuum plasma spraying, Ceramics International 36 (2010) 2235-2239.

[20] L. Wang, Q. Fu, F. Zhao, Improving the oxidation resistance of $\mathrm{MoSi}_{2}$ coating by reinforced with $\mathrm{Al}_{2} \mathrm{O}_{3}$ whiskers, Intermetallics 94 (2018) 106-113.

[21] D.A. Berztiss, R.R. Cerchiara, E.A. Gulbransen, F.S. Pettit, G.H. Meier, Oxidation of $\mathrm{MoSi}_{2}$ and comparison with other silicide materials, Mater. Sci. Eng. A 155 (1992) 165181. 
[22] P. Feng, X. Wang, Y. He, Y. Qiang, Effect of high-temperature preoxidation treatment on the low-temperature oxidation behavior of a $\mathrm{MoSi}_{2}$-based composite at $500^{\circ} \mathrm{C}$, Journal of Alloys and Compounds 473 (2009) 185-189.

[23] S. Melsheimer, M. Fietzek, V. Kolarik, A. Rahmel, M. Schutze, Oxidation of the intermetallics $\mathrm{MoSi}_{2}$ and $\mathrm{TiSi}_{2}$ - a comparison, Oxidation of Metals 47 (1997) 139-203.

[24] C.A. Schneider, W.S. Rasband, K.W. Eliceiri, NIH image to ImageJ: 25 years of image analysis, Nature Methods 9 (2012) 671-675.

[25] G.A. Yakaboylu, R.C. Pillai, K. Sabolsky, E.M. Sabolsky, Stability and electrical properties of $\mathrm{MoSi}_{2}$ - and $\mathrm{WSi}_{2}$-oxide electroconductive composites, J. Am. Ceram. Soc. 100 (2017) 4461-4475.

[26] J. Cook, A. Khan, E. Lee, R. Mahapatra, Oxidation of MoSiz-based composites, Mater. Sci. Eng. A 155 (1992) 183-198.

[27] M. Samadzadeh, C. Oprea, H.K. Sharif, T. Troczynski, Comparative studies of the oxidation of $\mathrm{MoSi}_{2}$ based materials: low-temperature oxidation $\left(300-900^{\circ} \mathrm{C}\right)$, International Journal of Refractory Metals and Hard Materials 66 (2017) 11-20.

[28] C.G. McKamey, P.F. Tortorelli, J.H. DeVan, C.A. Carmichael, A study of pest oxidation in polycrystalline $\mathrm{MoSi}_{2}$, J. Mater. Res. 7 (1992) 2747-2755.

[29] F. Mohammadi, K.C. Saraswat, J.D. Meindl, Kinetics of the thermal oxidation of WSi2, Appl. Phys. Lett. 35 (1979) 529-531.

[30] Y.T. Zhu, M. Stan, S.D. Conzone, D.P. Butt, Thermal oxidation kinetics of MoSizbased powders, J. Am. Ceram. Soc. 82 (1999) 2785-2790.

[31] C.M. Doland, R.J. Nemanich, Phase formation during reactive molybdenum-silicide formation , J. Mater. Res. 5 (1990) 2854-2864.

[32] D.D. Allred, M. Cai, Q. Wang, D.M. Hatch, A. Reyes-Mena, Raman spectroscopic analysis of Mo/Si multilayers, Journal of X-ray Science and Technology 3 (1992) 222-228. [33] Z. Jiang, X. Jiang, W. Liu, Z. Wu, Thermal stability of multilayer films Pt/Si, W/Si, Mo/Si, and W/C, J. Appl. Phys. 65 (1989) 196-200.

[34] M. Cai, D.D. Allred, A. Reyes-Mena, Raman spectroscopic study of the formation of t-MoSi $i_{2}$ from Mo/Si multilayers, J. Vac. Sci. Technol. A 12 (1994) 1535-1541. 
[35] H. Jeziorowski, H. Knozinger, P. Grange, P. Gajardo, Raman spectra of cobalt molybdenum oxide supported on silica, J. Phys. Chem. 84 (1980) 1825-1829.

[36] Y. Liang, C.R. Miranda, S. Scandolo, Infrared and Raman spectra of silica polymorphs from an ab initio parametrized polarizable force field, The Journal of Chemical Physics 125 (2006) 194524.

[37] K.J. Kingma, R.J. Heymley, Raman spectroscopic study of microcrystalline silica, American Mineralogist 79 (1994) 269-273.

[38] R. Krishnan, R. Kesavamoorthy, S. Dash, A.K. Tyagi, B. Raj, Raman spectroscopic and photoluminescence investigations on laser surface modified $\alpha-\mathrm{Al}_{2} \mathrm{O}_{3}$ coatings, Scripta Materialia 48 (2003) 1099-1104.

[39] V.K. Singh, M.E. Cura, X. Liu, L-S. Johansson, Y. Ge, S-P. Hannula, Tuning the mechanical and adsorption properties of silica with graphene oxide, ChemPlusChem 79 (2014) 1512-1522.

[40] J. Gabrusenoks, A. Veispals, A.V. Czarnowski, K-H. Meiwes-Broer, Infrared and Raman spectroscopy of $\mathrm{WO}_{3}$ and $\mathrm{CdWO}_{4}$, Electrochimica Acta 46 (2001) 2229-2231.

[41] M.P. Thi, G. Velasco, Raman study of $\mathrm{WO}_{3}$ thin films, Solid State Ionics 14 (1984) 217-220.

[42] O. Nos, P.A. Frigeri, J. Bertomeu, Real-time monitoring of the silicidation process of tungsten filaments at high-temperature used as catalysers for silane decomposition, Materials Chemistry and Physics 143 (2014) 881-888.

[43] C.Y. Tang, Y.N. Kwon, J.O. Leckie, Effect of membrane chemistry and coating layer on physiochemical properties of thin film composite polyamide RO and NF membranes, I. FTIR and XPS characterization of polyamide and coating layer chemistry, Desalination 242 (2009) 149-167.

[44] P. Swift, Adventitious carbon - the panacea for energy referencing, Surface and Interface Analysis 4 (1982) 47-51.

[45] J. Zhao, H. He, H. Wang, K. Yi, Interface characterization of Mo/Si multilayers, Chinese Opt. Lett. 14 (2016) 8-11. 
[46] J-K. Yoon, K-W. Lee, S-J. Chung, I-J. Shon, J-M. Doh, G-H. Kim, Growth kinetics and oxidation behavior of $\mathrm{WSi}_{2}$ coating formed by chemical vapor deposition of $\mathrm{Si}$ on $\mathrm{W}$ substrate, Journal of Alloys and Compounds 420 (2006) 199-206.

[47] G. A. Yakaboylu, R. C. Pillai, K. Sabolsky, and E. M. Sabolsky, "MoSiz- and WSi $2_{2}$ based embedded ceramic composite thermocouples for high-temperature and harshenvironment sensing," Sensors and Actuators A: Physical 272 (2018) 139-152.

[48] A. Hussnain, R.S. Rawat, T.K. Seng, R. Ahmad, T. Hussain, P. Lee, C. Zhong, S. Lu, Z. Zheng, Study of structural and mechanical properties of $\mathrm{WN} / \mathrm{a}-\mathrm{Si}_{3} \mathrm{~N}_{4}$ hard coatings grown by plasma focus, J. Fusion Energ. 34 (2015) 435-442.

[49] Ph.V. Kiryukhantsev-Korneev, I.V. Iatsyuk, N.V. Shvindina, E.A. Levashov, D.V. Shtansky, Comparative investigation of structure, mechanical properties, and oxidation resistance of Mo-Si-B and Mo-Al-Si-B coatings, Corrosion Science 123 (2017) 319-327.

[50] L. Hu, J. Chen, W. Liu, Q. Xue, C. Kajdas, Investigation of tribochemical behavior of Al-Si alloy against itself lubricated by amines, Wear 243 (2000) 60-67.

[51] U. Gottlieb, F. Nava, M. Affronte, O. Laborde, R. Madar, Electrical transport in metallic TM silicides, In: K. Maex, M.V. Rossum (eds.), Properties of Metal Silicides, Inspec/Iee, London, UK (1995) 189-204.

[52] Y.Q. Liu, G. Shao, P. Tsakiropoulos, On the oxidation behavior of $\mathrm{MoSi}_{2}$, Intermetallics 9 (2001) 125-136.

[53] A. Newman, S. Sampath, H. Herman, Processing and properties of $\mathrm{MoSi}_{2}-\mathrm{SiC}$ and $\mathrm{MoSi}_{2}-\mathrm{Al}_{2} \mathrm{O}_{3}$, Mater. Sci. Eng. A 261 (1999) 252-260.

[54] K. Kurokawa, A. Shibayama, A. Kobayashi, Formation of $\mathrm{SiO}_{2}$ scale in hightemperature oxidation of $\mathrm{WSi}_{2}$, Transactions of JWRI 36 (2007) 51-55.

[55] L.D. Cioccio, F. Baudin, P. Gergaud, V. Delaye, P.J. Jouneau, F. Rieutord, T. Signamarcheix, Modeling and integration phenomena of metal-metal direct bonding technology, ECS Transactions 64 (2014) 339-355.

[56] L. Wu, J.C. Yu, L. Zhang, X. Wang, W. Ho, Preparation of a highly active nanocrystalline $\mathrm{TiO}_{2}$ photocatalyst from titanium oxo cluster precursor, Journal of Solid State Chemistry 177 (2004) 2584-2590. 
[57] H. Li, Y. Yue, C. Miao, Z. Xie, W. Hua, Z. Gao, Dehydrogenation of ethylbenzene and propane over $\mathrm{Ga}_{2} \mathrm{O}_{3}-\mathrm{ZrO}_{2}$ catalysts in the presence of $\mathrm{CO}_{2}$, Catalysis Communications 8 (2007) 1317-1322.

[58] L. Black, K. Garbev, I. Gee, Surface carbonation of synthetic C-S-H samples: a comparison between fresh and aged C-S-H using X-ray photoelectron spectroscopy, Cement and Concrete Research 38 (2008) 745-750.

[59] G-J. Zhang, X-M. Yue, T. Watanabe, Addition effects of aluminum and in situ formation of alumina in $\mathrm{MoSi}_{2}$, Journal of Materials Science 34 (1999) 997-1001.

[60] F.W. Glaser, Heater bodies and their production, U.S. Patent, no. 2745928 (1956).

[61] S. Knittel, S. Mathieu, M. Vilasi, The oxidation behaviour of uniaxial hot pressed $\mathrm{MoSi}_{2}$ in air from 400 to $1400^{\circ} \mathrm{C}$, Intermetallics 19 (2011) 1207-1215.

[62] T. Kikkawa, N. Endo, Thermal reaction of WSix thin films with underlying Al films, J. Appl. Phys. 70 (1991) 2370-2375.

[63] M. Sundberg, H. Pettersson, A. Magnusson, Method of making a heating element of the molybdenum silicide type and a heating element, U.S. Patent, no. 8053710 B2 (2011).

[64] T. Maruyama, K. Yanagihara, K. Nagata, High temperature oxidation of intermetallic compounds of $\mathrm{Mo}\left(\mathrm{Si}_{1-\mathrm{x}}, \mathrm{Al}_{\mathrm{x}}\right)_{2}$, Corrosion Science 35 (1993) 939-944.

[65] D.A. Pankhurst, Z. Yuan, D. Nguyen-Manh, M-L. Abel, G. Shao, J.F. Watts, D.G. Pettifor, P. Tsakiropoulos, Electronic structure and bonding in $\mathrm{Mo}_{3} \mathrm{Si}_{2}, \mathrm{Mo}_{5} \mathrm{Si}_{3}$, and $\mathrm{Mo}(\mathrm{Si}, \mathrm{Al})_{2}$ alloys investigated by $\mathrm{X}$-ray photoelectron spectroscopy and density-functional theory, Physical Review B 71 (2005) 075114-1-6.

[66] M. Sundberg, G. Malmqvist, A. Magnusson, T. El-Raghy, Alumina forming high temperature silicides and carbides, Ceramics International 30 (2004) 1899-1904.

[67] S. Kobel, J. Pluschke, U. Vogt, T.J. Graule, $\mathrm{MoSi}_{2}-\mathrm{Al}_{2} \mathrm{O}_{3}$ electroconductive ceramic composites, Ceramics International 30 (2004) 2105-2110. 


\section{Conclusions and Future Work}

Due to the challenging high temperature and harsh environment conditions, there is a need for the development of electrical and advanced sensing materials, which can operate with high reliability, accuracy and sensitivity for extended operation hours without any degradation under such conditions. Therefore, in the three chapters (Chapter 2-3-4) of this research, the main objectives were to fabricate the various transition metal siliciderefractory oxide composites, and to achieve materials possessing high chemical/thermal stability, improved microstructural stability with reduced grain growth rate, enhanced oxidation resistance and high electrical conductivity. Different transition metal silicides $\left(\mathrm{MoSi}_{2}, \mathrm{WSi}_{2}, \mathrm{NbSi}_{2}, \mathrm{TaSi}_{2}, \mathrm{CrSi}_{2}\right)$ were incorporated with refractory oxide phases $\left(\mathrm{Al}_{2} \mathrm{O}_{3}\right.$, $\mathrm{ZrO}_{2}, \mathrm{Cr}_{2} \mathrm{O}_{3}$ ), and composite materials were successfully fabricated. Their phase and microstructural stability, oxidation kinetics and electrical properties were extensively investigated at high temperatures. All the composites exhibited high phase stability at temperatures of $1400^{\circ}-1600^{\circ} \mathrm{C}$, only with the formation of secondary metal silicide phases with 5-3 stoichiometry. On the other hand, solid-state reactions between starting chromium silicide and chromia resulted in the formation of different type of chromium silicide phases, depending on the initial silicide/oxide volume ratio. The results also demonstrated that grain growth rates were significantly reduced by addition of oxide phases into the composite structures, which could be highly beneficial for long-term use. Furthermore, increasing sintering temperature and oxide phase addition highly increased the oxidation resistance, particularly compared to the monolithic metal silicides. The chromium silicidebased composites, which were fabricated via solid-state reactions, also displayed enhanced oxidation resistance. All the composites exhibited a metallic type electrical conduction with substantially high electrical conductivities up to around $1000^{\circ} \mathrm{C}$.

In the Chapter 5, a microstructural image analysis method was developed based on free-path spacing between neighboring grains to determine the degree of homogeneity or mixedness of the composites quantitatively. This could be beneficial for understanding the 
microstructure-property relations better (e.g. percolation). In the Chapter 6, the transition metal silicide-refractory oxide thick-film ceramic composite thermocouples were fabricated, and their thermoelectric properties were extensively studied. Like bulk composites, the significant influence of the 5-3 metal silicide phases on the thermoelectric response was identified. Depending on the silicide/oxide volume ratio on the thermocouple legs, the fabricated composite thermocouples exhibited higher sensitivity than mostly used Pt-Rh-based thermocouples in a wide temperature region. In the Chapter 7, the results clearly presented that the alumina addition and high-temperature preoxidation treatment substantially lowered the oxidation rates and enhanced their oxidation resistance due to the formation of complex-structured, highly protective surface layers.

Based on the results of this research, further studies are needed as listed below:

- Thermal stability studies should be conducted at high-temperatures for extended hours (>100 hours) to understand their long-term phase stability and capability for high-temperature applications.

- The influence of the oxide phase concentration on the grain growth kinetics should be studied.

- The effect of the refractory oxide phase addition and its volume percentage should be examined by fabricating the composites with a very low amount of porosity.

- Isothermal and cyclic oxidation studies are needed to determine the oxidation kinetics at different temperatures (both in low- and high-temperature regime).

- The results clearly demonstrate that the secondary 5-3 silicide phases have significant influence on their properties. Their physical properties are also not wellknown in the literature. Therefore, it is crucial to synthesize these compounds and study their physical properties, to better understand the composite structures.

- Transmission electron microscopy (TEM) studies are important to characterize the amorphous silica grain boundary phase, and to better understand its effect on the microstructures (e.g. grain boundary wetting). 
- Their electrical properties need to be measured at higher temperatures $\left(>1000^{\circ} \mathrm{C}\right)$ by changing the platinum electrical connections.

- Thermoelectric characterization studies implied that there may be compositional changes at the junction, which influence the thermoelectric output. The junction of the two composite legs needs to be well characterized to understand their thermoelectric properties better.

- The high-temperature preoxidation treatment was shown to be a very efficient and practical method; and thus, it is essential to study the influence of different parameters (e.g. type of oxide phase, alumina concentration, preoxidation atmosphere, gas flow rate) on controlling the surface layer formation, and kinetics of preoxidation process. The high-temperature preoxidation studies should be also conducted on monolithic metal silicides to better understand the influence of the refractory oxide phase addition on preoxidation kinetics and surface layer composition.

- The high-temperature preoxidation method should be applied to the thick-film composite thermocouples, which are not embedded between alumina substrates, to enhance their oxidation resistance by forming a protective surface layer. Afterwards, their thermoelectric characterization needs to be carried out in air atmosphere to study their performance in real conditions. However, the preoxidation conditions should be carefully adjusted for thick-films based on the results achieved with bulk samples. 


\section{Curriculum Vitae}

\section{Education}

West Virginia University

Anadolu University

Anadolu University
Ph.D. in Material Sci. Eng.

M.Sc. in Nanotechnology

B.Sc. in Materials Sci. Eng.
2014-2018

2008-2011

2003-2008

\section{Thesis/Dissertation}

Ph.D. Thesis

M.Sc. Thesis

B.Sc. Thesis
Processing, stability and high-temperature properties of transition metal silicide-refractory oxide composites for electrical applications

\section{Publications}

(1) Yakaboylu, G.A., Sabolsky, K., Sabolsky, E.M., "Phase stability, microstructure and high-temperature properties of $\mathrm{NbSi}_{2}$ and TaSi2-oxide electroconductive ceramic composites", Journal of Materials Science, published online on 17 April 2018 (volume/issue/page numbers to be assigned).

(2) Yakaboylu, G.A., Pillai, R.C., Sabolsky, K., Sabolsky, E.M., "MoSi $i_{2}$ - and WSi2-based embedded ceramic composite thermocouples for high-temperature and harshenvironment sensing", Sensors and Actuators A: Physical 272, 139-152 (2018). 
(3) Yakaboylu, G.A., Pillai, R.C., Sabolsky, K., Sabolsky, E.M., "Stability and electrical properties of $\mathrm{MoSi}_{2}$ - and WSi2-oxide electroconductive composites", Journal of the American Ceramic Society 100:10, 4461-4475 (2017).

(4) Yakaboylu, G.A., Sabolsky, E.M., "Determination of a homogeneity factor for composite materials by a microstructural image analysis method", Journal of Microscopy 266:3, 263-272 (2017).

(5) Yakaboylu, G.A., Suvaci, E., "Method of producing micron-sized anatase-type titanium dioxide $\left(\mathrm{TiO}_{2}\right.$ ) rods", Turkish Patent Institute, TR 2012/04155B (2016).

(6) Sabolsky, E.M., Pillai, R.C., Sabolsky, K., Yakaboylu, G.A., Armour, B., Teter, A., Palmisiano, M., Close, T., "Refractory ceramic sensors for process and health monitoring of slagging gasifiers", ECS Transactions 66:37, 43-53 (2015).

\section{Presentations}

(1) Yakaboylu, G.A., Pillai, R.C., Sabolsky, K., Yumak, T., Sabolsky, E.M., “Transition Metal Silicide-Based Ceramic Composites for High Temperature and Harsh Environment Sensing", Oral presentation, to be presented at the Materials Science and Technology MS\&T’18, Columbus OH, October 14-18 (2018).

(2) Yakaboylu, G.A., Pillai, R.C., Sabolsky, K., Haynes, D.J., Sabolsky, E.M., “Metal Silicide-Refractory Oxide Ceramic Composites for High-Temperature and HarshEnvironment Sensing: Processing, Stability and Thermoelectric Properties", Oral presentation, to be presented at the 233rd ECS Meeting, Seattle WA, May 13-17 (2018).

(3) Yakaboylu, G.A., Pillai, R.C., Sabolsky, K., Sabolsky, E.M., "Metal SilicideRefractory Oxide Electroconductive Ceramic Composites for High-Temperature and Harsh-Environment Sensing Applications", Oral presentation, Materials Science and Technology MS\&T'17, Pittsburgh PA, October 8-12 (2017). 
(4) Yakaboylu, G.A., Pillai, R.C., Sabolsky, K., Sabolsky, E.M., "Processing of Metal Silicide/Refractory Oxide Composites for High-Temperature and Harsh-Environment Sensing Applications", Poster presentation, Gordon Research Conference (GRC), Ceramics, Solid State Studies in, South Hadley MA, July 31-August 5 (2016).

(5) Yakaboylu, G.A., Pillai, R.C., Armour, B., Sabolsky, K., Sabolsky, E.M., "Conductive Ceramic Composites for Fabricating High Temperature and Harsh Environment Sensors: Thermal Processing, Stability and Properties", Oral presentation, International Conference and Exposition on Advanced Ceramics and Composites, Daytona Beach FL, January 24-29 (2016).

(6) Yakaboylu, G.A., Pillai, R.C., Armour, B., Sabolsky, K., Sabolsky, E.M., "Development of Refractory Oxide/Metal Silicide Composites for High Temperature Harsh-Environment Sensor Applications", Oral presentation, Materials Science and Technology MS\&T’15, Columbus OH, October 4-8 (2015).

(7) Yakaboylu, G.A., Pillai, R.C., Chockalingam, S., Armour, B., Palmisiano, M., Sabolsky, K., Sabolsky, E.M., "Thermal Processing and Properties of Conductive Refractory Composites for High-Temperature Electrical Applications", Oral presentation, International Conference and Exposition on Advanced Ceramics and Composites, Daytona Beach FL, January 25-30 (2015). 